\title{
LIGAÇÕES EM ESTRUTURAS DE AÇO
}

\author{
Eng $^{0}$ Vitor Cesar Valenciani
}

Dissertação apresentada à Escola de Engenharia de São Carlos da Universidade de São Paulo, como parte dos requisitos para obtenção do título de Mestre em Engenharia de Estruturas.

ORIENTADOR: Prof. Dr. Maximiliano Malite 

da Informação do Serviço de Biblioteca - EESC-USP

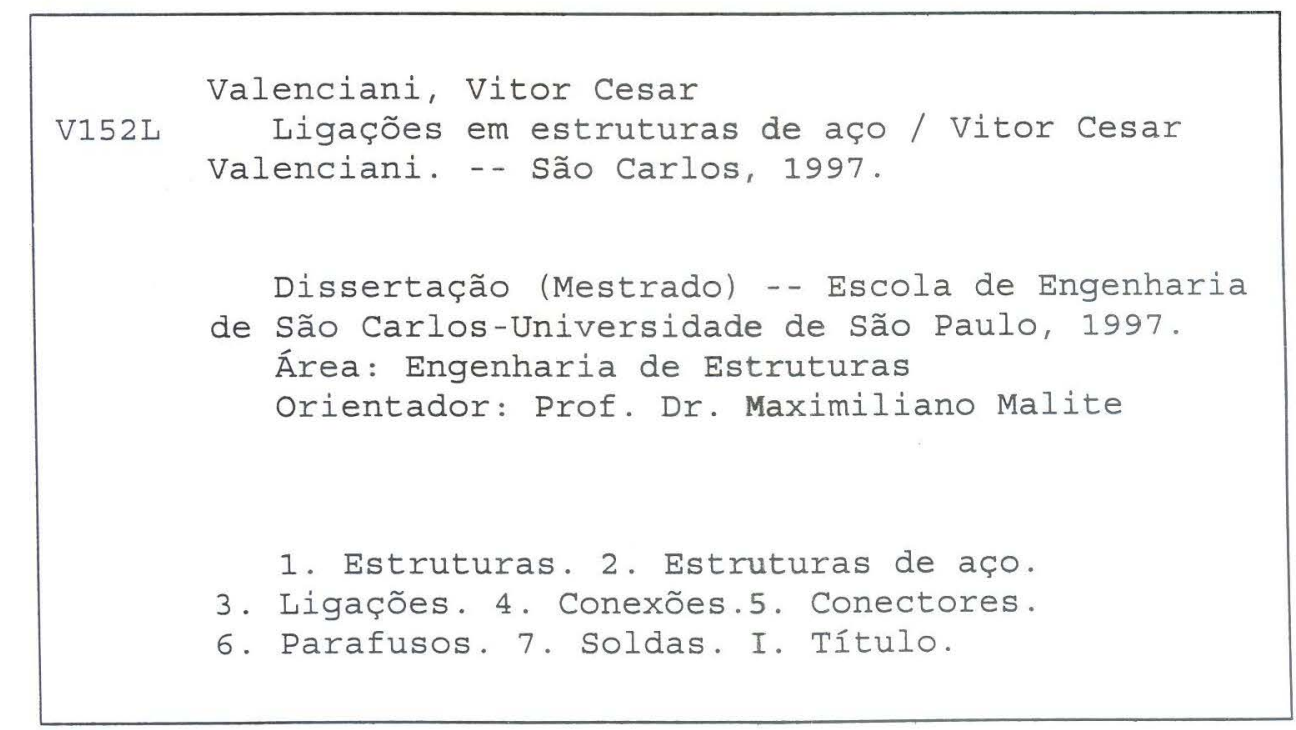


"Criar o que não existe ainda deve ser a pretensão de todo sujeito que está vivo"

Paulo Freire 
Dedico este trabalho a minha mãe Tereza e a minha irmã Sandra 


\section{AGRADECIMENTOS}

Ao Criador por ter me dado serenidade e determinação para a realização deste trabalho;

Ao Prof. Dr. Maximiliano Malite, orientador deste trabalho, meus sinceros agradecimentos, pela paciência, dedicação, amizade e pela excelente orientação com a qual muito aprendi e evolui tecnicamente;

A todos os professores e funcionários do Departamento de Estruturas da EESC/USP, que de uma maneira ou de outra colaboraram para a realização deste trabalho e ao Prof. Samuel Irati Novaes Gomes pela colaboração no capítulo referente à soldagem;

À Universidade Estadual Paulista "Júlio de Mesquita Filho" UNESP Campus Bauru, pela minha formação acadêmica;

À Coordenadoria de Aperfeiçoamento de Pessoal de Nível Superior CAPES, pela bolsa de estudo concedida;

A toda minha família, e em especial a minha mãe Tereza, pelo estimulo e pela compreensão da minha ausência em determinados momentos e principalmente a Tia Neide pelo incentivo e apoio;

A todos os meus amigos e amigas, principalmente os companheiros de Republica, pela convivência e amizade desenvolvida durante estes anos;

Ao meu pai Antônio Valenciani †. 


\section{SUMÁRIO}

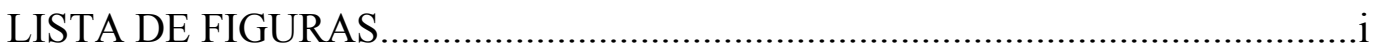

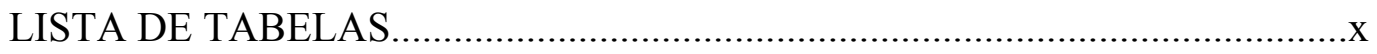

LISTA DE ABREVIATURAS E SIGLAS............................................................

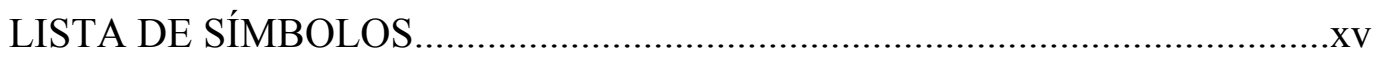

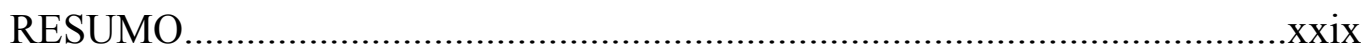

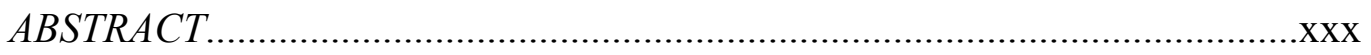

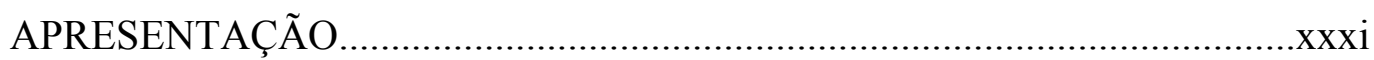

CAPÍTULO 1 CONECTORES ESTRUTURAIS.....................................................

1.1 Introdução e desenvolvimento histórico dos parafusos de alta resistência................1

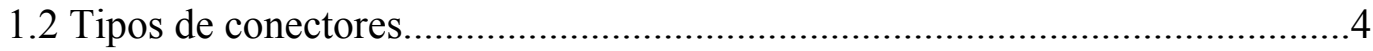

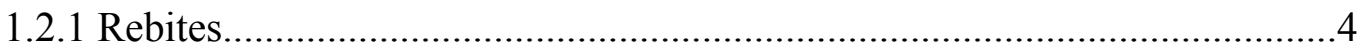

1.2.2 Parafusos de alta resistência..........................................................................6

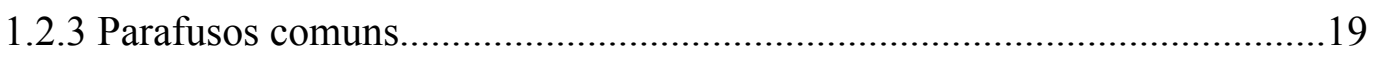

1.3 Relaxação em parafusos pré-tracionados..........................................................22

1.4 Reutilização de parafusos de alta resistência..........................................................23

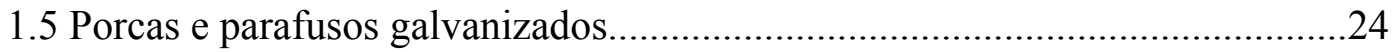

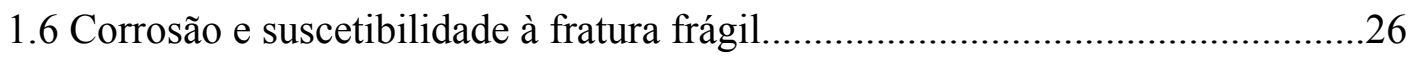

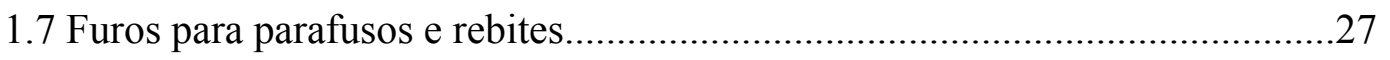

1.8 Outros tipos e especificações de conectores.........................................................33

1.8.1 Parafusos ASTM A354 e A687......................................................................

1.8.2 Parafusos de tolerância fina (usinados)............................................................33

1.8.3 Dispositivos de ancoragem........................................................................

1.8.4 Parafusos estriados e parafusos com indicador de força.....................................40

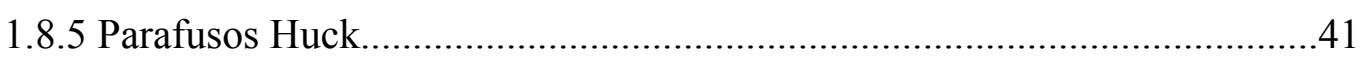

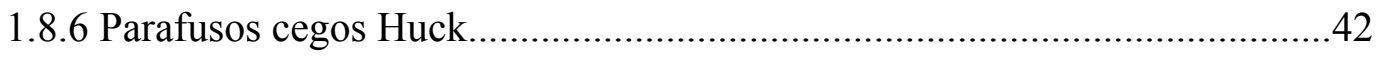

1.8.7 Parafusos com resina comprimida.................................................................43

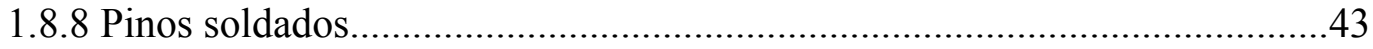

1.8.9 Fixadores auto-atarraxantes e auto-perfurantes.............................................4 
2.1 Introdução e desenvolvimento histórico......................................................47

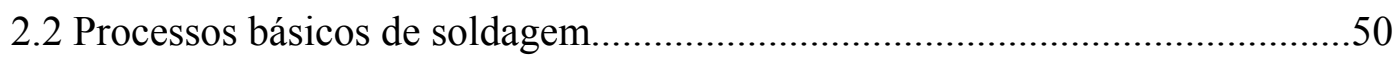

2.2.1 Soldagem a arco com eletrodo revestido (SMAW - Shield Metal Arc Welding). .54

2.2.2 Soldagem a arco submerso (SAW - Submerged Arc Welding).

2.2.3 Soldagem com gás de proteção (GMAW - Gas Metal Arc

Welding) .60

2.2.4 Soldagem arco elétrico com fluxo no núcleo (FCAW - Flux Cored Arc Welding). .66

2.2.5 Soldagem eletro-escória (ESW - Electroslag Welding) e soldagem eletro-gás

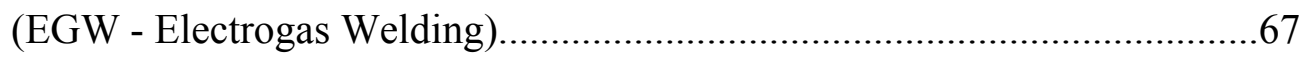

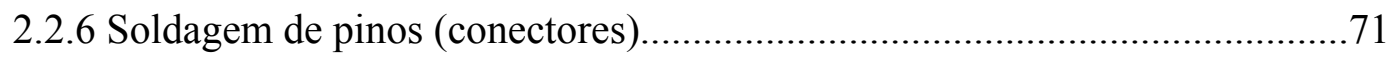

2.3 Fluxos de soldagem e classificação de eletrodos...................................................72

2.4 Posições de soldagem e tipos de juntas soldadas................................................85

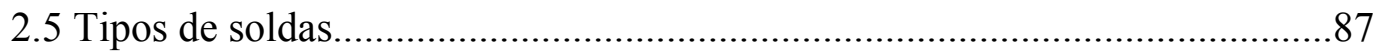

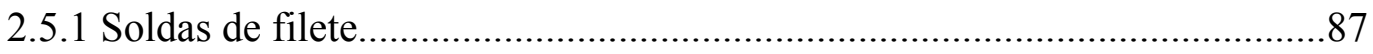

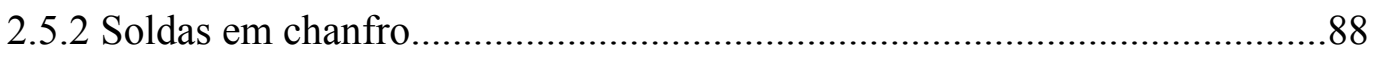

2.5.3 Soldas de tampão em furos e rasgos (ranhura)................................................89

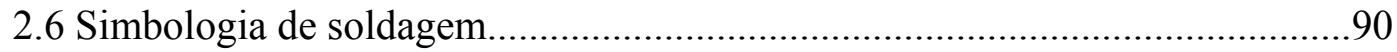

2.7 Fatores que afetam a qualidade de conexões soldadas.....................................92

2.7.1 Eletrodos, dispositivos de soldagem e procedimentos...................................92

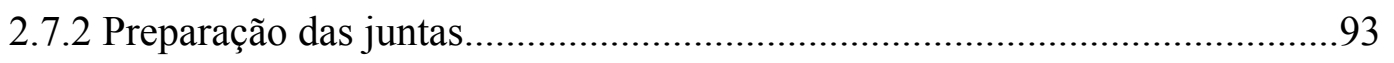

2.7.3 Controle de distorção...........................................................................95

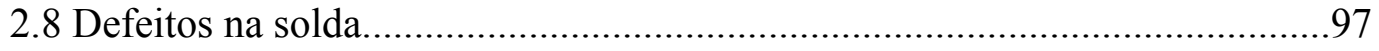

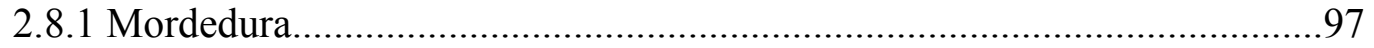

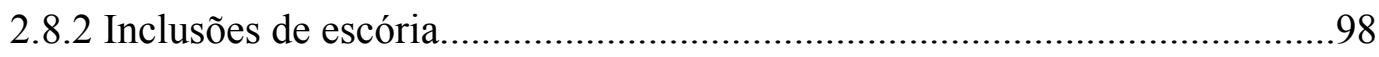

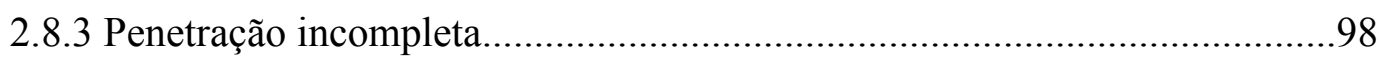

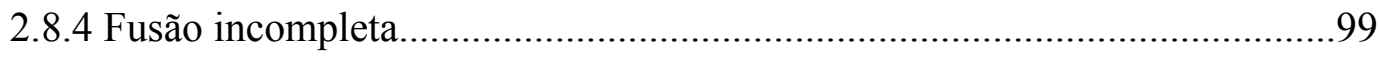

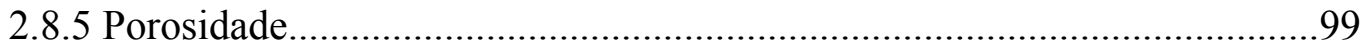

2.8.6 Trincas por introdução de hidrogênio na zona afetada pelo calor....................100

2.8.7 Trincas devido a solidificação do metal de solda.........................................101 
2.8.8 Rasgo lamelar. 102

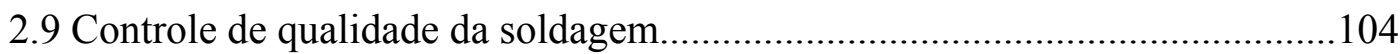

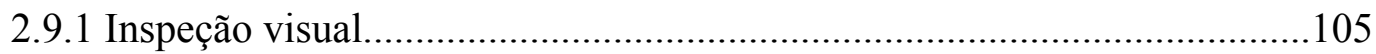

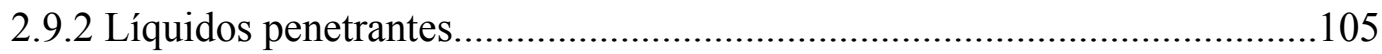

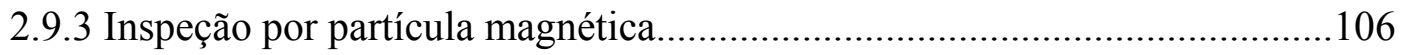

2.9.4 Inspeção radiográfica com raio X e raio Gama...........................................106

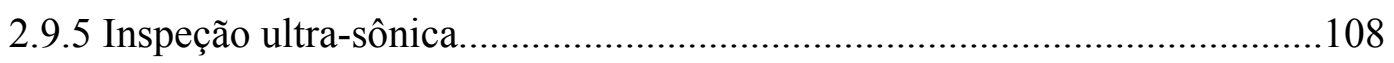

CAPÍTULO 3 - RESISTÊNCIA DE PARAFUSOS..........................................111

3.1 - Modos de falha em conexões parafusadas..................................................112

3.2 - Conexões por contato: parafusos sob força cortante......................................113

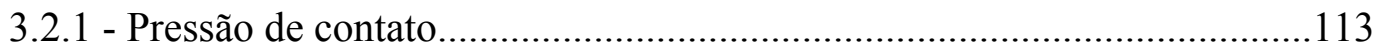

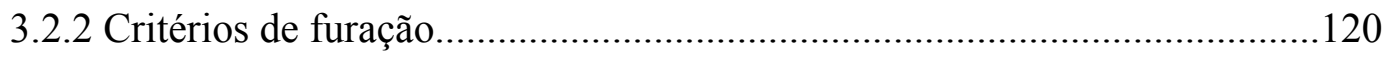

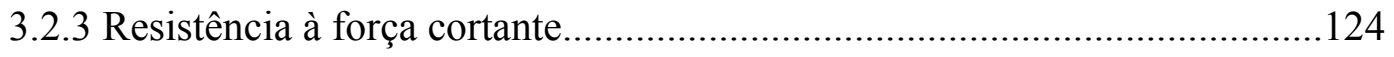

3.3 Conexões por contato: parafusos sob tração..................................................131

3.4 Conexões por contato: parafusos sob tração e força cortante combinadas..........134

3.5 Conexões por atrito: parafusos sob força cortante, combinada ou não com

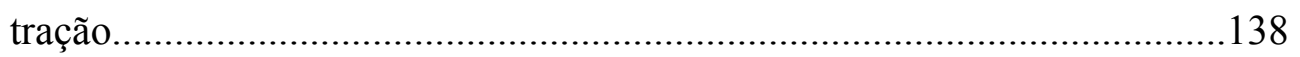

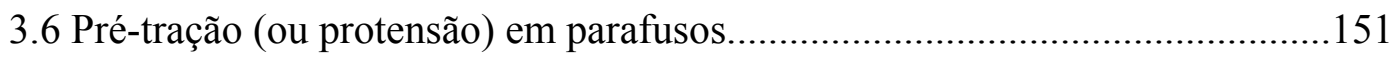

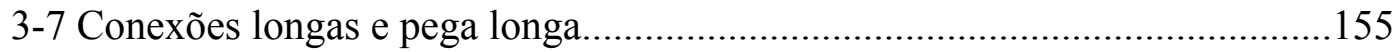

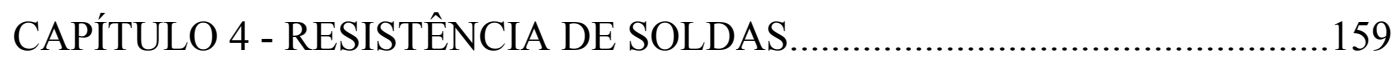

4.1 Áreas efetivas de cisalhamento e outros parâmetros dos cordões de solda..........159

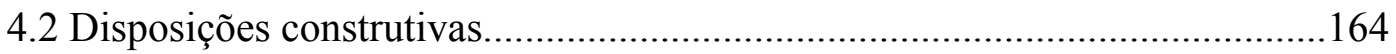

4.3 Considerações especiais a respeito de soldas de filete......................................171

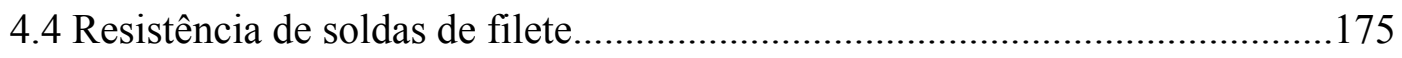

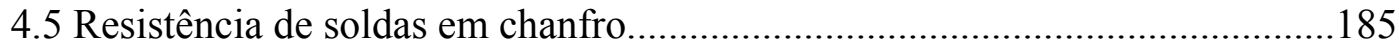

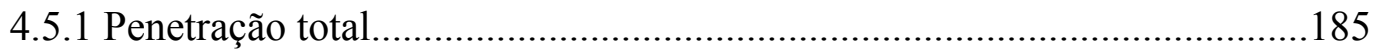

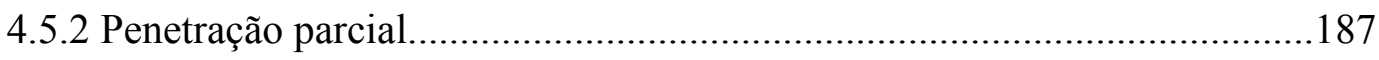

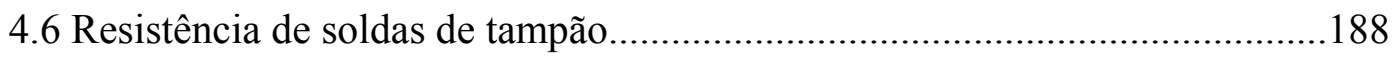




\section{CAPÍTULO 5 - CONEXÕES PARAFUSADAS SUJEITAS A CARREGAMENTO}

EXCÊNTRICO

5.1 Grupo de parafusos sob força cortante e momento de torção...........................194

5.2 Grupo de parafusos sob força cortante e momento fletor................................206

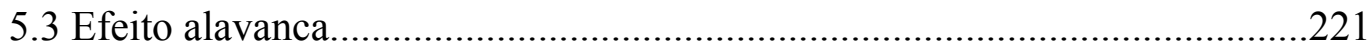

CAPÍTULO 6 - CONEXÕES SOLDADAS SUJEITAS A CARREGAMENTO EXCÊNTRICO..............................................................241

6.1 Grupo de soldas sob força cortante e momento de torção................................241

6.2 Grupo de soldas sob força cortante e momento fletor...................................253

CAPÍTULO 7 - EMENDAS EM BARRAS E OUTRAS CONEXÕES.................261

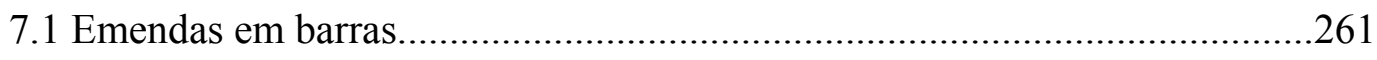

7.1.1 Emendas de colunas de edifícios.........................................................261

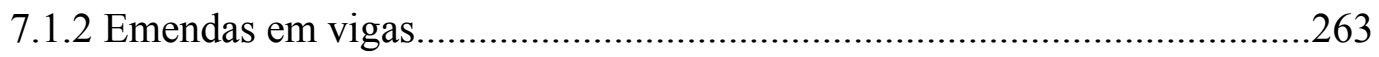

7.1.3 Emendas em barras axialmente solicitadas..............................................267

7.2 Solda de composição em perfis..............................................................270

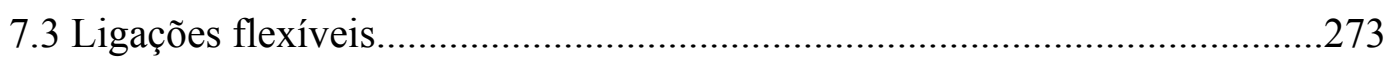

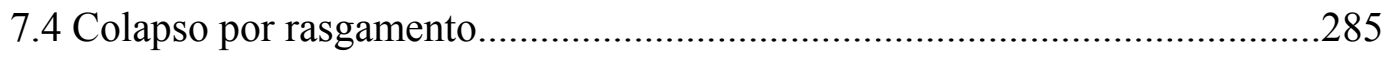

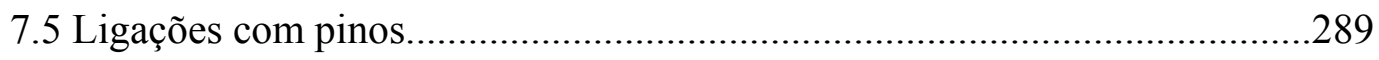

COMENTÁRIOS FINAIS E CONCLUSÕES..................................................298

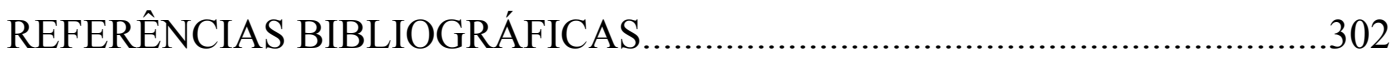




\section{LISTA DE FIGURAS}

\section{CAPÍTULO 1}

FIGURA 1-1 Geometria de rebites padrão.......................................................6

FIGURA 1-2 .Perfil básico para roscas métricas ISO ...............................................8

FIGURA 1-3 Identificação dos parafusos A325 e A490..........................................

FIGURA 1-4 Transmissão de esforços por atrito...................................................10

FIGURA 1-5 Transmissão de esforços por contato..............................................11

FIGURA 1-6 Relação típica força versus rotação da porca para parafusos A325 e A490.. 12

FIGURA 1-7 Alongamento em parafusos em um típico teste de ligação 15

FIGURA 1-8 Tração no parafuso versus alongamento para parafusos A490 de pequeno comprimento de pega.......................................................16

FIGURA 1-9 Sistemas de indicação direta de tração..............................................18

FIGURA 1-10 Parafusos ASTM A307 ...............................................................19

FIGURA 1-11 (a) Instalação repetida de parafusos A325 ......................................24

FIGURA 1-11 (b) Instalação repetida de parafusos A490......................................24

FIGURA 1-12 Comparação da relação tração no parafuso versus alongamento, entre parafusos A325 de $25 \mathrm{~mm}$ galvanizados e não galvanizados. .25

FIGURA 1-13 Furos em parafusos de alta resistência com diâmetro menor que $24 \mathrm{~mm}$.

FIGURA 1-14 Tração em parafusos A325 de 25 mm de diâmetro, apertados pelo método da rotação da porca, para furos normais, alargados e alongados. 30

FIGURA 1-15 Comparação entre os coeficientes de atrito médios .31

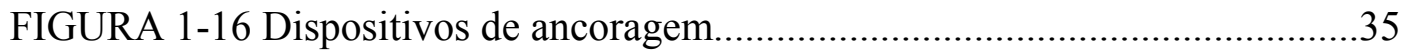

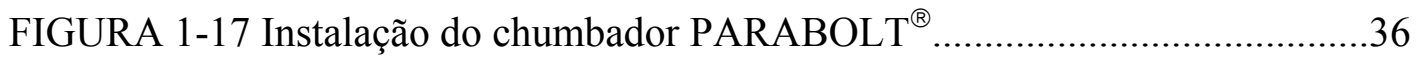

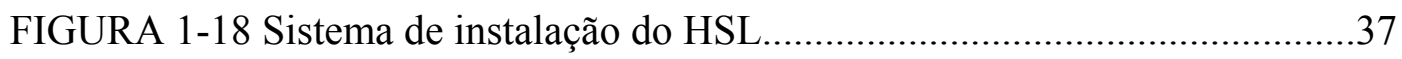

FIGURA 1-19 Sistema de instalação do HVA........................................................38

FIGURA 1-20 Sistema de instalação do Hilt Kwik Bolt II......................................39

FIGURA 1-21 Sistema de instalação do HDI.........................................................40

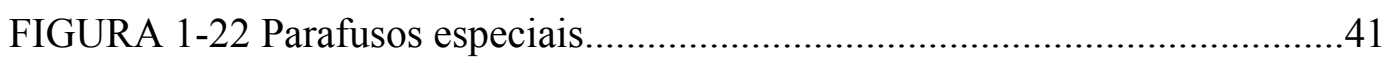


FIGURA 1-23 Seqüência de aperto para conectores Huck .42

FIGURA 1-24 Conectores cegos Huck................................................................42

FIGURA 1-25 Parafuso com resina comprimida................................................43

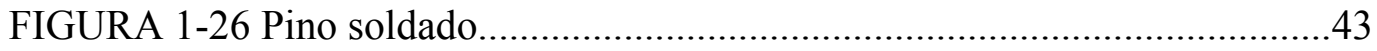

FIGURA 1-27 (a) Fixador auto-atarraxante..........................................................44

FIGURA 1-27 (b) Roscas para o conector auto-atarraxante...................................44

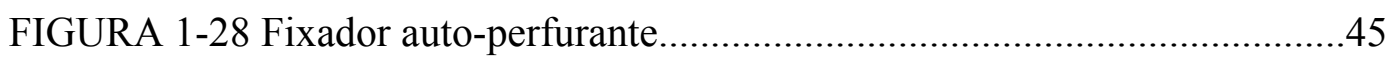

\section{CAPÍTULO 2}

FIGURA 2-1 Evolução dos processos de soldagem ao longo do tempo. .50

FIGURA 2-2 (a) Representação do circuito de soldagem e do oscilograma da tensão e da corrente no instante do acendimento do $\operatorname{arco}$ .52

FIGURA 2-2 (b) Aspecto do arco elétrico. .52

FIGURA 2-3 Representação do processo de soldagem a arco com eletrodo revestido (SMAW), processo manual. .55

FIGURA 2-4 Representação do processo de soldagem a arco submerso $(\mathrm{SAW}) \ldots . . . .57$

FIGURA 2-5 Representação do processo de soldagem com gás de proteção (GMAW)..... .60

FIGURA 2-6 Esquemas de transferência mostrando o comportamento da tensão e da corrente de soldagem. 62

FIGURA 2-7 Representação do processo de soldagem eletro-escória (ESW) .68

FIGURA 2-8 (a) Fases da soldagem de um conector tipo cavilha de cabeça.............71

FIGURA 2-8 (b) Pistola para soldadura automática de conectores. . .71

FIGURA 2-9 Juntas soldadas .86

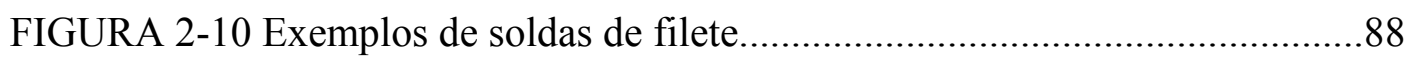

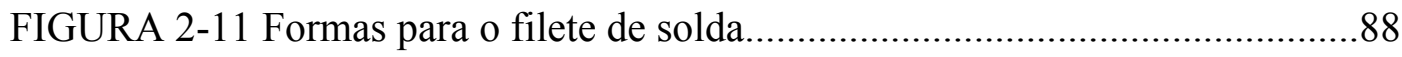

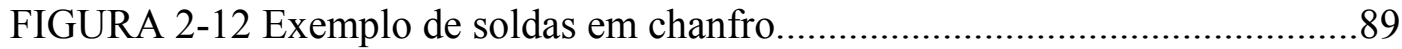

FIGURA 2-13 Exemplos de solda de tampão..........................................................90

FIGURA 2-14 Símbolos de solda segundo a AWS 2.4 ..........................................90 
FIGURA 2-15 Solda de filete com múltiplos passes..........................................92

FIGURA 2-16 Preparações de extremidades de soldas em chanfro...........................94

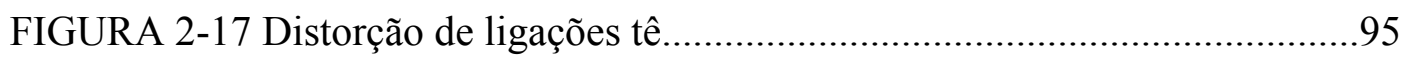

FIGURA 2-18 Exemplos de defeitos de mordedura.............................................97

FIGURA 2-19 Exemplos de inclusão de escória......................................................98

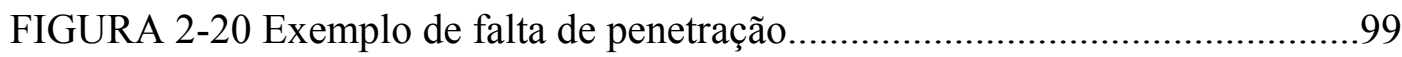

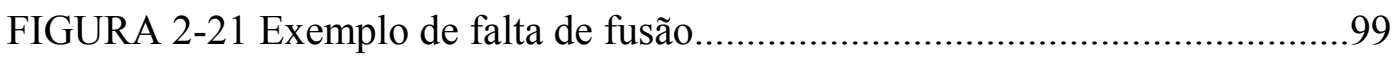

FIGURA 2-22 Exemplos de trincas na zona afetada pelo calor.............................101

FIGURA 2-23 Exemplos de trincas devido a solidificação do metal de solda...........102

FIGURA 2-24 Rasgo lamelar. 103

FIGURA 2-25 Esquema do teste de inspeção de fissuras por líquidos penetrantes 106

FIGURA 2-26 Influência dos defeitos no fluxo magnético......................................106

FIGURA 2-27 Fundamentos do método de inspeção por radiografia. 107

FIGURA 2-28 Exemplos de detecção de defeitos pelo método ultrasônico. 109

\section{CAPÍTULO 3}

FIGURA 3-1 (a) Conectores submetidos à tração.

FIGURA 3-1 (b) Conectores submetidos à força cortante.

FIGURA 3-1 (c) Conectores submetidos à tração e força cortante combinadas...... .111

FIGURA 3-2 Possíveis modos de falha em conexões parafusadas

FIGURA 3-3 Falha por cisalhamento no parafuso.

FIGURA 3-4 Resistência à pressão de contato relacionada com a distância à borda

FIGURA 3-5 (a) Símbolos de espaçamento de conectores.

FIGURA 3-5 (b) Distância de extremidade e borda para furos alongados.

FIGURA 3-6 (a),(b),(c) Representação esquemática de três estágios de carregamento numa conexão parafusada. 
FIGURA 3-6 (d) Força cortante nos parafusos em função do estágio de carregamento 125

FIGURA 3-7 Típicas curvas tensão de cisalhamento versus deslocamento relativo para parafusos A325 e

A490. 126

FIGURA 3-8 Típico gráfico força-deslocamento relativo para parafusos de $20 \mathrm{~mm}$ de diâmetro em cisalhamento 127

FIGURA 3-9 Dimensões $d_{1}$ e $d_{2}$, referentes a cabeça do parafuso ou porca. 133

FIGURA 3-10 (a) Diagrama de interação para parafusos comuns sob combinação de tração e força cortante. 134

FIGURA 3-10 (b) Aproximação do AISC/LRFD 93 [ 4 ] e NBR 8800 [ 7 ]. 134

FIGURA 3-11 Comportamento força-deslizamento em conexão com um único parafuso de alta resistência de $19 \mathrm{~mm}$ de diâmetro, em cisalhamento duplo 139

FIGURA 3-12 (a) Ensaio de curta duração 143

FIGURA 3-12 (b) Ensaio de longa duração (fluência). 143

FIGURA 3-12 (c) Dispositivo de ensaio. 143

FIGURA 3-13 Comportamento típico força-deslizamento observado nos ensaios, indicando a definição da força crítica de deslizamento 144

FIGURA 3-14 Influências dos métodos de aperto na tração no parafuso, para parafusos de diferentes lotes 151

FIGURA 3-15 (a) Relação força versus alongamento em parafusos A490 testados em tração por torque e tração direta. 152

FIGURA 3-15 (b) Relação força versus alongamento em parafusos A325 testados em tração por torque e tração direta 152

FIGURA 3-16 (a) Comportamento de parafusos A490 tracionados diretamente após torque 152

FIGURA 3-16 (b) Comportamento de parafusos A325 tracionados diretamente após torque 152

FIGURA 3-17 (a) Chapas conectadas por um parafuso pré-tracionado sob ação de tração externa 
FIGURA 3-17 (b) Forças na situação inicial: sem tração externa. 153

FIGURA 3-17 (c) Forças na situação final: com tração externa. 153

FIGURA 3-18 Gráficos relacionando tração final versus força externa aplicada......155

FIGURA 3-19 Gráfico de $T_{f}$ versus $P$ : modelo da NBR 8800 [ 7 ]. 155

FIGURA 3-20 Resistência média à força cortante em função do comprimento da conexão 156

FIGURA 3-21 Coeficiente $\beta$ proposto para levar em consideração a redução na capacidade de conexões parafusadas longas.

FIGURA 3-22 Comparação dos planos efetivos de cisalhamento .158

\section{CAPÍTULO 4}

FIGURA 4-1 Definições para filetes de solda. 160

FIGURA 4-2 Definições para soldas em chanfro.

FIGURA 4-3 Exemplos de gargantas efetivas em soldas de penetração parcial executadas pelo processo SMAW.

FIGURA 4-4 Garganta efetiva para soldas em superfícies curvas (flare groove welds). 162

FIGURA 4-5 Soldas em chanfro em juntas tê. 164

FIGURA 4-6 Efeito da espessura na dissipação do calor 165

FIGURA 4-7 (a), (b) Dimensão máxima do filete de solda. .166

FIGURA 4-7 (c) Motivo da limitação. 166

FIGURA 4-8 Soldas de filete intermitentes. 168

FIGURA 4-9 (a) Ligações de filete por superposição. 168

FIGURA 4-9 (b) Rotação excessiva em ligações por superposição. 168

FIGURA 4-10 Retornos de soldas de filete. .169

FIGURA 4-11 Limitações para furos e rasgos em soldas de tampão 170

FIGURA 4-12 Exemplo de solda de filete em furo ou rasgo.

FIGURA 4-13 (a) Solda alongada na direção da força. 171

FIGURA 4-13 (b) Solda convencional. 171

FIGURA 4-14 (a) Soldas insatisfatórias para conexões tracionadas. 172

FIGURA 4-14 (b) Soldas satisfatórias para conexões tracionadas. 
FIGURA 4-15 Conduta de soldas com filetes laterais curtos, amplamente espaçados. 172

FIGURA 4-16 Largura efetiva de uma ligação te não enrijecida.............................174

FIGURA 4-17 Comportamento força-deformação em filetes de solda....................175

FIGURA 4-18 Análise de soldas de filete..............................................................176

FIGURA 4-19 Distribuição típica de tensões em filetes de solda.....

FIGURA 4-20 Espessura da garganta efetiva para soldas de filete de penetração profunda. 188

\section{CAPÍTULO 5}

FIGURA 5-1 Tipos de conexões viga-pilar. 192

FIGURA 5-2 Conexões parafusadas sob força excêntrica.

FIGURA 5-3 Gráfico força versus rotação, idealizado para um grupo de parafusos solicitados excentricamente. 195

FIGURA 5-4 Excentricidade no plano de cisalhamento dos parafusos. 196

FIGURA 5-5 Força resultante devido ao momento 197

FIGURA 5-6 (a) Centro instantâneo de rotação para grupo de parafusos sob força qualquer.

FIGURA 5-6 (b) centro instantâneo de rotação para grupo de parafusos sob força paralela às colunas de parafusos. 199

FIGURA 5-7 Curva força-deformação em parafusos. 201

FIGURA 5-8 Exemplo de cálculo. .204

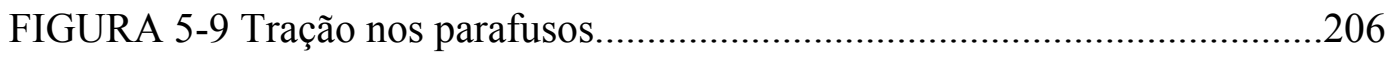

FIGURA 5-10 Distribuição de tensões............................................................207

FIGURA 5-11 Distribuição dos parafusos..........................................................209

FIGURA 5-12 Dimensões da conexão adotada no exemplo..................................211

FIGURA 5-13 Conexões por atrito com parafusos nas extremidades.....................213

FIGURA 5-14. Conexões por contato com parafusos nas extremidades..................214

FIGURA 5-15 Dimensões da conexão adotada no exemplo...................................216

FIGURA 5-16 Determinação das tensões admitindo distribuição

linear. .217 
FIGURA 5-17 Distribuição de tensões considerando análise

plástica 218

FIGURA 5-18 Conexão por contato com parafusos uniformemente espaçados. 219

FIGURA 5-19 Conexão viga pilar com tê nas mesas. 221

FIGURA 5-20 Deformação da ligação, mostrando o efeito alavanca. .221

FIGURA 5-21 Influência da rigidez à flexão das chapas em conexões tracionadas. .222

FIGURA 5-22 Conexões com quatro fileiras de parafusos.

FIGURA 5-23 Esquema de forças do efeito alavanca, modelo de Douty e

McGuire .224

FIGURA 5-24 Comparação entre resultados experimentais e analíticos pela expressão da ASCE (5.3.2). .225

FIGURA 5-25 Comparação entre resultados analíticos e

experimentais. .226

FIGURA 5-26 Esquema de forças do efeito alavanca, modelo de McCauley. .227

FIGURA 5-27 Efeito alavanca: modelo de viga. .232

FIGURA 5-28 Comparação entre razões Q/T teóricas e analíticas. 236

FIGURA 5-29 (a) Influência das deformações da mesa na localização da força resultante no parafuso.

FIGURA 5-29 (b) Definição de $b^{\prime}$ e $a^{\prime}$.

FIGURA 5-30 Comparação entre razões Q/T analíticas e experimentais com as distâncias modificadas.

FIGURA 5-31 Conexão do exemplo para a avaliação do efeito alavanca. 237

\section{CAPÍTULO 6}

FIGURA 6-1 Conexões soldadas com carregamento excêntrico. .241

FIGURA 6-2 Excentricidade no plano das soldas.

FIGURA 6-3 Análise do grupo de soldas apresentada em OWENS \& CHEAL [50] 
FIGURA 6-4 Grupo de soldas sob carregamento excêntrico: método do centro instantâneo de rotação

FIGURA 6-5 Análise de conexão soldada sob carregamento excêntrico

FIGURA 6-6 Excentricidade fora do plano das soldas. .253

FIGURA 6-7 Distribuição de tensões na solda. .256

FIGURA 6-8 (a) Cordão de solda sem "restrição". 257

FIGURA 6-8 (b) Cordão de solda com "restrição" na zona comprimida. .257

FIGURA 6-9 Forças atuando na solda. Modelo de DAWE \& KULAK [ 21 ]........258

\section{CAPÍTULO 7}

FIGURA 7-1 Tipos de emendas. 262

FIGURA 7-2 Emendas com cobrejuntas .263

FIGURA 7-3 Emenda no local de variação de seção 263

FIGURA 7-4 (a) Emenda de viga com solda de entalhe. .264

FIGURA 7-4 (b) Emenda de viga com chapas e solda de filete. .264

FIGURA 7-5 Emenda parafusada de perfil laminado.........................................264

FIGURA 7-6 Emendas em vigas com chapa de topo.........................................267

FIGURA 7-7 (a) Emenda parafusada com cantoneira simples..............................268

FIGURA 7-7 (b) Emenda parafusada com cantoneira dupla e chapa de miolo........268

FIGURA 7-7 (c) Emenda soldada com cantoneira dupla e chapa de miolo..............268

FIGURA 7-8 Exemplos de perfis soldados. 270

FIGURA 7-9 Distribuição de tensões normais e de cisalhamento na

flexão. 271

FIGURA 7-10 (a) Distribuição real da tensão de cisalhamento em seção

"I"...... .272

FIGURA 7-10 (b) Distribuição uniforme da tensão de cisalhamento na alma em seção

"I". 272

FIGURA 7-11 Ligações flexíveis com cantoneiras de assento. .273

FIGURA 7-12 Vigas apoiadas em cantoneiras de assento. 
FIGURA 7-13 Distribuição da pressão de contato..............................................277

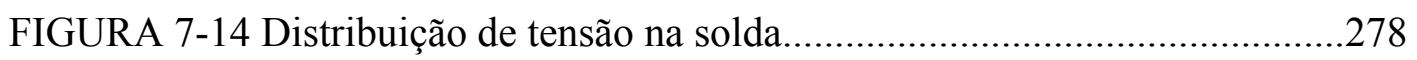

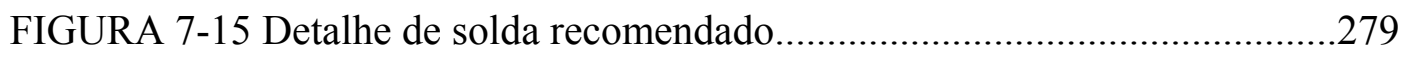

FIGURA 7-16 Conexões flexíveis com cantoneiras de alma.................................280

FIGURA 7-17 Hipótese da distribuição da força e momento na solda da cantoneira. .281

FIGURA 7-18 Tensões no ponto crítico da solda..............................................281

FIGURA 7-19 Distribuição das forças de tração nos parafusos..............................228

FIGURA 7-20 Forças de cisalhamento nos parafusos.........................................283

FIGURA 7-21 Conexão flexível viga-pilar utilizando chapa de cisalhamento..........284

FIGURA 7-22 Exemplos de colapso por rasgamento...........................................285

FIGURA 7-23 Bloco de cisalhamento em tração..................................................287

FIGURA 7-24 (a), (b), (c) Exemplos de cisalhamento em bloco (área efetiva de

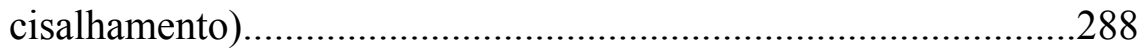

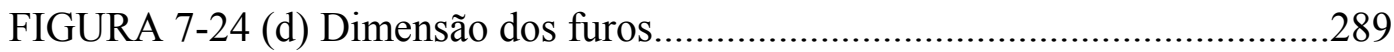

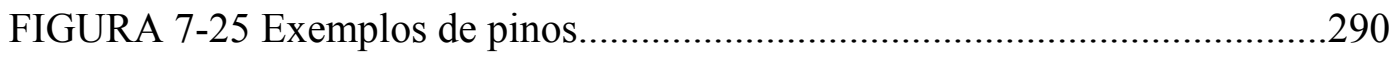

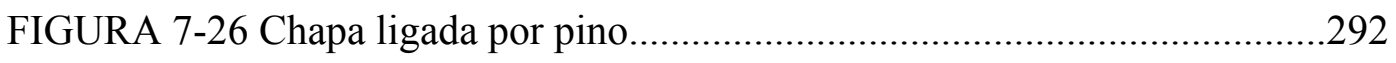

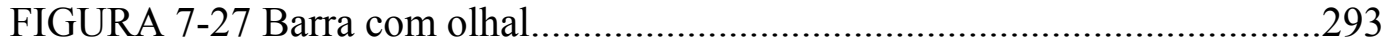

FIGURA 7-28 Chapa ligada por pino de acordo com o AISC/LRFD 93 [ 4 ].........294

FIGURA 7-29 Forças atuantes no pino................................................................295

FIGURA 7-30 Condições geométricas para chapas em conexões com pinos...........296 


\section{LISTA DE TABELAS}

\section{CAPÍTULO 1}

TABELA 1-1 - Características geométricas de parafusos de alta resistência. .6

TABELA 1-2 Força mínima de pré-tração no parafuso. . .12

TABELA 1-3. Rotação da porca a partir da posição de pré-torque. 14

TABELA 1-4 Características geométricas de parafusos comum. .19

TABELA 1-5 Dimensões nominais dos furos.. 28

TABELA 1-6 Limitações relativas ao emprego de furos alargados ou alongados........32

TABELA 1-7 Parafusos usinados, sextavados, em mm. .34

TABELA 1-8 Tabela dimensional e de resistência do chumbador

PARABOLT $^{\circledR} \ldots . .36$

TABELA 1-9 Tabela dimensional e de resistência do HSL .37

TABELA 1-10 Tabela dimensional e de resistência do HVA. .38

TABELA 1-11 Tabela dimensional e de resistência do Hilt Kwik Bolt II Padrão........39

TABELA 1-12 Tabela dimensional e de resistência do HDI. 40

\section{CAPÍTULO 2}

TABELA 2-1 Características e aplicações de processos de soldagem...... .53

TABELA 2-2 Condições de emprego dos processos de soldagem. .53

TABELA 2-3 Algumas características dos modos de transferência. 63

TABELA 2-4 Características definidas pelo penúltimo dígito da classificação AWS, para soldagem SMAW. 74

TABELA 2-5 Classificação comparativa de desempenho dos consumíveis mais utilizados em soldagem SMAW.

TABELA 2-6 Recomendações para a soldagem de aço-carbono, pelo processo SMAW

TABELA 2-7 Requisitos de propriedades mecânicas para o metal de solda, em soldagem SAW. .78

TABELA 2-8 Composição química de eletrodos para soldagem SAW 
TABELA 2-9 Parâmetros para soldagem de aço-carbono com soldagem SAW automática

TABELA 2-10 Composição química dos eletrodos nus para soldar aço-carbono e requisitos de propriedades mecânicas dos cordões de solda em CCPR $(+)$ (soldagem TIG e MIG/MAG) .82

TABELA 2-11 Valores recomendados para soldagem de aço-carbono, em soldagem TIG .82

TABELA 2-12 Parâmetros para soldagem MIG/MAG 83

TABELA 2-13 Tolerâncias dimensionais para os perfis soldados. .96

TABELA 2-14 Descontinuidades encontradas nos processos de soldagem 97

TABELA 2-15 Principais características dos métodos de inspeção de soldas 110

\section{CAPÍTULO 3}

TABELA 3-1 Valores de $\eta_{1}$ e $\eta_{2}$ 116

TABELA 3-2 Valores do incremento $C_{2}$ da distância de borda. 117

TABELA 3-3 Valores do incremento $C_{l}$ do espaçamento

TABELA 3-4 Resistência de cálculo à pressão de contato, baseada no diâmetro do parafuso 120

TABELA 3-5 Distância mínima do centro de um furo padrão à borda 123

TABELA 3-6 Propriedades mecânicas de parafusos comuns ISO. 130

TABELA 3-7 Propriedades mecânicas de parafusos de alta resistência ISO 130

TABELA 3-8 Valores de área bruta e área efetiva à tração 132

TABELA 3-9 Tração e força cortante combinadas, segundo a NBR 8800 [ 7 ]......135

TABELA 3-10 Resistências de conectores, segundo o AISC/LRFD 93 [ 4 ] e AISC/ASD [ 1 ]

TABELA 3-11 Tração e força cortante combinadas, segundo o RCSC

TABELA 3-12 Tensões críticas de "cisalhamento" por plano de contato para parafusos em conexões por atrito

TABELA 3-13 Valores do coeficiente de atrito $\mu$, segundo o EUROCODE 3 [ 24 ] 
TABELA 3-14 Valores do coeficiente de atrito $\mu$, segundo a NBR 8800 [ 7 ]........150

\section{CAPÍTULO 4}

TABELA 4-1 Garganta efetiva em soldas em chanfro de penetração parcial...... 162

TABELA 4-2 Dimensão mínima de uma solda de filete. .165

TABELA 4-3 Espessura mínima da garganta efetiva de uma solda em chanfro de penetração parcial. 165

TABELA 4-4 Propriedades mecânicas dos eletrodos e aços para metal base. 179

TABELA 4-5 Valores para o fator de correlação. 183

TABELA 4-6 Resistência de cálculo ao cisalhamento de soldas de filete $\phi R_{n}$, em $\mathrm{N} / \mathrm{mm}$, pelo processo SMAW 184

TABELA 4-7 Resistência de cálculo ao cisalhamento de soldas de filete $\phi R_{n}$, em $\mathrm{N} / \mathrm{mm}$, pelo processo SAW 185

TABELA 4-8 Resistência de cálculo de solda de chanfro de penetração total, de acordo com o AISC/LRFD 93 [ 4 ].... 186

TABELA 4-9 Resistência de cálculo de solda de chanfro de penetração total, de acordo com a NBR 8800 [ 7 ]

TABELA 4-10 Resistência de cálculo de solda de chanfro de penetração parcial, de acordo com o AISC/LRFD 93 [ 4 ].

TABELA 4-11 Resistência de cálculo de solda de chanfro de penetração parcial, de acordo com a NBR 8800 [ 7 ].

TABELA 4-12 Tensões admissíveis nas soldas, de acordo com o AISC/ASD [ 1 ]

\section{CAPÍTULO 5}

TABELA 5-1 Resistência ao deslizamento.

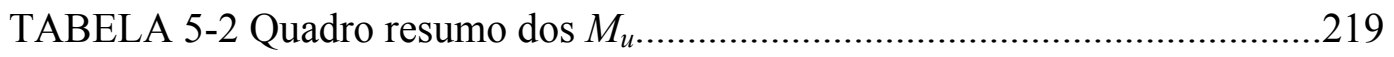

TABELA 5-3 Quadro resumo das forças alavanca..............................................240 
LISTA DE ABREVIATURAS E SIGLAS

\begin{tabular}{|c|c|}
\hline AISC & - American Institute of Steel Construction \\
\hline ANSI & - American National Standards Institute \\
\hline ASCE & - American Society of Civil Engineers \\
\hline ASD & - Allowable Stress Design \\
\hline ASTM & - American Society for Testing and Materials \\
\hline AWS & - American Welding Society \\
\hline $\mathrm{BS}$ & - British Standard \\
\hline $\mathrm{CA}$ & - Corrente Alternada \\
\hline $\mathrm{CC}$ & - Corrente Contínua \\
\hline CCPD & - Corrente Contínua de Polaridade Direta \\
\hline CCPR & - Corrente Contínua de Polaridade Reversa \\
\hline $\mathrm{CG}$ & - Centro de Gravidade \\
\hline CIR & - Centro Instantâneo de Rotação \\
\hline DIN & - Deutsche Institüt für Nurmung \\
\hline ECCS & - European Convention for Constructional Steelwork \\
\hline EESC & - Escola de Engenharia de São Carlos \\
\hline EGW & - Electrogas Welding \\
\hline ESW & - Electroslag Welding \\
\hline EUROCODE & - European Committee for Standardization \\
\hline FCAW & - Flux Cored Arc Welding \\
\hline GCSS & - German Committee for Structural Steelwork \\
\hline GMAW & - Gas Metal Arc Welding \\
\hline IPT & - Instituto de Pesquisas Tecnológicas \\
\hline ISO & - International Organization for Standardization \\
\hline LN & - Linha Neutra \\
\hline LNP & - Linha Neutra Plástica \\
\hline LRFD & - Load and Resistance Factor Design \\
\hline MAG & - Metal Active Gas \\
\hline MIG & - Metal Inert Gas \\
\hline NBR & - Norma Brasileira Registrada \\
\hline
\end{tabular}


RCRBS - Research Council on Riveted and Bolted Structural Joints

RCSC - Research Council on Structural Connections

SAW - Submerged Arc Welding

SET

- Departamento de Engenharia de Estruturas da Escola de Engenharia de São Carlos

SSPC - Steel Structures Painting Council

TIG - Tungsten Inert Gas

UNC - - Tipo de rosca apresentada na especificação ANSI B1.1-1974 


\section{LISTA DE SÍMBOLOS}

a) Letras romanas maiúsculas

A - área da seção transversal bruta do parafuso ou pino (EUROCODE 3);

- corrente

$A_{b} \quad$ - área efetiva de contato

$\mathrm{A}_{\mathrm{c}} \quad$ - área efetiva de pressão de contato entre as chapas

$\mathrm{A}_{\mathrm{cob}} \quad$ - área da cobrejunta

$\mathrm{A}_{\mathrm{f}} \quad$ - área de cada mesa

$\mathrm{A}_{\mathrm{g}} \quad$ - área bruta

$\mathrm{A}_{\mathrm{gt}} \quad$ - área bruta sujeita à tração (AISC)

$\mathrm{A}_{\mathrm{gv}} \quad$ - área bruta sujeita ao cisalhamento (AISC)

$\mathrm{A}_{\mathrm{i}} \quad$ - área dos parafusos tracionados, à distância $d_{i}$ em relação à extremidade da chapa

$\mathrm{A}_{\mathrm{MB}} \quad$ - área teórica da face de fusão

$\mathrm{A}_{\mathrm{n}} \quad$ - área líquida

$\mathrm{A}_{\text {net }} \quad$ - área da seção líquida (EUROCODE 3)

$\mathrm{A}_{\mathrm{nt}} \quad$ - área líquida sujeita à tração (AISC)

$\mathrm{A}_{\mathrm{nv}} \quad$ - área líquida sujeita ao cisalhamento (AISC)

$\mathrm{A}_{\mathrm{p}} \quad$ - área da seção transversal bruta do parafuso

$\mathrm{A}_{\mathrm{pb}} \quad$ - área efetiva de pressão de contato (AISC)

$\mathrm{A}_{\mathrm{r}} \quad$ - área efetiva do parafuso

$\mathrm{A}_{\mathrm{s}} \quad$ - área efetiva à tração (EUROCODE 3)

$\mathrm{A}_{\mathrm{sf}} \quad$ área efetiva ao cisalhamento (AISC)

$A_{t} \quad$ - área sujeita a tensões normais;

- área total das cobrejuntas

$\mathrm{A}_{\mathrm{V}} \quad$ - área sujeita a tensões de cisalhamento

$\mathrm{A}_{\mathrm{v} . \text { eff }}$ - área efetiva de cisalhamento (EUROCODE 3)

$\mathrm{A}_{\mathrm{w}} \quad$ - área da alma;

- área efetiva da solda;

$\mathrm{A}_{\mathrm{w}} \quad$ - área efetiva da solda de tampão que deve ser tomada como a área do furo ou 
rasgo (EUROCODE 3);

- área efetiva de cisalhamento da seção do pino

B - tração no parafuso incluindo o efeito alavanca

$\mathrm{B}_{\mathrm{p} . \mathrm{Rd}}$ - resistência de cálculo à força cortante por puncionamento do metal base junto à cabeça do parafuso ou porca (EUROCODE 3)

$\mathrm{B}_{\mathrm{R}} \quad$ - resistência de cálculo à tração do parafuso

C - constante;

- coeficiente adimencional que provem da relação entre $P$ e $r_{v}$ (AISC)

$\mathrm{C}_{\mathrm{f}} \quad$ - resultante das pressões de contato na situação final (com $P$ )

$\mathrm{C}_{\mathrm{i}} \quad$ - resultante das pressões de contato na situação inicial (sem $P$ )

$\mathrm{C}_{1}$ - incremento do espaçamento entre furos (AISC)

$\mathrm{C}_{2}$ - incremento da distância de borda (AISC)

$\mathrm{C}_{0} \quad$ - resultante da pressão de contato

E - módulo de elasticidade do aço

$\mathrm{F}_{\mathrm{b} . \mathrm{Rd}}$ - resistência de cálculo à pressão de contato (EUROCODE 3)

$\mathrm{F}_{\mathrm{EXX}}$ - resistência à tração do metal da solda (AISC)

$\mathrm{F}_{\mathrm{M}} \quad$ - força proveniente do momento

$\mathrm{F}_{\mathrm{Mx}}$ - força resultante do momento na direção $x$

$\mathrm{F}_{\mathrm{My}}$ - força resultante do momento na direção $y$

$\mathrm{F}_{\mathrm{p} . \mathrm{Cd}}$ - força de pré-tração (EUROCODE 3)

$F_{R} \quad$ - força resultante

$\mathrm{F}_{\mathrm{r}} \quad$ - força resultante mediante a soma vetorial das parcelas provenientes da força concêntrica e do momento de torção

$\mathrm{F}_{\mathrm{Sd}} \quad$ - força normal à seção do pino (EUROCODE 3)

$\mathrm{F}_{\text {s.Rd }} \quad$ - resistência de cálculo ao deslizamento (EUROCODE 3)

$\mathrm{F}_{\text {s.Rd.ser }}$ - resistência ao deslizamento (EUROCODE 3)

$\mathrm{F}_{\text {t.Rd }} \quad$ - resistência de cálculo à tração (EUROCODE 3)

$\mathrm{F}_{\mathrm{t} . \mathrm{Sd}} \quad$ - força de tração de cálculo (EUROCODE 3)

$\mathrm{F}_{\mathrm{u}} \quad$ - resistência à tração do metal base (AISC)

$\mathrm{F}_{\mathrm{V}} \quad$ - força resultante vertical

$\mathrm{F}_{\mathrm{v}} \quad$ - tensão crítica de "cisalhamento" para conexões sujeitas somente à força cortante (AISC) 
$\mathrm{F}_{\mathrm{vd}} \quad$ - força cortante de cálculo nos parafusos

$\mathrm{F}_{\mathrm{v} . \mathrm{Rd}}$ - resistência de cálculo à força cortante (EUROCODE 3)

$\mathrm{F}_{\mathrm{v} . \mathrm{Sd}}$ - força cortante de cálculo (EUROCODE 3)

$\mathrm{F}_{\mathrm{V} . S d . s e r}$ - força cortante nominal (EUROCODE 3)

$\mathrm{F}_{\mathrm{w} . \mathrm{Rd}}$ - resistência de cálculo por unidade de comprimento (EUROCODE 3)

$\mathrm{F}_{\mathrm{x}}, \mathrm{F}_{\mathrm{y}}, \mathrm{F}_{\mathrm{z}}$ - força na direção $x, y$ e $z$, respectivamente

$\mathrm{F}_{0} \quad$ - força por comprimento de solda localizada à uma distância unitária do CG do grupo de soldas

$\mathrm{H}_{\mathrm{b}} \quad$ - resultante das tensões

I - momento de inércia

$\mathrm{I}_{\mathrm{f}} \quad$ - momento de inércia das mesas

$\mathrm{I}_{\mathrm{p}} \quad$ - momento de inércia polar

$\mathrm{I}_{\mathrm{t}} \quad$ - momento de inércia total

$\mathrm{I}_{\mathrm{w}} \quad$ - momento de inércia da alma

$\mathrm{I}_{\mathrm{X}} \quad$ - momento de inércia em relação ao eixo $x$

$\mathrm{I}_{\mathrm{y}}$ - momento de inércia em relação ao eixo $y$

$\mathrm{I}_{\mathrm{xx}}, \mathrm{I}_{\mathrm{yy}}$ - momentos de inércia das linhas de soldas individuais, com respeito a seus próprios eixos centroidais (admitindo-se espessura unitária)

$\mathrm{K}$ - fator que relaciona $M$ com o momento de plastificação na junção mesaalma

L - comprimento da cantoneira;

- comprimento efetivo da solda ;

- comprimento total do grupo de soldas;

- espaçamento ou distância (AISC)

$\mathrm{L}_{\mathrm{s}} \quad$ - comprimento de solda necessário

$\mathrm{L}_{\mathrm{v}} \quad$ - comprimento da solda

$\mathrm{L}_{\mathrm{v}}, \mathrm{L}_{\mathrm{v} . \text {.eff }}$ - comprimentos referentes ao bloco de cisalhamento (EUROCODE 3)

$\mathrm{L}_{\mathrm{w}} \quad$ - comprimento da solda em metros (EUROCODE 3)

$\mathrm{L}_{1}$ - comprimento total de sobreposição na direção da transferência da força (EUROCODE 3)

$\mathrm{L}_{1}, \mathrm{~L}_{2}$ - comprimentos referentes ao bloco de cisalhamento (EUROCODE 3) 
M - momento atuando na conexão

$M_{B} \quad$ - momento junto ao eixo do parafuso

$\mathrm{M}_{\mathrm{f}} \quad$ - momento fletor transmitido pelas mesas

$\mathrm{M}_{\mathrm{n}} \quad$ - momento nominal

$M_{p} \quad$ - momento de plastificação

$\mathrm{M}_{\mathrm{Rd}}$ - resistência de cálculo à flexão do pino (EUROCODE 3)

$\mathrm{M}_{\mathrm{Sd}}$ - momento fletor em um pino (EUROCODE 3)

$\mathrm{M}_{\mathrm{S}} \quad$ - momento estático

$\mathrm{M}_{\mathrm{ue}} \quad$ - momento último obtido pelo método elástico tradicional

$\mathrm{M}_{\mathrm{us}} \quad$ - momento último obtido pelo método simplificado

$\mathrm{M}_{\text {up }} \quad$ - momento último obtido pelo método plástico

$\mathrm{M}_{\mathrm{w}} \quad$ - momento fletor transmitido pela alma

$\mathrm{M}_{\mathrm{x}} \quad$ - momento devido a excentricidade da força na direção $x$

- momento fletor em relação ao eixo $x$

$\mathrm{M}_{\mathrm{y}} \quad$ - momento devido a excentricidade da força na direção $y$

$\mathrm{M}_{1}, \mathrm{M}_{2}$ - momentos atuando nas faces da solda, necessários para o equilíbrio;

- momentos provenientes de forças excêntricas

$M_{1} \quad$ - momento fletor na interface entre a alma e a mesa;

- momento fletor que não ocasiona o descolamento entre as partes

$\mathrm{M}_{2} \quad$ - momento fletor que leva ao descolamento da parte superior da chapa;

- momento na linha do parafuso

$M_{3} \quad$ - momento fletor que caracteriza o estado limite último de plastificação total

$\mathrm{N}$ - extensão mínima do apoio

$\mathrm{N}_{\mathrm{b}}$ - número de parafusos em uma ligação (AISC)

$\mathrm{N}_{\mathrm{d}} \quad$ - solicitação normal de cálculo

$\mathrm{N}_{\mathrm{i}} \quad$ - força normal transmitida para cada elemento

$\mathrm{N}_{\text {net.Rd }}$ - plastificação da seção líquida (EUROCODE 3)

$\mathrm{N}_{\mathrm{s}} \quad$ - número de planos de contato (AISC)

P - força externa aplicada

$\mathrm{P}_{\mathrm{d}} \quad$ - força de cálculo atuando em um parafuso

$\mathrm{P}_{\mathrm{n}} \quad$ - força que corresponde à resistência nominal da conexão;

- tração transversal 
$\mathrm{P}_{\mathrm{S}} \quad$ - cisalhamento longitudinal

$\mathrm{P}_{\mathrm{t}} \quad$ - cisalhamento transversal

$\mathrm{P}_{\mathrm{x}}, \mathrm{P}_{\mathrm{y}}, \mathrm{P}_{\mathrm{z}}$ - componentes da força $P$

$\mathrm{P}_{\mathrm{u}} \quad$ - força fatorada na conexão, atuando em uma dada excentricidade, para um dado arranjo de parafusos;

- força nominal

Q - força alavanca;

- reações de interface provenientes da contração da solda

$\mathrm{R} \quad$ - abertura da raiz;

- resultante da pressão de contato;

- tensão residual longitudinal

$\mathrm{R}_{\mathrm{d}} \quad$ - reação de apoio de cálculo

$\mathrm{R}_{\mathrm{i}} \quad$ - força resultante de cisalhamento no parafuso em qualquer deslocamento dado;

- resistência ao cisalhamento de um elemento de solda

$\mathrm{R}_{\mathrm{iv}}, \mathrm{R}_{\mathrm{ih}}$ - componente vertical e horizontal da força $R_{i}$

$\mathrm{R}_{\mathrm{i}, \max }$ - força resistente máxima

$R_{i}, R_{j}$ - forças atuando nos elementos de solda verticais e horizontais, respectivamente

$\mathrm{R}_{\mathrm{i}, \text { ult }}$ - força última de cisalhamento em um elemento de comprimento unitário

$\mathrm{R}_{\mathrm{M}} \quad$ - força no parafuso proveniente do momento

$\mathrm{R}_{\mathrm{Mx}}, \mathrm{R}_{\mathrm{My}}$ - componentes da força $R_{M}$ em um parafuso

$\mathrm{R}_{\mathrm{n}} \quad$ - resistência nominal de contato

$\mathrm{R}_{\mathrm{nt}} \quad$ - resistência nominal à tração

$\mathrm{R}_{\mathrm{nv}} \quad$ - resistência nominal à força cortante;

- resistência nominal ao deslizamento

$\mathrm{R}_{\mathrm{Px}}, \mathrm{R}_{\mathrm{py}}$ - força em qualquer parafuso, devida à força $P$

$R_{R} \quad$ - força cortante resultante no parafuso

$\mathrm{R}_{\mathrm{ult}} \quad$ - resistência de cálculo do parafuso ao cisalhamento

$\mathrm{S} \quad$ - profundidade do chanfro

$\mathrm{T}$ - força de tração no parafuso

$\mathrm{T}_{\mathrm{b}}$ - força mínima de pré-tração no parafuso 
$\mathrm{T}_{\mathrm{d}} \quad$ - tração de cálculo no parafuso

$\mathrm{T}_{\mathrm{f}} \quad$ - força de tração no parafuso na situação final, ou seja, atuando $P$

$\mathrm{T}_{\mathrm{i}} \quad$ - tração em cada parafuso

$\mathrm{T}_{\mathrm{m}} \quad$ - tração mínima no parafuso (AISC)

$\mathrm{T}_{\mathrm{n}} \quad$ - tração nominal no parafuso

$\mathrm{T}_{\mathrm{r}} \quad$ - tração resultante

$\mathrm{T}_{\mathrm{u}} \quad$ - tração de cálculo da conexão (AISC)

$\mathrm{T}_{0} \quad$ - pré-tração nos parafusos

$\mathrm{T}_{1}$ - força de tração no parafuso mais solicitado

$\mathrm{V} \quad$ - força cortante

- tensão

$\mathrm{V}_{\mathrm{b}} \quad$ - força vertical resistida pelo comprimento de solda abaixo da linha neutra

$\mathrm{V}_{\mathrm{d}} \quad$ - cortante de cálculo no parafuso

$\mathrm{V}_{\text {eff.Rd }}$ - resistência efetiva do bloco de cisalhamento (EUROCODE 3)

$\mathrm{V}_{\mathrm{n}} \quad$ - cortante nominal no parafuso

W - módulo de resistência elástico

Z - módulo de resistência plástico

b) Letras romanas minúsculas

a - distância do eixo do parafuso à força alavanca;

- dimensão da garganta efetiva da solda;

- distância entre o centro de gravidade do grupo de parafusos e a seção da emenda;

- menor distância da extremidade do furo à extremidade da chapa medida paralelamente à direção da força aplicada

$a_{1}, a_{2}, a_{3}$ - distâncias de borda relativas ao bloco de cisalhamento (EUROCODE 3)

a' - distância corrigida de $a$

b - distância do parafuso à junção mesa-alma;

- largura da chapa;

- perna do filete

$b_{\text {eff }} \quad$ - comprimento efetivo (AISC)

$b_{\mathrm{eH}}$ - comprimento efetivo (EUROCODE 3) 
$\mathrm{b}_{1}, \mathrm{~b}_{2}, \mathrm{~b}_{3}$ - distâncias relacionadas à chapas de ligação de pinos

b' - distância corrigida de $b$

c - distância do parafuso à junção mesa-alma;

- menor distância da extremidade do furo à extremidade da chapa medida perpendicularmente à direção da força aplicada (EUROCODE 3)

d - altura da chapa;

- diâmetro nominal do parafuso;

- distância do elemento de solda ao centro de gravidade do conjunto

$d_{h} \quad$ - diâmetro do furo

$\mathrm{d}_{\mathrm{i}} \quad$ - distância do parafuso genérico $i$ em relação à extremidade da chapa

dL - porção elementar de solda

dM - parcela do momento referente ao elemento de ordenada $y$ em relação ao eixo $\mathrm{x}-\mathrm{X}$

$\mathrm{dM}_{\mathrm{x}}$ - momento no comprimento elementar devido à força na direção $x$

$\mathrm{dM}_{\mathrm{y}} \quad$ - momento no comprimento elementar devido à força na direção $y$

$\mathrm{d}_{\mathrm{m}} \quad$ - média da dimensões $d_{1}$ e $d_{2}$, tomando-se como base o menor valor calculado para a cabeça do parafuso ou porca (EUROCODE 3)

$\mathrm{d}_{\mathrm{o.t}} \quad$ - dimensão do furo na face tracionada (EUROCODE 3)

$\mathrm{d}_{\mathrm{o.v}}$ - dimensão do furo na face cisalhada (EUROCODE 3)

$d_{\mathrm{p}} \quad$ - diâmetro do pino

$\mathrm{d}_{1}, \mathrm{~d}_{2}$ - dimensões referentes à cabeça do parafuso ou porca (EUROCODE 3 )

$\mathrm{d}_{0} \quad$ - diâmetro do furo (EUROCODE 3)

d' - diâmetro do furo paralelo a alma do tê

e - base logarítmica natural;

- distância do centro do furo à borda;

e $\quad$ - distância da reação $R$ à seção crítica;

- excentricidade da força

$\mathrm{e}_{\mathrm{f}} \quad$ - distância da reação $R$ à borda da cantoneira

$\mathrm{e}_{\mathrm{r}} \quad$ - excentricidade reduzida

$\mathrm{e}_{\mathrm{x}}, \mathrm{e}_{\mathrm{y}}, \mathrm{e}_{\mathrm{z}}$ - excentricidade na direção $x, y$ e $z$, respectivamente

$\mathrm{e}_{1} \quad$ - distância do parafuso à borda do tê;

- mínima distância de borda medida na direção da força (EUROCODE 3) 
$\mathrm{e}_{2} \quad$ - distância entre parafusos do tê;

- mínima distância de borda medida na direção perpendicular à força

(EUROCODE 3)

$\mathrm{e}_{3}$ - mínima distância medida perpendicularmente ao eixo do furo alongado (EUROCODE 3)

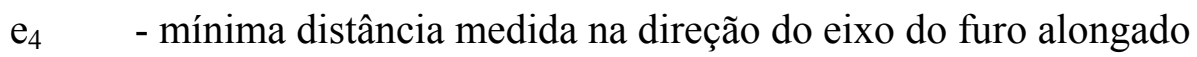
(EUROCODE 3)

f - nariz do chanfro

$\mathrm{f}_{\mathrm{c}} \quad$ - tensão de compressão máxima

$\mathrm{f}_{\mathrm{d}} \quad$ - tensão na alma

$f_{M} \quad$ - tensão devido ao momento

$\mathrm{f}_{\mathrm{p}} \quad$ - tensão admissível de contato (AISC)

$f_{R} \quad$ - tensão resultante

$\mathrm{f}_{\mathrm{t}} \quad$ - tensão admissível à tração do parafuso

$\mathrm{f}_{\mathrm{Td}} \quad$ - resistência de cálculo à tração (em termos de tensão) (AISC)

$f_{u} \quad$ - limite de resistência à tração do aço

$\mathrm{f}_{\mathrm{ub}} \quad$ - resistência à tração do material do parafuso (EUROCODE 3)

$\mathrm{f}_{\mathrm{up}} \quad$ - limite de resistência à tração do material do pino (EUROCODE 3)

$\mathrm{f}_{\mathrm{V}} \quad$ - tensão devido à força cortante

$\mathrm{f}_{\mathrm{Vd}} \quad$ - tensão de cisalhamento de cálculo no parafuso (AISC)

$\mathrm{f}_{\mathrm{v}} \quad$ - tensão de cisalhamento admissível

$\mathrm{f}_{\mathrm{vw} . \mathrm{d}} \quad$ - resistência de cálculo ao cisalhamento (EUROCODE 3)

$\mathrm{f}_{\mathrm{w}} \quad$ - resistência mínima à tração do metal da solda

$\mathrm{f}_{\mathrm{y}} \quad$ - limite de escoamento do aço

$f_{y p} \quad$ - limite de escoamento do aço da chapa (EUROCODE 3);

- limite de escoamento do material do pino (EUROCODE 3)

h - altura da alma

$\mathrm{h}_{\mathrm{f}} \quad$ - distância entre os centros das mesas

k - coeficiente;

- duas vezes a distância da extremidade do filete horizontal ao centro do filete vertical;

- espessura da mesa apoiada na cantoneira de assento; 
- parâmetro utilizado no cálculo da área efetiva

$\mathrm{k}_{\mathrm{s}} \quad$ - parâmetro que relaciona a dimensão dos furos (EUROCODE 3)

$\mathrm{k}_{1}, \mathrm{k}_{2}$ - coeficientes

$1_{\mathrm{S}} \quad$ - comprimento da solda

$1_{1}, 1_{2}, 1_{3}$ - distâncias

m - número de colunas de parafusos;

- número de planos de cisalhamento

$\mathrm{m}_{\mathrm{i}} \quad$ - quantidade de planos de corte necessários por elemento

n - distância do parafuso à posição da força alavanca;

- número dos furos na face de cisalhamento (EUROCODE 3);

- números de parafusos;

- número de parafusos em uma linha paralela à direção da força aplicada;

- número de planos de contato (EUROCODE 3);

- número mínimo de parafusos por coluna

p - espaçamento dos parafusos;

- largura de contribuição da mesa por par de parafusos;

- passo da rosca

$\mathrm{p}_{\mathrm{y}} \quad$ - força perpendicular ao eixo da barra, admitida uniformemente distribuída

$\mathrm{p}_{0} \quad$ - tensão de prova de carga

$p_{1} \quad-$ menor valor entre $e_{1} / 2$ ou $b+d / 2$;

- mínimo espaçamento entre parafusos na direção da força (EUROCODE 3)

$\mathrm{p}_{2}$ - espaçamento entre os parafusos medido perpendicularmente à direção da força (EUROCODE 3);

$p_{2} \quad-$ menor valor entre $e_{2}$ ou $b+d / 2$

q - fluxo de cisalhamento

r $\quad$ - ponto mais afastado em relação ao centro de gravidade;

- raio do chanfro;

- raio na ligação da mesa com a alma (EUROCODE 3);

- raio vetor

$\mathrm{r}_{\text {crit }}$ - distância do centro instantâneo de rotação ao elemento de solda, tendo a mínima razão $\Delta_{\mathrm{u}} / \mathrm{r}_{\mathrm{i}}$

$\mathrm{r}_{\mathrm{i}} \quad$ - coordenada polar do parafuso genérico $i$ em relação ao CIR; 
- distância do elemento de solda ao em relação ao CIR

$\mathrm{r}_{\mathrm{i}, \max }$ - distância radial do elemento crítico de solda

$\mathrm{r}_{\max } \quad$ - coordenada polar do parafuso mais afastado do CIR

$\mathrm{r}_{\mathrm{n}} \quad$ - distância radial do elemento crítico de solda

$\mathrm{r}_{0} \quad$ - distância entre o CIR e o CG da conexão

s - espaçamento de centro a centro dos furos

t - espessura;

- espessura do metal base ao longo do qual a solda é executada (perna do filete) (AISC)

$t_{\mathrm{A}}, \mathrm{t}_{\mathrm{B}}$ - espessuras

$\mathrm{t}_{\mathrm{c}} \quad$ - espessura da mesa para desenvolver a resistência $B_{R}$ nos parafusos sem efeito alavanca

$t_{\mathrm{e}} \quad$ - dimensão da garganta efetiva (AISC)

$t_{\mathrm{f}} \quad$ - espessura da mesa (EUROCODE 3)

$\mathrm{t}_{\min } \quad$ - mínima espessura de chapa para que não ocorra o efeito alavanca

$t_{p} \quad$ - espessura da chapa (EUROCODE 3);

- espessura do metal base sob a cabeça do parafuso ou porca (EUROCODE 3)

$t_{\text {req'd }} \quad$ - espessura da mesa requerida

$t_{\mathrm{w}} \quad$ - espessura da alma

$\mathrm{t}_{1} \quad$ - espessura da chapa

$\mathrm{x}_{0} \quad$ - coordenada do CG tendo como origem o CIR

y - posição da linha neutra

$\mathrm{y}_{\mathrm{i}} \quad$ - ordenada do parafuso genérico em relação à linha neutra

$\mathrm{y}_{0} \quad$ - coordenada do CG tendo como origem o CIR

z $\quad$ - distância entre o centro das mesas do perfil

c) Letras gregas maiúsculas

$\Delta_{\mathrm{i}}$ - deformação no parafuso que inclui deformações no parafuso por cisalhamento, flexão, esmagamento e ainda a deformação local das chapas;

- deformação nos elementos de solda

$\Delta_{\mathrm{i}, \max }$ - valor da deformação no elemento crítico de solda 
$\Delta_{\mathrm{m}} \quad$ - deformação do elemento na máxima resistência

$\Delta_{\max }$ - deformação máxima pré-estabelecida (de falha)

$\Delta_{\mathrm{u}} \quad$ - deformação do elemento quando a falha é iminente

$\Delta_{0} \quad$ - deformação para $\theta=0$, valor este baseado em ensaios

$\Sigma \quad$ - somatório

d) Letras gregas minúsculas

$\alpha \quad$ - ângulo do chanfro;

- coeficiente que relaciona $\mathrm{L} / \mathrm{d}$;

- coordenada do CG tendo como origem o CIR;

- parâmetro

$\beta \quad$ - coeficiente

$\beta_{\mathrm{Lw}}$ - fator de redução para levar em consideração efeitos de distribuição não uniforme de tensões ao longo do comprimento (EUROCODE 3)

$\beta_{\mathrm{w}} \quad$ - fator de correlação apropriado (similar a $\beta$ ) (EUROCODE 3)

$\delta \quad$ - ângulo da força aplicada $P$ em relação ao eixo $y$;

- deslocamento;

- parâmetro geométrico;

- componente vertical da deformação em cada elemento de solda na zona tracionada

$\delta_{\mathrm{A}} \quad$ - deformação na chapa

$\delta_{\mathrm{B}} \quad$ - deformação na chapa junto ao eixo do parafuso

$\delta_{\mathrm{p}} \quad$ - alongamento do parafuso

$\varepsilon_{\mathrm{c}} \quad$ - deformação na chapa

$\varepsilon_{\mathrm{p}} \quad$ - deformação do parafuso

$\phi \quad$ - coeficiente de resistência

$\phi_{\mathrm{b}} \quad$ - coeficiente de resistência na flexão do pino

$\phi_{\mathrm{sf}} \quad$ - coeficiente de resistência no cisalhamento da chapa (AISC)

$\phi_{\mathrm{t}} \quad$ - coeficiente de resistência na tração

$\phi_{\mathrm{v}} \quad$ - coeficiente de resistência à força cortante

$\gamma \quad$ - coeficiente (EUROCODE 3) 
$\gamma_{\mathrm{Mb}}$ - fator de segurança parcial, para resistência de conexões parafusadas (EUROCODE 3)

$\gamma_{M o} \quad$ - fator de segurança parcial, para resistência de perfis e seções transversais (EUROCODE 3)

$\gamma_{\mathrm{Mp}} \quad$ - fator de segurança parcial, para resistência de pinos (EUROCODE 3)

$\gamma_{\mathrm{Ms}}$ - fator de segurança parcial, para resistência ao deslizamento (EUROCODE 3)

$\gamma_{\text {Ms.ser }}$ - fator de segurança parcial para estado limite de utilização (EUROCODE 3)

$\gamma_{\text {Ms.ult }}$ - fator de segurança parcial para estado limite último (EUROCODE 3)

$\gamma_{\mathrm{Mw}}$ - fator de segurança parcial, para resistência de conexões soldadas

(EUROCODE 3)

$\eta_{1}, \eta_{2}$ - coeficientes que dependem do tipo do furo

$\lambda \quad$ - coeficiente;

- coeficiente de regressão

$\mu \quad$ - coeficiente;

- coeficiente de atrito;

- coeficiente de regressão

$\theta \quad$ - direção do filete em relação à força aplicada, em graus

$\theta_{\mathrm{i}} \quad$ - coordenada polar do parafuso $i$

$\sigma \quad$ - coeficiente (EUROCODE 3)

$\sigma_{\mathrm{c}} \quad$ - tensão de contato

$\sigma_{\mathrm{i}} \quad$ - tensão ideal

$\sigma_{\text {id }} \quad$ - tensão ideal de cálculo

$\sigma_{M} \quad$ - tensão de tração normal devida ao momento fletor

$\sigma_{\mathrm{w}} \quad$ - tensão efetiva (EUROCODE 3)

$\sigma_{\mathrm{x}} \quad$ - tensão normal paralela ao eixo da solda

$\sigma_{\mathrm{y}} \quad$ - tensão normal perpendicular ao eixo da solda

$\sigma_{\perp} \quad$ - tensão normal perpendicular a garganta efetiva da solda

$\sigma_{\|} \quad$ - tensão normal paralela ao eixo da solda

$\sigma_{0} \quad$ - pressão de contato inicial

$\tau \quad$ - tensão de cisalhamento 
$\tau_{\mathrm{m}} \quad$ - tensão de cisalhamento média na alma

$\tau_{\mathrm{u}} \quad$ - tensão de cisalhamento última do aço

$\tau_{\perp} \quad$ - tensão de cisalhamento no plano da garganta efetiva, perpendicular ao eixo da solda

$\tau_{\|} \quad$ - tensão de cisalhamento no plano da garganta efetiva, paralela ao eixo da solda

$\xi$ - fator de redução, devido ao tipo de furo

e) Índices compostos

b.p/m - área de contribuição do parafuso

e/k - parâmetro adimensional

FS - fator de segurança

$\phi \mathrm{R}_{\mathrm{n}} \quad$ - resistência de cálculo à pressão de contato;

- resistência de cálculo ao esmagamento do pino;

- resistência de cálculo ao rasgamento;

- resistência de cálculo da solda ao cisalhamento

$\phi \mathrm{R}_{\mathrm{nw}} \quad$ - resistência de cálculo de soldas (AISC)

$\phi \mathrm{R}_{\text {str }} \quad$ - resistência de cálculo ao deslizamento (AISC)

$\phi \mathrm{r}_{\mathrm{v}} \quad$ - resistência de cálculo de um único parafuso (AISC)

$\phi_{b} \mathrm{M}_{\mathrm{n}}$ - resistência de cálculo à flexão do pino

$\phi_{\mathrm{t}} \mathrm{N}_{\mathrm{n}} \quad$ - resistência de cálculo à tração de chapas de ligação

$\phi_{\mathrm{t}} \mathrm{R}_{\mathrm{nt}} \quad$ - resistência de cálculo à tração

$\phi_{\mathrm{sf}} \mathrm{N}_{\mathrm{n}}$ - resistência de cálculo ao cisalhamento na seção efetiva da chapa (AISC)

$\phi_{\mathrm{v}} \mathrm{R}_{\mathrm{nv}}$ - resistência de cálculo à força cortante;

- resistência de cálculo ao deslizamento

$\phi_{\mathrm{V}} \mathrm{V}_{\mathrm{n}}$ - resistência de cálculo ao corte do pino 
$\phi \mathrm{r}_{\mathrm{v}} \quad$ - resistência de cálculo de um único parafuso (AISC)

$\phi_{\mathrm{b}} \mathrm{M}_{\mathrm{n}}$ - resistência de cálculo à flexão do pino

$\phi_{\mathrm{t}} \mathrm{N}_{\mathrm{n}} \quad$ - resistência de cálculo à tração de chapas de ligação

$\phi_{\mathrm{t}} \mathrm{R}_{\mathrm{nt}} \quad$ - resistência de cálculo à tração

$\phi_{\mathrm{sf}} \mathrm{N}_{\mathrm{n}}$ - resistência de cálculo ao cisalhamento na seção efetiva da chapa (AISC)

$\phi_{\mathrm{v}} \mathrm{R}_{\mathrm{nv}}$ - resistência de cálculo à força cortante;

- resistência de cálculo ao deslizamento

$\phi_{\mathrm{v}} \mathrm{V}_{\mathrm{n}}$ - resistência de cálculo ao corte do pino 


\section{RESUMO}

VALENCIANI, V.C. (1997). Ligações em estruturas de aço. São Carlos, 1997, 309p. Dissertação (Mestrado) - Escola de Engenharia de São Carlos, Universidade de São Paulo.

Este trabalho consiste numa revisão bibliográfica sobre ligações em estruturas de aço. Inicialmente são abordados os dispositivos de ligação, enfatizando os tipos e as características estruturais dos conectores, os processos de soldagem mais empregados nas estruturas de aço e suas implicações. A seguir são apresentados os aspectos mais importantes sobre o comportamento estrutural de parafusos e soldas e a avaliação da resistência com base na norma brasileira NBR 8800 e nas principais normas estrangeiras aplicáveis. Finalmente, são apresentados e discutidos os modelos teóricos clássicos usualmente empregados para a avaliação de solicitações em ligações parafusadas e soldadas.

Palavras-chave: estruturas, estruturas de aço, ligações, conexões, conectores, parafusos, soldas. 
VALENCIANI, V.C. (1997). Steel structure connections. São Carlos, 1997, 309p. Dissertação (Mestrado) - Escola de Engenharia de São Carlos, Universidade de São Paulo.

This work gives a reference review on steel structure connections. First, connection designs are discussed, emphasizing the types of fasteners, their characteristics, the most common employed welding processes for steel structures and the technical implications. It is also presented the most important aspects regarding the structural behaviour of bolts, welds and the strength evaluation based on the Brazilian code NBR 8800, as well as on the main known foreign codes. Finally the classical theoretical analysis often adopted for the evaluation of welded and bolted connections are presented and discussed.

Keywords: structures, steel structures, connections, fasteners, bolts, welds. 


\section{APRESENTAÇÃO}

Até meados da década de 80, a “área de estruturas metálicas" do Departamento de Engenharia de Estruturas da Escola de Engenharia de São Carlos (SET-EESC-USP) obteve destaque pela atuação no ensino de graduação, e pelos relevantes serviços prestados à comunidade.

A partir de 1986, com a publicação da nova norma brasileira de estruturas de aço para edifícios, a NBR 8800/86, deu-se início no âmbito do SET, ao que pode ser denominada de "pós-graduação em estruturas metálicas".

Os primeiros trabalhos propostos consistiam num estudo abrangente dos elementos de estruturas de aço, buscando entender os fundamentos teóricos e as correspondentes calibrações que deram origem às prescrições contidas nas normas técnicas.

Neste contexto, ou seja, no estudo dos elementos de estruturas de aço, é que este trabalho se insere, abordando de forma abrangente e crítica o tema "ligações em estruturas de aço", segundo as prescrições da norma brasileira NBR 8800 e das principais normas estrangeiras (AISC/LRFD 86 e 93, AISC/ASD 89, EUROCODE 3, além das especificações da AWS citada pelos autores), enfocando os seguintes aspectos:

- dispositivos de ligação empregados (parafusos, conectores e soldas). Nessa abordagem são discutidos os principais aspectos relacionados à esses componentes. No caso dos parafusos são apresentadas as classificações, especificações, propriedades mecânicas, métodos de instalação e suas implicações, efeitos da relaxação e da reutilização de parafusos pré-tracionados, aspectos sobre a galvanização e a corrosão em parafusos e os tipos de furos utilizados. Além disso, procura-se de maneira ilustrativa apresentar alguns outros tipos de parafusos pouco utilizados, além de chumbadores e conectores de fixação para telhas e painéis.

No caso das soldas são discutidos os processos básicos de soldagem utilizados na fabricação de estruturas metálicas, a classificação e as influências dos eletrodos, arames e fluxos empregados nos processos, os tipos de solda e de juntas, além das posições de soldagem e simbologia básica. São discutidos 
também alguns aspectos que afetam a qualidade das conexões soldadas, além de ilustrar possíveis defeitos que possam aparecer nas soldas e os métodos mais empregados de inspeção para detectar possíveis descontinuidades.

- avaliação da resistência de parafusos e soldas. Para o caso de parafusos apresentase o comportamento destes sob solicitação de tração, cortante e dos dois esforços combinados, abordando conexões por contato e por atrito e os modos de falha tanto dos dispositivos quanto dos elementos de ligação (metal base). É incluída também uma análise a respeito do tipo de revestimento superficial e sua influência em conexões por atrito, além do efeito da pré-tração em parafusos solicitados axialmente e um breve comentário a respeito do comportamento de conexões longas (com muitos parafusos) e conexões cujos parafusos apresentam um longo comprimento de pega.

Para o caso das soldas a discussão da resistência é apresentada para as soldas de filete, soldas em chanfro e soldas de tampão, com as respectivas considerações a respeito das áreas efetivas de cisalhamento. Busca-se também apresentar disposições construtivas incluindo as limitações de execução, e alguns fatores que afetam o comportamento estrutural de certas soldas.

- modelos teóricos clássicos para a avaliação de solicitações em conexões parafusadas e soldadas. Para o caso das conexões consideradas "rígidas" são analisadas as conexões parafusadas e soldadas sujeitas a carregamento excêntrico, englobando parafusos e grupo de soldas sob força cortante e momento de torção e força cortante e momento fletor. São apresentados também, exemplos mostrando as diferenças entre os métodos elásticos e plásticos de cálculo e suas variações. Também é apresentado um estudo sobre o efeito alavanca em parafusos, com os procedimentos mais usuais de avaliação desse efeito.

Para o caso das conexões consideradas "flexíveis" são apresentados alguns dos tipos mais usuais destas ligações, com as recomendações para projeto.

- análise e comentários a respeito de outros tipos de conexões. Neste caso são abordadas emendas em pilares, emendas em vigas e emendas em barras 
solicitadas axialmente, além de alguns comentários a respeito da solda de composição de perfis. É abortado também o colapso por rasgamento dos elementos conectados, além de considerações de projeto a respeito de ligações executadas com pinos.

Como pode-se perceber os assuntos relacionados anteriormente são claramente ligados ao comportamento estrutural, ao projeto e aos aspectos construtivos das ligações em estruturas de aço, sendo basicamente divididos nos seguintes tópicos:

- Dispositivos de ligação (capítulos 1 e 2)

- Resistência dos dispositivos e dos elementos de ligação (capítulos 3 e 4)

- Solicitações nas ligações: modelos teóricos clássicos (capítulos 5, 6 e 7)

Cabe ainda salientar que tal assunto é amplamente difundido na bibliografia, havendo porém a carência de um texto, a nível nacional, que aborde especificamente o tema ligações. Desta forma, pretende-se que esta revisão bibliográfica contribua significativamente para os cursos de graduação, pós-graduação e em futuras pesquisas relacionadas ao tema.

O capítulo referente a introdução foi substituído pela inserção de tal assunto em cada capítulo, permitindo uma melhor articulação entre a referida introdução e o texto propriamente dito.

A extensa quantidade de símbolos é resultado da fidelidade à simbologia apresentada pelas diversas normas pesquisadas. 


\section{CAPÍTULO 1 - CONECTORES ESTRUTURAIS}

Vários aspectos diferenciam as estruturas metálicas dos outros tipos de estruturas, e entre estes, um dos mais significativos refere-se às ligações presentes entre as peças que compõem a estrutura.

As ligações em estruturas metálicas são constituídas por dois tipos de componentes: os elementos de ligação e os dispositivos de ligação.

Os elementos de ligação são componentes que facilitam ou que permitem a transmissão dos esforços gerados na estrutura, entre estes elementos tem-se os enrijecedores, as placas de base, as cantoneiras de assento, as chapas de nó (ou chapas de gusset), as cobrejuntas de alma e de mesa, entre outros.

Os dispositivos de ligação são os componentes que proporcionam a união entre os elementos de ligação e as partes da estrutura que se deseja conectar, entre estes componentes têm-se as soldas e os conectores. Esses conectores, de uma maneira geral, são divididos em parafusos comuns e de alta resistência, rebites e barras rosqueadas.

\subsection{Introdução e desenvolvimento histórico dos parafusos de alta resistência}

Segundo KULAK et al. [ 34 ], os primeiros experimentos indicando a possibilidade do uso de parafusos de alta resistência em construção de estruturas de aço foram relatados por C. Batho e E. H. Bateman no Steel Structures Committee of Scientific and Industrial Research na Grã Bretanha em 1934. Foi concluído também que parafusos com um limite de escoamento mínimo de aproximadamente $370 \mathrm{MPa}$ poderiam ser apertados suficientemente para fornecer uma adequada margem de segurança contra o deslizamento das partes conectadas.

De acordo com ensaios realizados na Universidade de Illinois, Wilson e Thomas relataram em 1938 que a resistência à fadiga de parafusos de alta resistência, devidamente apertados, instalados em furos alargados, era compatível com a resistência dos já consagrados rebites.

Segundo SALMON \& JOHNSON [ 60 ], em 1947 o Research Council on Riveted and Bolted Structural Joints (RCRBSJ) apresentou informações com base 
em extrapolação de estudos desenvolvidos em ligações rebitadas, utilizando principalmente a extensa bibliografia anotada por De Jonge, a qual foi completada em 1945. O Conselho patrocinou também estudos sobre parafusos de alta resistência e rebites, e o uso destes em conexões estruturais.

De acordo com KULAK et al. [ 34 ], a American Society for Testing and Materials (ASTM) em conjunto com o RCRBSJ preparou uma especificação para os materiais dos parafusos de alta resistência, inicialmente aprovada em 1949. Com isso, o conceito de parafusos de alta resistência e um sumário de pesquisas e procedimentos, foram apresentados para engenheiros e para a indústria de estruturas de aço.

De acordo com SALMON \& JOHNSON [ 60 ], usando resultados de pesquisa, o RCRBSJ preparou e emitiu sua primeira especificação para ligações estruturais usando parafusos de alta resistência, em janeiro de 1951, e os parafusos de alta resistência foram então adotados para construção de estruturas de edifícios e pontes, tanto para ações estáticas quanto para ações dinâmicas. Essa especificação também permitiu a substituição dos rebites, que nesta época eram largamente utilizados, por parafusos, na base de um para um. Além disso, foi assumida a transferência de forças por atrito em todas as ligações sob condições de serviço e o fator de segurança contra deslizamento foi estabelecido em um nível elevado, de tal maneira que o comportamento à fadiga foi similar ou superior àquele mostrado nas ligações rebitadas.

Segundo McCORMAC [ 41 ], esses parafusos não somente tornaram-se rapidamente o principal dispositivo de execução de conexões em campo, como também passaram a ser amplamente utilizados na fábrica.

Segundo KULAK et al. [ 34 ], durante a década de 50 ocorreram vários estudos sobre os procedimentos de instalação, sobre a resistência ao deslizamento em função das superfícies de contato e sobre o comportamento das ligações sob ações dinâmicas. De maneira conjunta, a experiência obtida em laboratório e em construção de pontes capacitaram o German Committee for Structural Steelwork (GCSS) a emitir um código preliminar de aplicação em 1956. Já na Grã-Bretanha, a evolução das aplicações e das especificações foi similar à que ocorreu nos Estados Unidos. O British Standards Institution emitiu uma British Standard (BS) 3139 
relacionando o material dos parafusos em 1959. Em 1960, a BS 3294 foi emitida estabelecendo o procedimento de projeto e a prática de campo (execução).

Em 1954 uma revisão foi feita nas especificações para incluir o uso de arruelas planas em superfícies inclinadas em 1:20 e para permitir o uso de chaves de impacto para a instalação de parafusos de alta resistência. Também em 1954, a revisão permitiu que as superfícies em contato fossem pintadas, quando fossem especificadas conexões por contato.

Segundo SALMON \& JOHNSON [ 60 ], em 1956 Munse concluiu que os parafusos de alta resistência deveriam ter uma elevada tração inicial, para que se tornassem eficientes e econômicos. Por volta de 1960 o valor recomendado para a mínima tração no parafuso foi aumentado. Além disso, a conexão por contato foi reconhecida como uma aceitável substituta para uma conexão rebitada, e a conexão projetada com base na resistência ao deslizamento, ou seja, por atrito, provavelmente somente seria necessária quando tração direta atuasse nos parafusos ou quando solicitações alternadas ocorressem. Também em 1960 um simples procedimento de instalação, entendido como método da rotação da porca, foi introduzido como uma alternativa para o método da chave calibrada previamente requerido.

Em 1962, o uso obrigatório de arruelas foi eliminado, exceto em situações especiais. Em 1964, os parafusos A490, mais resistentes, foram introduzidos.

Significativas mudanças foram feitas em 1976 quando resistências mais elevadas de parafusos foram reconhecidas, e outras resistências foram admitidas para parafusos usados em outros tipos de furos, diferentes do furo padrão.

A mais recente especificação do RCRBSJ, também chamado de RCSC mudou um pouco a filosofia de projeto para conexões por contato e para conexões por atrito.

\subsection{Tipos de conectores}




\subsubsection{Rebites}

Os rebites foram, por muitos anos, os únicos dispositivos de ligação empregados em elementos estruturais de aço. Seu comportamento estrutural era tido como satisfatório, entretanto, a partir da década de 50 se tornaram antieconômicos e são agora raramente usados em estruturas de aço. Hoje em dia, são empregados quase que somente na recuperação e reforços de antigas estruturas rebitadas.

A principal causa da obsolescência dos rebites foi o advento do parafuso de alta resistência e o aprimoramento das técnicas de soldagem, os quais correspondem a dispositivos mais econômicos, uma vez que há significativa redução de mão-deobra.

Segundo SALMON \& JOHNSON [ 60 ], o principal fator que retardou a imediata aceitação de parafusos de alta resistência foi o alto custo do material, que também incluía o uso de duas arruelas temperadas. Por volta de 1950 o reduzido custo de mão-de-obra para a instalação de parafusos não compensava o custo mais alto de seu material. Uma vez podendo ser reduzidas as arruelas para uma ou simplesmente serem eliminadas e contando com uma maior resistência de um parafuso, em comparação com o rebite, e podendo isso ser levado em consideração no projeto, parafusos de alta resistência tornaram-se econômicos.

O AISC/LRFD 93 [ 4 ] especifica, para confecção de rebites o aço ASTM A502, dividido em três categorias, disponíveis com diâmetros que variam entre 12,5 a $38 \mathrm{~mm}(1 / 2 "$ a $11 / 2 ")$.

- categoria 1, que é um aço carbono para uso geral $\left(f_{y}=190 \mathrm{MPa}\right)$;

- categoria 2 , que é um aço carbono-manganês para rebitamento de alta resistência $\left(f_{y}\right.$ $=260 \mathrm{MPa})$;

- categoria 3 , similar a categoria 2 , mas com acentuada resistência à corrosão.

É importante lembrar que tais propriedades mecânicas do aço virgem sofrem alterações devido ao processo de fabricação e instalação dos rebites.

Os rebites estruturais são introduzidos quentes dentro da conexão, aparentando uma leve cor vermelho cereja (rubro), e são inseridos em furos padrão (diâmetro do furo $2 \mathrm{~mm}$ maior que o diâmetro do rebite). Na conformação a quente 
de sua cabeça, um "encontrador" é utilizado para permitir a reação enquanto a formação da cabeça é executada normalmente por um martelo pneumático, causando no corpo do rebite uma expansão radial, preenchendo a folga existente no furo. Quando o rebite resfria ele se contrai, produzindo uma força de aperto entre as partes, e conseqüentemente, proporcionando um trabalho por atrito da conexão. Contudo, a força de aperto produzida pelo resfriamento do rebite, varia de rebite para rebite e por essa razão não pode ser levada em consideração nos projetos. Segundo OWENS \& CHEAL [ 50 ], os rebites devem ser considerados com cautela quando solicitados por tração e os projetistas têm tradicionalmente evitado seu uso para tal solicitação, sempre quando possível.

A maioria dos rebites são executados por martelamento que completam a rebitagem em apenas um golpe. Os rebitadores ou marteletes de rebitagem são ferramentas portáteis, a ar comprimido, que introduzem o rebite por uma rápida sucessão de golpes.

No que se refere a geometria, existem várias formas para as cabeças dos rebites. Quando não há restrição de espaçamento para a execução, uma cabeça prensada redonda pode ser utilizada. Quando este espaçamento é limitado pode-se usar tanto uma cabeça de forma achatada quanto plana. Já rebites com cabeça escareada são usados onde uma superfície nivelada é desejada, ou quando o espaçamento para execução é muito pequeno. A cabeça do rebite é marcada para identificar o fabricante e também a categoria com os números 1 ou 2. Sua geometria é mostrada na fig. 1-1. 

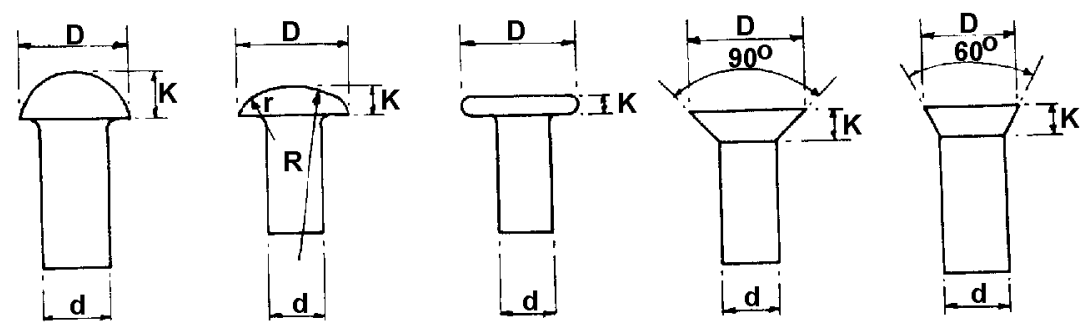

\begin{tabular}{|c|c|c|c|c|c|}
\hline Diâmetro da cabeça & & & & & \\
\hline Forjado a quente & $D=1,6 d$ & $D=2 d$ & & & $D=1,5 d$ \\
\hline Forjado a frio & $D=1,75 d$ & $D=2 d$ & $D=2 d$ & $D=2 d$ & \\
\hline Altura da cabeça & & & & & \\
\hline Forjada a quente & $K=0,65 d$ & $K=0,4 d$ & & & $K=\mathbf{0 , 4 3 d}$ \\
\hline Forjada a frio & $K=0,6 d$ & $K=0,4 d$ & $K=0,25 d$ & $K=0,5 d$ & \\
\hline Raio & & $r=0,6 d$ & & & \\
\hline & & $\mathbf{R}=\mathbf{3 d}$ & & & \\
\hline & $\begin{array}{l}\text { Rebite de } \\
\text { cabeça } \\
\text { moldada }\end{array}$ & $\begin{array}{l}\text { Rebite } \\
\text { universal }\end{array}$ & $\begin{array}{c}\text { Rebite de } \\
\text { cabeça plana }\end{array}$ & $\begin{array}{c}\text { Rebite } \\
\text { escareado }\end{array}$ & $\begin{array}{c}\text { Rebite } \\
\text { escareado }\end{array}$ \\
\hline
\end{tabular}

FIGURA 1-1 Geometria de rebites padrão. Adaptada de OWENS \& CHEAL [ 50 ].

\subsubsection{Parafusos de alta resistência}

Os parafusos estruturais se dividem em parafusos comuns e parafusos de alta resistência. Esses últimos possuem cabeça hexagonal pesada, usados com porca hexagonal pesada. Os parafusos hexagonais pesados têm menores porções rosqueadas que os outros parafusos, isto reduz a probabilidade de haver roscas inclusas no plano de corte. A tabela 1-1 fornece as principais características geométricas dos parafusos de alta resistência.

TABELA 1-1 Características geométricas de parafusos de alta resistência.

(a) Tabela de parafusos sextavados, em polegadas, segundo a norma ASTM A325/A490. Adaptada do AISC/ASD [ 1 ].

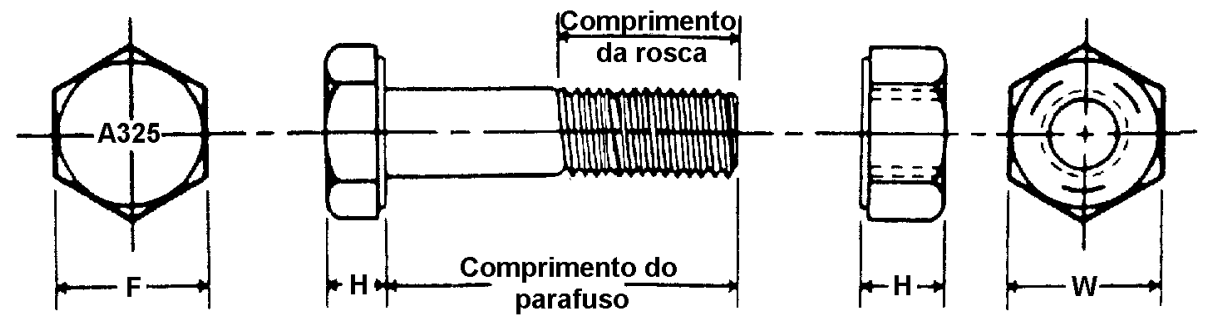

/continua 
continuação

\begin{tabular}{|c|c|c|c|c|c|}
\cline { 2 - 6 } \multicolumn{1}{c|}{} & \multicolumn{2}{|c|}{$\begin{array}{c}\text { Dimensões para parafusos estruturais } \\
\text { hexagonais pesados em polegadas }\end{array}$} & $\begin{array}{c}\text { Dimensões para porcas hexagonais } \\
\text { pesadas em polegadas }\end{array}$ \\
\hline $\begin{array}{c}\text { Diâmetro nominal dos } \\
\text { parafusos em } \\
\text { polegadas }\end{array}$ & $\mathrm{F}$ & $\mathrm{H}$ & $\begin{array}{c}\text { Comprimento } \\
\text { da rosca }\end{array}$ & $\mathrm{W}$ & $\mathrm{H}$ \\
\hline $1 / 2$ & $7 / 8$ & $5 / 16$ & 1 & $7 / 8$ & $31 / 64$ \\
\hline $5 / 8$ & $11 / 16$ & $25 / 64$ & $11 / 4$ & $11 / 16$ & $39 / 64$ \\
\hline $3 / 4$ & $11 / 4$ & $15 / 32$ & $13 / 8$ & $11 / 4$ & $47 / 64$ \\
\hline $7 / 8$ & $17 / 16$ & $35 / 64$ & $11 / 2$ & $17 / 16$ & $55 / 64$ \\
\hline 1 & $15 / 8$ & $39 / 64$ & $13 / 4$ & $15 / 8$ & $63 / 64$ \\
\hline $11 / 8$ & $113 / 16$ & $11 / 16$ & 2 & $113 / 16$ & $17 / 64$ \\
\hline $11 / 4$ & 2 & $25 / 32$ & 2 & 2 & $17 / 32$ \\
\hline $13 / 8$ & $23 / 16$ & $27 / 32$ & $21 / 4$ & $23 / 16$ & $111 / 32$ \\
\hline $11 / 2$ & $23 / 8$ & $15 / 16$ & $21 / 4$ & $23 / 8$ & $115 / 32$ \\
\hline
\end{tabular}

(b) Tabela de parafusos sextavados, em mm, segundo a norma DIN 6914. Porca segundo a DIN 6915 e arruela segundo a DIN 6916. Adaptada de SIDERBRÁS [ 65 ].
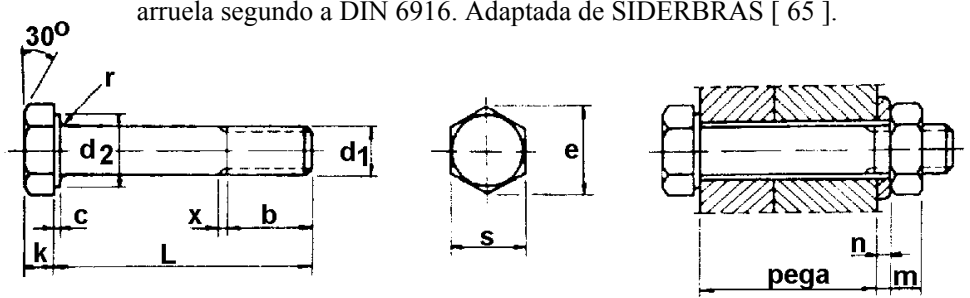

\begin{tabular}{|c|c|c|c|c|c|c|}
\hline $\mathrm{d}_{1}$ & $\mathrm{M} 12$ & $\mathrm{M} 16$ & $\mathrm{M} 20$ & $\mathrm{M} 22$ & $\mathrm{M} 24$ & $\mathrm{M} 27$ \\
\hline $\mathrm{b}(\mathrm{L} \leq 6 ”)$ & 21 & 26 & 31 & 32 & 34 & 37 \\
\hline $\mathrm{b}(\mathrm{L}>6 ”)$ & 23 & 28 & 33 & 34 & 39 & 43,5 \\
\hline $\mathrm{d}_{2}$ & 20 & 25 & 30 & 34 & 39 & 43,5 \\
\hline $\mathrm{c}$ & 0,4 & 0,6 & 0,8 & 0,8 & 0,8 & 0,8 \\
\hline $\mathrm{x}$ & \multicolumn{7}{|c|}{ Segundo a norma DIN 76 } \\
\hline $\mathrm{e}$ & 25,4 & 31,2 & 36,9 & 41,6 & 47,3 & 53,1 \\
\hline $\mathrm{k}$ & 8 & 10 & 13 & 14 & 15 & 17 \\
\hline $\mathrm{r}$ & 1,6 & 1,6 & 2 & 2 & 2 & 2,5 \\
\hline $\mathrm{m}$ & 10 & 13 & 16 & 18 & 19 & 22 \\
\hline $\mathrm{n}$ & 3 & 4 & 4 & 4 & 4 & 5 \\
\hline $\mathrm{s}$ & 22 & 27 & 32 & 36 & 41 & 46 \\
\hline
\end{tabular}

Um fator importante que deve ser levado em consideração é o perfil das roscas e suas tolerâncias de fabricação (ver fig. 1-2), tanto para parafusos de alta resistência quanto para parafusos comuns. A especificação destas tolerâncias deve ser feita com muito cuidado, de modo a se obter uma facilidade de fabricação e garantir a eficiência estrutural do parafuso. Com isso, parafusos que desviam-se de tolerâncias permitidas não deverão ser usados em conexões estruturais. 


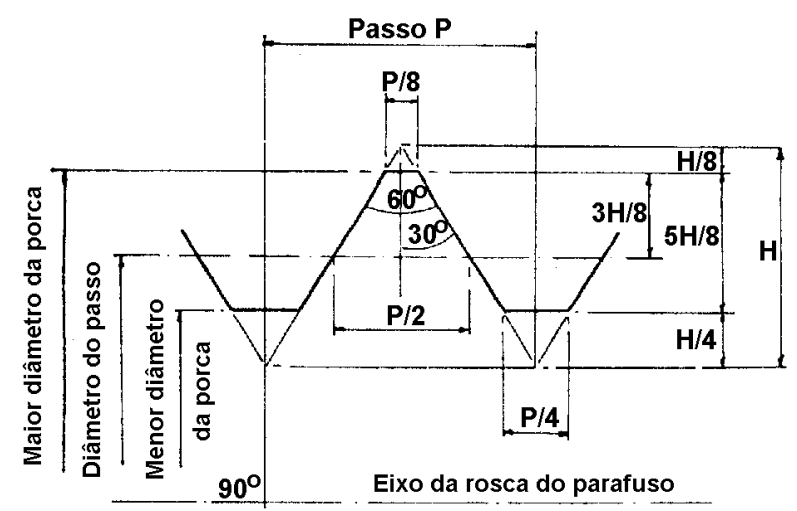

FIGURA 1-2 Perfil básico para roscas métricas ISO. Adaptada de OWENS \& CHEAL [ 50 ].

De acordo com o ENGINEERING FOR STEEL CONSTRUCTION [ 2 ], considerando a ASTM, tem-se as seguintes especificações para parafusos de alta resistência:

- parafusos ASTM A325: são parafusos de alta resistência para ligações com aço estrutural. São de aço de médio carbono com tratamento térmico, tendo um limite de escoamento de aproximadamente 560 a $630 \mathrm{MPa}$, que decresce com o aumento do diâmetro do parafuso.

Eles são indicados para uso geral em ligações estruturais e são disponíveis em três tipos com diâmetros que variam entre 12,5 a 38 mm (1/2" a 1 1/2"):

- tipo 1: aço de médio carbono para propósitos gerais de uso em elevadas temperaturas (é o único que será fornecido se nenhum tipo diferente for especificado).

- tipo 2: aço martensita de baixo carbono para propósitos gerais de uso, para aplicações à temperatura atmosférica.

- tipo 3: parafusos com maior resistência à corrosão atmosférica e características ao desgaste por intempéries compatíveis com os aços A242 ou A588.

Porcas de aços compatíveis ASTM A563 e arruelas ASTM F436 deverão ser especificadas incluindo a resistência ao desgaste por intempéries.

- parafusos ASTM A490: são parafusos de alta resistência para ligações com aços estruturais. São de aço-liga tratado termicamente, tendo um limite de escoamento de aproximadamente 790 a $900 \mathrm{MPa}$, dependendo do diâmetro. 
Indicados para uso geral em ligações estruturais, são disponíveis em três tipos com diâmetros que variam entre 12,5 a 38 mm (1/2" a $11 / 2$ ”):

- tipo 1: parafusos feitos com aço-liga, para aplicações em elevadas temperaturas.

- tipo 2: parafusos feitos com aço martensita de baixo carbono com diâmetros que variam de 12,5 a $25 \mathrm{~mm}(1 / 2 "$ a 1"), para aplicações à temperatura atmosférica.

- tipo 3: parafusos de aço-liga, tendo resistência à corrosão atmosférica e características ao desgaste por intempéries comparáveis aos aços A242 ou A588.

Porcas de aços compatíveis ASTM A563 e arruelas ASTM F436 deverão ser especificadas incluindo a resistência ao desgaste por intempéries. Parafusos A490 não devem ser galvanizados a quente, e cuidados devem ser tomados para seu uso em ambientes altamente corrosivos.

A figura 1-3 mostra a identificação dos parafusos A325 e A490.

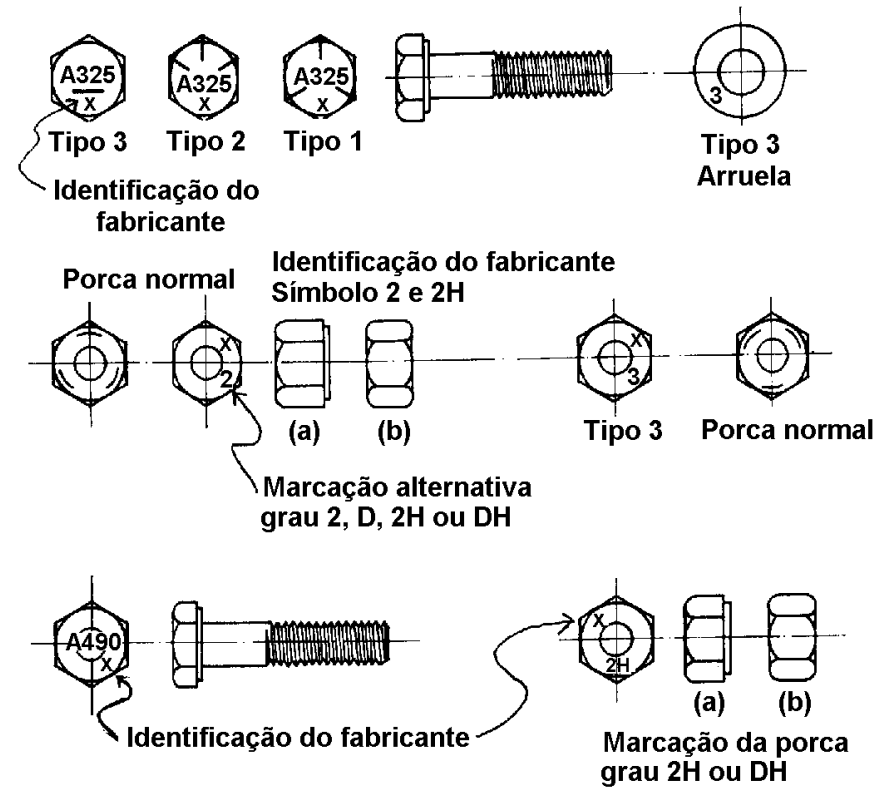

FIGURA 1-3 Identificação dos parafusos A325 e A490. Adaptada de BELLEI [ 11 ].

Na fig. 1-3 pode-se notar que as porcas apresentam marcações (D, 2H, etc.), essas marcas referem-se à dureza, identificando a composição química do aço e os tipos de tratamentos químicos com os quais as porcas são manufaturadas.

- parafusos ASTM A449: são parafusos de aço carbono temperado. Este é um parafuso que pode ser galvanizado a quente, e é disponível com e sem cabeça, sendo 
fornecido em três faixas de diâmetro. Eles são ocasionalmente usados quando diâmetros acima de 38 até 76 mm (1 1/2 até 3") são necessários.

O AISC permite o uso deste material como parafuso em conexões por contato para diâmetros superiores a $38 \mathrm{~mm}(1$ 1/2”), isto é, para diâmetros não disponíveis em parafusos A325 e A490. Este material é aceitável para parafusos de ancoragem de alta resistência ou para barras rosqueadas, em qualquer diâmetro disponível, para aplicações em tração.

Se esse material é utilizado como um parafuso solicitado à tração ou como um parafuso solicitado à força cortante em uma conexão por contato, ele deverá ser apertado para valores superiores a 50\% da mínima resistência à tração especificada, que depende do diâmetro do parafuso. Deste modo as porcas (ASTM A563) deverão reunir os requerimentos do A325 e uma arruela (ASTM F436) deverá ser instalada sobre a cabeça do parafuso.

Embora esse material apresente características mecânicas semelhantes ao A325, eles possuem duas importantes diferenças básicas: (a) os parafusos A449 não possuem o mesmo controle de qualidade que os A325 e (b) eles não são produzidos com as mesmas cabeças sextavadas e com as mesmas dimensões de porcas.

Esses parafusos mencionados são indicados para uso em conexões por atrito, onde a força é transmitida pelo atrito mobilizado entre as chapas (fig. 1-4) ou em conexões por contato, onde a força é transmitida pelo contato do corpo do parafuso com a parede do furo (fig. 1-5).

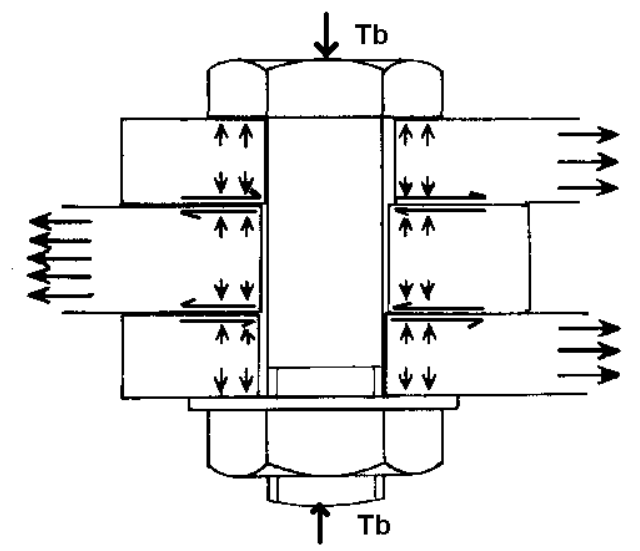

FIGURA 1-4 Transmissão de esforços por atrito. Adaptada de OWENS \& CHEAL [ 50 ]. 


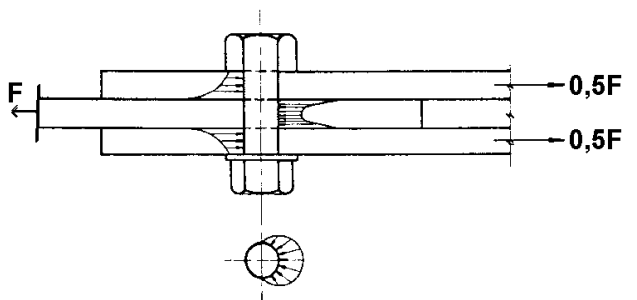

(a) Distribuição real das tensões

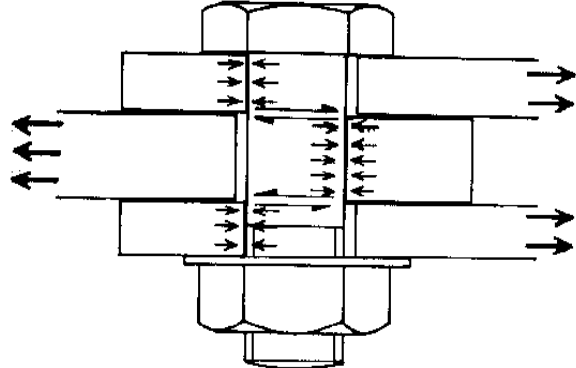

(b) Distribuição admitida para cálculo

FIGURA 1-5 Transmissão de esforços por contato. Adaptada de OWENS \& CHEAL [ 50 ] e SIDERBRÁS [ 65 ].

No caso de conexões por atrito os parafusos são convenientemente apertados para desenvolver nos mesmos uma força de tração suficiente para se obter altas forças de contato entre as partes. Com isso, as deformações da conexão sob força cortante, são muito pequenas até que a força de deslizamento seja alcançada.

Estes parafusos também podem ser usados em conexões onde forças de tração aplicadas externamente atuam no parafuso. Devido a seu alto pré-tracionamento e sua "rigidez" sob força cortante, eles são muito apropriados para uso em condições de solicitações de cisalhamento e/ou tração sob ações variáveis e em condições de fadiga.

Segundo a especificação RCSC 1985, todos os parafusos de alta resistência devem ser instalados com uma suficiente força de pré-tração.

Analisando o material do parafuso, observa-se que este exibe um comportamento tensão-deformação sem limite de escoamento definido, conforme fig. 1-6. Desta forma, é estabelecida uma tensão de escoamento convencional (método offset $0,2 \%$ ou deformação arbitrada $0,5 \%$ ) e uma força correspondente, denominada "carga de prova" (proof load), obtida pela área efetiva do parafuso $A_{r}$ multiplicada pela tensão de escoamento convencional.

A tensão relativa à carga de prova corresponde, no mínimo, a 70\% e $80 \%$ da mínima resistência à tração para parafusos A325 e A490, respectivamente.

Usando o método de instalação através da rotação da porca, para parafusos A325, nenhuma dificuldade é encontrada na obtenção da carga de prova, por exemplo, com meia volta a partir da condição de pré-torque. Já para parafusos A490, essa meia volta da condição de pré-torque, pode não ser suficiente para alcançar a carga de prova, o que também pode ocorrer para parafusos A325 longos. 


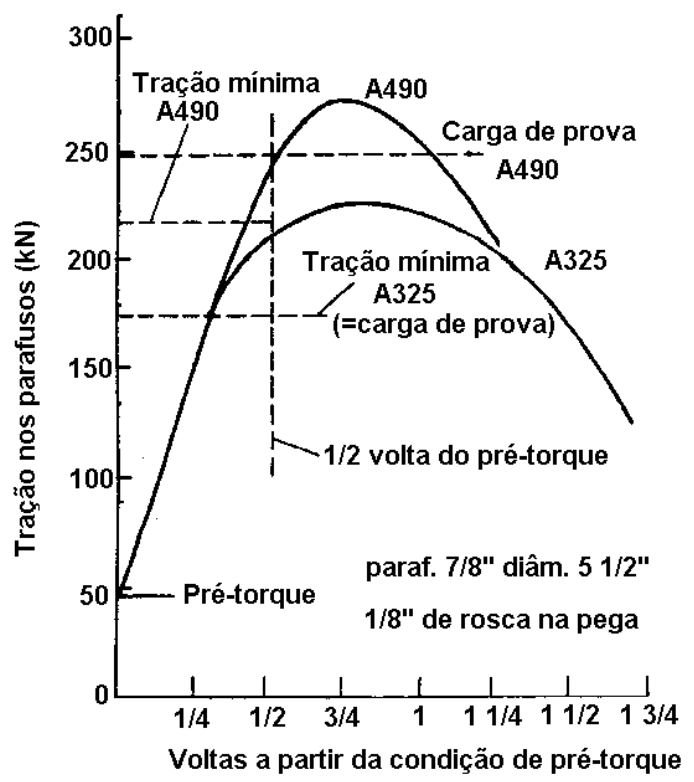

FIGURA 1-6 Relação típica força versus rotação da porca para parafusos A325 e A490. Adaptada de SALMON \& JOHNSON [ 60 ].

O AISC requer para conexões por atrito, uma pré-tração igual a $70 \%$ da mínima resistência à tração, conforme tabela 1-2. Este valor é igual à carga de prova (proof load) para os parafusos A325 e em torno de 85 a 90\% para os parafusos A490.

TABELA 1-2 Força mínima de pré-tração no parafuso* (AISC/LRFD 93 [ 4 ], AISC/ASD [ 1 ] e NBR 8800 [ 7 ]).

\begin{tabular}{|c|c|c|c|}
\hline \multicolumn{2}{|c|}{ Diâmetro do parafuso } & Parafusos A325 & Parafusos A490 \\
\hline pol. & $\mathrm{mm}$ & $\mathrm{T}_{\mathrm{b}}(\mathrm{kN})$ & $\mathrm{T}_{\mathrm{b}}(\mathrm{kN})$ \\
\hline $1 / 2$ & 12,5 & 53 & 67 \\
\hline $5 / 8$ & 16 & 85 & 107 \\
\hline $3 / 4$ & 19 & 125 & 156 \\
\hline $7 / 8$ & 22 & 173 & 218 \\
\hline 1 & 25 & 227 & 285 \\
\hline $11 / 8$ & 29 & 249 & 356 \\
\hline $11 / 4$ & 32 & 316 & 454 \\
\hline $13 / 8$ & 35 & 378 & 538 \\
\hline $11 / 2$ & 38 & 458 & 658 \\
\hline
\end{tabular}

* Igual à 70\% da mínima resistência a tração dos parafusos, como especificado pela ASTM para parafusos A325 e A490.

De acordo com SALMON \& JOHNSON [ 60 ], quando conexões resistentes ao deslizamento, ou seja conexões por atrito, não são requeridas e/ou quando os parafusos não são sujeitos à tração direta, os parafusos devem ser apertados na sua “condição de pré-torque". Essa condição é atingida quando todas as partes em uma ligação estão em contato firme, que é definida de uma maneira mais prática como o resultado de uns poucos impactos de uma chave de impacto ou ainda o máximo esforço de um homem usando uma chave comum de aperto. Caso contrário, o pré- 
tracionamento deverá ser tão alto quanto possível, obviamente, sem a ruptura do parafuso.

Segundo OWENS \& CHEAL [ 50 ], no momento da montagem da conexão, as superfícies de contato deverão estar livres de qualquer "contaminação" que possa reduzir o coeficiente de atrito ou impedir a fixação adequada entre as partes. $\mathrm{O}$ giro efetuado sobre a cabeça do parafuso ou no corpo da porca deverá sempre conduzir o aperto contra uma superfície que é normal ao eixo do parafuso. Para que isso ocorra em algumas situações, arruelas biseladas podem ser necessárias.

Segundo a NBR 8800 [ 7 ], para ligações estruturais, três procedimentos de aperto para o controle da pré-tração são estabelecidos: o aperto com chave calibrada; o método da rotação da porca; e os sistemas de indicação direta de tração.

O aperto com chave calibrada usa chaves de torque manual e chaves de impacto ajustadas para atingir um especificado torque. Segundo GAYLORD et al. [ 27 ], essas chaves são calibradas pelo aperto, através de um sistema hidráulico de medição de tração, usando um mínimo de três parafusos para o mesmo diâmetro. As chaves de impacto são fixadas para instalação do parafuso quando a determinada tração é obtida. As chaves de torque manual (torquímetros), têm uma escala de indicação de torque, possibilitando uma avaliação da tração no parafuso. A calibração do torque deverá ser feita ao menos uma vez ao dia ou quando a chave for utilizada em um parafuso de diâmetro diferente.

Segundo KULAK et al. [ 34 ], a chave é ajustada para fornecer uma tração no parafuso que deve ser no mínimo 5\% maior que a pré-tração requerida.

$\mathrm{O}$ método de aperto com chave calibrada apresenta várias desvantagens. Como trata-se essencialmente de controle de torque, fatores tal como o atrito entre a porca e a rosca do parafuso e entre a porca e a arruela são de grande importância. $O$ lubrificante solúvel em água presente nos parafusos pode ser degradado pela chuva ou umidade ou as roscas podem tornar-se contaminadas com graxa. O resultado é uma ocasional relação torque-tração que não é refletida no procedimento de calibração. Este método de instalação também apresenta problemas de campo quando existem comprimentos diferentes de parafusos em uma dada ligação, onde a chave deve ser calibrada para cada comprimento. 
Chaves usuais ou chaves de impacto podem ser usadas no método da rotação da porca. Segundo GAYLORD et al. [ 27 ], desenvolvido durante os anos 50 e 60, este método em essência, impõe um alongamento do parafuso ocasionado pela aplicação de um giro na porca. Para a rotação ser efetiva, a porca deve reagir contra a "base sólida" da junta. É portanto essencial, que antes da aplicação de qualquer volta determinada na porca, em todas as partes da conexão, todos os parafusos deverão estar colocados em contato na condição de pré-torque. Com isso, após fazer apropriadas marcas para que a rotação relativa entre o parafuso e a porca possa ser observada, a porca é então submetida à uma rotação, que deve ser superior à indicada na tabela 1-3. Este é certamente o mais comum e simples método de aperto.

TABELA 1-3. Rotação da porca ${ }^{(\mathrm{A})}$ a partir da posição de pré-torque. Adaptada da NBR 8800 [ 7 ].

\begin{tabular}{|c|c|c|c|}
\cline { 2 - 4 } \multicolumn{1}{c|}{} & \multicolumn{2}{c|}{ Disposição das faces externas das partes parafusadas } \\
\hline $\begin{array}{c}\text { Comprimento do parafuso } \\
\text { (medido da parte inferior da } \\
\text { cabeça à extremidade) }\end{array}$ & $\begin{array}{c}\text { Ambas as faces } \\
\text { normais ao eixo do } \\
\text { parafuso }\end{array}$ & $\begin{array}{c}\text { Uma das faces normais } \\
\text { ao eixo do parafuso e a } \\
\text { outra face inclinada não } \\
\text { mais que } 1: 20 \text { (sem } \\
\text { arruela biselada) }\end{array}$ & $\begin{array}{c}\text { Ambas as faces inclinadas } \\
\text { emão ao plano normal } \\
\text { ano do parafuso não } \\
\text { mais } 1: 20 \text { (sem arruelas } \\
\text { biseladas) }\end{array}$ \\
\hline Inferior ou igual a 4 diâmetros & $1 / 3$ de volta & $1 / 2$ volta & $2 / 3$ de volta \\
\hline $\begin{array}{c}\text { Acima de } 4 \text { diâmetros até no } \\
\text { máximo } 8 \text { diâmetros, inclusive }\end{array}$ & $1 / 2$ volta & $2 / 3$ de volta & $5 / 6$ de volta \\
\hline $\begin{array}{c}\text { Acima de } 8 \text { diâmetros até no } \\
\text { máximo } 12 \text { diâmetros }\end{array}$ & $2 / 3$ de volta & $5 / 6$ de volta & 1 volta \\
\hline
\end{tabular}

(A) A rotação da porca é considerada em relação aos parafusos, sem levar em conta o elemento que está sendo girado (porca ou parafuso). Para parafusos instalados com $1 / 2$ volta ou menos, a tolerância na rotação é mais ou menos $30^{\circ}$; para parafusos instalados com $2 / 3$ de volta ou mais, a tolerância na rotação é mais ou menos $45^{\circ}$.

(B) Nenhuma pesquisa foi feita para estabelecer o procedimento a ser usado para aperto pelo método da rotação da porca, para comprimentos de parafusos superiores a 12 diâmetros. Portanto, a rotação necessária deverá ser determinada por ensaios em um dispositivo que mesa a tração, adequado, que simule as considerações reais.

Segundo KULAK et al. [ 34 ], o controle de tração pelo método da rotação da porca é principalmente um controle de deformação. Se o alongamento no parafuso permanecer dentro do limite elástico, o ponto de pré-torque, a quantia e a exatidão da rotação na porca a partir da condição de pré-torque, influenciará na determinação da pré-tração. Todavia, na região inelástica a curva força versus alongamento é relativamente abatida, onde variações na condição de pré-torque resultam apenas em pequenas variações na força de pré-tração aplicada no parafuso (Isso pode ser notado na fig. 1-7). Este comportamento inelástico será uma característica de praticamente todos os parafusos instalados. 


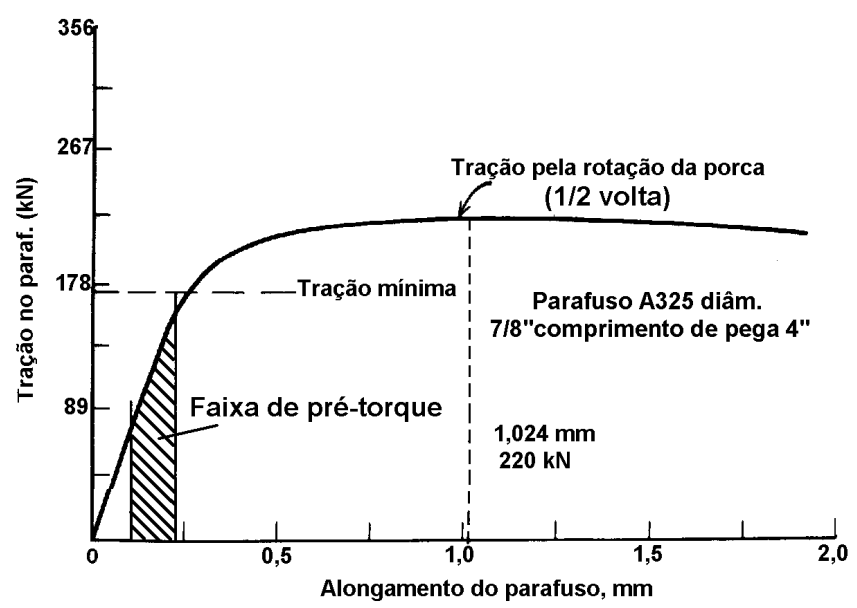

FIGURA 1-7 Alongamento em parafusos em um típico teste de ligação. Adaptada de KULAK et al. [ 34 ].

Pesquisas realizadas nos anos 60 indicaram que meia volta na porca a partir da condição de pré-torque, era adequada para todos os comprimentos dos parafusos A325. Em 1964 com a incorporação do parafuso A490 o método da rotação da porca foi então modificado novamente. Ensaios em parafusos A490 indicaram que quando o comprimento de pega situava-se em aproximadamente oito vezes o diâmetro do parafuso, uma maior rotação da porca (dois terços) era necessária para alcançar a requerida tração mínima. Apesar dessa rotação adicional não ser necessária para os parafusos A325, ela foi aplicada também a eles, devido a uniformidade de prática em campo.

Parafusos A325 com comprimento de pega superior a $100 \mathrm{~mm}$ (4”) ou 4 diâmetros e pequeno comprimento rosqueado sob a porca, submetida a rotação de meia volta, possuem suficiente capacidade de deformação para sustentar duas adicionais meias voltas antes da ruptura. Parafusos com comprimento longo de roscas no comprimento de pega podem admitir de três a cinco adicionais meias voltas.

Deve-se notar que a maior parte do alongamento ocasionado nos parafusos acontece na porção rosqueada sob a porca, um aumento nesse comprimento aumenta a ductilidade, e conseqüentemente o alongamento no parafuso.

A fig. 1-8 mostra resultados de ensaios realizados em parafusos A490 de grandes diâmetros e pequeno comprimento de pega. Devido ao relativo grande comprimento da rosca sob a porca $(22 \mathrm{~mm})$, esses parafusos apresentam razoável 
ductilidade para ambos os caso de baixa dureza e alta dureza. Todavia, pela mesma razão, um terço de volta a partir do pré-torque não foi suficiente para produzir a especificada tração mínima nos parafusos. Com isso, os usuários de parafusos de alta resistência de grandes diâmetros (acima de 25 mm), especialmente os A490, deverão estar atentos para as recomendações da especificação RCSC para instalação de parafusos com comprimentos de pega pequenos. Se tais parafusos são usados em ligações por atrito, testes de calibração em um artifício de indicação de força é aconselhável.

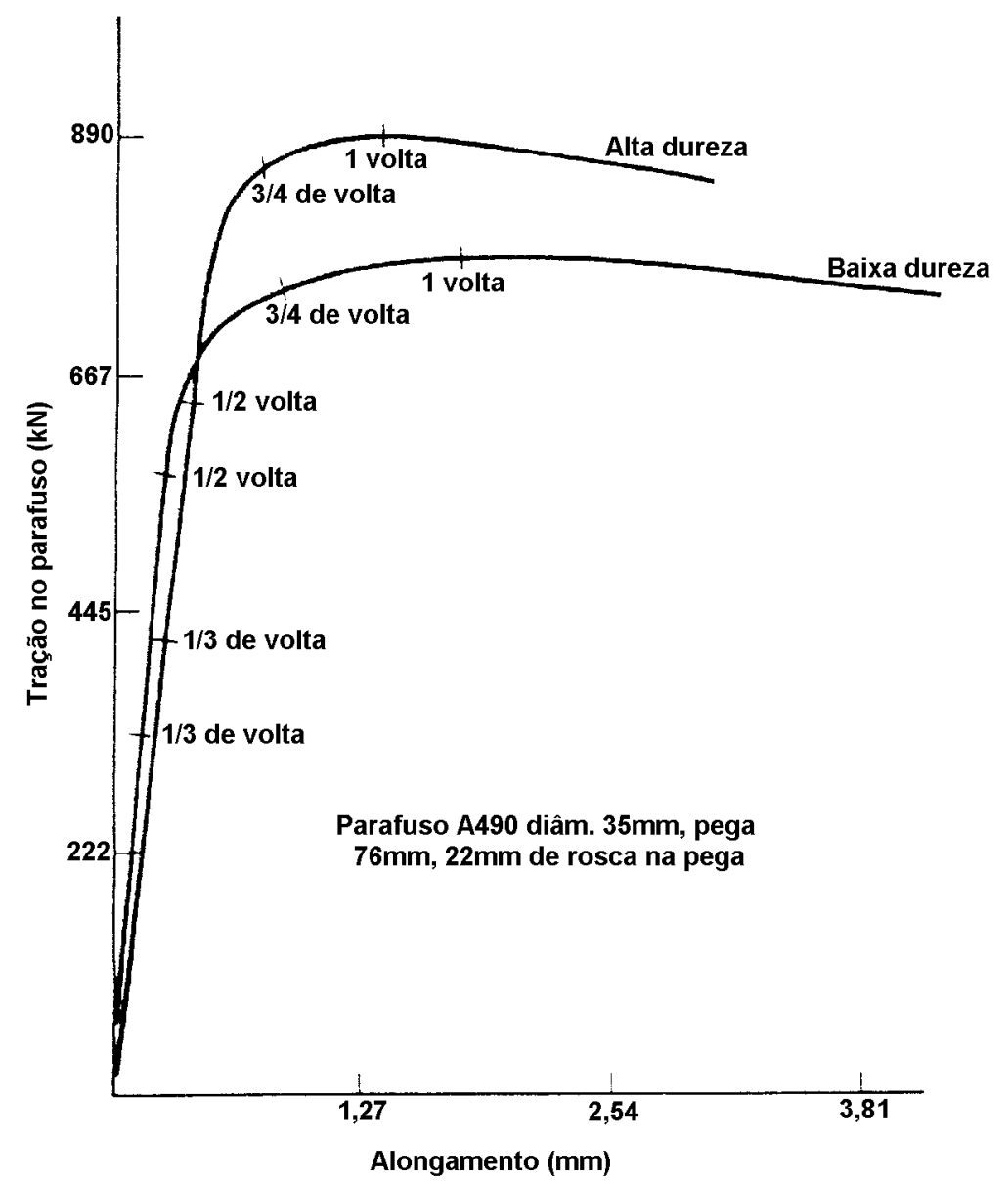

FIGURA 1-8 Tração no parafuso versus alongamento para parafusos A490 de pequeno comprimento de pega. Adaptada de KULAK et al. [ 34 ].

As especificações requerem que a inclinação nas superfícies parafusadas em contato com a cabeça do parafuso ou com a porca não excedam 1:20 em relação ao plano normal do eixo do parafuso. Pesquisas realizadas na Universidade de Illinois determinaram a influência de superfícies inclinadas em 1:20 quando arruelas biseladas são omitidas. Os parafusos A325 são dúcteis o suficiente para se deformar 
nesta inclinação. Maiores inclinações são indesejáveis, pois elas afetam a resistência do parafuso e sua ductilidade.

Através desses testes foi concluído que as conexões parafusadas com inclinação das faces de 1:20, sem arruelas biseladas, requerem uma adicional rotação da porca para garantir que a tração mínima no parafuso seja atingida (ver tabela 1-3). Naturalmente, essas arruelas podem ser usadas para eliminar as inclinações e deste modo, também eliminar a necessidade de voltas adicionais.

Segundo GAYLORD et al. [ 27 ], este método não é permitido, por alguns códigos, para parafusos com resistência mais elevada, devido a sua limitada ductilidade.

De acordo com KULAK et al. [ 34 ], independente do método de aperto (chave calibrada ou rotação da porca), arruelas são requeridas sob a cabeça e a porca dos parafusos A490, quando eles são usados para conectar materiais com um limite de escoamento inferior a $280 \mathrm{MPa}$, prevenindo assim, o excessivo esmagamento do material base. Caso contrário, elas são somente necessárias sob o elemento que gira.

A utilização de arruelas garante o desenvolvimento de um pré-tracionamento consistente e confiável. Sem ela, o precário contato entre a porca e/ou a cabeça do parafuso e o material conectado, poderia afetar esse pré-tracionamento.

Já no caso dos parafusos A325, levando-se em consideração resultados de ensaios, as especificações em geral não requerem o uso de arruelas, quando esses parafusos são instalados pelo método da rotação da porca. Quando eles são apertados com chave calibrada (controle de torque), uma arruela deve ser usada sob o elemento que gira.

A NBR 8800 [ 7 ] também especifica essas exigências citadas anteriormente.

Segundo GAYLORD et al. [ 27 ], em 1985 o RCSC permitiu o uso de métodos de aperto com indicação direta de tração, que apesar do nome, são artifícios que incorporam características para indiretamente indicar a tração no parafuso ou para automaticamente fornecer a desejada tração de aperto. Alguns deles são munidos com roscas normais ao parafuso que cisalham quando a correta tração no parafuso é obtida (ver fig. 1-9a). Um outro tipo é a utilização de um artifício onde usualmente uma arruela especial temperada é usada, contendo uma série de protuberâncias (ver fig. 1-9b). Essa arruela é colocada sob a porca ou cabeça do 
parafuso e possui propriedades tal que sua deformação é relacionada com a tração no parafuso. Com o aperto dos parafusos, as protuberâncias são achatadas e a folga presente entre a arruela e a porca é reduzida. A tração no parafuso é determinada pela medida da folga remanescente, que deve ser aproximadamente $0,38 \mathrm{~mm}$ ou menos.

Segundo OWENS \& CHEAL [ 50 ], esses sistemas de indicação direta de tração, como na fig. 1-9, não podem indicar o fluxo de tensões no parafuso, mas podem indicar que o parafuso em questão foi tracionado, atingindo sua carga de prova (proof load) ou valores acima dela.

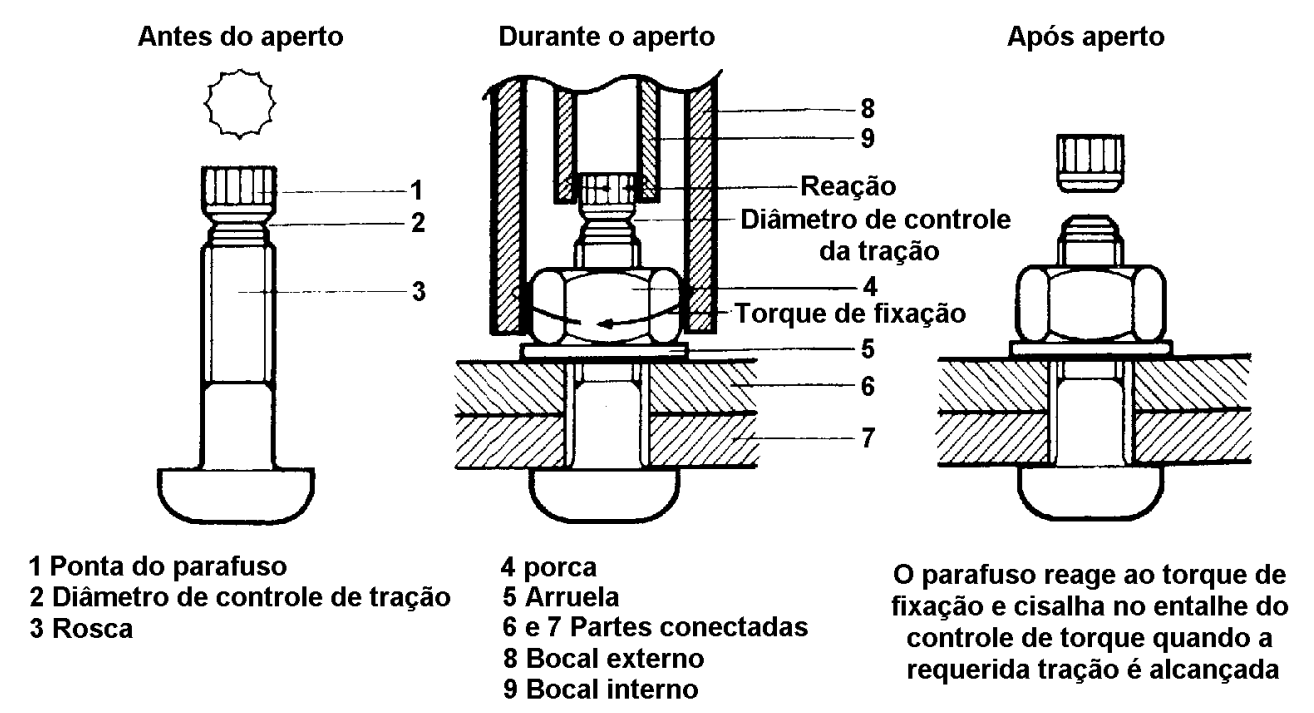

(a) Parafuso de controle de tração

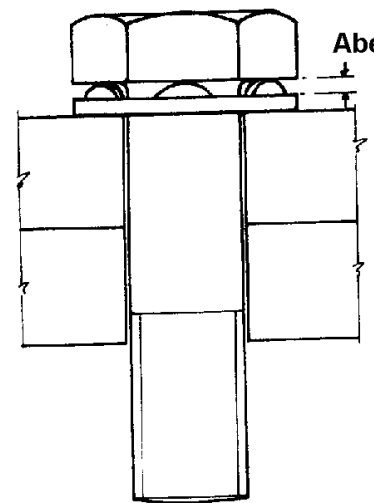

Antes do aperto

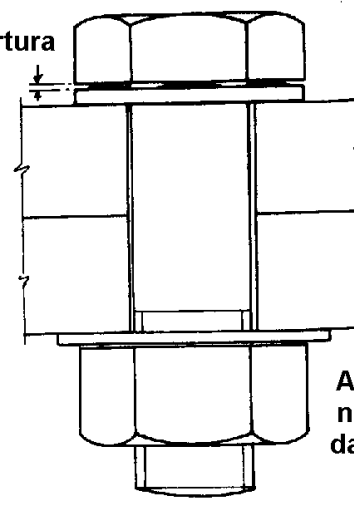

Após aperto

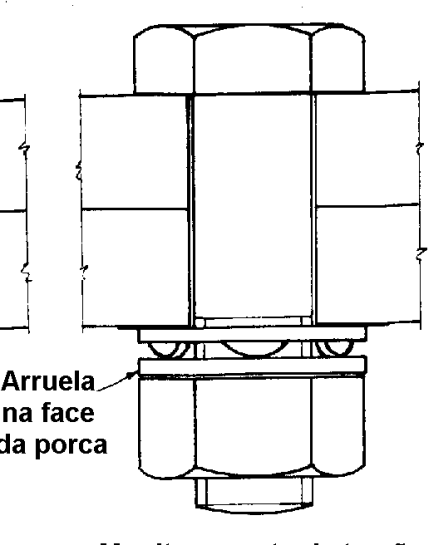

Monitoramento de tração e aperto do mesmo lado

Monitoramento de tração e aperto de lados opostos

(b) Arruelas com protuberâncias indicando pré-tração

FIGURA 1-9 Sistemas de indicação direta de tração. Adaptada de OWENS \& CHEAL [ 50 ]. 
Cuidados devem ser tomados nas situações onde exista uma interação entre os parafusos vizinhos, ou seja, onde o aperto de um parafuso influenciar no aperto dos parafusos próximos, fazendo com que eles percam parte da pré-tração aplicada anteriormente. Um procedimento recomendado para se minimizar tal interação, é colocar todos os parafusos de uma conexão na condição de pré-torque.

Este método está se tornando altamente popular, devido à existência de um registro permanente do aperto efetuado. Contudo, pelas razões esboçadas anteriormente, uma adequada inspeção é ainda requerida durante o aperto.

\subsubsection{Parafusos comuns}

O parafuso comum, de qualidade estrutural, mais utilizado é o ASTM A307. Esses parafusos são feitos de aço de baixo carbono com uma mínima resistência à tração de $415 \mathrm{MPa}$. Ao contrário do que se pode pensar esses parafusos podem, em certos casos, conduzir a uma conexão mais onerosa, devido a quantidade excessiva e ao conseqüente tamanho excessivo das chapas envolvidas. Estes parafusos comuns (fig. 1-10) podem vir com cabeça e porca quadradas ou mais comumente sextavadas, com ou sem rosca ao longo de todo o corpo do parafuso.

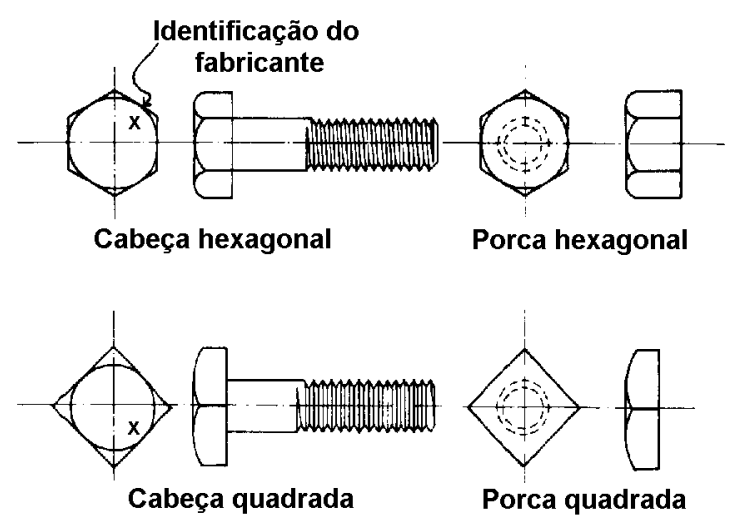

FIGURA 1-10 Parafusos ASTM A307. Adaptada de BELLEI [ 11 ].

A tabela 1-4 mostra as principais dimensões dos parafusos comuns.

TABELA 1-4 Características geométricas de parafusos comuns. Adaptada de SIDERBRÁS [ 65 ].

(a) Tabela de parafusos sextavados, em polegadas, segundo a norma ASTM A307 

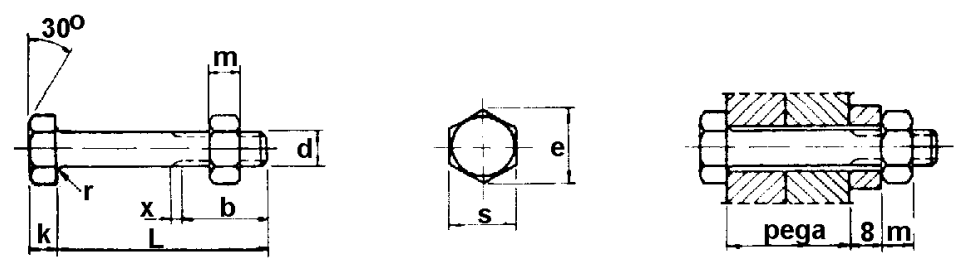

/continua

TABELA 1-4 Características geométricas de parafusos comuns. Adaptada de SIDERBRÁS [ 65 ].

(a) Tabela de parafusos sextavados, em polegadas, segundo a norma ASTM A307

continuação

\begin{tabular}{|c|c|c|c|c|c|c|c|c|c|}
\hline $\mathrm{d}$ & $3 / 8^{\prime \prime}$ & $1 / 2 "$ & $5 / 8 "$ & $3 / 4 "$ & $7 / 8 "$ & $1 "$ & $11 / 8^{\prime \prime}$ & $11 / 4 "$ & $11 / 2 "$ \\
\hline $\mathrm{e} \approx(\mathrm{mm})$ mín. & 15,70 & 21,00 & 26,20 & 31,50 & 36,70 & 42,00 & 47,20 & 52,50 & 63,00 \\
\hline $\mathrm{e} \approx(\mathrm{mm})$ máx. & 16,50 & 22,00 & 27,50 & 33,00 & 38,50 & 44,00 & 49,50 & 55,00 & 66,00 \\
\hline $\mathrm{k}(\mathrm{mm})$ mín. & 5,74 & 7,67 & 9,60 & 11,56 & 13,49 & 15,01 & 16,71 & 19,02 & 22,91 \\
\hline k (mm) máx. & 6,81 & 9,25 & 11,28 & 13,31 & 15,34 & 17,78 & 19,81 & 22,25 & 26,31 \\
\hline m (mm) mín. & 8,66 & 11,78 & 14,91 & 18,03 & 21,16 & 24,28 & 27,40 & 30,15 & 36,40 \\
\hline m (mm) máx. & 9,57 & 12,80 & 16,02 & 19,25 & 22,48 & 25,70 & 28,93 & 31,77 & 38,22 \\
\hline r (mm) mín. & 0,25 & 0,25 & 0,25 & 0,51 & 0,51 & 0,76 & 0,76 & 0,76 & 0,76 \\
\hline r (mm) máx. & 0,76 & 0,76 & 1,52 & 1,52 & 1,52 & 2,87 & 2,87 & 2,87 & 2,87 \\
\hline s (mm) mín. & 13,82 & 18,42 & 23,01 & 27,64 & 32,23 & 36,83 & 41,42 & 46,02 & 55,25 \\
\hline $\mathrm{s}(\mathrm{mm})$ máx. & 14,27 & 19,05 & 23,82 & 28,57 & 33,32 & 38,10 & 42,87 & 47,62 & 57,15 \\
\hline $\mathrm{b}(\mathrm{mm}) \mathrm{L} \leq 6 "$ mín. & 25,40 & 31,80 & 38,10 & 44,50 & 50,80 & 57,20 & 63,50 & 69,80 & 82,60 \\
\hline b (mm) L $\leq 6$ " máx. & 30,20 & 36,50 & 42,90 & 49,20 & 55,60 & 61,90 & 68,30 & 74,60 & 87,30 \\
\hline b (mm) L > 6" mín. & - & 38,10 & 44,50 & 50,80 & 57,20 & 63,50 & 69,80 & 76,20 & 88,90 \\
\hline b (mm) L > 6" máx. & - & 42,90 & 49,20 & 55,60 & 61,90 & 68,30 & 74,60 & 80,90 & 93,70 \\
\hline
\end{tabular}

(b) Tabela de parafusos sextavados, em mm, segundo a norma DIN 7990. Porca segundo a DIN 555 e arruela segundo a DIN 7989.
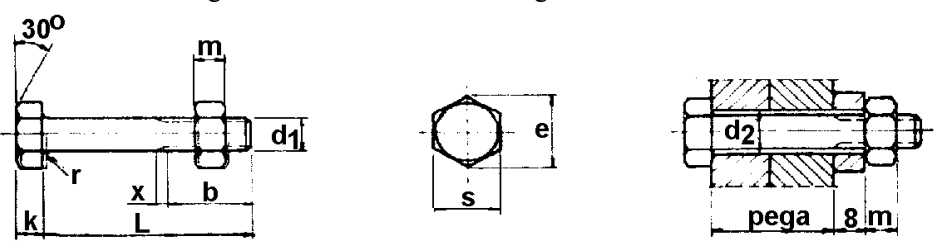

\begin{tabular}{|c|c|c|c|c|c|c|c|c|c|c|}
\hline $\mathrm{d}_{1}$ & $\mathrm{M} 10$ & $\mathrm{M} 12$ & $\mathrm{M} 16$ & $\mathrm{M} 20$ & $\mathrm{M} 22$ & $\mathrm{M} 24$ & $\mathrm{M} 27$ & $\mathrm{M} 30$ & $\mathrm{M} 33$ & $\mathrm{M} 36$ \\
\hline $\mathrm{b}$ & 17,5 & 19,5 & 23 & 26 & 28 & 29,5 & 32,5 & 35 & 38 & 40 \\
\hline $\mathrm{x}$ & 2,5 & 2,5 & 3 & 4 & 4 & 4,5 & 4,5 & 5 & 5 & 6 \\
\hline $\mathrm{e} \approx$ & 19,6 & 21,9 & 27,7 & 34,6 & 36,9 & 41,6 & 47,3 & 53,1 & 57,7 & 63,5 \\
\hline $\mathrm{k}$ & 7 & 8 & 10,5 & 13 & 14 & 15 & 17 & 19 & 21 & 23 \\
\hline $\mathrm{m}$ & 8 & 9,5 & 13 & 16 & 17 & 18 & 20 & 22 & 25 & 28 \\
\hline $\mathrm{r}$ & 0,5 & 1 & 1 & 1 & 1 & 1 & 1 & 1 & 1 & 1 \\
\hline $\mathrm{s}$ & 17 & 19 & 24 & 30 & 32 & 36 & 41 & 46 & 50 & 55 \\
\hline $\mathrm{d}_{2}$ & 11 & 13 & 17 & 21 & 23 & 25 & 28 & 31 & 34 & 37 \\
\hline
\end{tabular}

Indicados para uso geral, os parafusos A307 são disponíveis em duas categorias, denotando a resistência à tração e a especificação para uso, com diâmetros entre 6,3 a $100 \mathrm{~mm}(1 / 4 "$ " a $4 ")$ : 
- categoria A: parafusos e conectores tendo uma resistência à tração mínima de 414 $\mathrm{MPa}$, especificados para aplicações gerais

- categoria B: parafusos e conectores tendo a resistência à tração variando entre 414 a $690 \mathrm{MPa}$, especificados para ligações em tubos flangeados onde uma ou ambas as flanges são de ferro fundido.

A especificação A307 também especifica a categoria C, que são parafusos não rosqueados para ancoragens estruturais, tendo propriedades mecânicas conforme a especificação A36 (resistência à tração entre 400 e $550 \mathrm{MPa}$ ).

Segundo GAYLORD et al. [ 27 ], eles são recomendados para uso em estruturas não sujeitas a impactos ou vibrações e são usados tanto em construções de aço laminadas a quente quanto nas conformadas a frio. Seu principal uso é em estruturas leves, perfis de contraventamento, plataformas, passarelas (passadiços), terças, longarinas, pequenas tesouras, aplicações similares em que as forças são estáticas e relativamente baixas, e são também usados em conexões provisórias.

São indicados apenas em ligações por contato, ou seja, aquelas em que a força é transmitida pelo contato do corpo do parafuso com a parede do furo, conforme fig. 1-5.

Tradicionalmente esses parafusos são usados com uma só arruela sob a porca, apesar de muitos autores sugerirem a omissão desta.

Segundo OWENS \& CHEAL [ 50 ], na instalação e aperto desses parafusos nenhuma recomendação especial é feita. Para situações de ações estáticas os parafusos precisam somente ser apertados com chaves manuais de cabos longos, em uma condição confiável de aperto. Deste modo a indução de tração é relativamente pequena e não prejudicial.

Parafusos comuns não deverão ser especificados para elementos estruturais submetidos a carregamento cíclico, ou seja sob condições de fadiga. Apesar disso, porcas entalhadas com contra pinos, contra-porca e vários tipos de porcas de fecho podem ser usadas para prevenir afrouxamento, onde impactos e vibrações são uma consideração de projeto.

$\mathrm{Na}$ utilização dos chamados "parafusos pretos" (não estruturais) deve-se tomar precauções, pois esses parafusos possuem um baixo controle de qualidade, tanto nas características geométricas quanto na qualidade do aço empregado. 


\subsection{Relaxação em parafusos pré-tracionados}

Segundo KULAK et al. [ 34 ], devido ao alto nível de tensão na parte rosqueada de um parafuso instalado, alguma relaxação poderá ocorrer, de tal modo a afetar a performance do parafuso. Para avaliar a influência desta relaxação, estudos foram realizados em montagens com parafusos A325 e A354 categoria BD, apertados pelo método da rotação da porca, em aço A7. Com isso, observou-se que imediatamente após o aperto a perda média foi de $5 \%$ da máxima tração no parafuso. Esta diminuição na tração foi resultado da recuperação elástica.

Embora sem nenhum dado experimental disponível, parece razoável esperar um aumento da relaxação da pré-tração no parafuso quando o comprimento de pega é diminuído. Aumentando-se também o número de chapas dentro de um constante comprimento de pega pode-se aumentar a relaxação no parafuso. Grandes perdas na pré-tração do parafuso tem sido observadas para pequenos comprimentos de pega $(12,5 \mathrm{~mm}(1 / 2) "$ a $25,4 \mathrm{~mm}(1 "))$ em parafusos galvanizados.

Ensaios de relaxação em parafusos A325 e A354 BD mostram 4\% de perda na tração do parafuso após 21 dias, quando comparadas com à tração medida 1 minuto após o aperto. Noventa por cento desta perda ocorre durante o primeiro dia.

Por extrapolação de dados de ensaios, foi concluído que a relaxação após 100.000 horas (11,4 anos) poderá ser estimada em aproximadamente $6 \%$ da tração no parafuso logo após o aperto.

As características da relaxação em ligações com chapas e parafusos galvanizados são aproximadamente duas vezes maiores, e a referida relaxação é relacionada à espessura da camada de galvanização.

Baseado em testes realizados na Universidade Lehigh, também foi concluído, que dentro de certos limites, furos alargados ou alongados não afetam significativamente a perda de tração no parafuso, no instante seguinte à instalação. A perda de tração foi de aproximadamente $8 \%$ da pré-tração inicial. 


\subsection{Reutilização de parafusos de alta resistência}

Segundo KULAK et al. [ 34 ], desde que o método da rotação da porca é apropriado para induzir uma tração no parafuso, que excede o limite elástico na porção rosqueada, o repetido aperto de parafusos de alta resistência pode ser indesejável. Ensaios foram realizados para examinar a conduta de parafusos de alta resistência após o aperto de meia volta, afrouxando, e então reapertando (fig. 1-11a). Com isso, se verifica que os parafusos A325 podem ser reutilizados uma ou duas vezes.

Os parafusos de alta resistência novos possuem uma camada residual de óleo proveniente do processo de fabricação. Esta camada não é prejudicial, e não deverá ser removida. Os parafusos A325 novos geralmente possuem adequada capacidade de rotação da porca para permitir uma limitada reutilização, desde que o lubrificante original ainda esteja no parafuso ou óleo, graxa ou cera seja aplicada subseqüentemente.

Todavia, a reutilização de parafusos $\mathrm{A} 325$ revestidos não é recomendada. Testes têm indicado que a capacidade de rotação da porca em um parafuso é geralmente reduzida pela introdução de um revestimento. A menos que resultados indiquem o contrário, a reutilização de parafusos A325 revestidos não deverá ser permitida.

A fig. 1-11b mostra resultados típicos de parafusos A490 repetidamente instalados. Deve ser notado que a mínima tração requerida foi somente alcançada durante o primeiro e segundo ciclo. A conduta de parafusos A490 sob repetidos torques é mais crítica que para os A325, devido a isso a reutilização de parafusos A490 não é recomendada. 


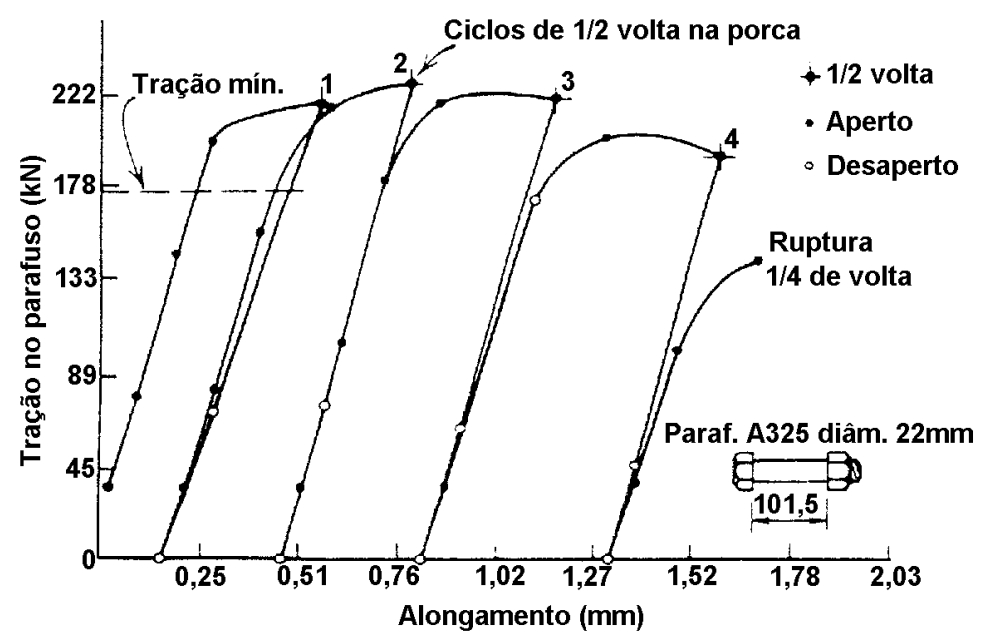

(a)

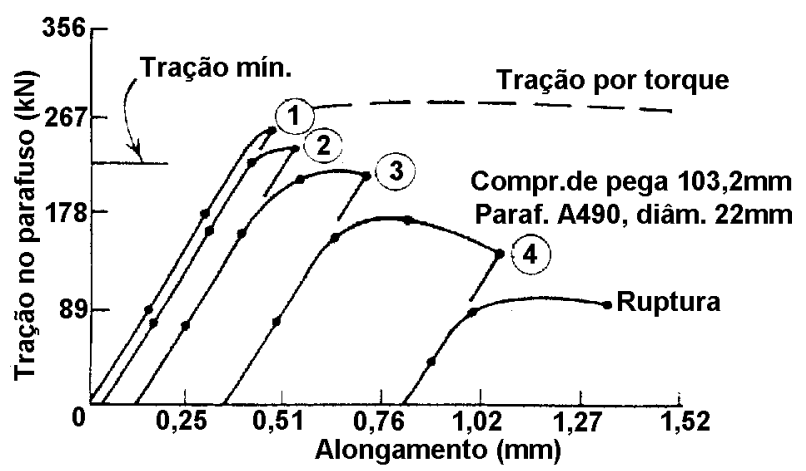

(b)

FIGURA 1-11 (a) Instalação repetida de parafusos A325; (b) instalação repetida de parafusos A490. Adaptada de KULAK et al. [ 34 ].

\subsection{Porcas e parafusos galvanizados}

Segundo KULAK et al. [ 34 ], a grande maioria das estruturas de aço são tratadas com uma superfície protetora para prevenir corrosão e conseqüentemente reduzir custos de manutenção. A galvanização é amplamente usada e fornece uma excelente proteção contra a corrosão.

A instalação de parafusos de alta resistência galvanizados pode ser afetada pela camada de zinco existente na rosca do parafuso. $\mathrm{O}$ atrito desta camada com a porca, quando o parafuso é apertado, ocasiona dificuldades em se alcançar a desejada tração no parafuso.

$O$ revestimento de zinco na superfície de um parafuso não afeta as suas propriedades de resistência estática. Todavia, se a tração no parafuso é induzida pela 
rotação da porca, uma redução na máxima tração em até $25 \%$ ocorre, dependendo das condições da rosca e da espessura da camada de zinco.

Além dessa redução na resistência à tração por torque, a adicional resistência ao atrito das roscas nos parafusos galvanizados causam um considerável decréscimo na ductilidade, como na fig. 1-12. Este elevado efeito do atrito pode ser reduzido substancialmente pela aplicação de lubrificantes nas roscas dos parafusos galvanizados. Como pode ser observado na fig. 1-12, não há nenhuma apreciável diferença entre a resistência à tração por torque de parafusos sem revestimento e parafusos galvanizados lubrificados com cera comercial ou álcool cetílico. Ensaios de calibração realizados com parafusos A490 mostram resultados similares aos resultados dos A325.

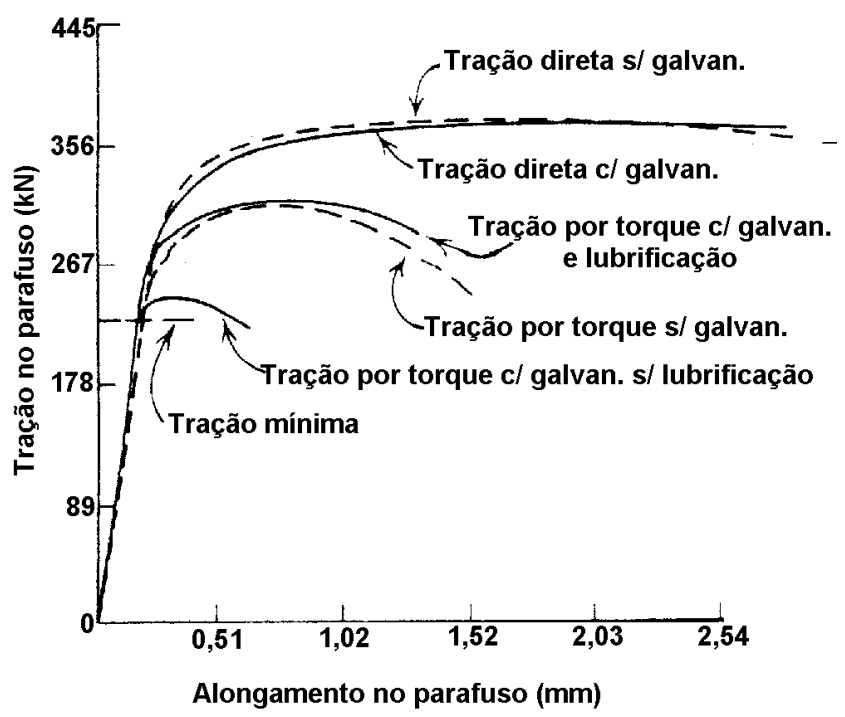

FIGURA 1-12 Comparação da relação tração no parafuso versus alongamento, entre parafusos A325 de 25 mm galvanizados e não galvanizados. Adaptada de KULAK et al. [ 34 ].

Uma alta tendência de falhas na rosca (esmagamento dos fios) foi observada nos ensaios de tração por torque em parafusos de alta resistência galvanizados. Para reduzir a possibilidade da ocorrência dessa indesejável falha, porcas mais duras deverão ser usadas nesses parafusos (porcas de qualidade $\mathrm{DH}$ ou $2 \mathrm{H}$ ).

Embora a galvanização forneça uma excelente proteção contra corrosão do parafuso, ela pode aumentar sua susceptibilidade à corrosão por fadiga e fraturas por introdução de hidrogênio. Isto se aplica especialmente aos parafusos A490 galvanizados, tanto que estes não são recomendados para uso em estruturas. 


\subsection{Corrosão e suscetibilidade à fratura frágil}

Segundo KULAK et al. [ 34 ], sob certas condições, o meio ambiente corrosivo pode ser prejudicial aos parafusos de alta resistência revestidos sujeitos à tensões. Fraturas por introdução de hidrogênio tão bem quanto corrosão sob fadiga, podem causar fratura frágil nos parafusos de alta resistência.

A corrosão sob fadiga envolve dissolução eletroquímica do metal sob influência de tensões de tração. Fratura por introdução de hidrogênio ocorre como o resultado de uma combinação de hidrogênio no arranjo de distribuição de átomos no metal, juntamente com tensões de tração. O hidrogênio produz uma dura estrutura martensita que é suscetível à fratura. A absorção de átomos de hidrogênio pelo aço é necessária para este tipo de falha ocorrer. Desde que a corrosão é freqüentemente acompanhada pela liberação de átomos de hidrogênio, essas fraturas podem ocorrer em ambientes corrosivos.

Através de resultados de ensaios, verificou-se que quanto mais alta a resistência do aço, mais sensível o material torna-se a esse tipo de fratura. O estudo indica, como já mencionado, a alta suscetibilidade dos parafusos A490 galvanizados à fratura por introdução de hidrogênio, que é causada pelo rompimento na película de zinco, que proporciona a entrada de átomos de hidrogênio dentro do metal. Se não há rompimento no revestimento, essa falha provavelmente não ocorrerá.

Concluiu-se também, que os parafusos A325 tratados termicamente dentro dos limites de dureza especificados, agem satisfatoriamente com respeito às fraturas por introdução de hidrogênio e corrosão sob fadiga, na maioria dos ambientes corrosivos. Atenção particular deverá ser dada na preparação dos parafusos galvanizados. Impróprios procedimentos de proteção contra corrosão induzem o aparecimento de fraturas frágeis por introdução de hidrogênio. Já os parafusos A490 sem revestimentos podem ser usados sem problemas de fratura frágil.

Segundo OWENS \& CHEAL [ 50 ], de maneira a garantir qualidade dos parafusos, alguns ensaios são geralmente especificados: ensaios de tração; prova de carga; dureza; ensaio de cunha, para avaliar se o parafuso acomoda sua cabeça sob contato não uniforme e ensaio de impacto. 
As porcas também são sujeitas aos testes de carga de prova e dureza.

Além da prática e informal checagem da geometria por meio de micrômetros, roscas padrão e machos de abrir roscas, a geometria das roscas pode ser checada com a ajuda de um esquiagrama (imagem sombreada projetada sobre uma superfície sensível, especialmente por raios X) que pode ser usado para ampliar a geometria da rosca do parafuso.

\subsection{Furos para parafusos e rebites}

Determinar o tamanho, o tipo e o arranjo dos furos para os conectores é uma importante parte do procedimento de projeto. A figura 1-13a mostra o furo padrão que desde a primeira aplicação de parafusos de alta resistência em 1947, é o mais freqüentemente usado. Salvo um outro tipo de furo especificado, o furo padrão é assumido. A figura 1-13 mostra os tipos de furos que são permitidos desde a especificação AISC 1978.

Segundo CRAWLEY \& DILLON [ 19 ], a principal razão do uso de furos alargados ou alongados é fornecer uma maior flexibilidade na montagem e ajuste das estruturas de aço. A complicada geometria e/ou elementos longos podem fazer conveniente a especificação de um destes tipos especiais de furos. Um furo alargado fornece a mesma folga em todas as direções, todavia, se um ajuste é necessário em uma particular direção, furos alongados podem ser utilizados. Deverá ser notado que nos furos alongados na fig. 1-13c e d, a abertura ovalada deve ser sempre orientada de modo que a direção da força seja normal ao comprimento dessa abertura, no caso de conexões por contato. Deve-se lembrar que todos os furos alargados e alongados requerem o uso de arruelas (ver tabela 1-6).

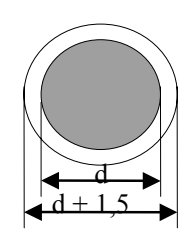

(a)

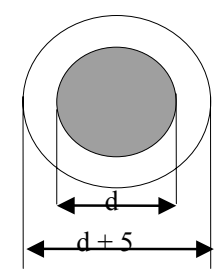

(b)

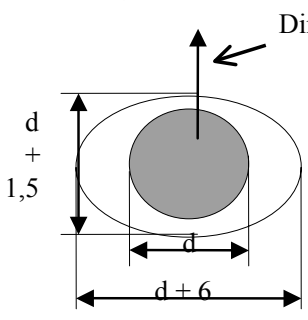

(c)

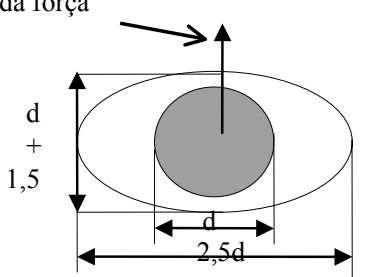

(d)

FIGURA 1-13 Furos em parafusos de alta resistência com diâmetro menor que 24 mm, conforme o AISC/LRFD 93 [ 4 ] e a NBR 8800 [ 7 ]. (a) Furo padrão; (b) furo alargado; (c) furo pouco alongado; (d) furo muito alongado. Adaptada de CRAWLEY \& DILLON [ 19 ]. 
Em quase todos os parafusos e rebites são utilizadas folgas nos furos para aliviar os problemas de ajustes durante a montagem. Conforme pode ser visto na tabela 1-5a, a NBR 8800 [ 7 ], similarmente ao AISC/LRFD 93 [ 4 ], fornece para furos padrão, o diâmetro do furo 1,5 mm (1/16") maior que o diâmetro do conector. Segundo OWENS \& CHEAL [ 50 ], esse valor é ligeiramente diferente dos $2 \mathrm{~mm}$ recomendado pela BS 5950, conforme tabela 1-5b. Já furos para parafusos de alta resistência, variam de acordo com o diâmetro.

TABELA 1-5 Dimensões nominais dos furos.

(a) Dimensões máximas de furos para parafusos .Adaptada da NBR 8800 [ 7 ].

\begin{tabular}{|c|c|c|c|c|}
\hline \multicolumn{5}{|c|}{ Dimensões em mm } \\
\hline $\mathrm{d}(\mathrm{mm})$ & $\begin{array}{l}\text { Furo padrão } \\
\text { (diâm.) }\end{array}$ & $\begin{array}{l}\text { Furo alargado } \\
\text { (diâm.) }\end{array}$ & $\begin{array}{c}\text { Furo pouco alongado } \\
\text { (largura } \mathrm{x} \\
\text { comprimento) }\end{array}$ & $\begin{array}{c}\text { Furo muito } \\
\text { alongado } \\
\text { (largura } \mathrm{x} \\
\text { comprimento) }\end{array}$ \\
\hline$\leq 24$ & $d+1,5$ & $d+5$ & $(d+1,5) \times(d+6)$ & $(d+1,5) \times 2,5 d$ \\
\hline 27 & 28,5 & 33 & $28,5 \times 35$ & $28,5 \times 67,5$ \\
\hline$\geq 30$ & $d+1,5$ & $d+8$ & $(d+1,5) \times(d+9,5)$ & $(d+1,5) \times 2,5 d$ \\
\hline \multicolumn{5}{|c|}{ Dimensões em polegadas* } \\
\hline$\leq 7 / 8^{\prime \prime}$ & $d+1 / 16^{\prime \prime}$ & $d+3 / 16 "$ & $\left(d+1 / 16^{\prime \prime}\right) \times(d+1 / 4 ”)$ & $(d+1 / 16 ") \times 2,5 d$ \\
\hline $1 "$ & $11 / 16^{\prime \prime}$ & $11 / 4^{\prime \prime}$ & $11 / 16 " x 15 / 16 "$ & $11 / 16 " \times 21 / 2 "$ \\
\hline$\geq 11 / 8^{\prime \prime}$ & $d+1 / 16^{\prime \prime}$ & $d+5 / 16^{\prime \prime}$ & $(\mathrm{d}+1 / 16 ”) \times\left(\mathrm{d}+3 / 8^{\prime \prime}\right)$ & $(d+1 / 16 ") \times 2,5 d$ \\
\hline
\end{tabular}

*Deve-se notar que esses valores em polegadas apresentada pela NBR 8800 [ 7 ], são os mesmos valores apresentados pela AISC/LRFD 93 [ 4 ], com a exceção do diâmetro 1/2" que usa como dimensão para os furos alargados 5/8" e para os furos pouco alongados $9 / 16 \times 11 / 16 "$.

(b) Dimensões máximas de furos para parafusos .(BS 5950: Part. 1, 1985). Adaptada de OWENS \& CHEAL [ 50 ].

\begin{tabular}{|c|c|c|c|c|c|}
\hline $\begin{array}{c}\mathrm{d} \\
(\mathrm{mm})\end{array}$ & $\begin{array}{c}\text { Furo padrão } \\
\text { para paraf. } \\
\text { comuns (diâm.) }\end{array}$ & $\begin{array}{c}\text { Furo padrão para } \\
\text { paraf. de alta } \\
\text { resistência(diâm. } \\
\text { ) }\end{array}$ & $\begin{array}{c}\text { Furo } \\
\text { alargado } \\
\text { (diâm.) }\end{array}$ & $\begin{array}{c}\text { Furo pouco } \\
\text { alongado (largura x } \\
\text { comprimento) }\end{array}$ & $\begin{array}{c}\text { Furo muito } \\
\text { alongado (largura } \\
\text { x comprimento) }\end{array}$ \\
\hline$\leq 22$ & $\mathrm{~d}+2$ & $\mathrm{~d}+2$ & $\mathrm{~d}+5$ & $(\mathrm{~d}+2) \times(\mathrm{d}+6)$ & $(\mathrm{d}+2) \times 2,5 . \mathrm{d}$ \\
\hline 24 & 27 & 27 & 30 & $27 \times 32$ & $27 \times 60$ \\
\hline$\geq 27$ & $\mathrm{~d}+3$ & $\mathrm{~d}+3$ & $\mathrm{~d}+8$ & $(\mathrm{~d}+3) \times(\mathrm{d}+10)$ & $(\mathrm{d}+3) \times 2,5 . \mathrm{d}$ \\
\hline
\end{tabular}

O EUROCODE 3 [ 24 ] apresenta as seguintes especificações para as folgas existentes nos furos:

- exceto para parafusos ajustados ou onde furos com pequena folga ou furos alargados são especificados, a folga em parafusos padrão deve ser: $1 \mathrm{~mm}$ para parafusos M12 e M14; 2 mm para os M16 a M24; 3 mm para os M27 e diâmetros superiores.

- furos com $2 \mathrm{~mm}$ de folga podem também ser especificados para parafusos M12 e M14, contanto que reuna os requerimentos de projeto. 
- a folga nominal de furos alargados para conexões por atrito deve ser: $3 \mathrm{~mm}$ para parafusos M12; $4 \mathrm{~mm}$ para os M14 a M22; $6 \mathrm{~mm}$ para os M24; $8 \mathrm{~mm}$ para os M27 e diâmetros superiores.

- os tamanhos nominais de furos pouco alongados em conexões por atrito não devem ser maiores que: $(\mathrm{d}$ - 1) mm por (d - 4) mm para parafusos M12 e M14; (d - 2) mm por (d - 6) mm para os M16 a M22; (d - 2) mm por (d - 8) mm para os M24; (d - 3) mm por (d - 10) mm para os M27 e diâmetros maiores, sendo $d$ o diâmetro nominal do parafuso.

- os tamanhos nominais de furos muito alongados para conexões por atrito devem não ser maiores que: $(\mathrm{d}$ - 1) mm por 2,5d para parafusos M12 e M14; (d - 2) mm por 2,5d para os M16 a M24; (d - 3) mm por 2,5d para os M27 e diâmetros superiores.

Tem sido estudado o efeito de furos alargados ou alongados em fatores como a perda de tração no parafuso após instalação, a resistência ao deslizamento, bem como nos procedimentos de aperto.

Segundo KULAK et al. [ 34 ], o comportamento força versus deformação em ligações com parafusos de alta resistência montados em furos alongados ou alargados dependem, entre outros fatores, da força de aperto do parafuso, do diâmetro dos furos e das condições da superfície do material base.

Ensaios têm indicado que esses furos podem significativamente influenciar o nível da pré-tração no parafuso, como mostrado na fig. 1-14. Pode-se observar que os parafusos A325 com 25 mm (1") de diâmetro, instalados em furos com 1/4" de folga, apresentaram a mesma tração média independente da utilização de arruela sob a porca. A tração alcançada no parafuso foi aproximadamente $118 \%$ da mínima tração requerida, isto é aproximadamente $15 \%$ menor que a tração média que é observada em ligações com 1/16" de folga. Depressões na chapa sob a cabeça do parafuso ocorrem durante o aperto e são maiores que as depressões observadas com o usual $1 / 16$ " de folga. Elevado atrito localizado tanto na chapa quanto na porca ocorrem com furos alargados, quando arruelas são omitidas sob o elemento que gira. Os parafusos de $25 \mathrm{~mm}$ (1") de diâmetro, instalados com somente uma arruela sob o elemento que gira em furos com 5/16" de folga apresentaram ruptura antes de atingir a mínima tração requerida. A cabeça dos parafusos esmaga significativamente a 
chapa ao redor dos furos, mas quando arruelas são colocadas sob a cabeça e a porca do parafuso, a tração no parafuso alcança limites entre 110 a 144\% da mínima tração requerida.

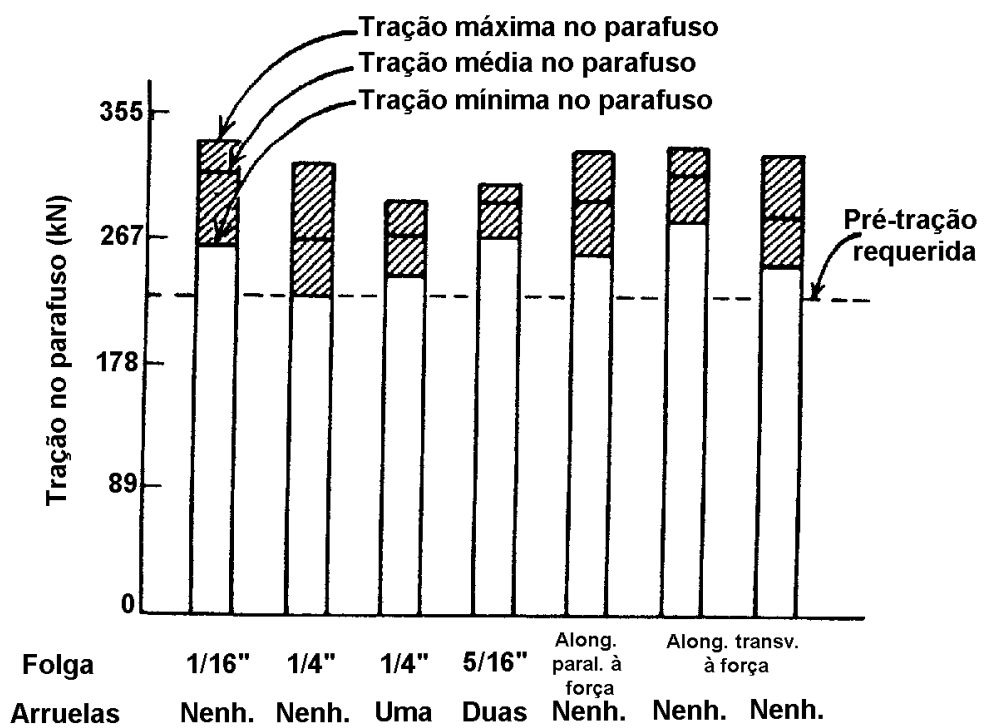

FIGURA 1-14 Tração em parafusos A325 de $25 \mathrm{~mm}$ de diâmetro, apertados pelo método da rotação da porca, para furos padrão, alargados e alongados, onde cada barra representa 24 parafusos em três ligações. Adaptada de KULAK et al. [ 34 ].

Em outro ensaio, parafusos A490 de grandes diâmetros (29 mm) foram instalados em furos alargados com 5/16" de folga e arruelas padrão foram usadas sob a cabeça do parafuso e da porca. Apesar do polimento observado, foi principalmente o abaulamento das arruelas sob a alta pré-tração, que impediu que a pré-tração mínima especificada fosse alcançada. Ela somente foi atingida quando arruelas mais espessas foram usadas (5/16").

O esmagamento da chapa ou o abaulamento da arruela, significa que a prescrita rotação na porca pode não produzir o alongamento necessário do parafuso. Ao se utilizar chave calibrada como procedimento de instalação, deve-se tomar o devido cuidado na calibração da chave, adotando-se corpos-de-prova com as mesmas características da ligação em questão.

Parafusos instalados pelo método da rotação da porca em furos alongados também mostraram um decréscimo na tração média do parafuso quando comparado com parafusos instalados em furos padrão com 1/16" de folga.

Um sumário dos coeficientes de atrito observados em função da geometria do furo para condições de furos alargados e alongados é mostrado na fig. 1-15. Foi concluído que o coeficiente de atrito médio para ligações com furos com até 1/4" de 
folga não mudaram com a variação do alargamento. As ligações com furos de 5/16" de folga mostraram $17 \%$ de decréscimo no coeficiente de atrito para superfícies laminadas limpas. O coeficiente de atrito para ligações com furos alongados apresentou 22 a 33\% de decréscimo quando comparado à situação de furos padrão. Um decréscimo na resistência ao deslizamento com a remoção do material da chapa ao redor do parafuso (caso de furo alargado), era esperado devido ao resultado das altas pressões de contato na referida região. Estas elevadas pressões de contato adjacentes ao furo, tendem a achatar as irregularidades superficiais e desse modo reduzir o coeficiente de atrito da conexão.

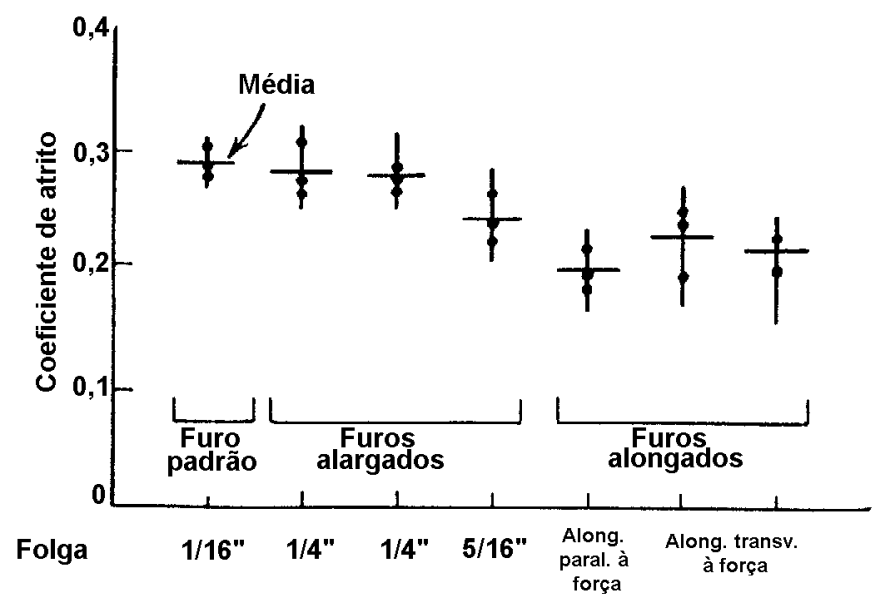

FIGURA 1-15 Comparação entre os coeficientes de atrito médios. Adaptada de KULAK et al. [ 34 ].

A resistência ao deslizamento é também afetada pelo decréscimo da força de aperto que tem sido observada em ligações com furos alongados e alargados. Os efeitos combinados de mudança do coeficiente de atrito e da redução da força de aperto na resistência ao deslizamento é estimada para causar aproximadamente $15 \%$ de redução na resistência ao deslizamento de conexões com furos alargados e aproximadamente $30 \%$ de redução em furos alongados.

Estudos têm também avaliado a influência de furos alargados na resistência ao deslizamento de superfícies revestidas. Estes trabalhos mostraram que para furos com até $1 / 4$ " de folga, não houve significativo efeito no coeficiente de atrito.

Segundo a NBR 8800 [ 7 ], de maneira similar ao que apresenta o AISC/LRFD 93 [ 4 ], nas ligações com furos alargados ou alongados, devem ser observados os tipos de ligação permitidos e as limitações indicadas na tabela 1-6. 
TABELA 1-6 Limitações relativas ao emprego de furos alargados ou alongados. Adaptada da NBR 8800 [ 7 ].

\begin{tabular}{|c|c|c|c|}
\hline & & \multicolumn{2}{|r|}{ Limitações } \\
\hline Tipo de furo & $\begin{array}{l}\text { Tipo de ligação } \\
\text { permitido }\end{array}$ & Posição do furo & Arruelas $^{(a)}$ \\
\hline Alargado & Por atrito & $\begin{array}{c}\text { Em qualquer uma ou em } \\
\text { todas as chapas da } \\
\text { ligação }\end{array}$ & $\begin{array}{l}\text { Endurecidas, sobre furos alargados em } \\
\text { chapas externas da ligação }\end{array}$ \\
\hline Pouco alongado & Por atrito & $\begin{array}{c}\text { Em qualquer uma ou em } \\
\text { todas as chapas da } \\
\text { ligação. Qualquer } \\
\text { posição, } \\
\text { independentemente da } \\
\text { direção da solicitação }\end{array}$ & $\begin{array}{c}\text { Sobre furos pouco alongados em } \\
\text { chapas externas da ligação; tais } \\
\text { arruelas devem ser endurecidas } \\
\text { quando }\end{array}$ \\
\hline Pouco alongado & Por contato & $\begin{array}{l}\text { Em qualquer uma ou em } \\
\text { todas as chapas da } \\
\text { ligação. Maior dimensão } \\
\text { normal à direção da } \\
\text { solicitação } \\
\end{array}$ & $\begin{array}{l}\text { os parafusos forem de alta resistência: } \\
\text { ASTM A325 e ASTM A490 }\end{array}$ \\
\hline Muito alongado & Por atrito & $\begin{array}{c}\text { Em somente uma das } \\
\text { partes da ligação, para a } \\
\text { mesma superfície de } \\
\text { contato. Qualquer } \\
\text { posição, } \\
\text { independentemente da } \\
\text { direção da solicitação }\end{array}$ & $\begin{array}{l}\text { Arruelas de chapa ou barras chatas } \\
\text { contínuas, de aço estrutural, com } \\
\text { espessura mínima de } 8 \text { mm e com } \\
\text { furos padrão, devem ser usadas sobre } \\
\text { furos muito alongados em chapas } \\
\text { externas. Tais arruelas ou barras } \\
\text { devem ter dimensões suficientes para } \\
\text { cobrir }\end{array}$ \\
\hline Muito alongado & Por contato & \begin{tabular}{|c|} 
Em somente uma das \\
partes da ligação, para a \\
mesma superfície de \\
contato. Maior \\
dimensão normal à \\
direção da solicitação
\end{tabular} & $\begin{array}{c}\text { totalmente os furos alongados após a } \\
\text { instalação dos parafusos. Quando } \\
\text { necessário, usar arruelas endurecidas } \\
\text { (nota a). Estas serão colocadas sobre } \\
\text { aquelas arruelas de chapa ou barras } \\
\text { contínuas }\end{array}$ \\
\hline
\end{tabular}

(a) Quando forem usados parafusos ASTM A490 de diâmetro superior a 25,4 mm, em furos alongados ou alargados, nas chapas externas da ligação, deverão ser usadas arruelas endurecidas de acordo com a ASTM F436, porém, com espessura mínima de 8 $\mathrm{mm}$, em lugar das arruelas padrão.

Os parafusos ajustados ou de tolerância fina, mencionados na seção 1.8.2, são ocasionalmente usados para reduzir o deslocamento relativo entre as partes, quando uma conexão sob solicitação de força cortante é requerida e não é praticável usar uma conexão por atrito. Devido a isso os furos para tais conectores devem apresentar uma folga não superior a $0,15 \mathrm{~mm}$.

Geralmente os furos são executados por broqueamento, contudo alguns códigos permitem que o puncionamento seja utilizado para ligações submetidas à 
ações estáticas e para limitadas espessuras de chapas. Segundo OWENS \& CHEAL [ 50 ], o uso de furos puncionados é restringido, porque a ação mecânica do puncionamento causa uma plastificação do material, ao redor do furo, tendo como conseqüência a formação de um material frágil (baixa ductilidade). Esse material pode proporcionar o aparecimento de fissuras, comprometendo a conexão.

Os furos para parafusos ajustados, geralmente são executados por um broqueamento de menor diâmetro e alargados após uma pré-montagem.

\subsection{Outros tipos e especificações de conectores}

\subsubsection{Parafusos ASTM A354 e A687}

Segundo o ENGINEERING FOR STEEL CONSTRUCTION [ 2 ], os conectores ASTM A354 (parafusos, pinos, e outros conectores rosqueados externamente de aço-liga temperado, disponíveis até $100 \mathrm{~mm}$ (4”) de diâmetro) e o ASTM A687 (parafusos e pinos sem cabeça, de alta resistência, disponíveis em diâmetros de 32 até $76 \mathrm{~mm}$ ( 1 1/4" até 3" )), não são reconhecidos pelo AISC para aplicações estruturais, requerendo pré-tracionamento durante a instalação. Deste modo, para aplicações altamente tracionadas, deverá se tomar cuidado com esses conectores no que se refere às especificações ASTM. As porcas e as arruelas deverão ser selecionadas pelas especificações ASTM A563 e F436 para que haja compatibilidade de resistência. Também pode ser apropriado especificar as dimensões das cabeças sextavadas e das porcas sextavadas para certas aplicações.

\subsubsection{Parafusos de tolerância fina (usinados)}

Segundo manual da SIDERBRÁS [ 66 ], estes parafusos são empregados em estruturas sujeitas a ações dinâmicas, como no caso de ligações de vigas de rolamento e ligações de pontes ferroviárias. Devido ao seu custo elevado os parafusos de tolerância fina têm o uso restrito em construções metálicas no Brasil. A tabela 1-7 mostra os principais dados geométricos desses parafusos. 

DIN 555 e arruela segundo a DIN 7989. Adaptada de SIDERBRÁS [ 65 ].
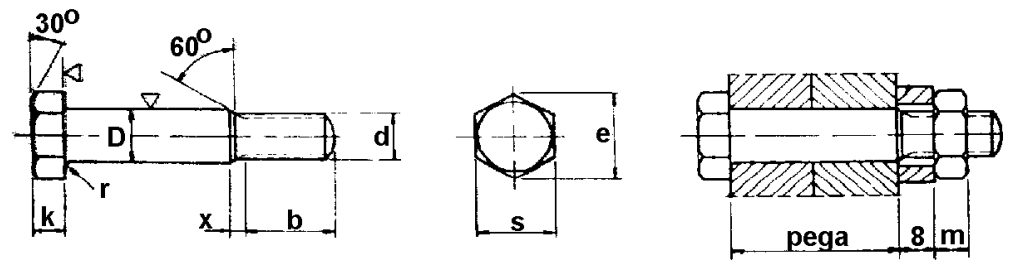

\begin{tabular}{|c|c|c|c|c|c|c|c|c|c|}
\hline $\mathrm{d}$ & $\mathrm{M} 10$ & $\mathrm{M} 12$ & $\mathrm{M} 16$ & $\mathrm{M} 20$ & $\mathrm{M} 22$ & $\mathrm{M} 24$ & $\mathrm{M} 27$ & M30 & M33 \\
\hline $\mathrm{D}$ & 11 & 13 & 17 & 21 & 23 & 25 & 28 & 31 & 34 \\
\hline $\mathrm{b}$ & 17,5 & 19,5 & 23 & 26 & 28 & 29,5 & 32,5 & 35 & 38 \\
\hline $\mathrm{x}$ & 2,5 & 2,5 & 3 & 4 & 4 & 4,5 & 4,5 & 5 & 5 \\
\hline $\mathrm{e} \approx$ & 19,6 & 21,9 & 27,7 & 34,6 & 36,9 & 41,6 & 47,3 & 53,1 & 57,7 \\
\hline $\mathrm{k}$ & 7 & 8 & 10,5 & 13 & 14 & 15 & 17 & 19 & 21 \\
\hline $\mathrm{m}$ & 8 & 9,5 & 13 & 16 & 17 & 18 & 20 & 22 & 25 \\
\hline $\mathrm{r}$ & 0,5 & 1 & 1 & 1 & 1 & 1 & 1 & 1 & 1 \\
\hline $\mathrm{s}$ & 17 & 19 & 24 & 30 & 32 & 36 & 41 & 46 & 50 \\
\hline
\end{tabular}

\subsubsection{Dispositivos de ancoragem}

Tipos tradicionais de dispositivos de ancoragem, utilizados para fixação em concreto, são mostrados na fig. 1-16. Segundo OWENS \& CHEAL [ 50 ], o parafuso J (tipo a), em particular, torna-se "desajeitado" para fixação em comprimentos acima de $600 \mathrm{~mm}$ e em diâmetros acima de $25 \mathrm{~mm}$. O parafuso com tubo-luva (tipo c), possui a vantagem de proporcionar uma pequena liberdade de ajuste na montagem da ligação. Os tipos (d) até (g) são usualmente chumbados dentro dos furos moldados ou perfurados no concreto, apesar de poderem ser fixados no local antes da concretagem. O material de preenchimento pode consistir tanto de resina epóxi quanto de argamassa de cimento.

Perdas de pré-tração provenientes da fluência do concreto serão minimizadas pelo uso de barras de alta resistência à tração e de comprimento suficiente. Em situações de fadiga, será apropriado especificar uma nova pré-tração após 12 meses, quando a maior parte de perda por fluência já tiver ocorrido.

O dispositivo tipo (h) é um exemplo de um parafuso de expansão que é também fixado dentro de um furo perfurado. $\mathrm{O}$ aperto do parafuso causa uma ação de 
cunhamento desenvolvida pela ampliação do cilindro externo, fixando-o na superfície do concreto, dentro do furo.

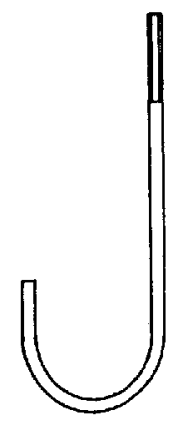

(a)

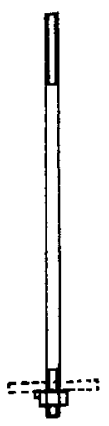

(b)

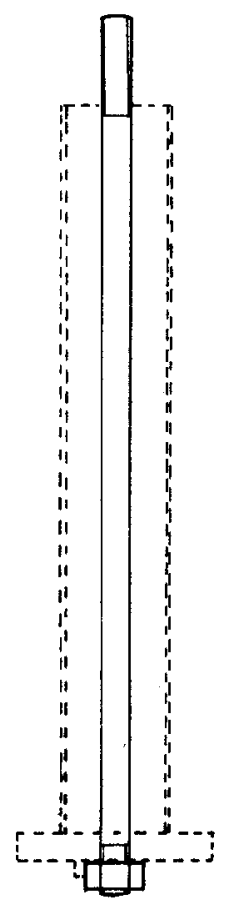

(c)

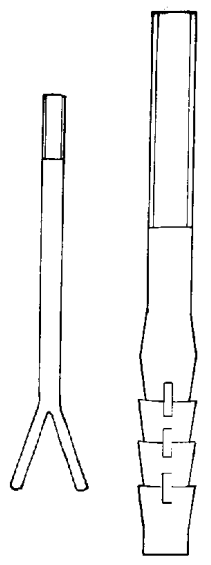

(d)

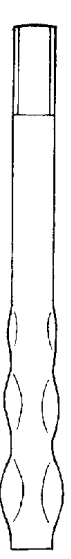

(e)

(f)

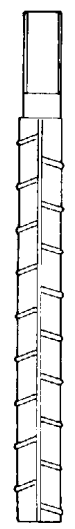

(g)

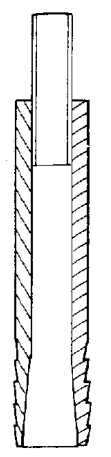

(h)

FIGURA 1-16 Dispositivos de ancoragem. (a) Parafuso J; (b) parafuso com chapa de extremidade; (c) parafuso com tuboluva; (d) parafuso de extremidade dividida; (e) parafuso farpado; ( f) parafuso dentado; (g) parafuso com rugosidades; (h) parafuso de expansão. Adaptada de OWENS \& CHEAL $\lceil 501$.

Os furos para esses dispositivos, segundo OWENS \& CHEAL [ 50 ], usualmente requerem $2 \mathrm{~mm}$ de folga. Em casos específicos considerações deverão ser dadas para especificação de espaçamentos maiores em circunstâncias apropriadas.

Esses dispositivos de ancoragem devem ser utilizados com cautela e sempre seguindo as recomendações dos fabricantes. Em situações suspeitas, deve-se proceder a ensaios para avaliação do comportamento estrutural.

Para ilustrar melhor, um exemplo de parafuso de expansão é o chumbador PARABOLT $^{\circledR}$ (ver fig. 1-17) composto de um parafuso de aço, uma presilha de aço inox, montada na seção "cônica" do parafuso, porca e arruela.

O parafuso é fabricado com aço carbono SAE 1040/45. A presilha, a porca e a arruela são produzidas por estampagem. Além disso, o parafuso, a porca e a arruela são zincadas por deposição eletrolítica. 
Durante o processo de instalação a presilha que envolve a seção "cônica", expande-se continuamente à medida em que a porca é apertada, atingindo elevada resistência de fixação.

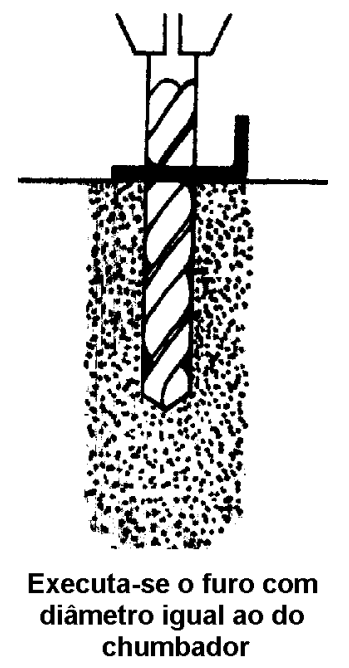

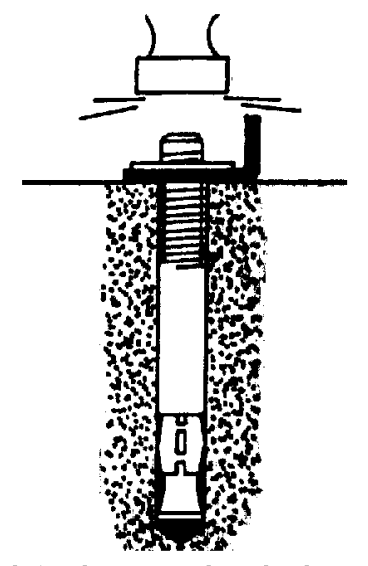

Introduz-se o chumbador no furo deixando fios de rosca suficientes para a colocação da arruela e da porca

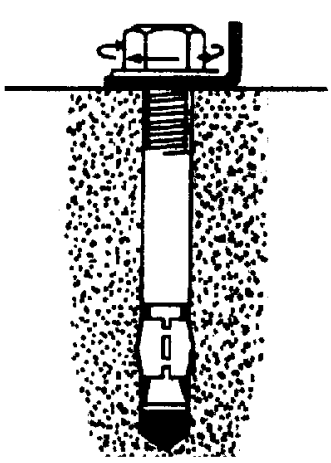

Inicia-se o aperto da porca até que o chumbador encontre resistência suficiente

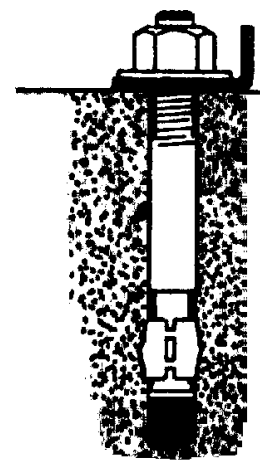

o chumbador

fixou-se definitivamente

FIGURA 1-17 Instalação do chumbador PARABOLT ${ }^{\circledR}$. Extraída do catálogo da USM do Brasil.

A tabela 1-8 apresenta características dimensionais e de resistência do chumbador PARABOLT ${ }^{\circledR}$.

TABELA 1-8 Tabela dimensional e de resistência do chumbador PARABOLT ${ }^{\circledast}$. Extraída do catálogo da USM do

\begin{tabular}{|c|c|c|c|c|c|c|}
\hline Código & $\begin{array}{c}\text { Diâmetro e } \\
\text { comprimento } \\
(\mathrm{mm})\end{array}$ & $\begin{array}{l}\text { Diâmetro do } \\
\text { furo }(\mathrm{mm})\end{array}$ & $\begin{array}{l}\text { Profundidade } \\
\text { mínima no } \\
\text { concreto }(\mathrm{mm})\end{array}$ & $\begin{array}{c}\text { Compri- } \\
\text { mento da } \\
\text { rosca }(\mathrm{mm})\end{array}$ & Rosca UNC & Tração (sem FS) \\
\hline PB-644 & $6,3 \times 44,4$ & 6,3 & 28,5 & 19,0 & 20fios/pol & \multirow{3}{*}{\begin{tabular}{|} 
Resultado do ensaio \\
IPT-SP \\
média $1.530 \mathrm{kgf} 30 \%$ \\
margem de \\
segurança $1.070 \mathrm{kgf}$ \\
\end{tabular}} \\
\hline PB-657 & $6,3 \times 57,1$ & 6,3 & 28,5 & 22,2 & 20fios/pol & \\
\hline PB-682 & $6,3 \times 82,5$ & 6,3 & 28,5 & 22,2 & 20fios/pol & \\
\hline PB-957 & $9,5 \times 57,1$ & 9,5 & 38,0 & 19,0 & 16fios/pol & \multirow{3}{*}{\begin{tabular}{|} 
Resultado do ensaio \\
IPT-SP \\
média $4.056 \mathrm{kgf} 30 \%$ \\
margem de \\
segurança $2.840 \mathrm{kgf}$
\end{tabular}} \\
\hline PB-976 & $9,5 \times 76,2$ & 9,5 & 38,0 & 31,7 & 16fios/pol & \\
\hline PB-995 & $9,5 \times 95,2$ & 9,5 & 38,0 & 31,7 & 16fios/pol & \\
\hline PB-1370 & $12,6 \times 69,8$ & 12,6 & 57,1 & 28,5 & 13fios/pol & \multirow{3}{*}{\begin{tabular}{|} 
Resultado do ensaio \\
IPT-SP \\
média $4.777 \mathrm{kgf} 30 \%$ \\
margem de \\
segurança $3.344 \mathrm{kgf}$ \\
\end{tabular}} \\
\hline PB-13102 & $12,6 \times 101,6$ & 12,6 & 57,1 & 31,7 & 13fios/pol & \\
\hline PB-13133 & $12,6 \times 133,3$ & 12,6 & 57,1 & 31,7 & 13fios/pol & \\
\hline PB-1689 & $15,8 \times 88,8$ & 15,8 & 69,8 & 38,0 & 11 fios/pol & \multirow{3}{*}{$\begin{array}{c}\text { Resultado do ensaio } \\
\text { IPT-SP } \\
\text { média } 9.234 \mathrm{kgf} 30 \% \\
\text { margem de } \\
\text { segurança } 6.463 \mathrm{kgf}\end{array}$} \\
\hline PB-16127 & $15,8 \times 127,0$ & 15,8 & 69,8 & 38,0 & 11 fios/pol & \\
\hline PB-16178 & $15,8 \times 177,7$ & 15,8 & 69,8 & 38,0 & 11 fios/pol & \\
\hline PB-19108 & $19,0 \times 107,9$ & 19,0 & 82,5 & 38,0 & 10fios/pol & \multirow{3}{*}{$\begin{array}{c}\text { Resultado do ensaio } \\
\text { IPT-SP } \\
\text { média } 13.086 \mathrm{kgf} \\
30 \% \text { margem de } \\
\text { segurança } 9.160 \mathrm{kgf} \\
\end{array}$} \\
\hline PB-19159 & $19,0 \times 158,7$ & 19,0 & 82,5 & 38,0 & 10fios/pol & \\
\hline PB-19216 & $19,0 \times 215,9$ & 19,0 & 82,5 & 38,0 & 10fios/pol & \\
\hline
\end{tabular}


A HILT $^{\circledR}$ apresenta uma série de chumbadores de expansão para ancoragem. Entre eles pode-se citar os seguintes:

- ancoragem de expansão para solicitações altas e dinâmicas HSL. Seu anel de plástico permite a fixação em furos mais largos e evita o giro no interior do furo.
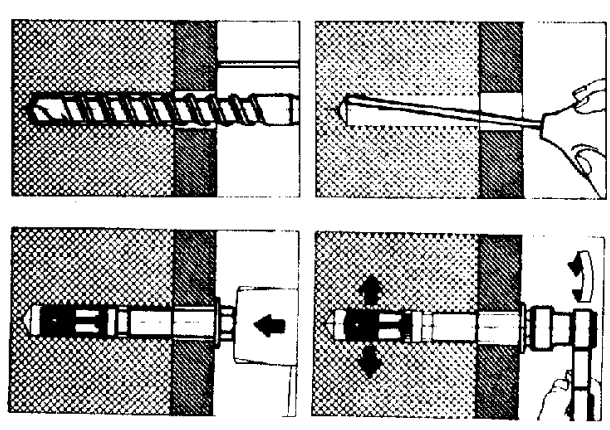

FIGURA 1-18 Sistema de instalação do HSL. Extraída do catálogo da HILT ${ }^{\circledast}$.

TABELA 1-9 Tabela dimensional e de resistência do HSL. Extraída do catálogo da HILT ${ }^{\circledast}$.

\begin{tabular}{|c|c|c|c|c|c|c|c|}
\hline \multirow[b]{2}{*}{ Descrição } & \multirow[b]{2}{*}{$\begin{array}{c}\phi \text { da broca } \\
=\phi \text { ext. da } \\
\text { ancoragem } \\
(\mathrm{mm})\end{array}$} & \multirow[b]{2}{*}{$\begin{array}{l}\text { Compri- } \\
\text { mento de } \\
\text { ancora- } \\
\text { gem }(\mathrm{mm})\end{array}$} & \multirow[b]{2}{*}{$\begin{array}{l}\text { Profundida- } \\
\text { de mín. de } \\
\text { encrava- } \\
\text { mento } \\
(\mathrm{mm})\end{array}$} & \multirow[b]{2}{*}{$\begin{array}{l}\text { Espessura } \\
\text { máx. a } \\
\text { fixar }(\mathrm{mm})\end{array}$} & \multicolumn{2}{|c|}{$\begin{array}{c}\text { Valores de força recomendados em } \\
\text { concreto de } 282 \mathrm{kgf} / \mathrm{cm}^{2}\end{array}$} & \multirow[b]{2}{*}{$\begin{array}{c}\text { Torque } \\
\text { máximo } \\
\text { (pés- } \\
\text { libras) }\end{array}$} \\
\hline & & & & & $\begin{array}{c}\text { Para a extração } \\
\text { (kgf) }\end{array}$ & $\begin{array}{l}\text { Para o corte } \\
\quad(\mathrm{kgf})\end{array}$ & \\
\hline HSL M 8/20 & 12 & 95 & 65 & 20 & 762 & 1.084 & 20 \\
\hline HSL M 8/40 & 12 & 115 & 65 & 40 & 762 & 1.084 & 20 \\
\hline HSL M 10/20 & 15 & 107 & 75 & 20 & 1.104 & 1.719 & 40 \\
\hline HSL M 10/40 & 15 & 127 & 75 & 40 & 1.104 & 1.719 & 40 \\
\hline HSL M 12/25 & 18 & 120 & 80 & 25 & 1.460 & 2.458 & 60 \\
\hline HSL M 12/50 & 18 & 145 & 80 & 50 & 1.460 & 2.458 & 60 \\
\hline HSL M 16/25 & 24 & 148 & 105 & 25 & 2.626 & 4.374 & 150 \\
\hline HSL M 16/50 & 24 & 173 & 105 & 50 & 2.626 & 4.374 & 150 \\
\hline HSL M 20/30 & 28 & 183 & 130 & 30 & 3.315 & 5.853 & 300 \\
\hline HSL M 20/60 & 28 & 213 & 130 & 60 & 3.315 & 5.853 & 300 \\
\hline HSL M 24/30 & 32 & 205 & 155 & 30 & 4.472 & 8.141 & 525 \\
\hline HSL M 24/60 & 32 & 235 & 155 & 60 & 4.472 & 8.141 & 525 \\
\hline
\end{tabular}

- sistema de ancoragem química HVA para fixações de alta resistência. Este sistema consiste de dois componentes: uma ampola de resina adesiva (HEA) e uma barra com rosca (HSA) com porca e arruela ou ampola (HEA) e ancoragens com rosca interna (HFA) para fixações seguras. Possui um excelente comportamento sob 
solicitações dinâmicas e a composição da resina propicia um perfeito comportamento em qualquer ambiente.

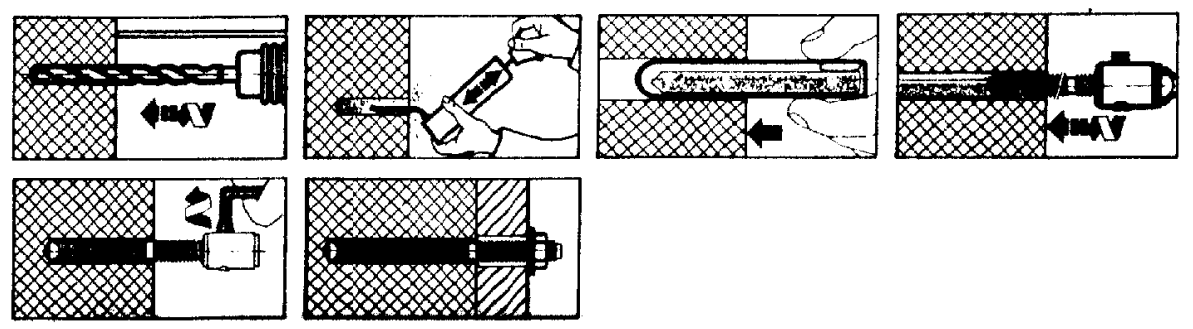

FIGURA 1-19 Sistema de instalação do HVA. Extraída do catálogo da

TABELA 1-10 Tabela dimensional e de resistência do HVA. Extraída do catálogo da HILT ${ }^{\circledR}$.

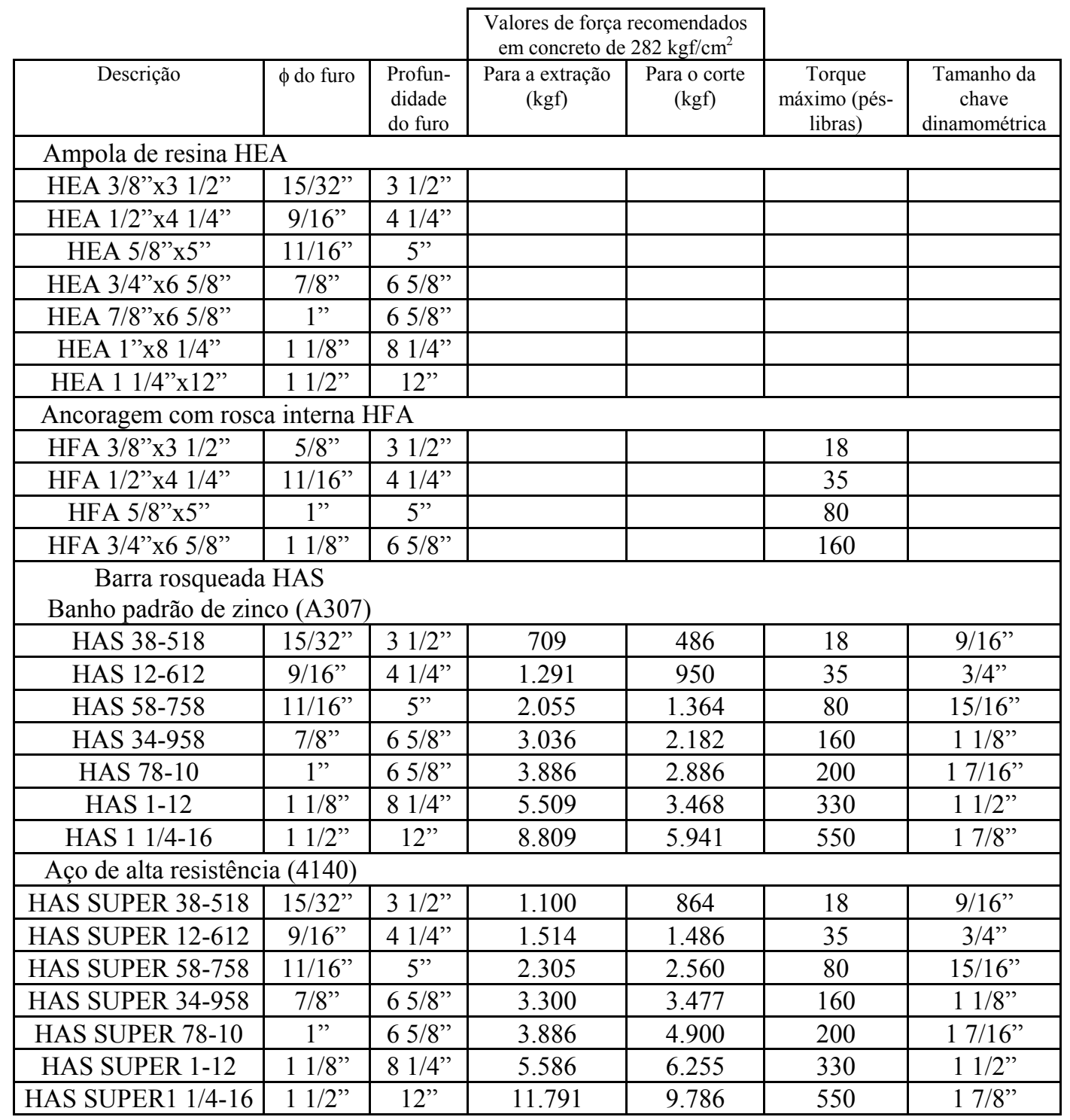


- ancoragem universal Hilt Kwik Bolt II, para múltiplas aplicações sob solicitações médias.
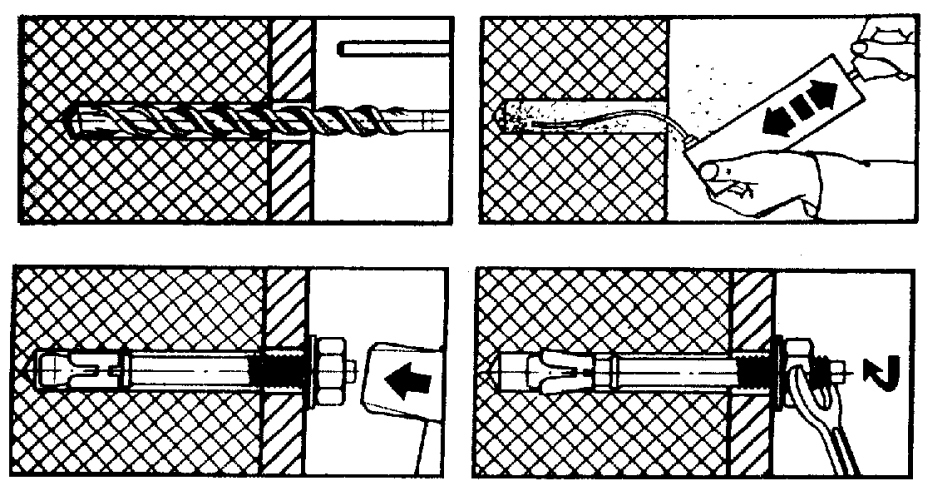

FIGURA 1-20 Sistema de instalação do Hilt Kwik Bolt II. Extraída do catálogo da HILT ${ }^{\circledR}$.

TABELA 1-11 Tabela dimensional e de resistência do Hilt Kwik Bolt II Padrão. Extraída do catálogo da

\begin{tabular}{|c|c|c|c|c|c|c|}
\hline \multirow[b]{2}{*}{ Descrição } & \multirow[b]{2}{*}{$\begin{array}{l}\phi \text { do } \\
\text { furo }\end{array}$} & \multirow[b]{2}{*}{$\begin{array}{l}\text { Comprimento } \\
\text { de ancoragem }\end{array}$} & \multirow[b]{2}{*}{$\begin{array}{c}\text { Profundidade mín. } \\
\text { de colocação }\end{array}$} & \multirow[b]{2}{*}{$\begin{array}{l}\text { Comprimento da } \\
\text { rosca }\end{array}$} & \multicolumn{2}{|c|}{$\begin{array}{l}\text { Valores de força recomendados } \\
\text { em concreto de } 282 \mathrm{kgf} / \mathrm{cm}^{2}\end{array}$} \\
\hline & & & & & $\begin{array}{c}\text { Para a extração } \\
\text { (kgf) }\end{array}$ & $\begin{array}{l}\text { Para o corte } \\
\text { (kgf) }\end{array}$ \\
\hline KB II 14-134 & $1 / 4 "$ & $13 / 4 "$ & $11 / 8^{\prime \prime}$ & $3 / 4 "$ & 172 & 195 \\
\hline KB II 14-214 & $1 / 4 "$ & $21 / 4 "$ & $11 / 8^{\prime \prime}$ & $3 / 4 "$ & 172 & 195 \\
\hline KB II 14-314 & $1 / 4 "$ & $31 / 4 "$ & $11 / 8^{\prime \prime}$ & $3 / 4 "$ & 172 & 195 \\
\hline KB II 38-214 & $3 / 8^{\prime \prime}$ & $21 / 4^{\prime \prime}$ & $15 / 8^{\prime \prime}$ & $7 / 8^{\prime \prime}$ & 340 & 499 \\
\hline KB II 38-3 & $3 / 8^{\prime \prime}$ & $3 "$ & $15 / 8^{\prime \prime}$ & $11 / 8^{\prime \prime}$ & 340 & 499 \\
\hline KB II 38-334 & $3 / 8^{\prime \prime}$ & $33 / 4 "$ & $15 / 8^{\prime \prime}$ & $11 / 8^{\prime \prime}$ & 340 & 499 \\
\hline KB II 38-5 & $3 / 8^{\prime \prime}$ & $5 "$ & $15 / 8^{\prime \prime}$ & $11 / 8^{\prime \prime}$ & 340 & 499 \\
\hline KB II 12-234 & $1 / 2 "$ & $23 / 4 "$ & $21 / 4 "$ & $11 / 4^{\prime \prime}$ & 657 & 894 \\
\hline KB II 12-334 & $1 / 2 "$ & $33 / 4 "$ & $21 / 4 "$ & $11 / 4^{\prime \prime}$ & 657 & 894 \\
\hline KB II 12-412 & $1 / 2 "$ & $41 / 2^{\prime \prime}$ & $21 / 4^{\prime \prime}$ & $11 / 4^{\prime \prime}$ & 657 & 894 \\
\hline KB II 12-512 & $1 / 2 "$ & $51 / 2^{\prime \prime}$ & $21 / 4^{\prime \prime}$ & $11 / 4^{\prime \prime}$ & 657 & 894 \\
\hline KB II 58-334 & $5 / 8^{\prime \prime}$ & $33 / 4 "$ & $23 / 4 "$ & $11 / 2^{\prime \prime}$ & 966 & 1.392 \\
\hline KB II 58-434 & $5 / 8 "$ & $43 / 4^{\prime \prime}$ & $23 / 4 "$ & $11 / 2 "$ & 966 & 1.392 \\
\hline KB II 58-6 & $5 / 8^{\prime \prime}$ & $6 "$ & $23 / 4 "$ & $11 / 2 "$ & 966 & 1.392 \\
\hline KB II 58-7 & $5 / 8 "$ & $7 "$ & $23 / 4 "$ & $11 / 2^{\prime \prime}$ & 966 & 1.392 \\
\hline KB II 34-434 & $3 / 4 "$ & $43 / 4 "$ & $31 / 4^{\prime \prime}$ & $11 / 2^{\prime \prime}$ & 1.211 & 1.877 \\
\hline KB II 34-512 & $3 / 4 "$ & $51 / 2 "$ & $31 / 4^{\prime \prime}$ & $11 / 2 "$ & 1.211 & 1.877 \\
\hline KB II 34-7 & $3 / 4 "$ & $7 "$ & $31 / 4^{\prime \prime}$ & $11 / 2^{\prime \prime}$ & 1.211 & 1.877 \\
\hline KB II 34-8 & $3 / 4 "$ & $8 "$ & $31 / 4^{\prime \prime}$ & $11 / 2^{\prime \prime}$ & 1.211 & 1.877 \\
\hline KB II 1-6 & $1 "$ & $6 "$ & $41 / 2 "$ & $21 / 4^{\prime \prime}$ & 2.118 & 3.692 \\
\hline KB II 1-9 & $1 "$ & 9" & $41 / 2 "$ & $21 / 4^{\prime \prime}$ & 2.118 & 3.692 \\
\hline
\end{tabular}


- ancoragem universal Hilt HDI com rosca interna com cone de expansão incorporado, baseada no princípio de expansão por impacto. Aplicável sob solicitações médias.

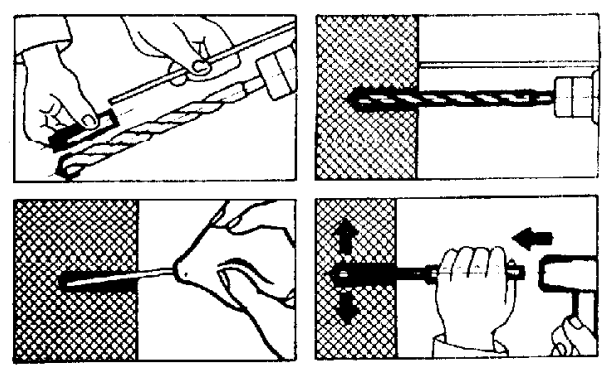

FIGURA 1-21 Sistema de instalação do HDI. Extraída do catálogo da HILT ${ }^{\circledR}$.

TABELA 1-12 Tabela dimensional e de resistência do HDI. Extraída do catálogo da HILT ${ }^{\circledast}$.

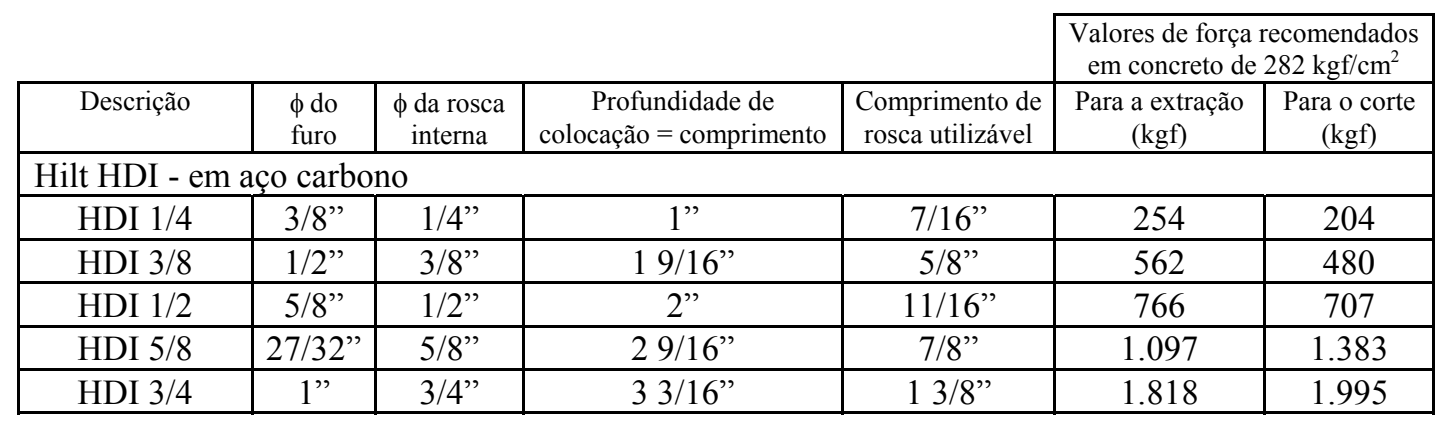

A HILT $^{\circledR}$ também apresenta vários outros tipos de ancoragem utilizadas em divisórias e paredes ocas ou maciças, materiais ocos e aplicações especiais em concreto e rocha.

\subsubsection{Parafusos estriados e parafusos com indicador de força}

Segundo o ENGINEERING FOR STEEL CONSTRUCTION [ 2 ], as especificações RCRBJ permitem o uso de outros parafusos quando eles reúnem os requerimentos esboçados para parafusos usuais. Dois tipos são ilustrados na fig. 122. A figura 1-22a mostra um parafuso estriado (interference-body) que é conduzido dentro do furo e desenvolve um firme ajuste, impedindo o deslizamento. A figura 122 b corresponde a um parafuso com indicador de tração que é instalado por uma ferramenta especial que rompe por torção a extremidade do parafuso quando a desejada tração é alcançada. O seu processo de instalação é exemplificado na fig. 19 a. 


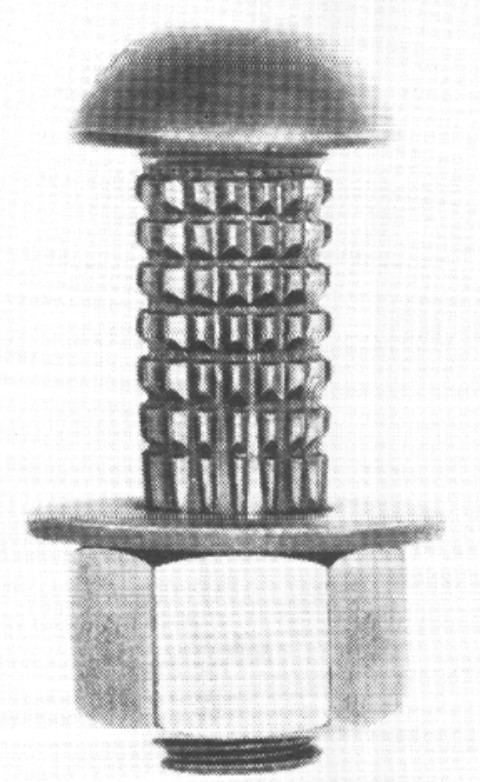

(a)

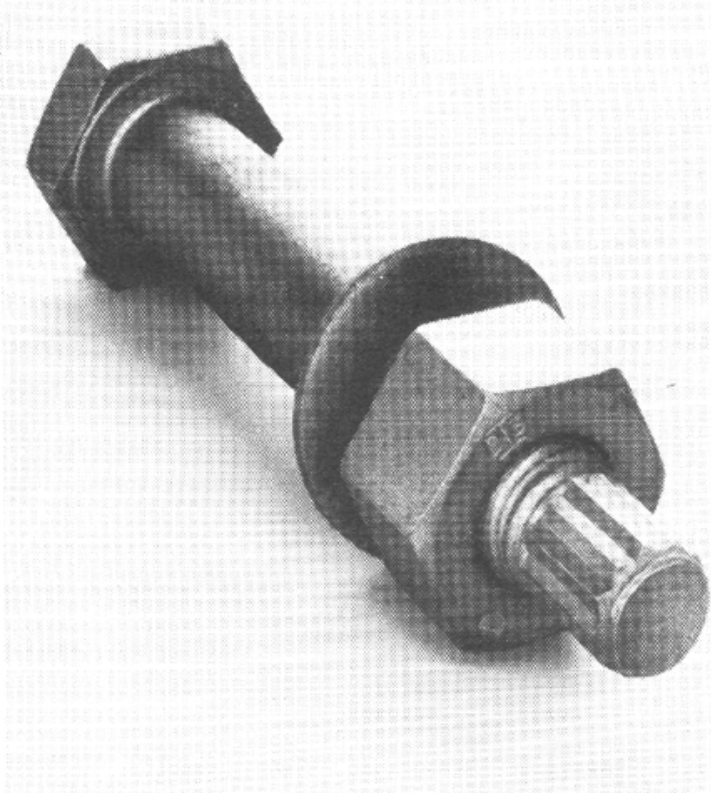

(b)

FIGURA 1-22 Parafusos especiais. (a) Parafuso interference-body de alta resistência; (b) parafuso indicador de tração. Adaptada de ENGINEERING FOR STEEL CONSTRUCTION [ 2 ].

Segundo SALMON \& JOHNSON [ 60 ], parafusos estriados são raramente utilizados em estruturas de aço. Seu diâmetro real é levemente maior que o do furo dentro do qual ele é conduzido. Na introdução deste parafuso, ele apara a face interna do furo, produzindo um firme ajuste. Este tipo de parafuso é particularmente usado em conexões por contato e em conexões submetidas à tensões reversas. Ele é feito de aço do tipo A325 e permite o aperto da porca sem simultaneidade de fixação da cabeça do parafuso.

\subsubsection{Parafusos Huck}

O parafuso Huck é um tipo especial de parafuso de alta resistência, de instalação mais rápida que o convencional parafuso torqueado. Eles são geralmente instalados com um único sistema de operação de aperto que não pode ser repetido. A seqüência de aperto é mostrada na fig. 1-23. 


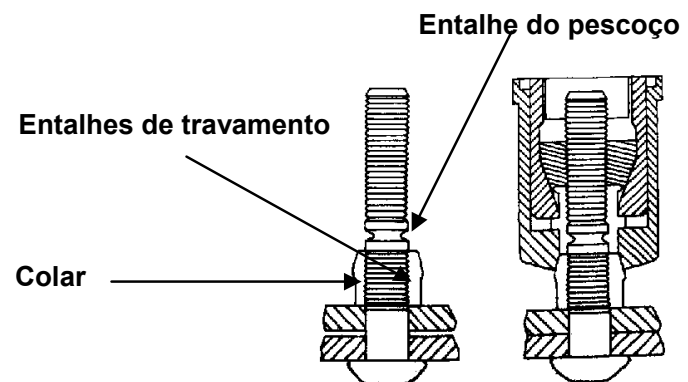

(a) (b)

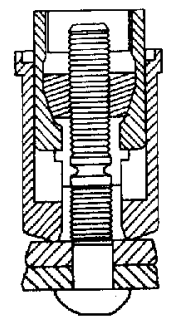

(c)

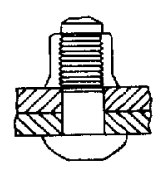

(d)

FIGURA 1-23 Seqüência de aperto para parafusos Huck. (a) O pino é inserido e o colar colocado; (b) a ferramenta de tracionamento puxa o pino, reagindo no colar, puxando as chapas; (c) com o aumento da tração a ferramenta molda o colar sobre os entalhes de travamento; (d) a ferramenta continua tracionando até o pino quebrar-se no entalhe do pescoço de quebradura. Adaptada de OWENS \& CHEAL [ 50 ].

\subsubsection{Parafusos cegos Huck}

A figura 1-24 mostra o parafuso Huck que pode ser usado em situações onde é somente possível acessar um lado da conexão. Ele é usado com a mesma ferramenta de aperto que os parafusos Huck comuns. A principal diferença é que o colar é agora fixado em uma luva que tem o mesmo diâmetro que a cabeça do pino. A parte extrema da luva é amolecida de modo que o primeiro efeito da ferramenta na extremidade do pino é torcer a extremidade da luva para formar uma cabeça efetiva. A ação subseqüente produz uma seqüência de resultados similares àqueles mostrados na fig. 1-23.

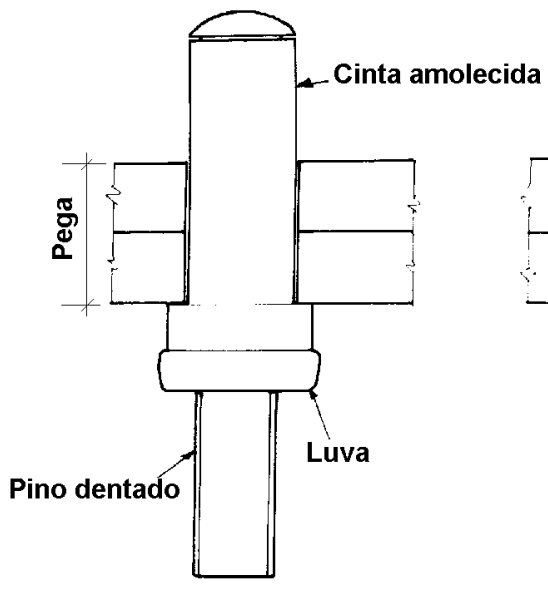

(a)

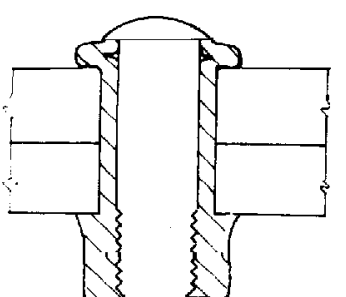

(b)

FIGURA 1-24 Parafusos cegos Huck. (a) Preparado para aperto; (b) parafuso instalado. Adaptada de OWENS \& CHEAL [ 50 ].

\subsubsection{Parafusos com resina comprimida}


Segundo OWENS \& CHEAL [ 50 ], em substituição aos parafusos ajustados e às conexões por atrito, o sistema de parafuso com injeção, como na fig. 1-25, pode oferecer uma alternativa econômica.

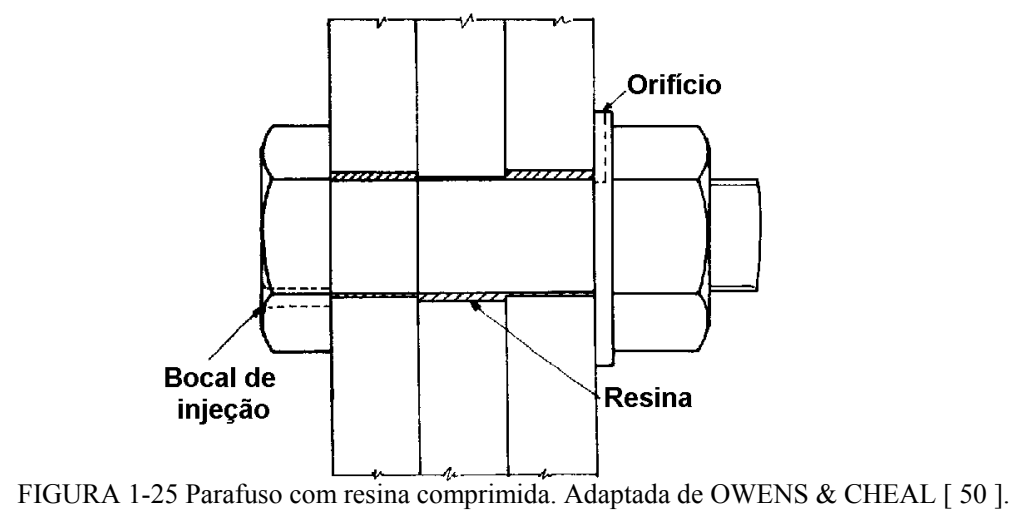

\subsubsection{Pinos soldados}

Segundo CRAWLEY \& DILLON [ 19 ], estes conectores são rosqueados, com uma das extremidades soldada a um perfil de aço ou chapa, como na fig. 1-26. Nesse conector, a solda é executada automaticamente. Uma extremidade do pino rosqueado é inserido dentro de uma ferramenta manual eletrificada e a outra extremidade é levada em contato com o metal base na posição desejada. Quando o contato é feito e a ferramenta disparada, o pino é imediatamente fundido ao metal base (mais detalhes na seção 2.2.6). Tochas de soldagem, materiais, tipos de pinos, etc., variam de acordo com os diferentes fabricantes. Tipicamente os fabricantes usam um material para o pino tendo $345 \mathrm{MPa}$ como limite de escoamento e uma correspondente resistência de cálculo ao cisalhamento igual a $165 \mathrm{MPa}$.

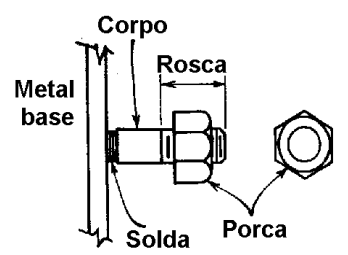


As vantagens dos pinos soldados consistem na redução dos furos no metal base e na possibilidade de utilização em algumas posições que não são acessíveis para colocação de parafusos convencionais, basta lembrar que não há necessidade de travar uma extremidade quando se aperta a porca. Todavia, pinos soldados são mais caros que outros tipos de conectores mecânicos.

\subsubsection{Fixadores auto-atarraxantes e auto-perfurantes}

São usualmente empregados na fixação de painéis de vedação (telhas), que abrange desde a cobertura ao fechamento de estruturas de pequeno e grande porte.

De acordo com RODHES [ 58 ], esses fixadores dividem-se em dois tipos distintos, dependendo se eles requerem ou não pré-furação. Os parafusos autoatarraxantes convencionais (fig. 1-27a) requerem pré-furação e se inserem dentro de um número de subgrupos, dependendo do tipo da rosca, cabeça e arruela. Esses fixadores na formação efetiva do furo, induzem tensões compressivas que aumentam à resistência ao desatamento. Os parafusos auto-atarraxantes com pontas, são usados para fixar elementos com espessura inferior a $2 \mathrm{~mm}$. Fixadores com roscas cortadas têm menor resistência ao desatamento e são caracterizados por um ou mais lados cortados e cavidades aparadas (fig. 1-27b).

Esses fixadores possuem boa resistência e confiabilidade. Eles são apresentados com dois acabamentos superficiais: cadmiado e galvanizado, de acordo com as condições corrosivas, mencionadas posteriormente.
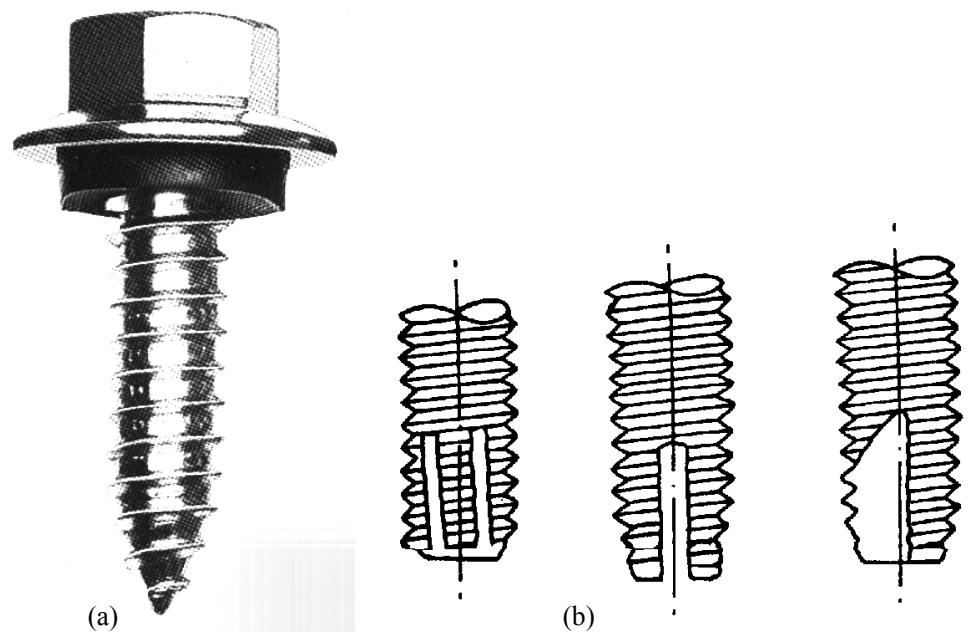

FIGURA 1-27 (a) Fixador auto-atarraxante; (b) roscas para o parafuso auto-atarraxante. Extraída do catálogo da TW Buildex ${ }^{\circledR}$. 
Nos fixadores auto-perfurantes (fig. 1-28), toda e qualquer tipo de préfuração é eliminada, e sua fixação é realizada em uma única operação.

Esses parafusos proporcionam ótima estanqueidade e solidarizam os painéis (telhas) aos elementos estruturais, melhorando o comportamento estrutural, pois conferem efeito diafragma.

Os fixadores auto-perfurantes são produzidos com os seguintes acabamentos: - fixador com cabeça revestida em aço inoxidável, para suportar condições atmosféricas altamente agressivas;

- fixador galvanizado com cobertura de polímero em toda sua superfície, com forte resistência à corrosão, desenvolvido para condições corrosivas de grandes centros urbanos;

- fixador cadmiado, que assegura vida útil prolongada em ambientes moderadamente corrosivos;

- fixador galvanizado, que garante uma boa resistência em ambientes com condições pouco corrosivas.

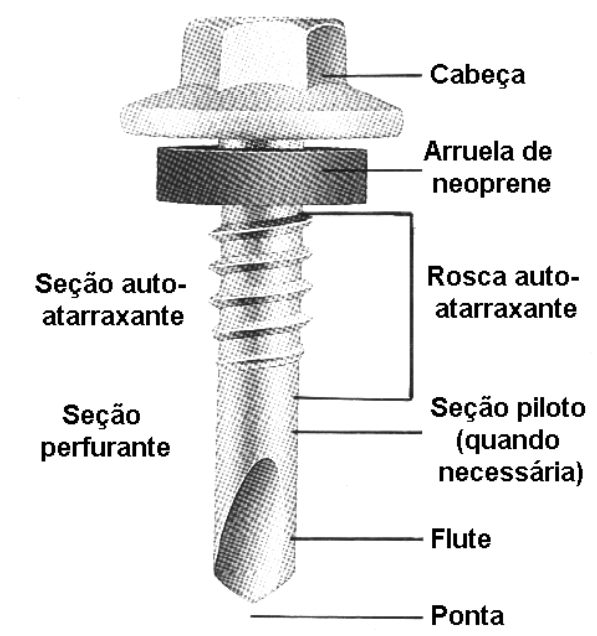

FIGURA 1-28 Fixador auto-perfurante. Extraída do catálogo da TW Buildex ${ }^{\circledR}$.

Ambos os fixadores, auto-atarraxante e auto-perfurante, são usualmente combinados com arruelas. Elas servem para aumentar a capacidade de contato e/ou a capacidade de vedação. Mas o uso de arruelas de material elastomérico (neoprene) causam uma redução na resistência e "rigidez" da conexão.

Ambos os fixadores são feitos com um aço médio carbono conformado a frio e tratado termicamente. 
Em todos os tipos de parafusos de fixação, é importante respeitar as instruções dos fabricantes em ralação a procedimentos de instalação (diâmetros de furos pré-perfurados, torques de aperto, etc.). 


\section{CAPÍTULO 2 - PROCESSOS DE SOLDAGEM E IMPLICAÇÕES}

A soldagem segundo QUITES \& DUTRA [ 57 ], pode ser encarada sob dois aspectos, que são: reparação e fabricação. Tem-se que por muito tempo a soldagem foi considerada somente como um processo de reparação, sendo que apenas no segundo quarto deste século é que ocorreu sua aceitação em fabricações que requerem qualidade estrutural. Com isso, QUITES \& DUTRA [ 57 ] definem soldagem como “ a operação que visa a união de duas peças, assegurando na junta, a continuidade das propriedades químicas e físicas". Deste modo, uma operação de soldagem é obtida pela interposição de material adicional na junta e pela aplicação de energia, de modo a produzir a fusão do material de adição e do material de base.

\subsection{Introdução e desenvolvimento histórico}

Segundo SALMON \& JOHNSON [ 60 ], historiadores têm especulado que os egípcios podem ter sido os primeiros a usarem soldagem por pressão, por volta de aproximadamente 5.000 a.C. A soldagem por forjamento foi o primeiro dos processos inventados para ligar peças de metais. Hoje soldagem por forjamento é praticamente uma arte esquecida.

Em 1822, segundo QUITES \& DUTRA [ 57 ], N. R. Benardos inventou a soldagem elétrica por fusão, onde o processo constava do estabelecimento de um arco elétrico entre um eletrodo de carvão e o material de base. O material de adição era introduzido a parte. Esse sistema foi modificado em 1889 por Zerener introduzindo mais um eletrodo de carvão, onde neste caso o arco elétrico não se produzia entre o eletrodo e a peça, mas sim nos dois eletrodos de carvão. Nesse processo nem o material de base nem o de adição eram percorridos por corrente, podendo ser aplicado à materiais não condutores de eletricidade.

Segundo SALMON \& JOHNSON [ 60 ], pequenos progressos em tecnologia de soldagem ocorreram até 1877. A origem da soldagem por resistência iniciou em torno de 1877, quando o Professor Elihu Thompson iniciou uma série de experimentos invertendo a polaridade de uma bobina de transformador. Ele recebeu 
sua primeira patente em 1885 e a primeira máquina de soldagem por resistência foi demonstrada no American Institute Fair em 1887.

N. G. Slavianoff em 1888 na Rússia foi o primeiro a usar o processo a arco de metal usando eletrodos nus, assim surgiu em 1890 o processo Slavianoff, onde o arco elétrico ocorria entre um eletrodo consumível e as peças do metal base. Coffin trabalhando independentemente também investigou o processo a arco de metal e foi lançada uma patente em 1892. Em 1889, A. P. Strohmeyer introduziu o conceito de eletrodos de metais revestidos para eliminar os problemas associados ao uso de eletrodos nus. Assim, segundo QUITES \& DUTRA [ 57 ] em 1905, com a invenção do primeiro eletrodo revestido por Kjellberg, teve inicio a época da soldagem elétrica moderna.

Thomas Fletcher em 1887, segundo SALMON \& JOHNSON [ 60 ], usou um maçarico queimando hidrogênio e oxigênio, e mostrou que ele podia cortar ou fundir metais. Em 1901-1903 Fouche e Picard desenvolveram maçaricos que podiam ser usados com acetileno, desenvolvendo a soldagem e corte a oxiacetileno.

O período entre 1903 e 1918 observou-se o uso de soldagem primeiramente como um método de reparo, o mesmo ocorrido durante a I Guerra Mundial (19141918), onde as técnicas de soldagem foram desenvolvidas para serem especialmente adaptadas para reparos de navios que haviam sidos prejudicados.

Após a I Guerra Mundial (1918) continuou-se a experimentação com eletrodos nus e vários fluxos de gases inertes para proteger o arco e a área soldada. Nessa época, embora constatassem melhorias nas propriedades da solda, esse processo não teve o merecido desenvolvimento. Em 1930, mediante a utilização de eletrodos permanentes de tungstênio, desenvolveu-se a soldagem TIG (Tungsten Inert Gas), que consiste em uma soldagem sob atmosfera gasosa com eletrodos de tungstênio. Em 1940 se deu o início da soldagem MIG (Metal Inert Gas), que consiste em uma soldagem com eletrodo consumível em atmosfera gasosa inerte. Mais tarde, segundo QUITES \& DUTRA [ 57 ], em virtude dos gases até então usados (hélio e argônio), passou-se a utilizar o $\mathrm{CO}_{2}$ como gás de proteção, no entanto apesar do $\mathrm{CO}_{2}$ ser um gás inerte, ele decompõe-se na região do arco formando uma atmosfera composta de $\mathrm{CO}$ e $\mathrm{O}_{2}$. Com o posterior uso de eletrodos contendo elementos desoxidantes, a partir de 1950 a soldagem com eletrodo nu em atmosfera 
ativa de $\mathrm{CO}_{2}$, que tomou o nome de processo MAG (Metal Active Gas), passou a ser usada em larga escala.

Segundo SALMON \& JOHNSON [ 60 ], durante o período de 1930 a 1950 muitas melhorias ocorreram, incluindo em 1932 a introdução do uso de fluxo granular para proteger a solda, que quando acoplada ao uso de um eletrodo alimentado continuamente resultou no desenvolvimento da soldagem a arco submerso SAW (Submerged Arc Welding). Este processo, amplamente utilizado a partir dos anos 80, foi patenteado em 1935.

Em 1958, a soldagem FCAW (Flux Cored Arc Welding) auto protegida foi desenvolvida, na qual o fluxo granular usado para proteger a solda é contido dentro do núcleo do eletrodo contínuo, chamado eletrodo tubular, deste modo permitindo o maior uso de equipamentos automáticos e semi-automáticos.

Segundo COOPER [ 17 ], os tipos mais comuns de conexões usadas em oficinas hoje em dia são as soldadas, sendo muito comuns também em montagens de campo. De certa forma isso representou uma mudança revolucionária, porque durante a década de 30 o tipo mais comum de conexão era a rebitada, que foi progressivamente substituída por parafusos e soldas devido ao avanço das respectivas tecnologias.

A partir dos anos 80 a automação vem tornando-se um significativo fator em tecnologia de soldagem e o extensivo uso de soldagens robóticas vem ocorrendo.

Hoje em dia, já existem mais de quarenta processos de soldagem conhecidos, como ilustra a fig. 2-1, que mostra a evolução dos processos de soldagem ao longo do tempo. 


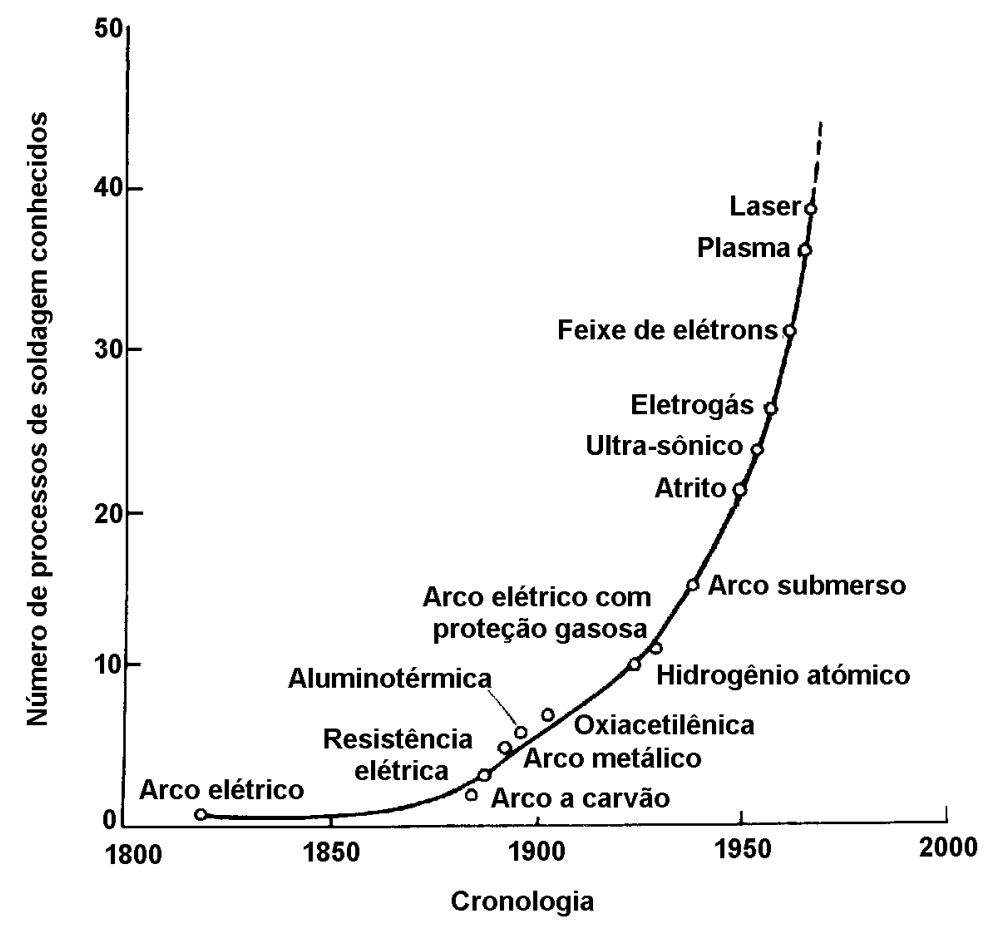

FIGURA 2-1 Evolução dos processos de soldagem ao longo do tempo. Adaptada de WAINER et al.[ 72 ].

\subsection{Processos básicos de soldagem}

Segundo GAYLORD et al. [ 27 ], soldagem é considerada como um processo de união de partes de metal por meios de aquecimento e pressão, que causa fusão das partes (soldagem por resistência), ou por meio de aquecimento do metal até sua temperatura de fusão, com ou sem a adição de metal de enchimento (soldagem por fusão). A soldagem por fusão usualmente emprega tanto um arco elétrico quanto uma chama de oxiacetileno para o aquecimento do metal. O arco elétrico é usado pela maioria dos processos de soldagem.

De acordo com QUITES \& DUTRA [ 57 ], o arco elétrico é a passagem de corrente elétrica através de um gás. Porém todo gás é isolante elétrico quando submetido a campos elétricos de intensidades normais. Para exemplificar, o ar situado entre dois eletrodos afastados de $1 \mathrm{~mm}$, necessita de uma diferença de potencial de 4.000 volts para tornar-se condutor. Um gás torna-se condutor quando passa a possuir íons e elétrons livres, ou seja, se ioniza, e seu comportamento muda totalmente de modo a receber a denominação de plasma, também chamado de quarto estado da matéria. $\mathrm{O}$ arco elétrico é uma forma particular de plasma, que é mantido 
por uma diferença de potencial elétrico entre dois eletrodos. As partículas de carga têm desta maneira um sentido preferencial de percurso e os seus choques, entre si, com os eletrodos e com os átomos neutros, criam condições para a continuidade do processo de soldagem. Com isso, conceitualmente, "arco elétrico é a passagem de uma grande quantidade de corrente elétrica, que chega a milhares de ampères, através de uma atmosfera gasosa e entre dois eletrodos submetidos a uma diferença de potencial que pode ser de uns poucos volts". A vantagem de se utilizar um arco elétrico como fonte de calor é a alta concentração de calor, na qual se permite obter em pequeno espaço, elevadas temperaturas, limitando a zona de influência calorífica; uma outra vantagem é que o arco pode subsistir em qualquer atmosfera gasosa, proporcionando uma menor contaminação do banho metálico.

O processo mais simples de obtenção de um arco elétrico, consiste no aquecimento do gás existente entre o eletrodo e o material de base, sujeitando-o a um bombardeio de elétrons. Para se obter isso basta dispor de uma diferença de potencial entre a peça e o eletrodo (tensão em vazio). Como pode ser visto na fig. 2-2a, quando se toca o eletrodo na peça (instante $t_{1}$ ), a tensão cai rapidamente, não atingindo $o$ valor zero devido a resistência de contato, com isso a corrente cresce a um valor próximo da corrente de curto-circuito. Deste modo, por efeito Joule, a região presente no contato se aquece até a incandescência. Com isso, devido a quantidade de calor liberado torna-se fácil o desprendimento dos elétrons dos átomos do ambiente gasoso, por efeito da emissão termoiônica da zona incandescente. Deste modo, o gás se ioniza. Com essa ionização pode-se afastar o eletrodo e o material de base, por exemplo em $4 \mathrm{~mm}$, que o arco permanecerá.

De acordo com QUITES E DUTRA [ 57 ], a forma do arco é aproximadamente cônica, possuindo seu vértice numa região muito pequena do eletrodo e sua base sobre a peça, como na fig. 2-2b. A distância entre a mancha catódica, que é a região de incidência do arco no polo negativo e o centro de incidência de bombardeio de elétrons, chamado ânodo é o comprimento do arco. 

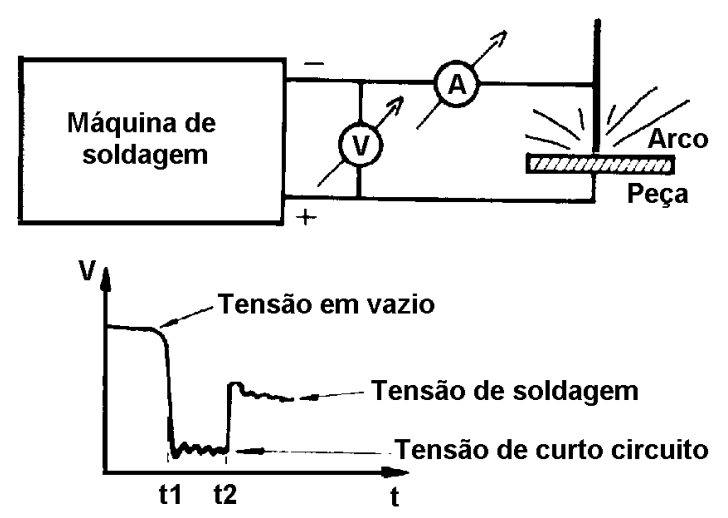

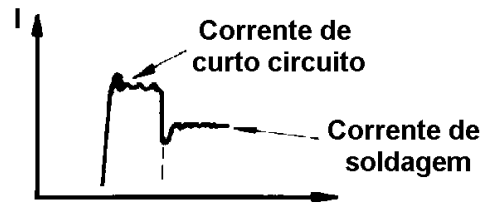

(a)

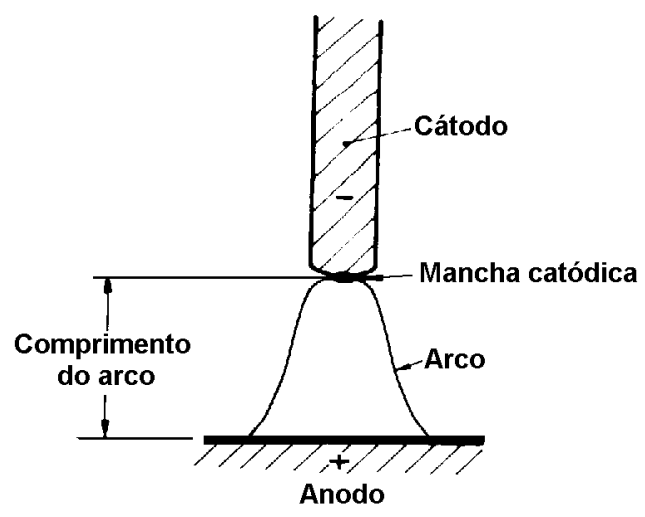

(b)

FIGURA 2-2 (a) Representação do circuito de soldagem, do oscilograma da tensão e da corrente no instante do acendimento do arco, (b) aspecto do arco elétrico. Adaptada de QUITES \& DUTRA [ 57 ].

Os elétrons emitidos do cátodo passam pelo arco e alcançam o ânodo, entregando a sua energia cinética em forma de calor. Os íons são acelerados próximos à região do cátodo, colidindo com o mesmo. Com isso, o cátodo é aquecido fornecendo a temperatura necessária para a emissão de elétrons. Com as colisões mútuas entre as partículas de carga e átomos neutros, o gás no interior do arco é elevado a temperaturas que chegam a $6.000^{\circ} \mathrm{C}$, formando um plasma térmico altamente luminoso, formado por elétrons, íons, átomos e moléculas.

De acordo com WAINER et al. [ 72 ], cada processo de soldagem possui suas vantagens e limitações, e um adequado balanço determinará suas aplicações típicas.

Há processos de soldagem que possuem um uso específico para um determinado metal. Na tabela 2-1 são mostradas as vantagens e inconvenientes dos processos e algumas aplicações e a tabela 2-2 apresenta em função do tipo e espessura do material, quais os processos comerciais de soldagem que podem ser aplicados. A seguir serão descritos os principais processos utilizados em estruturas de aço. 
TABELA 2-1 Características e aplicações de processos de soldagem. Adaptada de WAINER et al. [ 72 ].

\begin{tabular}{|c|c|c|c|}
\hline Processo & Vantagens & Desvantagens & Emprego \\
\hline $\begin{array}{l}\text { Eletrodo revestido } \\
\text { (SMAW) }\end{array}$ & $\begin{array}{l}\text { Grande versatilidade no projeto de } \\
\text { junta e na posição de soldagem. } \\
\text { Baixo custo. } \\
\text { Uniões com excelentes } \\
\text { propriedades. } \\
\text { Não exige grandes ajustes da } \\
\text { estrutura. }\end{array}$ & $\begin{array}{l}\text { Mão-de-obra habilidosa. } \\
\text { Freqüente mudança de } \\
\text { eletrodos. } \\
\text { Na soldagem com várias } \\
\text { camadas é necessário remover a } \\
\text { escória em cada passe. }\end{array}$ & $\begin{array}{l}\text { Processo mais usado na } \\
\text { fabricação e na } \\
\text { manutenção. }\end{array}$ \\
\hline Arco submerso (SAW) & $\begin{array}{l}\text { Processo automático. } \\
\text { Alta taxa de deposição }\end{array}$ & $\begin{array}{l}\text { Somente na posição plana ou } \\
\text { horizontal. } \\
\text { Restrito aos aços. } \\
\text { Cuidado no posicionamento da } \\
\text { junta. }\end{array}$ & $\begin{array}{l}\text { Solda de topo ou em } \\
\text { ângulo com mais de } 1 \mathrm{~m} \\
\text { de comprimento e } 5 \text { a } 50 \\
\text { mm de espessura. }\end{array}$ \\
\hline TIG & $\begin{array}{l}\text { Grande versatilidade manual ou } \\
\text { automática, tipo de junta, posição } \\
\text { de soldagem. } \\
\text { Soldas com elevada qualidade. } \\
\text { Adequado para metais ferrosos e } \\
\text { não ferrosos. }\end{array}$ & $\begin{array}{l}\text { Elevado custo de consumíveis. } \\
\text { Mão-de-obra habilidosa. } \\
\text { Soldagem com várias camadas } \\
\text { em solda de topo com espessura } \\
\text { acima de } 5 \text { mm. } \\
\text { Inadequada para utilização em } \\
\text { locais abertos. }\end{array}$ & $\begin{array}{l}\text { Passe da raiz em aços } \\
\text { ligados. } \\
\text { Usado em união de não- } \\
\text { ferrosos e inoxidáveis. }\end{array}$ \\
\hline MIG gás inerte & $\begin{array}{l}\text { Solda com alta qualidade para a } \\
\text { maioria das ligas. } \\
\text { Alta taxa de deposição. } \\
\text { Processo semi ou totalmente } \\
\text { automatizado. }\end{array}$ & $\begin{array}{l}\text { Custo elevado do gás inerte. } \\
\text { Mão-de-obra habilidosa. } \\
\text { Cuidado com o posicionamento } \\
\text { da junta. } \\
\text { Inadequada para utilização em } \\
\text { locais abertos. }\end{array}$ & $\begin{array}{l}\text { Usado em aços inoxidáveis } \\
\text { e ligas não-ferrosas. }\end{array}$ \\
\hline $\begin{array}{l}\mathrm{MAG}-\mathrm{CO}_{2} \text { com } \\
\text { transferência por } \\
\text { borrifo }\end{array}$ & $\begin{array}{l}\text { Elevada penetração. } \\
\text { Alta taxa de deposição. } \\
\text { Baixo custo dos gases. }\end{array}$ & $\begin{array}{l}\text { Posição plana. } \\
\text { Somente para aços-carbono e de } \\
\text { baixa liga com espessura de } 6 \\
\text { mm. } \\
\text { Cuidado com o posicionamento } \\
\text { da junta. } \\
\text { Inadequada para utilização em } \\
\text { locais abertos. }\end{array}$ & $\begin{array}{l}\text { Usado para aços-carbono e } \\
\text { de baixa liga. } \\
\text { Para grandes produções e } \\
\text { soldas de qualidade. }\end{array}$ \\
\hline $\begin{array}{l}\text { MAG-CO } \mathrm{CO}_{2} \text { com } \\
\text { transferência por curto- } \\
\text { circuito }\end{array}$ & $\begin{array}{l}\text { Processo semi-automático. } \\
\text { Todas posições de soldagem. } \\
\text { Boa qualidade de solda. } \\
\text { Baixo custo dos gases. } \\
\text { Usado em chapas finas de aço (1- } \\
4 \mathrm{~mm}) \text {. } \\
\text { Tolerância com mau } \\
\text { posicionamento da junta. }\end{array}$ & $\begin{array}{l}\text { Somente para aços-carbono e de } \\
\text { baixa liga. } \\
\text { Ocorrência de falta de fusão } \\
\text { com soldador sem prática. } \\
\text { Inadequada para utilização em } \\
\text { locais abertos. }\end{array}$ & $\begin{array}{l}\text { Fabricação de } \\
\text { equipamentos com chapa } \\
\text { fina. } \\
\text { Passe de raiz em chapas } \\
\text { grossas. }\end{array}$ \\
\hline MIG pulsado & $\begin{array}{l}\text { Processo semi-automático. } \\
\text { Todas as posições de soldagem. } \\
\text { Aplicado a maioria das ligas e } \\
\text { espessuras. } \\
\text { Qualidade de solda muito boa. }\end{array}$ & $\begin{array}{l}\text { Equipamento complexo. } \\
\text { Custo moderado do processo. } \\
\text { Inadequada para utilização em } \\
\text { locais abertos. }\end{array}$ & $\begin{array}{l}\text { Usado principalmente em } \\
\text { soldagem de aço-carbono, } \\
\text { inox e não-ferrosos. }\end{array}$ \\
\hline Eletro-escória & $\begin{array}{l}\text { Soldagem automática com alta } \\
\text { velocidade. } \\
\text { Alta taxa de deposição. } \\
\text { Usado em aço-carbono e de baixa } \\
\text { liga c/ espessura acima de 50mm. }\end{array}$ & $\begin{array}{l}\text { Posição vertical de soldagem. } \\
\text { Solda e a zona afetada pelo } \\
\text { calor com estruturas grosseiras, } \\
\text { exigindo tratamento térmico } \\
\text { após soldagem. } \\
\text { Cuidado na montagem da } \\
\text { estrutura. }\end{array}$ & $\begin{array}{l}\text { Soldagem de chapas } \\
\text { grossas de aço. }\end{array}$ \\
\hline
\end{tabular}

TABELA 2-2 Condições de emprego dos processos de soldagem. Adaptada de WAINER et al. [ 72

\begin{tabular}{|l|l|c|c|c|c|c|c|}
\hline Materiais & Espessuras & $\begin{array}{l}\text { Eletrodo } \\
\text { revestido }\end{array}$ & $\begin{array}{l}\text { Arco } \\
\text { submerso }\end{array}$ & $\begin{array}{l}\text { MIG ou } \\
\text { MAG }\end{array}$ & FCAW & TIG & Eletro escória \\
\hline Aço-carbono & até $3 \mathrm{~mm}$ & $\mathrm{x}$ & $\mathrm{x}$ & $\mathrm{x}$ & & $\mathrm{x}$ & \\
& 3 a $6 \mathrm{~mm}$ & $\mathrm{x}$ & $\mathrm{x}$ & $\mathrm{x}$ & $\mathrm{x}$ & $\mathrm{x}$ & \\
& 6 a $19 \mathrm{~mm}$ & $\mathrm{x}$ & $\mathrm{x}$ & $\mathrm{x}$ & $\mathrm{x}$ & & $\mathrm{x}$ \\
& acima de $19 \mathrm{~mm}$ & $\mathrm{x}$ & $\mathrm{x}$ & $\mathrm{x}$ & $\mathrm{x}$ & & \\
\hline Aço de baixa liga & até $3 \mathrm{~mm}$ & $\mathrm{x}$ & $\mathrm{x}$ & $\mathrm{x}$ & & $\mathrm{x}$ & \\
& 3 a $6 \mathrm{~mm}$ & $\mathrm{x}$ & $\mathrm{x}$ & $\mathrm{x}$ & $\mathrm{x}$ & $\mathrm{x}$ & \\
& 6 a $19 \mathrm{~mm}$ & $\mathrm{x}$ & $\mathrm{x}$ & $\mathrm{x}$ & $\mathrm{x}$ & & \\
\hline
\end{tabular}




\section{\begin{tabular}{|l|c|c|c|c|c|c|c|}
\hline & acima de $19 \mathrm{~mm}$ & $\mathrm{x}$ & $\mathrm{x}$ & $\mathrm{x}$ & $\mathrm{x}$ & $\mathrm{x}$ \\
\hline 2.2.1 Soldagem a arco com eletrodo revestido (SMAW - Shield Metal Arc
\end{tabular} Welding)}

Segundo WAINER et al. [ 72 ], este processo teve início no começo do século, com a utilização de arames nus para cercas, ligados à rede elétrica. Arames enferrujados ou cobertos de cal, proporcionavam uma melhor estabilidade do arco, deste modo no início da primeira década o revestimento ácido foi adotado. Revestindo o arame com asbestos (pó de silicato), a poça de solda ficava protegida, enquanto o uso de algodão aumentava a penetração do arco, dando início ao revestimento celulósico. Em meados da década de 30 desenvolveu-se os revestimentos rutílicos. No início da década de 40 desenvolveu-se os revestimentos básicos, e em meados da década de 50 adicionou-se o pó de ferro. No Brasil esse processo é o mais utilizado, sendo empregado em grande variedade de aplicações.

Em uma soldagem executada com um eletrodo nu, segundo QUITES \& DUTRA [ 57 ], após a fusão no ar, o eletrodo perde por oxidação grande quantidade de seu carbono, manganês e silício, enquanto que o nitrogênio existente no ar forma nitretos. Esses nitretos juntamente com os óxidos formados, ficam confinados na solda reduzindo sua resistência e ductilidade. Para evitar isso, é necessário formar em torno do arco uma atmosfera gasosa, que neste caso, é obtida pela queima do revestimento incorporado no eletrodo.

Segundo GAYLORD et al. [ 27 ], a maioria dos procedimentos de soldagem manual é executada com processos a arco elétrico com eletrodos revestidos. Neste processo, mostrado na fig. 2-3, o eletrodo é colocado em uma garra para estabelecer contato elétrico e é posicionado pelo soldador. O revestimento obtido pelo uso de eletrodos totalmente revestidos é feito com um material de tal composição, que grandes quantidades de gases são produzidos no aquecimento do arco, protegendo o metal de solda contra a ação do nitrogênio e do oxigênio da atmosfera, já que nenhum gás protetor é utilizado. O revestimento é fundido em uma razão mais lenta que o metal do núcleo, o que direciona e concentra o fluxo do arco. O revestimento também forma uma escória que flutua sobre o metal fundido protegendo-o da contaminação atmosférica enquanto resfria, além de controlar a taxa de resfriamento, 
contribuindo no acabamento do cordão. Essa escória é facilmente removida após ocorrer o resfriamento.

Segundo CUNHA [ 20 ], o revestimento também possui a função de isolamento elétrico, pois ele é um mau condutor de eletricidade, isolando a alma do eletrodo, evitando-se assim aberturas de $\operatorname{arcos}$ laterais e conseqüentemente orientando o arco; função de ionização, pois contém silicatos de sódio e potássio que ionizam a atmosfera do arco, facilitando a passagem da corrente elétrica, originando um arco estável; função metalúrgica, pois pode contribuir como um elemento de liga, de maneira a alterar as propriedades da solda.

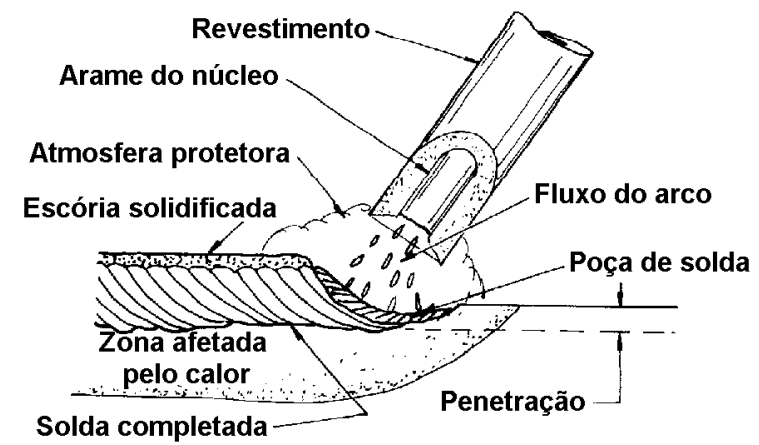

FIGURA 2-3 Representação do processo de soldagem a arco com eletrodo revestido (SMAW), processo manual. Adaptada de OWENS \& CHEAL [ 50 ].

De acordo com WAINER et al. [ 72 ], a corrente de soldagem controla todas as características operatórias do processo, o aspecto do cordão, as propriedades da junta soldada, além de controlar a magnitude e a distribuição da energia térmica presente no arco. A intensidade da corrente é um parâmetro determinante, levando em consideração a taxa de deposição, e é também o mais importante efeito controlador da penetração da solda, da largura e do reforço do cordão (metal de solda excedente depositado para reforçar o cordão), além da diluição (metal base fundido na soldagem). A corrente de soldagem possui também um efeito inversamente proporcional sobre a velocidade de resfriamento.

A segunda mais importante variável operacional é a velocidade de avanço. A altura e a largura do cordão variam inversamente com a velocidade de avanço. Considerando altas correntes a energia de soldagem pode ser mantida reduzida, com o uso de altas velocidades de avanço. 
Um dos principais fatores limitantes da faixa útil de corrente de soldagem é o diâmetro do eletrodo. Ele controla a densidade de corrente por unidade de área de seção transversal da alma do eletrodo. A escolha de um maior diâmetro de eletrodo maximiza a taxa de deposição, e esse maior diâmetro é função de fatores como a posição de soldagem, formato do chanfro e tipo de revestimento.

O ângulo do eletrodo em relação a peça é também uma variável importante, pois ajusta o fluxo térmico, controla o banho na poça de fusão e influencia no formato do cordão.

Este é certamente o processo mais versátil, podendo ser usado em todas as posições de soldagem. Além disso, o eletrodo pode ser conduzido a locais de difícil acesso, onde outros processos não atingem e a montagem do processo é extremamente simples. É provavelmente, o processo mais comum em fabricação de estruturas.

Segundo OWENS \& CHEAL [ 50 ], a qualidade da soldagem é relacionada com a habilidade do operador. Um bom soldador tem que possuir amplo conhecimento do processo e um alto nível de habilidade de manipulação. Devido à necessidade de bons soldadores e velocidades de deposição relativamente baixas, este pode ser um processo caro. Ele foi tradicionalmente respeitado como o processo que foi capaz de produzir as mais altas qualidades de soldas, mas esta reputação é agora ameaçada pelos recentes avanços de outros processos mais eficientes.

Segundo CUNHA [ 20 ], o equipamento de soldagem para este processo consiste de uma fonte de energia, cabos de ligação, um porta eletrodo, um conector terra, além do próprio eletrodo. Deve-se salientar que o suprimento de energia pode ser tanto corrente contínua quanto alternada.

Segundo OWENS \& CHEAL [ 50 ], diâmetros típicos de eletrodos para trabalhos estruturais variam entre 2,5 e $6 \mathrm{~mm}$. Voltagem de circuitos abertos são usualmente 50-90 V, dependendo do eletrodo; tão logo quando o arco é formado, a voltagem cai para valores entre 20 e 35 V. Correntes típicas alcançam de 50 a 400 ampères, depositando com velocidades entre 20 e $100 \mathrm{~g} / \mathrm{min}$. Aplicável a espessuras acima de $2 \mathrm{~mm}$.

Segundo OWENS \& CHEAL [ 50 ], um tipo equivalente à soldagem SMAW é a soldagem automática com eletrodo revestido contínuo. Ambos os eletrodos têm 
seção transversal similar, mas ao invés de contato manual, o eletrodo nesse processo é montado em um tambor e incorporado dentro um contínuo sistema de alimentação em uma soldagem automática.

\subsubsection{Soldagem a arco submerso (SAW - Submerged Arc Welding)}

Segundo WAINER et al. [ 72 ], esse processo teve início em 1935, sendo utilizado em fabricação de tubos e navios. No período de 1939-1945 (II Guerra Mundial) seu uso foi intensificado. No Brasil esse tipo de soldagem é amplamente usado na fabricação de tubos, navios, perfis, plataformas marítimas, trocadores de calor e equipamentos pesados.

Segundo GAYLORD et al. [ 27 ], neste processo o arame eletrodo é alimentado mecanicamente a partir de uma bobina para a pistola ou cabeçote de soldagem, e pela velocidade mantém-se um comprimento constante de arco. Além disso, o arco é inteiramente submerso em um fluxo granular, onde altas correntes podem ser usadas sem perigo do ar suspender gotículas de líquido ou haver respingos. Esse fluxo granular é um material fusível que é alimentado na área de trabalho por gravidade em uma quantidade suficiente para submergir o arco completamente. Alguns dos materiais granulares fundem-se para formar um revestimento sobre a solda, que além de protege-lá da atmosfera, ajuda no controle do grau de velocidade de resfriamento da mesma. A fig. 2-4 mostra uma representação de um único arame individual submerso no arco, no referido processo de soldagem. 


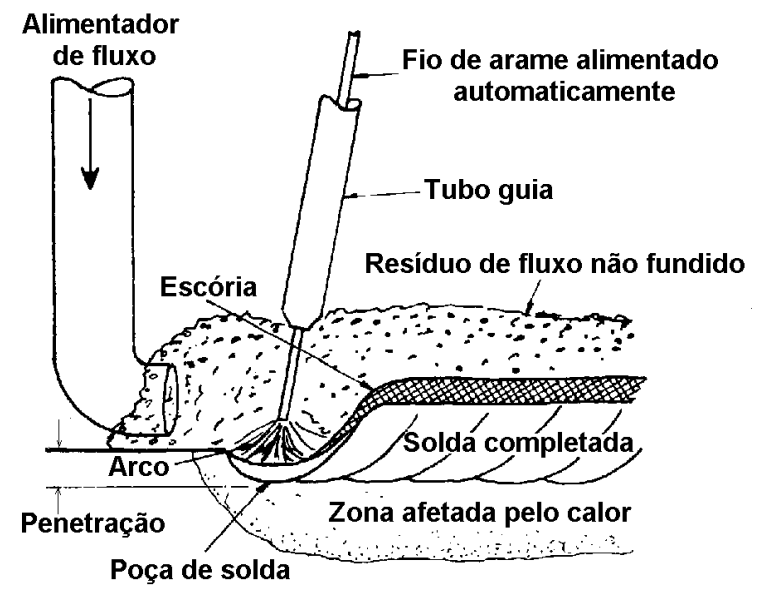

FIGURA 2-4 Representação do processo de soldagem a arco submerso (SAW). Adaptada de OWENS \& CHEAL [ 50 ].

Segundo WAINER et al. [ 72 ], a corrente elétrica determina a taxa de deposição, a profundidade de penetração da poça de solda, além de controlar a quantidade de metal base fundido. Uma elevação da corrente aumenta a penetração e a taxa de deposição. Uma corrente muito alta produz um cordão muito alto e estreito, e mordeduras. Uma corrente muito baixa produz um arco instável.

O tipo de corrente também influencia no processo de soldagem. A CCPR $(+)$ (corrente contínua de polaridade reversa) é recomendada quando uma rápida seqüência de deposição de passes ou penetração total são recomendadas. Essa corrente diminui a porosidade e melhora o formato do cordão de solda. A CCPD (-) (corrente contínua de polaridade direta) fornece uma taxa de deposição 30\% maior que a obtida por CCPR $(+)$, produzindo uma menor penetração.

A velocidade de soldagem controla o tamanho do cordão e a penetração. Velocidades excessivamente altas aumentam a tendência da ocorrência de mordeduras, e estimulam o apagamento do arco, proporcionando o surgimento de trincas e porosidades. Velocidades excessivamente baixas produzem cordões em forma de chapéu, sujeitos à trincas, e cordões rugosos, além de respingos e inclusões de escória, devido à grande poça de solda formada.

Tem-se também que o aumento da distância tubo de contato/peça, que é a distância entre o ponto de contato elétrico no bico do cabeçote e a ponta do eletrodo, aumenta a taxa de deposição.

Um outro fator de influência é a tensão do arco, que influencia a forma da seção transversal do cordão e a aparência da solda. Deste modo, um aumento da 
tensão produz um cordão mais amplo e largo, aumenta o consumo de fluxo, aumenta a resistência à porosidade e aumenta o teor de liga proveniente do fluxo. Contudo, tensões excessivamente altas produzem cordão em forma de chapéu, sujeito à trincas, além de tornar difícil a remoção da escória.

Utilizando um eletrodo de diâmetro maior, a largura do cordão aumenta e diminui a densidade da corrente, a penetração e a taxa de deposição.

Segundo OWENS \& CHEAL [ 50 ], a velocidade de deposição para esse processo é consideravelmente maior, comparada com a soldagem a arco com eletrodo revestido ou soldagem com $\mathrm{CO}_{2}(\mathrm{MAG})$. Pode-se ainda aumentar esse grau de deposição pelo uso de dois ou três arames eletrodos na mesma poça de solda.

A aparência da solda é boa, particularmente devido a natureza automática do processo e ao natural aplainamento e confinamento da escória fundida. Requisitos mínimos de proteção não são necessários, pois nenhum arco de soldagem é visível, gerando pouca fumaça. O uso de altas correntes também produz uma melhor penetração em comparação com a ocorrida nos outros processos.

As duas principais desvantagens deste processo são: primeiro, devido ao fluxo granular, pode-se somente ser utilizado em posições planas e horizontais e segundo, em altas velocidades de deposição, metais de solda de baixa resistência podem ser produzidos devido a uma associada baixa velocidade de resfriamento, conduzindo para uma microestrutura altamente refinada. Todavia, o pré aquecimento da chapa pode aliviar esta segunda desvantagem.

As altas correntes usadas causam considerável fusão do metal base, deste modo menos metal de enchimento é requerido e a abertura da junta pode ser menor que a necessária para outros processos de soldagem.

Segundo CUNHA [ 20 ], esse processo de soldagem aplica-se a uma ampla faixa de espessuras, sendo mais utilizado em soldagem de chapas espessas de aço, como por exemplo: vasos de pressão, tanques, tubos de grandes diâmetros e vigas.

Nesse processo a alimentação do eletrodo nu e o comprimento do arco são controlados pelo alimentador de arame e pela fonte de energia, no caso de processo semi-automático. No caso de processo automático um mecanismo de avanço movimenta tanto o alimentador do fluxo quanto o arame, e normalmente um sistema de recuperação de fluxo recircula o fluxo granular não utilizado. 
Segundo OWENS \& CHEAL [ 50 ], diâmetros de eletrodos para trabalhos estruturais variam entre 2 e $5 \mathrm{~mm}$. A voltagem de soldagem varia entre 30 e $40 \mathrm{~V}$. Correntes para soldagem de um só arame podem atingir 1.200A. A taxa de deposição para soldagem de um só arame pode atingir $300 \mathrm{~g} / \mathrm{min}$ e 5 vezes esse valor para grupos de diversos arames. Aplicável a espessuras acima de $5 \mathrm{~mm}$. Até $15 \mathrm{~mm}$ de espessura pode-se soldar chapas sem chanfrar as bordas e, em vários passes, é possível soldar chapas espessas, com até $50 \mathrm{~mm}$.

\subsubsection{Soldagem com gás de proteção (GMAW - Gas Metal Arc Welding)}

Segundo WAINER et al. [ 72 ], este processo teve início no começo dos anos 30. Ele foi viabilizado somente depois da II Guerra Mundial, para soldagem de magnésio e suas ligas e mais tarde para os outros metais, utilizando gás inerte. Posteriormente introduziu-se o $\mathrm{CO}_{2}$.

Esse tipo de soldagem é também chamada de soldagem com gás ativo (MAG), adequado para soldagem de aços de baixo carbono e aços de baixa liga ou soldagem com gás inerte (MIG), adequado para soldagem de aços carbono, aços de baixa, média e alta liga, aços inoxidáveis, alumínio, magnésio, cobre e suas ligas, sendo que este termo é propriamente aplicado somente para soldagem onde o gás de proteção é argônio ou hélio.

Segundo OWENS \& CHEAL [ 50 ], neste processo, o eletrodo nu, o arco e a poça de solda são protegidos da atmosfera somente pelo gás de proteção, como na fig. 2-5. Geralmente não há fluxo, não ocorrendo a formação de escórias, que é comum nos outros processos. Uma mangueira flexível fornece a tocha de soldagem, o arame eletrodo, o gás de proteção e a corrente elétrica, todos eles automaticamente controlados. 


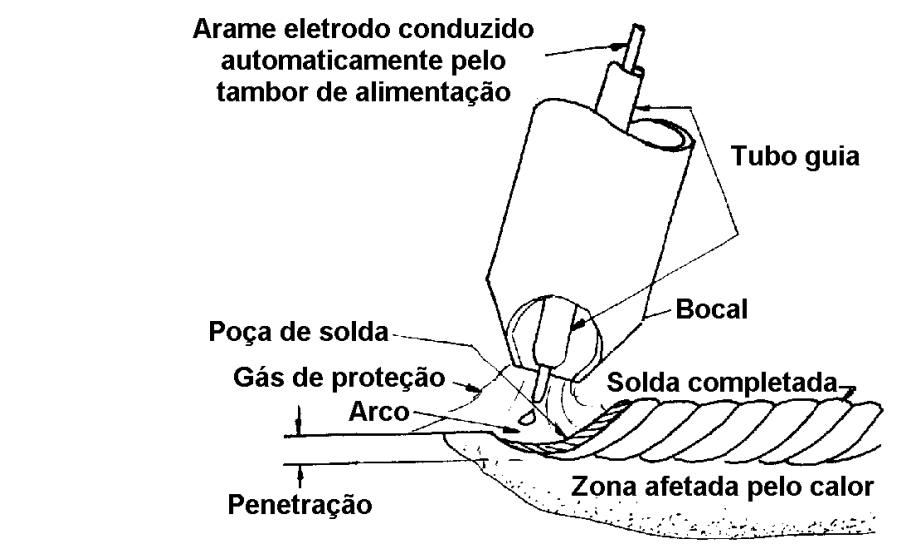

FIGURA 2-5 Representação do processo de soldagem com gás de proteção (GMAW). Adaptada de OWENS \& CHEAL [ 50 ].

O gás protetor é usualmente dióxido de carbono, algumas vezes com uma certa adição de argônio, para aços carbono/manganês e aços carbono. O argônio como um gás de proteção favorece a soldagem de todos os metais, todavia, devido ao seu custo, outros gases de proteção e suas misturas são aceitáveis e recomendados para a soldagem de aços.

Segundo GOMES [ 29 ], as características deste processo dependem do método de transferência do eletrodo à poça da solda. Essa transferência pode acontecer por queda livre quando o material atravessa o arco na forma de gotículas, ou pode acontecer transferência por curto-circuito, onde o arco é extinto em intervalos regulares e o arame participa do metal de solda quando entra em contato com a poça de solda fundida.

No método de transferência por queda livre há a subdivisão em transferência globular, transferência por borrifo e transferência pulsada.

A transferência globular, ver fig. 2-6a (MIG/MAG), que é pouco utilizada, é caracterizada pela formação de uma gota grande, bem maior que o diâmetro do arame, que se desprende por gravidade; ocorre em corrente baixa e pode ser conseguida quando arames de aço são utilizados juntamente com uma proteção de dióxido de carbono. As vezes essa transferência é irregular e instável, com uma grande quantidade de respingos. Ela pode gerar falta de penetração, falta de fusão e excessivo reforço do cordão de solda.

$\mathrm{Na}$ transferência por borrifo, ver fig. 2-6b (MIG), que é a mais indicada devido a estabilidade do arco e a alta taxa de deposição, a freqüência de transferência 
é aumentada e o arco torna-se mais estável com um baixo nível de respingos. Para isso ocorrer a corrente de soldagem é aumentada e o gás argônio é usado, diminuindo o tamanho da gota até atingir aproximadamente o tamanho do arame consumível. Este tipo de transferência, onde a penetração é elevada, é adequado para soldagem de chapas espessas, devido a quantidade de calor gerado.

A transferência pulsada, ver fig. 2-6c (MIG) produz transferência por pulverização em uma corrente de intensidade média, muito mais baixa que aquelas usadas para transferência por borrifo. Nesse processo os níveis de respingos são desprezíveis. Devido a menor quantidade de calor gerado pode-se soldar espessuras mais finas. Suas aplicações incluem soldagem de aços de alta resistência e baixa liga.

No caso de transferência por curto-circuito, ver fig. 2-6d (MIG/MAG) a corrente de centelhamento é insuficiente para fundir o arame, quando este é dirigido em direção à chapa. O intervalo do arco gradualmente diminui, levando o arame a tocar na poça de solda, ocasionando um curto-circuito. A corrente cresce rapidamente e na ruptura do curto-circuito desprende uma porção do arame e o arco se restabelece. Esse tipo de transferência é recomendado para soldagem de chapas finas em aço carbono, onde a penetração não é grande, mas existe o problema de respingos e instabilidade do arco.

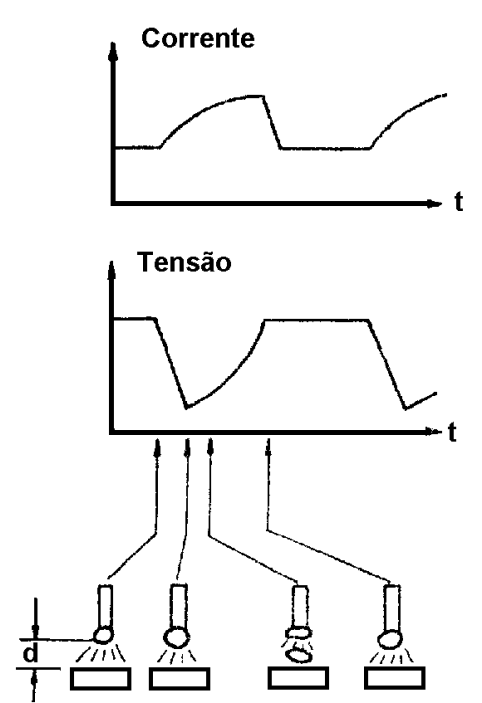

(a) Transferência globular
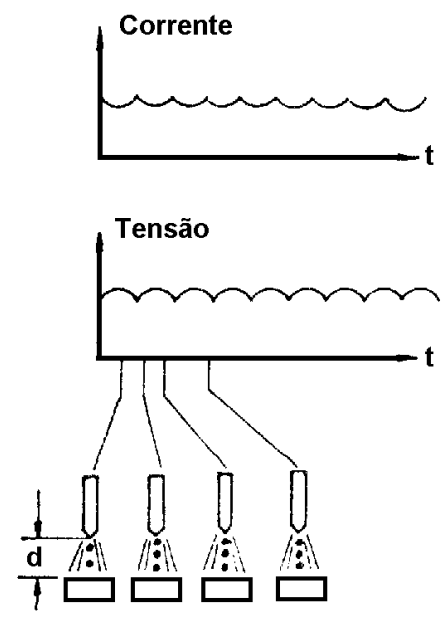

(b) Transferência por borrifo 


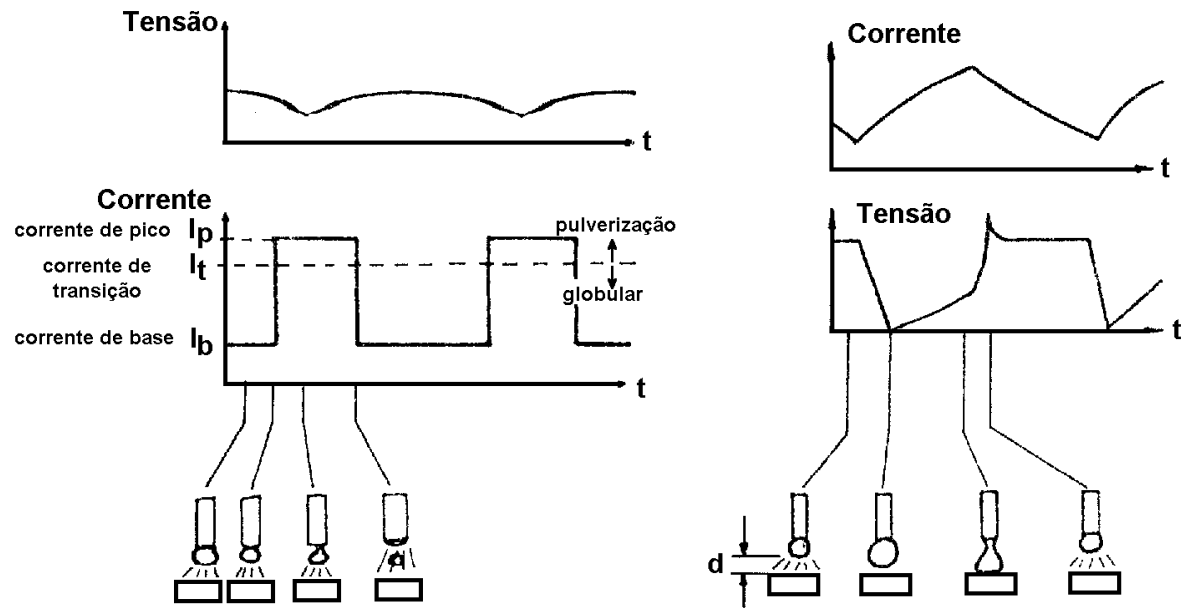

FIGURA 2-6 Esquemas de transferência mostrando o comportamento da tensão e da corrente de soldagem. Adaptada de WAINER et al. [ 72 ].

De uma maneira qualitativa, segundo WAINER et al. [ 72 ], a tabela 2-3 resume algumas características dos tipos de transferência.

TABELA 2-3 Algumas características dos modos de transferência. Adaptada de WAINER et al. [ 72 ].

\begin{tabular}{|c|c|c|c|c|c|}
\hline $\begin{array}{c}\text { Tipo de } \\
\text { transferência }\end{array}$ & Gás de proteção & $\begin{array}{c}\text { Posição de } \\
\text { soldagem }\end{array}$ & $\begin{array}{c}\text { Energia de } \\
\text { soldagem * }\end{array}$ & Penetração * & $\begin{array}{c}\text { Estabilidade } \\
\text { do arco }\end{array}$ \\
\hline Globular & todos & plana & 1,2 & 1,2 & intermediário \\
\hline Borrifo & $\begin{array}{c}\text { argônio e misturas } \\
\text { ricas em argônio }\end{array}$ & $\begin{array}{c}\text { plana/horizontal } \\
\text { (em ângulo) }\end{array}$ & 1,8 & 1,8 & boa \\
\hline Arco Pulsado & $\begin{array}{c}\text { argônio e misturas } \\
\text { ricas em argônio }\end{array}$ & todas & $1,2-1,6$ & $1,2-1,6$ & boa \\
\hline Curto-circuito & todos & todas & 1,0 & 1,0 & ruim \\
\hline
\end{tabular}

* Valores relativos tomada como base a transferência por curto-circuito

Segundo WAINER et al. [ 72 ], a adição de gases ativos $\left(\mathrm{CO}_{2}\right.$ e/ou oxigênio $)$ aos gases inertes (argônio e hélio) melhora e estabilidade do arco, além de mudar o contorno do cordão na seção transversal, diminuir a ocorrência de respingos e de mordedura e aumentar a penetração. Segundo SALMON \& JOHNSON [ 60 ], para soldagem de aço carbono e aços de baixa liga, recentes pesquisas indicam que melhor performance é obtida usando uma mistura de $80 \%$ de $\mathrm{CO}_{2}$ e $20 \%$ de hélio, onde tradicionalmente tem sido recomendado tanto o uso de uma mistura de $75 \%$ de argônio e $25 \%$ de $\mathrm{CO}_{2}$, ou $100 \%$ de $\mathrm{CO}_{2}$. Para aços de baixa liga onde dureza é um 
fator importante, é recomendado o uso de uma mistura de $60 \%$ a $70 \%$ de hélio, $25 \%$ a $30 \%$ de argônio e $4 \%$ a $5 \%$ de $\mathrm{CO}_{2}$

Segundo GOMES [ 29 ], para aços carbono e de baixa liga tem-se as seguintes misturas de gases:

- $\mathrm{CO}_{2}$ (gás de baixo custo; boas características de fusão; proteção eficiente; transferência por curto-circuito; grande penetração; elevada velocidade de soldagem);

- Argônio + 1 a 7\% de $\mathrm{CO}_{2}+$ até $3 \%$ de $\mathrm{O}_{2}$ (baixo aporte de calor; arco estável; transferência por borrifo e curto-circuito sobre seções finas);

- Argônio +8 a $15 \%$ de $\mathrm{CO}_{2}+$ até $3 \%$ de $\mathrm{O}_{2}$ (boa estabilidade do arco para transferência por curto-circuito, borrifo e arco pulsado; fusão satisfatória e perfil do cordão de solda ruim);

- Argônio + 16 a 23\% de $\mathrm{CO}_{2}$ (melhora as características de fusão para o método de transferência por curto-circuito);

- Argônio +1 a $8 \%$ de $\mathrm{O}_{2}$ (transferência por curto circuito; para baixa mistura de $\mathrm{O}_{2}$ conveniente transferência por borrifo e arco pulsado; utilizado para aços carbono e aços inoxidáveis).

De acordo com WAINER et al. [ 72 ], tem-se também a seguinte seleção de misturas de gases:

- Argônio + 3 a 5\% de $\mathrm{O}_{2}$ (aço carbono; transferência por borrifo; boa estabilidade do arco; poça de solda facilmente controlável; diminui a ocorrência de mordedura; melhora o contorno de penetração);

- Argônio $+2 \%$ de $\mathrm{O}_{2}$ (aço de baixa liga; transferência por borrifo; diminui a ocorrência de mordedura; boa tenacidade da solda);

- Argônio + 20 a 25\% de $\mathrm{CO}_{2}$ (aço carbono; transferência por curto-circuito; espessura até 3,5 mm; elevada velocidade de soldagem; diminui a distorção e respingo; boa penetração);

- Argônio + 50\% de $\mathrm{CO}_{2}$ (aço carbono; transferência por curto-circuito; espessuras acima de 3,5 mm; diminui os respingos; bom controle da poça de fusão na posição vertical e sobrecabeça); 
- 60 a 70\% de hélio +25 a 35\% de argônio + 1 a 5\% de $\mathrm{CO}_{2}$ (aço de baixa liga; transferência por curto-circuito; tenacidade razoável; excelente estabilidade do arco; poucos respingos);

- Argônio $+10 \%$ de $\mathrm{CO}_{2}+5 \%$ de $\mathrm{O}_{2}$ (usado na Europa para aços carbono); - $\mathrm{CO}_{2}+20 \%$ de $\mathrm{O}_{2}$ (usado no Japão para aços carbono).

Esses gases, além de proteger o metal fundido da atmosfera, controlam o arco e as características de transferência do metal; afetam a penetração, a largura da poça de fusão, a forma da região soldada e a velocidade de soldagem; influenciam nas perdas de elementos químicos, na temperatura da poça de fusão, na sensibilidade à fissuração e porosidade e controlam os defeitos de mordedura. Deve-se levar em consideração que quanto mais denso for o gás, mais eficiente será a proteção do arco.

A polaridade da corrente influencia no modo de transferência. No processo MIG/MAG a corrente mais utilizada é a CCPR $(+)$.

Quando se utiliza valores elevados de tensão pode-se ocasionar porosidades, excesso de respingos e mordeduras. Utilizando valores baixos de tensão, pode-se proporcionar também o aparecimento de porosidades.

Quando a tocha de soldagem é manual o processo é considerado semiautomático e apesar dos consumíveis serem controlados automaticamente, a habilidade de manipulação é ainda requerida. Todavia, o processo é usualmente incorporado dentro dos processos automáticos. Suas vantagens particulares como um "processo automático" é que ele pode ser utilizado para várias posições de soldagem.

Segundo OWENS \& CHEAL [ 50 ], com seu precoce desenvolvimento, esse processo possuía uma medíocre reputação em relação à qualidade. Sua aparência não era muito boa, com muitos respingos. Todavia, com a utilização de operadores habilidosos e modernas aparelhagens, particularmente àquelas com corrente contínua, a qualidade da solda nesse processo é hoje comparada com a soldagem a arco com eletrodo revestido, e uma vez que há eficiente proteção da poça de solda em relação aos elementos atmosféricos, as soldas são mais resistentes, mais dúcteis e mais imunes à ações corrosivas. A velocidade de deposição é certamente mais alta, conduzindo à uma maior economia. Nesse processo, existe também uma baixa 
liberação de gás e fumaça e uma ampla faixa de materiais e espessuras que podem ser soldadas.

O equipamento de soldagem MIG/MAG, segundo CUNHA [ 20 ], consiste em uma tocha de soldagem, que contém um tubo de contato para transmitir a corrente de soldagem para o eletrodo e um bico de gás para direcionar o gás de proteção, além de um suprimento de energia, um suprimento de gás e uma sistema para o acionamento do arame.

Segundo OWENS \& CHEAL [ 50 ], diâmetros típicos de eletrodos para trabalhos estruturais variam entre 0,75 e $2,00 \mathrm{~mm}$. Voltagens de soldagem variam entre 20 e $30 \mathrm{~V}$. Correntes típicas ficam entre 50 e 200A para transferência por curtocircuito e 150 a 500A para transferência por borrifo. Velocidades de deposição podem atingir $150 \mathrm{~g} / \mathrm{min}$ para soldagem descendente com transferência por borrifo.

Um outro processo usando gás inerte é o processo de arco tungstênio (TIG). Nesse processo, segundo QUITES \& DUTRA [ 57 ], a fusão dos metais é produzida por um arco elétrico que é produzido em uma atmosfera de gás inerte (argônio, hélio e suas misturas), entre um eletrodo de tungstênio não consumível e o metal base. $\mathrm{O}$ gás possui um caráter ionizante e protege o metal de solda contra a oxidação. $O$ metal de enchimento, se requerido, é somado pela alimentação de uma barra de soldagem, dentro da poça de solda. Os eletrodos de tungstênio embora considerados não consumíveis, se gastam, sendo que um eletrodo de $170 \mathrm{~mm}$ possui vida útil de aproximadamente 30 horas.

As características do arco elétrico alteram-se de acordo com o tipo de corrente utilizada, por exemplo, segundo WAINER et al. [ 72 ], quando se usa corrente contínua de polaridade direta (eletrodo negativo) existe um fluxo de elétrons em direção ao metal base, aquecendo-o mais em relação ao eletrodo, tendo como conseqüência uma grande e estreita penetração. No caso da corrente contínua com polaridade reversa (eletrodo positivo), existe um fluxo de elétrons em direção ao eletrodo, aquecendo-o mais, tendo como conseqüência uma pequena e larga penetração.

Esse processo é utilizado em aços comuns e especiais, principalmente em espessuras finas (inferior a $3 \mathrm{~mm}$ ). Os eletrodos são relativamente caros e a mão-de- 
obra para esse processo deve possuir boa formação e submeter-se a treinamentos adequados.

\subsubsection{Soldagem arco elétrico com fluxo no núcleo (FCAW - Flux Cored Arc Welding)}

A soldagem FCAW é um processo similar ao GMAW (MIG/MAG), porém utilizando uma escória protetora. Nesse processo, segundo QUITES \& DUTRA [ 57 ], a proteção do arco é feita pela queima do fluxo em pó contido no arame tubular. Outra maneira de se proteger o fluxo é envolver o arco por um fluxo adicional de gás protetor aplicado externamente, que flui do mesmo bocal que emerge o eletrodo. Em ambas as aplicações o material do núcleo do eletrodo, que contém ingredientes geradores de gases e vapores de proteção do arco elétrico da ação do ar, produzem uma relativamente fina escória de revestimento para proteger a solidificação do metal de solda. Essa escória também ajuda a desoxidar o material de base e o metal de solda, além de introduzir elementos necessários de liga para corrigir a composição química da mesma. Segundo GAYLORD et al. [ 27 ], o FCAW é usualmente um processo semi-automático onde o canhão, que controla a velocidade de alimentação, é mantido e manipulado por um soldador. Esse processo também pode ser usado em máquinas de soldagem, em que o operador monitora o arco durante a progressão mecanizada.

\subsubsection{Soldagem eletro-escória (ESW - Electroslag Welding) e soldagem eletro- gás (EGW - Electrogas Welding)}

Segundo WAINER et al. [ 72 ], por volta do ano de 1900 já eram conhecidos os fundamentos do processo eletro-escória, mas somente a partir de 1950 este processo de soldagem foi desenvolvido no Instituto de Soldagem Elétrica E. O. Paton em Kiev, na antiga URSS. Em 1960, no Instituto Bratislava, na Checoslováquia, os engenheiros belgas absorveram as técnicas do processo, divulgando-as ao mundo ocidental. 
Esses processos automáticos são somente usados para soldagem de extremidade em chapas espessas, na posição vertical ou aproximadamente vertical. Como mostrado na fig. 2-7, as chapas são simplesmente posicionadas com uma abertura da raiz que varia de $40 \mathrm{~mm}$ para espessuras entre 170 a $200 \mathrm{~mm}$ e $25 \mathrm{~mm}$ para espessuras entre 50 a $75 \mathrm{~mm}$. Nenhuma preparação especial das juntas para executar a soldagem é requerida, com isso as chapas devem ser cortadas sem chanfros.

Segundo OWENS \& CHEAL [ 50 ], na soldagem eletro-escória o calor é produzido pela passagem de uma corrente elétrica ao longo do fluxo fundido, gerado pela fusão do eletrodo e das extremidades do metal base, desta forma uma grande poça de solda é criada, contida nos dois lados pelas chapas presentes na soldagem e nos outros lados pelas sapatas de retenção, as quais são resfriadas com água. A escória fundida condutiva, que acompanha a soldagem, protege a solda e funde o metal de enchimento e o metal de base. Desde que a escória sólida não é condutiva, um arco elétrico entre o eletrodo e a base da junta é requerido para iniciar o processo, através da fusão da escória e o aquecimento das chapas, desta forma o fluxo é conduzido em seu estado fundido. Segundo CUNHA [ 20 ], quando uma camada espessa de escória se forma, toda a ação do arco cessa, e a corrente de soldagem passa do eletrodo através da escória, por condução elétrica. O calor é gerado pela resistência da escória fundida à passagem da corrente de soldagem e é suficiente para fundir o eletrodo e as faces da chapa. Com isso, segundo WAINER et al. [ 72 ], a principal função da escória é transformar energia elétrica em energia térmica, deste modo, a condutibilidade elétrica e sua variação de acordo com a temperatura tornamse as principais características da escória. O eletrodo fundido e o metal base fundido formam a solda abaixo do banho de escória fundida. Um ou mais eletrodos podem ser alimentados automaticamente pelo topo da ligação dentro da poça de solda. 


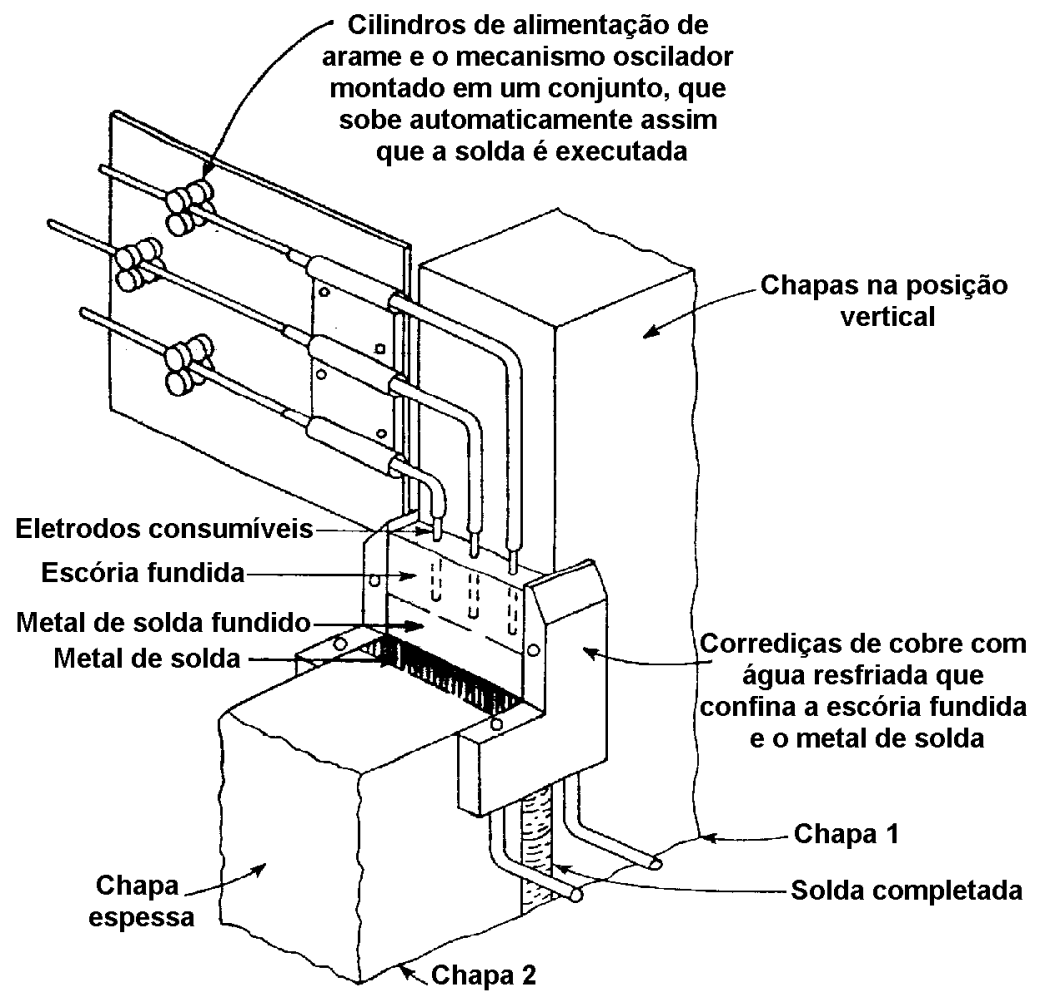

FIGURA 2-7 Representação do processo de soldagem eletro-escória (ESW) . Adaptada de COOPER [ 17 ].

As vantagens desse processo são: a alta taxa de deposição; a homogeneidade da solda ao longo da espessura; a soldagem espessa em um único passe; o processo é totalmente mecanizado e estável, que independe do tipo de corrente; a soldagem é bastante econômica, pois consome cerca de 15 a 20\% menos de energia elétrica que no processo SAW e cerca de 5 a $10 \%$ a menos de fluxo; geralmente não requer préaquecimento ou pós-aquecimento devido a lentidão do processo; apresenta mínima distorção e o arco não é visível.

O processo eletro-escória é um processo automático, que consta do seguinte equipamento básico, segundo WAINER et al. [ 72 ]:

- fonte de energia, são utilizados transformadores-retificadores de tensão constante, que fornecem 750 a $1.000 \mathrm{~A}$ em corrente contínua;

- alimentador de arame e oscilador, a velocidade de alimentação varia entre 17 e 150 $\mathrm{mm} / \mathrm{s}$, para cobrir eletrodos entre 2,4 a 3,2 $\mathrm{mm}$. O oscilador é necessário sempre que a espessura da chapa ou a largura de soldagem que cabe a cada eletrodo ultrapassar $50 \mathrm{~mm}$. Geralmente é utilizado um eletrodo oscilante para espessuras até $130 \mathrm{~mm}$, dois até $230 \mathrm{~mm}$ e três até $500 \mathrm{~mm}$. Quando não é disponível um mecanismo de 
oscilação, usa-se um eletrodo a cada múltiplo de $75 \mathrm{~mm}$ de espessura. A velocidade de oscilação varia entre 8 a $40 \mathrm{~mm} / \mathrm{s}$;

- tubo guia do eletrodo, que existem dois tipos: o convencional (não consumível) que geralmente não excede $13 \mathrm{~mm}$ e o consumível que é fundido de acordo com o avanço da soldagem, normalmente possui diâmetro externo de $16 \mathrm{~mm}$ e o interno varia entre 3,2 e $4,8 \mathrm{~mm}$;

- sapata de retenção de escória, sua função é delimitar o banho de escória e a poça de fusão, além de resfriar a zona de solda;

- controles de soldagem e cabos de conexão elétrica.

Segundo WAINER et al. [ 72 ] existem algumas variáveis do processo que devem ser consideradas.

Um aumento da corrente de soldagem eleva a profundidade da poça de fusão, devido ao aumento da velocidade de alimentação do eletrodo, além de provocar uma redução na resistência ao fissuramento da junta.

Um aumento da tensão de soldagem provoca aumento da penetração e da largura da poça, além de aumentar a resistência ao fissuramento da junta. Baixos valores de tensão provocam curto-circuitos ou centelhamento da poça de fusão, ao passo que tensões muito elevadas provocam formações de respingos na parte superior do banho de escória. Recomenda-se tensões de 40 e $55 \mathrm{~V}$ para eletrodos de 3,2 mm de diâmetro.

Um banho de escória pouco profundo causa respingos e centelhamento na superfície do banho, já banhos profundos diminuem a largura da poça e não permitem adequada troca de calor dentro da escória. A profundidade ideal é de 40 $\mathrm{mm}$, mas pode atingir valores entre 25 a $50 \mathrm{~mm}$ em profundidade.

A velocidade de alimentação do eletrodo afeta a profundidade do banho de escória e da poça de fusão e a largura total da solda.

Um aumento da distância entre a superfície do banho de escória e o término do tubo guia, chamado extensão do eletrodo, aumenta a resistência elétrica do eletrodo, aumentando a corrente de soldagem. Para eletrodos de diâmetro de 3,2 mm essa distância varia entre 50 a 75 mm. 
Esse processo de soldagem, empregado geralmente em aços carbono, é utilizado em soldagem estrutural, maquinarias e vasos de pressão destinados à industrias marítimas e petroquímicas, industria naval e estruturas oceânicas, além de peças fundidas.

Segundo CUNHA [ 20 ], apesar de similar em seus elementos básicos ao processo eletro-escória, no processo de soldagem eletro-gás o calor é produzido por um arco elétrico e não pela resistência elétrica do fluxo e é usada somente corrente contínua, enquanto no processo eletro-escória pode ser usada também corrente alternada. Segundo GAYLORD et al. [ 27 ], tanto eletrodos sólidos quanto eletrodos tubulares com fluxo no núcleo podem ser usados, nos dois tipos de soldagem. O gás de proteção é fornecido tanto pelo eletrodo com fluxo no núcleo, quanto pelo gás fornecido externamente, onde no caso do uso de eletrodo sólido, usa-se uma mistura de $80 \%$ de argônio e $20 \%$ de $\mathrm{CO}_{2}$. As espessuras soldadas variam entre 10 e 100 $\mathrm{mm}$.

Segundo WAINER et al. [ 72 ], as tensões de soldagem variam entre $30 \mathrm{e}$ 55V. A extensão do eletrodo é de aproximadamente $40 \mathrm{~mm}$, onde para eletrodo tubular chega entre 60 a $75 \mathrm{~mm}$. Espessuras maiores que $30 \mathrm{~mm}$ recomenda-se o mecanismo de oscilação, cuja velocidade é de 7 e $8 \mathrm{~mm} / \mathrm{s}$. É recomendado abertura da raiz de $17 \mathrm{~mm}$.

Os componentes desse processo, segundo CUNHA [ 20 ], são: fonte de energia de corrente contínua (CCPR (+)); dispositivo alimentador do arame; tocha de soldagem, que guia o eletrodo, transmite a corrente e fornece o gás; sapatas de retenção; oscilador da pistola de soldagem; e o equipamento para suprir o gás de proteção.

De acordo com WAINER et al. [ 72 ], esse tipo de soldagem é principalmente utilizada para soldagem de aços carbono e de baixa liga, sendo utilizado em cascos de navios, pontes, tanques de armazenamento, vigas, estruturas oceânicas, etc.

Soldagem eletro-escória ou eletro-gás produzem, relativamente, grandes tamanhos de grânulos como resultado do lento grau de resfriamento da solda. Esta condição também produz migração de carbono da porção da solda que resfria primeiro, para a parte que resfria por último. Segundo GAYLORD et al. [ 27 ], como resultado, a seção central de tais soldas podem consistir de um material com grandes 
tamanhos de grânulos. Grandes tensões residuais podem estar presentes, como um resultado da contração das espessas peças da ligação. Sob estas condições a solda deve ser suscetível à fraturas frágeis. Esta condição é mais crítica na presença de uma trinca. Uma maneira de amenizar este problema é requerer o aquecimento da coluna de soldagem.

\subsubsection{Soldagem de pinos (conectores)}

Referido na seção 1.8.8, segundo SALMON \& JOHNSON [ 60 ], o processo de soldagem de um pino de metal em um material base é essencialmente um processo automático (ver fig. 2-8) similar em características ao processo SMAW. O pino serve como um eletrodo e um arco elétrico é criado entre a extremidade do pino e a chapa. A proteção é executada pela colocação de dois anéis cerâmicos ao redor da extremidade do pino na pistola de soldadura. Este anel serve também para moldar a seção soldada, proporcionando que a zona de ligação apresente um aspecto regular.

A pistola de soldadura é colocada na posição e o arco é criado. Após um pequeno instante, a pistola dirige o pino dentro da poça fundida e a solda é completada deixando um pequeno filete ao redor do mesmo. A penetração total através do corpo do pino é obtida e a solda é completada usualmente em menos de um segundo.
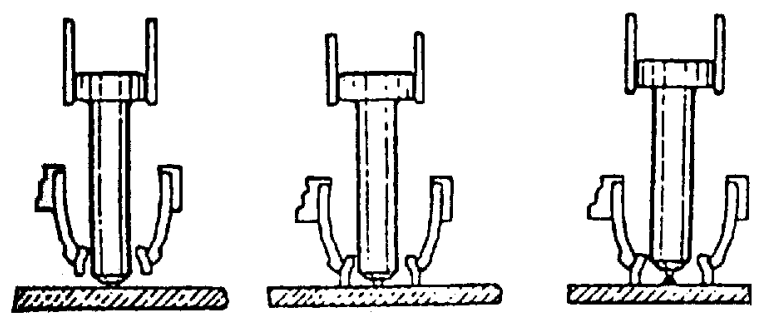

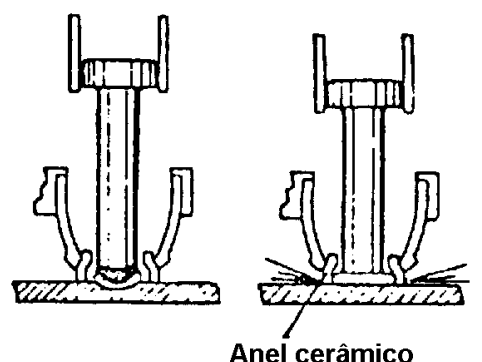

(a)

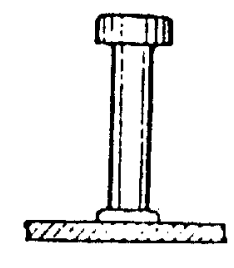

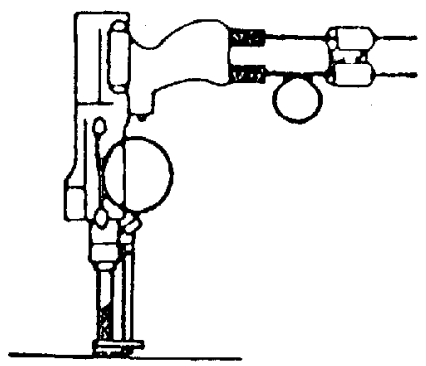

(b)

FIGURA 2-8 (a) Fases da soldagem de um conector tipo cavilha de cabeça; (b) pistola para soldadura automática de conectores. Adaptada de LAMAS et al. [ 35 ]. 


\subsection{Fluxos de soldagem e classificação de eletrodos}

Segundo CUNHA [ 20 ], o fluxo, que é um composto granular de origem mineral, protege a poça de fusão da atmosfera, através da cobertura que a escória fundida exerce sobre o metal. Além disso, o fluxo purifica a poça de solda, modifica a composição química do metal de solda e influência no acabamento e nas propriedades mecânicas da solda.

Segundo OWENS \& CHEAL [ 50 ], os fluxos para serem usados nos diversos tipos de soldagem, variam seus componentes e funções consideravelmente de processo para processo, mas é possível categorizar seus constituintes nos seguintes tipos:

- formas de gases que se decompõem para suprir gases de proteção quando ocorre aquecimento. Os carbonatos produzem $\mathrm{CO}_{2}$, fluoretos desenvolvem fluoreto de proteção e materiais orgânicos produzem hidrocarbonetos e $\mathrm{CO}_{2}$;

- formas das escórias que produzem a crosta de escória para proteção do metal de solda após solidificação. Estes incluem carbonetos de cálcio e manganês, titânio, silício, manganês e óxidos de ferro, silicatos e argilas;

- arcos iniciadores e estabilizadores. Estes são tanto metálicos, tal como níquel pulverizado ou ferro, ou elementos produzindo íons de potássio e sódio, tal como feldspato e argila;

- agentes de fluxo. Estes reduzem impurezas na solda, e eles são geralmente carbonatos e óxidos;

- desoxidantes. Reduzem agentes, de modo que ferrosilício, ferromanganês e ferro triturado são adicionados para reduzir o oxigênio da poça de solda;

- minerais controlando propriedades físicas do fluxo. Estes influenciam o perfil das gotas e o desprendimento da escória, e inclui muitos dos óxidos e fluoretos requeridos para outras funções;

- adições metálicas. Ferro triturado e ligas ferrosas podem ser adicionadas para melhorar o grau de velocidade de deposição;

- aglutinantes tal como mica, silicato de sódio e aglutinantes orgânicos são adicionados para melhorar a resistência do fluxo. 
A AWS classifica os fluxos em quatro tipos, baseada no método de fabricação, que são: fluxos fundidos, fluxos aglutinados, fluxos aglomerados e fluxos misturados.

A classificação de fluxos varia também com alguns fatores de avaliação de desempenho, como controle da composição química do metal depositado, capacidade de conduzir altas correntes para soldar juntas de grandes espessuras em um único passe e capacidade de soldar pequenas espessuras usando altas velocidades.

Em soldagem eletro-escória há consideravelmente mais tempo disponível para interações entre o fluxo fundido e a poça de solda, e esta interação pode significativamente alterar a composição do metal de solda. Independente das adições associadas com essa interação, fluxos eletro-escória têm muitas similaridades com àqueles por soldagem a arco submerso.

Os eletrodos para soldagem SMAW são classificados com base nas propriedades mecânicas do metal de solda, com a posição de soldagem, com o tipo de revestimento e com o tipo da corrente requerida. Eletrodos para SMAW são cobertos pela AWS A5.1 e AWS A5.5. Cada eletrodo é identificado por um número de código $\mathrm{E} \underline{\mathrm{XXX}} \underline{\mathrm{X}} \underline{\mathrm{X}}$ - $\underline{\mathrm{X}}$, onde $\mathrm{E}$ representa “eletrodo" e X representa um número. Os primeiros dois (ou três) números indicam a mínima resistência à tração do metal de solda, em ksi. O próximo número denota a posição em que cada eletrodo pode ser usado. O número 1 significa todas as posições, o número 2 plana e horizontal, o número 3 soldagem plana somente e o número 4 posição plana, horizontal, sobrecabeça e vertical descendente. $\mathrm{O}$ penúltimo número, que varia de 0 a 8 , denota o tipo de revestimento, o tipo de corrente (contínua ou alternada) e a polaridade (direta ou reversa), melhor exemplificado na tabela 2-4. Polaridade direta significa que o eletrodo é negativo. A referência após o traço é utilizada somente pela especificação AWS A-5.5, indicando a composição química do material. Tem-se os seguintes sufixos com as seguintes composições químicas aproximadas: A1 (0,5\% Mo); B1 (0,5\% Cr, 0,5\% Mo); B2 (1,25\% Cr, 0,5\% Mo); B2L (1,25\% Cr, 0,5\% Mo (baixo carbono)); B4L (2\% Cr; 0,5\% Mo (baixo carbono)); C1 (2,5\% Ni); C2 (3,5\% $\mathrm{Ni})$; C3 (1\% Ni); B3 (2,25\% Cr, 1\% Mo); B3L (2,25\% Cr, 1\% Mo (baixo carbono)); D1 (1,5\% Mn, 1,5\% Mo); D2 (2\% Mn, 1,5\% Mo); G (aço de alta resistência com 5 
diferentes composições de $\mathrm{Mn}, \mathrm{Ni}, \mathrm{Cr}$, Mo e V); M (aço de alta resistência com 4 diferentes composições de $\mathrm{Mn}, \mathrm{Ni}, \mathrm{Cr}$, Mo e V).

TABELA 2-4 Características definidas pelo penúltimo dígito da classificação AWS, para soldagem SMAW. Adaptada de CUNHA [ 20 ].

\begin{tabular}{|c|c|c|c|c|c|c|c|c|c|}
\hline Dígito & 0 & 1 & 2 & 3 & 4 & 5 & 6 & 7 & 8 \\
\hline $\begin{array}{l}\text { Tipo de } \\
\text { corrente }\end{array}$ & $\begin{array}{l}\mathrm{CC}^{+} \\
\mathrm{CA}\end{array}$ & $\begin{array}{l}\mathrm{CC}^{+} \\
\mathrm{CA}\end{array}$ & $\begin{array}{l}\mathrm{CC}^{-} \\
\mathrm{CA}\end{array}$ & $\begin{array}{l}\mathrm{CA} \\
\mathrm{CC}^{+} \\
\mathrm{CC}^{-} \\
\end{array}$ & $\begin{array}{l}\mathrm{CA} \\
\mathrm{CC}^{+} \\
\mathrm{CC}^{-} \\
\end{array}$ & $\mathrm{CC}^{+}$ & $\begin{array}{l}\mathrm{CA} \\
\mathrm{CC}^{+}\end{array}$ & $\begin{array}{l}\mathrm{CA} \\
\mathrm{CC}^{-}\end{array}$ & $\begin{array}{l}\mathrm{CA} \\
\mathrm{CC}^{+}\end{array}$ \\
\hline $\begin{array}{c}\text { Tipo de } \\
\text { arco }\end{array}$ & $\begin{array}{c}\text { Intenso c/ } \\
\text { salpico }\end{array}$ & Intenso & $\begin{array}{l}\text { Médio c/ } \\
\text { salpico }\end{array}$ & Leve & Leve & Médio & Médio & Leve & Leve \\
\hline $\begin{array}{l}\text { Penetra- } \\
\text { ção }\end{array}$ & Grande & Grande & Fraca & Fraca & Fraca & Média & Média & Média & Média \\
\hline $\begin{array}{l}\text { Revesti- } \\
\text { mento }\end{array}$ & * & $\begin{array}{l}\text { Celulósico } \\
\text { (com } \\
\text { silicato de } \\
\text { K) }\end{array}$ & $\begin{array}{c}\text { Rutílico } \\
\left(\mathrm{TiO}_{2} \mathrm{e}\right. \\
\text { silicato de } \\
\mathrm{Na})\end{array}$ & $\begin{array}{l}\text { Rutílico } \\
\left(\mathrm{TiO}_{2} \text { e }\right. \\
\text { silicato de } \\
\mathrm{K})\end{array}$ & $\begin{array}{c}\text { Rutílico } \\
\left(\mathrm{TiO}_{2},\right. \\
\text { silicatos, pó } \\
\text { de ferro } \\
20 \%)\end{array}$ & $\begin{array}{l}\text { Básico } \\
\text { (calcário, } \\
\text { silicato de } \\
\mathrm{Na} \text { ) }\end{array}$ & $\begin{array}{c}\text { Básico } \\
\left(\mathrm{TiO}_{2},\right. \\
\text { calcário, } \\
\text { silicato de } \\
\text { K) }\end{array}$ & $\begin{array}{c}\text { Ácido } \\
\text { (óxido de } \\
\text { ferro } \\
\text { (FeO), } \\
\text { silicato de } \\
\text { Na, pó de } \\
\text { ferro) } \\
\end{array}$ & $\begin{array}{c}\text { Básico } \\
\text { (calcário } \\
\mathrm{TiO}_{2}, \\
\text { silicatos, } \\
\text { pó de } \\
\text { ferro } 25 \text { a } \\
40 \% \text { ) }\end{array}$ \\
\hline Escória & $\begin{array}{l}\text { Pouca: } \\
\text { remoção } \\
\text { fácil }\end{array}$ & $\begin{array}{l}\text { Pouca: } \\
\text { remoção } \\
\text { fácil }\end{array}$ & $\begin{array}{c}\text { Densa: } \\
\text { auto- } \\
\text { destacável } \\
\end{array}$ & $\begin{array}{c}\text { Densa: } \\
\text { auto- } \\
\text { destacável } \\
\end{array}$ & $\begin{array}{c}\text { Densa: } \\
\text { auto- } \\
\text { destacável } \\
\end{array}$ & Espessa & Espessa & $\begin{array}{c}\text { Ácida: } \\
\text { facilmente } \\
\text { destacável } \\
\end{array}$ & Espessa \\
\hline $\begin{array}{l}\text { Teor de } \\
\text { hidrogê- } \\
\text { nio }\end{array}$ & $\begin{array}{c}\text { Elevado } \\
20 \mathrm{ml} / 100 \mathrm{~g}\end{array}$ & $\begin{array}{c}\text { Elevado } \\
20 \mathrm{ml} / 100 \mathrm{~g}\end{array}$ & $\begin{array}{l}\text { Moderado } \\
15 \mathrm{ml} / 100 \mathrm{~g}\end{array}$ & $\begin{array}{l}\text { Moderado } \\
15 \mathrm{ml} / 100 \mathrm{~g}\end{array}$ & $\begin{array}{l}\text { Moderado } \\
15 \mathrm{ml} / 100 \mathrm{~g}\end{array}$ & $\begin{array}{c}\text { Baixo } \\
2 \mathrm{ml} / 100 \mathrm{~g}\end{array}$ & $\begin{array}{c}\text { Baixo } \\
2 \mathrm{ml} / 100 \mathrm{~g}\end{array}$ & $\begin{array}{c}\text { Modero } \\
15 \mathrm{ml} / 100 \mathrm{~g}\end{array}$ & $\begin{array}{c}\text { Baixo } \\
2 \mathrm{ml} / 100 \mathrm{~g}\end{array}$ \\
\hline $\begin{array}{l}\text { Veloci- } \\
\text { dade de } \\
\text { fusão }\end{array}$ & Elevada & Elevada & Regular & Regular & Regular & Baixa & Baixa & Elevada & Baixa \\
\hline $\begin{array}{c}\text { Posição } \\
\text { de } \\
\text { soldagem }\end{array}$ & Todas & Todas & $\begin{array}{c}\text { Plana e } \\
\text { plana } \\
\text { horizontal }\end{array}$ & Plana & $\begin{array}{c}\text { Todas } \\
\text { menos } \\
\text { vertical } \\
\text { descendente }\end{array}$ & Todas & Todas & $\begin{array}{c}\text { Plana e } \\
\text { horizontal }\end{array}$ & Todas \\
\hline Usos & $\begin{array}{c}\text { Onde é } \\
\text { importante } \\
\text { grande } \\
\text { penetração }\end{array}$ & $\begin{array}{c}\text { Onde é } \\
\text { importante } \\
\text { grande } \\
\text { penetração }\end{array}$ & $\begin{array}{l}\text { Chaparia } \\
\text { fina e } \\
\text { média - } \\
\text { bom } \\
\text { acabamen- } \\
\text { to }\end{array}$ & $\begin{array}{l}\text { Chaparia } \\
\text { fina e } \\
\text { média - } \\
\text { bom } \\
\text { acabamen- } \\
\text { to }\end{array}$ & $\begin{array}{c}\text { Chaparia } \\
\text { fina e média } \\
\text { - bom } \\
\text { acabamento }\end{array}$ & $\begin{array}{c}\text { Aços } \\
\text { baixa liga } \\
\text { (altamente } \\
\text { higroscó- } \\
\text { pico) }\end{array}$ & $\begin{array}{c}\text { Aços } \\
\text { baixa liga } \\
\text { (altamente } \\
\text { higroscó- } \\
\text { pico) }\end{array}$ & $\begin{array}{c}\text { Aços } \\
\text { carbono }\end{array}$ & $\begin{array}{c}\text { Aços } \\
\text { baixa liga } \\
\text { (altamente } \\
\text { higroscó- } \\
\text { pico) }\end{array}$ \\
\hline
\end{tabular}

* xx 10 celulósico (com silicato de $\mathrm{Na}$ ), xx 20 celulósico (com óxido de ferro - FeO), xx 30 celulósico (com óxido de ferro $\mathrm{FeO})$

Pode-se mencionar algumas regras elementares aplicáveis aos aços-carbono, levando em consideração os comportamentos dos vários revestimentos, posições de soldagem e geometria da junta. A tabela 2-5, extraída e adaptada de WAINER et al. [ 72 ], atribui nota a alguns eletrodos mais utilizados, levando em consideração suas características operacionais e depósitos produzidos, podendo ser utilizada como um meio para uma seleção de um desejado consumível. 
TABELA 2-5 Classificação comparativa de desempenho dos consumíveis mais utilizados em soldagem SMAW. Adaptada de WAINER et al. [ 72 ].

\begin{tabular}{|c|c|c|c|c|c|c|c|c|c|c|}
\hline & E6010 & E6011 & E6012 & E6013 & E7014 & E7016 & E7018 & E7024 & E6027 & E7028 \\
\hline $\begin{array}{c}\text { Soldagem em topo, posição plana, } \\
\text { espessura maior que 6 mm }\end{array}$ & 4 & 5 & 3 & 8 & 9 & 7 & 9 & 9 & 10 & 10 \\
\hline $\begin{array}{c}\text { Soldagem em topo, todas as } \\
\text { posições, espessura maior que 6mm }\end{array}$ & 10 & 9 & 5 & 8 & 6 & 7 & 6 & NA & NA & NA \\
\hline $\begin{array}{c}\text { Soldagem em filete, posições plana } \\
\text { ou horizontal }\end{array}$ & 2 & 3 & 8 & 7 & 9 & 5 & 9 & 10 & 9 & 9 \\
\hline $\begin{array}{c}\text { Soldagem em filete, todas as } \\
\text { posições }\end{array}$ & 10 & 9 & 6 & 7 & 7 & 8 & 6 & NA & NA & NA \\
\hline $\begin{array}{c}\text { Chaparia espessa ou altamente } \\
\text { restrita }\end{array}$ & 8 & 8 & 6 & 8 & 8 & 10 & 9 & 7 & 8 & 9 \\
\hline Taxa de deposição & 4 & 4 & 5 & 5 & 6 & 4 & 6 & 10 & 10 & 8 \\
\hline Penetração & 10 & 9 & 6 & 5 & 6 & 7 & 7 & 4 & 8 & 7 \\
\hline $\begin{array}{c}\text { Aparência do cordão, ausência de } \\
\text { mordeduras }\end{array}$ & 6 & 6 & 8 & 9 & 9 & 7 & 10 & 10 & 10 & 10 \\
\hline Ausência de defeitos & 6 & 6 & 3 & 5 & 7 & 10 & 9 & 8 & 9 & 9 \\
\hline Ductilidade & 6 & 7 & 4 & 5 & 6 & 10 & 10 & 5 & 10 & 10 \\
\hline Resistência ao impacto & 8 & 8 & 4 & 5 & 8 & 10 & 10 & 9 & 9 & 10 \\
\hline Ausência de respingos & 1 & 2 & 6 & 7 & 9 & 6 & 8 & 10 & 10 & 9 \\
\hline Tolerância à má preparação da junta & 6 & 7 & 10 & 8 & 9 & 4 & 4 & 8 & NA & 4 \\
\hline Facilidade e conforto na soldagem & 7 & 6 & 8 & 9 & 10 & 6 & 8 & 10 & 10 & 9 \\
\hline Facilidade na remoção da escória & 9 & 8 & 6 & 8 & 8 & 4 & 7 & 9 & 9 & 8 \\
\hline NA Não aplićn & & & & & & & & \\
\hline
\end{tabular}

NA = Não aplicável

A tabela 2-6, também extraída e adaptada de WAINER et al. [ 72 ], apresenta informações sobre eletrodos, em função de parâmetros geométricos das juntas e parâmetros operacionais da soldagem.

TABELA 2-6 Recomendações para a soldagem de aço-carbono, pelo processo SMAW. Adaptada de WAINER et al. [ 72 ]

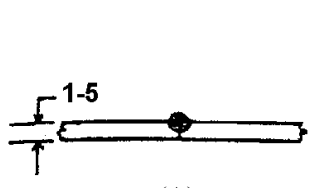

(A)

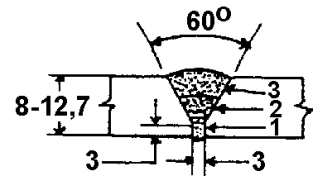

(B)

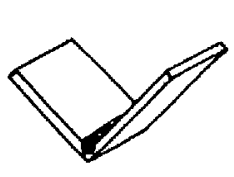

(C)

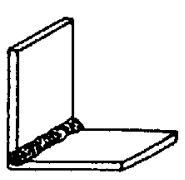

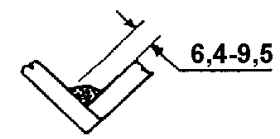

(D)

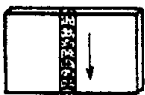

(E)

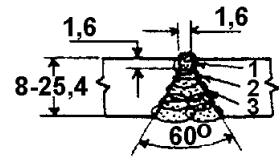

$60^{\circ}$

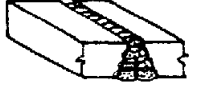

(F)

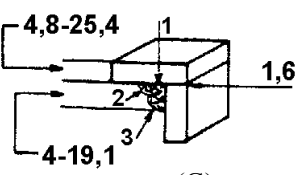

(G)

(a) Posição plana; soldagem de topo sem chanfro (fig. A).

\begin{tabular}{|l|c|c|c|c|c|c|}
\hline Espessura do material (mm) & 1,20 & 1,50 & 1,90 & 2,65 & 3,35 \\
\hline Número de passes & \multicolumn{5}{|c|}{1} \\
\hline Classificação do eletrodo segundo a AWS & \multicolumn{5}{|c|}{ E6010; E6011 } \\
\hline Diâmetro do eletrodo (mm) & 2,4 & 3,2 & 3,2 & 4,0 & 4,8 \\
\hline Corrente (A) & $40-50$ & $70-100$ & $80-105$ & $120-130$ & $135-145$ \\
\hline Velocidade de soldagem (cm/min) & $50-65$ & $70-90$ & $65-80$ & $50-75$ & $45-70$ \\
\hline
\end{tabular}

(b) Posição plana; soldagem de topo com chanfro em V (fig. B).

\begin{tabular}{|l|c|c|c|}
\hline Espessura do material $(\mathrm{mm})$ & 8,0 & 9,5 & 12,7 \\
\hline
\end{tabular}




\begin{tabular}{|l|c|c|c|c|c|c|c|}
\hline Número de passes & 1 & 2 & 1 & 2 e 3 & 1 & 2 & 3 \\
\hline $\begin{array}{l}\text { Classificação do eletrodo } \\
\text { segundo a AWS }\end{array}$ & E6011 & E6027 & E6011 & E6027 & E6011 & E6011 & E6027 \\
\hline Diâmetro do eletrodo (mm) & 4,0 & 4,0 & 4,0 & 4,0 & 4,0 & 6,4 & 6,4 \\
\hline Corrente (A) de soldagem & 135 & 240 & 135 & 240 & 135 & 275 & 400 \\
\hline $\begin{array}{l}\text { Velocidade } \\
(\mathrm{cm} / \mathrm{min})\end{array}$ & $15-20-35$ & $15-20$ & $30-35$ & $15-20$ & $20-25$ & $25-30$ \\
\hline
\end{tabular}

TABELA 2-6 Recomendações para a soldagem de aço-carbono, pelo processo SMAW. Adaptada de WAINER et al. [ 72 ]

(c) Posição plana e horizontal; soldagem em ângulo (fig. C).

continuação

\begin{tabular}{|l|c|c|c|c|c|}
\hline Espessura do material (mm) & 1,20 & 1,50 & 1,90 & 2,65 & 3,35 \\
\hline Número de passes & \multicolumn{5}{|c|}{1} \\
\hline Classificação do eletrodo segundo a AWS & E6013 & \multicolumn{4}{|c|}{ E6012; E6013 } \\
\hline Diâmetro do eletrodo (mm) & 2,4 & 3,2 & 4,0 & 4,$8 ; 4,0$ & 4,8 \\
\hline Corrente (A) & 70 & $95-105$ & $140-155$ & $160-190$ & $200-210$ \\
\hline Velocidade de soldagem (cm/min) & $35-45$ & $35-50$ & $40-50$ & $35-60$ & $35-50$ \\
\hline
\end{tabular}

(d) Posição plana; soldagem em ângulo (fig. D).

\begin{tabular}{|c|c|c|c|c|c|}
\hline Perna da solda (mm) & $\overline{6,4}$ & & 7,1 & 8,0 & 9,5 \\
\hline Espessura do material $(\mathrm{mm})$ & 8,0 & & 9,5 & & 12,7 \\
\hline Número de passes & \multicolumn{5}{|c|}{1} \\
\hline Classificação do eletrodo segundo a AWS & \multicolumn{5}{|c|}{ E7024 } \\
\hline Diâmetro do eletrodo $(\mathrm{mm})$ & 4,8 & 5,6 & 6,4 & 6,4 & 8,0 \\
\hline Corrente (A) & 275 & 325 & 375 & 375 & 475 \\
\hline Velocidade de soldagem $(\mathrm{cm} / \mathrm{min})$ & $35-40$ & $40-45$ & $35-40$ & $35-40$ & $28-30$ \\
\hline
\end{tabular}

(e) Soldagem de topo, vertical, descendente (fig. E).

\begin{tabular}{|l|c|c|c|c|c|}
\hline Espessura do material (mm) & 1,20 & 1,50 & 1,90 & 2,65 & 3,35 \\
\hline Número de passes & \multicolumn{5}{|c|}{1} \\
\hline Classificação do eletrodo segundo a AWS & \multicolumn{5}{|c|}{ E6010; E6011 } \\
\hline Diâmetro do eletrodo (mm) & 2,4 & 3,2 & 3,2 & 4,0 & 4,8 \\
\hline Corrente (A) A & $45-55$ & $75-110$ & $90-115$ & $130-140$ & $150-155$ \\
\hline Velocidade de soldagem (cm/min) & $60-75$ & $75-95$ & $70-80$ & $55-80$ & $45-75$ \\
\hline
\end{tabular}

(f) Soldagem de topo com chanfro em V, na posição sobrecabeça (fig. F).

\begin{tabular}{|l|c|c|c|c|c|c|c|c|c|c|}
\hline $\begin{array}{l}\text { Espessura do material } \\
\text { (mm) }\end{array}$ & \multicolumn{2}{|c|}{8,0} & \multicolumn{2}{c|}{9,5} & \multicolumn{2}{c|}{12,7} & \multicolumn{2}{c|}{19,1} & \multicolumn{2}{c|}{25,4} \\
\hline Número de passes & 1 & 2 & 1 & $2-3$ & 1 & $2-5$ & 1 & $2-9$ & 1 & $2-13$ \\
\hline $\begin{array}{l}\text { Classificação do eletrodo } \\
\text { segundo a AWS }\end{array}$ & E6010 & E7018 & E6010 & E7018 & E6010 & E7018 & E6010 & E7018 & E6010 & E7018 \\
\hline $\begin{array}{l}\text { Diâmetro do eletrodo } \\
\text { (mm) }\end{array}$ & 3,2 & 4,0 & 3,2 & 4,0 & 3,2 & 4,0 & 3,2 & 4,0 & 3,2 & 4,0 \\
\hline Corrente (A) & 110 & 170 & 110 & 170 & 110 & 170 & 110 & 170 & 110 & 170 \\
\hline $\begin{array}{l}\text { Velocidade de soldagem } \\
\text { (cm/min) }\end{array}$ & 11 & 9 & 11 & 9 & 11 & 10 & 11 & 11 & 11 & 10 \\
\hline
\end{tabular}

(g) Soldagem em ângulo na posição sobrecabeça (fig. G).

\begin{tabular}{|c|c|c|c|c|c|c|c|c|}
\hline Perna da solda $(\mathrm{mm})$ & 4,0 & 4,8 & 6,4 & 8,0 & 9,5 & 12,7 & 15,9 & 19,1 \\
\hline $\begin{array}{l}\text { Espessura do material } \\
(\mathrm{mm})\end{array}$ & 4,8 & 6,4 & 8,0 & 9,5 & 12,7 & 15,9 & 19,1 & 25,4 \\
\hline Número de passes & 1 & 1 & 1 & $1-2$ & $1-3$ & $1-6$ & $1-10$ & $1-15$ \\
\hline $\begin{array}{l}\text { Classificação do eletrodo } \\
\text { segundo a AWS }\end{array}$ & \multicolumn{8}{|c|}{ E6010 } \\
\hline $\begin{array}{l}\text { Diâmetro do eletrodo } \\
(\mathrm{mm})\end{array}$ & 4,0 & \multicolumn{7}{|c|}{4,8} \\
\hline Corrente (A) & 130 & \multicolumn{7}{|c|}{170} \\
\hline $\begin{array}{l}\text { Velocidade de soldagem } \\
\text { no } 1^{\circ} \text { passe }(\mathrm{cm} / \mathrm{min})\end{array}$ & $18-20$ & $22-24$ & $12-13$ & \multicolumn{5}{|c|}{$17-19$} \\
\hline
\end{tabular}


Os revestimentos dos eletrodos, segundo QUITES \& DUTRA [ 57 ], podem ser reunidos em três grupos: os revestimentos a base mineral, que protegem o metal de solda dos efeitos nocivos do oxigênio e nitrogênio do ar; os revestimentos a base de matéria orgânica, que protegem por meio de uma cortina gasosa; e os revestimentos a base de carbonato de cálcio, que protegem pelos dois meios. Dentro de cada um desses grupos, têm-se ainda tipos particulares indicados a seguir:

- revestimento oxidante, composto principalmente de óxido de ferro e manganês; produz uma escória espessa, compacta e facilmente destacável; produz cordões de bom aspecto; é usado para soldas "sem responsabilidade"; obtém-se pequena penetração.

- revestimento ácido, composto a base de óxido de ferro, óxido de manganês e sílica; produz uma escória abundante de fácil remoção; indicado somente na posição plana; obtém-se média penetração. Apresentam bons fluxos estabilizadores e produzem uma solda de excelente qualidade de contorno. Todavia, a solda muitas vezes terá alto conteúdo de oxigênio, hidrogênio e silício com conseqüente baixa resistência e dureza.

- revestimento rutílico; possui uma grande quantidade de rutilo $\left(\mathrm{TiO}_{2}\right)$; produz uma escória espessa, compacta, facilmente descartável e cordões de bom aspecto; soldável em todas as posições; obtém-se penetração média ou pequena; por sua versatilidade é chamado de eletrodo universal.

- revestimento titânico; derivado do tipo rutílico, porém com um mais alto teor de óxido de titânio e com escória mais fluida; obtém-se média penetração.

- revestimento básico; possui grande quantidade de carbonato de cálcio e possui um baixo teor de hidrogênio; produz pouca escória e com aspecto vítreo; o material depositado possui boas características mecânicas; é aplicado em soldagens de grande responsabilidade e de grandes espessuras; obtém-se média penetração.

- revestimento celulósico; contém grandes quantidades de substâncias orgânicas combustíveis; produz grandes quantidades de gases protetores e pouca escória; a soldagem com esse revestimento é difícil em virtude dos gases formados não serem de fácil ionização; produz muito salpico, resultando uma solda de mau aspecto; obtém-se grande penetração, porém com aumento do nível de hidrogênio e da probabilidade de ocorrer trincas. 
Os fluxo para arames com fluxo no núcleo, para uso sem qualquer gás de proteção, não segue a classificação esboçada anteriormente. Todos eles contém fluoreto de cálcio para dar proteção de gás fluoreto e alguns contém carbonato de cálcio para originar dióxido de carbono. Em alguns, a desoxidação é conduzida pelo alumínio, em outros pelo pó de ferro. Rutilo é algumas vezes usado.

Segundo ENGINEERING FOR STEEL CONSTRUCTION [ 2 ], de uma maneira mais específica, temos que os eletrodos para soldagem SMAW são feitos de uma variedade de composições de baixo carbono, a partir de um mínimo de 0,05\% para um limite entre $0,07 \%$ a $0,15 \%$. O revestimento do eletrodo é composto de uma mistura de silicatos aglutinantes e materiais pulverizados, tal como fluoretos, carbonatos, óxidos, ligas de metal e celulose.

Para soldagem de aços de baixa liga ou de alto carbono, eletrodos de baixo hidrogênio são requeridos pela AWS para serem usados no processo SMAW para todos os aços.

Quanto maior a resistência à tração de um aço soldado, mais baixa deve ser a umidade do revestimento do eletrodo para evitar a fissura da solda. Para isso, tem-se os eletrodos de baixo hidrogênio (E7015, E7016, E7018 e E7028) que contém carbonato de sódio como revestimento, e possuem uma limitada umidade (hidrogênio) em teor de peso. Os revestimentos das séries E70 podem conter uma máxima umidade de 0,04\%, mas as séries E120 são limitadas em somente 0,015\%.

Combinações de fluxo e eletrodos para SAW são cobertos pela AWS A5.23 e AWS A5.17. Segundo CUNHA [ 20 ], um fluxo para soldagem SAW (F $\underline{X} \underline{X}$ ) é designado pela letra $\mathrm{F}$ seguida por dois dígitos denotando a mínima resistência à tração do metal de solda depositado, resultante da combinação do fluxo com determinada classificação de eletrodo (ver tabela 2-7). O outro dígito indica a menor temperatura na qual a resistência ao impacto do metal de solda depositado, iguala ou excede $27 \mathrm{~J}$ no ensaio de impacto Charpy de chanfro $\mathrm{V}$, onde os números $0,2,4,5,6$ e 8 referentes a este dígito, referem-se às temperaturas de ensaio mínimas de $-18^{\circ} \mathrm{C}$, $29^{\circ} \mathrm{C},-40^{\circ} \mathrm{C},-46^{\circ} \mathrm{C},-51^{\circ} \mathrm{C},-62^{\circ} \mathrm{C}$, respectivamente, para a obtenção do mínimo nível de energia de $27 \mathrm{~J}$. A letra $\mathrm{Z}$ indica que o ensaio de impacto não é requerido. 


\begin{tabular}{|c|c|c|c|}
\hline Classificação do fluxo & $\begin{array}{c}\text { Resistência à tração } \\
(\mathrm{MPa})\end{array}$ & $\begin{array}{c}\text { Limite de escoamento* } \\
(\mathrm{MPa})\end{array}$ & $\begin{array}{c}\text { Alongamento mínimo* } \\
(\%)\end{array}$ \\
\hline F6X-EXXXX & $414-552$ & 351 & 22 \\
\hline F7X-EXXXX & $483-655$ & 400 & 22 \\
\hline
\end{tabular}

* Limite de escoamento mínimo (offset $0,2 \%$ ) e alongamento medido em comprimento padrão de $51 \mathrm{~mm}$.

Esta classificação é seguida por uma série de letras e números denotando o eletrodo usado (E $\underline{\mathrm{XXXX}})$, para classificar o fluxo. A letra E representa “eletrodo", os próximos dígitos que variam de dois a quatro referem-se a composição química do eletrodo (L, M, H significam eletrodos de baixo teor de manganês, médio teor de manganês, e alto teor de manganês, respectivamente; $\mathrm{K}$ significa eletrodo de aço acalmado ao silício). A tabela 2-8 fornece a composição química desses eletrodos, em porcentagem.

Segundo o ENGINEERING FOR STEEL CONSTRUCTION [ 2 ], os fluxos para esse processo podem ser tanto fundidos quanto aglomerados, que são constituintes finamente triturados "colados" junto a silicatos. Esses fluxos devem ser adequadamente armazenados para evitar umidade.

De acordo com a AWS e segundo QUITES \& DUTRA [ 57 ], os fluxos são classificados de acordo com as propriedades mecânicas do material depositado por um determinado eletrodo, em combinação com o fluxo.

TABELA 2-8 Composição química de eletrodos para soldagem SAW. Adaptada de CUNHA [ 20 ].

\begin{tabular}{|c|c|c|c|}
\hline $\begin{array}{c}\text { Classificação } \\
\text { AWS }\end{array}$ & Carbono & Manganês & Silício \\
\hline $\begin{array}{c}\text { Baixo Manganês } \\
\text { EL8 } \\
\text { EL8K } \\
\text { EL12 }\end{array}$ & $\begin{array}{c}0,10 \\
0,10 \\
0,07 \text { a } 0,15\end{array}$ & $\begin{array}{l}0,30 \text { a } 0,55 \\
0,30 \text { a } 0,55 \\
0,35 \text { a } 0,60\end{array}$ & $\begin{array}{c}0,05 \\
0,10 \text { a } 0,20 \\
0,05\end{array}$ \\
\hline $\begin{array}{c}\text { Médio Manganês } \\
\text { EM5K * } \\
\text { EM12 } \\
\text { EM12K } \\
\text { EM13K } \\
\text { EM15K }\end{array}$ & $\begin{array}{c}0,06 \\
0,07 \text { a } 0,15 \\
0,07 \text { a } 0,15 \\
0,07 \text { a } 0,19 \\
0,12 \text { a } 0,20\end{array}$ & $\begin{array}{l}0,90 \text { a } 1,40 \\
0,85 \text { a } 1,25 \\
0,85 \text { a } 1,25 \\
0,90 \text { a } 1,40 \\
0,85 \text { a } 1,25\end{array}$ & $\begin{array}{c}0,40 \text { a } 0,70 \\
0,05 \\
0,15 \text { a } 0,35 \\
0,45 \text { a } 0,70 \\
0,15 \text { a } 0,35\end{array}$ \\
\hline $\begin{array}{c}\text { Alto Manganês } \\
\text { EH14 }\end{array}$ & a $0,18^{0,10}$ & 1,75 a 2,25 & 0,05 \\
\hline
\end{tabular}

* Este eletrodo possui ainda $0,035 \%$ de enxofre; $0,03 \%$ de fósforo; $0,15 \%$ de cobre; 0,05 a $0,15 \%$ de titânio; 0,02 a $0,12 \%$ de zircônio; e 0,05 a $0,15 \%$ de alumínio, além de $0,5 \%$ de outros elementos.

Segundo WAINER et al. [ 72 ], a tabela 2-9 apresenta alguns parâmetros de soldagem para arco submerso automático, tomando-se como base as juntas mostradas. 
TABELA 2-9 Parâmetros para soldagem de aço-carbono com soldagem SAW automática. Adaptada de WAINER et al. [ 72 ].

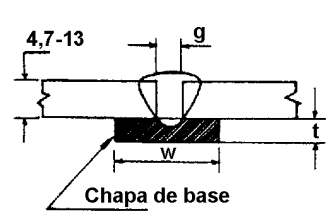

(A)

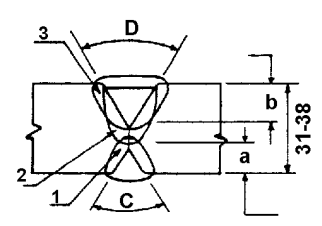

(D)

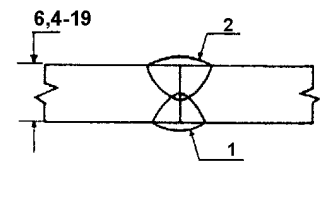

(B)

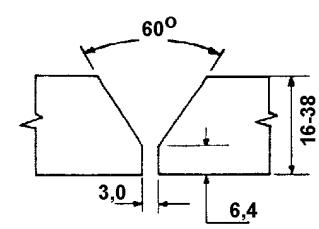

(E)
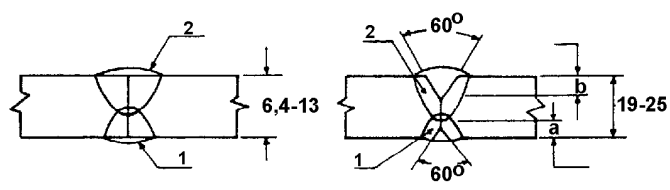

(C)

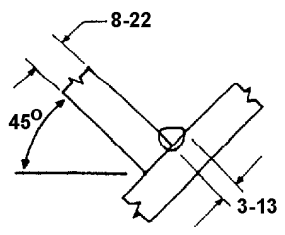

(F)

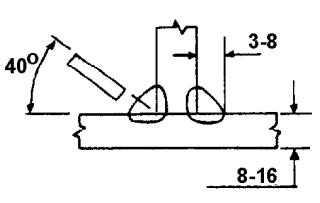

(G)

(a) Soldagem usando eletrodo nu de $\phi$ de 4,8 mm, para junta de topo com chapa de base de aço, fig. (A). Soldagem em um único passe. Posição de soldagem plana.

\begin{tabular}{|c|c|c|c|c|c|c|}
\hline $\begin{array}{c}\text { Espessura da } \\
\text { chapa e (mm) }\end{array}$ & Corrente (A) CCPR (+) & Tensão (V) & Velocidade (cm/min) & $\mathrm{t}(\mathrm{mm})$ & $\mathrm{w}(\mathrm{mm})$ & Folga g (mm) \\
\hline 4,8 & 800 & 32 & 125 & 4,8 & 20 & 2,4 \\
\hline 6,4 & 850 & 33 & 82 & 6,4 & 25 & 3,2 \\
\hline 9,5 & 900 & 34 & 60 & 8,0 & 25 & 4,0 \\
\hline 12,7 & 1000 & 35 & 42 & 9,5 & 25 & 4,8 \\
\hline
\end{tabular}

(b)Soldagem usando eletrodo nu de $\phi$ de 4,8 mm, para junta de topo, fig. (B). Posição de soldagem plana.

\begin{tabular}{|c|c|c|c|c|}
\hline Espessura da chapa e (mm) & Corrente (A) CCPR $(+)$ & Tensão (V) & Velocidade $(\mathrm{cm} / \mathrm{min})$ & Passe \\
\hline 6,4 & 600 & 31 & 175 & 1 \\
\hline 6,4 & 750 & 33 & 175 & 2 \\
\hline 9,5 & 650 & 33 & 120 & 1 \\
\hline 9,5 & 800 & 35 & 120 & 1 \\
\hline 12,7 & 750 & 35 & 87 & 2 \\
\hline 12,7 & 850 & 36 & 87 & 1 \\
\hline 16,0 & 750 & 35 & 60 & 2 \\
\hline 16,0 & 850 & 36 & 60 & 1 \\
\hline 19,0 & 800 & 36 & 55 & 2 \\
\hline 19,0 & 900 & 37 & 55 & \\
\hline
\end{tabular}

(c) Soldagem com eletrodo nu, para junta de topo, fig. (C). Posição de soldagem plana.

\begin{tabular}{|c|c|c|c|c|c|c|c|}
\hline $\begin{array}{c}\text { Espessura da } \\
\text { chapa e }(\mathrm{mm})\end{array}$ & $\begin{array}{c}\text { Diâmetro do } \\
\text { eletrodo (mm) }\end{array}$ & Passe & $\begin{array}{c}\text { Corrente (A) } \\
\text { CCPR }(+)\end{array}$ & $\begin{array}{c}\text { Tensão } \\
(\mathrm{V})\end{array}$ & $\begin{array}{c}\text { Velocidade } \\
(\mathrm{cm} / \mathrm{min})\end{array}$ & $\begin{array}{c}\text { Profundidade a } \\
(\mathrm{mm})\end{array}$ & $\begin{array}{c}\text { Profundidade b } \\
(\mathrm{mm})\end{array}$ \\
\hline 6,4 & 4,0 & 1 & 475 & 29 & 120 & - & - \\
\hline 6,4 & 4,0 & 2 & 575 & 32 & 120 & - & - \\
\hline 12,7 & 4,8 & 1 & 700 & 35 & 67 & - & - \\
\hline 12,7 & 4,8 & 2 & 950 & 36 & 67 & - & - \\
\hline 19,0 & 4,8 & 1 & 700 & 35 & 75 & 3,0 & 10,0 \\
\hline
\end{tabular}




\begin{tabular}{|l|l|l|l|l|l|l|l|}
\hline 19,0 & 4,8 & 2 & 950 & 36 & 40 & 3,0 & 10,0 \\
\hline 25,0 & 4,8 & 1 & 850 & 35 & 34 & 10,0 & 10,0 \\
\hline 25,0 & 4,8 & 2 & 1000 & 36 & 42 & 10,0 & 10,0 \\
\hline
\end{tabular}

(d) Soldagem com eletrodo nu com $\phi$ de 4,8 mm, para junta de topo, fig. (D). Posição de soldagem plana.

\begin{tabular}{|c|c|c|c|c|c|c|c|c|}
\hline $\begin{array}{c}\text { Espessura da } \\
\text { chapa e (mm) }\end{array}$ & Passe & Corrente (A) & $\begin{array}{c}\text { Tensão } \\
(\mathrm{V})\end{array}$ & $\begin{array}{c}\text { Velocidade } \\
(\mathrm{cm} / \mathrm{min})\end{array}$ & $\begin{array}{c}\text { Profundidade a } \\
(\mathrm{mm})\end{array}$ & $\begin{array}{c}\text { Profundidade b } \\
(\mathrm{mm})\end{array}$ & $\begin{array}{c}\text { Ângulo } \\
\mathrm{C}\end{array}$ & $\begin{array}{c}\text { Angulo } \\
\mathrm{D}\end{array}$ \\
\hline 31,0 & 1 & 850 & 35 & 34 & 10,0 & 16,0 & $60^{\circ}$ & $70^{\circ}$ \\
\hline 31,0 & 2 & 1000 & 36 & 30 & 10,0 & 16,0 & $60^{\circ}$ & $70^{\circ}$ \\
\hline 31,0 & 3 & 850 & 35 & 22 & 10,0 & 16,0 & $60^{\circ}$ & $70^{\circ}$ \\
\hline 38,0 & 1 & 1000 & 36 & 22 & 13,0 & 16,0 & $70^{\circ}$ & $90^{\circ}$ \\
\hline 38,0 & 2 & 1000 & 36 & 25 & 13,0 & 16,0 & $70^{\circ}$ & $90^{\circ}$ \\
\hline 38,0 & 3 & 950 & 34 & 28 & 13,0 & 16,0 & $70^{\circ}$ & $90^{\circ}$ \\
\hline
\end{tabular}

TABELA 2-9 Parâmetros para soldagem de aço-carbono com soldagem SAW automática. Adaptada de WAINER et al. [ 72 ].

continuação

(e) Soldagem com eletrodo nu com $\phi$ de 4,0 mm, com chanfro em V, fig. (E). Corrente: 550 A CCPR (+); tensão: 28 V; velocidade: $40 \mathrm{~cm} / \mathrm{min}$. Posição de soldagem plana.

\begin{tabular}{|c|c|c|c|}
\hline Espessura da chapa e (mm) & 16,0 & 25,0 & 38,0 \\
\hline Passe & $2-7$ & $2-14$ & $2-28$ \\
\hline
\end{tabular}

OBS.: o primeiro passe deve ser feito com eletrodo revestido (E7018), de diâmetro $4 \mathrm{~mm}, 16 \mathrm{~A}, 23 \mathrm{~V}, 20 \mathrm{~cm} / \mathrm{min}$.

(f) Soldagem com eletrodo nu, para soldas em ângulo, fig. (F). Soldagem em um só passe. Posição de soldagem plana.

\begin{tabular}{|c|c|c|c|c|c|}
\hline $\begin{array}{l}\text { Espessura da } \\
\text { chapa e (mm) }\end{array}$ & $\begin{array}{l}\text { Tamanho do } \\
\text { filete } \mathrm{f}(\mathrm{mm})\end{array}$ & $\begin{array}{l}\text { Diâmetro do eletrodo } \\
(\mathrm{mm})\end{array}$ & Corrente (A) CCPR (+) & Tensão (V) & $\begin{array}{c}\text { Velocidade } \\
(\mathrm{cm} / \mathrm{min})\end{array}$ \\
\hline 8,0 & 3,2 & 3,2 & 425 & 26 & 150 \\
\hline 9,5 & 4,8 & 4,0 & 575 & 28 & 100 \\
\hline 12,7 & 6,4 & 4,8 & 675 & 31 & 75 \\
\hline 16,0 & 8,0 & 4,8 & 775 & 34 & 55 \\
\hline 19,0 & 9,5 & 4,8 & 850 & 35 & 45 \\
\hline 22,0 & 12,7 & 4,8 & 950 & 36 & 30 \\
\hline 25,0 & 16,0 & 4,8 & 1000 & 37 & 22 \\
\hline 32,0 & 19,0 & 4,8 & 1000 & 38 & 17 \\
\hline
\end{tabular}

(g) Soldas em ângulo em um único passe, fig. (G). Posição de soldagem plana.

\begin{tabular}{|c|c|c|c|c|c|}
\hline $\begin{array}{l}\text { Espessura da } \\
\text { chapa e }(\mathrm{mm})\end{array}$ & $\begin{array}{l}\text { Tamanho do } \\
\text { filete } \mathrm{f}(\mathrm{mm})\end{array}$ & $\begin{array}{l}\text { Diâmetro do eletrodo } \\
(\mathrm{mm})\end{array}$ & Corrente (A) CCPR (+) & Tensão (V) & $\begin{array}{c}\text { Velocidade } \\
(\mathrm{cm} / \mathrm{min})\end{array}$ \\
\hline 8,0 & 3,2 & 3,2 & 425 & 23 & 125 \\
\hline 9,5 & 4,0 & 3,2 & 420 & 25 & 105 \\
\hline 11,0 & 4,8 & 3,2 & 450 & 27 & 85 \\
\hline 12,7 & 6,4 & 4,0 & 525 & 28 & 60 \\
\hline 16,0 & 8,0 & 4,0 & 575 & 30 & 40 \\
\hline
\end{tabular}

Os eletrodos para soldagem GMAW são cobertos pela AWS A5.28 e AWS A5.18. Esses eletrodos possuem a seguinte denominação ER XX S-X, a letra E representa "eletrodo", $\mathrm{R}$ significa arame nu (pode ser usado arame alimentado com independente fonte de aquecimento, ou seja, arco tungstênio), os dois dígitos seguintes identificam a mínima resistência à tração, em ksi e a letra $\mathrm{S}$ significa eletrodo sólido (pode existir eletrodo com fluxo no núcleo), já o último número identifica a composição química do material.

A tabela 2-10 retirada da AWS 5.18 e mostrada por WAINER et al. [ 72 ], apresenta a classificação de eletrodos nus de aço-carbono, fornecendo sua 
composição química tanto para soldagem TIG, quanto para MIG/MAG, além disso indica requisitos necessários das propriedades mecânicas para os metais de adição.

TABELA 2-10 Composição química dos eletrodos nus para soldar aço-carbono e requisitos de propriedades mecânicas dos cordões de solda em CCPR $(+)$ (soldagem TIG e MIG/MAG). Adaptada de WAINER et al. [ 72 ].

\begin{tabular}{|c|c|c|c|c|c|c|c|c|}
\hline \multirow[t]{2}{*}{$\begin{array}{l}\text { Classificação } \\
\text { AWS }\end{array}$} & \multicolumn{3}{|c|}{$\begin{array}{c}\text { Composição química (\% em } \\
\text { peso) })^{\text {(a) (b) }}\end{array}$} & \multirow[t]{2}{*}{$\begin{array}{c}\text { Gás de } \\
\text { proteção }\end{array}$} & \multirow{2}{*}{$\begin{array}{l}\text { Limite de } \\
\text { resistência } \\
\mathrm{MPa} \\
\end{array}$} & \multirow{2}{*}{$\begin{array}{c}\text { Limite de } \\
\text { escoamento em } \\
0,2 \% \mathrm{MPa} \\
\end{array}$} & \multirow[t]{2}{*}{$\begin{array}{l}\text { Alongamento } \\
\text { em } 50 \mathrm{~mm} \%\end{array}$} & \multirow{2}{*}{$\begin{array}{l}\text { Requisito } \\
\text { mínimo de } \\
\text { impacto }\end{array}$} \\
\hline & $\mathrm{C}$ & $\mathrm{Mn}$ & $\mathrm{Si}$ & & & & & \\
\hline ER70S-2 ${ }^{(\mathrm{c})}$ & $\begin{array}{l}0,07 \\
\text { máx. }\end{array}$ & $\begin{array}{c}0,90 \mathrm{a} \\
1,40\end{array}$ & $\begin{array}{c}0,40 \mathrm{a} \\
0,70\end{array}$ & $\mathrm{CO}_{2}$ & $\geq 500$ & $\geq 420$ & $\geq 22$ & $27 \mathrm{~J} \mathrm{a}-29^{\circ} \mathrm{C}$ \\
\hline ER70S-3 & $\begin{array}{c}0,06 \text { a } \\
0,15\end{array}$ & $\begin{array}{c}0,90 \mathrm{a} \\
1,40 \\
\end{array}$ & $\begin{array}{c}0,45 \mathrm{a} \\
0,70 \\
\end{array}$ & $\mathrm{CO}_{2}$ & $\geq 500$ & $\geq 420$ & $\geq 22$ & $27 \mathrm{~J} \mathrm{a}-18^{\circ} \mathrm{C}$ \\
\hline ER70S-4 & $\begin{array}{c}0,07 \text { a } \\
0,15\end{array}$ & $\begin{array}{c}1,00 \mathrm{a} \\
1,50\end{array}$ & $\begin{array}{c}0,65 \mathrm{a} \\
0,80\end{array}$ & $\mathrm{CO}_{2}$ & $\geq 500$ & $\geq 420$ & $\geq 22$ & não se aplica \\
\hline ER70S-5 ${ }^{(\mathrm{d})}$ & $\begin{array}{c}0,07 \text { a } \\
0,19\end{array}$ & $\begin{array}{c}0,90 \mathrm{a} \\
1,40 \\
\end{array}$ & $\begin{array}{c}0,30 \mathrm{a} \\
0,60 \\
\end{array}$ & $\mathrm{CO}_{2}$ & $\geq 500$ & $\geq 420$ & $\geq 22$ & não se aplica \\
\hline ER70S-6 & $\begin{array}{c}0,07 \text { a } \\
0,15\end{array}$ & $\begin{array}{c}1,40 \mathrm{a} \\
1,85\end{array}$ & $\begin{array}{c}0,80 \mathrm{a} \\
1,15\end{array}$ & $\mathrm{CO}_{2}$ & $\geq 500$ & $\geq 420$ & $\geq 22$ & $27 \mathrm{~J} \mathrm{a}-29^{\circ} \mathrm{C}$ \\
\hline ER70S-7 & $\begin{array}{c}0,07 \text { a } \\
0,15\end{array}$ & $\begin{array}{c}1,50 \mathrm{a} \\
2,00\end{array}$ & $\begin{array}{c}0,50 \mathrm{a} \\
0,80 \\
\end{array}$ & $\mathrm{CO}_{2}$ & $\geq 500$ & $\geq 420$ & $\geq 22$ & $27 \mathrm{~J} \mathrm{a}-18^{\circ} \mathrm{C}$ \\
\hline ER70S-G & \multicolumn{3}{|c|}{$\begin{array}{l}\text { Sem requisitos de análise } \\
\text { química, por acordo entre } \\
\text { fabricante e usuário }\end{array}$} & $\begin{array}{l}\text { Por acordo } \\
\text { entre } \\
\text { fabricante } \\
\text { e usuário }\end{array}$ & $\geq 500$ & $\geq 420$ & $\geq 22$ & $\begin{array}{c}\text { Por acordo } \\
\text { entre } \\
\text { fabricante e } \\
\text { usuário }\end{array}$ \\
\hline
\end{tabular}

(a) Em todos os tipos especificados $\mathrm{P} \leq 0,025 \%$; $\mathrm{S} \leq 0,035 \%$; $\mathrm{Cu} \leq 0,5 \%$

(b) Níquel, cromo, molibdênio e vanádio podem estar presentes, mas não devem ser adicionados intencionalmente

(c) Possui também 0,05 a $0,15 \%$ de Ti; 0,02 a $0,12 \%$ de $\mathrm{Zr}$; e 0,05 a $0,15 \%$ de $\mathrm{Al}$

(d) Possui também 0,50 a $0,90 \%$ de $\mathrm{Al}$

Para a soldagem TIG, a tabela 2-11 mostra alguns dados para a soldagem de aço-carbono para as juntas de topo na posição plana mostrada.

TABELA 2-11 Valores recomendados para soldagem de aço-carbono, em soldagem TIG. Adaptada de WAINER et al. [ 72 ]. 


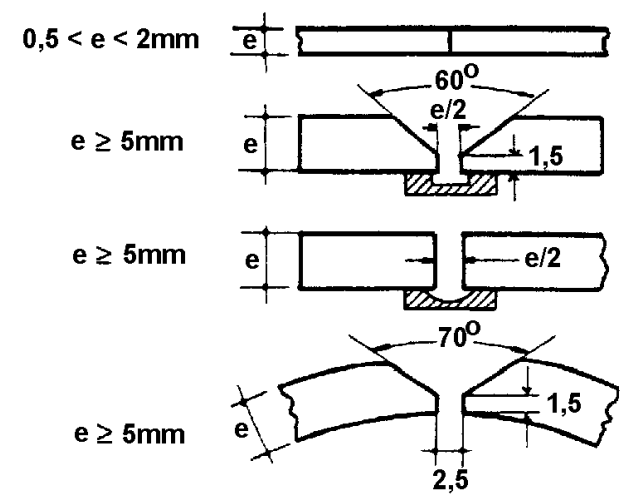

Juntas para aço carbono na posição plana, topo a topo

\begin{tabular}{|c|c|c|c|c|c|c|}
\hline Espessura (mm) & $\begin{array}{c}\text { Diâmetro do } \\
\text { eletrodo de } \\
\text { enchimento } \\
(\mathrm{mm})\end{array}$ & $\begin{array}{c}\text { Diâmetro do } \\
\text { eletrodo no } \\
\text { passe da raiz } \\
(\mathrm{mm})\end{array}$ & $\begin{array}{c}\text { Velocidade de } \\
\text { soldagem }(\mathrm{cm} / \mathrm{min})\end{array}$ & Corrente de & soldagem (A) & \multirow[t]{2}{*}{$\begin{array}{c}\text { Vazão de } \\
\text { argônio (1/min) }\end{array}$} \\
\hline & & & & Passe de raiz & Outros passes & \\
\hline 0,5 & 1,6 & - & $15-25$ & $15-20$ & $15-30$ & 4 \\
\hline 0,8 & 1,6 & - & $30-40$ & $25-30$ & $35-50$ & 4 \\
\hline 1,0 & 1,6 & 0,8 & $30-50$ & $25-35$ & $35-60$ & 4 \\
\hline 1,2 & 1,6 & 1,2 & $40-80$ & $35-70$ & $50-80$ & 4 \\
\hline 1,5 & 1,6 & 1,2 & $50-100$ & $50-70$ & $70-100$ & 5 \\
\hline 2,0 & 3,2 & 1,2 & $70-120$ & $70-90$ & $80-120$ & 5 \\
\hline
\end{tabular}

Segundo WAINER et al. [ 72 ], a tabela 2-12a apresenta sugestões de parâmetros de soldagem MAG com transferência por curto-circuito. Nas tabelas 2$12 \mathrm{~b}$ até 2-12e são fornecidas sugestões de parâmetros de soldagem MIG, levando em consideração transferência por borrifo. As tabelas 2-12f, 2-12g e 2-12h apresentam sugestões de parâmetros para soldagem MAG, levando em consideração transferência globular.

TABELA 2-12 Parâmetros para soldagem MIG/MAG. Adaptada de WAINER et al. [ 72 ].

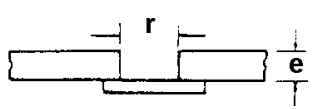

(A)

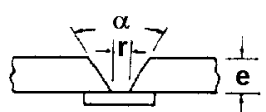

(B)

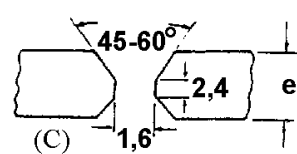

(C)

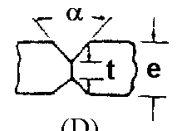

(D)

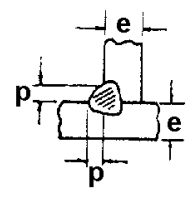

(E)

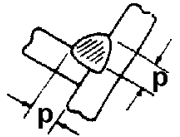

(F)

Tipos de juntas empregadas

(a) Parâmetros de soldagem em junta topo a topo na posição plana para aço-carbono ou de baixa liga. (preparação da junta A).

\begin{tabular}{|c|c|c|c|c|c|c|}
\hline e $(\mathrm{mm})$ & $\mathrm{r}(\mathrm{mm})$ & $\begin{array}{c}\phi \text { do eletrodo nu } \\
(\mathrm{mm})\end{array}$ & $\begin{array}{c}\text { Velocidade de alimentação do } \\
\text { eletrodo } \mathrm{nu}(\mathrm{m} / \mathrm{min})\end{array}$ & Corrente (A) & $\begin{array}{c}\text { Tensão } \\
(\mathrm{V})\end{array}$ & $\begin{array}{c}\text { Velocidade de } \\
\text { soldagem }(\mathrm{cm} / \mathrm{min})\end{array}$ \\
\hline 1,6 & 0,8 & 0,8 & 6,6 & $110-130$ & 19 & 63 \\
\hline 1,6 & 1,6 & 1,2 & 4,3 & $140-160$ & 20 & 89 \\
\hline
\end{tabular}




\begin{tabular}{|l|l|l|l|l|l|l|}
\hline 3,0 & 1,2 & 0,8 & 7,6 & $120-140$ & 21 & 51 \\
\hline 3,0 & 1,6 & 1,2 & 4,3 & $140-160$ & 21 & 63 \\
\hline
\end{tabular}

OBS.: o gás de proteção é o $\mathrm{CO}_{2}$ puro, com vazão de 15 a $20 \mathrm{l} / \mathrm{min}$; a distância entre o tubo de contato e a peça é de $6 \mathrm{~mm}$; soldagem em apenas um passe.

(b) Parâmetros de soldagem em junta topo a topo na posição plana para aço-carbono ou de baixa liga. (preparação da junta A).

\begin{tabular}{|c|c|c|c|c|c|c|}
\hline $\mathrm{e}(\mathrm{mm})$ & $\mathrm{r}(\mathrm{mm})$ & $\begin{array}{c}\phi \text { do eletrodo nu } \\
(\mathrm{mm})\end{array}$ & $\begin{array}{c}\text { Velocidade de alimentação do } \\
\text { eletrodo nu }(\mathrm{m} / \mathrm{min})\end{array}$ & Corrente (A) & $\begin{array}{c}\text { Número } \\
\text { de passes }\end{array}$ & $\begin{array}{c}\text { Velocidade de } \\
\text { soldagem }(\mathrm{cm} / \mathrm{min})\end{array}$ \\
\hline 3,2 & 1,6 & 0,9 & 9,2 & $180-200$ & 1 & 57 \\
\hline 4.8 & 0 & 1,6 & 4,8 & $340-410$ & 2 & 64 \\
\hline 6,4 & 4,8 & 1,6 & 4,8 & $300-340$ & 1 & 24 \\
\hline
\end{tabular}

OBS.: o gás de proteção é o argônio com $5 \%$ de oxigênio, com vazão de 18 a 25 1/min; a distância entre o tubo de contato e a peça é de 12 a $16 \mathrm{~mm}$; tensão de 26 a $27 \mathrm{~V}$.

(c) Parâmetros de soldagem em junta topo a topo na posição plana para aço-carbono ou de baixa liga. (preparação da junta B), com $\mathrm{r}=2,4 \mathrm{~mm}$ e $\left.\alpha=45-60^{\circ}\right)$.

\begin{tabular}{|c|c|c|c|c|c|c|}
\hline $\mathrm{e}(\mathrm{mm})$ & $\begin{array}{c}\text { Número } \\
\text { de passes }\end{array}$ & $\begin{array}{c}\phi \text { do eletrodo nu } \\
(\mathrm{mm})\end{array}$ & $\begin{array}{c}\text { Velocidade de alimentação do } \\
\text { eletrodo } \mathrm{nu}(\mathrm{m} / \mathrm{min})\end{array}$ & Corrente (A) & $\begin{array}{c}\text { Tensão } \\
(\mathrm{V})\end{array}$ & $\begin{array}{c}\text { Velocidade de } \\
\text { soldagem }(\mathrm{cm} / \mathrm{min})\end{array}$ \\
\hline 6,4 & 2 & 1,2 & 10,5 & $300-350$ & $29-31$ & 48 \\
\hline 6,4 & 2 & 1,6 & 4,5 & $280-320$ & $25-26$ & 36 \\
\hline 9,5 & 2 & 1,6 & 5,6 & $320-370$ & $26-27$ & 36 \\
\hline 12,7 & 4 & 1,6 & 5,1 & $300-350$ & $26-27$ & 48 \\
\hline
\end{tabular}

OBS.: o gás de proteção é o argônio com 5\% de oxigênio, com vazão de 18 a 25 1/min; a distância entre o tubo de contato e a peça é de 12 a $16 \mathrm{~mm}$

/continua

TABELA 2-12 Parâmetros para soldagem MIG/MAG. Adaptada de WAINER et al. [ 72 ]. continuação

(d) Parâmetros de soldagem em junta topo a topo na posição plana para aço-carbono ou de baixa liga. (preparação da junta C).

\begin{tabular}{|c|c|c|c|c|c|c|}
\hline e (mm) & $\begin{array}{c}\text { Número } \\
\text { de passes }\end{array}$ & $\begin{array}{c}\phi \text { do eletrodo nu } \\
(\mathrm{mm})\end{array}$ & $\begin{array}{c}\text { Velocidade de alimentação do } \\
\text { eletrodo } \mathrm{nu}(\mathrm{m} / \mathrm{min})\end{array}$ & Corrente (A) & $\begin{array}{c}\text { Tensão } \\
(\mathrm{V})\end{array}$ & $\begin{array}{c}\text { Velocidade de } \\
\text { soldagem }(\mathrm{cm} / \mathrm{min})\end{array}$ \\
\hline 9,5 & 2 & 1,2 & 9,5 & $280-330$ & $29-30$ & 36 \\
\hline 9,5 & 2 & 1,6 & 4,4 & $280-320$ & $25-26$ & 30 \\
\hline 12,7 & 4 & 1,6 & 4,8 & $300-340$ & $26-27$ & 48 \\
\hline 15,9 & 4 & 1,6 & 5,1 & $300-350$ & $26-27$ & 39 \\
\hline 19,1 & 4 & 1,6 & 5,1 & $300-350$ & $26-27$ & 36 \\
\hline
\end{tabular}

OBS.: o gás de proteção é o argônio com 5\% de oxigênio, com vazão de 18 a 25 1/min; a distância entre o tubo de contato e a peça é de 12 a $16 \mathrm{~mm}$.

(e) Parâmetros de soldagem em junta em ângulo na posição plana ou horizontal para aço-carbono ou de baixa liga. (preparação da junta E).

\begin{tabular}{|c|c|c|c|c|c|c|}
\hline $\mathrm{e}(\mathrm{mm})$ & $\mathrm{p}(\mathrm{mm})$ & $\begin{array}{c}\phi \text { do eletrodo nu } \\
(\mathrm{mm})\end{array}$ & $\begin{array}{c}\text { Velocidade de alimentação do } \\
\text { eletrodo nu }(\mathrm{m} / \mathrm{min})\end{array}$ & Corrente $(\mathrm{A})$ & $\begin{array}{c}\text { Tensão } \\
(\mathrm{V})\end{array}$ & $\begin{array}{c}\text { Velocidade de } \\
\text { soldagem }(\mathrm{cm} / \mathrm{min})\end{array}$ \\
\hline 6,4 & 4,7 & 1,2 & 8,9 & $260-320$ & $26-27$ & 63 \\
\hline 7,9 & 6,3 & 0,8 & 12,7 & $260-320$ & $26-27$ & 36 \\
\hline 7,9 & 6,3 & 1,2 & 9,5 & $270-330$ & $26-27$ & 46 \\
\hline 7,9 & 6,3 & 1,6 & 5,9 & $320-380$ & $25-26$ & 48 \\
\hline 9,5 & 7,8 & 0,8 & 15,2 & $260-320$ & $27-28$ & 25 \\
\hline 9,5 & 7,8 & 1,2 & 12,1 & $300-370$ & $27-28$ & 33 \\
\hline 9,5 & 7,8 & 1,6 & 5,9 & $320-380$ & $25-26$ & 30 \\
\hline 12,7 & 9,4 & 1,6 & 5,9 & $320-380$ & $25-26$ & 23 \\
\hline
\end{tabular}

OBS.: o gás de proteção é o argônio com $2 \%$ de oxigênio, com vazão de 18 a 25 1/min; a distância entre o tubo de contato e a peça é de 14 a $20 \mathrm{~mm}$.

(f) Parâmetros de soldagem em junta topo a topo na posição plana para aço-carbono. (preparação da junta $B, \operatorname{com} \alpha=40^{\circ}$ ).

\begin{tabular}{|c|c|c|c|c|c|c|c|}
\hline $\mathrm{e}(\mathrm{mm})$ & $\mathrm{r}(\mathrm{mm})$ & $\begin{array}{c}\phi \text { do eletrodo } \\
\mathrm{nu}(\mathrm{mm})\end{array}$ & $\begin{array}{c}\text { Velocidade de alimentação } \\
\text { do eletrodo nu }(\mathrm{m} / \mathrm{min})\end{array}$ & $\begin{array}{c}\text { Corrente } \\
(\mathrm{A})\end{array}$ & $\begin{array}{c}\text { Tensão } \\
(\mathrm{V})\end{array}$ & $\begin{array}{c}\text { Velocidade de } \\
\text { soldagem } \\
(\mathrm{cm} / \mathrm{min})\end{array}$ & $\begin{array}{c}\text { Distância tubo de } \\
\text { contato/peça } \\
(\mathrm{mm})\end{array}$ \\
\hline 6,4 & 3,2 & 1,2 & 13,0 & $300-340$ & 38 & 38 & 22 \\
\hline
\end{tabular}




\begin{tabular}{|l|l|l|l|l|l|l|l|}
\hline 10,0 & 3,2 & 1,2 & 12,7 & $290-330$ & 32 & 32 & 25 \\
\hline 10,0 & 3,2 & 1,6 & 10,3 & $370-430$ & 35 & 40 & 25 \\
\hline 12,0 & 2,4 & 1,2 & 12,7 & $280-320$ & 33 & 16 & 28 \\
\hline 12,0 & 3,2 & 1,6 & 10,2 & $370-410$ & 36 & 23 & 28 \\
\hline
\end{tabular}

OBS.: o gás de proteção é o $\mathrm{CO}_{2}$, com vazão de 15 a 22 1/min; a soldagem é feita em apenas um passe.

(g) Parâmetros de soldagem em junta topo a topo na posição plana para aço-carbono. (preparação da junta $\mathrm{D}$, com $\alpha=40-60^{\circ}$ ).

\begin{tabular}{|c|c|c|c|c|c|c|c|c|}
\hline e (mm) & $\begin{array}{c}\mathrm{f} \\
(\mathrm{mm})\end{array}$ & $\begin{array}{c}\phi \text { do eletrodo } \\
\mathrm{nu}(\mathrm{mm})\end{array}$ & $\begin{array}{c}\text { Velocidade de } \\
\text { alimentação do eletrodo } \\
\text { nu (m/min) }\end{array}$ & $\begin{array}{c}\text { Corrente } \\
(\mathrm{A})\end{array}$ & $\begin{array}{c}\text { Tensão } \\
(\mathrm{V})\end{array}$ & $\begin{array}{c}\text { Velocidade } \\
\text { de soldagem } \\
(\mathrm{cm} / \mathrm{min})\end{array}$ & $\begin{array}{c}\text { Distância tubo } \\
\text { de } \\
\text { contato/peça } \\
(\mathrm{mm})\end{array}$ & $\begin{array}{c}\text { Número } \\
\text { de } \\
\text { passes }\end{array}$ \\
\hline 20 & 2,0 & 1,2 & 12,7 & $290-330$ & 33 & 32 & 25 & $2\left(60^{\circ}\right)$ \\
\hline 20 & 6,0 & 1,6 & 10,7 & $400-450$ & 38 & 44 & 22 & $2\left(40^{\circ}\right)$ \\
\hline 25 & 1,6 & 1,2 & 12,7 & $280-320$ & 33 & 19 & 28 & $2\left(60^{\circ}\right)$ \\
\hline 25 & 6,0 & 1,6 & 10,7 & $370-430$ & 36 & 23 & 25 & $2\left(60^{\circ}\right)$ \\
\hline
\end{tabular}

OBS.: o gás de proteção é o $\mathrm{CO}_{2}$, com vazão de 15 a 22 1/min.

(h) Parâmetros de soldagem em junta angular na posição plana para aço-carbono. (preparação da junta F).

\begin{tabular}{|c|c|c|c|c|c|c|c|}
\hline $\mathrm{p}(\mathrm{mm})$ & $\begin{array}{l}\text { Número } \\
\text { de } \\
\text { passes }\end{array}$ & $\begin{array}{c}\phi \text { do eletrodo } \\
\text { nu (mm) }\end{array}$ & $\begin{array}{l}\text { Velocidade de alimentação } \\
\text { do eletrodo nu (m/min) }\end{array}$ & $\begin{array}{l}\text { Corrente } \\
\text { (A) }\end{array}$ & $\begin{array}{l}\text { Tensão } \\
\text { (V) }\end{array}$ & $\begin{array}{c}\text { Velocidade de } \\
\text { soldagem } \\
(\mathrm{cm} / \mathrm{min}) \\
\end{array}$ & $\begin{array}{c}\text { Distância tubo de } \\
\text { contato/peça } \\
(\mathrm{mm})\end{array}$ \\
\hline 3 & 1 & 0,8 & 5,9 & $90-110$ & $19^{*}$ & 30 & 6 \\
\hline 3 & 1 & 1,2 & 3,6 & $140-170$ & $20^{*}$ & 40 & 10 \\
\hline 5 & 1 & 0,8 & 5,9 & $90-110$ & $19^{*}$ & 19 & 6 \\
\hline 5 & 1 & 1,2 & 3,6 & $140-170$ & $21^{*}$ & 30 & 10 \\
\hline 6 & 1 & 1,2 & 11,2 & $300-340$ & 35 & 51 & 16 \\
\hline 6 & 1 & 1,6 & 7,1 & $400-450$ & 37 & 59 & 16 \\
\hline 10 & 1 & 1,2 & 11,4 & $290-330$ & 35 & 25 & 18 \\
\hline 10 & 1 & 1,6 & 7,1 & $400-450$ & 37 & 30 & 18 \\
\hline 12 & 1 & 1,2 & 11,4 & $290-330$ & 35 & 16 & 20 \\
\hline 12 & 1 & 1,6 & 8,9 & $400-450$ & 37 & 19 & 20 \\
\hline 20 & 3 & 1,2 & 11,4 & $290-330$ & 35 & 26 & 22 \\
\hline 20 & 3 & 1,6 & 9,1 & $400-450$ & 37 & 33 & 22 \\
\hline
\end{tabular}

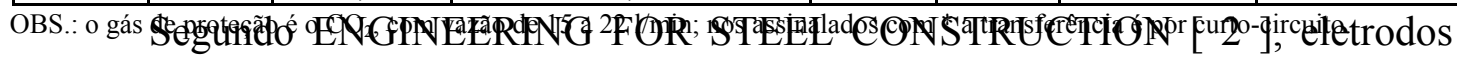

para soldagem FCAW são determinados pela AWS A5.20 e AWS A5.29. Com isso, para o eletrodo EXXT-X , E significa "eletrodo", o primeiro dígito eqüivale à mínima resistência à tração, o segundo dígito representa o código de soldagem $(0$ posição plana e horizontal, 1 todas as posições), T significa que o eletrodo é tubular com fluxo no núcleo, e o último dígito diferencia os grupos de eletrodos entre si, conforme características, tais como: necessidade ou não do uso de gás protetor (geralmente $\mathrm{CO}_{2}$ ), tipo de corrente recomendada, características operacionais e a composição química do metal depositado.

Os consumíveis (arames e fluxos) usados para soldagem eletro-escória são cobertos pela AWS A5.25, que requerem eletrodos que contenham níquel para fornecer valores ao teste de impacto Charpy de chanfro em $\mathrm{V}$ tanto para $0^{\circ} \mathrm{F}$ quanto para $-20^{\circ} \mathrm{F}$. De modo a exemplificar sua classificação, temos que para o fluxo FES62, F refere-se ao fluxo, ES fluxo eletro-escória, 6 é a mínima resistência à tração (60ksi), e 2 significa a menor temperatura ao teste de impacto Charpy de chanfro V. Completando tem-se que para o eletrodo EWT1, E significa eletrodo, W metal de 
solda testado quando depositado, T eletrodo tubular com fluxo no núcleo, e 1 é o número da composição.

\subsection{Posições de soldagem e tipos de juntas soldadas}

As juntas podem ser executadas de diversas posições de soldagem como mostra a fig. 2-9a. De acordo com SALMON \& JOHNSON [ 60 ], o tipo de ligação depende de fatores tais como tamanho e forma dos perfis envolvidos na ligação, o tipo de solicitação, a área ligada disponível para soldagem e os relativos custos dos vários tipos de soldas. Os tipos básicos de juntas soldadas são: extremidade, sobreposição, te, canto e borda, como mostrados na fig. 2-9b, e descritos logo em seguida, segundo SALMON \& JOHNSON [ 60 ].

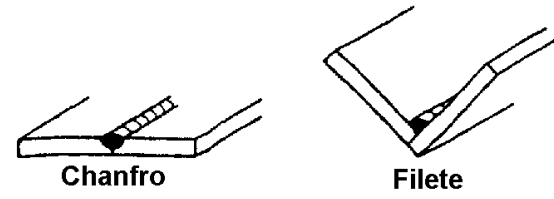

(a1) Plana

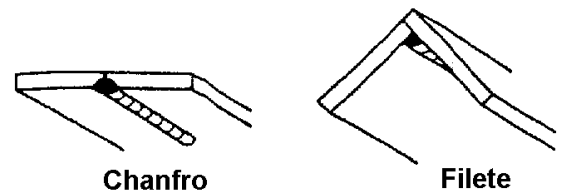

(a3) Sobre-cabeça

(a) Posições de soldagem

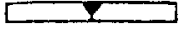

(b1) Extremidade

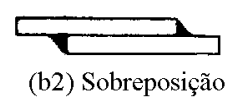

(b) Tipos de juntas soldadas

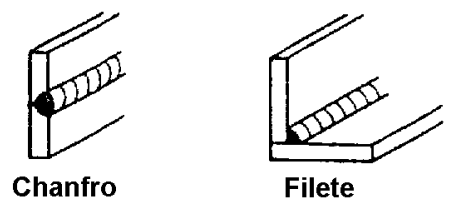

(a2) Horizontal

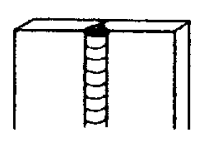

Chanfro

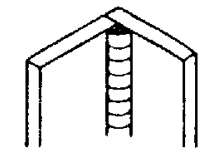

Filete

(a4) Vertical

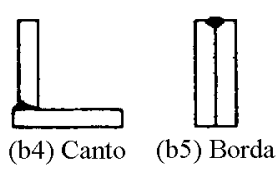

FIGURA 2-9 Juntas soldadas. Adaptada de GAYLORD et al. [ 27 ].

A junta de extremidade, ou de topo, é usada principalmente para unir as extremidades de chapas niveladas de mesma espessura ou com espessuras relativamente próximas. A principal vantagem deste tipo de junta é eliminar a excentricidade desenvolvida nas juntas de uma só sobreposição. Quando utilizadas em conjunto com soldas em chanfro de penetração total, as ligações de extremidade minimizam o tamanho de uma conexão e são usualmente mais agradáveis esteticamente. Sua principal desvantagem consiste no fato que as extremidades para 
serem conectadas, devem usualmente ser especialmente preparadas e muito cuidadosamente alinhadas antes da soldagem. Pequenos ajustes são possíveis e as partes devem ser cuidadosamente detalhadas e fabricadas. Devido à estes cuidados, a maioria das ligações de extremidade são executadas em fabrica onde os processos de soldagem podem ser mais cuidadosamente controlados.

A junta de sobreposição é o tipo mais comum. Ela tem duas principais vantagens: facilidade de ajuste, pois as partes presentes na ligação não requerem a precisão na fabricação exigida nos outros tipos de juntas, podendo ser levemente deslocadas para acomodar pequenos erros de fabricação ou para fazer ajustes de comprimento; a outra vantagem é a facilidade de união, pois as extremidades das partes não necessitam de preparações especiais e são usualmente cortadas com maçarico. As juntas de sobreposição utilizam soldas de filete e são por essa razão, apropriadas para soldagem tanto em oficina quanto em campo. As partes são na maioria dos casos simplesmente posicionadas sem o uso de gabaritos especiais, sendo que ocasionalmente esse posicionamento pode ser feito por um pequeno número de parafusos de montagem, que podem ser tanto deixados no local ou removidos após a soldagem estar completada.

Uma outra vantagem das juntas de sobreposição é a facilidade da união de chapas de diferentes espessuras.

A junta tê é utilizada para fabricar perfis tais como o perfil "T" e o perfil "I", e para fixação de enrijecedores em geral.

As juntas de canto são usadas principalmente para constituir seções caixão, sendo também empregadas na fixação de enrijecedores de extremidade.

As juntas de borda são geralmente não estruturais, sendo freqüentemente utilizadas para manter duas ou mais chapas em uma determinada posição ou para manter alinhamento inicial.

\subsection{Tipos de soldas}

Os quatro tipos usuais de soldas são: filete, chanfro, tampão em furo e tampão em rasgo (ranhura). Segundo SALMON \& JOHNSON [ 60 ], os quatro tipos representam as seguintes porcentagens de utilização nas construções soldadas: soldas 
de filete $80 \%$, soldas em chanfro $15 \%$, e os remanescentes $5 \%$ correspondem a tampão em furo, em rasgo e outras soldas especiais.

\subsubsection{Soldas de filete}

As soldas de filete apresentam seção transversal aproximadamente triangular, e ligam superfícies não coplanares, como na fig. 2-10. Devido a facilidade de execução e versatilidade, são as mais utilizadas. Os filetes na fig. 2-10 são convexos, mas soldas que possuem filetes em forma côncava (fig. 2-11c), segundo SIDERBRÁS [ 65 ], são de melhor qualidade, consomem menos eletrodos, possuem uma melhor penetração e apresentam um melhor fluxo de tensões, porém sua execução é mais trabalhosa.

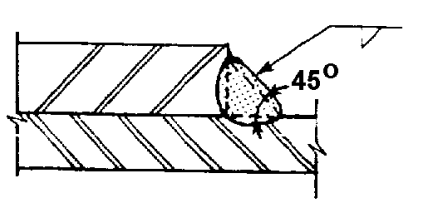

(a) Filetes em chapas sobrepostas

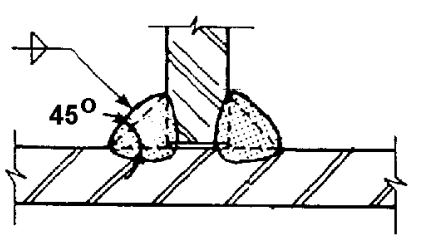

(b) Filetes em chapas ortogonais

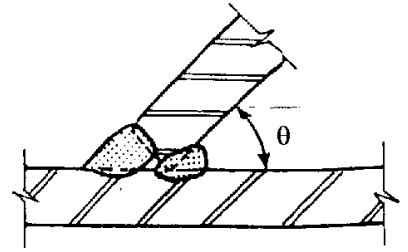

(c) Filetes em chapas não ortogonais FIGURA 2-10 Exemplos de soldas de filete. Adaptada de COOPER [ 17 ].

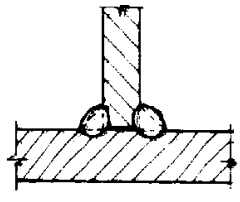

(a) Solda convexa

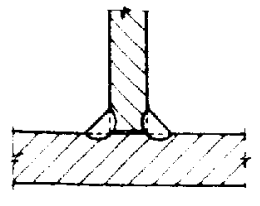

(b) Solda plana

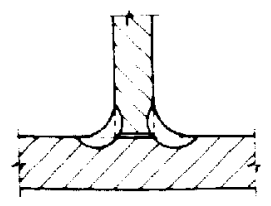

(c) solda côncava

FIGURA 2-11 Formas para o filete de solda. Adaptada de SIDERBRÁS [ 65 ].

Segundo SALMON \& JOHNSON [ 60 ], as soldas de filete geralmente requerem menor precisão na fabricação, devido à sobreposição das partes, e conseqüentemente são mais vantajosas para soldagem em campo. Além disso, as extremidades das partes raramente necessitam preparações especiais, tal como chanfros, desde que as condições da extremidade resultantes do corte por chama ou corte por cisalhamento sejam adequadas. 


\subsubsection{Soldas em chanfro ${ }^{1}$}

O principal uso de soldas em chanfro é para conectar perfis estruturais que são alinhados no mesmo plano. Segundo GAYLORD et al. [ 27 ], a solda em chanfro é feita na abertura (chanfro), entre duas partes presentes na ligação. As ligações soldadas em chanfro, podem ser de penetração parcial ou total. Em alguns casos a penetração é intencionalmente parcial, de tal maneira que a solda é menos profunda que a espessura da parte ligada, enquanto em outros casos ela é parcial devido ao procedimento de soldagem não produzir efetiva penetração, caso contrário será uma solda de penetração total. Alguns exemplos de soldas em chanfro são mostrados na fig. 2-12.

A escolha entre chanfros simples ou duplos é usualmente uma questão do custo de preparação versus o consumo de metal de solda. De uma maneira geral, segundo QUITES \& DUTRA [ 57 ], a finalidade da preparação das extremidades a serem soldadas é obter uma junta adequada para a soldagem, levando em consideração os seguintes aspectos: o processo de soldagem; a localização da soldagem; a espessura do material e o tipo da junta; as tensões e as deformações resultantes; a economia na preparação das faces soldadas e na quantidade de material de preenchimento depositado; a natureza do material de base e a penetração que é necessária nas faces soldadas.

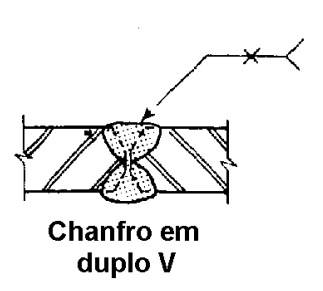

(a) Penetração total

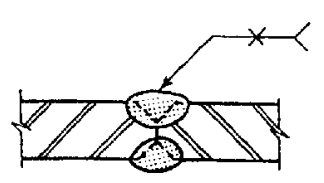

Chanfro em

duplo V

(b) Penetração parcial
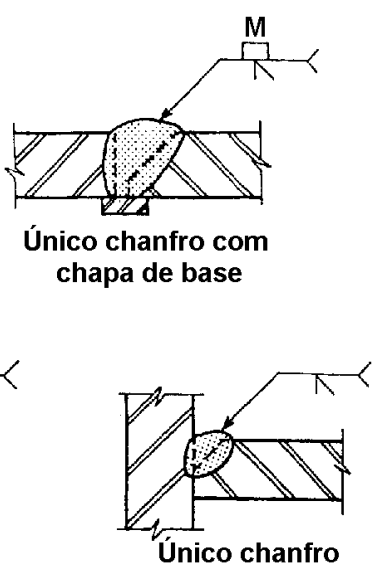

Único chanfro

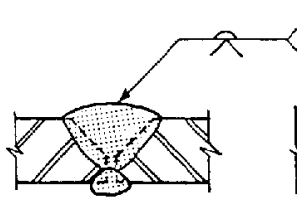

Único V reforçado
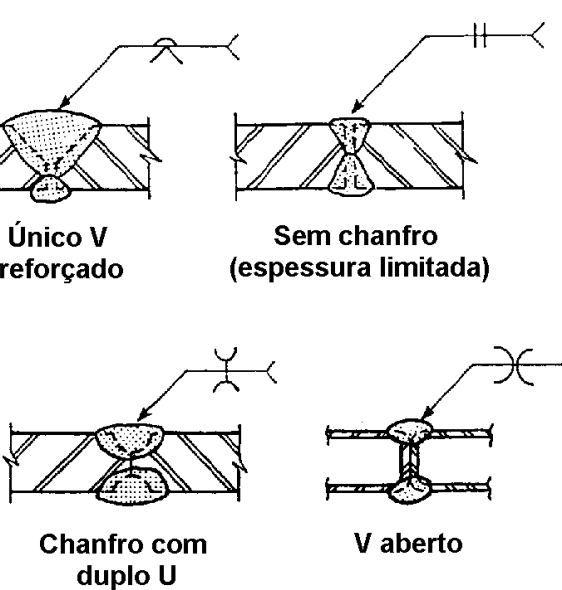

FIGURA 2-12 Exemplo de soldas em chanfro. Adaptada de COOPER [ 17 ].

\footnotetext{
${ }^{1}$ Solda em chanfro é a denominação utilizada pela área tecnológica de soldagem, diferente da NBR
} 


\subsubsection{Soldas de tampão em furos e rasgos (ranhura)}

Uma solda de tampão é feita pela deposição de metal de solda em um furo circular, ou em um rasgo, em uma ou duas partes sobrepostas. Este furo, ou rasgo deve ser preenchido completamente. Essas soldas podem ser usadas exclusivamente em uma conexão, ou elas podem ser usadas em combinação com soldas de filete como na fig. 2-13. Segundo SALMON \& JOHNSON [ 60 ], a principal finalidade destas soldas é transmitir cisalhamento em uma ligação de sobreposição, quando o tamanho da conexão limita o comprimento disponível para o filete. Essas soldas são também indicadas para impedir o empenamento das partes sobrepostas.

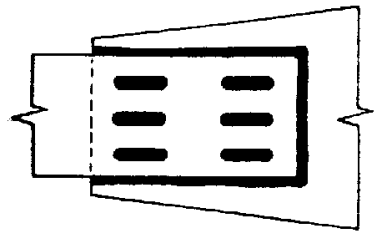

(a) Solda de ranhura combinada com solda de filete

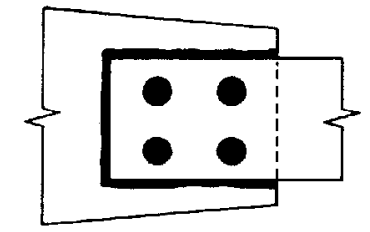

(b) Soda de tampão em furos combinada com solda de filete FIGURA 2-13 Exemplos de solda de tampão. Adaptada de SALMON \& JOHNSON [ 60 ].

\subsection{Simbologia de soldagem}

Devido à necessidade de um método simples e preciso para a comunicação entre o projetista e o executor, a AWS (American Welding Society) recomendou, em 1940, um sistema completo de especificações, por meio de símbolos ideográficos, os quais podem descrever qualquer combinação possível de soldas em uma junta. Os símbolos padrões da AWS, indicados na fig. 2-14, indicam o tipo, tamanho, comprimento e localização da solda, bem como outras instruções especiais. A fig. 214b mostra localizações padronizadas para os vários elementos de um símbolo de soldagem. 


\begin{tabular}{|c|c|c|c|c|c|c|c|c|}
\hline \multicolumn{9}{|c|}{ Símbolos Básicos de Solda } \\
\hline \multirow[b]{2}{*}{ Rebordo } & \multirow[b]{2}{*}{ Filete } & \multirow[b]{2}{*}{ Tampão } & \multicolumn{6}{|c|}{ Ranhura ou Chanfro } \\
\hline & & & Reto & $\mathrm{V}$ & Meio V & $\bar{U}$ & $\bar{J}$ & Filetes convexos \\
\hline$\infty$ & & & 11 & & V & & & $\bar{r}$ \\
\hline \multicolumn{9}{|c|}{ Símbolos Suplementares } \\
\hline \multirow{2}{*}{\multicolumn{2}{|c|}{$\begin{array}{c}\text { Solda com } \\
\text { chapa de base }\end{array}$}} & \multirow[b]{2}{*}{ Afastamento } & \multirow{2}{*}{\multicolumn{2}{|c|}{ Toda volta }} & \multirow{2}{*}{\multicolumn{2}{|c|}{$\begin{array}{c}\text { Solda de } \\
\text { campo }\end{array}$}} & \multicolumn{2}{|c|}{ Contorno } \\
\hline & & & & & & & Esmerilhar & Convexa \\
\hline$\perp$ & & - & & 0 & P & & 一 & 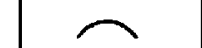 \\
\hline
\end{tabular}

(a) Símbolos de solda elétrica. Adaptada de SANTOS [ 61 ].

FIGURA 2-14 Símbolos de solda segundo a AWS 2.4.

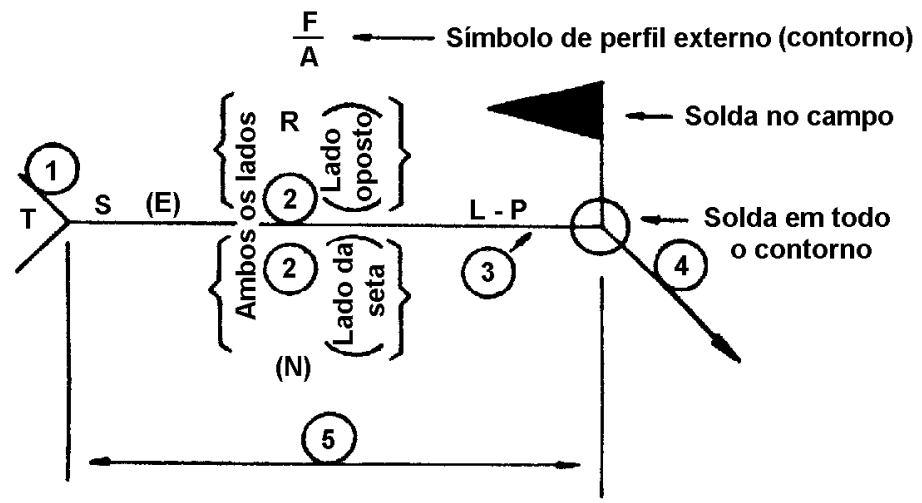

(b) Localizações padronizadas dos elementos no símbolo de soldagem. Adaptada de BELLEI [ 11 ].

1 - Cauda do símbolo, que pode ser omitida quando não se usar nenhuma referência;

2 - Símbolo básico de solda ou referência de chanfro de solda a ser consultado;

3 - Linha de referência;

4 - Seta ligando a linha de referência ao lado indicado da junta;

5 - Os elementos constantes desta área permanecem inalterados, mesmo nos casos em que a cauda e a seta do símbolo são invertidas;

A - Ângulo do chanfro;

F - Símbolo (tipo) de acabamento;

(E) - Garganta efetiva;

L - Comprimento da solda;

$\mathrm{P}$ - Espaçamento entre centros de soldas intermitentes;

(N) - Número de soldas por pontos;

$\mathrm{R}$ - Abertura da raiz, altura do enchimento para soldas de tampão;

S - Profundidade de preparação: dimensão ou resistência para certas soldas;

$\mathrm{T}$ - Especificação, processo ou outra referência.

FIGURA 2-14 Símbolos de solda segundo a AWS 2.4.

Segundo BELLEI [ 11 ], o significado de "lado da seta" e "lado oposto" referem-se à posição da seta em relação à junta a ser soldada. O símbolo de soldagem para uma solda a ser executada do "lado da seta" é desenhado no lado inferior da linha de referência. Já o símbolo de soldagem desenhado na parte superior da linha de referência "lado oposto" significa que a solda deve ser executada no outro lado da junta. As soldas que envolvem operações em ambos os lados da junta possuem símbolos nos dois lados da linha de referência. 
CARNASCIALI [ 16 ] cita algumas considerações importantes: as setas com seus símbolos devem ser utilizadas, tanto quanto necessárias, quando houver uma mudança brusca na direção do cordão, com exceção se o cordão for o mesmo para todo o contorno; todos o cordões são considerados contínuos, salvo indicações ao contrário; as dimensões, os comprimentos e os espaçamentos devem ser indicados em milímetros ao lado dos símbolos; a cauda da seta deve ser utilizada somente quando houver particularidades da soldagem.

\subsection{Fatores que afetam a qualidade de conexões soldadas}

\subsubsection{Eletrodos, dispositivos de soldagem e procedimentos}

Segundo SALMON \& JOHNSON [ 60 ], o tamanho do eletrodo selecionado é baseado na dimensão nominal da solda e na satisfatória corrente elétrica dos dispositivos de soldagem. Desde que a maioria das máquinas de soldagem possuem controles para reduzir a saída de corrente, eletrodos menores que a máxima capacidade podem facilmente ser acomodados e utilizados.

Desde que o metal de solda no arco de soldagem é depositado por um campo eletromagnético e não por gravidade, o soldador não é limitado para posições de soldagem planas e horizontais. O projetista deverá evitar, sempre quando possível, as posições sobre cabeça e vertical descendente, uma vez que são as mais difíceis para se executar. As ligações soldadas em oficina são usualmente executadas nas posições plana e horizontal, mas soldas de campo podem requerer qualquer posição de soldagem, dependendo da orientação da conexão. A posição de soldagem para soldas de campo deverá ser cuidadosamente considerada pelo projetista.

Segundo GAYLORD et al. [ 27 ], o posicionamento do eletrodo para a execução da soldagem é também um fator importante. Para uma solda de filete, o eletrodo comumente deverá se posicionar no meio do ângulo formado entre as duas faces de fusão. Além disso, ele deve inclinar-se em aproximadamente 20 graus na direção de percorrimento.

Os mais eficientes filetes de solda são aqueles que podem ser feitos em um único passe. Grandes filetes de soldas podem usualmente requerer dois ou mais 
passes, fig. 2-15. A maior dimensão do filete num único passe depende da posição de soldagem e não deverá exceder o seguinte: $8 \mathrm{~mm}$ na posição horizontal e sobrecabeça, 9,5 mm na posição plana e 12,5 mm na posição vertical.

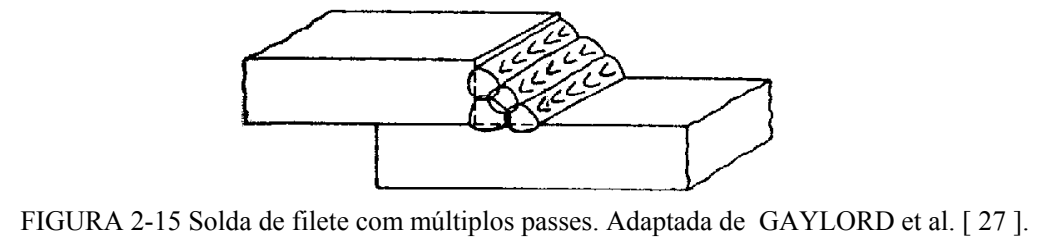

\subsubsection{Preparação das juntas}

Para soldas de filete não é requerida a preparação das extremidades. Já em soldas em chanfro, é geralmente necessário preparar as superfícies dos elementos presentes na união. A preparação ideal das partes tem por objetivos básicos facilitar o acesso do eletrodo em toda espessura da junta a ser soldada, garantindo que o metal de solda seja satisfatoriamente depositado e minimizar o volume de metal de solda depositado, pois este é relativamente caro.

O mais crítico passe da soldagem é o primeiro e a parte mais crítica da preparação da solda é a preparação da raiz. A abertura da raiz é a separação das partes presentes na ligação e é feita para os eletrodos acessarem a base da conexão.

Para que a poça de solda possa penetrar na face profunda, a abertura da raiz não deve ser muito estreita, contudo para essa poça ser estabelecida, essa abertura não deve ser muito larga. Os tamanhos da espessura da raiz e da profundidade da raiz dependem da escolha do processo de soldagem, das variáveis de soldagem e das posições de soldagem. Segundo OWENS \& CHEAL [ 50 ], valores típicos dessa abertura para soldagem a arco com eletrodo revestido ou soldagem semi-automática MAG com $\mathrm{CO}_{2}$, são de 2-3 mm e 1-2 mm, respectivamente. Para soldagem a arco submerso valores típicos podem estar entre 0-2 $\mathrm{mm}$ e 4-6 $\mathrm{mm}$, devido à melhor penetração alcançada com esse processo. Se devido a tolerância estrutural, a abertura da raiz não puder ser mantida dentro dos limites apropriados, uma chapa de base ou apoio pode ser utilizada em conjunto com a larga abertura da raiz, para suportar a poça de solda. Preparações de extremidades típicas para soldas em chanfro são mostradas na fig. 2-16. 

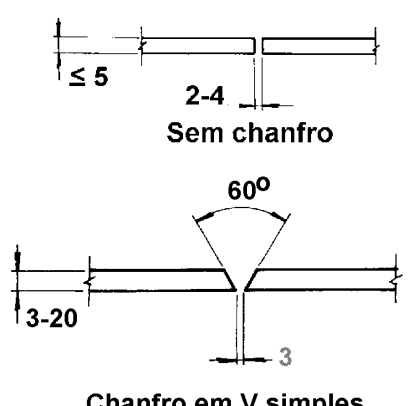

Chanfro em V simples

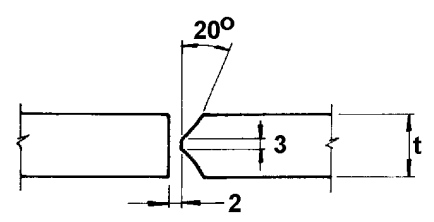

Chanfro em J duplo
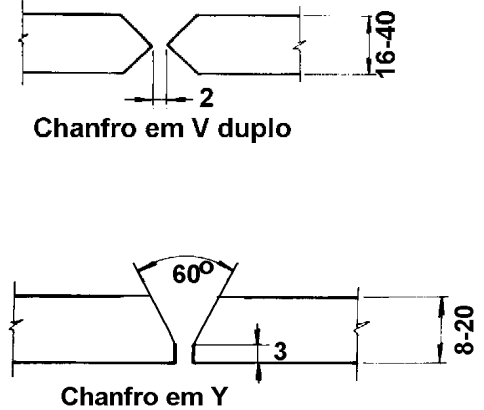

Chanfro em $Y$

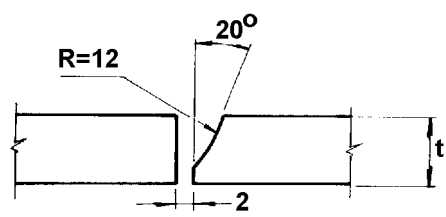

Chanfro em $\mathrm{J}$ simples
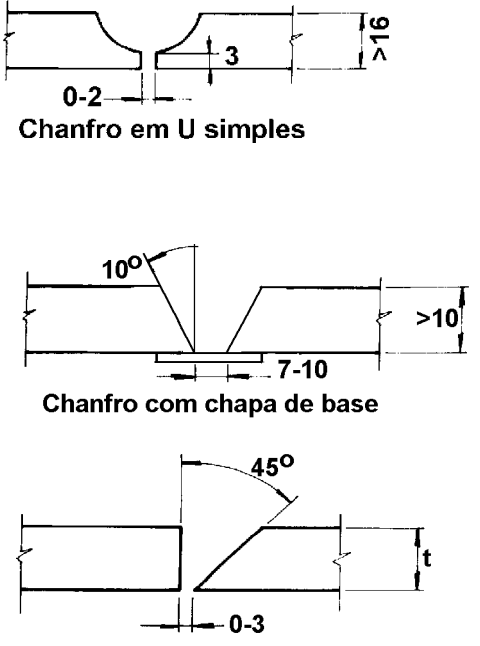

Chanfro em bisel simples

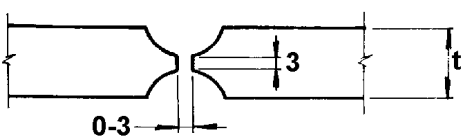

Chanfro em U duplo

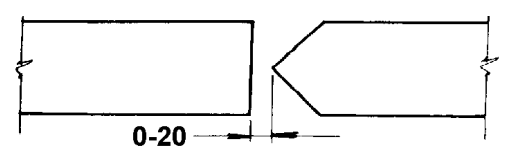

Chanfro em bisel duplo

(a) Chanfros em soldas de extremidade. Adaptada de SIDERBRÁS [ 65 ] e BELLEI [ 11 ].

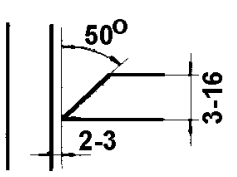

Chanfro em $\mathrm{V}$

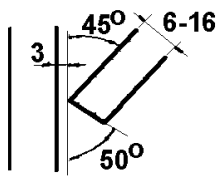

Chanfro em $V$

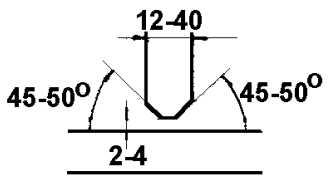

Chanfro em $Y$ duplo

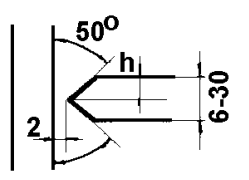

Chanfro em K

(b) Chanfros em soldas tê. Adaptada de SIDERBRÁS [ 65 ].

FIGURA 2-16 Preparações de extremidades de soldas em chanfro.

Referindo-se à fig. 2-16, segundo SIDERBRÁS [ 65 ], as soldas sem chanfro podem ser executadas com espessuras até $10 \mathrm{~mm}$ pelo processo de soldagem MAG com $\mathrm{CO}_{2}$. As soldas em $\mathrm{V}$ tornam-se antieconômicas para chapas com espessuras superiores a $15 \mathrm{~mm}$, porque necessitam muito material de preenchimento, ocasionando maiores deformações na chapa. Já as soldas em Y reduzem a quantidade de material de preenchimento. As soldas em V duplo, muito empregadas em soldas 
de grande espessura, necessitam menor quantidade de eletrodos, exigindo porém, solda nos dois lados. Soldas em J e U reduzem o consumo de eletrodos, mas o chanfro é de execução mais trabalhosa.

\subsubsection{Controle de distorção}

Segundo OWENS \& CHEAL [ 50 ], logo que uma gota de solda fundida é depositada e inicia o resfriamento, essa gota começa a solidificar-se, e conseqüentemente contrair-se, tanto longitudinalmente quanto transversalmente ao seu eixo. Esta contração introduz tensões residuais tanto no metal de solda quanto no metal base, o que provoca distorções significativas nos elementos. A figura 2-17 ilustra tal efeito.

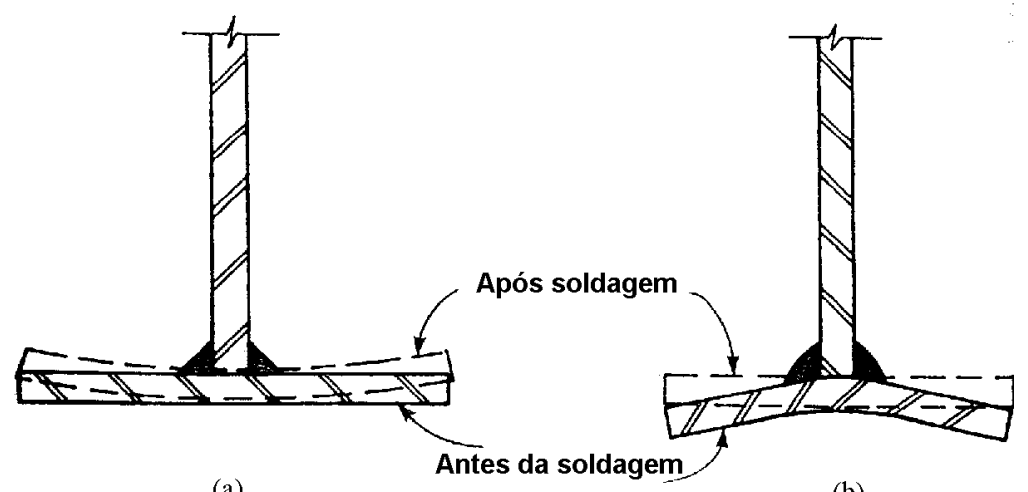

(a)

(b)

FIGURA 2-17 Distorção de ligações te. (a) Chapa reta curva-se devido à contração da solda; (b) chapa pré-curvada torna-se reta após soldagem. Adaptada de COOPER [ 17 ].

A contração transversal provoca distorções angulares e fora do plano. Há alguns meios apropriados para controlar estas distorções. Um é pré-ajustar os elementos ou usar chapas com pré-curvatura antes da soldagem, de tal forma que após à soldagem a distorção associada à geometria final seja aceitável, como na fig. 2-17b. Outro meio muito empregado é a execução de seqüências de soldas intermitentes, com posterior preenchimentos dos espaços intermediários. Além disso, é interessante usar o mínimo metal de solda possível, e fazer a solda com uma mínima quantidade de passes.

Segundo SALMON \& JOHNSON [ 60 ], para minimizar a contração e garantir adequada ductilidade, a AWS tem estabelecido um mínimo pré-aquecimento 
e temperaturas de inter-passes. Para soldas requerendo mais de um passe em uma operação de soldagem ao longo da junta, a temperatura de inter-passe é a temperatura da solda depositada quando o próximo passe é iniciado.

Segundo BELLEI [ 11 ], em função da experiência, foram estabelecidos três padrões de tolerância para perfis "I" soldados, que são: padrão I, para estruturas que requerem maior rigor dimensional, tais como: pilares de edifícios de múltiplos andares, vigas de rolamento, pontes ferroviárias, etc.; padrão II, para estruturas convencionais, tais como: galpões industriais, exceto vigas de rolamento, vigas de edifícios, etc.; padrão III, para estruturas secundárias e complementares, tais como: estacas, postes, escadas, etc.

A tabela 2-13 fornece algumas tolerâncias dimensionais para um perfil "I" soldado, de modo a quantificar o controle de distorção.

TABELA 2-13 Tolerâncias dimensionais para os perfis soldados. Adaptada de BELLEI [ 11 ]. 


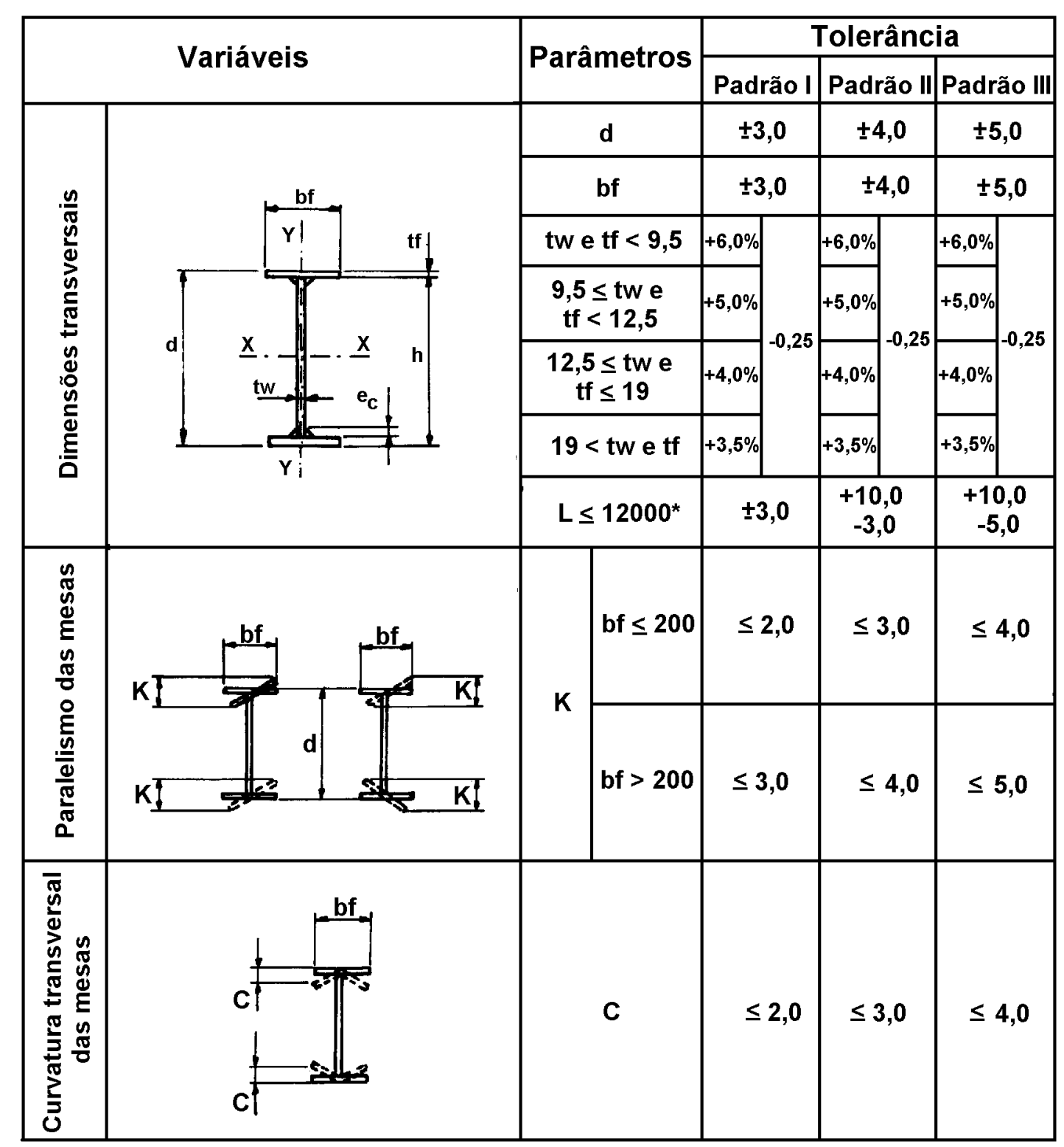

*Para perfil com comprimento L maior que $12000 \mathrm{~mm}$, admite-se uma tolerância adicional de $+1,0 \mathrm{~mm}$ para cada metro

\subsection{Defeitos na solda}

As principais descontinuidades comumente encontradas nos vários processos de soldagem são mostradas na tabela 2-14, e analisadas logo depois.

TABELA 2-14 Descontinuidades encontradas nos processos de soldagem. Adaptada de CUNHA [ 20 ].

\begin{tabular}{|c|c|c|c|c|c|c|}
\hline $\begin{array}{c}\text { Processo de } \\
\text { soldagem }\end{array}$ & Porosidade & $\begin{array}{c}\text { Inclusão de } \\
\text { escória }\end{array}$ & $\begin{array}{c}\text { Penetração } \\
\text { incompleta }\end{array}$ & $\begin{array}{c}\text { Fusão } \\
\text { incompleta }\end{array}$ & $\begin{array}{c}\text { Morde- } \\
\text { dura }\end{array}$ & Fissuras \\
\hline SMAW & $\mathrm{X}$ & $\mathrm{X}$ & $\mathrm{X}$ & $\mathrm{X}$ & $\mathrm{X}$ & $\mathrm{X}$ \\
\hline SAW & $\mathrm{X}$ & $\mathrm{X}$ & $\mathrm{X}$ & $\mathrm{X}$ & $\mathrm{X}$ & $\mathrm{X}$ \\
\hline TIG & $\mathrm{X}$ & Inclusão de W & & $\mathrm{X}$ & & $\mathrm{X}$ \\
\hline GMAW & $\mathrm{X}$ & $\mathrm{X}$ & $\mathrm{X}$ & $\mathrm{X}$ & $\mathrm{X}$ & $\mathrm{X}$ \\
\hline
\end{tabular}




\begin{tabular}{|c|c|c|c|c|c|c|}
\hline ESW & $\mathrm{X}$ & $\mathrm{X}$ & $\mathrm{X}$ & $\mathrm{X}$ & & $\mathrm{X}$ \\
\hline $\mathrm{EGW}$ & $\mathrm{X}$ & $\mathrm{X}$ & $\mathrm{X}$ & $\mathrm{X}$ & & $\mathrm{X}$ \\
\hline
\end{tabular}

\subsubsection{Mordedura}

Mordedura significa um entalhe fundido dentro do metal base adjacente à extremidade de uma solda e deixado sem preenchimento de metal de solda. A mordedura mostrada na fig. 2-18a, segundo OWENS \& CHEAL [ 50 ], é geralmente formada quando grande quantidade de metal base é levado dentro da poça de solda e algum distúrbio na poça impede a deposição neste ponto. Este distúrbio pode ser ocasionado por uma alta corrente, produzindo excessiva turbulência na poça de solda. Provavelmente a situação mais comum para este tipo de mordedura, ocorre com a deposição de grandes passes únicos do metal de solda na posição horizontal/vertical, para formar um filete de solda. Os defeitos de fenda mostrados na fig. 2-18b ocorrem provavelmente se é produzido aquecimento insuficiente no metal base, na imediata vizinhança da poça de solda.

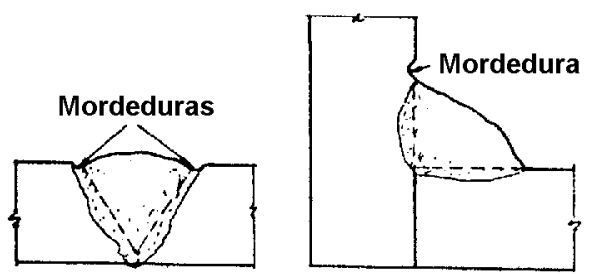

(a)

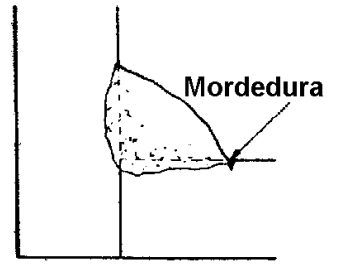

(b)

FIGURA 2-18 Exemplos de defeitos de mordedura. (a) Mordedura larga e curvada; (b) mordedura estreita. Adaptada de OWENS \& CHEAL [ 50 ].

Esses defeitos são facilmente detectados visualmente e podem ser corrigidos pela deposição adicional de material de solda.

\subsubsection{Inclusões de escória}

Essas escórias são partículas não metálicas, de densidade mais baixa que o metal de solda fundido, usualmente derivadas do fluxo, que são apanhadas pela poça de solda, como na fig. 2-19. Suas inclusões podem aparecer em soldas de múltiplos passes, e nesta situação, são usualmente ocasionadas pelo limpamento inadequado entre os passes e também por um rápido resfriamento da solda que pode capturar a escória antes que ela possa subir para a superfície. Isso tudo é somado muitas vezes com formas desfavoráveis do filete ou uma seqüência incorreta do mesmo. Segundo 
OWENS \& CHEAL [ 50 ], elas podem assumir considerável comprimento e, por essa razão, influenciar a resistência da seção transversal. Alternativamente elas podem ocorrer na raiz da solda, usualmente como um resultado da abertura da raiz ser demasiadamente estreita

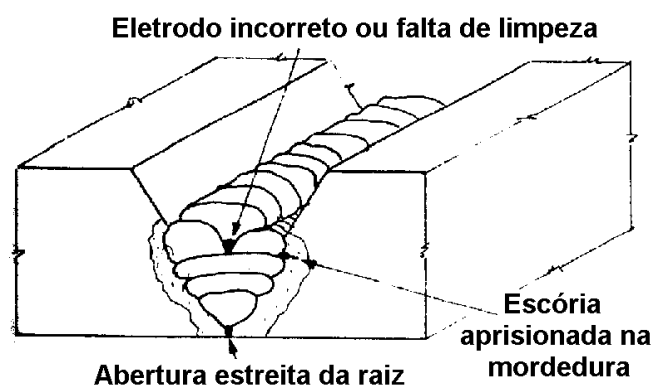

FIGURA 2-19 Exemplos de inclusão de escória. Adaptada de OWENS \& CHEAL [ 50 ].

\subsubsection{Penetração incompleta}

Segundo SALMON \& JOHNSON [ 60 ], penetração incompleta significa a solda estender-se em uma distância mais rasa, através da profundidade do chanfro, onde penetração completa foi especificada. Isto pode ocorrer na raiz ou raramente entre passes, em uma solda executada com múltiplos passes (ver fig. 2-20). Esse defeito pode ser causado por corrente de soldagem insuficiente, dando uma insatisfatória concentração de energia dentro da poça de solda e também pode ser causado quando um excessivo grau de velocidade de soldagem é utilizado. Alternativamente, segundo OWENS \& CHEAL [ 50 ], esse defeito pode surgir quando se utiliza um eletrodo de grande diâmetro na soldagem, quando a abertura da raiz é demasiadamente pequena, ou quando a seqüência de soldagem do filete de solda é incorreta. Estes problemas podem ser corrigidos pela modificação do procedimento de soldagem.

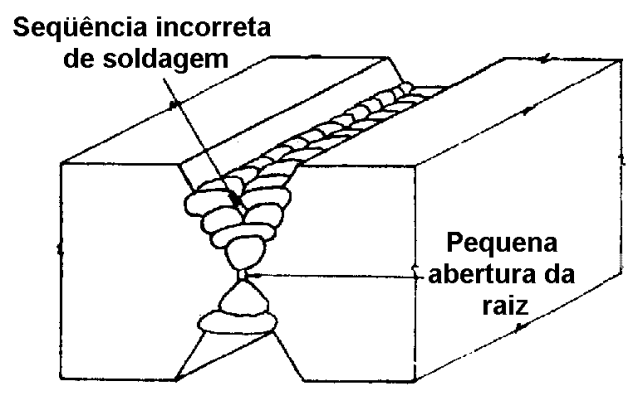

FIGURA 2-20 Exemplo de falta de penetração. Adaptada de OWENS \& CHEAL [ 50 ]. 


\subsubsection{Fusão incompleta}

Como diz o próprio nome, é a fusão incompleta do metal base e/ou do metal de solda. Este defeito, exemplificado na fig. 2-21, é uma forma menos extrema de falta de penetração. Isto pode ser causado por formas mais brandas da mesma falha que conduz a falta de penetração, como o uso de corrente insuficiente e rápido grau de velocidade de soldagem e pode, em adição, ser um resultado da contaminação ocasionada por ferrugem, escória, óxidos, ou outros materiais estranhos presentes na superfície da ligação. Segundo OWENS \& CHEAL [ 50 ], isto pode ser corrigido por uma melhor limpeza e/ou com uma modificação do processo de soldagem.

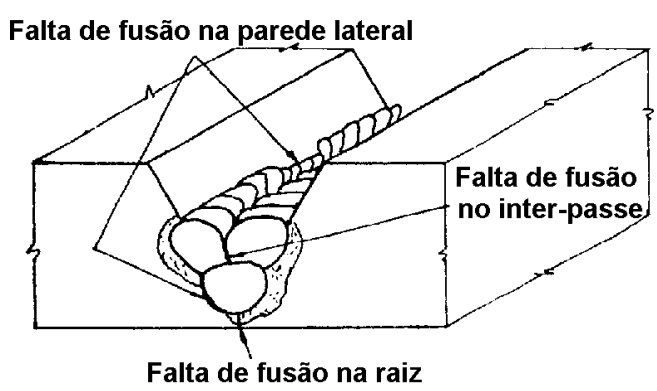

FIGURA 2-21 Exemplo de falta de fusão. Adaptada de OWENS \& CHEAL [ 50 ].

\subsubsection{Porosidade}

Porosidade é a formação de pequenos vazios no metal de solda, e é causada pela captura de gás na poça de solda fundida, durante o processo de resfriamento. As cavidades são geralmente esféricas mas podem ser alongadas. Segundo OWENS \& CHEAL [ 50 ], elas surgem porque a solubilidade do gás na poça de solda diminui quando a temperatura recua. $\mathrm{O}$ gás pode surgir por alguma contaminação da chapa ou do eletrodo, por um turbulento fluxo de gás quando o processo com proteção gasosa é utilizado, ou também quando se utiliza um longo arco com fluxos básicos, além do uso excessivo de altas correntes. Segundo SALMON \& JOHNSON [ 60 ], a porosidade pode ocorrer uniformemente dispersada através da solda, ou ela pode ser uma grande bolsa concentrada na raiz de um filete de solda ou na raiz próxima à uma 
chapa de base, em uma solda em chanfro, devido à ineficiência do processo de soldagem e descuidado uso destas chapas.

\subsubsection{Trincas por introdução de hidrogênio na zona afetada pelo calor}

Este tipo de trinca, mostrado na fig. 2-22, geralmente ocorre nas zonas afetadas pelo calor após à soldagem. Segundo OWENS \& CHEAL [ 50 ], as trincas ocorrem com mais freqüência quando a temperatura abaixa de $300^{\circ} \mathrm{C}$. Entretanto, estas podem não ocorrer inicialmente e desenvolver-se consideravelmente mais tarde, ou seja, durante a vida útil da estrutura. O mecanismo de ruptura depende de alguns fatores interligados. O grau de resfriamento na zona afetada pelo calor pode ser similarmente associado a um rápido resfriamento, que dependendo da composição do aço, pode causar um considerável endurecimento e uma perda da sua ductilidade. O hidrogênio pode ser introduzido dentro da região do arco da solda pela umidade do fluxo ou por contaminação de hidrocarbono. Nas altas temperaturas, o metal de solda e a zona afetada pelo calor, dissolvem significativas quantidades de qualquer hidrogênio disponível. Quando a temperatura cai, a solubilidade do hidrogênio diminui e ocorrem concentrações de gases que formam vazios microscópicos com alta pressão. O metal de solda pode acomodar-se devido a sua ductilidade, mas a zona afetada pelo calor torna-se excessivamente quebradiça, desenvolvendo trincas ou fissuras.

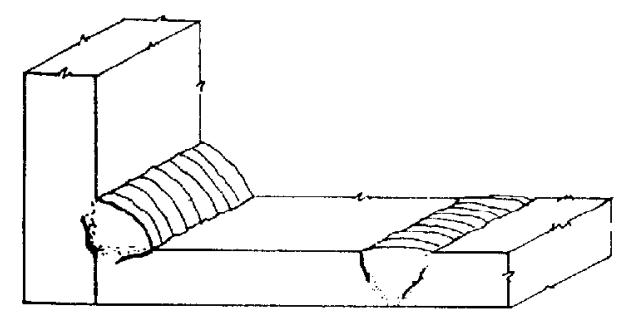

FIGURA 2-22 Exemplos de trincas na zona afetada pelo calor. Adaptada de OWENS \& CHEAL [ 50 ].

Segundo OWENS \& CHEAL [ 50 ], existem alguns parâmetros chave para eliminar esta forma de trinca: 
- observar a composição do material, onde a suscetibilidade ao aparecimento da trinca depende da qualidade temperável do material base, que depende de sua composição, como o elevado teor de carbono;

- o controle do teor de hidrogênio. Independente à composição do material base, os eletrodos devem sempre estar apropriadamente secos e a junta deve ser livre de contaminação. Eletrodos básicos (hidrogênio controlado) deverão ser usados.

- o grau de velocidade de resfriamento. Quanto menor a velocidade de resfriamento, menor é a suscetibilidade de um material tornar-se quebradiço sob tensão, ocasionada pela introdução de gás. Além disso, uma maior diminuição do grau de velocidade de resfriamento, fornece mais tempo para o excesso de hidrogênio dispersar-se na solda e na zona afetada pelo calor.

\subsubsection{Trincas devido a solidificação do metal de solda}

Segundo OWENS \& CHEAL [ 50 ], esta forma de defeito é usualmente uma trinca longitudinal que se forma após o metal de solda estar solidificado (ver fig. 223). Deste modo, sabe-se que devido ao fluxo de calor, a porção central da poça de solda é a última a solidificar-se. Desde que a maioria das impurezas têm ponto de fusão mais baixo que o aço, elas podem concentrar-se nesta região e formar fitas semi-contínuas de segregados. Somado a isso, nas soldas contínuas o resfriamento após solidificação tenta contrair a solda e esta por sua vez pode trincar nestas regiões de fragilidade.

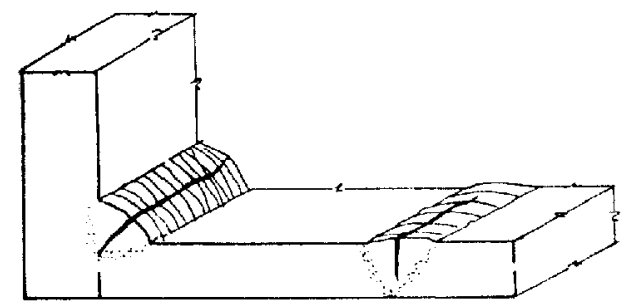

FIGURA 2-23 Exemplos de trincas devido a solidificação do metal de solda. Adaptada de OWENS \& CHEAL [ 50 ]

A composição é o parâmetro mais importante no controle desta forma de trinca. Assim, impurezas como enxofre e fósforo são as mais significativas, e têm que ser minimizadas no eletrodo e no metal base. Tal como a trinca na zona afetada pelo calor, o grau de restrição é também um parâmetro significativo. 
Essa trinca é mais provável para desenvolver-se com penetração profunda, com soldagem a arco submerso, devido a alta diluição. Se ela ocorrer nesta situação, uma mudança no procedimento de soldagem, para menores passes de solda, com baixa energia no arco e conseqüentemente menor penetração, deverá aliviar o problema. Quando em soldagem manual, em aços com elevado teor de enxofre, eletrodos básicos com controle de hidrogênio deverão ser utilizados porque eles possuem uma maior ductilidade que os outros eletrodos. Alternativamente, eletrodos com elevado teor de manganês podem ser usados, porque o sulfeto de manganês que é formado, tem um ponto de fusão mais elevado que os sulfetos ferrosos e por esta razão não podem concentrar-se no centro da solda.

\subsubsection{Rasgo lamelar}

Este problema tem considerável importância em projeto de conexões. Ele é causado pelos defeitos surgidos durante o processo de laminação do aço base e a deformação ocorrida por contração após à soldagem.

Como o aço é laminado, partículas esferoidais de impurezas tornam-se alongadas dentro dos elementos, em formas descontínuas, como na fig. 2-24a. Estas descontinuidades, segundo OWENS \& CHEAL [ 50 ], reduzem a resistência da espessura e a ductilidade do aço, comparado com suas propriedades em outras direções.

Se, como mostra a fig. 2-24b, tais chapas são incorporadas dentro de conexões soldadas, onde elas são sujeitas à significativas deformações ao longo da espessura, devido a contração da soldagem na presença de restrição, então o rasgo lamelar poderá ocorrer. Eles estão geralmente na sub-superfície e por essa razão não detectáveis por inspeção visual.

A incidência do rasgo lamelar pode ser reduzida pelo cuidado no detalhamento. A fig. 2-24c mostra versões revisadas de alguns detalhes que são menos suscetíveis ao rasgo. Todavia, em algumas ligações, grandes deformações ao longo da espessura são inevitáveis, e nestas situações, segundo OWENS \& CHEAL [ 50 ], duas medidas preventivas são praticáveis. A tradicional prevenção, como na fig. 2-24d, é revestir a chapa anteriormente à soldagem, com metal solda de baixa 
resistência e alta ductilidade, que possa acomodar as deformações. A segunda prevenção é especificar aços que tenham garantia das propriedades ao longo da espessura. Todavia, deverá ser notado que esses aços são consideravelmente mais caros que outros materiais e seu uso deverá ser restrito à situações com uma significativa probabilidade de rasgo lamelar e onde a integridade estrutural é essencial para segurança.

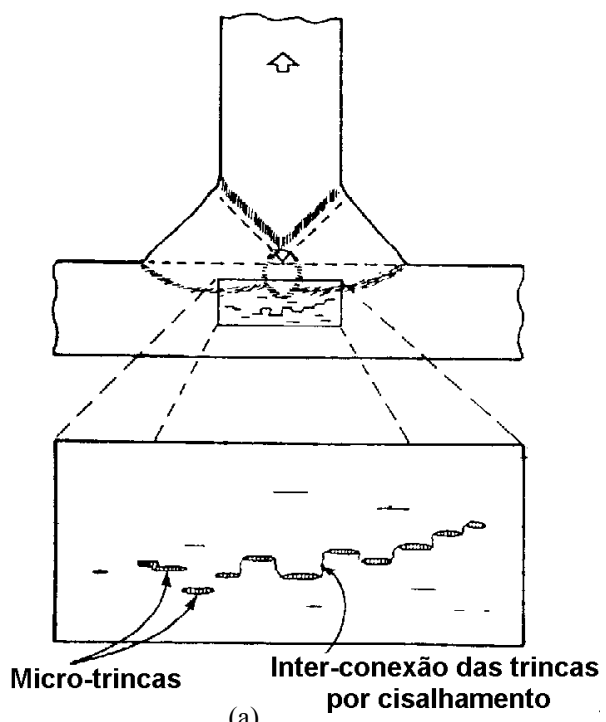

(a)

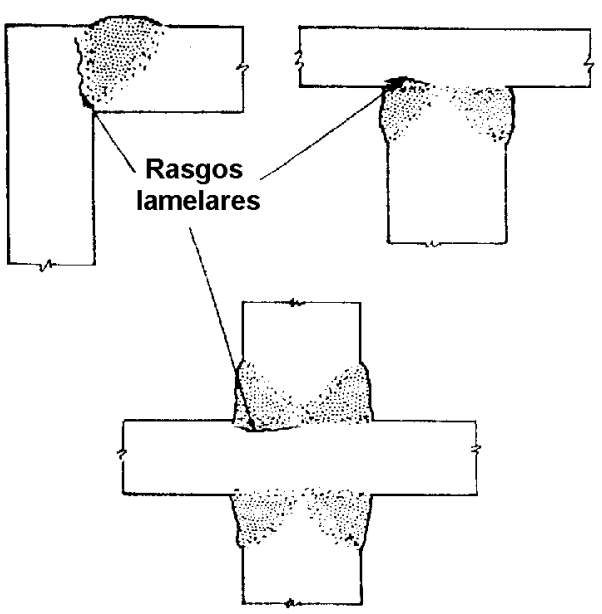

(b)

Ruptura
FIGURA 2-24 Rasgo lamelar. (a) Impu ez̧s ặhatadas no łço através de pnicro-trincas na direção de laminação; (b) rasgos

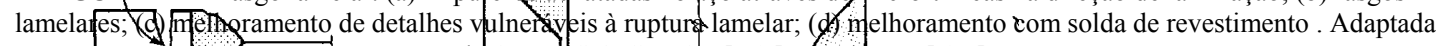

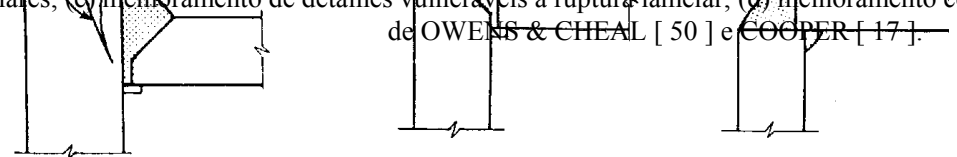

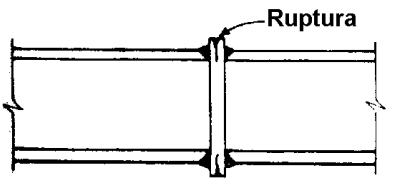

Detalhes vulneráveis

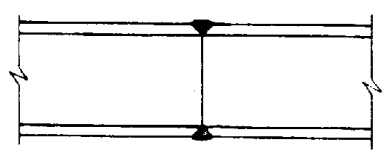

Detalhes melhorados

(c)

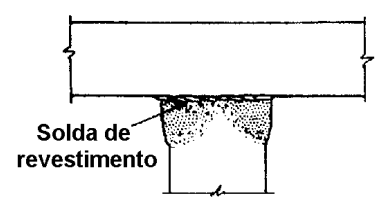

(d)

FIGURA 2-24 Rasgo lamelar. (a) Impurezas achatadas no aço através de micro-trincas na direção de laminação; (b) rasgos lamelares; (c) melhoramento de detalhes vulneráveis à ruptura lamelar; (d) melhoramento com solda de revestimento . Adaptada de OWENS \& CHEAL [ 50 ] e COOPER [ 17 ].

\subsection{Controle de qualidade da soldagem}

Segundo GAYLORD et al. [ 27 ], a produção de uma solda idônea é governada por muitos fatores. O tipo de ligação, sua preparação e execução, a abertura da raiz, etc., são tão importantes, quanto a posição de soldagem, a corrente 
de soldagem e voltagem, o comprimento do arco e o grau de velocidade de percorrimento. A acessibilidade para a operação de soldagem é também importante, deste modo a qualidade de uma solda é determinada por uma considerável condição do posicionamento do eletrodo.

Os procedimentos de qualificação procedem com as propriedades dos metais, o tipo de chanfro e posição de soldagem, o eletrodo e sua dimensão, a corrente e voltagem e os requerimentos para pré-aquecimento do metal base. $\mathrm{O}$ operador deve também ser qualificado para executar a soldagem, desenvolvendo testes em testemunhos (corpos-de-prova), que devem apresentar a requerida resistência e ductilidade. Todavia, a qualificação de procedimentos e do operador não são o bastante para garantir soldas satisfatórias, deste modo, a inspeção torna-se importante.

A inspeção e o procedimento de controle deverá começar antes que o primeiro arco seja desferido, contínuo do começo ao fim do procedimento de soldagem, e se necessário, um pré-teste na ligação deverá ser feito para garantir seu satisfatório desempenho.

É também importante a interpretação dos resultados de inspeção de uma solda, pois alguns defeitos podem ser relativamente não importantes, enquanto outros podem ser críticos em específicas situações de serviço.

São apresentados a seguir os principais métodos de inspeção de soldagem.

\subsubsection{Inspeção visual}

A mais fundamental forma de checagem de cordões de solda e a mais barata é pela inspeção visual, que depende da competência do observador. Ela pode ser usada para checar a qualidade de preparação da solda, a fissura no passe da raiz, o alinhamento dos passes da solda em uma solda com múltiplos passes, a limpeza entre os passes, os defeitos de mordedura, porosidade e contorno da superfície e a geometria final da solda.

Geralmente, usa-se este método como preliminar de um dos outros descritos a seguir, ou para soldas de menor responsabilidade. 


\subsubsection{Líquidos penetrantes}

Segundo OWENS \& CHEAL [ 50 ], o penetrante é um líquido colorido de baixa viscosidade que é atraído para dentro de qualquer superfície defeituosa através da ação de capilaridade. Este líquido é pulverizado sobre a solda e após um breve intervalo de penetração, o excesso de fluido é cuidadosamente removido. Um revelador, à base de talco ou gesso, é então pulverizado sobre a solda e nos materiais circunvizinhos. Ele atrairá o penetrante em qualquer defeito que ele tenha penetrado, por efeito de capilaridade, indicando claramente sua presença, através da coloração do revelador (ver fig. 2-25). Um procedimento similar consta de um líquido fluorescente que detecta imperfeições superficiais expostas à uma luz escura.

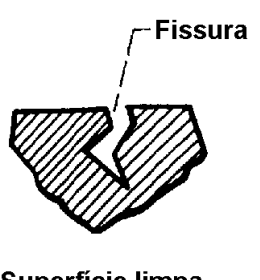

Superfície limpa

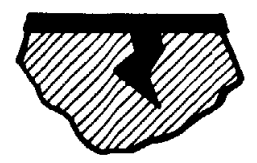

Penetrante aplicado

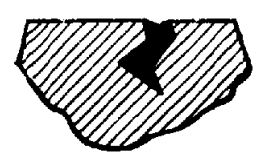

Excesso removido

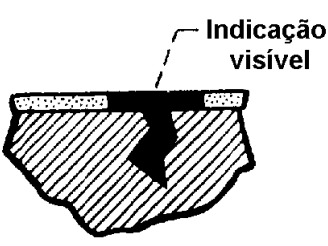

Revelador aplicado

FIGURA 2-25 Esquema do teste de inspeção de fissuras por líquidos penetrantes. Adaptada de ENGINEERING FOR STEEL CONSTRUCTION [ 2 ].

\subsubsection{Inspeção por partícula magnética}

Esta técnica monitora o vazamento de fluxo magnético que ocorre na presença de qualquer defeito na superfície ou próximo à superfície (aproximadamente 2,54 mm) quando a peça base é magnetizada. Usualmente um pó seco magnético vermelho é aplicado na superfície a ser analisada e um fluxo magnético é induzido no corpo base através de magnétos. Este pó colorido é atraído por qualquer vazamento do fluxo magnético, deste modo salientando os defeitos (ver fig. 2-26). As partículas mantidas magnetizadas mostram a localização, o tamanho e a forma das descontinuidades. Segundo OWENS \& CHEAL [ 50 ], para uma máxima sensibilidade, uma série de direções de fluxo deverão ser analisadas, pois as falhas somente aparecem, se elas cortam transversalmente a linha de fluxo. 


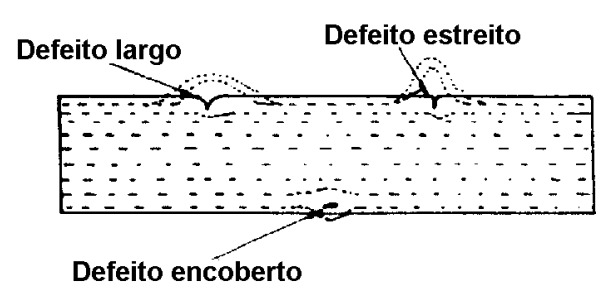

FIGURA 2-26 Influência dos defeitos no fluxo magnético. Adaptada de OWENS \& CHEAL [ 50 ].

O sistema de magnetização pode ser desajeitado para certas posição de uso, sendo mais agradável para testar componentes em uma linha de montagem.

\subsubsection{Inspeção radiográfica com raio $X$ e raio Gama}

$\mathrm{Na}$ inspeção por radiografia usa-se radiações de ondas curtas, tal como raios $\mathrm{X}$ ou raios Gama, para descobrir falhas na superfície e sub-superfície da solda. Deste modo, se uma solda é sujeita a uma forma de radiação, haverá uma emissão mais alta nas regiões onde existem defeitos, pois a irradiação encontra menos resistência. Esta variação pode ser registrada por meios de filmes fotográficos, como na fig. 2-27.

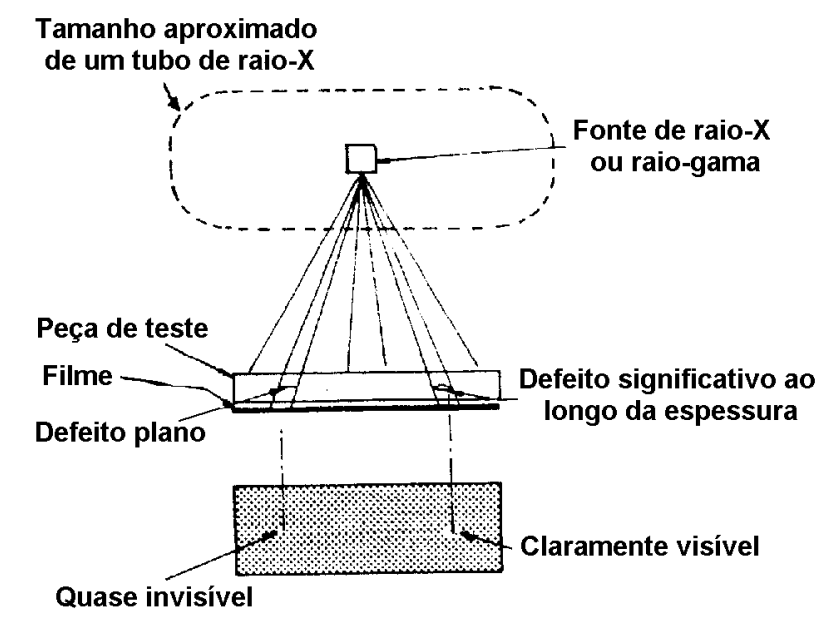

FIGURA 2-27 Fundamentos do método de inspeção por radiografia. Adaptada de OWENS \& CHEAL [ 50 ].

Segundo OWENS \& CHEAL [ 50 ], é necessário variar a intensidade e o comprimento de onda das emissões, em ordem para alcançar uma ótima penetração na solda. Com raios $\mathrm{X}$ isto é obtido pela modificação do tubo de voltagem. Um aumento ampliará a intensidade e reduzirá o comprimento de onda. Isto fornece um mais intenso raio X com grande penetração. Os raios Gama, geralmente possuem menores comprimentos de onda que os raios $\mathrm{X}$, dando grandes penetrações. 
Diferentes fontes têm diferentes energias e comprimentos de onda. Quanto mais baixa a energia da fonte, melhor será o contraste no filme. Uma fonte popular é o irídio-192, que dá um negativo perfeito de alta qualidade para chapas de espessura entre $12-60 \mathrm{~mm}$.

As vantagens dos raios $\mathrm{X}$ são que sua intensidade da radiação pode ser variada; ele é mais sensitivo e desde que a fonte pode ser desligada, é somente necessário tomar precauções de segurança durante o tempo de exposição, antes de se preocupar com um contínuo protegimento pesado. Os raios Gama possuem a vantagem do equipamento ser menor, mais barato e mais móvel que a unidade de raio $\mathrm{X}$, além de fornecerem uma maior penetração e poderem ser utilizados em seções espessas.

Esses sistemas são muito mais sofisticados que as técnicas descritas anteriormente. Eles requerem total treinamento dos operadores, complexos equipamentos e elaboradas precauções de segurança para evitar riscos de radiação. Sua principal vantagem é que ele possibilita que os defeitos da sub-superfície sejam detectados. Todavia, sua sensibilidade para defeitos que não possuem uma significativa dimensão na direção ao longo da espessura é pobre, onde a fissura deve ocupar aproximadamente $1,5 \%$ da espessura ao longo do metal. Além disso, a restrição física para arranjar a fonte oposta de radiação do filme pode criar dificuldades em geometrias complexas.

O custo dos equipamentos e precauções torna-se esse método o mais caro, com isso os sistemas ultra-sônicos vem gradualmente suplementado-se e superando a radiografia.

\subsubsection{Inspeção ultra-sônica}

A inspeção ultra-sônica é efetiva na localização de defeitos existentes na superfície e sub-superfície da solda. Este processo de inspeção é análogo a um radar. Segundo GAYLORD et al. [ 27 ], ondas sonoras de alta freqüência enviadas através de uma área a ser inspecionada, são refletidas pelas descontinuidades e densidades diferentes. O som é produzido por um cristal cerâmico polarizado, energizado por uma corrente elétrica que motiva o cristal a vibrar. A reflexão das ondas de som são 
monitoradas por um receptor, convertendo-as para energia elétrica, e exibindo-as com padrões visuais em um osciloscópio.

Segundo OWENS \& CHEAL [ 50 ], dois modos de operação são empregados. Onde a direção do pulso é normal às superfícies, como na fig. 2-28a, é possível localizar a profundidade e qualquer defeito diretamente devido ao sistema de auto calibração. Haverá ecos separados pelo defeito e pela extrema delimitação e uma simples proporção pode ser usada para determinar a profundidade do defeito. Já onde o pulso está inclinado em relação à superfície, nenhum eco haverá na face extrema e qualquer eco por essa razão será prova de um defeito, como mostra a fig. 2-28b. Em muitos casos, diferentes direções sondadas deverão ser efetuadas, de modo a examinar diferentes partes da mesma solda.

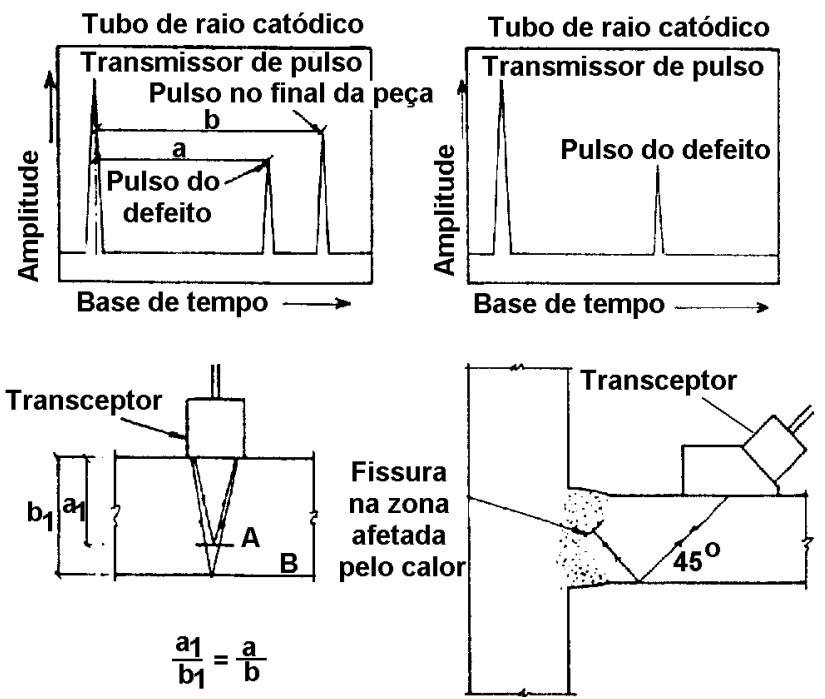

FIGURA 2-28 Exemplos de detecção de defeitos pelo método ultra-sônico. (a) Defeito em uma chapa plana; (b) fissura na zona afetada pelo calor em um ligação soldada em tê. Adaptada de OWENS \& CHEAL [ 50 ].

Com inspeção ultra-sônica é possível sondar defeitos internos em uma larga variedade de soldas. O equipamento é portátil e seguro e o método pode detectar todos os mais comuns defeitos encontrados em soldas, com adequada sensibilidade.

Soldas eletro-escória são difíceis para inspecionar por esse método, pois possuem grânulos extremamente grosseiros; mas em aços de baixa liga o processo pode detectar descontinuidades planas menores que $0,40 \mathrm{~mm}$.

O método de inspeção ultra-sônico é mais versátil, rápido e econômico que o método radiográfico. 


\section{Na tabela 2-15 é resumida as principais características dos métodos de} inspeção aqui discutidos.

TABELA 2-15 Principais características dos métodos de inspeção de soldas. Adaptada de BELLEI [ 11 ] e ENGINEERING FOR STEEL CONSTRUCTION [ 2 ].

\begin{tabular}{|c|c|c|}
\hline $\begin{array}{l}\text { Método de } \\
\text { inspeção }\end{array}$ & Características & Limitações \\
\hline Visual & $\begin{array}{c}\text { O mais comum e mais econômico. } \\
\text { Particularmente bom para soldas com um único } \\
\text { passe. }\end{array}$ & $\begin{array}{c}\text { Detecta somente trincas superficiais grosseiras, excessos } \\
\text { e falta de solda e imperfeições. }\end{array}$ \\
\hline $\begin{array}{c}\text { Liquido } \\
\text { penetrante }\end{array}$ & $\begin{array}{l}\text { Utilizado quando a geometria da peça é } \\
\text { complexa, dificultando a operação do } \\
\text { equipamento de partículas magnéticas. } \\
\text { Uso instantâneo em qualquer lugar. } \\
\text { Detecta defeitos superficiais como trincas } \\
\text { (micro-trincas da ordem de } 0,001 \text { mm de } \\
\text { largura), fissuras, porosidade, mordeduras. }\end{array}$ & $\begin{array}{c}\text { Detecta somente descontinuidades superficiais. } \\
\text { Ondulações de soldas reentrantes e ranhuras podem dar } \\
\text { falsas indicações. } \\
\text { Exame de custo mais elevado do que o de partículas } \\
\text { magnéticas. }\end{array}$ \\
\hline $\begin{array}{l}\text { Partícula } \\
\text { magnética }\end{array}$ & $\begin{array}{c}\text { Detecta defeitos na superfície e sub-superfície } \\
\text { como trincas, fissuras, porosidade, mordeduras e } \\
\text { sobreposição. } \\
\text { Detecta descontinuidades lineares da ordem de } \\
0,5 \mathrm{~mm} \text {, além de descontinuidades mascaradas } \\
\text { por esmerilhamento, óxidos etc., e as escondidas } \\
\text { sob pinturas. } \\
\text { É um exame mais rápido e econômico do que o } \\
\text { de líquido penetrante. } \\
\text { Indicações podem ser apanhadas e preservadas } \\
\text { em fitas plásticas. }\end{array}$ & $\begin{array}{c}\text { Requer relativa lisura da superfície. } \\
\text { Descuidado uso de pontas magnetizadas podem } \\
\text { abandonar defeitos de golpeamento de arco. } \\
\text { Necessita que o campo magnético seja gerado } \\
\text { perpendicularmente à descontinuidade. } \\
\text { Necessita em certos casos de desmagnetização da peça. } \\
\text { Limpeza posterior. } \\
\text { Depende da força do campo magnético. }\end{array}$ \\
\hline Radiográfico & $\begin{array}{c}\text { Detecta defeitos internos como porosidade, } \\
\text { escória, vazios, fissuras, irregularidades, falta de } \\
\text { fusão. } \\
\text { Indicado para espessuras entre } 4 \mathrm{~mm} \text { e } 70 \mathrm{~mm} . \\
\text { Um filme negativo é registro permanente. } \\
\text { Distinção mais fácil do tipo de descontinuidade } \\
\text { detectada. } \\
\text { Executado em qualquer tipo de superfície. }\end{array}$ & $\begin{array}{c}\text { Defeitos devem ocupar mais que aproximadamente 1,5\% } \\
\text { da espessura para registrar. } \\
\text { Somente fissuras paralelas ao colidimento são } \\
\text { registradas. } \\
\text { Necessidade de acesso pelos dois lados da superfície } \\
\text { inspecionada. } \\
\text { Radiação perigosa, havendo a necessidade de evacuação } \\
\text { de todo pessoal próximo à área em que está realizando a } \\
\text { radiografia. } \\
\text { Tempo de exposição aumenta com a espessura. } \\
\text { Custo mais elevado do que o ultra-sônico. } \\
\text { Resultado duvidoso para soldas de filete. }\end{array}$ \\
\hline Ultra-sônico & $\begin{array}{c}\text { Detecta fissuras em qualquer orientação, } \\
\text { escória, falta de fusão, inclusões, rupturas } \\
\text { lamelares, vazios. } \\
\text { Pode examinar minuciosamente quase qualquer } \\
\text { espessura comercial. } \\
\text { Alta sensibilidade na detecção de pequenos }\end{array}$ & $\begin{array}{c}\text { Superfícies devem ser lisas. } \\
\text { Equipamento deve ser freqüentemente calibrado. } \\
\text { Operador deve ser qualificado. } \\
\text { Grânulos excessivamente grosseiros fornecem falsas } \\
\text { indicações. } \\
\text { Defeitos classificados por tamanho podem não ser muito }\end{array}$ \\
\hline
\end{tabular}




\begin{tabular}{|c|c|c|}
\hline & $\begin{array}{c}\text { defeitos. } \\
\text { Precisão na localização da descontinuidade e } \\
\text { estimativa do tamanho. } \\
\text { Inspeção rápida. } \\
\text { Necessidade de acesso por somente uma } \\
\text { superfície do elemento ensaiado. }\end{array}$ & $\begin{array}{l}\text { exatos. } \\
\text { O sistema pode ser também sensível à defeitos pequenos } \\
\text { que não são nocivos à estrutura. } \\
\text { Falta de registro permanente. } \\
\text { Difícil aplicação em peças de geometria complexa. }\end{array}$ \\
\hline
\end{tabular}




\section{CAPÍTULO 3 - RESISTÊNCIA DE PARAFUSOS}

As conexões parafusadas são geralmente classificadas de acordo com a solicitação que ocorre nos parafusos, isto é, tração, força cortante ou tração e força cortante combinadas. A figura 3-1 apresenta exemplos destas solicitações.

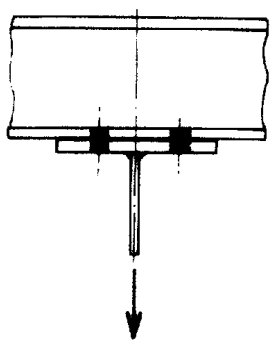

(a) Tração

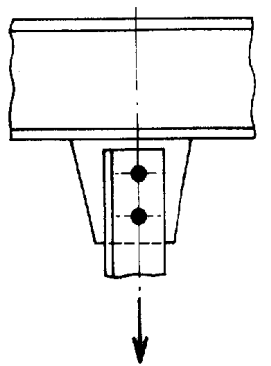

(b) Força cortante

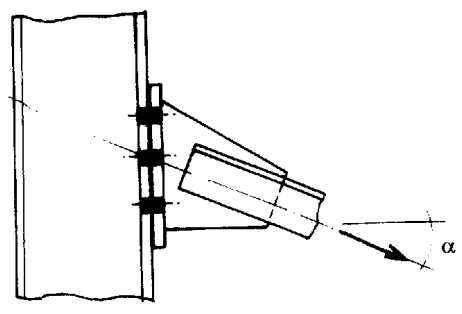

(c) Tração e força cortante

FIGURA 3-1 (a) Parafusos submetidos à tração; (b) parafusos submetidos à força cortante; (c) parafusos submetidos à tração e força cortante combinadas. Adaptada de MALITE et al. [ 40 ].

De acordo com MALITE et al. [ 40 ], a NBR 8800 [ 7 ] especifica que uma conexão de barra tracionada ou comprimida, seja ela soldada, parafusada ou rebitada, deve ser dimensionada de forma que sua resistência de cálculo seja igual ou superior à solicitação de cálculo ou a uma porcentagem especificada da resistência de cálculo da barra.

Desta forma, a NBR 8800 [ 7 ] prescreve que as referidas conexões devem ser dimensionadas para forças de cálculo nunca inferiores a $50 \%$ das resistências de cálculo da barra aos tipos de força normal (tração ou compressão) que nela atuam. Esta condição estabelece uma compatibilidade entre a resistência da barra e da conexão.

Além disso, as conexões de barras tracionadas ou comprimidas, excetuandose diagonais de travejamento de barras compostas, tirantes constituídos de barras redondas e elementos secundários em geral, devem ser dimensionadas para uma solicitação de cálculo igual a $40 \mathbf{~ k N}$.

\section{1 - Modos de falha em conexões parafusadas}


Os possíveis estados limites últimos ou modos de falha que podem controlar a resistência de uma conexão parafusada são mostrados na fig. 3-2.

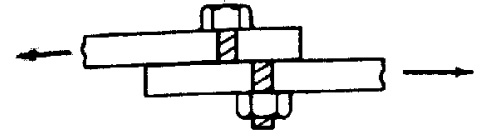

(a) Falha por cisalhamento do parafuso

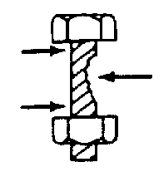

(c) Falha por pressão de contato no parafuso (esmagamento)

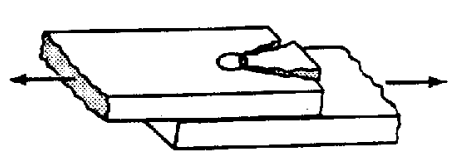

(b) Falha por cisalhamento da chapa (rasgamento)

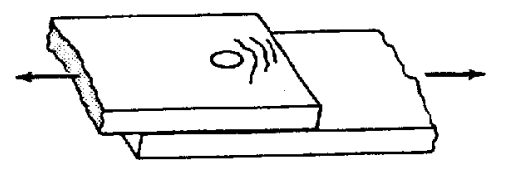

(d) Falha por pressão de contato na chapa (esmagamento)

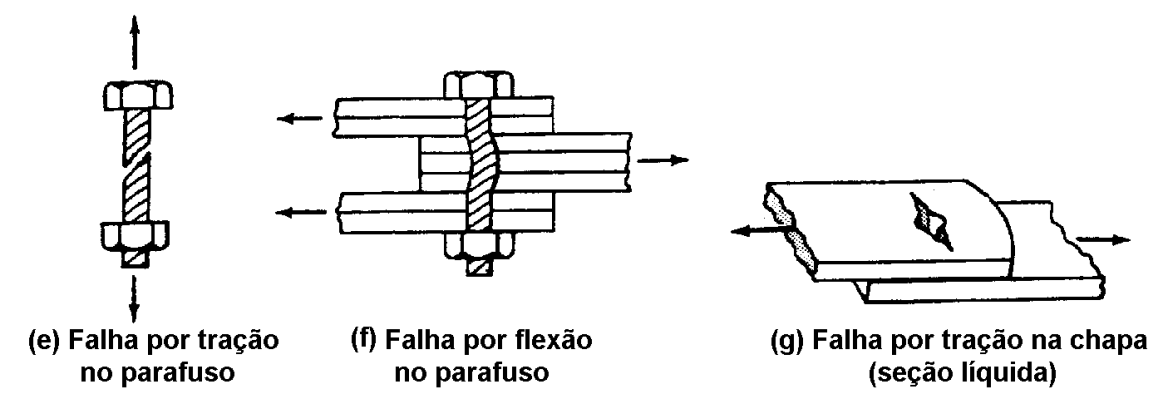

FIGURA 3-2 Possíveis modos de falha em conexões parafusadas. Adaptada de SALMON \& JOHNSON [ 60 ].

A falha pode ocorrer no parafuso ou no metal base, dependendo das dimensões destes elementos (diâmetro e comprimento do parafuso, largura e espessura do metal base), assim como da distância entre parafusos e da localização destes em relação às bordas do metal base.

Levando em consideração esforços agindo perpendicularmente ao eixo do parafuso (parafusos sob força cortante), tem-se as seguintes considerações referentes aos modos de falha:

- quando o diâmetro do parafuso é pequeno em relação às dimensões do metal base, a falha provável é o cisalhamento do parafuso (fig. 3-2a). Este tipo de falha é melhor ilustrado através da fig. 3-3, onde pode-se visualizar a ruptura por cisalhamento de um parafuso. A falha por esmagamento do parafuso (fig. 3-2c) raramente ocorre.

- quando a relação comprimento/diâmetro do parafuso é grande, a flexão pode ser determinante (fig. 3-2f). 
- quando o diâmetro do parafuso é grande frente às dimensões do metal base, a falha deverá ocorrer junto ao metal base, por esmagamento (fig. 3-2d) ou por rasgamento (fig. 3-2b). Nos casos em que a seção do metal base é severamente reduzida pela presença dos furos, poderá ocorrer a ruptura por tração na seção líquida (fig. 3-2g).

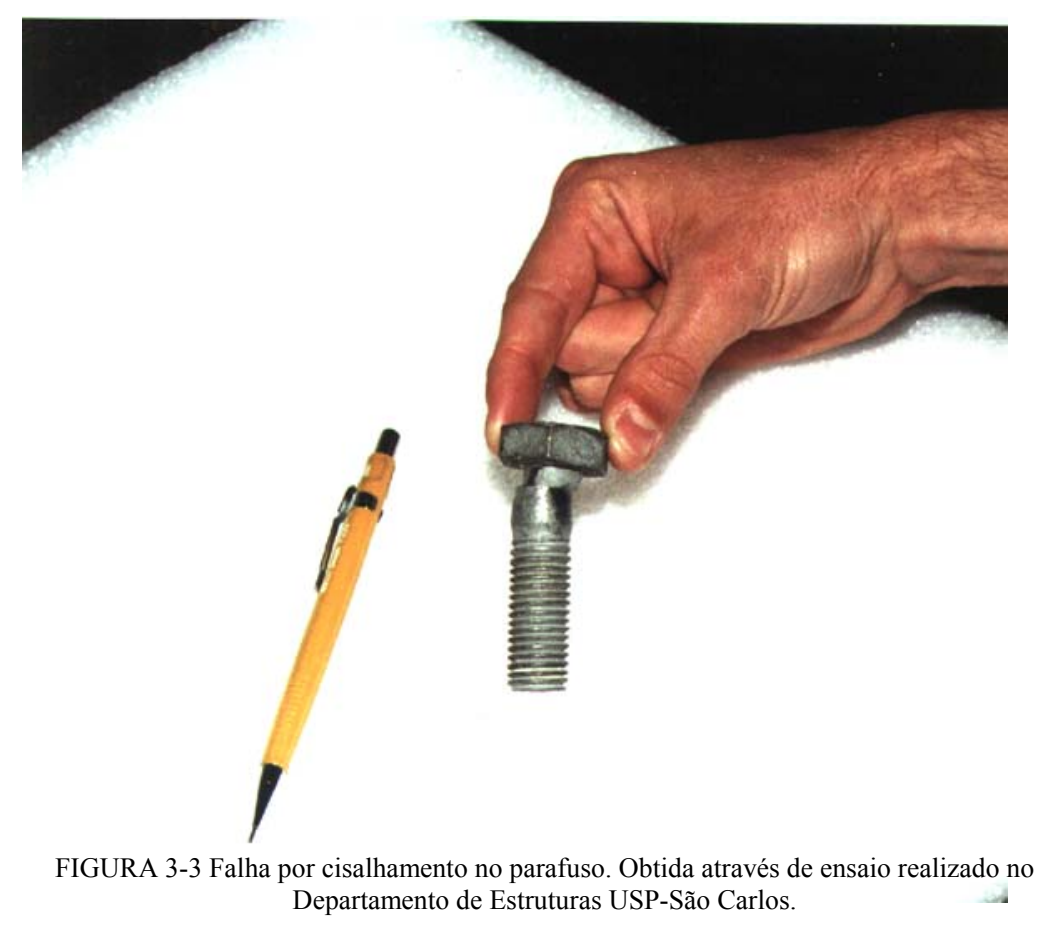

\section{2 - Conexões por contato: parafusos sob força cortante}

\subsection{1 - Pressão de contato}

Na determinação da resistência, o estado limite último de contato relaciona-se com a deformação ao redor do furo, como mostrado na fig. 3-2d, ou com o rasgamento do metal base (fig. 3-2b).

A relação entre tensões de contato e o rasgamento do metal base junto à borda pode ser avaliada de maneira simplificada, admitindo que a ruptura ocorra ao longo das linhas tracejadas 1-1 e 2-2 mostradas na fig. 3-4. O ângulo $\theta$ pode ser tomado de maneira conservadora como zero, definindo planos de ruptura paralelos à força $P$.

Segundo GAYLORD et al. [ 27 ], a força $P$ que correspondente à ruptura do metal base por rasgamento ao longo das linhas paralelas à força $P$ é : 


$$
P=2\left(L-\frac{d}{2}\right) t \tau_{u}
$$

onde: $\tau_{\mathrm{u}}=$ tensão de cisalhamento última do metal base, que é $\approx 0,62 \mathrm{f}_{\mathrm{u}}$

$\mathrm{f}_{\mathrm{u}}=$ limite de resistência à tração do metal base

Rescrevendo a expressão 3.2.1, obtém-se:

$$
\mathrm{P}=2 \mathrm{~d}\left(\frac{\mathrm{L}}{\mathrm{d}}-\frac{1}{2}\right) \mathrm{t} 0,62 \mathrm{f}_{\mathrm{u}}=1,24 \mathrm{dtf}_{\mathrm{u}}\left(\frac{\mathrm{L}}{\mathrm{d}}-\frac{1}{2}\right)
$$

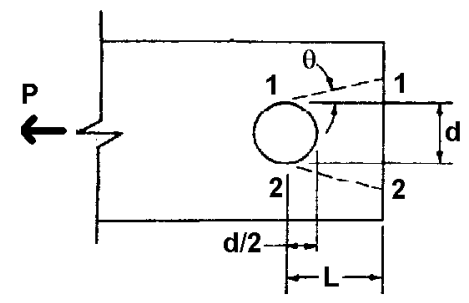

FIGURA 3-4 Resistência à pressão de contato relacionada com a distância à borda. Adaptada de SALMON \& JOHNSON [ 60 ].

Esta força $P$ pode ser associada a uma pressão de contato $f_{p}$, definida pela relação entre $P$ e a área efetiva de contato $A_{b}$, dada pelo produto entre o diâmetro do parafuso e a espessura do metal base, deste modo:

$$
P=f_{p} d t=f_{p} A_{b}
$$

É interessante registrar que a distribuição da pressão de contato ao redor do perímetro do furo é complexa. Para propósito de projetos, admite-se uma distribuição uniforme na área efetiva de pressão de contato $A_{b}$.

Igualando as expressões 3.2.2 e 3.2.3, obtém-se:

$$
\frac{\mathrm{L}}{\mathrm{d}}=\frac{\mathrm{f}_{\mathrm{p}}}{1,24 \mathrm{f}_{\mathrm{u}}}+\frac{1}{2}
$$

Esta expressão está em conformidade com resultados experimentais, até um determinado limite da relação $L / d$, pois a partir deste limite ocorre uma alteração no mecanismo de falha, passando a ocorrer o esmagamento do metal base (fig. 3-2d) e não mais o rasgamento entre furo e borda (fig. 3-2b). Na prática, a relação $f_{p} / f_{u}$ situase entre 1 e 3, o que pode aproximar a expressão 3.2.4 para: 


$$
\frac{\mathrm{L}}{\mathrm{d}} \approx \frac{\mathrm{f}_{\mathrm{p}}}{\mathrm{f}_{\mathrm{u}}} \rightarrow \mathrm{L}=\frac{\mathrm{f}_{\mathrm{p}} \mathrm{d}}{\mathrm{f}_{\mathrm{u}}}=\frac{\mathrm{f}_{\mathrm{p}} \mathrm{dt}}{\mathrm{f}_{\mathrm{u}} \mathrm{t}}=\frac{\mathrm{P}}{\mathrm{f}_{\mathrm{u}} \mathrm{t}}
$$

Associando $P$ à resistência nominal de contato $R_{n}$, tem-se:

$\mathrm{R}_{\mathrm{n}}=\mathrm{Ltf} \mathrm{f}_{\mathrm{u}}$

A área efetiva de pressão de contato foi definida como $A_{b}=d t$, assim:

$$
R_{n}=\frac{L}{d} d t f_{u}=\alpha A_{b} f_{u}
$$

A expressão apresentada pelas normas para a avaliação da resistência do metal base tem a forma da expressão 3.2.7 definida anteriormente. O parâmetro $\alpha$ assume o valor máximo $(3,0)$, o que corresponde à mudança do tipo de falha: de rasgamento para esmagamento.

Segundo a NBR 8800 [ 7 ], a resistência de cálculo à pressão de contato no furo, já levando em conta a resistência ao rasgamento entre dois furos consecutivos ou entre um furo extremo e a borda, é dada por :

$$
\phi \mathrm{R}_{\mathrm{n}}=\phi\left(\alpha \mathrm{A}_{\mathrm{b}} \mathrm{f}_{\mathrm{u}}\right)
$$

onde: $\phi=0,75$

$\alpha=3,0$ para esmagamento sem possibilidade de rasgamento;

$\alpha=(\mathrm{s} / \mathrm{d})-\eta_{1} \leq 3,0$ para rasgamento entre dois furos consecutivos, cujos centros estejam espaçados de $s$, quando a força no parafuso não for ortogonal à reta que liga os centros destes furos, caso contrário $\alpha=3,0$;

$\alpha=(\mathrm{e} / \mathrm{d})-\eta_{2} \leq 3,0$ para rasgamento entre furo e uma borda situada à uma distância $e$ do centro do furo, quando a força no parafuso não for paralela à borda, caso contrário $\alpha=3,0$. Havendo duas bordas a considerar (furos próximos aos cantos), prevalece a que der o menor valor de $\alpha$

$\mathrm{s}=$ espaçamento de centro a centro dos furos (neste caso, $\mathrm{L}=\mathrm{s}-0,5 \mathrm{~d}$ )

$\mathrm{e}=$ distância do centro do furo à borda (neste caso, $\mathrm{L}=\mathrm{e}$ )

$\mathrm{d}=$ diâmetro nominal do parafuso

$\eta_{1}, \eta_{2}=$ coeficientes que dependem do tipo do furo, dados na tabela 3-1 
De acordo com QUEIROZ [ 56 ], para o rasgamento entre dois furos padrão consecutivos, a área de rasgamento é igual a $2(\mathrm{~s}-0,5 \mathrm{~d}) \mathrm{t}$ e a tensão que provoca o rasgamento é igual a $0,5 f_{u}$ (o valor avaliado experimentalmente é $\tau_{\mathrm{u}}=0,62$ a $0,70 \mathrm{f}_{\mathrm{u}}$, portanto conclui-se que o valor de $0,5 f_{u}$ é uma aproximação feita pelo autor). Desta forma:

$R_{\mathrm{n}}=2(\mathrm{~s}-0,5 \mathrm{~d}) \mathrm{t}\left(0,5 \mathrm{f}_{\mathrm{u}}\right)=\mathrm{dtf}_{\mathrm{u}}[(\mathrm{s} / \mathrm{d})-0,5]$

Com isso, deduz-se o valor de $\eta_{1}=0,5$ para furos padrão.

Para o rasgamento entre um furo padrão e a borda, a área de rasgamento considerada é igual a 2et. Desta forma:

$$
\mathrm{R}_{\mathrm{n}}=2 \mathrm{e} \mathrm{t}\left(0,5 \mathrm{f}_{\mathrm{u}}\right)=\mathrm{dtf}_{\mathrm{u}}[(\mathrm{e} / \mathrm{d})-0]
$$

Com isso, deduz-se o valor de $\eta_{2}=0$ para furos padrão.

TABELA 3-1 Valores de $\eta_{1}$ e $\eta_{2}$, segundo a NBR 8800 [ 7 ].

\begin{tabular}{|c|c|c|}
\hline Tipo de furo & $\eta_{1}$ & $\eta_{2}$ \\
\hline Furo padrão ou furo alongado na direção perpendicular de rasgamento & 0,50 & 0 \\
\hline Furo alargado & 0,72 & 0,12 \\
\hline Furo pouco alongado na direção de rasgamento & 0,83 & 0,20 \\
\hline Furo muito alongado na direção de rasgamento & 1,94 para $\mathrm{d} \leq 40$ & 0,75 \\
\hline Furo muito alongado na direção de rasgamento* & 2,0 para $\mathrm{d}>40$ & 0,75 \\
\hline
\end{tabular}

* Caso haja uma diferença $y$, entre a maior dimensão do furo muito alongado, dada na tabela 1-5 do capítulo 1, e a maior dimensão efetivamente utilizada, o valor de $\eta_{1}$ pode ser reduzido de $y / d$ e o valor de $\eta_{2}$ pode ser reduzido de $y /(2 d)$.

O AISC/LRFD 93 [ 4 ] estabelece para situações usuais onde $L \geq 1,5 \mathrm{~d}$ e $\mathrm{s} \geq$ 3d, com dois ou mais furos na direção da força, as seguintes expressões para resistência de cálculo à pressão de contato:

( $L$ e $s$ são definidos da seguinte forma:

$L=$ distância na direção da força, da borda ao centro de um furo padrão ou ao centro de um furo pouco ou muito alongado de eixo perpendicular à direção da força. Para furos alargados e furos pouco ou muito alongados de eixo paralelo à direção força, $L$ deve ser acrescido pelo incremento $C_{2}$ da tabela 3-2.

$s=$ espaçamento na direção da força entre centros de furos padrão ou entre centros de furos pouco ou muito alongados de eixo perpendicular à direção da força. Para furos alargados e furos pouco ou muito alongados paralelos à direção da força, $s$ deve ser acrescido pelo incremento $C_{1}$ da tabela 3-3) 


\begin{tabular}{|c|c|c|c|c|}
\hline \multirow{2}{*}{$\begin{array}{c}\text { Diâmetro nominal } \\
\text { do parafuso }\end{array}$} & $\begin{array}{c}\text { Furos } \\
\text { alargados }\end{array}$ & \multicolumn{2}{|l|}{ Furos alongados } \\
\cline { 3 - 4 } & & Eixo perpendicular à borda & \multirow{2}{|c|}{$\begin{array}{c}\text { Eixo paralelo à } \\
\text { borda }\end{array}$} \\
\cline { 3 - 3 } & & Pouco alongado & Muito alongado & \\
\hline$\leq 7 / 8 ”$ & $1 / 16$ & $1 / 8$ & \multirow{2}{*}{$3 / 4 \mathrm{~d}$} & \multirow{2}{*}{0} \\
\hline $1 "$ & $1 / 8$ & $1 / 8$ & & \\
\hline$\geq 11 / 8 ”$ & $1 / 8$ & $3 / 16$ & \\
\hline
\end{tabular}

TABELA 3-3 Valores do incremento $C_{1}$ do espaçamento (valores em polegadas). Adaptada do AISC/LRFD 93 [ 4 ].

\begin{tabular}{|c|c|c|c|c|}
\hline $\begin{array}{c}\text { Diâmetro nominal } \\
\text { do parafuso }\end{array}$ & $\begin{array}{c}\text { Furos } \\
\text { alargados }\end{array}$ & \multicolumn{2}{|c|}{ Furos alongados } & \multirow{2}{|c|}{ Eixo perpendicular } \\
\cline { 3 - 4 } & & $\begin{array}{c}\text { Eixo paralelo à direção da } \\
\text { força }\end{array}$ & \multirow{2}{*}{$\begin{array}{c}\text { Muito direção da força } \\
\text { alongado }\end{array}$} & \\
\cline { 3 - 3 } & & $\begin{array}{c}\text { Pouco alongado } \\
1 / 2 \mathrm{~d}-1 / 16 \\
17 / 16\end{array}$ & \multirow{2}{*}{0} \\
\hline$\leq 7 / 8 ”$ & $1 / 8$ & $3 / 16$ & $1 / 2 \mathrm{~d}-1 / 16$ & \\
\hline $1 "$ & $3 / 16$ & $5 / 16$ & & \\
\hline$\geq 11 / 8 ”$ & $1 / 4$ & & &
\end{tabular}

Quando a deformação ao redor do furo não é uma consideração de projeto (deformação no furo pode exceder $6,35 \mathrm{~mm}(0,25 "))$, a resistência de cálculo à pressão de contato pode ser avaliada como:

- entre furo e borda:

$$
\phi \mathrm{R}_{\mathrm{n}}=\phi \mathrm{Ltf}_{\mathrm{u}} \leq \phi 3,0 \mathrm{~A}_{\mathrm{b}} \mathrm{f}_{\mathrm{u}}
$$

onde: $\phi=0,75$

- entre furos consecutivos:

$$
\phi \mathrm{R}_{\mathrm{n}}=\phi(\mathrm{s}-\mathrm{d} / 2) \mathrm{tf}_{\mathrm{u}} \leq \phi 3,0 \mathrm{~A}_{\mathrm{b}} \mathrm{f}_{\mathrm{u}}
$$

onde: $\phi=0,75$

Quando se deseja limitar as deformações na parede dos furos (deformação inferior a $6,35 \mathrm{~mm}(0,25$ ”)) basta reduzir o valor de $\alpha$, o que é previsto pelo AISC/LRFD 93 [ 4 ] e pelo AISC/ASD [ 1 ].

Desta forma, para todos os furos exceto furos muito alongados perpendiculares à direção da força:

$$
\phi \mathrm{R}_{\mathrm{n}}=\phi 2,4 \mathrm{f}_{\mathrm{u}} \mathrm{A}_{\mathrm{b}}
$$

onde: $\phi=0,75$ 
Para furos muito alongados perpendiculares à direção da força:

$$
\phi \mathrm{R}_{\mathrm{n}}=\phi 2,0 \mathrm{f}_{\mathrm{u}} \mathrm{A}_{\mathrm{b}}
$$

onde: $\phi=0,75$

Quando $\mathrm{L}<1,5 \mathrm{~d}$ ou $\mathrm{s}<3 \mathrm{~d}$ ou para um único parafuso, tem-se as seguintes expressões:

Para todos os furos exceto furos muito alongados perpendiculares à direção da força:

- para um único furo ou entre furo e borda quando existem dois ou mais parafusos na direção da força:

$$
\phi \mathrm{R}_{\mathrm{n}}=\phi \mathrm{Ltf}_{\mathrm{u}} \leq \phi 2,4 \mathrm{f}_{\mathrm{u}} \mathrm{A}_{\mathrm{b}}
$$

onde: $\phi=0,75$

- entre furos consecutivos:

$$
\phi \mathrm{R}_{\mathrm{n}}=\phi(\mathrm{s}-\mathrm{d} / 2) \mathrm{tf}_{\mathrm{u}} \leq \phi 2,4 \mathrm{f}_{\mathrm{u}} \mathrm{A}_{\mathrm{b}}
$$

onde: $\phi=0,75$

Para furos muito alongados perpendiculares à direção da força:

- para um único furo ou entre furo e borda quando existem dois ou mais parafusos na direção da força:

$$
\phi \mathrm{R}_{\mathrm{n}}=\phi \mathrm{Ltf}_{\mathrm{u}} \leq \phi 2,0 \mathrm{f}_{\mathrm{u}} \mathrm{A}_{\mathrm{b}}
$$

onde: $\phi=0,75$

- entre furos consecutivos:

$$
\phi \mathrm{R}_{\mathrm{n}}=\phi(\mathrm{s}-\mathrm{d} / 2) \mathrm{tf}_{\mathrm{u}} \leq \phi 2,0 \mathrm{f}_{\mathrm{u}} \mathrm{A}_{\mathrm{b}}
$$

onde: $\phi=0,75$

Segundo o AISC/ASD [ 1 ], a resistência à pressão de contato é dividida pelo fator de segurança $F S$, que é tradicionalmente 2 neste caso. Admitindo-se a área efetiva de pressão de contato (d.t), e quando $\mathrm{L} \geq 1,5 \mathrm{~d}$ e $\mathrm{s} \geq 3 \mathrm{~d}$ (lembrando que os 
mesmos incrementos $C_{1}$ e $C_{2}$ apresentados nas tabelas 3-3 e 3-2, respectivamente, também são utilizados pelo AISC/ASD [ 1 ]) tem-se as seguintes tensões admissíveis de contato:

Para furos padrão, alargados ou furos pouco alongados com dois ou mais parafusos na direção da força:

$$
\mathrm{f}_{\mathrm{p}}=\frac{\mathrm{R}_{\mathrm{n}}}{\text { FS d t }}=\frac{2,4 \mathrm{f}_{\mathrm{u}} \mathrm{dt}}{2,0 \mathrm{~d} \mathrm{t}^{\mathrm{t}}}=1,2 \mathrm{f}_{\mathrm{u}}
$$

Para furos muito alongados com o eixo perpendicular à direção da força e com dois ou mais parafusos na direção da força:

$$
f_{p}=f_{u}
$$

Quando a deformação ao redor do furo não é uma consideração de projeto, é valida a seguinte expressão:

$$
\mathrm{f}_{\mathrm{p}}=\frac{\mathrm{R}_{\mathrm{n}}}{\mathrm{FS} \mathrm{d} \mathrm{t}}=\frac{3,0 \mathrm{f}_{\mathrm{u}} \mathrm{dt}}{2,0 \mathrm{~d} \mathrm{t}}=1,5 \mathrm{f}_{\mathrm{u}}
$$

De acordo com o EUROCODE 3 [ 24 ], em estado limite último a força cortante de cálculo $F_{v . S d}$ de um parafuso, não deverá exceder a resistência de cálculo à pressão de contato $F_{b . R d}\left(\right.$ correspondente a $\phi R_{n}$ da NBR 8800 [ 7 ]).

$$
\mathrm{F}_{\mathrm{b} . \mathrm{Rd}}=\frac{2,5 \sigma \mathrm{f}_{\mathrm{u}} \mathrm{dt}}{\gamma_{\mathrm{Mb}}}
$$

onde: $\sigma=$ menor valor entre $\frac{\mathrm{e}_{1}}{3 \mathrm{~d}_{0}} ; \frac{\mathrm{p}_{1}}{3 \mathrm{~d}_{0}}-\frac{1}{4} ; \frac{\mathrm{f}_{\mathrm{ub}}}{\mathrm{f}_{\mathrm{u}}}$ ou 1,0

$\mathrm{e}_{1}, \mathrm{p}_{1}=$ definidos na fig. $3-5 \mathrm{a}$

$\mathrm{d}=$ diâmetro do parafuso

$\mathrm{d}_{0}=$ diâmetro do furo

$\mathrm{t}=$ espessura da chapa

$\mathrm{f}_{\mathrm{u}}=$ resistência à tração do metal base

$\mathrm{f}_{\mathrm{ub}}=$ resistência à tração do material do parafuso

$\gamma_{\mathrm{Mb}}=1,25$ (fator de segurança parcial) 
Esta resistência de cálculo à pressão de contato se aplica somente quando a distância $e_{2}$ não for menor que $1,5 d_{0}$ e o espaçamento $p_{2}$ medido transversalmente à direção da força não for menor que 3, $0 d_{0}\left(e_{2}\right.$ e $p_{2}$ definidos na fig. 3-5a).

Se $e_{2}$ é reduzido para $1,2 d_{0}$ e/ou $p_{2}$ é reduzido para $2,4 d_{0}$, então a resistência à pressão de contato deverá ser multiplicada por 2/3. Para valores intermediários $1,2 d_{0}$ $<e_{2} \leq 1,5 d_{0}$ e/ou $2,4 d_{0}<p_{2} \leq 3 d_{0}$ o valor de $F_{b . R d}$ pode ser determinado por interpolação linear.

Para parafusos em furos de espaçamento normal, valores conservadores de $F_{b . R d}$, baseados no diâmetro do parafuso, podem ser obtidos pela tabela 3-4.

TABELA 3-4 Resistência de cálculo à pressão de contato, baseada no diâmetro do parafuso. Adaptada de EUROCODE 3 [ 24 1

Valores conservadores para parafusos em furos padrão com $\gamma_{\mathrm{Mb}}=1,25$

\begin{tabular}{|c|c|c|c|}
\hline $\begin{array}{c}\text { Classe de contato } \\
\text { nominal }\end{array}$ & Mínima dimensão $\mathrm{e}_{1}$ & Mínima dimensão $\mathrm{p}_{1}$ & $\begin{array}{c}\text { Resistência de cálculo à } \\
\text { pressão de contato } \mathrm{F}_{\mathrm{b} . \mathrm{Rd}}\end{array}$ \\
\hline Baixa & $1,7 \mathrm{~d}$ & $2,5 \mathrm{~d}$ & $1,0 \mathrm{f}_{\mathrm{u}} \mathrm{dt}^{*}$ \\
\hline Média & $2,5 \mathrm{~d}$ & $3,4 \mathrm{~d}$ & $1,5 \mathrm{f}_{\mathrm{u}} \mathrm{dt}^{*}$ \\
\hline Alta & $3,4 \mathrm{~d}$ & $4,3 \mathrm{~d}$ & $2,0 \mathrm{f}_{\mathrm{u}} \mathrm{dt}^{*}$ \\
\hline
\end{tabular}

* Mas $\mathrm{F}_{\mathrm{b} . \mathrm{Rd}} \leq 2,0 \mathrm{f}_{\mathrm{ub}} \mathrm{dt}$

\subsubsection{Critérios de furação}

Em geral, as normas estabelecem critérios de distância à borda e espaçamento entre parafusos. Segundo OWENS \& CHEAL [ 50 ], os critérios de distâncias e espaçamentos mínimos são especificados pelas seguintes razões:

- proporcionar um espaço adequado para o aperto dos parafusos;

- limitar qualquer interação adversa entre altas tensões de contato provenientes dos parafusos vizinhos;

- para eliminar qualquer tendência ao rompimento ou evitar deformações da chapa no plano, ocasionadas durante o broqueamento ou puncionamento dos furos (esta razão refere-se particularmente ao critério de mínima distância à borda);

- garantir adequada resistência do metal base na eventual ruptura de parafusos.

Segundo SALMON \& JOHNSON [ 60 ], quando a distância à borda é no mínimo 1,5d, as expressões definidas anteriormente se aplicam. Entretanto, quando 
são utilizados valores mais elevados da resistência à pressão de contato, a mínima distância à borda pode ser calculada pela expressão geral 3.2.6.

Igualando-se a força de cálculo $P_{d}$ à resistência de cálculo à pressão de contato $\phi R_{n}$, tem-se segundo o AISC/LRFD 93 [ 4 ]:

$$
L \geq\left(\frac{\mathrm{R}_{\mathrm{n}}}{\mathrm{f}_{\mathrm{u}} \mathrm{t}}\right) \quad \therefore \mathrm{L} \geq\left(\frac{\mathrm{P}_{\mathrm{d}}}{\phi \mathrm{f}_{\mathrm{u}} \mathrm{t}}\right)
$$

onde: $\phi=0,75$

$\mathrm{P}_{\mathrm{d}}=$ força de cálculo atuando em um parafuso

E segundo o AISC/ASD [ 1 ], usando o fator de segurança igual a 2 tem-se:

$$
L \geq\left(\frac{2 P}{f_{u} t}\right)
$$

Da mesma forma, quando o espaçamento dos parafusos na direção da força é no mínimo $3 d$ os valores dados pelas expressões definidas anteriormente se aplicam. Sob outras condições, é utilizada a expressão geral 3.2.6, adicionada do raio do furo $d_{h} / 2$, para se obter um espaçamento mínimo de centro a centro. Tomando-se $P_{d}=$ $\phi R_{n}$, segundo o AISC/LRFD 93 [ 4 ] tem-se:

$$
\mathrm{s} \geq\left(\frac{\mathrm{R}_{\mathrm{n}}}{\mathrm{f}_{\mathrm{u}} \mathrm{t}}+\frac{\mathrm{d}_{\mathrm{h}}}{2}\right) \quad \therefore \mathrm{s} \geq\left(\frac{\mathrm{P}_{\mathrm{d}}}{\phi \mathrm{f}_{\mathrm{u}} \mathrm{t}}+\frac{\mathrm{d}_{\mathrm{h}}}{2}\right)
$$

onde: $\phi=0,75$

$\mathrm{s}=$ espaçamento de centro a centro dos furos (não deve ser menor que 2,67d)

Pelo AISC/ASD [ 1 ], usando o fator de segurança igual a 2 tem-se:

$$
\mathrm{s} \geq\left(\frac{2 \mathrm{P}_{\mathrm{d}}}{\mathrm{f}_{\mathrm{u}} \mathrm{t}}+\frac{\mathrm{d}_{\mathrm{h}}}{2}\right)
$$

Segundo o EUROCODE 3 [ 24 ], tem-se os seguintes posicionamentos de furos para parafusos e rebites (ver fig. 3-5):

- mínima distância de borda $e_{1}$, medida na direção da força, não deverá ser menor que $1,2 d_{0}\left(d_{0}\right.$ é o diâmetro do furo). 
- mínima distância de borda $e_{2}$, medida na direção perpendicular à força, não deverá ser menor que $1,5 d_{0}$. Essa distância mínima pode ser reduzida para $1,2 d_{0}$, desde que a resistência de cálculo à pressão de contato também seja reduzida.

- mínimo espaçamento $p_{1}$ entre parafusos, na direção da força, não deverá ser menor que $2,2 d_{0}$. $\mathrm{O}$ espaçamento $p_{2}$ entre os parafusos, medido perpendicularmente à direção da força, não deverá ser menor que 3,0d, Este espaçamento pode ser reduzido para $2,4 d_{0}$, desde que a resistência de cálculo à pressão de contato também seja reduzida.

- para furos alongados (ver fig. 3-5b), a mínima distância $e_{3}$, medida perpendicularmente ao eixo do furo, não deverá ser menor que $1,5 d_{0}$. A mínima distância $e_{4}$, medida na direção do eixo do furo, também não deverá ser menor que $1,5 d_{0}$.

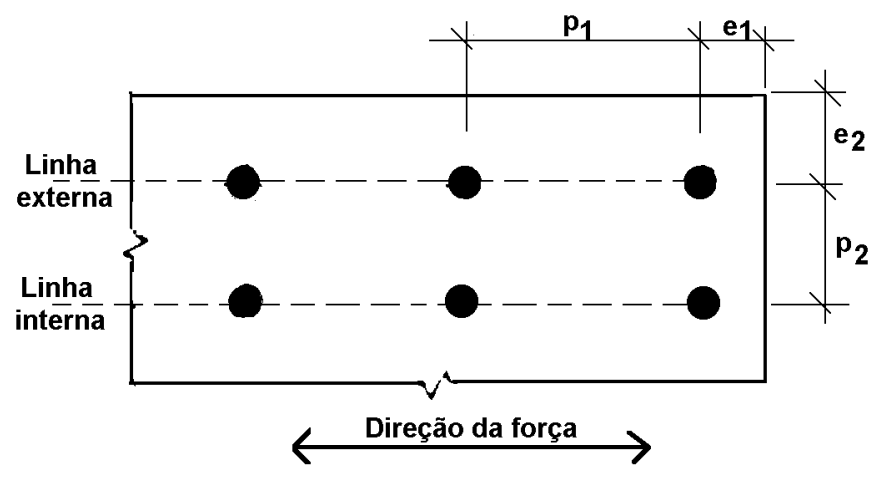

(a)

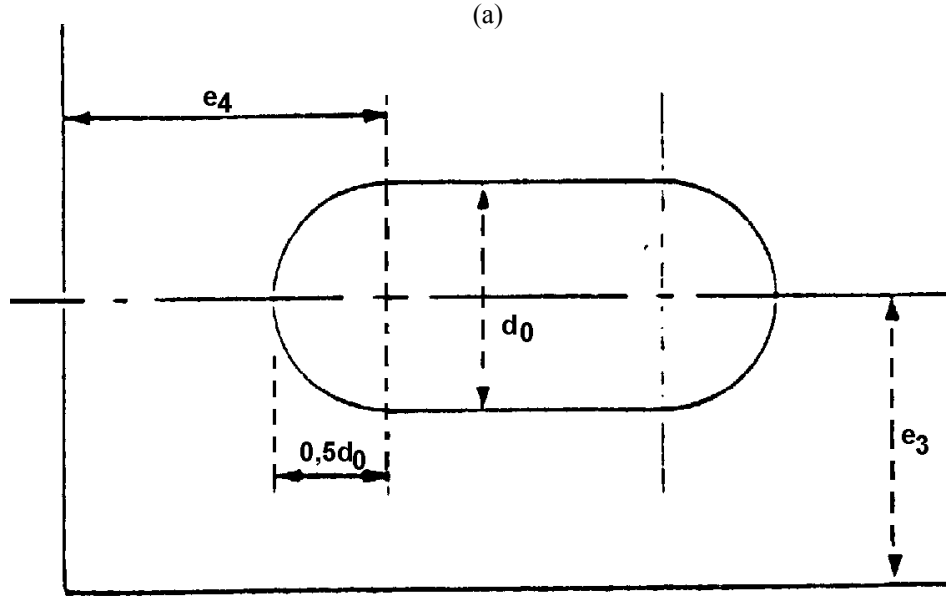

(b)

FIGURA 3-5 (a) Símbolos de espaçamento de parafusos; (b) distância de extremidade e borda para furos alongados. Adaptada de EUROCODE 3 [ 24 ].

A NBR 8800 [ 7 ], especifica que a mínima distância entre centros de furos padrão, alargados ou alongados, não pode ser inferior a $2,7 d$, de preferência $3 d$, sendo $d$ o diâmetro nominal do parafuso. 
A maioria das especificações fornece uma distância mínima de extremidade para todos os parafusos em qualquer direção rumo à borda. Esses valores, segundo a NBR 8800 [ 7 ], são mostrados na tabela 3-5.

TABELA 3-5 Distância mínima do centro de um furo padrão à borda ${ }^{(\mathrm{A})}$. Adaptada da NBR 8800 [ 7 ].

\begin{tabular}{|c|c|c|c|}
\hline \multicolumn{2}{|c|}{ Diâmetro (d) } & \multirow[b]{2}{*}{$\begin{array}{c}\text { Borda cortada com serra ou } \\
\text { tesoura }(\mathrm{mm})\end{array}$} & \multirow[b]{2}{*}{$\begin{array}{c}\text { Borda laminada ou cortada a } \\
\text { maçarico }(\mathrm{mm})^{(\mathrm{B})(\mathrm{D})}\end{array}$} \\
\hline ASTM & ISO & & \\
\hline & M 12 & 21 & 18 \\
\hline $12,5 \mathrm{~mm}\left(1 / 2{ }^{\prime \prime}\right)$ & & 22 & 19 \\
\hline $16 \mathrm{~mm}\left(5 / 8^{\prime \prime}\right)$ & M 16 & 29 & 22 \\
\hline \multirow[t]{2}{*}{$19 \mathrm{~mm}(3 / 4 ")$} & & 32 & 26 \\
\hline & M 20 & $35^{(\mathrm{C})}$ & 27 \\
\hline \multirow[t]{2}{*}{$22 \mathrm{~mm}\left(7 / 8^{\prime \prime}\right)$} & M 22 & $38^{(\mathrm{C})}$ & 29 \\
\hline & M 24 & 42 & 31 \\
\hline $25 \mathrm{~mm}(1 ")$ & & 44 & 32 \\
\hline \multirow[t]{2}{*}{29 mm (1 1/8”) } & M 27 & 50 & 38 \\
\hline & M 30 & 53 & 39 \\
\hline \multirow[t]{2}{*}{$32 \mathrm{~mm}\left(1 \mathrm{1} / 4^{\prime \prime}\right)$} & & 57 & 41 \\
\hline & M 33 & 58 & 42 \\
\hline$>32 \mathrm{~mm}\left(1 \mathrm{1} / 4^{\prime \prime}\right)$ & $>$ M 33 & $1,75 . d$ & $1,25 . d$ \\
\hline
\end{tabular}

(A) Para furos alargados ou alongados essas distâncias não podem ser inferiores ao apresentado na tabela, acrescido de $\beta$ d, onde $\beta=0$ para furos alongados na direção paralela à borda considerada; $\beta=0,12$ para furos alargados; $\beta=0,20$ para furos pouco alongados na direção perpendicular à borda considerada; $\beta=0,75$ para furos muito alongados na direção perpendicular à borda considerada.

(B) As bordas cortadas com maçaricos devem ser lisas e isentas de entalhes.

(C) Nas extremidades de cantoneiras de ligação de vigas, esta distância pode ser igual a $32 \mathrm{~mm}$.

(D) O AISC/LRFD 86 [ 3 ], recomenda que todas as distâncias nesta coluna podem ser reduzidas em 3,175 mm (1/8"), quando o furo estiver em um ponto onde as tensões não excedam $25 \%$ da máxima resistência de cálculo do elemento.

Além das exigências relativas aos espaçamentos e distâncias mínimas, as normas estabelecem valores máximos para as distâncias entre furos ou entre furos e bordas, cujo objetivo principal é garantir o contato eficiente entre as partes conectadas, amenizando os problemas de corrosão e de empenamentos nestas regiões.

A NBR 8800 [ 7 ], o AISC/ASD [ 1 ] e o AISC/LRFD 86 [ 3 ] prescrevem que a máxima distância do centro de um furo à borda mais próxima deverá ser $12 \mathrm{t}$ (não excedendo $150 \mathrm{~mm}$ ), onde $t$ é a espessura da parte conectada em análise.

O AISC/LRFD 93 [ 4 ] além da especificação anterior, também prescreve que o máximo espaçamento longitudinal de parafusos, para elementos em contato contínuo deve ser: (a) para elementos pintados ou não pintados protegidos contra corrosão, o espaçamento não deverá exceder 24 vezes a espessura da chapa mais fina ou $300 \mathrm{~mm}$ (12”); (b) para perfis de aço não pintados, não protegidos à corrosão 
atmosférica, o espaçamento não deverá exceder 14 vezes a espessura da chapa mais fina ou $180 \mathrm{~mm}\left(7^{\prime \prime}\right)$.

Segundo o EUROCODE 3 [ 24 ], quando os perfis são expostos a intempéries ou outros agentes corrosivos, as distâncias de borda máximas não deverão exceder $40 \mathrm{~mm}+4 \mathrm{t}$, onde $t$ é a espessura da parte conectada externa mais fina. Em outros casos essas distâncias não deverão exceder $12 \mathrm{t}$ ou $150 \mathrm{~mm}$, qualquer que seja o maior.

O EUROCODE 3 [ 24 ], também apresenta as seguintes prescrições em relação aos espaçamentos máximos:

- máximo espaçamento em perfis comprimidos; $p_{1}$ e $p_{2}$ não deverão exceder $14 \mathrm{t}$ ou $200 \mathrm{~mm}$;

- máximo espaçamento em perfis tracionados; o espaçamento $p_{1}$ dos parafusos na linha interna pode ser duas vezes o prescrito para perfis em compressão $\left(\mathrm{p}_{1} \leq 28 \mathrm{t}\right.$ ou $\leq 400 \mathrm{~mm}$ ), desde que o espaçamento nas linhas externas não exceda o dado para perfis comprimidos $\left(\mathrm{p}_{1} \leq 14 \mathrm{t}\right.$ ou $\left.\leq 200 \mathrm{~mm}\right)$. Ambos esses valores podem ser multiplicados por 1,5 em perfis não expostos à intempéries ou outros agentes corrosivos.

\subsubsection{Resistência à força cortante}

Nas ligações parafusadas, cuja força resultante é perpendicular ao eixo dos parafusos, a transmissão desta força ocorre por meio de dois mecanismos: o atrito mobilizado entre as partes e o contato do corpo dos parafusos nos respectivos furos. Em grande parte das conexões, a força real atuante (de serviço) é bem inferior àquela avaliada no projeto, portanto, desde que haja uma pequena pré-tração dos parafusos, o mecanismo de atrito acaba sendo responsável pela transmissão desta força.

Analisando o comportamento resistente de uma conexão com vários parafusos alinhados (fig. 3-6), submetida a um carregamento crescente, observa-se os seguintes estágios de comportamento:

- inicialmente a força é transmitida pelo atrito mobilizado nas extremidades, não havendo deslizamentos (fig. 3-6a); 
- quando o atrito nas extremidades é vencido, ocorre o contato destes parafusos extremos na parede dos furos, havendo pequenas deformações nestas regiões e conseqüentemente pequenos deslizamentos (fig. 3-6b);

- aumentando-se a força, a zona de deslizamento caminha para a porção central da conexão, até que a resistência global ao atrito seja vencida, surgindo elevadas deformações e elevados deslizamentos relativos, que é função das folgas existentes entre parafusos e furos (fig. 3-6c);

- na seqüência, os parafusos e o metal base das extremidades vão sofrendo elevadas deformações e conseqüentemente atingindo a plastificação, tendendo a uma uniformização da força transmitida, fenômeno este mais acentuado quanto maior for a ductilidade dos aços envolvidos (fig. 3-6d).

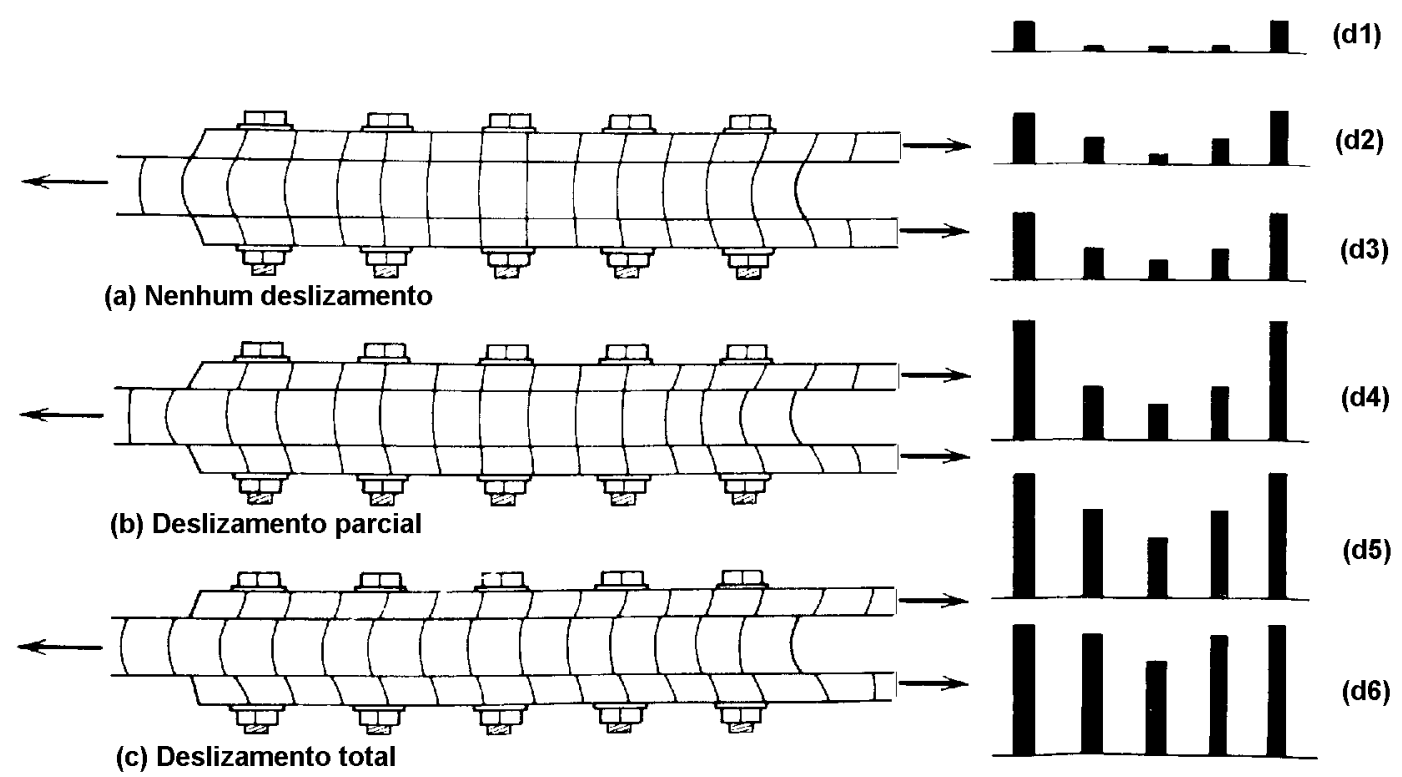

(d)

FIGURA 3-6 (a),(b),(c) Representação esquemática de três estágios de carregamento numa conexão parafusada; (d1) a (d6) força cortante nos parafusos em função do estágio de carregamento. Adaptada de KULAK et. al. [ 34 ].

Nas conexões com muitos parafusos (seis ou mais), é provável a ocorrência de falha nos parafusos extremos antes que ocorra a uniformização da força entre os parafusos, uma vez que pode haver grandes deformações nas extremidades da conexão. Para as conexões com poucos parafusos, é provável a ocorrência desta uniformização, uma vez que as deformações e deslizamentos observados atingem valores relativamente pequenos.

Vários pesquisadores têm analisado experimentalmente o comportamento de parafusos submetidos à força cortante, aplicando tração ou compressão nas chapas 
constituintes dos corpos-de-prova. Resultados típicos de ensaios em parafusos ASTM A325 e ASTM A490 são mostrados na fig. 3-7. Segundo KULAK et al. [ 34 ], tal como esperado, os parafusos A490 apresentam maior resistência à força cortante e menor ductilidade que os A325.

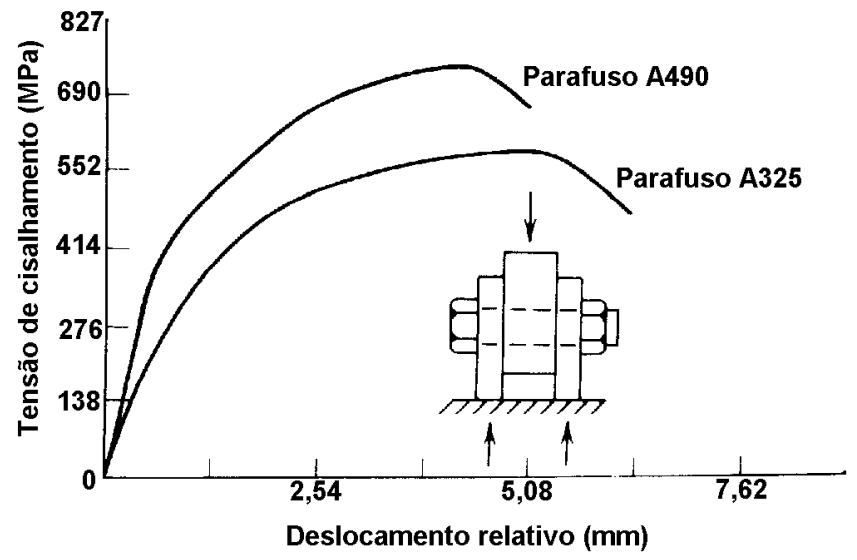

FIGURA 3-7 Típicas curvas tensão de cisalhamento versus deslocamento relativo para parafusos A325 e A490. Adaptada de KULAK et al. [ 34 ].

Da análise experimental verifica-se que a razão entre a resistência à força cortante e a resistência à tração independe do aço do parafuso. A resistência à força cortante média é aproximadamente $62 \%$ da resistência à tração, o que está em conformidade com o critério de resistência de von Mises.

Os ensaios têm mostrado também que a força de aperto nos parafusos (prétração) não tem efeito significativo na sua resistência à força cortante, alterando apenas o atrito mobilizado entre as partes da conexão, e conseqüentemente o instante em que ocorre o deslizamento.

Segundo OWENS \& CHEAL [ 50 ], a resistência da conexão é influenciada consideravelmente pela posição da porção rosqueada do parafuso, em relação aos planos de cisalhamento. A presença de rosca nos planos de cisalhamento reduzem não só a resistência da conexão como também sua ductilidade, ou seja, sua capacidade de deformação (ver fig. 3-8).

Segundo a NBR 8800 [ 7 ], a resistência de cálculo à força cortante para um parafuso, exceto nos casos de pega longa (pega superior a 5d) e ligações de grande comprimento, deve ser tomada com base na resistência à pressão de contato nos furos e na resistência à força cortante do parafuso (a que for mais crítica). 


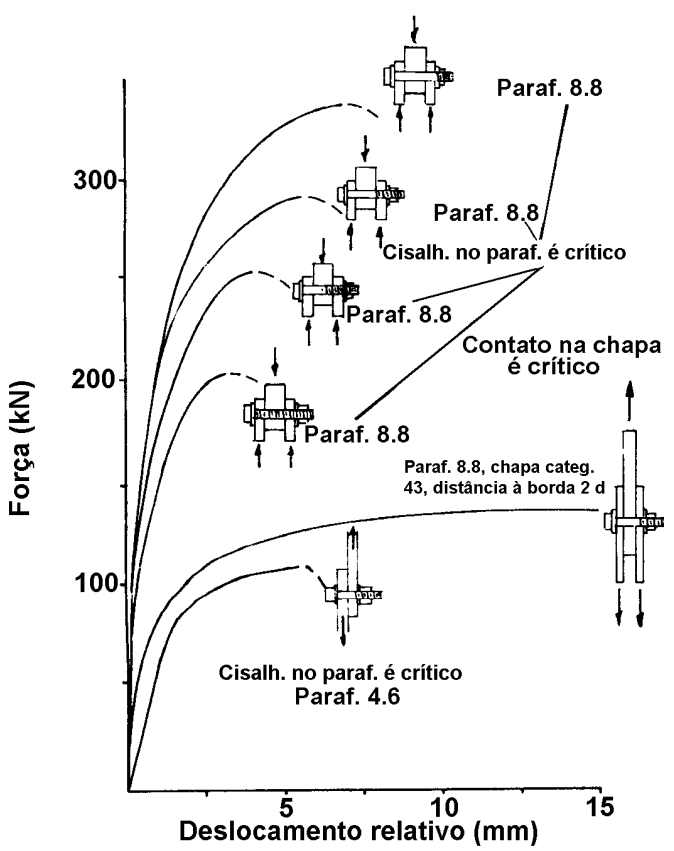

FIGURA 3-8 Típico gráfico força-deslocamento relativo para parafusos de $20 \mathrm{~mm}$ de diâmetro em cisalhamento. Adaptada de OWENS \& CHEAL [ 50 ].

A resistência de cálculo à força cortante $\phi_{v} R_{n}$ para um parafuso, de acordo com a NBR 8800 [ 7 ], para rosca fora do plano de cisalhamento é:

$$
\phi_{\mathrm{v}} \mathrm{R}_{\mathrm{nv}}=\phi_{\mathrm{v}} \mathrm{mA}_{\mathrm{p}} \tau_{\mathrm{u}}=\phi_{\mathrm{v}} \mathrm{mA}_{\mathrm{p}} 0,60 \mathrm{f}_{\mathrm{u}}
$$

onde: $\mathrm{m}=$ número de planos de cisalhamento

$\mathrm{A}_{\mathrm{p}}=$ área da seção transversal bruta do parafuso

$\phi_{\mathrm{v}}=0,65$ para parafusos ASTM A325 e ASTM A490

$\phi_{\mathrm{v}}=0,60$ para parafusos comuns

$\tau_{\mathrm{u}}=$ tensão de cisalhamento última, cujo valor é aproximadamente $60 \%$ do limite de resistência à tração. O AISC/LRFD 93 [ 4 ] utiliza o fator 0,62 ao invés de 0,60, deste modo:

$$
\phi_{\mathrm{v}} \mathrm{R}_{\mathrm{nv}}=\phi_{\mathrm{v}} \mathrm{mA}_{\mathrm{p}} 0,62 \mathrm{f}_{\mathrm{u}}
$$

Segundo SALMON \& JOHNSON [ 60 ], o AISC/LRFD 86 [ 3 ] estabelecia $\phi_{\mathrm{v}}=0,65$ ou 0,60 na expressão 3.2.28 para o caso de força cortante. O AISC/LRFD 93 [ 4 ] visando uniformizar os valores dos coeficientes de resistência para estados limites de ruptura, estabelece $\phi_{\mathrm{v}}=0,75$ que é o valor freqüentemente utilizado. Esta alteração requer um ajuste na expressão original, reduzindo em $20 \%$ a resistência nominal do parafuso. Assim: 


$$
\phi_{\mathrm{v}} \mathrm{R}_{\mathrm{nv}}=\phi_{\mathrm{v}}\left(0,8 \mathrm{~mA}_{\mathrm{p}} 0,62 \mathrm{f}_{\mathrm{u}}\right)=\phi_{\mathrm{v}}\left(0,50 \mathrm{~mA}_{\mathrm{p}} \mathrm{f}_{\mathrm{u}}\right)
$$

onde: $\phi_{\mathrm{v}}=0,75$

Se a rosca agora estiver no plano de cisalhamento, a área da raiz da rosca deverá ser usada no lugar de $A_{p}$. Esta área é tomada como 0,70 a 0,75 da área bruta. Deste modo a resistência de cálculo à força cortante torna-se:

$$
\phi_{\mathrm{v}} \mathrm{R}_{\mathrm{nv}}=\phi_{\mathrm{v}}\left(0,8 \mathrm{~m} 0,75 \mathrm{~A}_{\mathrm{p}} 0,62 \mathrm{f}_{\mathrm{u}}\right)=\phi_{\mathrm{v}}\left(0,37 \mathrm{~mA}_{\mathrm{p}} \mathrm{f}_{\mathrm{u}}\right)
$$

Devido aos coeficientes 0,8 e 0,75 serem aproximados, o AISC/LRFD 93 [ 4 ] estabelece a seguinte expressão:

$$
\phi_{\mathrm{v}} \mathrm{R}_{\mathrm{nv}}=\phi_{\mathrm{v}}\left(0,40 \mathrm{~mA}_{\mathrm{p}} \mathrm{f}_{\mathrm{u}}\right)
$$

onde $\phi_{\mathrm{v}}=0,75$

A NBR 8800 [ 7 ] utiliza a seguinte expressão para rosca no plano de cisalhamento:

$$
\phi_{\mathrm{v}} \mathrm{R}_{\mathrm{nv}}=\phi_{\mathrm{v}}\left(0,42 \mathrm{~mA}_{\mathrm{p}} \mathrm{f}_{\mathrm{u}}\right)
$$

onde: $\phi_{\mathrm{v}}=0,65$ para parafusos ASTM A325 e ASTM A490

$\phi_{\mathrm{v}}=0,60$ para parafusos comuns

Segundo SALMON \& JOHNSON [ 60 ], em termos de tensões admissíveis, a resistência nominal é dividida por um fator de segurança que eqüivale à relação $\gamma / \phi$. Deste modo, dividindo a resistência nominal à força cortante pelo tradicional fator de segurança igual a $(2,5)$, obtém-se a tensão de cisalhamento admissível para rosca fora do plano de cisalhamento, dada por:

$$
f_{v}=\left(\frac{0,62 f_{u}}{2,5}\right)=0,25 f_{u}
$$

Para rosca contida no plano de cisalhamento, a área da seção transversal deverá ser reduzida, ou de forma equivalente, deverá ser reduzida a tensão de cisalhamento admissível. O AISC/ASD [ 1 ] tem preferido manter a área bruta do 
parafuso $A_{p}$, reduzindo a tensão admissível a $70 \%$ daquela estabelecida para rosca fora do plano de cisalhamento. É interessante lembrar que este fator 0,7 corresponde ao limite inferior da relação área líquida/área bruta dos parafusos.

$$
\mathrm{f}_{\mathrm{v}}=0,7\left(\frac{0,62 \mathrm{f}_{\mathrm{u}}}{2,5}\right)=0,175 \mathrm{f}_{\mathrm{u}}
$$

Segundo o EUROCODE 3 [ 24 ], no estado limite último a força cortante de cálculo $F_{v . S d}$ de um parafuso não deverá exceder a resistência de cálculo à força cortante $F_{v \cdot R d}\left(\right.$ correspondente a $\phi_{\mathrm{v}} \mathrm{R}_{\mathrm{nv}}$ da NBR 8800 [ 7 ]).

Para rosca inclusa no plano de cisalhamento, por plano de cisalhamento:

$$
\begin{aligned}
& F_{v \cdot R d}=\frac{0,6 f_{u b} A_{s}}{\gamma_{M b}} \text { (classe de resistência 4.6, 5.6 e 8.8) } \\
& F_{v . R d}=\frac{0,5 f_{u b} A_{s}}{\gamma_{M b}} \quad(\text { classe de resistência 4.8, 5.8 e 10.9) }
\end{aligned}
$$

Para rosca fora do plano de cisalhamento, por plano de cisalhamento:

$$
\mathrm{F}_{\mathrm{v} . \mathrm{Rd}}=\frac{0,6 \mathrm{f}_{\mathrm{ub}} \mathrm{A}}{\gamma_{\mathrm{Mb}}}
$$

onde: $\mathrm{A}=$ área da seção transversal bruta do parafuso (correspondente a $A_{p}$ da NBR 8800 [ 7 ])

$$
\begin{aligned}
& \mathrm{A}_{\mathrm{s}}=\text { área efetiva à tração (correspondente a } \mathrm{A}_{\mathrm{r}} \text { da NBR } 8800[7] \text { ) } \\
& \gamma_{\mathrm{Mb}}=1,25 \text { (fator de segurança parcial) } \\
& \mathrm{f}_{\mathrm{ub}}=\text { resistência à tração do material do parafuso }
\end{aligned}
$$

Os valores de $F_{v \cdot R d}$ estabelecidos anteriormente são aplicáveis somente a parafusos utilizados em furos com folgas nominais, não excedendo àquelas fornecidas para furos padrão. Os parafusos M12 e M14 também podem ser utilizados com $2 \mathrm{~mm}$ de folga (a folga nominal estabelecida para estes parafusos é $1 \mathrm{~mm}$ ), contanto que para parafusos de classes 4.8, 5.8, 6.8 e 10.9 o valor de $F_{v \cdot R d}$ seja multiplicado por 0,85 e esse valor de $F_{v . R d}$, se reduzido, não seja menor que a resistência de cálculo à pressão de contato $F_{b . R d}$. 
As propriedades mecânicas dos parafusos utilizados pelo EUROCODE 3 [ 24 ] são definidas pela ISO na forma (X.Y). O primeiro termo (X) é um décimo da mínima resistência à tração do material do parafuso em $\mathrm{kgf} / \mathrm{mm}^{2}$. O segundo termo (Y) é um décimo da porcentagem da razão da mínima tensão de escoamento com a mínima resistência à tração. A tabela 3-6, apresenta algumas propriedades mecânicas de parafusos comuns ISO.

TABELA 3-6 Propriedades mecânicas de parafusos comuns ISO. Adaptada de OWENS \& CHEAL [ 50 ].

\begin{tabular}{|c|c|c|c|c|c|}
\hline & & \multicolumn{4}{|c|}{ Classe de resistência } \\
\hline \multicolumn{2}{|c|}{ Propriedades mecânicas } & 4.6 & 8.8 & 10.9 & 12.9 \\
\hline \multirow[t]{4}{*}{ Resistência à tração } & $\mathrm{kgf} / \mathrm{mm}^{2}$ (mín.) & 40 & 80 & 100 & 120 \\
\hline & MPa (mín.) & 392 & 785 & 981 & 1177 \\
\hline & kgf/mm² (máx.) & 55 & 100 & 120 & 140 \\
\hline & MPa (máx.) & 539 & 981 & 1177 & 1373 \\
\hline Dureza Vickers & (mín)-(máx.) & $110-170$ & $225-300$ & $280-370$ & $330-440$ \\
\hline \multirow[t]{2}{*}{ Tensão de escoamento } & kgf/mm² (mín.) & 24 & - & - & - \\
\hline & Mpa (mín.) & 235 & - & - & - \\
\hline \multirow{2}{*}{$\begin{array}{l}\text { Tensão de escoamento } \\
\text { (método offset } 0,2 \% \text { ) }\end{array}$} & kgf/mm² (mín.) & - & 64 & 90 & 108 \\
\hline & Mpa (mín.) & - & 628 & 883 & 1059 \\
\hline Alongamento na ruptura & (mín. \%) & 25 & 12 & 9 & 8 \\
\hline
\end{tabular}

No caso de parafusos de alta resistência, duas categorias de materiais podem ser especificadas: material de classe geral que tem propriedades mecânicas similares àqueles da classe 8.8 para parafusos comuns, e material de classe superior, que corresponde à classe 10.9. A tabela 3-7 apresenta algumas propriedades mecânicas de parafusos de alta resistência ISO.

TABELA 3-7 Propriedades mecânicas de parafusos de alta resistência ISO. Adaptada de OWENS \& CHEAL [ 50 ].

\begin{tabular}{|c|c|c|c|c|}
\hline \multicolumn{2}{|c|}{ Propriedades mecânicas } & $\begin{array}{c}\text { Classe geral } \leq \\
\text { M24 }\end{array}$ & $\begin{array}{c}\text { Classe geral > } \\
\text { M24 }\end{array}$ & Classe superior \\
\hline Resistência à tração & MPa (mín.) & 827 & 725 & 981 \\
\hline Dureza Vickers & (mín)-(máx.) & $260-330$ & $225-292$ & $280-380 / 370$ \\
\hline $\begin{array}{c}\text { Tensão de escoamento } \\
\text { (método offset 0,2\%) }\end{array}$ & $\mathrm{MPa}$ & 635 & 558 & 882 \\
\hline Alongamento na ruptura & (mín. \%) & 12 & 12 & 9 \\
\hline
\end{tabular}

Segundo OWENS \& CHEAL [ 50 ], um aspecto importante que deve ser levado em consideração nas conexões com vários parafusos na direção da força, é a distribuição da força cortante entre parafusos não ajustados, ou seja, aqueles que são inseridos em furos maiores que o diâmetro nominal do parafuso, o que geralmente acontece na prática. 
Nestes casos, alguns parafusos do grupo podem não atingir a situação de contato e, por esta razão não contribuir na resistência da conexão, provocando a falha prematura de outros parafusos. Este fato é mais significativo para o caso de rosca inclusa nos planos de cisalhamento, uma vez que a ductilidade da conexão é reduzida nestes casos.

Os modelos teóricos de cálculo usualmente empregados admitem a distribuição uniforme da força cortante entre todos os parafusos da conexão, o que deve ser visto com restrições em algumas situações.

\subsection{Conexões por contato: parafusos sob tração}

A resistência à tração de um parafuso é controlada pela porção rosqueada. A área efetiva da porção rosqueada é baseada no diâmetro do núcleo mais a área de um fio de rosca contido na seção. Esta área é calculada pela expressão:

$$
\mathrm{A}_{\mathrm{r}}=\frac{\pi}{4}(\mathrm{~d}-\mathrm{kp})^{2}
$$

onde: $\mathrm{d}=$ diâmetro nominal do parafuso

$\mathrm{p}=$ passo da rosca

$\mathrm{k}=0,9743$ (rosca UNC - parafusos ASTM) e 0,9382 ( rosca métrica ISO)

De acordo com o estado limite de ruptura da parte rosqueada (modo de falha mostrado na fig. 3-2e), o AISC/LRFD 93 [ 4 ] e a NBR 8800 [ 7 ], estabelecem que a resistência de cálculo à tração de um parafuso é:

$$
\phi_{\mathrm{t}} \mathrm{R}_{\mathrm{nt}}=\phi_{\mathrm{t}} \mathrm{f}_{\mathrm{u}} \mathrm{A}_{\mathrm{r}}
$$

onde: $\phi_{\mathrm{t}}=0,75$ para parafusos ASTM A325 e ASTM A490, segundo a NBR 8800

[ 7 ], e para todos os parafusos, segundo o AISC/LRFD 93 [ 4 ]

$\phi_{\mathrm{t}}=0,65$ para demais parafusos, segundo a NBR 8800 [ 7 ]

$\mathrm{f}_{\mathrm{u}}=$ resistência à tração do material do parafuso

$\mathrm{A}_{\mathrm{r}}=$ área líquida efetiva correspondente à área da porção rosqueada do parafuso. A razão desta área efetiva à tração pela área bruta $A_{p}$ é limitada entre 0,75 a 0,79. Deste modo, em termos de área bruta $A_{p}$, a expressão 3.3.2 resulta:

$$
\phi_{\mathrm{t}} \mathrm{R}_{\mathrm{nt}}=\phi_{\mathrm{t}} 0,75 \mathrm{~A}_{\mathrm{p}} \mathrm{f}_{\mathrm{u}}
$$


onde: $A_{p}=$ área da seção transversal bruta de um parafuso

Ou, alternativamente, segundo a NBR 8800 [ 7 ], para diâmetros nominais acima de $25 \mathrm{~mm}$ :

$$
\phi_{\mathrm{t}} \mathrm{R}_{\mathrm{nt}}=\phi_{\mathrm{t}} 0,95 \mathrm{~A}_{\mathrm{r}} \mathrm{f}_{\mathrm{u}}
$$

A tabela 3-8 fornece os valores de $A_{p}$ e $A_{r}$.

TABELA 3-8 Valores de área bruta e área efetiva à tração, segundo a NBR 8800 [ 7 ]

\begin{tabular}{|c|c|c|c|c|c|}
\hline ISO & UNC & $\mathrm{p}$ (passo em mm) & $\mathrm{A}_{\mathrm{p}}\left(\mathrm{mm}^{2}\right)$ & $\mathrm{A}_{\mathrm{r}}\left(\mathrm{mm}^{2}\right)$ & $\mathrm{A}_{\mathrm{r}} / \mathrm{A}_{\mathrm{p}}$ \\
\hline $\mathrm{M} 12$ & - & 1,75 & 113 & 84,3 & 0,75 \\
\hline- & $1 / 2 "(12,5 \mathrm{~mm})$ & 1,95 & 126 & 91,6 & 0,73 \\
\hline- & $5 / 8 ”(16 \mathrm{~mm})$ & 2,31 & 198 & 146 & 0,74 \\
\hline M16 & - & 2,00 & 201 & 157 & 0,78 \\
\hline- & $3 / 4 "(19 \mathrm{~mm})$ & 2,54 & 285 & 215 & 0,75 \\
\hline M20 & - & 2,50 & 314 & 245 & 0,78 \\
\hline M22 & - & 2,50 & 380 & 303 & 0,80 \\
\hline- & $7 / 8 ”(22 \mathrm{~mm})$ & 2,82 & 388 & 293 & 0,77 \\
\hline M24 & - & 3,00 & 452 & 353 & 0,78 \\
\hline- & $1 ”(25 \mathrm{~mm})$ & 3,18 & 506 & 391 & 0,77 \\
\hline M27 & - & 3,00 & 573 & 459 & 0,80 \\
\hline- & $11 / 8 "(29 \mathrm{~mm})$ & 3,63 & 641 & 492 & 0,77 \\
\hline M30 & - & 3,50 & 707 & 561 & 0,79 \\
\hline- & $11 / 4 "(32 \mathrm{~mm})$ & 3,63 & 792 & 625 & 0,79 \\
\hline M33 & - & 3,50 & 855 & 694 & 0,81 \\
\hline- & $13 / 8 ”(35 \mathrm{~mm})$ & 4,23 & 958 & 745 & 0,78 \\
\hline M36 & - & 4,00 & 1018 & 817 & 0,80 \\
\hline- & $11 / 2 ”(38 \mathrm{~mm})$ & 4,23 & 1140 & 907 & 0,80 \\
\hline M42 & - & 4,50 & 1385 & 1120 & 0,81 \\
\hline- & $13 / 4 ”(44 \mathrm{~mm})$ & 5,08 & 1552 & 1226 & 0,79 \\
\hline M48 & - & 5,00 & 1810 & 1470 & 0,81 \\
\hline- & $2 "(50 \mathrm{~mm})$ & 5,64 & 2027 & 1613 & 0,80 \\
\hline
\end{tabular}

De acordo com o AISC/ASD [ 1 ], a resistência admissível à tração é dada pela resistência nominal (expressão 3.3.3 sem o coeficiente $\phi_{t}$ ), dividida por um fator de segurança igual a $(2,0)$. Assim:

$$
\mathrm{R}=0,5\left(0,75 \mathrm{~A}_{\mathrm{p}} \mathrm{f}_{\mathrm{u}}\right)=0,375 \mathrm{~A}_{\mathrm{p}} \mathrm{f}_{\mathrm{u}}=\mathrm{A}_{\mathrm{p}} \mathrm{f}_{\mathrm{t}}
$$

onde: $\mathrm{f}_{\mathrm{t}}=$ tensão admissível à tração do parafuso

De acordo com o EUROCODE 3 [ 24 ], a solicitação de cálculo, incluindo o efeito alavanca, não deverá exceder a resistência de cálculo à tração $B_{t . R d}$. $\mathrm{O}$ valor de $B_{t . R d}$ deverá ser o menor entre a resistência de cálculo à tração $F_{t . R d}$ (correspondente a 
$\phi_{t} R_{n t}$ da NBR 8800 [ 7 ]) e a resistência de cálculo à força cortante por puncionamento do metal base junto à cabeça do parafuso ou porca $B_{p . R d}$.

$$
\begin{aligned}
& \mathrm{F}_{\mathrm{t} . \mathrm{Rd}}=\frac{0,9 \mathrm{f}_{\mathrm{ub}} \mathrm{A}_{\mathrm{s}}}{\gamma_{\mathrm{Mb}}} \\
& \mathrm{B}_{\mathrm{p} . \mathrm{Rd}}=\frac{0,6 \pi \mathrm{d}_{\mathrm{m}} \mathrm{t}_{\mathrm{p}} \mathrm{f}_{\mathrm{u}}}{\gamma_{\mathrm{Mb}}}
\end{aligned}
$$

onde: $f_{u b}=$ resistência à tração do material do parafuso

$\mathrm{f}_{\mathrm{u}}=$ resistência à tração do metal base

$\mathrm{A}_{\mathrm{s}}=$ área efetiva à tração

$\gamma_{\mathrm{Mb}}=1,25$ (fator de segurança parcial)

$\mathrm{t}_{\mathrm{p}}=$ espessura do metal base sob a cabeça do parafuso ou porca

$\mathrm{d}_{\mathrm{m}}=$ média da dimensões $d_{1}$ e $d_{2}$, tomando-se como base o menor valor calculado para a cabeça do parafuso ou porca (ver fig. 3-9)

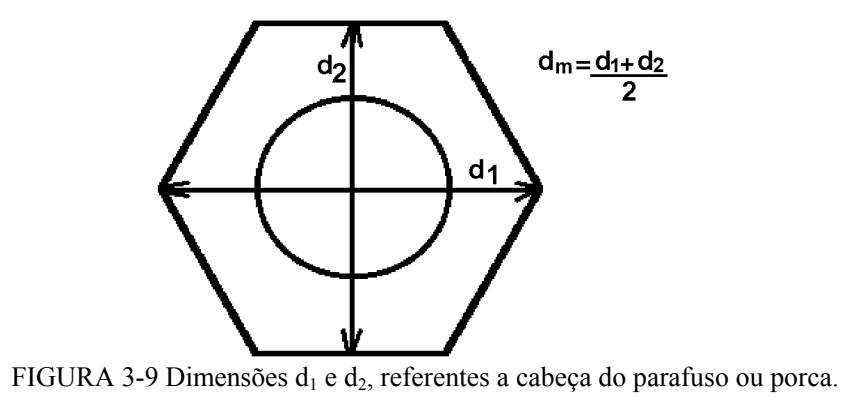

Segundo a NBR 8800 [ 7 ], na determinação da solicitação de cálculo, para parafusos sujeitos à tração, além das solicitações externas, deve ser levado em consideração o efeito alavanca, se existir, e excluída a força de pré-tração obtida nos parafusos.

\subsection{Conexões por contato: parafusos sob tração e força cortante combinadas}

Em grande parte das conexões, ocorre a atuação simultânea de força cortante e tração nos parafusos, o que evidentemente corresponde à uma situação mais desfavorável que a atuação dos dois esforços isoladamente. Na fig. 3-10a pode ser visualizada a interação entre os dois esforços, tomando-se como referência as relações entre os esforços atuantes e a resistência à tração. 
Para que a atuação simultânea dos dois esforços seja considerada, é interessante notar a variação na relação resistência à força cortante pela resistência à tração. Segundo OWENS \& CHEAL [ 50 ], para rosca inclusa no plano de cisalhamento esta relação varia de 0,63 a 0,68 e para rosca esclusa, de 0,75 a 0,89 .

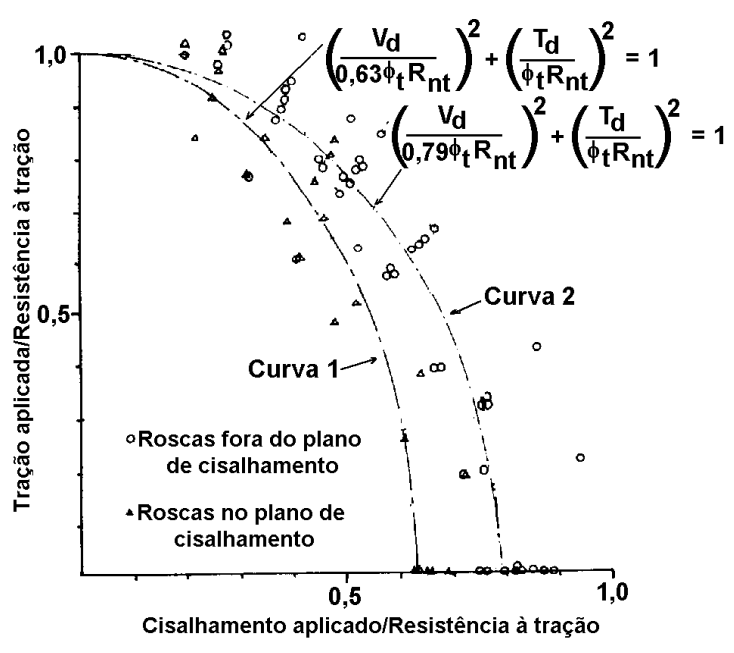

(a)

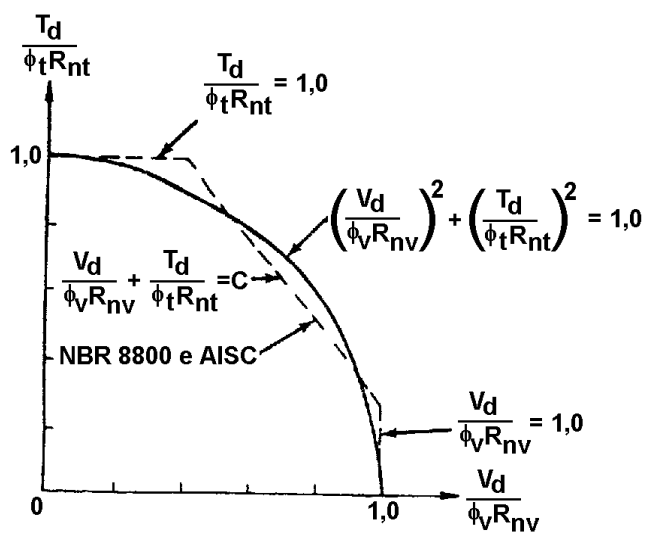

(b)

FIGURA 3-10 (a) Diagrama de interação para parafusos comuns sob combinação de tração e força cortante; (b) aproximação do AISC/LRFD 93 [ 4 ] e NBR 8800 [ 7 ]. Adaptada de OWENS \& CHEAL [ 50 ] e SALMON \& JOHNSON [ 60 ].

Segundo OWENS \& CHEAL [ 50 ], o comportamento de conexões parafusadas sob esforços isolados é relativamente complexo, a atuação dos dois esforços simultaneamente conduz à uma situação ainda mais complicada.

A análise deste caso tem sido feita mediante a formulação de expressões de interação empíricas, as quais se aproximam dos resultados obtidos experimentalmente. A fig. 3-10a apresenta duas expressões propostas para os casos de rosca inclusa e rosca esclusa no plano de cisalhamento, curvas 1 e 2 respectivamente, onde o fator 0,79 que aparece na curva 2 foi obtido simplesmente pela relação $(0,63 / 0,8)$, onde 0,8 corresponde à relação média entre a área efetiva à tração e a área bruta do corpo do parafuso.

Para a avaliação da resistência, é usual e compatível com os resultados de ensaios, adotar uma expressão circular para definir a região de segurança, dada por:

$$
\left(\frac{\mathrm{T}_{\mathrm{d}}}{\phi_{\mathrm{t}} \mathrm{R}_{\mathrm{nt}}}\right)^{2}+\left(\frac{\mathrm{V}_{\mathrm{d}}}{\phi_{\mathrm{v}} \mathrm{R}_{\mathrm{nv}}}\right)^{2} \leq 1,0
$$

onde: $T_{d}=$ tração de cálculo no parafuso 
$\mathrm{V}_{\mathrm{d}}=$ cortante de cálculo no parafuso, por plano de corte

$\phi_{\mathrm{t}} \mathrm{R}_{\mathrm{nt}}=$ resistência de cálculo à tração

$\phi_{\mathrm{v}} \mathrm{R}_{\mathrm{nv}}=$ resistência de cálculo à força cortante, por plano de corte

O AISC/LRFD 93 [ 4 ] e a NBR 8800 [ 7 ] têm simplificado a expressão de interação circular adotando três trechos lineares, como indicado na fig. 3-10b. Na reta horizontal despreza-se a influência da força cortante, na reta vertical despreza-se a influência da tração, já o trecho inclinado é expresso pela seguinte expressão:

$$
\left(\frac{\mathrm{T}_{\mathrm{d}}}{\phi_{\mathrm{t}} \mathrm{R}_{\mathrm{nt}}}\right)+\left(\frac{\mathrm{V}_{\mathrm{d}}}{\phi_{\mathrm{v}} \mathrm{R}_{\mathrm{nv}}}\right)=\mathrm{C}
$$

As normas adotam a constante $C$ aproximadamente igual a 1,25.

Isolando $T_{d}$ na expressão 3.4.2, obtém-se:

$$
\mathrm{T}_{\mathrm{d}}=\mathrm{C} \phi_{\mathrm{t}} \mathrm{R}_{\mathrm{nt}}-\mathrm{V}_{\mathrm{d}}\left(\frac{\phi_{\mathrm{t}} \mathrm{R}_{\mathrm{nt}}}{\phi_{\mathrm{v}} \mathrm{R}_{\mathrm{nv}}}\right)
$$

Substituindo os valores de $\phi_{t} R_{n t}, \phi_{v} R_{n v}$ e $\mathrm{C}=1,25$ para cada tipo de parafuso, na expressão 3.4.3, obtém-se as expressões contidas na NBR 8800 [ 7 ], as quais estão apresentadas na tabela 3-9.

TABELA 3-9 Tração e força cortante combinadas, segundo a NBR 8800 [ 7 ].

\begin{tabular}{|c|c|}
\hline Tipo de parafuso & $\begin{array}{c}\text { Limitação adicional do valor da resistência de } \\
\text { cálculo à tração por parafuso ou barra rosqueada }\end{array}$ \\
\hline $\begin{array}{c}\text { Parafusos ASTM A307 ou ISO 4.6, ASTM A449 } \\
(\mathrm{d}>38 \text { mm) e barras rosqueadas em geral }\end{array}$ & $\phi_{\mathrm{t}} \mathrm{R}_{\mathrm{nt}} \leq 0,64 \mathrm{f}_{\mathrm{u}} \mathrm{A}_{\mathrm{p}}-1,93 \mathrm{~V}_{\mathrm{d}}$ \\
\hline Parafusos ASTM A325 e A490 & $\begin{array}{c}\phi_{\mathrm{t}} \mathrm{R}_{\mathrm{nt}} \leq 0,69 \mathrm{f}_{\mathrm{u}} \mathrm{A}_{\mathrm{p}}-1,93 \mathrm{~V}_{\mathrm{d}} \text { (plano de corte passa } \\
\text { pela rosca) } \\
\phi_{\mathrm{t}} \mathrm{R}_{\mathrm{nt}} \leq 0,69 \mathrm{f}_{\mathrm{u}} \mathrm{A}_{\mathrm{p}}-1,50 \mathrm{~V}_{\mathrm{d}} \text { (plano de corte não } \\
\text { passa pela rosca) }\end{array}$ \\
\hline
\end{tabular}

Nota: $\mathrm{V}_{\mathrm{d}}$ é a força cortante por plano de corte.

As especificações do AISC têm apresentado as expressões de interação sob forma de tensões, dividindo todos os termos pela área bruta $A_{p}$.

Substituindo as expressões de $\phi_{t} R_{n t}$ e $\phi_{v} R_{n v}$ para roscas fora do plano de cisalhamento, a expressão 3.4.3 torna-se: 


$$
\begin{aligned}
& \frac{\mathrm{T}_{\mathrm{d}}}{\mathrm{A}_{\mathrm{p}}}=\mathrm{C}\left(\frac{\phi 0,75 \mathrm{f}_{\mathrm{u}} \mathrm{A}_{\mathrm{p}}}{\mathrm{A}_{\mathrm{p}}}\right)-\frac{\mathrm{V}_{\mathrm{d}}}{\mathrm{A}_{\mathrm{p}}}\left(\frac{\phi 0,75 \mathrm{f}_{\mathrm{u}} \mathrm{A}_{\mathrm{p}}}{0,75.0,50 \mathrm{f}_{\mathrm{u}} \mathrm{A}_{\mathrm{p}}}\right) \\
& \mathrm{f}_{\mathrm{Td}}=\phi\left(0,75 \mathrm{f}_{\mathrm{u}} \mathrm{C}-2 \mathrm{f}_{\mathrm{Vd}}\right)
\end{aligned}
$$

Substituindo o valor de $\mathrm{C}=1,3$ (na versão do AISC/LRFD 86 [ 3 ] C = 1,25), e o valor de $f_{u}=120 \mathrm{ksi}$ (parafusos A325), na expressão 3.4.5, a resistência de cálculo à tração (em termos de tensão) é dada por:

$$
\mathrm{f}_{\mathrm{Td}}=\phi\left(117-2 \mathrm{f}_{\mathrm{Vd}}\right) \quad(\mathrm{em} \mathrm{ksi})
$$

onde: $f_{\mathrm{Vd}}=$ tensão de cisalhamento de cálculo no parafuso, que deve ser menor ou igual a resistência de cálculo à força cortante

$$
\phi=0,75
$$

O AISC/LRFD 93 [ 4 ] para parafusos A325 com roscas fora do plano de cisalhamento apresenta a seguinte expressão:

$$
\mathrm{f}_{\mathrm{Td}}=\phi\left(117-1,5 \mathrm{f}_{\mathrm{Vd}}\right) \leq \phi 90 \quad \text { (em ksi) }
$$

onde: $\phi 90=$ resistência de cálculo à tração, com a tração atuando isoladamente

O uso de 1,5 ao invés de 2,0 na expressão 3.4.7 é proveniente do caráter conservador desta expressão linear de interação. Desta forma o AISC/LRFD 93 [ 4 ] adota a resistência à força cortante como sendo $0,62 f_{u} A_{p}$ e não $0,5 f_{u} A_{p}$, o que implica o valor aproximado de 1,5.

A tabela 3-10 apresenta as limitações de resistência para conectores sujeitos à tração, força cortante e tração e força cortante combinadas, para conexões por contato, segundo as normas americanas AISC/LRFD 93 [ 4 ] e AISC/ASD [ 1 ]. 
TABELA 3-10 Resistências de conectores segundo o AISC/LRFD 93 [ 4 ] e AISC/ASD [ 1 ].

\begin{tabular}{|c|c|c|c|c|c|c|}
\hline & \multicolumn{3}{|c|}{ AISC/LRFD } & \multicolumn{3}{|c|}{ AISC/ASD } \\
\hline $\begin{array}{l}\text { Tipo de } \\
\text { conector }\end{array}$ & $\begin{array}{c}\text { Tração }^{(\mathrm{c})}, \\
\mathrm{MPa}\end{array}$ & $\begin{array}{l}\text { Força } \\
\text { cortante } \\
\text { (c) } \mathrm{MPa}\end{array}$ & $\begin{array}{c}\text { Tração e força } \\
\text { cortante }^{(\mathrm{c})}, \mathrm{MPa} \\
\text { combinadas }^{\text {comba }},\end{array}$ & $\begin{array}{l}\text { Tração, } \\
\mathrm{MPa}\end{array}$ & $\begin{array}{c}\text { Força } \\
\text { cortante, } \\
\mathrm{MPa} \\
\end{array}$ & $\begin{array}{c}\text { Tração e força } \\
\text { cortante } \\
\text { combinadas }^{(\mathrm{k})}, \mathrm{MPa}\end{array}$ \\
\hline $\begin{array}{c}\text { Parafuso } \\
\text { A307 }\end{array}$ & $310^{(\mathrm{d})}$ & $165^{(\mathrm{g}, \mathrm{h})}$ & $407-1,9 \mathrm{f}_{\mathrm{Vd}} \leq 310^{(\mathrm{g})}$ & $138^{(\mathrm{d})}$ & $69^{(\mathrm{g}, \mathrm{h})}$ & $179-1,8 f_{\mathrm{Vd}} \leq 138$ \\
\hline $\begin{array}{l}\text { Parafuso } \\
\text { A325 }\end{array}$ & $621^{(\mathrm{e})}$ & $330^{(\mathrm{h})}$ & $807-1,9 f_{\mathrm{Vd}} \leq 621$ & $303^{(i)}$ & $145^{(\mathrm{h})}$ & $\left(303^{2}-4,39 f_{\mathrm{Vd}}^{2}\right)^{0,5}$ \\
\hline $\begin{array}{l}\text { Parafuso } \\
\text { A325 }\end{array}$ & $621^{(\mathrm{e})}$ & $413^{(h)}$ & $807-1,5 f_{\mathrm{Vd}} \leq 621$ & $303^{(i)}$ & $207^{(\mathrm{h})}$ & $\left(303^{2}-2,15 f_{\mathrm{Vd}}^{2}\right)^{0,5}$ \\
\hline $\begin{array}{l}\text { Parafuso } \\
\text { A490 }\end{array}$ & $779^{(\mathrm{e})}$ & $413^{(\mathrm{h})}$ & $1010-1,9 f_{\mathrm{Vd}} \leq 779$ & $372^{(i)}$ & $193^{(\mathrm{h})}$ & $\left(372^{2}-3,75 f_{\mathrm{Vd}}^{2}\right)^{0,5}$ \\
\hline $\begin{array}{l}\text { Parafuso } \\
{\text { A } 490^{(b)}}^{(b}\end{array}$ & $779^{(\mathrm{e})}$ & $517^{(\mathrm{h})}$ & $1010-1,5 f_{V d} \leq 779$ & $372^{(i)}$ & $276^{(\mathrm{h})}$ & $\left(372^{2}-1,82 f_{V d}^{2}\right)^{0,5}$ \\
\hline $\begin{array}{c}\text { Barras } \\
\text { rosqueadas e } \\
\text { paraf. A449 } \\
(\mathrm{d}>38 \mathrm{~mm})^{\text {(a) }}\end{array}$ & $0,75 f_{u}^{(d)}$ & $0,40 f_{u}$ & $\begin{array}{c}0,98 f_{u}-1,9 f_{V d} \leq \\
0,75 f_{u}\end{array}$ & $0,33 \mathrm{f}_{\mathrm{u}}^{(\mathrm{d})}$ & $0,17 f_{u}$ & $\begin{array}{c}0,43 f_{u}-1,8 f_{V d} \leq \\
0,33 f_{u}\end{array}$ \\
\hline $\begin{array}{c}\text { Barras } \\
\text { rosqueadas e } \\
\text { paraf. A449 } \\
(\mathrm{d}>38 \mathrm{~mm})^{(\mathrm{b})}\end{array}$ & $0,75 f_{u}^{(d)}$ & $0,50 \mathrm{f}_{\mathrm{u}}^{(\mathrm{d})}$ & $\begin{array}{c}0,98 f_{u}-1,5 f_{V d} \leq \\
0,75 f_{u}\end{array}$ & $0,33 f_{u}^{(d)}$ & $0,22 f_{u}$ & $\begin{array}{c}0,43 f_{u}-1,4 f_{V d} \leq \\
0,33 f_{u}\end{array}$ \\
\hline $\begin{array}{c}\text { Rebites } \\
\text { A502 tipo } 1\end{array}$ & $310^{(\mathrm{d})}$ & $172^{(\mathrm{h})}$ & $407-1,8 f_{\mathrm{Vd}} \leq 310$ & $158^{(\mathrm{d})}$ & $120^{(\mathrm{h})}$ & $207-1,3 f_{V d} \leq 158$ \\
\hline $\begin{array}{c}\text { Rebites } \\
\text { A502 tipo } 2\end{array}$ & $414^{(\mathrm{d})}$ & $227^{(\mathrm{h})}$ & $538-1,8 f_{\mathrm{Vd}} \leq 414$ & $200^{(\mathrm{d})}$ & $152^{(\mathrm{h})}$ & $262-1,2 f_{V d} \leq 200$ \\
\hline
\end{tabular}

(a) Rosca no plano de cisalhamento

(b) Rosca fora do plano de cisalhamento

(c) Esses valores são resistências nominais e devem ser multiplicadas por $\phi=0,75$, para se obter as resistências de cálculo

(d) Somente carregamento estático

(e) Para parafusos A325 e A490 sujeitos a fadiga ver apêndice K3 do AISC/LRFD 93 [ 4 ]

(g) Roscas permitidas no plano de cisalhamento

(h) Quando conexões por contato usadas para unir perfis tracionados, possuem um comprimento paralelo à linha da força, que exceder $1270 \mathrm{~mm}$, os valores deverão ser reduzidos em $20 \%$

(i) Para parafusos A325 e A490 sujeitos a fadiga ver apêndice K4.3 do AISC/ASD[ 1 ]

(k) Quando as tensões admissíveis são aumentadas por efeitos sísmicos ou ventos, as constantes nessas fórmulas deverão ser aumentadas por $1 / 3$, mas os coeficientes de $f_{V d}$ não deverão ser aumentados.

Tendo em vista o caráter conservador da expressões do AISC, GAYLORD et al. [ 27 ] recomenda as expressões do RCSC (Research Council on Structural Connections), cuja expressão básica é:

$$
\mathrm{f}_{\mathrm{Td}}=\phi\left(\mathrm{f}_{\mathrm{u}}^{2}-\mathrm{Cf}_{\mathrm{Vd}}^{2}\right)^{0,5}
$$

onde: $\phi=0,75$

Desta maneira, para os parafusos A325 e A490, tem-se as seguintes expressões: 


\begin{tabular}{|c|c|c|}
\hline Tipo de parafuso & Projeto em estados limites & Projeto em tensões admissíveis \\
\hline $\begin{array}{c}\text { Parafuso A325 (plano de corte } \\
\text { não passa pela rosca) }\end{array}$ & $\mathrm{f}_{\mathrm{Td}}=\phi\left(90^{2}-2,25 \mathrm{f}_{\mathrm{Vd}}{ }^{2}\right)^{0,5}$ & $\mathrm{f}_{\mathrm{Td}}=\left(44^{2}-2,15 \mathrm{f}_{\mathrm{Vd}}\right)^{0,5}$ \\
\hline $\begin{array}{c}\text { Parafuso A325 (plano de corte } \\
\text { passa pela rosca) }\end{array}$ & $\mathrm{f}_{\mathrm{Td}}=\phi\left(90^{2}-3,52 \mathrm{f}_{\mathrm{Vd}}{ }^{2}\right)^{0,5}$ & $\mathrm{f}_{\mathrm{Td}}=\left(44^{2}-4,39 \mathrm{f}_{\mathrm{Vd}}{ }^{2}\right)^{0,5}$ \\
\hline $\begin{array}{c}\text { Parafuso A490 (plano de corte } \\
\text { não passa pela rosca) }\end{array}$ & $\mathrm{f}_{\mathrm{Td}}=\phi\left(113^{2}-2,27 \mathrm{f}_{\mathrm{Vd}}{ }^{2}\right)^{0,5}$ & $\mathrm{f}_{\mathrm{Td}}=\left(54^{2}-1,82 \mathrm{f}_{\mathrm{Vd}}\right)^{2,5}$ \\
\hline $\begin{array}{c}\text { Parafuso A490 (plano de corte } \\
\text { passa pela rosca) }\end{array}$ & $\mathrm{f}_{\mathrm{Td}}=\phi\left(113^{2}-3,54 \mathrm{f}_{\mathrm{Vd}}{ }^{2}\right)^{0,5}$ & $\mathrm{f}_{\mathrm{Td}}=\left(54^{2}-3,72 \mathrm{f}_{\mathrm{Vd}}{ }^{2}\right)^{0,5}$ \\
\hline
\end{tabular}

De acordo com EUROCODE 3 [ 24 ], parafusos sujeitos à força cortante e tração deverão satisfazer a seguinte condição:

$$
\frac{F_{v . S d}}{F_{v . R d}}+\frac{F_{t . S d}}{1,4 F_{t . R d}} \leq 1,0
$$

onde: $\mathrm{F}_{\mathrm{v} . S d}=$ força cortante de cálculo por parafuso (correspondente a $V_{d}$ )

$\mathrm{F}_{\mathrm{v} . \mathrm{Rd}}=$ resistência de cálculo à força cortante por parafuso

$\mathrm{F}_{\mathrm{t} . S d}=$ força de tração de cálculo por parafuso (correspondente a $T_{d}$ )

$\mathrm{F}_{\mathrm{t} . \mathrm{Rd}}=$ resistência de cálculo à tração por parafuso

\subsection{Conexões por atrito: parafusos sob força cortante, combinada ou não com tração}

Uma conexão por atrito (ou do tipo atrito) é definida como aquela em que a força é transferida pelo atrito que pode ser mobilizado entre as superfícies em contato. A força de atrito é conseguida pelo aperto dos parafusos e pelas condições de rugosidade das superfícies em contato.

Quando a força atuante é maior que a força de atrito, ocorrerá deslizamento e conseqüentemente uma mudança no comportamento da conexão, ou seja: de atrito para contato. Portanto, o deslizamento caracteriza um estado limite de utilização e o contato um estado limite último, que deve ser sempre verificado.

Como pode ser observado na fig. 3-11, inicialmente a força é transferida pelo atrito mobilizado entre as superfícies em contato. Segundo OWENS \& CHEAL [ 50 ], no inicio a conexão mostra pequeno deslizamento devido ao entrosamento entre os interstícios (irregularidades) das superfícies em contato, correspondendo à uma alta "rigidez" que é a característica mais importante destas conexões. 
Com o aumento da força, os interstícios iniciam o processo de plastificação por cisalhamento e conseqüentemente o deslizamento aumenta. Quando a força se iguala a força de atrito estático, há um repentino movimento, o que pode colocar o parafuso em contato com a parede do respectivo furo. Caso contrário, há apenas um deslizamento parcial, ou seja, o deslizamento é interrompido após um pequeno movimento. A partir deste instante, um acréscimo da força provoca novo deslizamento e provavelmente leva o parafuso ao contato com a parede do furo.

Uma vez em contato, a força é transmitida parcialmente pelo contato e parcialmente pelo atrito. Com o aumento das tensões de cisalhamento no parafuso, associadas às elevadas tensões de tração provenientes da pré-tração, ocorre a plastificação do parafuso que induz a uma redução na pré-tração (relaxação) e conseqüentemente na força de atrito, portanto, no estado limite último, pode-se assumir a total transferência da força por contato.

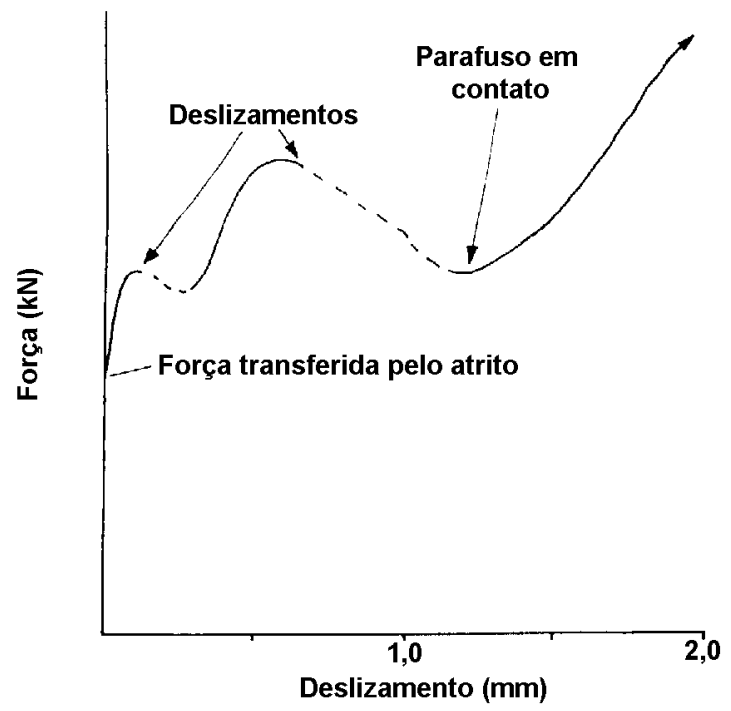

FIGURA 3-11 Comportamento força-deslizamento em conexão com um único parafuso de alta resistência de 19 mm de diâmetro, em cisalhamento duplo. Adaptada de OWENS \& CHEAL [ 50 ].

A força de pré-tração (ou protensão) no parafuso, $T_{b}$, é igual à força de aperto das partes presentes na conexão. A resistência ao deslizamento é dada pela força de atrito mobilizada, ou seja, $\mu T_{b}$, onde $\mu$ é o coeficiente de atrito. Os valores do coeficiente de atrito variam de 0,2 a 0,6 dependendo das condições das superfícies em contato, que muitas vezes requerem tratamento superficial.

Segundo KULAK et al. [ 34 ], tem sido demostrado que os revestimentos protetores alteram as características de deslizamento das conexões parafusadas. 
Conseqüentemente, o projeto das conexões por atrito deve levar em consideração a presença de tais revestimentos na avaliação da resistência ao deslizamento.

No início da aplicação das conexões por atrito, o uso de revestimentos foi limitado ou proibido pelas especificações. Estas restrições foram baseadas em pesquisas, que indicaram uma baixa resistência ao deslizamento em superfícies revestidas, principalmente as galvanizadas. Entretanto, como continuação das pesquisas, foram desenvolvidos alguns revestimentos que conduzem a valores adequados da resistência ao deslizamento, os quais foram incluídos na especificação do RCRBSJ em 1970, que passou a permitir o uso de certos revestimentos e tratamentos superficiais em conexões por atrito.

Os tipos mais freqüentes de revestimentos protetores podem ser classificados como:

- galvanização por imersão a quente, com ou sem tratamento de superfície (para aumentar a resistência ao deslizamento).

Requerem a remoção da carepa de laminação, feita usualmente através de decapagem (banho de ácido). Na seqüência, o elemento é revestido com uma camada metálica, por imersão num banho de metal quente, que são ligas de ferro-zinco ou zinco puro.

Ensaios de deslizamento, de curta duração, indicam que a galvanização a quente implica em uma baixa resistência ao deslizamento, com coeficientes de atrito entre 0,08 e 0,36 (valor médio igual a 0,19). A baixa resistência ao deslizamento é causada pela camada relativamente macia de zinco, que atua como lubrificante entre as superfícies. Os ensaios mostraram também que o coeficiente de atrito decresce com o aumento da espessura do revestimento.

Um significativo aumento no coeficiente de atrito pode ser alcançado por tratamentos superficiais adequados, como por exemplo a escovação com escova de aço, jateamento de areia e tratamentos químicos.

- metalização com pulverização de zinco, alumínio ou uma combinação destes dois metais. 
Corresponde à pulverização de um metal quente. As superfícies a serem metalizadas devem estar isentas de óleos e graxas e rugosas por jateamento.

Ensaios de deslizamento, de curta duração, têm mostrado que elevados valores da resistência ao deslizamento podem ser alcançados com esse tratamento. Quando o revestimento é espesso, comparado com as irregularidades superficiais resultantes do jateamento, o coeficiente de atrito resulta relativamente baixo, o que também ocorre para revestimentos muito finos (15 a $25 \mu \mathrm{m})$. A espessura ideal do revestimento situa-se entre $(50$ e $100 \mu \mathrm{m})$.

As superfícies metalizadas com alumínio apresentam valores mais elevados do coeficiente de atrito que as metalizadas com zinco, fato este proveniente da maior dureza da camada de alumínio quando comparada com a de zinco.

- tintas ricas em zinco, com veículos orgânicos ou inorgânicos.

São revestimentos que contém alto conteúdo de pó de zinco, propiciando eficaz proteção à corrosão e elevada resistência à abrasão e não requerem grandes espessuras.

Em geral, conduzem a baixos valores do coeficiente de atrito e a variabilidade destes valores é elevada em função do tratamento utilizado. Desta forma, recomendase o uso destas tintas em superfícies jateadas ou escovadas para se obter maior resistência ao deslizamento.

As tintas com veículo inorgânico conduzem a valores mais elevados do coeficiente de atrito que as tintas com veículo orgânico. Por exemplo, as tintas a base de silicato de zinco fornecem superfícies com elevada resistência ao deslizamento.

- banhos ou pinturas de vinilo.

São facilmente aplicáveis, fornecem de moderada a boa proteção contra corrosão e são relativamente baratos. 
Os resultados de ensaios de deslizamento, de curta duração, em superfícies previamente jateadas com areia, mostraram que o tempo de exposição das superfícies antes da montagem não tem influência significativa no coeficiente de atrito. Os valores encontrados para o coeficiente de atrito em superfícies com banho de vinilo, jateadas com areia, são aproximadamente os mesmos das superfícies laminadas limpas, ou seja, sem revestimento, cujo valor médio obtido para os aços A7, A36 e A440 foi 0,33 .

É importante registrar que as especificações prescrevem o jateamento com areia antes da aplicação do revestimento de vinilo.

Para superfícies laminadas, isentas de revestimento, é de fundamental importância a maneira como se realiza a limpeza das superfícies, o que implica nas condições de rugosidade. Se a carepa de laminação é removida por escovamento com ferramenta elétrica, ocorre um semi polimento das superfícies e uma redução de 25 a $30 \%$ no coeficiente de atrito, quando comparado ao obtido em superfícies escovadas manualmente. Já a limpeza por jateamento aumenta o coeficiente de atrito para a maioria dos aços analisados, tendo sido encontrado valor médio igual a 0,51 para os aços A7, A36 e Fe37.

O AISC apresenta um método de ensaio para a avaliação do coeficiente de atrito em conexões parafusadas, que foi desenvolvido pelos professores Joseph $A$. Yura e Karl H. Frank da Universidade do Texas - Austin. Este método foi aprovado pelo RCSC em 1984, e seu esquema geral e dimensões dos elementos estão apresentados na fig. 3-12.

Este método prevê ensaio de curta duração (fig. 3-12a) e ensaio de longa duração (fig. 3-12b) para avaliação do efeito da fluência, ou seja, para avaliar o desempenho do revestimento para ações de longa duração.

$\mathrm{Na}$ figura 3-12c pode-se observar o dispositivo de ensaio, constituído basicamente por um soquete que aplica a pressão de contato entre as chapas e de uma prensa ou máquina de ensaio que aplica a força de compressão no corpo-de-prova. É interessante observar que a porca interna é broqueada, de maneira a deslizar livremente entre o soquete e o corpo-de-prova. 

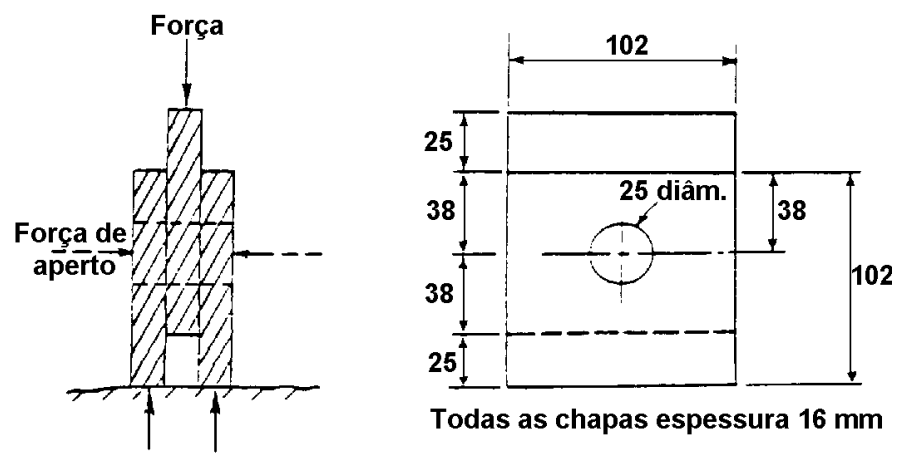

(a)

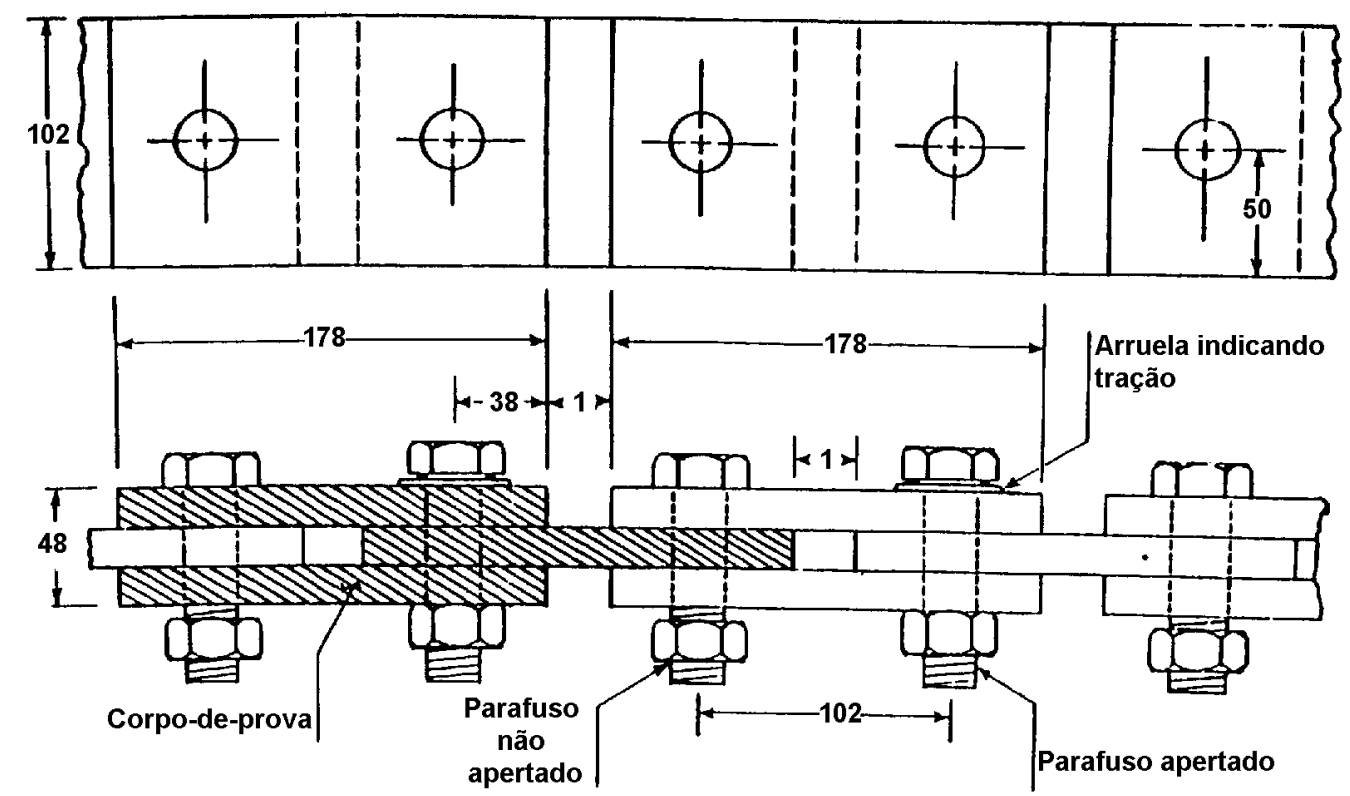

(b)

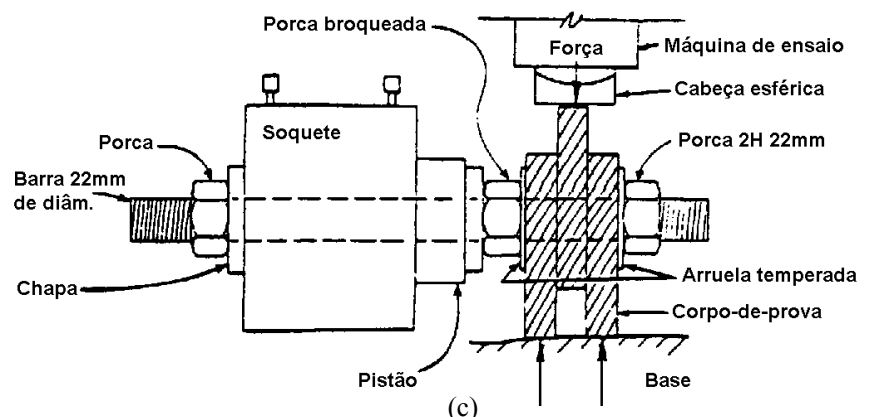

FIGURA 3-12 (a) Ensaio de curta duração; (b) ensaio de longa duração (fluência); (c) dispositivo de ensaio. Adaptada do AISC/ASD [ 1 ].

Neste ensaio é registrada a resposta força-deslizamento, mostrada na fig. 3-

13. Três tipos de curvas são usualmente observadas e a força crítica de deslizamento é definida da seguinte maneira:

- curva (a): é dada pelo pico da curva, desde que o deslizamento correspondente não ultrapasse $0,5 \mathrm{~mm}$. 
- curva (b): corresponde ao ponto de mudança brusca na taxa de deslizamento.

- curva (c): corresponde a um deslizamento de $0,5 \mathrm{~mm}$.

O coeficiente de atrito é obtido pela relação (força crítica de deslizamento)/(2 $\mathrm{x}$ força de aperto). $\mathrm{O}$ fator 2 no denominador corresponde à existência de dois planos de contato no corpo-de-prova.

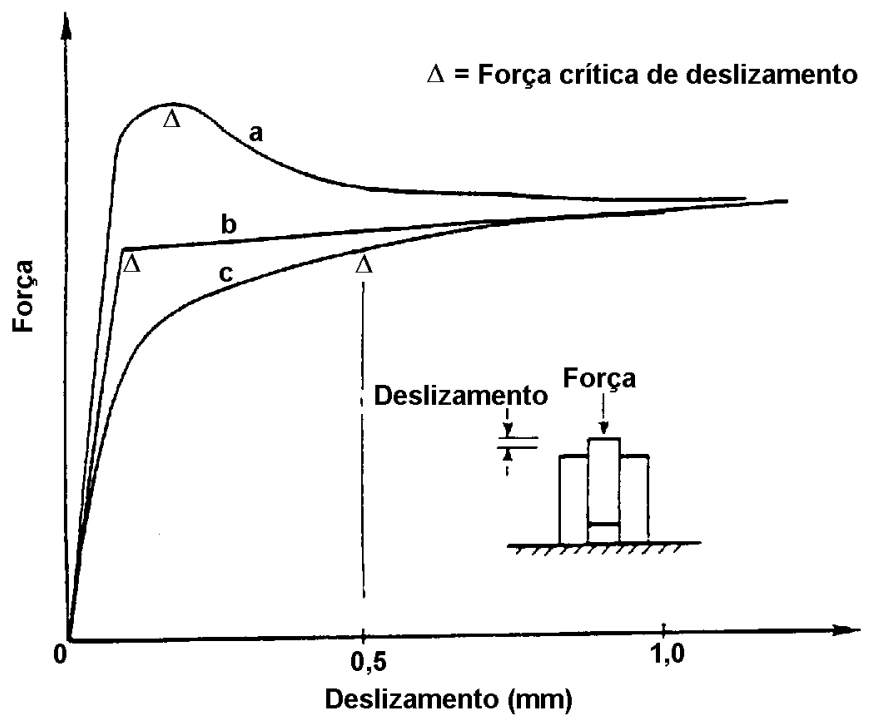

FIGURA 3-13 Comportamento típico força-deslizamento observado nos ensaios, indicando a definição da força crítica de deslizamento. Adaptada do AISC/ASD [ 1 ].

Segundo SALMON \& JOHNSON [ 60 ], o AISC tem utilizado o mesmo conceito de tensão admissível ou resistência de cálculo, empregado no projeto de conexões tipo contato, buscando com isto uniformizar o projeto de conexões parafusadas. Desta maneira, são apresentados valores de tensões críticas de "cisalhamento", obtidas pela força crítica de deslizamento $\mu T_{b}$ dividida pela área bruta do parafuso $A_{p}$.

É interessante observar que os valores das tensões críticas de "cisalhamento" nos parafusos são os mesmos tomando-se o AISC/ASD [ 1 ] e o AISC/LRFD 86 [ 3 ], considerando que o deslizamento é um estado limite de utilização e, portanto, a verificação é feita com valores nominais das ações e da resistência. A tabela 3-12 resume estes valores.

TABELA 3-12 Tensões críticas de "cisalhamento" por plano de contato para parafusos em conexões por atrito (valores em MPa). Adaptada de SALMON \& JOHNSON [ 59 ].

Tipo de furo e direção da aplicação da força

\begin{tabular}{|c|c|c|c|}
\hline \multicolumn{4}{|c|}{ Tipo de furo e direção da aplicação da força } \\
\hline \multicolumn{2}{|c|}{ Direção qualquer ${ }^{(\mathrm{b})}$} & Transversal $^{(\mathrm{b})}$ & Paralela $^{(\mathrm{c})}$ \\
\hline Padrão & Alargado e & Muito & Muito \\
\hline
\end{tabular}




\begin{tabular}{|c|c|c|c|c|c|c|c|c|}
\cline { 2 - 9 } \multicolumn{2}{c|}{} & \multicolumn{2}{c|}{ pouco along. } & \multicolumn{2}{c|}{ alongado } & \multicolumn{2}{c|}{ alongado } \\
\hline Condição das superf. em contato & A325 & A490 & A325 & A490 & A325 & A490 & A325 & A490 \\
\hline $\begin{array}{c}\text { Classe A }(\mu=0,33) \text { : Superfícies } \\
\text { laminadas limpas e superfícies } \\
\text { jateadas em condições } \\
\text { superficiais Classe A }\end{array}$ & 117 & 145 & 103 & 124 & 83 & 103 & 69 & 90 \\
\hline $\begin{array}{c}\text { Classe B }(\mu=0,50): \text { Superfícies } \\
\text { jateadas e superfícies jateadas em } \\
\text { condições superficiais Classe B }\end{array}$ & 193 & 234 & 165 & 200 & 138 & 165 & 117 & 138 \\
\hline $\begin{array}{c}\text { Classe C }(\mu=0,40): \text { Superfícies } \\
\text { galvanizadas por imersão a quente } \\
\text { e superfícies rugosas }\end{array}$ & 152 & 186 & 131 & 158 & 110 & 131 & 96 & 110 \\
\hline
\end{tabular}

(a) A classificação das superfícies como classe $\mathrm{A}$ ou B, incluem aquelas superfícies que produzem um coeficiente de atrito médio, não inferior à 0,33 ou 0,50 , respectivamente;

(b) Esses valores foram multiplicados por $\phi=1,0$;

(c) Esses valores foram multiplicados por $\phi=0,85$

O AISC/LRFD 93 [ 4 ] além da verificação utilizando valores nominais das ações e da resistência, também prevê a verificação com valores de cálculo. Esta uniformização visa facilitar o dimensionamento, utilizando apenas solicitações de cálculo. O resultado final, ou seja, o número necessário de parafusos, deverá ser aproximadamente o mesmo para os dois procedimentos uma vez que houve calibração entre eles. Dessa forma, a resistência de cálculo ao deslizamento é tomada como:

$$
\phi \mathrm{R}_{\mathrm{str}}=\phi 1,13 \mu \mathrm{T}_{\mathrm{m}} \mathrm{N}_{\mathrm{b}} \mathrm{N}_{\mathrm{s}}
$$

onde: $\mu=$ coeficiente de atrito, conforme primeira coluna da tabela 3-12

$\mathrm{T}_{\mathrm{m}}=$ tração mínima no parafuso

$\mathrm{N}_{\mathrm{b}}=$ número de parafusos em uma ligação

$\mathrm{N}_{\mathrm{s}}=$ número de planos de contato

$\phi=1,0$ para furos padrão; 0,85 para furos alargados e furos pouco alongados; 0,70 para furos muito alongados transversal à direção da força e 0,60 para furos muito alongados paralelos à direção da força.

Como a resistência ao deslizamento está diretamente relacionada com a distribuição de pressão de contato entre as superfícies (área de efetivo contato), a presença de furos alargados ou alongados conduzem a uma situação mais desfavorável que a situação de furos padrão. Por esta razão, as normas estabelecem valores reduzidos desta resistência ao deslizamento para o caso de outros furos que não sejam os furos padrão. 
Segundo OWENS \& CHEAL [ 50 ], forças de tração externas produzem uma redução na pressão de contato e conseqüentemente uma redução na resistência ao deslizamento. Os resultados experimentais têm mostrado que há uma redução linear da resistência ao deslizamento em função da tração externa. Com base nesta observação, foi proposta uma expressão linear de interação para parafusos sob força cortante e tração combinadas.

O AISC, citado por SALMON \& JOHNSON [ 60 ], prescreve uma expressão linear de interação para esforços combinados, porém de forma mais conservadora que para conexões por contato. A constante $C$ é reduzida de 1,3 (conexões por contato) para 1,0 resultando:

$$
\frac{\mathrm{V}_{\mathrm{n}}}{\mathrm{F}_{\mathrm{v}} \mathrm{A}_{\mathrm{p}}}+\frac{\mathrm{T}_{\mathrm{n}}}{\mathrm{T}_{\mathrm{b}}} \leq 1,0
$$

onde: $F_{v}=$ tensão crítica de "cisalhamento" para conexões sujeitas somente a força cortante

$\mathrm{A}_{\mathrm{p}}=$ área da seção transversal bruta do parafuso

$\mathrm{V}_{\mathrm{n}}=$ cortante nominal no parafuso

$\mathrm{T}_{\mathrm{n}}=$ tração nominal no parafuso

$\mathrm{T}_{\mathrm{b}}=$ força de pré-tração no parafuso

Resolvendo a expressão 3.5.2 para $\mathrm{f}_{\mathrm{v}}=\mathrm{V}_{\mathrm{n}} / \mathrm{A}_{\mathrm{p}}$, e substituindo os valores de $F_{v}$, obtém-se as expressões do AISC/ASD [ 1 ] e AISC/LRFD 86 [ 3 ] para esforços combinados:

$$
\begin{aligned}
& f_{v} \leq 117\left(1-\frac{T_{n}}{T_{b}}\right)(\text { em MPa }) \text { parafusos A325, furo padrão } \\
& f_{v} \leq 145\left(1-\frac{T_{n}}{T_{b}}\right)(\text { em MPa) parafusos A490, furo padrão }
\end{aligned}
$$

O AISC/LRFD 93 [ 4 ] além da verificação feita utilizando valores nominais das solicitações, também faz a verificação utilizando as solicitações de cálculo. Desta forma, quando se usa as solicitações de cálculo como base para o cálculo de 
conexões por atrito, sujeitas a uma tração externa $T_{n}$, a resistência ao deslizamento $\phi R_{s t r}$, deve ser multiplicada pelo seguinte fator:

$$
\left[1-\mathrm{T}_{\mathrm{u}} /\left(1,13 \mathrm{~T}_{\mathrm{m}} \mathrm{N}_{\mathrm{b}}\right)\right]
$$

onde: $T_{\mathrm{u}}=$ tração de cálculo da conexão

De acordo com o EUROCODE 3 [ 24 ], a resistência ao deslizamento da conexão, referente a um parafuso de alta resistência pré-tracionado, deve ser tomada como:

$$
\mathrm{F}_{\mathrm{s} . \mathrm{Rd}}=\frac{\mathrm{k}_{\mathrm{s}} \mathrm{n \mu}}{\gamma_{\mathrm{Ms}}} \mathrm{F}_{\mathrm{p} . \mathrm{Cd}}
$$

onde: $\mathrm{F}_{\mathrm{p} . \mathrm{Cd}}=$ força de pré-tração $=0,7 \mathrm{~A}_{\mathrm{s}} \mathrm{f}_{\mathrm{ub}}\left(\right.$ correspondente a $T_{b}$ da NBR $8800[7$ ]) $\mathrm{f}_{\mathrm{ub}}=$ limite de resistência à tração do parafuso

$\mathrm{A}_{\mathrm{s}}=$ área efetiva à tração (correspondente a $A_{r}$ da NBR 8800 [ 7 ])

$\mu=$ coeficiente de atrito (conforme tabela 3-13)

$\mathrm{n}=$ número de planos de contato (interfaces de atrito)

$\mathrm{k}_{\mathrm{s}}=1,0$ para furos padrão

$\mathrm{k}_{\mathrm{s}}=0,85$ para furos alargados ou pouco alongados

$\mathrm{k}_{\mathrm{s}}=0,70$ para furos muito alongados

$\gamma_{\mathrm{Ms}}=$ fator de segurança parcial, tomado como:

- para furos padrão e furos alongados perpendicularmente à direção da força:

$$
\begin{aligned}
& \gamma_{\text {Ms.ult }}=1,25 \text { (para estado limite último) } \\
& \gamma_{\text {Ms.ser }}=1,10 \text { (para estado limite de utilização) }
\end{aligned}
$$

- para furos alargados ou furos alongados paralelos à direção da força, a conexão deve ser projetada como categoria $\mathrm{C}$, em estado limite último. Neste caso:

$$
\gamma_{\text {Ms.ult }}=1,40
$$

O EUROCODE 3 [ 24 ] divide as conexões parafusadas em cinco categorias, descritas a seguir, sendo as categorias A, B, e C referentes a conexões sob força cortante e as categorias D e E referentes a conexões sob tração: 
- categoria A (tipo contato): parafusos comuns (aço baixo carbono) ou parafusos de alta resistência das classes 4.6 até 10.9. A pré-tração não é necessária. A força cortante de cálculo $F_{v . S d}$ não deve exceder a resistência de cálculo à força cortante $F_{v . R d}$ nem a resistência de cálculo à pressão de contato $F_{b . R d}$.

- categoria B (resistência ao deslizamento em estado limite de utilização): parafusos de alta resistência pré-tracionados com controle de aperto. O deslizamento não deve ocorrer em estado limite de utilização. A força cortante nominal $F_{v \text {.Sd.ser }}$ não deve exceder a resistência ao deslizamento $F_{s . R \text { d.ser }}$. A força cortante de cálculo $F_{v . S d}$ não deve exceder a resistência de cálculo à força cortante $F_{v . R d}$ nem a resistência de cálculo à pressão de contato $F_{b . R d}$.

- categoria C (resistência ao deslizamento em estado limite último): parafusos de alta resistência pré-tracionados com controle de aperto. $\mathrm{O}$ deslizamento não deve ocorrer no estado limite último. A força cortante de cálculo $F_{v . S d}$ não deve exceder a resistência de cálculo ao deslizamento $F_{S . R d}$ nem a resistência de cálculo à pressão de contato $F_{b . R d}$. Deve-se verificar também a plastificação da seção líquida, dada por:

$$
\mathrm{N}_{\text {net.Rd }}=\frac{\mathrm{A}_{\text {net }} \mathrm{f}_{\mathrm{y}}}{\gamma_{\mathrm{Mo}}}
$$

onde: $\mathrm{A}_{\text {net }}=$ área da seção líquida

$\mathrm{f}_{\mathrm{y}}=$ limite de escoamento do metal base

$\gamma_{\mathrm{Mo}}=1,1$

- categoria D (parafusos sem pré-tração): parafusos comuns e de alta resistência das classes 4.6 a 10.9. Não deve ser usada para os casos de significativas variações da força de tração. Entretanto, pode ser usada nas situações de ação de vento.

- categoria E (parafusos de alta resistência pré-tracionados com controle de aperto): empregada em situações de fadiga.

Para conexões tracionadas das categorias D e E, nenhum tratamento das superfícies de contato é necessário, exceto quando as conexões da categoria E são 
sujeitas à esforços combinados. Para estas duas categorias, a força de tração de cálculo $F_{t . S d}$ não deve exceder a resistência de cálculo à tração $F_{t . R d}$.

TABELA 3-13 Valores do coeficiente de atrito $\mu$, segundo o EUROCODE 3 [ 24 ].

\begin{tabular}{|l|c|}
\hline \multicolumn{1}{|c|}{ Classe específica de tratamento superficial } & Coeficiente de atrito $\mu$ \\
\hline $\begin{array}{l}\text { Classe A: } \\
\text {-superfícies jateadas, sem produto da corrosão; } \\
\text { - superfícies jateadas e metalizadas com alumínio; } \\
\text { - superfícies jateadas e metalizadas com zinco tal } \\
\text { que } \mu \geq 0,5 .\end{array}$ & 0,50 \\
\hline $\begin{array}{l}\text { Classe B: } \\
\text { - superfícies jateadas e pintadas com tinta à base } \\
\text { de silicato de zinco alcalino, espessura do } \\
\text { revestimento entre } 50 \text { e } 80 \mu \text { m. }\end{array}$ & 0,40 \\
\hline $\begin{array}{l}\text { Classe C: } \\
\text { - superfícies limpas com escovas de aço ou a } \\
\text { fogo, sem produto da corrosão. }\end{array}$ & 0,30 \\
\hline $\begin{array}{l}\text { Classe D: } \\
- \text { superfície não tratada. }\end{array}$ & 0,20 \\
\hline
\end{tabular}

Para o caso de solicitação combinada, o EUROCODE 3 [ 24 ] estabelece que a resistência ao deslizamento da conexão, por parafuso, deve ser avaliada por:

Categoria B: resistência ao deslizamento em estado limite de utilização:

$$
\mathrm{F}_{\mathrm{s} . \text { Rd.ser }}=\frac{\mathrm{k}_{\mathrm{s}} \mathrm{n} \mu\left(\mathrm{F}_{\mathrm{p} . \mathrm{Cd}}-0,8 \mathrm{~F}_{\mathrm{t} . \mathrm{Sd} . \mathrm{ser}}\right)}{\gamma_{\text {Ms.ser }}}
$$

Categoria C: resistência ao deslizamento em estado limite último:

$$
\mathrm{F}_{\mathrm{s} . \mathrm{Rd}}=\frac{\mathrm{k}_{\mathrm{s}} \mathrm{n} \mu\left(\mathrm{F}_{\mathrm{p} . \mathrm{Cd}}-0,8 \mathrm{~F}_{\mathrm{t} . \mathrm{Sd}}\right)}{\gamma_{\text {Ms.ult }}}
$$

Segundo a NBR 8800 [ 7 ], a resistência ao deslizamento de uma conexão utilizando parafusos de alta resistência, sujeitos à força cortante, combinada ou não com tração, por plano de corte é:

$\phi_{\mathrm{v}} \mathrm{R}_{\mathrm{nv}}=\mu \xi\left(\mathrm{T}_{\mathrm{b}}-\mathrm{T}\right)$

onde: $\phi_{\mathrm{v}}=1,00$

$\mu=$ coeficiente de atrito, conforme tabela 3-14

$\mathrm{T}_{\mathrm{b}}=$ força mínima de pré-tração inicial no parafuso

$\mathrm{T}=$ força de tração no parafuso, calculada com base nas ações nominais, porém, com a carga permanente multiplicada por 0,75 , caso isto seja mais desfavorável 
$\xi=$ fator de redução, devido ao tipo de furo $(\xi=1,00$ para furos padrão; $\xi=$ 0,85 para furos alargados ou pouco alongados $(\xi=0,70$, caso a ocorrência de deslizamento esteja associada a qualquer tipo de redução de resistência ou acréscimo de solicitação); $\xi=0,70$ para furos muito alongados $(\xi=0,50$ para a solicitação na direção do alongamento do furo))

TABELA 3-14 Valores do coeficiente de atrito $\mu$, segundo a NBR 8800 [ 7 ].

\begin{tabular}{|c|c|}
\hline Condições das superfícies das partes parafusadas & Coeficiente de atrito $\mu$ \\
\hline $\begin{array}{l}\text { (a) Superfícies laminadas limpas, isentas de óleos ou graxas, jateadas ou } \\
\text { não, sem pintura } \\
\text { (b) Superfícies galvanizadas por imersão à quente, com rugosidade } \\
\text { superficial aumentada através da aplicação de jateamento ou escova de aço, } \\
\text { após a galvanização e antes da montagem } \\
\text { (c) Superfícies jateadas e pintadas com tintas orgânicas ou inorgânicas ricas } \\
\text { em zinco, conforme SSPC*-PS } 12.00 \\
\text { (d) Superfícies jateadas, metalizadas com zinco ou alumínio, conforme } \\
\text { AWS C2.2 (sem utilizar tratamentos posteriores descritos na seção IV } \\
\text { daquela norma) }\end{array}$ & $\begin{array}{l}0,32 \\
\text { (os coeficientes de } \\
\text { atrito para as condições } \\
\text { "b", "c" e "d", são } \\
\text { superiores a 0,32; } \\
\text { entretanto, este valor } \\
\text { deve ser usado nos } \\
\text { cálculos para evitar a } \\
\text { ocorrência de outros } \\
\text { estados limites) }\end{array}$ \\
\hline (e) Superfícies nas quais seja aplicado banho vinílico conforme SSPC*_PT 3 & 0,25 \\
\hline
\end{tabular}

Segundo KULAK et al. [ 34 ], além do coeficiente de atrito, a força de aperto inicial do parafuso é um dos principais fatores que controlam a força de deslizamento de uma conexão. Uma variação na força de aperto inicial afeta diretamente a força de deslizamento da conexão. Experiências têm mostrado que as efetivas trações nos parafusos em uma ligação, usualmente excedem a mínima tração requerida pelas especificações.

Como já se sabe, os parafusos podem ser apertados pelo método da rotação da porca ou utilizando chaves calibradas. O método da rotação da porca é principalmente baseado em um controle de alongamento, ao passo que o método da chave calibrada é baseado no controle de torque aplicado. Na fig. 3-14 a influência do método de aperto na tração alcançada no parafuso é mostrada para dois lotes, tendo diferentes propriedades mecânicas. Quando o método da chave calibrada é usado, a tração no parafuso $T_{i C}$ é aproximadamente a mesma para ambos os lotes, desde que a chave seja ajustada para cada lote. Todavia, se o método da rotação da porca é empregado, o alongamento médio nos parafusos será aproximadamente o mesmo para ambos os lotes. Conseqüentemente as trações $T_{i A}$ e $T_{i B}$ diferem, como ilustrado na fig. 3-14. 


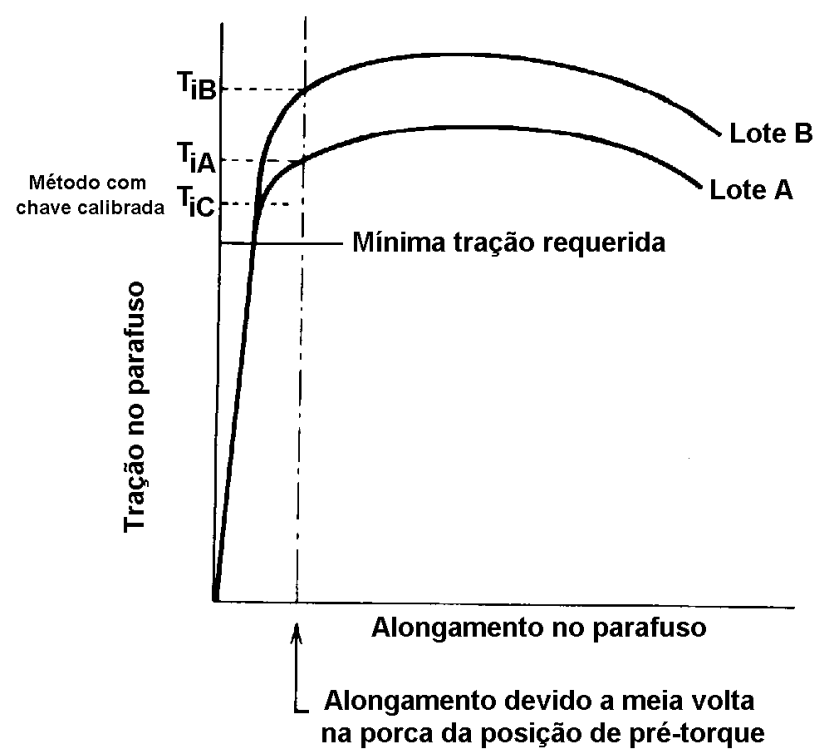

FIGURA 3-14 Influência dos métodos de aperto na tração no parafuso, para parafusos de diferentes lotes. Adaptada de KULAK et al. [ 34 ].

\subsection{Pré-tração (ou protensão) em parafusos}

Na prática, a pré-tração do parafuso é usualmente introduzida pelo seu aperto, ou seja, de forma indireta. Na operação de giro da porca por exemplo, são mobilizados o atrito entre a porca, a arruela e o material base, e o atrito entre a porca e o corpo do parafuso que provocam torção no parafuso. Portanto, trata-se de uma situação diferente daquela referente à aplicação direta de tração no parafuso.

Torqueando-se um parafuso até a ruptura, observa-se uma redução tanto na força última como na deformação última, quando comparadas com os valores determinados pelo ensaio de tração direta, conforme pode ser notado na fig. 3-15 referente a parafusos ASTM A490 e A325. 


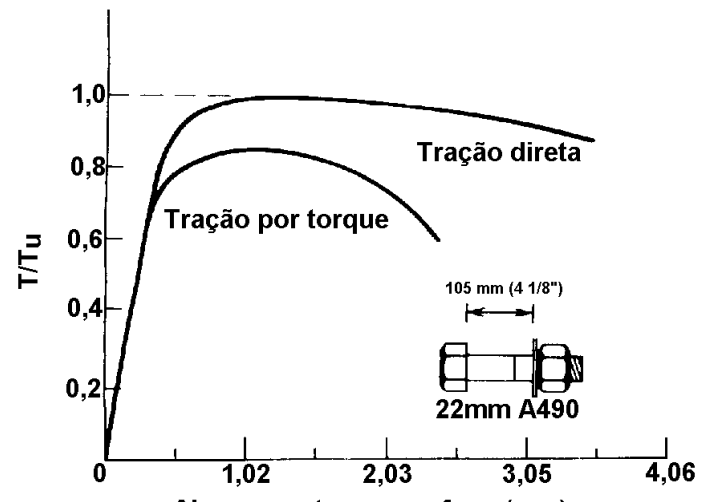

Alongamento no parafuso $(\mathrm{mm})$

(a)

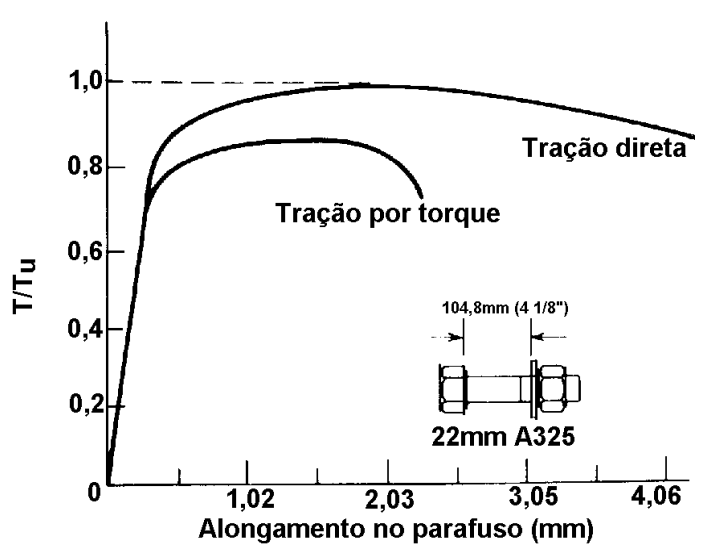

(b)

FIGURA 3-15 (a) Relação força versus alongamento em parafusos A490 testados em tração por torque e tração direta; (b) idem para parafusos A325. Adaptada de KULAK et al. [ 34 ].

Solicitando um parafuso em tração direta, após ele ter sido pré-tracionado pela rotação da porca (tração por torque), não são observadas diminuições significativas na capacidade do parafuso, como ilustra a fig. 3-16, portanto as tensões de cisalhamento provenientes da torção têm efeito desprezível na capacidade do mesmo.

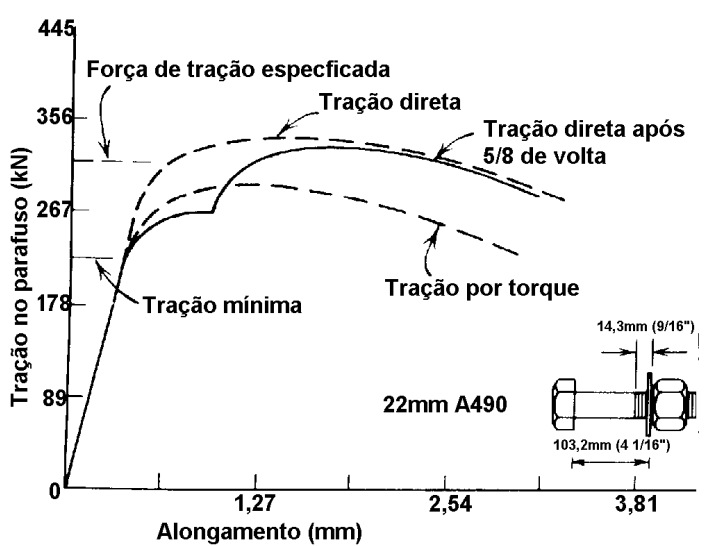

(a)

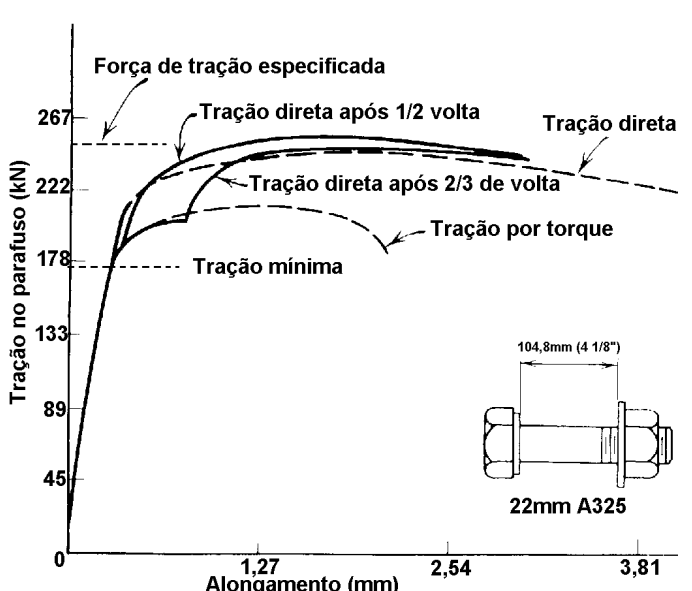

(b)

FIGURA 3-16 (a) Comportamento de parafusos A490 tracionados diretamente após torque; (b) idem para parafusos A325. Adaptada de KULAK [ 34 ].

Um modelo simples para o entendimento do comportamento de uma conexão parafusada, com o parafuso pré-tracionado e solicitada à tração externa, é mostrado em SALMON \& JOHNSON [ 60 ]. Este modelo é constituído por duas chapas e um único parafuso pré-tracionado, sob duas situações: inicialmente sem nenhuma força 
externa de tração $(P=0)$ e posteriormente sob a ação de uma força externa de tração $P$ (fig. 3-17).

Tomando-se o equilíbrio nas duas situações, tem-se:

sem a força externa $\mathrm{P}: \quad \mathrm{C}_{\mathrm{i}}=\mathrm{T}_{\mathrm{b}}$

com a força externa $P: \quad P+C_{f}=T_{f}$

onde: $T_{b}=$ pré-tração inicial no parafuso

$\mathrm{T}_{\mathrm{f}}=$ força de tração no parafuso na situação final, ou seja, atuando $P$

$\mathrm{P}=$ força externa aplicada

$\mathrm{C}_{\mathrm{i}}=$ resultante das pressões de contato na situação inicial (sem $P$ )

$\mathrm{C}_{\mathrm{f}}=$ resultante das pressões de contato na situação final $(\operatorname{com} P)$

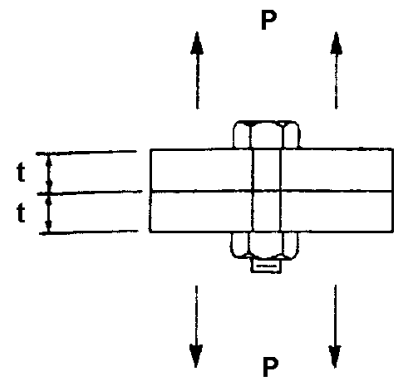

(a)

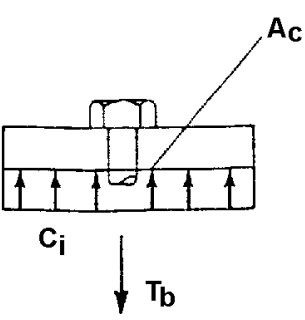

(b)

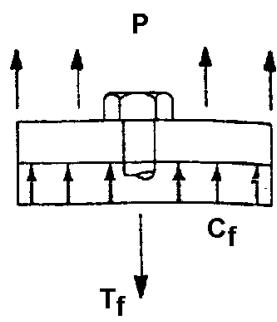

(c)

FIGURA 3-17 (a) Chapas conectadas por um parafuso pré-tracionado sob ação de tração externa; (b) forças na situação inicial: sem tração externa $(P=0)$; (c) forças na situação final: com tração externa $P$. Adaptada de SALMON \& JOHNSON [ 60 ].

É intuitivo imaginar que a força externa $P$ atuando sobre o sistema provoque uma descompressão entre as chapas (alívio na pressão de contato) e, pela compatibilidade de deformações, um alongamento no parafuso. Com isso, tem-se:

$\varepsilon_{\mathrm{p}}=$ deformação do parafuso, dada por:

$$
\varepsilon_{\mathrm{p}}=\frac{\mathrm{T}_{\mathrm{f}}-\mathrm{T}_{\mathrm{b}}}{\mathrm{EA}_{\mathrm{p}}}
$$

$\varepsilon_{\mathrm{c}}=$ deformação na chapa, dada por:

$$
\varepsilon_{\mathrm{c}}=\frac{\mathrm{C}_{\mathrm{i}}-\mathrm{C}_{\mathrm{f}}}{\mathrm{EA}_{\mathrm{c}}}
$$

onde: $A_{p}=$ área do parafuso

$\mathrm{A}_{\mathrm{c}}=$ área efetiva de pressão de contato entre as chapas

$\mathrm{E}=$ módulo de elasticidade do aço 
Igualando-se as deformações no parafuso e na chapa:

$\varepsilon_{\mathrm{p}}=\varepsilon_{\mathrm{c}} \rightarrow \frac{\mathrm{T}_{\mathrm{f}}-\mathrm{T}_{\mathrm{b}}}{\mathrm{EA}_{\mathrm{p}}}=\frac{\mathrm{C}_{\mathrm{i}}-\mathrm{C}_{\mathrm{f}}}{\mathrm{EA}_{\mathrm{c}}}$

Substituindo os valores de $C_{i}$ e $C_{f}$ na expressão 3.6.5, obtém-se:

$\mathrm{T}_{\mathrm{f}}=\mathrm{T}_{\mathrm{b}}+\left(\frac{\mathrm{P}}{1+\frac{\mathrm{A}_{\mathrm{c}}}{\mathrm{A}_{\mathrm{p}}}}\right)$

ou

$C_{f}=C_{i}-\left(\frac{P}{1+\frac{A_{p}}{A_{c}}}\right)$

Portanto, conhecendo-se a relação $A_{c} / A_{p}$ é possível avaliar $T_{f}$ e $C_{f}$.

Admitindo um espaçamento entre parafusos da ordem de $3 \mathrm{~d}$, tem-se:

$\mathrm{A}_{\mathrm{c}}=(3 \mathrm{~d})^{2}-\frac{\pi \mathrm{d}^{2}}{4} \cong 8,2 \mathrm{~d}^{2} \quad ; \quad \mathrm{A}_{\mathrm{p}}=\frac{\pi \mathrm{d}^{2}}{4}=0,785 \mathrm{~d}^{2}$

$\therefore \mathrm{A}_{\mathrm{c}} / \mathrm{A}_{\mathrm{p}}=10,44$

A bibliografia apresenta a relação entre áreas $A_{c} / A_{p}=10$, o que leva a:

$\mathrm{T}_{\mathrm{f}}=\mathrm{T}_{\mathrm{b}}+0,09 \mathrm{P}$
$\mathrm{C}_{\mathrm{f}}=\mathrm{T}_{\mathrm{b}}-0,91 \mathrm{P}$

O descolamento entre as chapas ocorre quando $C_{f}$ se anula, ou seja:

$\mathrm{C}_{\mathrm{f}}=\mathrm{T}_{\mathrm{b}}-0,91 \mathrm{P}=0 \rightarrow \mathrm{P}=1,1 \mathrm{~T}_{\mathrm{b}}$

Estes resultados são mostrados na fig. 3-18a, relacionando a tração final no parafuso em função da força externa aplicada. 


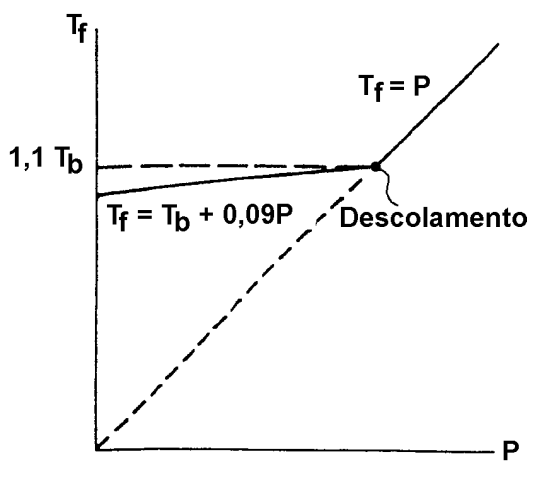

(a)

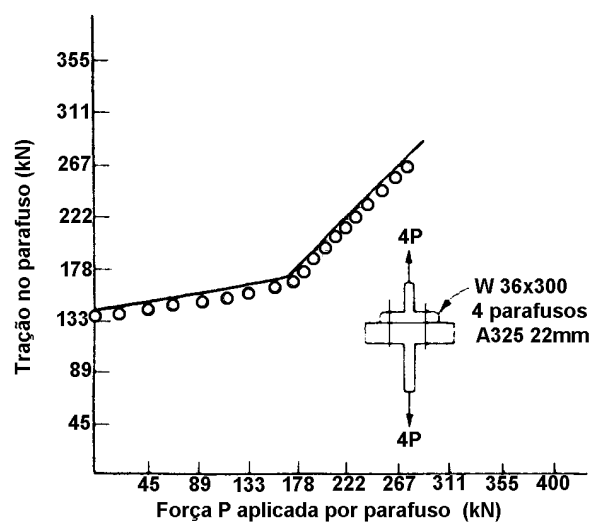

(b)

FIGURA 3-18 Gráficos relacionando tração final versus força externa aplicada; (a) admitindo $A_{c} / A_{p}=10$; (b) resultados de ensaios. Adaptada de GAYLORD et al. [ 27 ].

Pela expressão 3.6 .9 observa-se que, ao se aplicar uma tração externa, 9\% desta força é somada à pré-tração no parafuso, e a parcela restante $(91 \%)$ provoca o alívio da pressão de contato entre as chapas.

De acordo com MALITE et al. [ 40 ], a NBR 8800 [ 7 ] adota um modelo simplificado e conservador, admitindo que a totalidade da força externa $P$ provoca alívio na pressão de contato entre as chapas. Este comportamento é ilustrado na fig. 3-19.

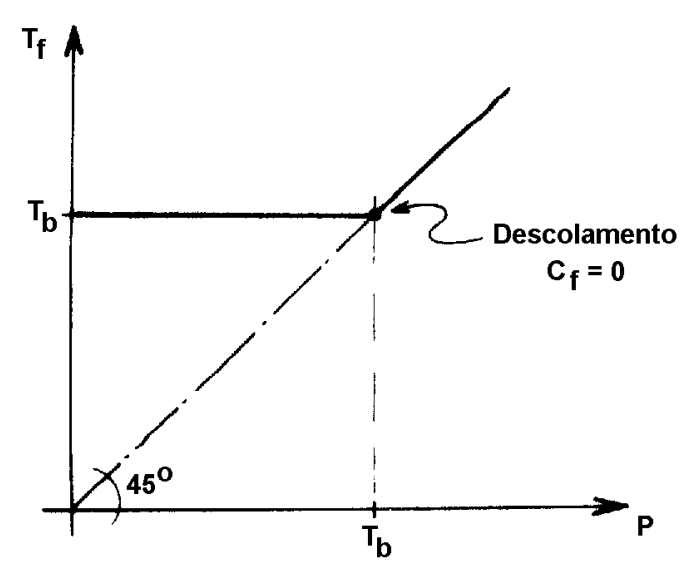

FIGURA 3-19 Gráfico de T $T_{\mathrm{f}}$ versus P: modelo da NBR 8800 [ 7 ]. Extraída de MALITE et al. [ 40 ].

\section{3-7 Conexões longas e pega longa}

Segundo OWENS \& CHEAL [ 50 ], o comprimento de conexões longas (comprimento elevado na direção da força) é caracterizado por uma distribuição não uniforme da força entre os parafusos, o que é incompatível com os modelos teóricos 
empregados para a análise das conexões, os quais admitem, no estado limite último, uma distribuição uniforme da força entre os parafusos.

A capacidade de distribuição da força entre os parafusos está diretamente relacionada com a ductilidade dos mesmos, pois os parafusos extremos vão se deformando e "repassando" a força aos adjacentes. Nas conexões longas, provavelmente ocorrerá a falha dos parafusos extremos antes que a uniformização da força entre todos os parafusos seja atingida, pois esta situação exigiria uma enorme capacidade de deformação dos parafusos.

Este efeito é mais marcante em juntas tracionadas, e muitas pesquisas têm sido realizadas para quantificar este efeito. A fig. 3-20 mostra a perda de eficiência em uma conexão, em função do comprimento da mesma.

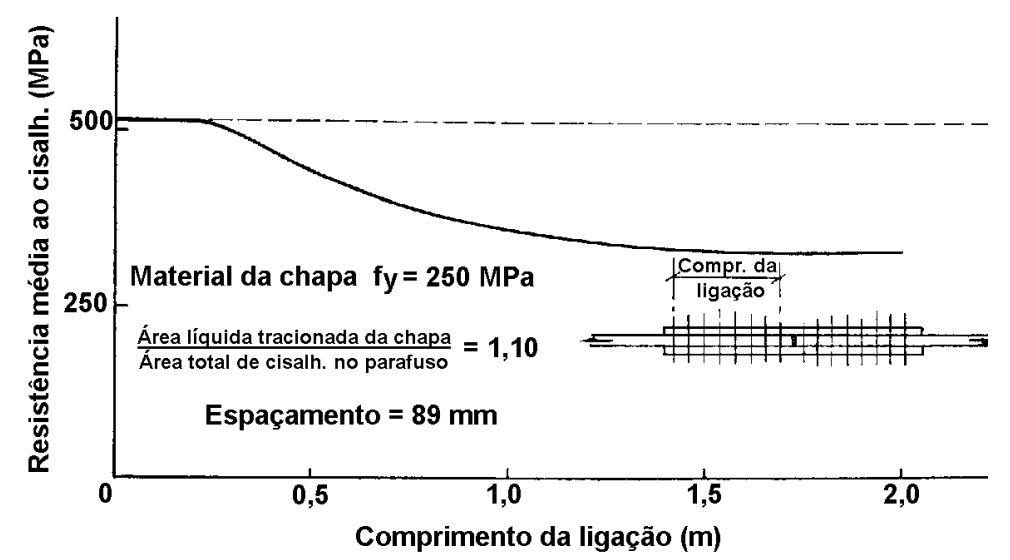

FIGURA 3-20 Resistência média à força cortante em função do comprimento da conexão. Adaptada de OWENS \& CHEAL [ 50 ].

$\mathrm{Na}$ prática, as conexões longas devem ser evitadas. Caso contrário, é usual adotar um fator de redução na resistência global da conexão ou uma majoração na força cortante por parafuso, para levar em consideração a não uniformidade da força cortante entre os parafusos.

De acordo com NBR 8800 [ 7 ], se conexões por contato, usadas em emendas de barras tracionadas, tiverem um comprimento superior a $630 \mathrm{~mm}$ na direção da força aplicada, a força cortante de cálculo nos parafusos, bem como a solicitação de cálculo usada para verificar a pressão de contato, serão multiplicadas por 1,25.

Esta variação abrupta nas solicitações para considerar o comportamento de conexões longas, não parece ser um bom critério. O EUROPEAN CONVENTION FOR CONSTRUCTIONAL STEELWORK [ 23 ] recomenda para um espaçamento 
entre o primeiro e o último parafuso $\leq 15 d$, onde $d$ é o diâmetro do parafuso, que a capacidade da ligação pode ser tomada como a soma das resistências dos parafusos. Quando o espaçamento é maior que $15 d$, a capacidade da ligação é $\beta$ vezes a soma das resistências dos parafusos. Valores de $\beta$ são mostrados na fig. 3-21.

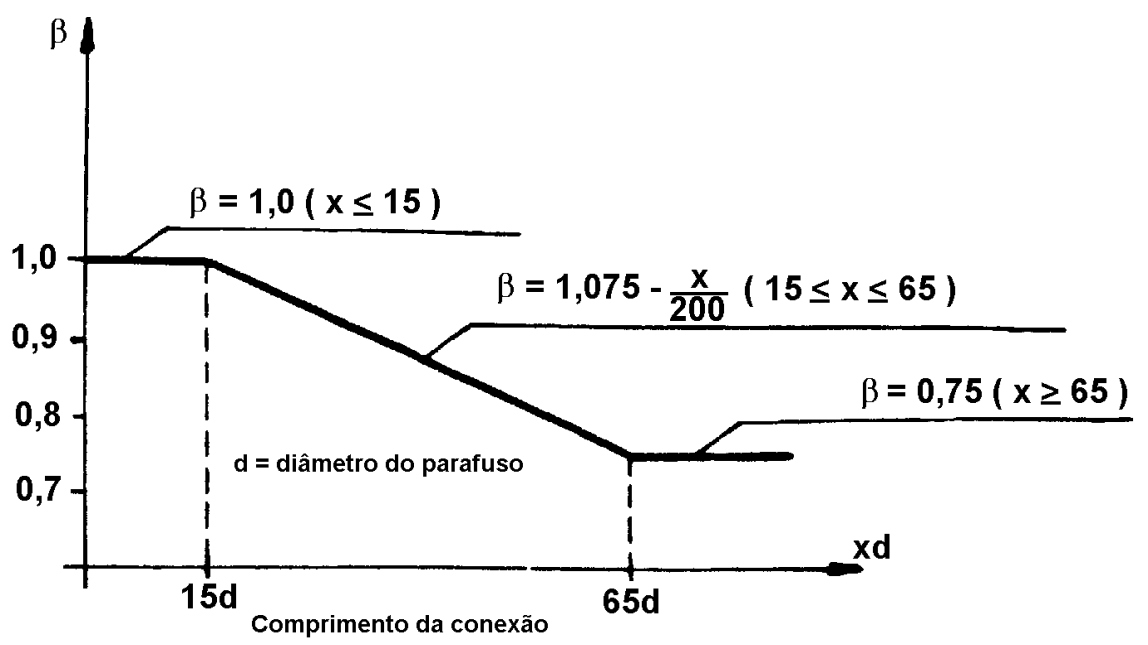

FIGURA 3-21 Coeficiente $\beta$ proposto para levar em consideração a redução na capacidade de conexões parafusadas longas. Adaptada do EUROPEAN CONVENTION FOR CONSTRUCTIONAL STEELWORK [ 23 ].

Quando a relação entre o comprimento de pega e o diâmetro do parafuso ultrapassa o valor 5, fica caracterizada a denominada "pega longa". O comprimento de pega é definido pela soma das espessuras das partes conectadas. Neste caso, o efeito de flexão no corpo do parafuso passa a ser significativo e não deve mais ser desprezado.

É interessante salientar que, ao contrário do que parece, a resistência à força cortante de um parafuso longo é maior que a de um parafuso curto, de mesmo diâmetro e material. Isto ocorre porque quanto maior a deformação por flexão, maior será a área efetiva de cisalhamento do parafuso, o que pode ser notado na fig. 3-22. O plano de cisalhamento em parafusos curtos situam-se aproximadamente a $90^{\circ}$ do eixo do parafuso, enquanto que nos parafusos longos estes planos são inclinados.

Entretanto, nas conexões por contato, este aumento de capacidade dos parafusos não é considerado, uma vez que isto ocorre sob grandes deformações e conseqüentemente grandes deslizamentos da conexão, o que não é desejado numa estrutura. Em geral, as normas especificam um aumento na quantidade de parafusos que é proporcional ao excesso de pega. 
Por exemplo, a NBR 8800 [ 7 ] estabelece que, com exceção de parafusos ASTM A325 e A490, montados com pré-tração, quando o comprimento de pega excede $5 d$ ( $d$ é o diâmetro do parafuso), o número de parafusos deve ser aumentado $1 \%$ para cada $1,5 \mathrm{~mm}$ adicionais de pega.

No caso de conexões por atrito, o comprimento de pega não tem influência significativa no comportamento da conexão, entretanto é importante no estabelecimento da pré-tração quando o método de controle de tração é a rotação da porca. Por exemplo, quando o comprimento de pega é maior que oito vezes o diâmetro, meia volta da condição de pré-torque em geral não é suficiente para fornecer a necessária pré-tração.

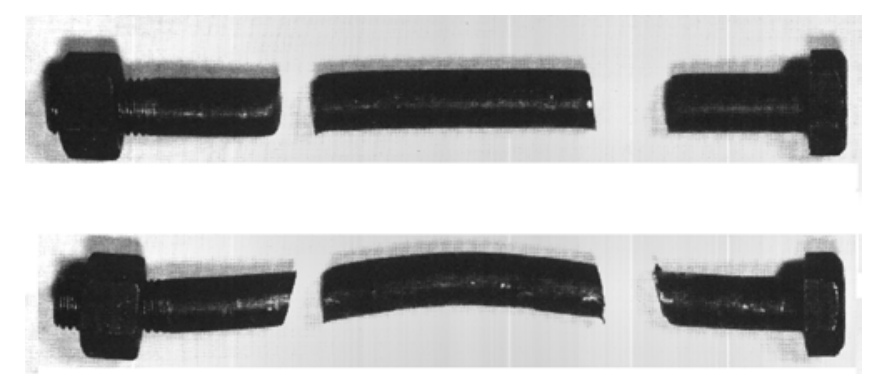

FIGURA 3-22 Comparação dos planos efetivos de cisalhamento. Adaptado de KULAK et al. [ 34 ]. 


\section{CAPÍTULO 4 - RESISTÊNCIA DE SOLDAS}

A utilização de solda possui várias vantagens e desvantagens. Segundo BELLEI [ 11 ], dentre as vantagens pode-se citar:

- a economia de material, pois a soldagem permite o aproveitamento total do material, ou seja, área líquida igual a área bruta. Além disso, as estruturas soldadas permitem eliminar grande quantidade dos elementos de ligação (chapas e perfis auxiliares), em relação às estruturas parafusadas (em algumas estruturas, como pontes e treliças é possível economizar $15 \%$ ou mais de peso em aço);

- estruturas soldadas são mais "rígidas", pois os elementos normalmente estão soldados diretamente um ao outro, diferentemente de conexões parafusadas, onde a união é feita através de chapas ou cantoneiras;

- conexões soldadas usam uma quantidade menor de peças, tendo como resultado um menor tempo de detalhe, fabricação e montagem.

Dentre as desvantagens de conexões soldadas pode-se citar:

- estruturas soldadas de grandes extensões sofrem uma redução no comprimento devido aos efeitos cumulativos de retração;

- necessidade da colocação de geradores quando a energia elétrica é insuficiente;

- conexões soldadas são mais susceptíveis a falhas por fadiga, em comparação com conexões parafusadas.

\section{1 Áreas efetivas de cisalhamento e outros parâmetros dos cordões de solda}

Um parâmetro muito importante no estudo da resistência de soldas é a garganta efetiva, que é a parte da solda assumida para ser efetiva na transferência de tensão e pode ser considerada como uma mínima profundidade do plano de falha esperado.

Tanto para soldas de filete quanto para soldas em chanfro, além da garganta efetiva, existem outros importantes parâmetros que devem ser definidos. No caso de soldas de filete, segundo a SIDERBRÁS [ 66 ], têm-se as seguintes definições (ver fig. 4-1): 
- face de fusão - região da superfície original do metal base onde ocorreu a fusão do metal base e do metal da solda;

- raiz da solda - linha comum às duas faces de fusão;

- perna do filete $b$ - menor dos lados, medidos nas faces de fusão, do maior triângulo inscrito dentro da seção transversal da solda (o filete de solda é especificado através da dimensão de sua perna);

- garganta efetiva $a$ - é a mais curta distância entre a raiz da solda e a hipotenusa desse triângulo inscrito;

- comprimento efetivo da solda $L$ - comprimento total da solda de dimensão uniforme, incluindo os retornos nas extremidades;

- área efetiva da solda $A_{W}$ - área considerada como de resistência da solda, que é igual à garganta efetiva vezes o comprimento efetivo $\left(A_{W}=a . L\right)$;

- área teórica da face de fusão $A_{M B}$ - área considerada como de resistência do metal base junto à solda, que é igual à perna do filete vezes o comprimento efetivo $\left(\mathrm{A}_{\mathrm{MB}}=\right.$ b.L).

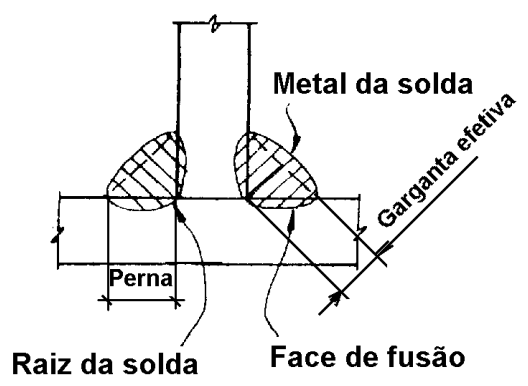

(a)

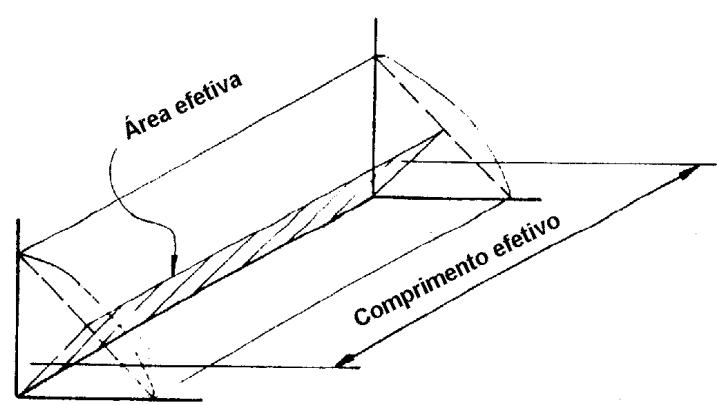

(b)

FIGURA 4-1 Definições para filetes de solda. Adaptada de SIDERBRÁS [ 66 ].

As pernas do filete são usualmente iguais, mas em algumas condições pernas desiguais são requeridas. Para o caso de filete de pernas iguais a dimensão da garganta efetiva é $0,707 b$. A NBR 8800 [ 7 ], considera que a maior penetração de soldas de filete executadas a arco submerso, justifica uma maior liberdade na definição da garganta efetiva. Nesta especificação a garganta efetiva para este tipo de solda é:

$$
\begin{array}{ll}
a=b & \text { para } \quad b \leq 9,5 \mathrm{~mm} \\
a=0,707 b+2,8 \mathrm{~mm} & \text { para } \quad b \geq 9,5 \mathrm{~mm}
\end{array}
$$


O EUROCODE 3 [ 24 ] especifica que a garganta efetiva, para uma solda de filete, não deverá ser inferior a $3 \mathrm{~mm}$. Além disso, é especificado que quando a solda de filete é feita pelo processo de soldagem a arco submerso, a garganta efetiva pode ser aumentada em $20 \%$ ou $2 \mathrm{~mm}$, qualquer que seja o menor.

Para as soldas em chanfro, segundo a SIDERBRÁS [ 66 ], são feitas as seguintes definições e notações, exemplificadas na fig. 4-2, que são: ângulo do chanfro $\alpha$; profundidade do chanfro $S$; nariz do chanfro $f$; raio do chanfro $r$; abertura da raiz $R$.

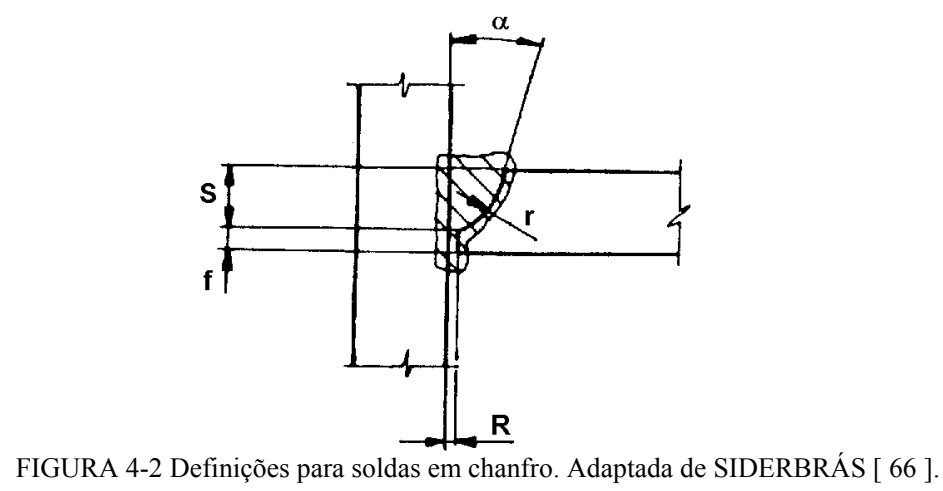

O comprimento efetivo $L$, que é o comprimento real da solda, no caso de solda em chanfro, deve coincidir com a largura da peça ligada, já a área efetiva $A_{W}$ é o produto da garganta efetiva pelo comprimento efetivo $\left(\mathrm{A}_{\mathrm{W}}=\mathrm{a} \cdot \mathrm{L}\right)$.

A garganta efetiva para solda em chanfro de penetração total, é a menor espessura das chapas conectadas. Já a garganta efetiva para soldas em chanfro de penetração parcial dependem da forma da ligação, exemplificadas na fig. 4-3.

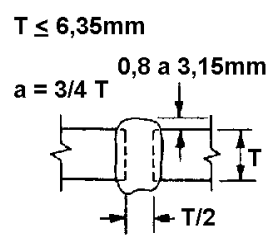

(a) Sem chanfro

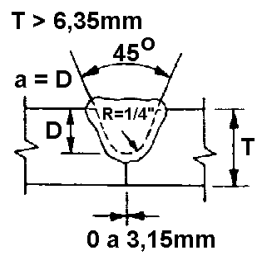

(b) Chanfro em U

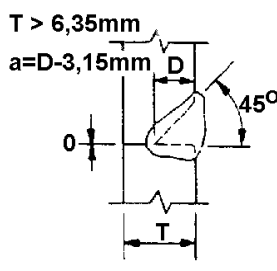

(c) Bisel simples

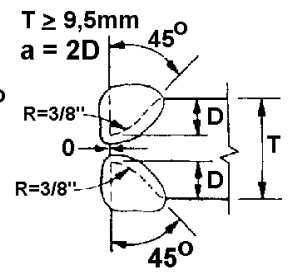

(d) Chanfro em duplo $\mathbf{J}$

FIGURA 4-3 Exemplos de gargantas efetivas $a$ em soldas de penetração parcial executadas pelo processo SMAW. Adaptada de GAYLORD et al. [ 27 ], através da ANSI/AWS D 1.1, 1988.

A solda com o chanfro reto (ou sem chanfro) é considerada de penetração parcial porque ela é soldada por apenas um lado, sem chapa de base. 
Segundo a NBR 8800 [ 7 ], a garganta efetiva para soldas em chanfro de penetração parcial é apresentada na tabela 4-1.

TABELA 4-1 Garganta efetiva em soldas em chanfro de penetração parcial. Adaptada da NBR 8800 [ 7 ].

\begin{tabular}{|c|c|c|c|}
\hline $\begin{array}{c}\text { Processo de } \\
\text { soldagem }\end{array}$ & $\begin{array}{c}\text { Posição de } \\
\text { soldagem }\end{array}$ & Tipo de chanfro & Garganta efetiva \\
\hline \multirow{2}{*}{$\begin{array}{c}\text { SMAW } \\
\text { SAW }\end{array}$} & \multirow{2}{*}{ Todas } & Chanfro em J ou U & \multirow{2}{*}{ Profundidade do chanfro } \\
\cline { 3 - 4 } $\begin{array}{c}\text { GMAW } \\
\text { FCAW }\end{array}$ & $\begin{array}{c}\text { Chanfro em bisel ou chanfro em V, } \\
\text { com ângulo de abertura } \geq 60^{\circ}\end{array}$ & \\
\cline { 3 - 4 } & & $\begin{array}{c}\text { Chanfro em bisel ou chanfro em V, } \\
\text { com ângulo de abertura entre } 45^{\circ} \text { e } 60^{\circ}\end{array}$ & $\begin{array}{c}\text { Profundidade do chanfro } \\
\text { menos 3 mm }\end{array}$ \\
\hline
\end{tabular}

As normas do AISC estabelecem os mesmos critérios para avaliação da garganta efetiva.

Segundo o EUROCODE 3 [ 24 ], em soldas de penetração parcial, para chanfro em U, V, J ou bisel, a garganta efetiva deve ser tomada como a profundidade nominal de preparação menos $2 \mathrm{~mm}$, a menos que um valor maior seja justificado por ensaios.

O EUROCODE 3 [ 24 ] menciona que a espessura da garganta efetiva de soldas em superfícies curvas (flare groove welds), como na fig. 4-4, deve ser determinada por meio da avaliação das soldas, para cada conjunto de condições de procedimento de soldagem.

A solda avaliada deve ser secionada e medida, para estabelecer a técnica de soldagem que garantirá que a pretendida garganta efetiva seja alcançada na produção.
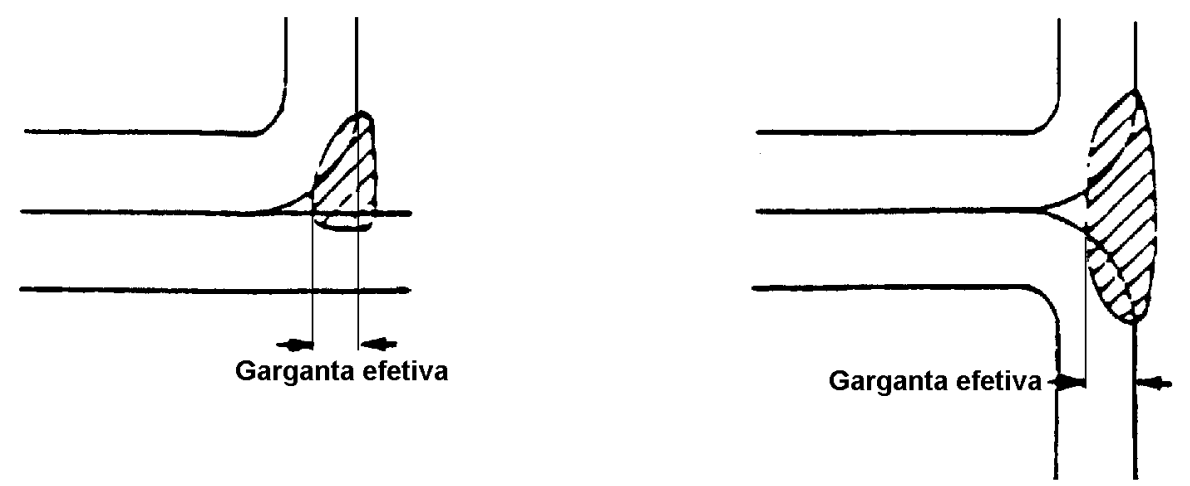

FIGURA 4-4 Garganta efetiva para soldas em superfícies curvas (flare groove welds). Adaptada do EUROCODE 3 [ 24 ]. 

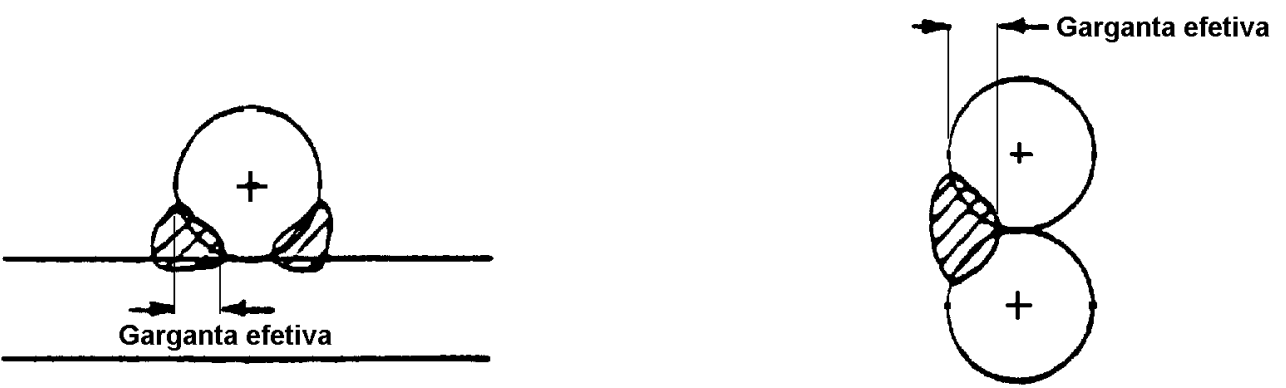

FIGURA 4-4 Garganta efetiva para soldas em superfícies curvas (flare groove welds). Adaptada do EUROCODE 3 [ 24 ].

De acordo com a NBR 8800 [ 7 ], no que se refere a soldas de tampão em furo ou rasgo, a área efetiva de cisalhamento para essas soldas deve ser igual a área nominal da seção transversal do furo ou rasgo, no plano das superfícies em contato.

A NBR 8800 [ 7 ] especifica, se forem utilizados em uma ligação dois ou mais tipos de solda, que a resistência de cálculo de cada um desses tipos deve ser determinada separadamente e referida ao eixo do grupo, para se determinar a resistência de cálculo da combinação. Todavia, isso não é aplicável se soldas de filete são superpostas a soldas em chanfro, utilizando-se nos cálculos somente a resistência das últimas.

De maneira diferente, no EUROCODE 3 [ 24 ], a resistência de ligações em te consistindo de um par de soldas em chanfro de penetração parcial, reforçadas pela sobreposição de soldas de filete, pode ser determinada considerando uma solda em chanfro de penetração total, se a espessura total da garganta efetiva nominal, excluindo o espaço não soldado, não for inferior à espessura $t$ da parte soldada, contanto que o espaço não soldado não seja maior que t/5 ou $3 \mathrm{~mm}$, qualquer que seja o menor, como mostra a fig. 4-5a.

A resistência dessas ligações em tê, que não reunirem os requerimentos anteriores, deve ser determinada como uma "solda de filete de penetração profunda" (discutida posteriormente, de acordo com o EUROCODE 3 [ 24 ]), onde a garganta efetiva deve ser tomada como a espessura nominal menos $2 \mathrm{~mm}$, como mostra a fig. $4-5 b$. 


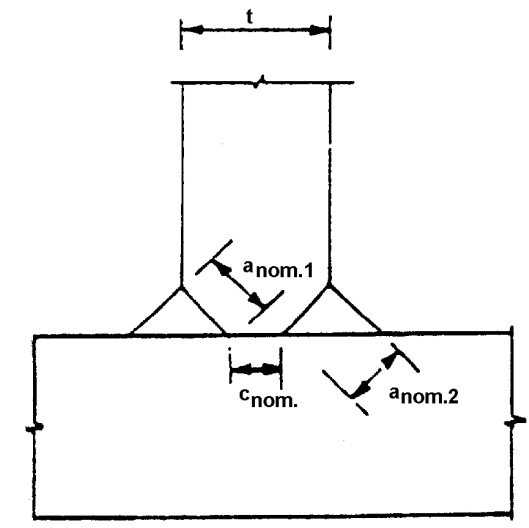

$\mathrm{a}_{\text {nom.1 }}+\mathrm{a}_{\text {nom. } 2} \geq \mathrm{t}$

$\mathrm{c}_{\text {nom. }} \leq \mathrm{t} / 5 \mathrm{e} \mathrm{c}_{\text {nom. }} \leq 3 \mathrm{~mm}$

(a)

FIGURA 4-5 Soldas em chanfro em juntas tê. Adaptada do EUROCODE 3 [ 24 ]

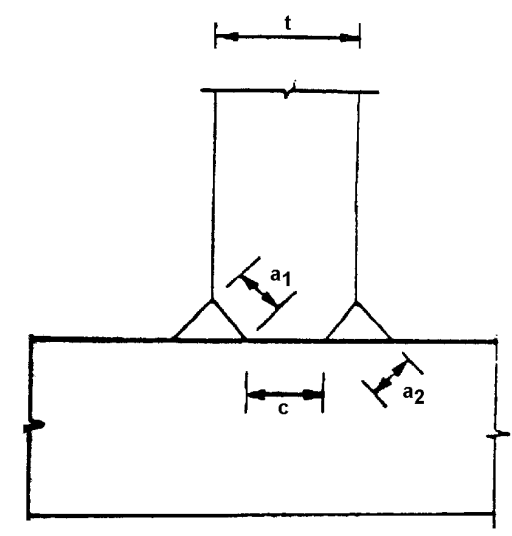

$\mathrm{a}_{1}=\mathrm{a}_{\text {nom.1 }}-2 \mathrm{~mm}$

$\mathrm{a}_{2}=\mathrm{a}_{\text {nom.2 }}-2 \mathrm{~mm}$

(b)

\subsection{Disposições construtivas}

Segundo SALMON \& JOHNSON [ 60 ], uma chapa espessa permite dissipação de calor na direção vertical (ao longo da espessura) e horizontal (no próprio plano), já uma chapa fina fica limitada apenas à uma dissipação horizontal (fig. 4-6). Desta forma, na soldagem de chapas espessas, o calor é "absorvido" mais rapidamente pela região da soldagem, provocando uma rápida diminuição da temperatura nesta região. Desde que uma temperatura mínima é necessária para fundir o metal base, é necessário especificar uma dimensão mínima da solda, compatível com a máxima espessura das partes conectadas, e que seja suficiente para controlar a transferência de calor na chapa. Caso contrário, haverá um rápido resfriamento do metal da solda, o que poderá provocar redução na ductilidade e conseqüentemente o aparecimento de trincas. 


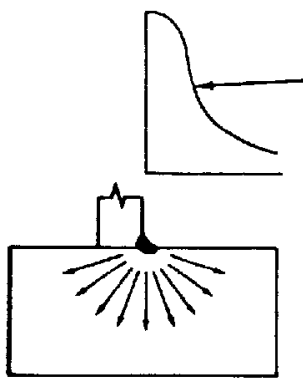

(a) Chapa espessa

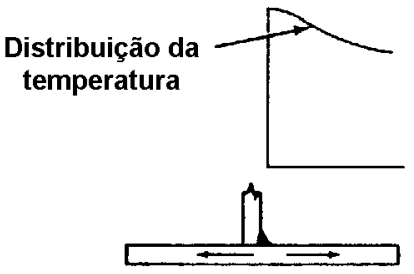

(b) Chapa fina

FIGURA 4-6 Efeito da espessura na dissipação do calor. Adaptada de SALMON \& JOHNSON [ 60 ].

Para assegurar a fusão e minimizar a distorção, a NBR 8800 [ 7 ] fornece uma dimensão mínima de solda, baseada na maior espessura das chapas presentes na ligação. Esses requerimentos para soldas de filetes, baseados na dimensão da perna do filete e para soldas em chanfro de penetração parcial, baseados na garganta efetiva, são fornecidos nas tabelas 4-2 e 4-3.

TABELA 4-2 Dimensão mínima de uma solda de filete. Adaptada da NBR 8800 [ 7 ].

\begin{tabular}{|c|c|}
\hline $\begin{array}{c}\text { Maior espessura do metal base na junta } \\
(\mathrm{mm})\end{array}$ & $\begin{array}{c}\text { Dimensão nominal mínima da solda de filete } \\
(\mathrm{mm})(\mathrm{b})\end{array}$ \\
\hline$\leq 6,35$ & 3 \\
\hline Acima de 6,35 até 12,5 & 5 \\
\hline Acima de 12,5 até 19 & 6 \\
\hline$>19$ & 8 \\
\hline
\end{tabular}

(a) Executadas somente com um passe;

(b) A dimensão da solda deve ser estabelecida em função da parte mais espessa, exceto que tal dimensão não necessita ultrapassar a espessura da parte menos espessa, desde que seja obtida a resistência de cálculo necessária. Para essa exceção e para se obter uma solda de boa qualidade, devem ser tomados cuidados especiais, usando-se pré-aquecimento.

Na tabela 4-2, a razão da limitação do filete de solda em $8 \mathrm{~mm}$ é porque ele é o maior filete que pode ser depositado, em um único passe, pelo processo SMAW.

TABELA 4-3 Espessura mínima da garganta efetiva de uma solda em chanfro de penetração parcial. Adaptada da NBR 8800 [ 7

\begin{tabular}{|c|c|}
\hline Maior espessura do metal base na junta $(\mathrm{mm})^{] \cdot}$ & Espessura mínima da garganta efetiva $^{(\mathrm{a})}(\mathrm{mm})$ \\
\hline$\leq 6,35$ & 3 \\
\hline Acima de 6,35 até 12,5 & 5 \\
\hline Acima de 12,5 até 19 & 6 \\
\hline Acima de 19 até 37,5 & 8 \\
\hline Acima de 37,5 até 57 & 10 \\
\hline Acima de 57 até 152 & 13 \\
\hline$>152$ & 16 \\
\hline
\end{tabular}

(a) A dimensão da solda deve ser estabelecida em função da parte mais espessa, exceto que tal dimensão não necessita ultrapassar a espessura da parte menos espessa, desde que seja obtida a resistência de cálculo necessária. Para essa exceção e para se obter uma solda de boa qualidade, devem ser tomados cuidados especiais, usando-se pré-aquecimento.

A máxima dimensão nominal de soldas de filete, ao longo dos cantos das partes presentes na ligação é limitada pela NBR 8800 [ 7 ], de maneira a prevenir a 
fusão do metal base no local onde o filete encontra o canto da chapa, se o filete for feito na espessura total desta chapa. Essa máxima dimensão nominal pode ser vista na fig. 4-7. A fig. 4-7c mostra o motivo dessa limitação, segundo o AISC/LRFD 93 [ 4 ].
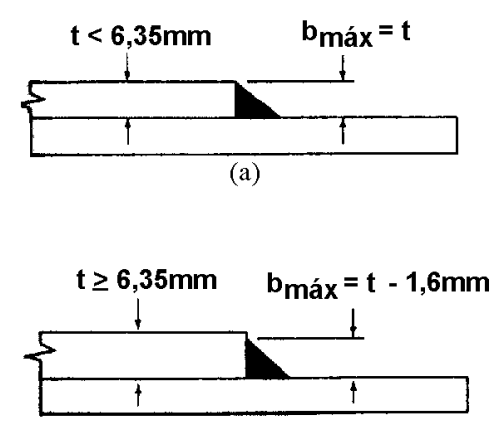

(b)

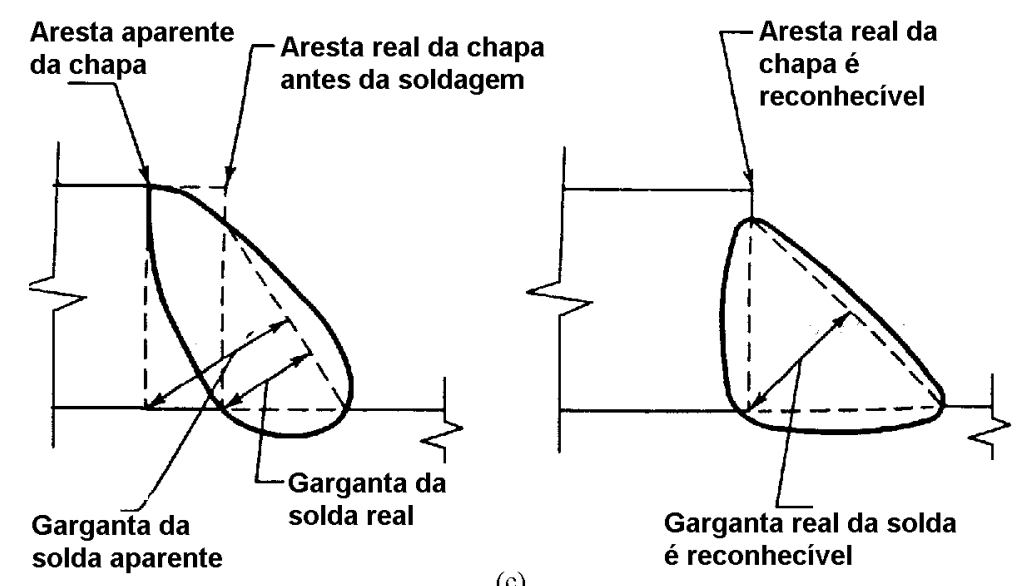

FIGURA 4-7 (a), (b) Dimensão máxima do filete de solda; (c) motivo da limitação. Adaptada de SALMON \& JOHNSON [ 60 ] e do AISC/LRFD 93 [ 4 ].

A condição estabelecida na fig. 4-7b não vale, se nos desenhos essa solda for indicada como reforçada durante a execução, de modo a obter a espessura total desejada.

As soldas de filete são propensas à defeitos nas extremidades inicial e final, onde é comum a ocorrência de descontinuidades durante o refriamento e contração da poça de solda, acarretando uma leve forma cônica ao filete nestas regiões. Diante disto, algumas normas definem o comprimento efetivo do filete como sendo menor que o comprimento real, descontando assim uma parte referente às extremidades do cordão de solda. Para filetes contínuos esta diferença não é muito significativa, entretanto pode ser significativa para os filetes intermitentes. 
Segundo a NBR 8800 [ 7 ], o comprimento mínimo efetivo de um filete de solda, não pode ser inferior a 4 vezes sua dimensão nominal ou, então, essa dimensão nominal da solda deve ser considerada para não exceder $1 / 4$ de seu comprimento efetivo. Adicionalmente, o comprimento efetivo de uma solda de filete não pode ser inferior a $40 \mathrm{~mm}$.

O AISC/LRFD 93 [ 4 ] especifica que o máximo comprimento efetivo de um filete de solda, solicitado por forças paralelas à solda, tal como juntas sobrepostas, não deverá exceder 70 vezes o comprimento da perna do filete, ou seja, sua dimensão nominal. Com isso, uma distribuição uniforme de tensões pode ser assumida ao longo desse comprimento efetivo.

Segundo a NBR 8800 [ 7 ], soldas de filete intermitentes podem ser usadas, quando a resistência de cálculo exigida for inferior à uma solda contínua da menor dimensão nominal permitida ou para ligar elementos de barras compostas (ver fig. 48). O comprimento efetivo para esse tipo de solda, não pode ser inferior a 4 vezes a dimensão nominal da solda, nem menor que $40 \mathrm{~mm}$. O uso dessas soldas requerem cuidados especiais no que se refere a flambagens locais e corrosão.

O EUROCODE 3 [ 24 ] especifica que o espaçamento entre soldas de filete intermitentes, não pode ser maior que o menor valor entre: $200 \mathrm{~mm}$; 12 vezes a espessura da parte mais fina quando as partes conectadas estão em compressão; 16 vezes a espessura da parte mais fina quando as partes conectadas estão em tração; e 1/4 da distância entre enrijecedores, quando essas soldas são utilizadas para conectar enrijecedores à uma chapa ou outra parte sujeita a compressão ou cisalhamento.

Na fabricação de um perfil, no qual as chapas são conectadas por meio de soldas de filete intermitentes, um filete contínuo de solda deve ser colocado em cada extremidade da chapa, em um comprimento igual a pelo menos 3/4 da largura da mais estreita chapa presente. 


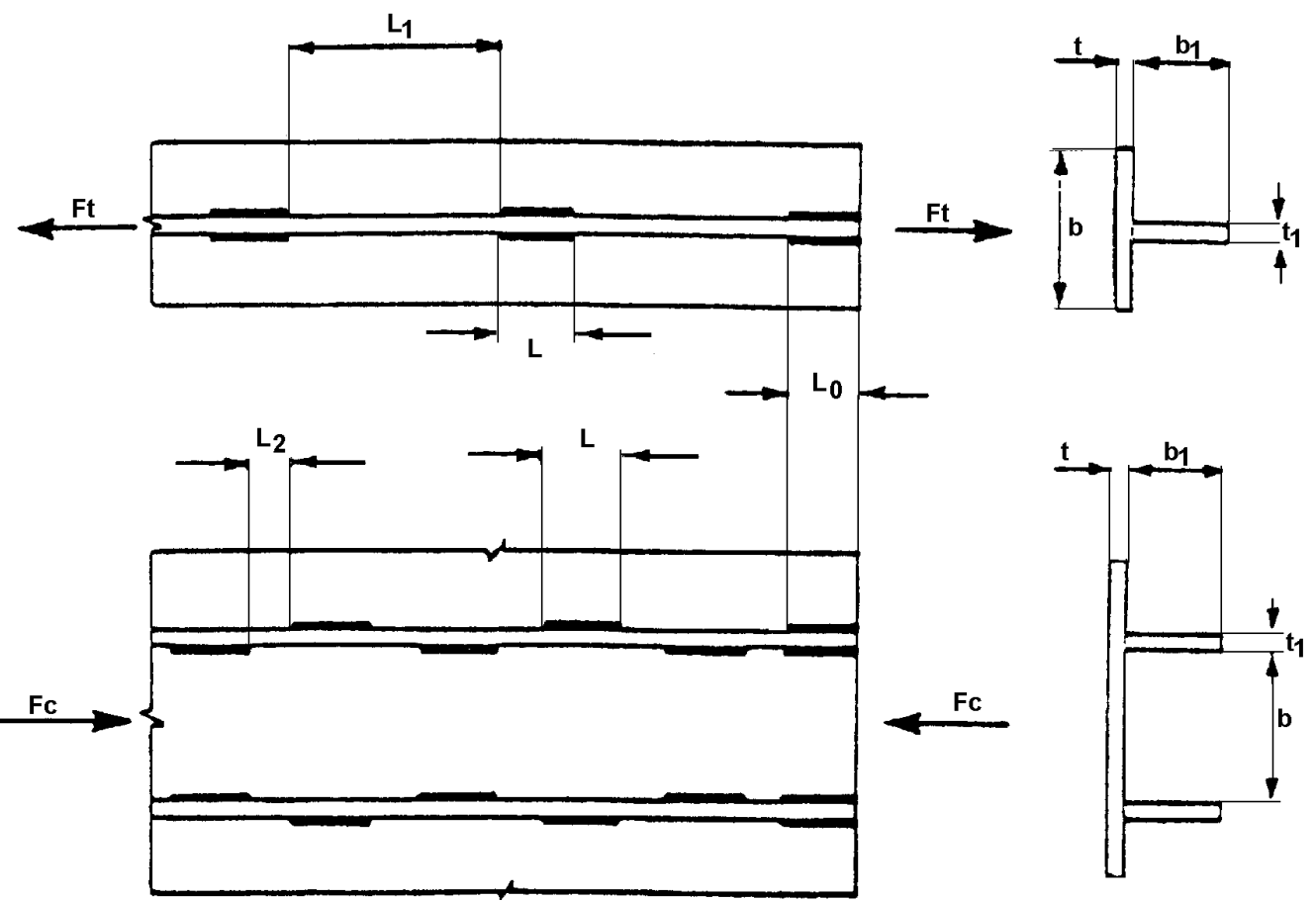

$\mathrm{L} \geq 4$ vezes a dimensão nominal ou $40 \mathrm{~mm}$

$\mathrm{L}_{0} \geq 0,75 \mathrm{~b}$ ou $0,75 \mathrm{~b}_{1}$ - qualquer que seja menor

$\mathrm{L}_{1} \geq 16 \mathrm{t}$ ou $16 \mathrm{t}_{1}$ ou $200 \mathrm{~mm}$ - qualquer que seja menor

$\mathrm{L}_{2} \geq 12 \mathrm{t}$ ou $12 \mathrm{t}_{1}$ ou $0,25 \mathrm{~b}$ ou $200 \mathrm{~mm}$ - qualquer que seja menor

FIGURA 4-8 Soldas de filete intermitentes. Adaptada do EUROCODE 3 [ 24 ] e NBR 8800 [ 7 ].

Em ligações por sobreposição, como na fig. 4-9a, a NBR 8800 [ 7 ] especifica que o cobrimento mínimo deve ser igual a 5 vezes a espessura da parte ligada menos espessa e não inferior a $25 \mathrm{~mm}$. Esta especificação é para garantir que a rotação resultante na ligação, quando tracionada, não seja excessiva, como na fig. 4-9b.

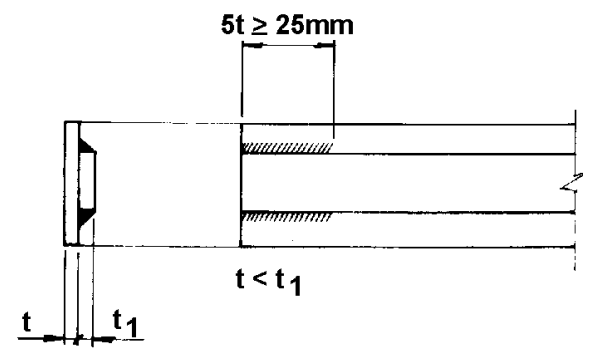

(a)

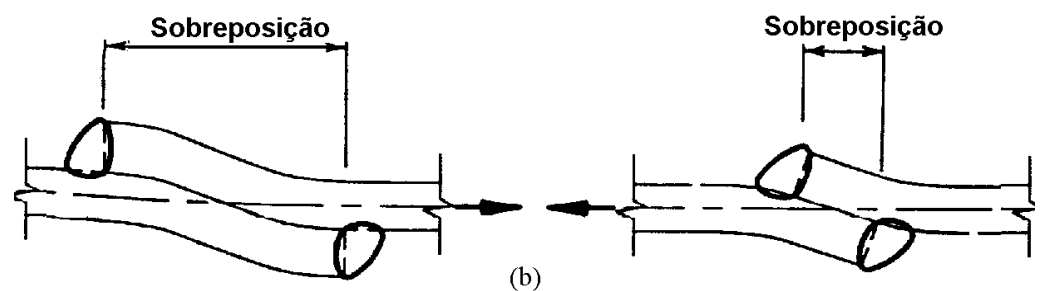

FIGURA 4-9 (a) Ligações de filete por sobreposição; (b) rotação excessiva em ligações por sobreposição Adaptada de BELLEI [ 11 ] e do AISC/LRFD 93 [ 4 ]. 
Outra recomendação feita pela NBR 8800 [ 7 ] é o uso de retornos finais, como na fig. 4-10, sempre que possível, retornando continuamente ao redor dos cantos em uma distância mínima de 2 vezes a dimensão nominal da solda.

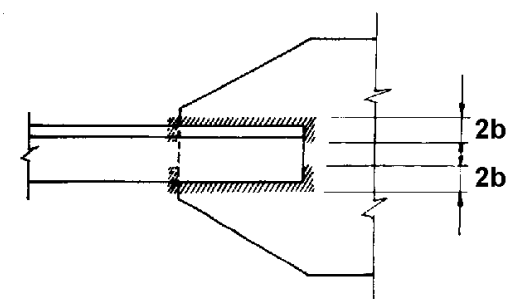

FIGURA 4-10 Retornos de soldas de filete. Adaptada de BELLEI [ 11 ].

Segundo o AISC/LRFD 93 [ 4 ], os retornos extremos não são essenciais nas conexões com soldas de filete, tendo um desprezível efeito na sua resistência. Seu uso tem sido especificado para garantir que a dimensão da solda seja mantida acima do seu comprimento, aumentando a resistência à fadiga em conexões de extremidade flexíveis solicitadas ciclicamente e aumentando a capacidade de deformações plásticas para tais conexões.

Há numerosas conexões soldadas onde não são possíveis executar retornos extremos. Entretanto, essas ligações não requerem tais retornos extremos quando a dimensão da solda é adequada e fadiga não é uma consideração de projeto.

Segundo a NBR 8800, pode-se usar soldas de filete, com ângulo entre as faces de fusão entre $60^{\circ}$ e $120^{\circ}$. Contudo, para outros ângulos a solda é considerada inadequada para a transmissão de esforços, conseqüentemente, ela não pode ser considerada como uma solda estrutural. O EUROCODE 3 [ 24 ], permite o uso de soldas de filete com ângulos menores que $60^{\circ}$, todavia em tais casos a solda deve ser considerada como uma solda em chanfro de penetração parcial.

Segundo a NBR 8800 [ 7 ], para soldas de tampão em furos, o diâmetro dos furos não pode ser inferior à espessura da parte que os contém acrescida de $8 \mathrm{~mm}$, nem maior que 2,25 vezes a espessura da solda. Já a distância de centro a centro desses furos deve ser igual ou superior a 4 vezes o diâmetro do furo, como mostra a fig. 4-11.

Para o caso de soldas de tampão em rasgo, o comprimento do rasgo não pode ser maior que 10 vezes a espessura da solda. Já a largura dos rasgos não pode ser 
inferior à espessura da parte que os contém acrescida de $8 \mathrm{~mm}$, nem maior que 2,25 vezes a espessura da solda. O espaçamento entre as linhas de centro dos rasgos, medido na direção transversal ao rasgo, deve ser igual ou superior a 4 vezes a largura desse rasgo. Já a distância de centro a centro dos rasgos, localizados na mesma linha longitudinal ao comprimento dos mesmos, deve ser igual ou superior a 2 vezes o comprimento dos rasgos. Essas limitações também são ilustradas na fig. 4-11.

As extremidades desses rasgos devem possuir forma semicircular, ou apresentar cantos arredondados de raio não inferior à espessura da parte que os contém, exceto para extremidades que se estendem até a borda do elemento.

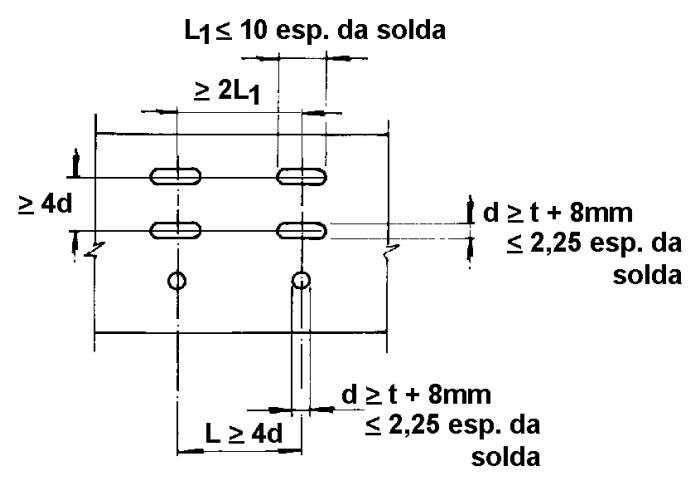

FIGURA 4-11 Limitações para furos e rasgos em soldas de tampão. Adaptada de BELLEI [ 11 ].

A espessura de soldas de tampão situadas em material de espessura igual ou inferior a $16 \mathrm{~mm}$, deve ser igual a espessura desse material, caso contrário, a espessura da solda deve ser no mínimo igual à metade da espessura do mesmo material, mas não inferior a $16 \mathrm{~mm}$.

A NBR 8800 [ 7 ] também especifica que soldas de filete em furos ou rasgos podem ser usadas, como na fig. 4-12, para transmitir forças paralelas à superfície de contato, prevenir separação ou flambagem das partes ou para ligar componentes de barras de seção compostas. Lembrando que essas soldas não podem ser consideradas como soldas de tampão.

O EUROCODE 3 [ 24 ] especifica que o diâmetro do furo circular ou a largura do rasgo para esse tipo de solda não deve ser menor que 4 vezes a espessura da parte que o contém. 


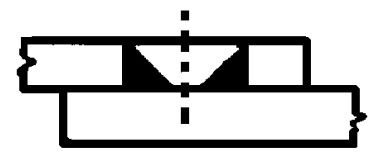

FIGURA 4-12 Exemplo de solda de filete em furo ou rasgo. Adaptada do EUROCODE 3 [ 24 ].

O EUROCODE 3 [ 24 ] considera que a resistência de cálculo para esse tipo de solda deve ser avaliada da mesma maneira que uma solda de filete.

\subsection{Considerações especiais a respeito de soldas de filete}

Segundo GAYLORD et al. [ 27 ], qualquer descontinuidade abrupta ou mudança na seção do perfil, tal como um chanfro ou um canto reentrante agudo, interrompe a transmissão de tensões ao longo de linhas planas. Estas concentrações não são críticas para ações estáticas ou para casos onde somente algumas poucas mil repetições de tensões máximas são prováveis para ocorrer. Todavia, elas são significativas onde fadiga é uma consideração de projeto. A fig. 4-13a mostra uma junta em que a solda é alongada na direção da força, para produzir uma transferência de tensão mais uniforme, do que aquela mostrada por uma solda convencional, como na fig. 4-13b.

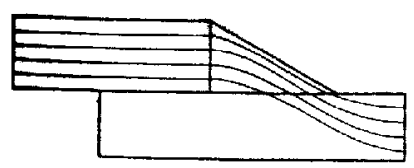

(a)

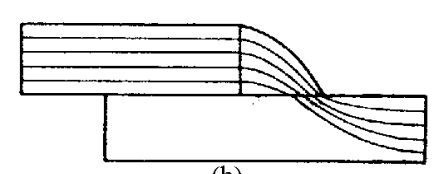

(b)

FIGURA 4-13 (a) Solda alongada na direção da força; (b) solda convencional. Adaptada de GAYLORD et al. [ 27 ].

Segundo OWENS \& CHEAL [ 50 ], ligações soldadas em apenas um lado, como na fig. 4-14a, sujeitas à tração, devem ser evitadas. Não é possível qualquer distribuição uniforme de tensão na garganta do filete de solda, para soldas não simétricas, que possa estar em equilíbrio com a força aplicada. A excentricidade entre a linha de ação da força e o centróide da garganta inevitavelmente cria um momento na garganta efetiva da solda. Esta excentricidade pode ser evitada (ou amenizada) através de um arranjo simétrico dos filetes (fig. 4-14b). 


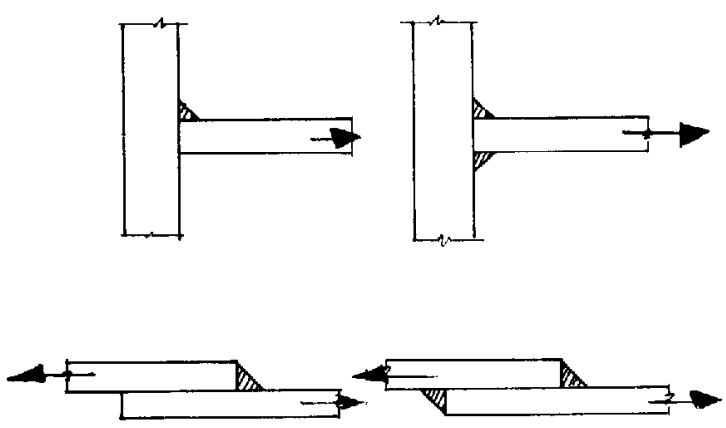

(a)

(b)

FIGURA 4-14 (a) Soldas insatisfatórias para conexões tracionadas; (b) soldas satisfatórias para conexões tracionadas. Adaptada de OWENS \& CHEAL [ 50 ].

Segundo OWENS \& CHEAL [ 50 ], para a maioria dos casos práticos, é possível desprezar a influência da concentração de tensão nas partes conectadas, para a avaliação da resistência da conexão. Um caso interessante de se apresentar é o de soldas de filete laterais curtas, amplamente espaçadas (fig. 4-15). A deformação por cisalhamento que ocorre na chapa conectada, causa concentração de tensões transversais nas extremidades do filete de solda, as quais serão associadas às tensões longitudinais (ver fig. 4-15a).

Alguns modos de falha prováveis são mostrados na fig. 4-15b, sendo que em alguns casos pode haver uma significativa perda de eficiência estrutural da conexão (fig. 4-15c). A maioria das normas, incluindo a NBR 8800 [ 7 ], prescreve que o espaçamento entre filetes laterais deve ser menor que o comprimento do filete.

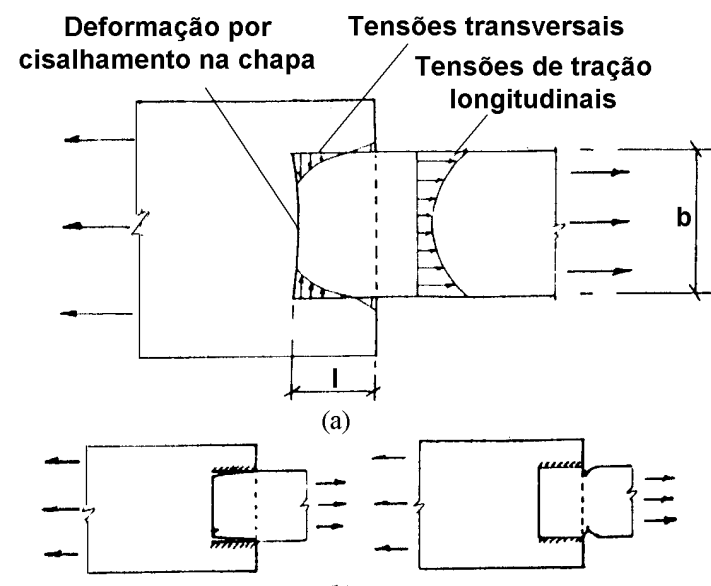

(b)

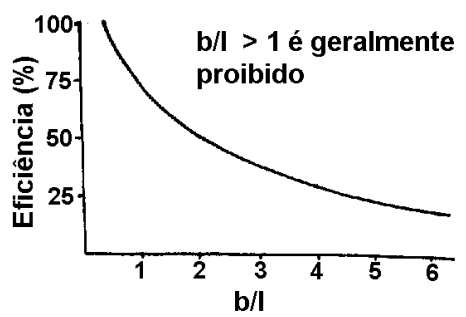

(c)

FIGURA 4-15 Conduta de soldas com filetes laterais curtos, amplamente espaçados. (a) distribuição de tensões; (b) modos de falha (c) perda de eficiência. Adaptada de OWENS \& CHEAL [ 50 ].

A NBR 8800 [ 7 ] especifica também que o espaçamento transversal de soldas de filete longitudinais usadas em ligações de extremidade, não pode ultrapassar 200 
mm, a não ser que no projeto sejam tomadas precauções para se evitar flexão transversal excessiva na ligação.

Soldas longas constituem outra situação onde a deformação das partes conectadas influenciam consideravelmente a distribuição das forças, causando uma significativa distribuição não uniforme de tensões e conseqüentemente influenciando a resistência da solda.

Segundo OWENS \& CHEAL [ 50 ], este efeito é de limitada importância prática devido à boa ductilidade dos filetes de solda em cisalhamento, a qual permite um uniformização das tensões antes que ocorra a ruptura da solda. De acordo com algumas normas, este efeito torna-se significativo para soldas acima de 1,5 $\mathrm{m}$ de comprimento e, nestes casos, são previstas reduções na capacidade das respectivas soldas.

De acordo com o EUROCODE 3 [ 24 ], em ligações de sobreposição longas, a resistência de cálculo de um filete de solda deve ser reduzida pela multiplicação de um fator de redução $\beta_{L w}$ para levar em consideração efeitos de distribuição não uniforme de tensões ao longo do comprimento.

Para filetes em ligações de sobreposição maiores que 150 vezes a garganta efetiva, o fator de redução deverá ser:

$$
\beta_{\mathrm{Lw} .1}=1,2-0,2 \mathrm{~L}_{1} /(150 \mathrm{a}) \text { mas } \quad \beta_{\mathrm{Lw} .1} \leq 1,0
$$

onde: $\mathrm{L}_{1}=$ comprimento total de sobreposição na direção da transferência da força $\mathrm{a}=$ garganta efetiva

Para filetes de solda maiores que $1,7 \mathrm{~m}$, conectando enrijecedores transversais em chapas de perfis, o fator de redução deverá ser:

$$
\beta_{\mathrm{Lw} .2}=1,1-\mathrm{L}_{\mathrm{w}} / 17 \text { mas } \quad \beta_{\mathrm{Lw} .2} \leq 1,0 \text { e } \beta_{\mathrm{Lw} .2} \geq 0,6
$$

onde: $\mathrm{L}_{\mathrm{w}}=$ comprimento da solda em metros

Segundo o EUROCODE 3 [ 24 ], quando a distribuição de tensões ao longo de uma solda é significativamente influenciada pelo enrijecimento dos perfis ou partes conectadas, a não uniformidade de distribuição de tensões pode ser desprezada, desde que a resistência de cálculo seja correspondentemente reduzida. 
O comprimento efetivo de ligações soldadas, projetadas para transferir forças transversais em uma mesa não enrijecida, de seção I, H ou seção caixão, deverá ser reduzido. Em uma ligação te com uma chapa, como na fig. 4-16, na redução do comprimento efetivo, deve ser considerado, na avaliação, o metal base e a solda.

Com isso, para uma seção "I" ou "H" o comprimento efetivo $b_{e H}$ deverá ser obtido por:

$$
\mathrm{b}_{\mathrm{eH}}=\mathrm{t}_{\mathrm{w}}+2 \mathrm{r}+7 \mathrm{t}_{\mathrm{f}} \quad \text { mas } \quad \mathrm{b}_{\mathrm{eH}} \leq \mathrm{t}_{\mathrm{w}}+2 \mathrm{r}+7\left(\mathrm{t}_{\mathrm{f}}^{2} / \mathrm{t}_{\mathrm{p}}\right)\left(\mathrm{f}_{\mathrm{y}} / \mathrm{f}_{\mathrm{yp}}\right)
$$

onde: $f_{y}=$ limite de escoamento do aço do perfil

$f_{y p}=$ limite de escoamento do aço da chapa

$t_{w}, t_{f}, t_{p}, r=$ conforme fig. $4-16$

Se $b_{e H}$ for menor que 0,7 vezes a largura total, a ligação deverá ser enrijecida.

Para uma seção caixão a largura efetiva deverá ser obtida por:

$b_{e H}=2 t_{w}+5 t_{f} \quad$ mas $\quad b_{e H} \leq 2 t_{w}+5\left(t_{f}^{2} / t_{p}\right)\left(f_{y} / f_{y p}\right)$

As soldas conectando a chapa à mesa devem ter uma resistência de cálculo por unidade de comprimento, não inferior à resistência de cálculo por unidade de largura da chapa.
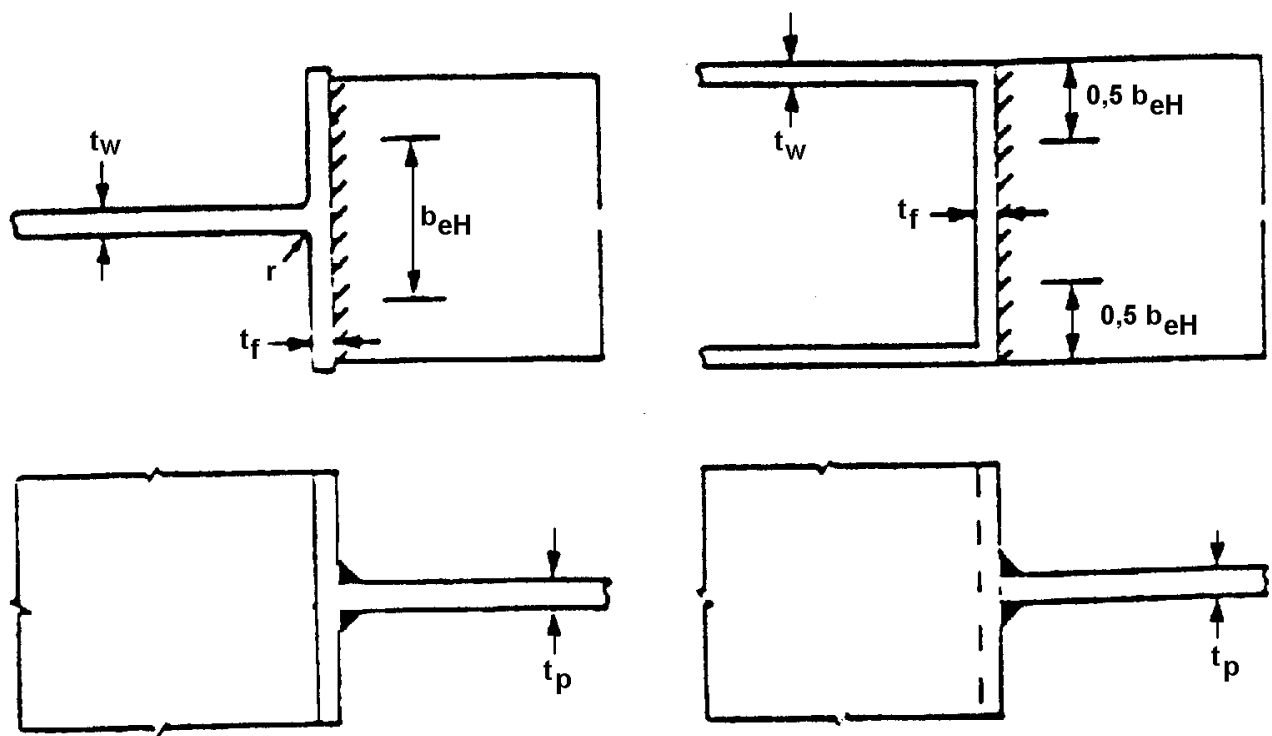

FIGURA 4-16 Largura efetiva de uma ligação tê não enrijecida. Adaptada de EUROCODE 3 [ 24 ].

\subsection{Resistência de soldas de filete}


O comportamento estrutural de soldas de filete varia de acordo com a direção da força em relação ao eixo da solda, ver fig. 4-17. Quando $\theta=90^{\circ}$ o eixo da solda é normal à força, e a solda desenvolve sua mais elevada resistência. Segundo OWENS \& CHEAL [ 50 ], neste caso a tensão média na garganta efetiva, na ruptura, é aproximadamente igual à resistência à tração do metal de solda, todavia a ductilidade é muito limitada, com máxima capacidade de deformação $\Delta_{i} / b$ antes da falha de aproximadamente 0,06 . No outro extremo, quando $\theta=0^{\circ}$, o eixo da solda é paralelo à força, e a resistência ao cisalhamento da solda é limitada para pouco mais que metade da resistência à tração do metal de solda. Todavia, esse filete apresenta consideravelmente maior ductilidade, onde a máxima capacidade de deformação antes da falha é maior que 0,15. Direções intermediárias mostram valores intermediários para resistência e ductilidade. Devido a esta ductilidade, as soldas solicitadas tanto paralelamente quanto perpendicularmente ao seu eixo são assumidas, para propósito de projeto, para resistirem igualmente em qualquer lugar ao longo de seu comprimento.

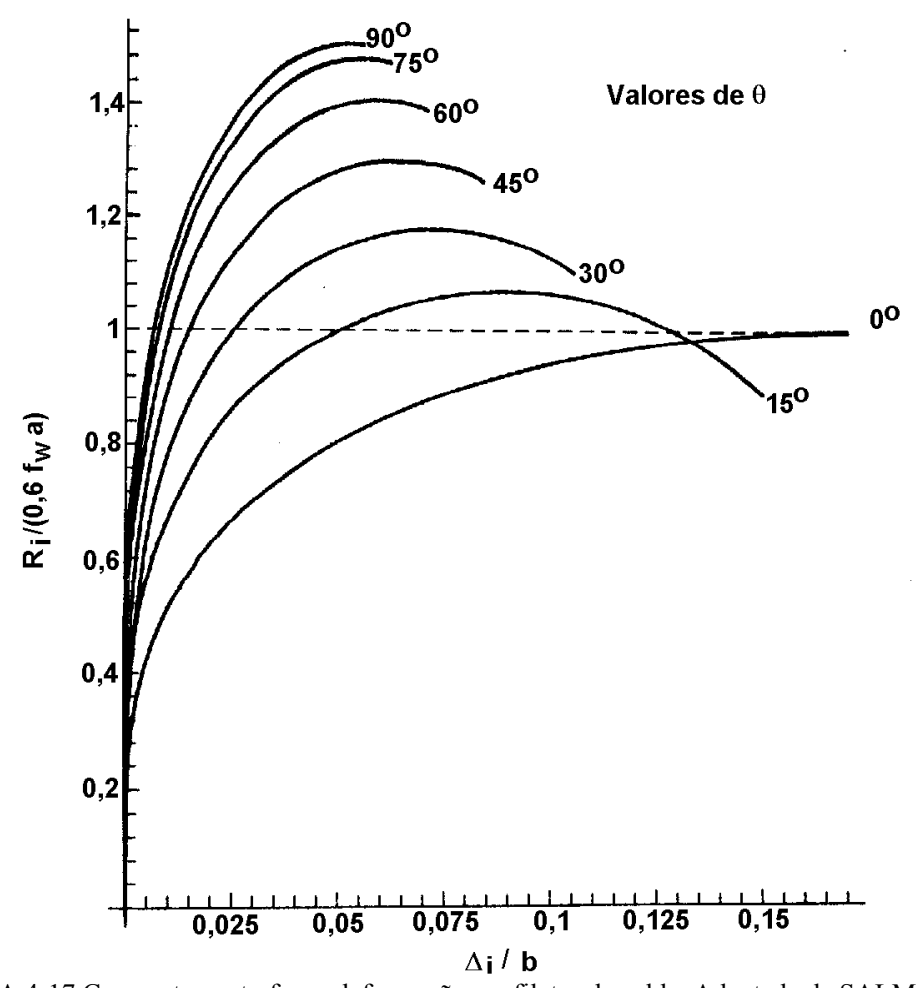

FIGURA 4-17 Comportamento força-deformação em filetes de solda. Adaptada de SALMON \& JOHNSON [ 60 ]. As especificações AISC/ASD [ 1 ] e AISC/LRFD 86 [ 3 ] consideram apenas

a resistência de soldas longitudinais $\left(\theta=0^{\circ}\right)$, não prevendo valores maiores desta 
resistência para outras direções da solda. Com isto, a resistência ao cisalhamento do filete de solda, por unidade de comprimento, é dada por $\left(0,60 \mathrm{f}_{\mathrm{w}} \mathrm{a}\right)$. A última edição do AISC, o AISC/LRFD 93 [ 4 ], permite aumentar a resistência da solda em função da direção $\theta$, o que será apresentado mais adiante.

A verdadeira distribuição de tensões em soldas de filete é complexa. De modo a exemplificar, OWENS \& CHEAL [ 50 ] mostra na fig. 4-18a uma distribuição de esforços resultantes no filete de solda sob cisalhamento longitudinal $P_{s}$, cisalhamento transversal $P_{t}$ e tração transversal $P_{n}$. Além dessas forças aplicadas haverá também os momentos $M_{1}$ e $M_{2}$ atuando nas faces da solda, necessários para o equilíbrio; reações de interface $Q$ provenientes da contração da solda durante o resfriamento e as forças oriundas de tensões residuais como a tensão residual longitudinal $R$ mostrada.

É possível limitar essa análise em um grupo simplificado de tensões médias na garganta efetiva da solda, como faz o EUROCODE 3 [ 24 ], mostrado na fig. 4$18 \mathrm{~b}$, onde $\sigma_{\perp}$ é a tensão normal perpendicular à garganta efetiva da solda, $\sigma_{\|}$é a tensão normal paralela ao eixo da solda, $\tau_{\perp}$ é a tensão de cisalhamento no plano da garganta efetiva, perpendicular ao eixo da solda e $\tau_{\|}$é a tensão de cisalhamento no plano da garganta efetiva, paralela ao eixo da solda. Esta simplificação pode somente ser justificada se a ductilidade do aço é reconhecida e, mais importante, se é possível alcançar equilíbrio das forças aplicadas com um grupo de tensões médias.

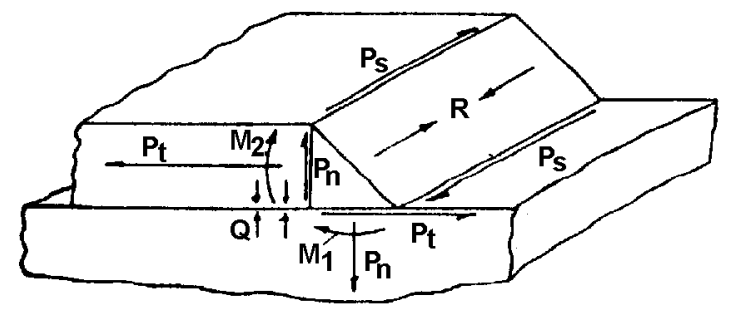

(a)

FIGURA 4-18 Análise de soldas de filete. (a) Esforços em soldas de filete; (b) tensões médias simplificadas na garganta efetiva do filete de solda. Adaptada de OWENS \& CHEAL [ 50 ].

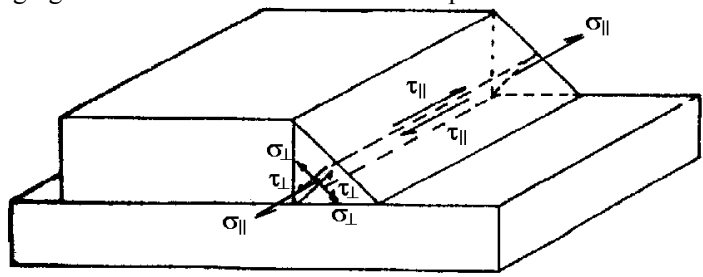

(b)

FIGURA 4-18 Análise de soldas de filete. (a) Esforços em soldas de filete; (b) tensões médias simplificadas na garganta efetiva do filete de solda. Adaptada de OWENS \& CHEAL [ 50 ]. 
A figura 4-19a, adaptada de SALMON \& JOHNSON [ 60 ], mostra a distribuição de tensões (em serviço) para filetes longitudinais, onde a efetiva variação das tensões de cisalhamento nos pontos A e B dependem do comprimento da solda e da relação entre as larguras das chapas presentes na ligação. A fig. 4-19b mostra a típica variação das tensões de cisalhamento em soldas de filete solicitadas transversalmente ao seu eixo, e a fig. 4-19c a distribuição de tensões em soldas de filete usadas em conexões tê, que corresponde à uma distribuição bem mais complexa.
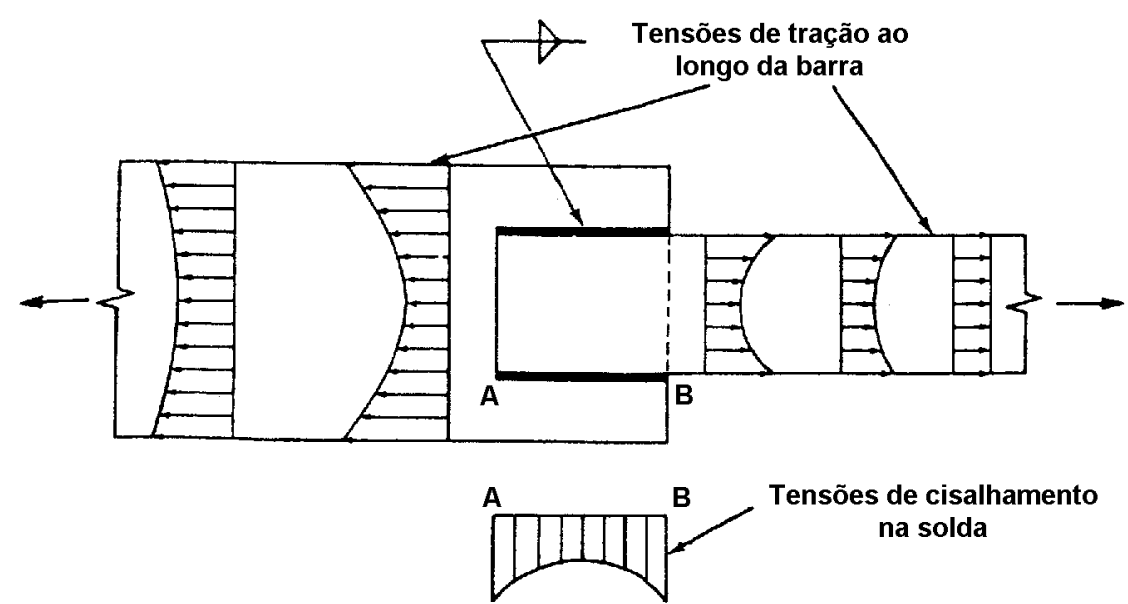

(a)

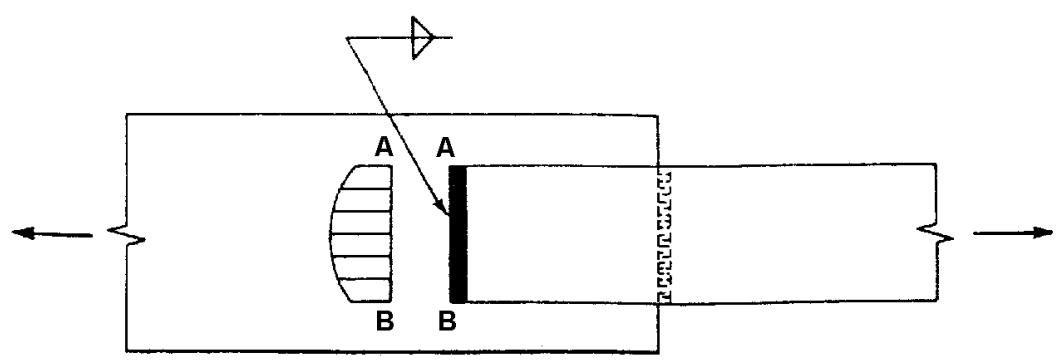

(b)

FIGURA 4-19 Distribuição típica de tensões em filetes de solda. (a) Filetes longitudinais; (b) filetes transversais; (c) filetes em ligação tê. Adaptada de SALMON \& JOHNSON [ 59 ]. 


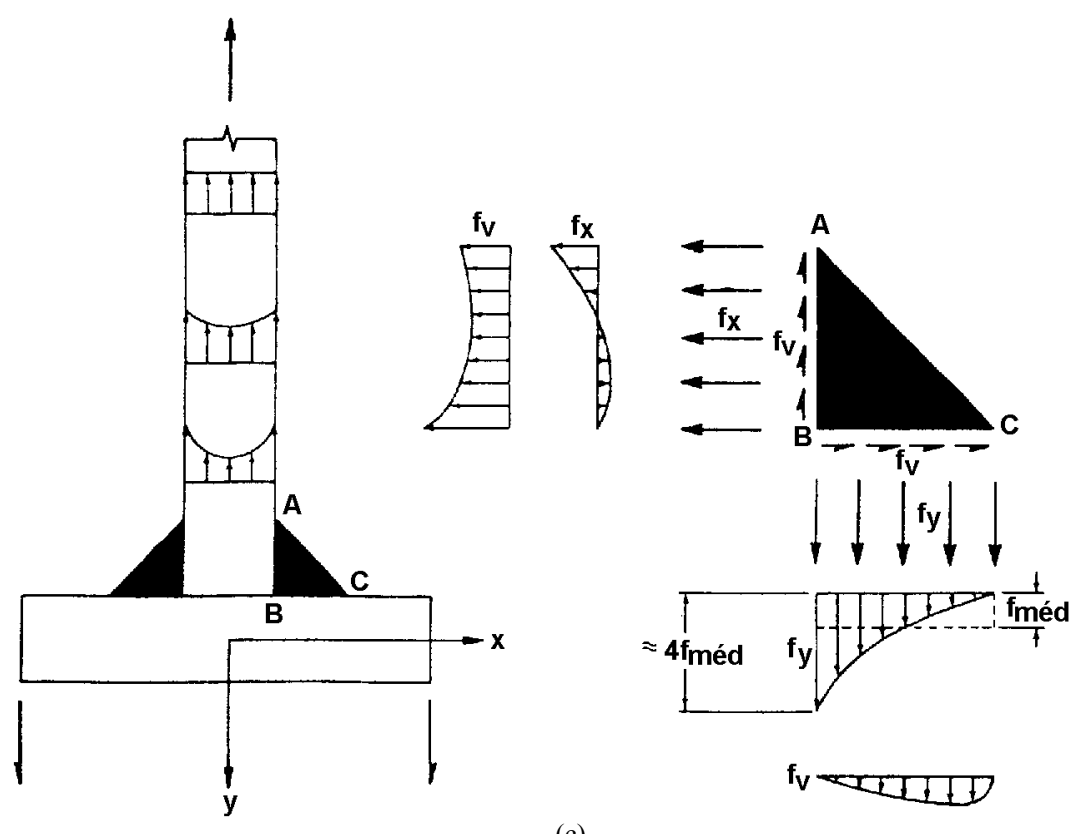

(c)

FIGURA 4-19 Distribuição típica de tensões em filetes de solda. (a) Filetes longitudinais; (b) filetes transversais; (c) filetes em ligação tê. Adaptada de SALMON \& JOHNSON [ 59 ].

Segundo OWENS \& CHEAL [ 50 ], a mais simples aproximação para projeto é ignorar a variação da resistência do filete de solda com a direção da força e limitar a tensão na garganta efetiva a um certo valor. Por exemplo, as forças aplicadas por unidade de comprimento podem ser somadas vetorialmente e então divididas pela garganta efetiva da solda, para determinar uma tensão média. Esta tensão média na garganta efetiva é associada à uma tensão de cisalhamento na solda, sendo que na realidade ela corresponde à soma vetorial de tensões normais (tração ou compressão) e cisalhamento.

Segundo MALITE et al. [ 40 ], citando a NBR 8800 [ 7 ], a resistência de cálculo de soldas de filete, soldas em chanfro e soldas de tampão, é baseada em dois estados limites últimos: a ruptura da solda na seção efetiva e o escoamento do metal base na face de fusão.

A NBR 8800 [ 7 ] também especifica que para soldas de filete, soldas em chanfro e soldas de tampão, em nenhuma situação a resistência da solda poderá ser tomada maior que do que a resistência do metal base na ligação e também deve-se sempre usar para cada metal base o metal de solda compatível, dado na tabela 4-4. Essa tabela também fornece algumas propriedades mecânicas dos eletrodos. 
TABELA 4-4 Propriedades mecânicas dos eletrodos e aços para metal base ${ }^{(\mathrm{A}),(\mathrm{B}),(\mathrm{C}),(\mathrm{D})}$. Adaptada de GAYLORD et al. [ 27 ]; SALMON \& JOHNSON [ 60 ] e NBR 8800 [ 7 ].

\begin{tabular}{|c|c|c|c|c|c|c|c|c|}
\hline \multicolumn{4}{|c|}{ Processos de soldagem e categoria do eletrodo } & \multicolumn{4}{|c|}{ Propriedades mecânicas } & \multirow[b]{2}{*}{$\begin{array}{c}\text { Designação ASTM e ABNT } \\
\text { para metais de bases } \\
\text { compatíveis }\end{array}$} \\
\hline SMAW & SAW & GMAW & FCAW & $\begin{array}{l}\text { Mín. } \\
\text { resist. à } \\
\text { tração, } \\
\text { MPa }\end{array}$ & $\begin{array}{l}\text { Mín. } \\
\text { limite } \\
\text { de } \\
\text { escoa. } \\
\text { MPa }\end{array}$ & $\begin{array}{l}\text { Mín. } \\
\text { along. } \\
\text { em } 2 \\
\text { pol., } \\
\%\end{array}$ & $\begin{array}{l}\text { Mín. } \\
\text { resist. ao } \\
\text { impacto J } \\
\text { em }-18^{\circ} \mathrm{C}\end{array}$ & \\
\hline \multirow[t]{2}{*}{ E60XX } & & & & 462 & 345 & $17-25$ & $*$ & \multirow{6}{*}{$\begin{array}{l}\text { ASTM: A36 } 6^{(\mathrm{D})}, \text { A53 categoria } \\
\text { B, A500, A501, A529, A507 } \\
\text { Grau 40 } \\
\text { Grau } 36 ;^{(\mathrm{D})}, 45^{(\mathrm{D})}, \text { e 50, A709 } \\
\text { ABNT }^{(\mathrm{D})} \text { : NBR 6648, NBR } \\
\text { 6649, NBR 6650, NBR } 7007 \\
\text { (MR 250), NBR } 8261 \text { (Grau } \\
\text { A) }\end{array}$} \\
\hline & $\begin{array}{l}\text { F6XX- } \\
\text { EXXX }\end{array}$ & & & $427-552$ & 345 & 25 & * & \\
\hline \multirow[t]{4}{*}{ E70XX } & & & & 482 & 393 & $17-22$ & $*$ & \\
\hline & $\begin{array}{l}\text { F7XX- } \\
\text { EXXX }\end{array}$ & & & $482-655$ & 414 & 22 & $*$ & \\
\hline & & ER70S-X & & 496 & 414 & $20-22$ & * & \\
\hline & & & $\begin{array}{c}\text { E6XT-X } \\
\text { E7XT-X } \\
\text { (exceto }-2 \text {, } \\
-3,-10,-G S \text { ) } \\
\end{array}$ & - & - & - & - & \\
\hline $\mathrm{E} 0 \mathrm{XX} \mathrm{X}^{(\mathrm{F})}$ & $\begin{array}{l}\text { F7XX- } \\
\text { EXXX }\end{array}$ & ER70S-X & $\begin{array}{c}\text { E7XT-X } \\
\text { (exceto -2, } \\
-3,-10,-\mathrm{GS} \text { ) }\end{array}$ & \# & $\#$ & \# & \# & $\begin{array}{l}\text { ASTM: A242 }{ }^{(\mathrm{E})}, \mathrm{A} 441, \mathrm{~A} 572 \\
\text { Grau } 42 \text { e } 50 ; \text { A588 } \\
\text { 100mm); }(\mathrm{t} \leq \\
50 \mathrm{~W} \\
\text { ABNT: NBR } 5000, \mathrm{Grau} 50 \text { e } \\
\text { 5004, NBR 5008 }{ }^{(\mathrm{E})}, \mathrm{NBR} \\
5920^{(\mathrm{E})}, \mathrm{NBR} 5921^{(\mathrm{E})}, \mathrm{NBR} \\
7007(\mathrm{AR} 345), \mathrm{NBR} 7007 \\
(\text { AR290), NBR 7007 (AR } \\
\text { COR345 A OU B) })^{(\mathrm{E})}, \mathrm{NBR} \\
8261(\text { Graus B e C) } \\
\end{array}$ \\
\hline \multirow[t]{3}{*}{$\begin{array}{c}\text { E80XX- } \\
X^{(\mathrm{F})} \\
\end{array}$} & & & & 551 & 462 & $16-19$ & $*$ & \multirow[t]{3}{*}{ ASTM A572 Grau 60 e 65} \\
\hline & $\begin{array}{c}\text { F8XX- } \\
\text { EXX-XX }\end{array}$ & ER80S-X & & $\overline{551}$ & 462 & 18 & $27,1^{(a)}$ & \\
\hline & & & E8XTX-X & $551-655$ & 469 & 18 & $27,1^{@}$ & \\
\hline \multirow[t]{4}{*}{$\begin{array}{c}\text { E100XX- } \\
X^{(\mathrm{F})} \\
\end{array}$} & & & & 689 & 600 & $\overline{13-16}$ & $*$ & \multirow{4}{*}{$\begin{array}{l}\text { ASTM A514 (espessura acima } \\
\text { de } 2 \text { 1/2"); A709 Grau } 100 \text { e } \\
\text { 100W (2 1/2" a 4") }\end{array}$} \\
\hline & $\begin{array}{l}\text { F10XX- } \\
\text { EXX-XX }\end{array}$ & & & $689-896$ & 606 & 16 & $27,1^{@}$ & \\
\hline & & ER100S-X & & 689 & 620 & 16 & $27,1^{@}$ & \\
\hline & & & E10XTX-X & $689-793$ & 606 & 16 & $27,1^{@}$ & \\
\hline \multirow[t]{4}{*}{$\begin{array}{c}\text { E110XX- } \\
X^{(\mathrm{F})} \\
\end{array}$} & & & & 758 & 669 & 15 & * & \multirow{4}{*}{$\begin{array}{l}\text { ASTM A514 ( } 2 \text { 1/2" e } \\
\text { superior); A } 709 \text { categorias } 100 \\
\text { e 100W (2 1/2" e superior) }\end{array}$} \\
\hline & $\begin{array}{l}\text { F11XX- } \\
\text { EXX-XX }\end{array}$ & & & $758-896$ & 675 & 15 & $27,1^{\circledR}$ & \\
\hline & & ER110S-X & & 758 & 675 & 15 & $27,1^{@}$ & \\
\hline & & & E11XTX-X & $758-862$ & 675 & 15 & $27,1^{@}$ & \\
\hline
\end{tabular}

(A) Em juntas constituídas de metais base com duas tensões de escoamento ou limites de resistência diferentes entre si, pode ser usado metal de solda compatível com o metal base de menor resistência; no entanto, devem ser usados eletrodos de baixo hidrogênio se um dos metais base o exigir.

(B) Quando for feito alívio de tensões nas soldas, o metal da solda não pode conter mais de $0,05 \%$ de vanádio.

(C) Ver item 4.16 da AWS D1.1-82 para requisitos referentes ao metal da solda usado $\mathrm{cm}$ os processos eletro-gás e eletroescória.

(D) Devem ser usados somente eletrodos de baixo hidrogênio ao soldar esses aços, com espessuras maiores que $25 \mathrm{~mm}$, em estruturas sujeitas à fadiga.

(E) Podem ser necessários processos e materiais de soldagem especiais (Por ex.: eletrodos de baixa liga E80XX) para atender a características de resistência à corrosão atmosférica e de resistência ao choque.

(F) Somente eletrodos de baixo hidrogênio (E7015, E7016, E7018, E7028)

* Não requerido

@ Aplicável somente para pontes

- Não fornecido

\# Equivalente aos anteriores

Para soldas de filete, a NBR 8800 [ 7 ] apresenta a resistência de cálculo com base em duas situações relativas ao tipo de solicitação e orientação: tração ou 
compressão paralelas ao eixo da solda ou cisalhamento na seção efetiva. No primeiro caso, a resistência de cálculo da solda é admitida como sendo a mesma do metal base, ou seja, a solda de filete não precisa ser verificada desde que seja usado metal de solda compatível com o metal base. No segundo caso, a solicitação de cálculo é associada ao cisalhamento resultante da soma vetorial de todas as forças de cálculo, produzindo tensões normais ou de cisalhamento na superfície de contato das partes ligadas, a qual deve ser comparada à resistência de cálculo ao cisalhamento $\phi R_{n}$ da solda. Com base nos estados limites aplicáveis tem-se:

Para ruptura da solda na seção efetiva:

$$
\phi \mathrm{R}_{\mathrm{n}}=\phi \mathrm{A}_{\mathrm{w}} 0,60 \mathrm{f}_{\mathrm{w}}
$$

onde: $\mathrm{A}_{\mathrm{w}}=$ área efetiva da solda

$\mathrm{f}_{\mathrm{W}}=$ resistência mínima à tração do metal da solda (para metal de solda E60XX, F6X-EXXX e E6XT-X, $f_{\mathrm{w}}=415 \mathrm{MPa}$ e para E70XX, F7X-EXXX, ER70S-X e E7XT-X, $\left.\mathrm{f}_{\mathrm{w}}=485 \mathrm{MPa}\right)$

$\phi=0,75$

Para escoamento do metal base na face de fusão:

$$
\phi \mathrm{R}_{\mathrm{n}}=\phi \mathrm{A}_{\mathrm{MB}} 0,60 \mathrm{f}_{\mathrm{y}}
$$

onde: $\mathrm{A}_{\mathrm{MB}}=$ área teórica da face de fusão que é o produto da menor perna do filete pelo comprimento da solda

$f_{y}=$ limite de escoamento do metal base de menor $f_{y}$ na junta $\phi=0,9$

Nas expressões anteriores como se trata de cisalhamento, o valor 0,6 é proveniente do critério de von Mises aplicado ao caso de cisalhamento puro.

Segundo SALMON \& JOHNSON [ 60 ], de acordo com o AISC/LRFD 93 [ 4 ], a resistência de cálculo de soldas de filete sujeitas a cisalhamento na seção efetiva é baseada em dois estados limites últimos que são: a ruptura da solda na seção efetiva, que não deve ser maior que a ruptura do metal base na face de fusão. Nesse caso, metal de solda com resistência igual ou inferior ao metal de solda compatível 
pode ser usado. Deste modo, a resistência de cálculo $\phi R_{n w}$ (equivalente a $\phi R_{n}$, da NBR 8800 [ 7 ]) de soldas de filete por unidade de comprimento é dada por:

Para ruptura da solda na seção efetiva, por tensões de cisalhamento:

$$
\phi \mathrm{R}_{\mathrm{nw}}=\phi \mathrm{t}_{\mathrm{e}} 0,60 \mathrm{~F}_{\mathrm{EXX}}
$$

onde: $t_{\mathrm{e}}=$ dimensão da garganta efetiva (correspondente ao parâmetro $a$ definido no item 4.1)

$\mathrm{F}_{\mathrm{EXX}}=$ resistência à tração do metal da solda (correspondente a $f_{w}$, da NBR $8800[7])$

$\phi=0,75$

Para ruptura do metal base na face de fusão, por tensões de cisalhamento:

$\phi \mathrm{R}_{\mathrm{nw}}=\phi \mathrm{t} 0,60 \mathrm{~F}_{\mathrm{u}}$

onde: $\mathrm{t}$ = espessura do metal base ao longo do qual a solda é executada, ou seja, a perna do filete

$\mathrm{F}_{\mathrm{u}}=$ resistência à tração do metal base

$\phi=0,75$

Deve-se notar que o AISC/LRFD 93 [ 4 ], diferentemente da NBR 8800 [ 7 ], não leva em consideração o estado limite último referente ao escoamento do metal base na face de fusão, mas sim sua ruptura por cisalhamento.

De maneira similar à NBR 8800 [ 7 ], o AISC/LRFD 93 [ 4 ] também considera tração ou compressão paralelas ao eixo da solda, onde a resistência de cálculo é a mesma do metal base, indicando que essa resistência por unidade de comprimento deve ser tomada como:

Para escoamento do metal base na face de fusão, por tensões normais:

$$
\phi \mathrm{R}_{\mathrm{nw}}=\phi \mathrm{tF}_{\mathrm{y}}
$$

onde: $\mathrm{F}_{\mathrm{y}}=$ limite de escoamento do metal base (correspondente a $f_{y}$, da NBR 8800 [ 7 ])

$$
\phi=0,9
$$


Como já mencionado, para filetes de solda cuja direção em relação à força aplicada difere de $\theta=0^{\circ}$, ou seja, filetes não longitudinais, é permitido modificar a expressão 4.4.3 de maneira a considerar o aumento de resistência da referida solda em função da direção $\theta$. Esta expressão modificada é apresentada no apêndice J2.4 do AISC/LRFD 93 [ 4 ] e transcrita a seguir:

$$
\phi \mathrm{R}_{\mathrm{nw}}=\phi \mathrm{t}_{\mathrm{e}} 0,60 \mathrm{~F}_{\mathrm{EXX}}\left(1,0+0,50 \operatorname{sen}^{1,5} \theta\right)
$$

onde: $\phi=0,75$

$\theta=$ direção do filete em relação à força aplicada, em graus

Nota-se que para $\theta=90^{\circ}$ (filete transversal) a resistência é $50 \%$ maior que a do filete longitudinal $\left(\theta=0^{\circ}\right)$.

O EUROCODE 3 [ 24 ] especifica que as tensões residuais e tensões não participantes na transferência de forças, não precisam ser incluídas na verificação da resistência de uma solda. Isto se aplica especificamente à tensões normais paralelas ao eixo da solda $\sigma_{\|}$.

Segundo o EUROCODE 3 [ 24 ], nas ligações onde rótulas plásticas podem ser formadas, as soldas devem ser projetadas para fornecer ao menos a mesma resistência de cálculo que a mais fraca parte conectada. Em outra ligações, onde a capacidade de deformação para a rotação da ligação é requerida, devido a possibilidade de excessivo deslocamento, as soldas requerem suficiente resistência, para não romperem antes do escoamento do metal base adjacente. Em geral, isto será satisfeito se a resistência de cálculo da solda não for inferior que $80 \%$ da resistência de cálculo da mais fraca parte conectada.

De acordo com o EUROCODE 3 [ 24 ], a resistência de uma solda de filete pode ser considerada adequada, se em todos os pontos de seu comprimento a resultante de todas as forças por unidade de comprimento, transmitida através da solda, não exceder a resistência de cálculo $F_{w \cdot R d}\left(\right.$ similar a $\phi R_{n}$, na NBR 8800 [ 7 ]). Com isso, independentemente da orientação da solda, a resistência de cálculo por unidade de comprimento, deve ser determinada por:

$$
\mathrm{F}_{\mathrm{w} \cdot \mathrm{Rd}}=\mathrm{f}_{\mathrm{vw} \cdot \mathrm{d}} \mathrm{a}
$$


onde: $\mathrm{f}_{\mathrm{vw} . \mathrm{d}}=$ resistência de cálculo ao cisalhamento

$\mathrm{a}=$ garganta efetiva

A resistência de cálculo ao cisalhamento da solda deve ser determinada por:

$f_{v w . d}=\frac{f_{u} / \sqrt{3}}{\beta_{w} \gamma_{M w}}$

onde: $f_{u}=$ resistência à tração última nominal da parte conectada mais fraca

$\gamma_{\mathrm{Mw}}=1,25$ (fator de segurança parcial)

$\beta_{\mathrm{w}}=$ fator de correlação apropriado (deve ser tomado através da tabela 4-5)

TABELA 4-5 Valores para o fator de correlação. Adaptada do EUROCODE 3 [ 24 ].

\begin{tabular}{|c|c|c|}
\hline Grau do aço & Resistência última à tração $\mathrm{f}_{\mathrm{u}}$ & Fator de correlação $\beta_{\mathrm{w}}$ \\
\hline $\mathrm{EN} 10025$ & \multicolumn{2}{|c|}{} \\
\hline $\mathrm{F}_{\mathrm{e}} 360$ & $360 \mathrm{MPa}$ & 0,8 \\
\hline $\mathrm{F}_{\mathrm{e}} 430$ & $430 \mathrm{MPa}$ & 0,85 \\
\hline $\mathrm{F}_{\mathrm{e}} 510$ & $510 \mathrm{MPa}$ & 0,9 \\
\hline $\mathrm{prEN} 10113$ & & 0,8 \\
\hline $\mathrm{F}_{\mathrm{e}} \mathrm{E} 275$ & $390 \mathrm{MPa}$ & 0,9 \\
\hline $\mathrm{F}_{\mathrm{e}} \mathrm{E} 355$ & $490 \mathrm{MPa}$ & \multicolumn{2}{|c|}{} \\
\hline \multicolumn{2}{|l|}{}
\end{tabular}

Valores intermediários de $f_{u}$ e $\beta_{w}$ podem ser determinados por interpolação linear.

O EUROCODE 3 [ 24 ] fornece um outro método alternativo para o cálculo da resistência de soldas de filete. Neste método, as forças transmitidas por unidade de comprimento da solda, são resolvidas dentro de componentes paralelas e transversais ao eixo longitudinal da solda e normais e transversais ao plano da garganta efetiva. Com isso, uma distribuição uniforme de tensões é assumida na seção da garganta efetiva, conduzindo a tensões normais $\left(\sigma_{\perp}\right.$ e $\left.\sigma_{\|}\right)$e tensões de cisalhamento $\left(\tau_{\perp}\right.$ e $\left.\tau_{\|}\right)$, já definidas anteriormente e mostradas na fig. 4-18b.

Como já mencionado, a tensão normal $\sigma_{\|}$paralela ao eixo da solda não é considerada na verificação da resistência da solda.

Com isso, a resistência de uma solda de filete será suficiente se as seguintes condições forem satisfeitas:

$$
\begin{aligned}
& {\left[\sigma_{\perp}^{2}+3\left(\tau_{\perp}^{2}+\tau \|^{2}\right)\right]^{0,5} \leq \mathrm{f}_{\mathrm{u}} /\left(\beta_{\mathrm{w}} \gamma_{\mathrm{Mw}}\right)} \\
& \text { e } \quad \sigma_{\perp} \leq f_{u} / \gamma_{M w}
\end{aligned}
$$


Segundo OWENS \& CHEAL [ 50 ], deve-se notar que a maioria dos métodos que avaliam a resistência de cálculo, variando com a direção de aplicação da força, usam variações da fórmula básica de resistência do International Institute of Welding que é:

$$
\sigma_{\mathrm{w}}=\beta \cdot \sqrt{ }\left[\sigma_{\perp}^{2}+\gamma\left(\tau_{\perp}^{2}+\tau_{\|}^{2}\right)\right]
$$

onde: $\sigma_{\mathrm{w}}=$ tensão efetiva

Os valores de $\gamma$ eram tomados variando entre 1,8 e 3,0, sendo que o último valor foi considerado o usual, devido a similaridade com o critério de escoamento de von Mises. Já $\beta$ (correspondente a $\beta_{w}$ ) é uma função da resistência do metal base com a resistência do metal de solda, geralmente tomado como uma função da resistência do metal base.

As tabelas 4-6 e 4-7 apresentam a resistência de cálculo ao cisalhamento de soldas de filete, por unidade de comprimento, de acordo com o AISC/LRFD 93 [ 4 ], similar a NBR 8800 [ 7 ], para os processos SMAW e SAW, respectivamente.

TABELA 4-6 Resistência de cálculo ao cisalhamento de soldas de filete $\phi R_{n}$, em N/mm, pelo processo SMAW. Adaptada de SALMON \& JOHNSON [ 60 ].

\begin{tabular}{|c|c|c|c|c|c|c|c|}
\cline { 3 - 8 } \multicolumn{2}{c}{} & \multicolumn{6}{c|}{ Mínima resistência à tração da solda (MPa) } \\
\hline $\begin{array}{c}\text { Dimensão } \\
\text { nominal } b(\mathrm{~mm})\end{array}$ & $\begin{array}{c}\text { Garganta efetiva } \\
a(\mathrm{~mm})\end{array}$ & 415 & 485 & 550 & 620 & 690 & 760 \\
\hline 3 & $2,12^{(\mathrm{a})}$ & $396^{(\mathrm{b})}$ & 463 & 525 & 592 & 659 & 725 \\
\hline 4 & 2,83 & 528 & 617 & 700 & 789 & 878 & 967 \\
\hline 5 & 3,54 & 660 & 772 & 875 & 986 & 1098 & 1209 \\
\hline 6 & 4,24 & 792 & 926 & 1050 & 1184 & 1317 & 1451 \\
\hline 8 & 5,66 & 1056 & 1234 & 1400 & 1578 & 1756 & 1934 \\
\hline 10 & 7,07 & 1320 & 1543 & 1750 & 1973 & 2195 & 2418 \\
\hline 12 & 8,48 & 1584 & 1852 & 2100 & 2367 & 2634 & 2902 \\
\hline 14 & 9,90 & 1848 & 2160 & 2450 & 2762 & 3073 & 3385 \\
\hline 16 & 11,31 & 2113 & 2469 & 2800 & 3156 & 3512 & 3869 \\
\hline 18 & 12,73 & 2377 & 2777 & 3150 & 3551 & 3951 & 4352 \\
\hline 20 & 14,14 & 2641 & 3086 & 3500 & 3945 & 4390 & 4836 \\
\hline
\end{tabular}

(a) $\mathrm{a}=0,707 \mathrm{~b}=0,707(3)=2,12 \mathrm{~mm}$

(b) $\phi$ a $\left(0,60 \mathrm{f}_{\mathrm{w}}\right)=0,75(2,12)(0,60) 415=396 \mathrm{~N} / \mathrm{mm}$ 
TABELA 4-7 Resistência de cálculo ao cisalhamento de soldas de filete $\phi R_{n}$, em N/mm, pelo processo SAW. Adaptada de SALMON \& JOHNSON [ 60 ].

\begin{tabular}{|c|c|c|c|c|c|c|c|}
\multicolumn{9}{c|}{ Adaptada de SALMON \& JOHNSON [ 60]. } \\
\cline { 3 - 8 } & \multicolumn{7}{c|}{ Mínima resistência à tração da solda (MPa) } \\
\hline $\begin{array}{c}\text { Dimensão } \\
\text { nominal } b(\mathrm{~mm})\end{array}$ & $\begin{array}{c}\text { Garganta efetiva } \\
a(\mathrm{~mm})\end{array}$ & 415 & 485 & 550 & 620 & 690 & 760 \\
\hline 3 & $3^{(\mathrm{a})}$ & $560^{(\mathrm{c})}$ & 655 & 742 & 837 & 931 & 1026 \\
\hline 4 & $4^{(\mathrm{a})}$ & 747 & 873 & 990 & 1116 & 1242 & 1368 \\
\hline 5 & $5^{(\mathrm{a})}$ & 934 & 1091 & 1237 & 1395 & 1552 & 1710 \\
\hline 6 & $6^{(\mathrm{a})}$ & 1120 & 1309 & 1485 & 1674 & 1863 & 2052 \\
\hline 8 & $8^{(\mathrm{a})}$ & 1494 & 1746 & 1980 & 2232 & 2484 & 2736 \\
\hline 10 & $9,87^{(\mathrm{b})}$ & 1843 & 2154 & 2443 & 2754 & 3065 & 3375 \\
\hline 12 & 11,28 & 2107 & 2463 & 2793 & 3148 & 3504 & 3859 \\
\hline 14 & 12,70 & 2371 & 2771 & 3143 & 3543 & 3943 & 4343 \\
\hline 16 & 14,11 & 2635 & 3080 & 3493 & 3937 & 4382 & 4826 \\
\hline 18 & 15,53 & 2899 & 3388 & 3843 & 4332 & 4821 & 5310 \\
\hline 20 & 16,94 & 3163 & 3697 & 4193 & 4726 & 5260 & 5793 \\
\hline
\end{tabular}

(a) $\mathrm{a}=\mathrm{b}=$ dimensão da perna, para dimensões $\leq 9,5 \mathrm{~mm}$

(b) $\mathrm{a}=0,707 \mathrm{~b}+2,8 \mathrm{~mm}$ para dimensões $>9,5 \mathrm{~mm}$

(c) $\phi \mathrm{a}\left(0,60 \mathrm{f}_{\mathrm{w}}\right)=0,75 \mathrm{a}(0,60) 415=0,75(3)(0,60)(415)=560 \mathrm{~N} / \mathrm{mm}$

\subsection{Resistência de soldas em chanfro}

Segundo GAYLORD et al. [ 27 ], ligações com soldas de chanfro são mais eficientes que ligações com soldas de filete, pois requerem menos metal de solda depositado que em soldas de filete de igual resistência e eliminam a necessidade de elementos adicionais na conexão, como as cobrejuntas por exemplo. Além disso, devido à sua maior resistência à tensões cíclicas e ao impacto, são preferíveis para os casos de elementos solicitados dinamicamente.

\subsubsection{Penetração total}

Conforme descrito por SALMON \& JOHNSON [ 60 ], soldas em chanfro de penetração total são projetadas para ter a mesma resistência, na área efetiva, que as partes presentes na ligação. Soldas sujeitas à tração normal na área efetiva devem ser especificadas com metal de solda compatível $^{2}$ (conforme tabela 4-4). Em compressão, onde a estabilidade do elemento conectado é usualmente o fator preponderante, permite-se que a resistência do metal de solda seja uma classificação (10 ksi ou $69 \mathrm{Mpa}$ ) abaixo do metal de solda compatível.

\footnotetext{
${ }^{2}$ Esta compatibilidade refere-se à classe de resistência dos metais e provém da tabela 4.1 da AWS D1.1
} 
Quando se especifica metal de solda compatível, este é mais resistente que o metal base, deste modo, a resistência de ligações soldadas é controlada pelas propriedades do metal base.

O AISC/LRFD 93 [ 4 ] apresenta as resistências de cálculo $\phi R_{n w}$ de uma solda de chanfro de penetração total, de acordo com o tipo e orientação, conforme a tabela 4-8.

TABELA 4-8 Resistência de cálculo de solda de chanfro de penetração total, de acordo com o AISC/LRFD 93 [ 4 ].

\begin{tabular}{|c|c|c|c|c|}
\hline $\begin{array}{c}\text { Tipo de solicitação e } \\
\text { orientação }\end{array}$ & Material & $\phi$ & $\begin{array}{c}\text { Resistência } \\
\text { nominal }\end{array}$ & $\begin{array}{c}\text { Requisitos para resistência da } \\
\text { solda }^{\text {(a) }}\end{array}$ \\
\hline $\begin{array}{l}\text { Tração normal à seção } \\
\text { efetiva da solda }\end{array}$ & Base & 0,90 & $\mathrm{~F}_{\mathrm{y}}$ & $\begin{array}{c}\text { Solda compatível deve ser } \\
\text { usada }\end{array}$ \\
\hline $\begin{array}{l}\text { Compressão normal à } \\
\text { seção efetiva da solda }\end{array}$ & \multirow[t]{2}{*}{ Base } & \multirow[t]{2}{*}{0,90} & \multirow[t]{2}{*}{$\mathrm{F}_{\mathrm{y}}$} & \multirow{3}{*}{$\begin{array}{l}\text { Metal de solda com um nível } \\
\text { de resistência igual ou } \\
\text { inferior que o metal de solda } \\
\text { compatível é permitido }\end{array}$} \\
\hline $\begin{array}{c}\text { Tração ou compressão } \\
\text { paralela ao eixo da solda }\end{array}$ & & & & \\
\hline $\begin{array}{c}\text { Cisalhamento na seção } \\
\text { efetiva }\end{array}$ & $\begin{array}{l}\text { Base } \\
\text { Solda }\end{array}$ & $\begin{array}{l}0,90 \\
0,80 \\
\end{array}$ & $\begin{array}{c}0,60 \mathrm{~F}_{\mathrm{y}} \\
0,60 \mathrm{~F}_{\mathrm{EXX}}\end{array}$ & \\
\hline
\end{tabular}

(a) Metal de solda com um nível de resistência acima do metal de solda compatível é permitido.

A NBR 8800 [ 7 ], de maneira similar ao AISC/LRFD 93 [ 4 ], estabelece as resistências de cálculo, conforme a tabela 4-9.

TABELA 4-9 Resistência de cálculo de solda de chanfro de penetração total, de acordo com a NBR 8800 [ 7 ].

\begin{tabular}{|c|c|c|}
\hline Tipo de solicitação e orientação & $\phi$ & Resistência nominal $R_{n}^{\left({ }^{(a)}\right.}$ \\
\hline Tração ou compressão paralelas ao eixo da solda & & Mesma do metal base \\
\hline Tração normal à seção efetiva da solda & \multirow[t]{2}{*}{0,90} & \multirow[t]{2}{*}{$\mathrm{A}_{\mathrm{w}} \mathrm{f}_{\mathrm{y}}$} \\
\hline Compressão normal à seção efetiva da solda & & \\
\hline Cisalhamento (soma vetorial) na seção efetiva & $\begin{array}{l}0,90 \\
0,75 \\
\end{array}$ & $\begin{array}{l}\text { O menor dos dois valores: } \\
\text { a) Metal base: } 0,60 \mathrm{~A}_{\mathrm{w}} \mathrm{f}_{\mathrm{y}} \\
\text { b) Metal da solda: } 0,60 \mathrm{~A}_{\mathrm{w}} \mathrm{f}_{\mathrm{w}}\end{array}$ \\
\hline
\end{tabular}

(a) Em soldas sujeitas à tensões não uniformes, a solicitação de cálculo e a resistência de cálculo serão determinadas com base em comprimentos efetivos unitários.

Segundo o EUROCODE 3 [ 24 ], a resistência de cálculo de soldas em chanfro de penetração total deve ser tomada igual a resistência de cálculo da parte conectada mais fraca, desde que a solda seja especificada com eletrodo adequado, os quais produzirão soldas com limite de escoamento e resistência à tração não inferiores a do metal base.

\subsubsection{Penetração parcial}


Segundo OWENS \& CHEAL [ 50 ], soldas em chanfro de penetração parcial requerem maior cautela. Devido a perda de ductilidade, algumas normas impedem o seu uso no caso de solicitação de tração.

O AISC/LRFD 93 [ 4 ] apresenta as resistências de cálculo $\phi R_{n w}$, de uma solda de chanfro de penetração parcial, de acordo com o tipo e orientação, conforme a tabela 4-10.

TABELA 4-10 Resistência de cálculo de solda de chanfro de penetração parcial, de acordo com o AISC/LRFD 93 [ 4 ].

\begin{tabular}{|c|c|c|c|c|}
\hline $\begin{array}{l}\text { Tipo de solicitação e } \\
\text { orientação }\end{array}$ & Material & $\phi$ & $\begin{array}{l}\text { Resistência } \\
\text { nominal }\end{array}$ & $\begin{array}{l}\text { Requisitos para resistência da } \\
\text { solda }\end{array}$ \\
\hline $\begin{array}{l}\text { Compressão normal à } \\
\text { seção efetiva da solda }\end{array}$ & \multirow[t]{2}{*}{ Base } & \multirow[t]{2}{*}{0,90} & \multirow[t]{2}{*}{$\mathrm{F}_{\mathrm{y}}$} & \multirow{4}{*}{$\begin{array}{l}\text { Metal de solda com um nível } \\
\text { de resistência igual ou } \\
\text { inferior que o metal de solda } \\
\text { compatível é permitido }\end{array}$} \\
\hline $\begin{array}{c}\text { Tração ou compressão } \\
\text { paralelas ao eixo da } \\
\text { solda }^{(\mathrm{c})}\end{array}$ & & & & \\
\hline $\begin{array}{c}\text { Cisalhamento paralelo } \\
\text { ao eixo da solda }\end{array}$ & $\begin{array}{l}\text { Base } \\
\text { Solda } \\
\end{array}$ & 0,75 & $\begin{array}{c}\text { (b) } \\
0,60 \mathrm{~F}_{\mathrm{EXX}}\end{array}$ & \\
\hline $\begin{array}{c}\text { Tração normal à seção } \\
\text { efetiva da solda }\end{array}$ & $\begin{array}{l}\text { Base } \\
\text { Solda }\end{array}$ & $\begin{array}{l}0,90 \\
0,80 \\
\end{array}$ & $\begin{array}{c}\mathrm{F}_{\mathrm{y}} \\
0,60 \mathrm{~F}_{\mathrm{EXX}}\end{array}$ & \\
\hline
\end{tabular}

(a) Metal de solda com um nível de resistência acima do metal de solda compatível é permitido.

(b) O cálculo do material conectado é coberto pelas seções J4 e J5 do AISC/LRFD 93 [ 4 ].

(c) Soldas de filete e soldas de entalhe de penetração parcial, ligando os elementos componentes de perfis soldados (mesas e almas), podem ser calculadas sem considerar as tensões de tração ou de compressão nesses elementos, paralelas ao eixo da solda

Para a determinação da resistência de cálculo de soldas de chanfro de penetração parcial, a NBR 8800 [ 7 ] também leva em consideração o tipo de solicitação e a orientação. As resistências de cálculo $\phi R_{n}$ são apresentadas na tabela 4-11.

TABELA 4-11 Resistência de cálculo de solda de chanfro de penetração parcial, de acordo com a NBR 8800 [ 7 ].

\begin{tabular}{|c|c|c|}
\hline Tipo de solicitação e orientação & $\phi$ & Resistência nominal $R_{n}{ }^{(a)}$ \\
\hline Tração ou compressão paralelas ao eixo da solda ${ }^{(b)}$ & & Mesma do metal base \\
\hline $\begin{array}{l}\text { Tração ou compressão normais à seção efetiva da } \\
\text { solda }\end{array}$ & $\begin{array}{l}0,90 \\
0,75\end{array}$ & $\begin{array}{l}\text { O menor dos dois valores: } \\
\text { a) Metal base: } A_{w} f_{y} \\
\text { b) Metal da solda: } 0,60 A_{w} f_{w}\end{array}$ \\
\hline Cisalhamento (soma vetorial) na seção efetiva & $\begin{array}{l}0,90 \\
0,75\end{array}$ & $\begin{array}{l}\text { O menor dos dois valores: } \\
\text { a) Metal base: } 0,60 \mathrm{~A}_{\mathrm{w}} \mathrm{f}_{\mathrm{y}} \\
\text { b) Metal da solda: } 0,60 \mathrm{~A}_{\mathrm{w}} \mathrm{f}_{\mathrm{w}}\end{array}$ \\
\hline
\end{tabular}

(a) Em soldas sujeitas à tensões não uniformes, a solicitação de cálculo e a resistência de cálculo serão determinadas com base em comprimentos efetivos unitários.

(b) Soldas de filete e soldas de entalhe de penetração parcial, ligando os elementos componentes de perfis soldados (mesas e almas), podem ser calculadas sem considerar as tensões de tração ou de compressão nesses elementos, paralelas ao eixo da solda; deverão ser considerados, entretanto, tensões de cisalhamento causadas pelas forças cortantes e os efeitos locais.

Segundo o EUROCODE 3 [ 24 ], a resistência de soldas em chanfro de penetração parcial deve ser avaliada da mesma maneira que uma solda de "filete de penetração profunda". A diferença do filete para o filete de penetração profunda 
consiste na garganta efetiva nominal. $\mathrm{O}$ filete de penetração profunda possui uma garganta efetiva nominal maior que o filete normal (fig. 4-20). Essa penetração pode ser obtida utilizando soldagem a arco submerso.

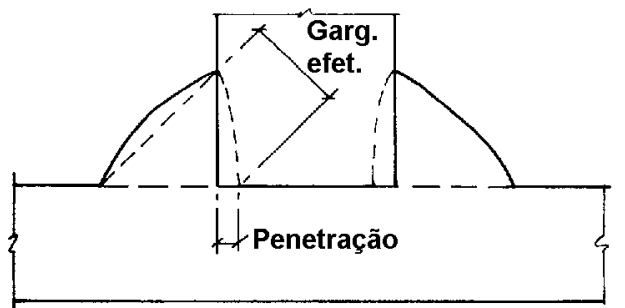

FIGURA 4-20 Espessura da garganta efetiva para soldas de filete de penetração profunda. Adaptada de OWENS \& CHEAL [ 50 ].

\subsection{Resistência de soldas de tampão}

Segundo a NBR 8800 [ 7 ], as soldas de tampão em furos ou rasgos podem ser usadas para transmitir forças paralelas às superfícies de contato, em ligações por sobreposição, ou o que é mais freqüente, não serem admitidas como solda estrutural, sendo especificadas apenas para impedir a flambagem ou a separação das partes sobrepostas.

A resistência de soldas de tampão é baseada na área do plano de cisalhamento entre as partes conectadas. A NBR 8800 [ 7 ] e o AISC/LRFD 93 [ 4 ] apresentam a resistência de cálculo de soldas de tampão, admitindo como solicitação resultante o cisalhamento na seção efetiva. Desta forma, dois estados limites são aplicáveis:

Ruptura da solda na seção efetiva:

$$
\phi \mathrm{R}_{\mathrm{n}}=\phi \mathrm{A}_{\mathrm{w}} 0,60 \mathrm{f}_{\mathrm{w}}
$$

onde: $\phi=0,75$

Escoamento do metal base na face de fusão:

$$
\phi \mathrm{R}_{\mathrm{n}}=\phi \mathrm{A}_{\mathrm{MB}} 0,60 \mathrm{f}_{\mathrm{y}}
$$

onde: $\phi=0,9$

Segundo o EUROCODE 3 [ 24 ], a resistência de cálculo de uma solda de tampão em furo ou rasgo deve ser tomada como:

$$
F_{w \cdot R d}=f_{v w . d} A_{w}
$$

onde: $f_{\mathrm{vw} . \mathrm{d}}=$ resistência de cálculo ao cisalhamento da solda 
$\mathrm{A}_{\mathrm{w}}=$ área efetiva da solda de tampão que deve ser tomada como a área do furo ou rasgo

O AISC/ASD [ 1 ] apresenta as tensões admissíveis para soldas de filete, de chanfro e de tampão, admitindo fator de segurança FS =2. A tabela 4-12 mostra tais valores.

TABELA 4-12 Tensões admissíveis nas soldas, de acordo com o AISC/ASD [ 1 ].

\begin{tabular}{|c|c|c|}
\hline $\begin{array}{c}\text { Tipo de solicitação e } \\
\text { orientação }\end{array}$ & Tensão admissível & Requisitos para resistência da solda ${ }^{(a)}$ \\
\hline \multicolumn{3}{|c|}{ Soldas em chanfro de penetração total } \\
\hline $\begin{array}{l}\text { Tração normal à seção } \\
\text { efetiva da solda }\end{array}$ & Mesma do metal base & Metal de solda compatível deve ser usado \\
\hline $\begin{array}{l}\text { Compressão normal à } \\
\text { seção efetiva da solda }\end{array}$ & Mesma do metal base & \multirow{3}{*}{$\begin{array}{l}\text { Metal de solda com um nível de resistência } \\
\text { igual ou inferior que o metal de solda } \\
\text { compatível é permitido }\end{array}$} \\
\hline $\begin{array}{c}\text { Tração ou compressão } \\
\text { paralelas ao eixo da } \\
\text { solda } \\
\end{array}$ & Mesma do metal base & \\
\hline $\begin{array}{c}\text { Cisalhamento (soma } \\
\text { vetorial) na seção efetiva }\end{array}$ & $\begin{array}{c}0,30 \mathrm{f}_{\mathrm{w}} \text {, excetuando-se a } \\
\text { tensão de cisalhamento no } \\
\text { metal base, que não deverá } \\
\text { exceder } 0,40 \mathrm{f}_{\mathrm{y}}\end{array}$ & \\
\hline \multicolumn{3}{|c|}{ Soldas em chanfro de penetração parcial } \\
\hline $\begin{array}{l}\text { Compressão normal à } \\
\text { seção efetiva da solda }\end{array}$ & Mesma do metal base & \multirow{4}{*}{$\begin{array}{c}\text { Metal de solda com um nível de resistência } \\
\text { igual ou inferior que o metal de solda } \\
\text { compatível é permitido }\end{array}$} \\
\hline $\begin{array}{l}\text { Tração ou compressão } \\
\text { paralelas ao eixo da } \\
\text { solda }^{(\text {b) }} \\
\end{array}$ & Mesma do metal base & \\
\hline $\begin{array}{l}\text { Cisalhamento paralelo } \\
\text { ao eixo da solda }\end{array}$ & $\begin{array}{l}0,30 \mathrm{f}_{\mathrm{w}}, \text { excetuando-se a } \\
\text { tensão no metal base, que } \\
\text { não deverá exceder } 0,40 \mathrm{f}_{\mathrm{y}}\end{array}$ & \\
\hline $\begin{array}{l}\text { Tração normal à seção } \\
\text { efetiva da solda }\end{array}$ & $\begin{array}{l}0,30 \mathrm{f}_{\mathrm{w}} \text {, excetuando-se a } \\
\text { tensão no metal base, que } \\
\text { não deve exceder } 0,60 \mathrm{f}_{\mathrm{y}} \\
\end{array}$ & \\
\hline \multicolumn{3}{|l|}{ Soldas de filete } \\
\hline $\begin{array}{c}\text { Cisalhamento (soma } \\
\text { vetorial) na seção efetiva }\end{array}$ & $\begin{array}{l}0,30 \mathrm{f}_{\mathrm{w}} \text {, excetuando-se a } \\
\text { tensão de cisalhamento no } \\
\text { metal base, que não deverá } \\
\text { exceder } 0,40 \mathrm{f}_{\mathrm{y}}\end{array}$ & \multirow[t]{2}{*}{$\begin{array}{l}\text { Metal de solda com um nível de resistência } \\
\text { igual ou inferior que o metal de solda } \\
\text { compatível é permitido }\end{array}$} \\
\hline $\begin{array}{c}\text { Tração ou compressão } \\
\text { paralelas ao eixo da } \\
\text { solda }^{(\text {b) }}\end{array}$ & Mesma do metal base & \\
\hline
\end{tabular}

/continua

TABELA 4-12 Tensões admissíveis nas soldas, de acordo com o AISC/ASD [ 1 ].

continuação

\begin{tabular}{|c|c|c|}
\hline $\begin{array}{c}\text { Tipo de solicitação e } \\
\text { orientação }\end{array}$ & Tensão admissível & Requisitos para resistência da solda ${ }^{\text {(a) }}$ \\
\hline \multicolumn{2}{|c|}{ Soldas de tampão em furos ou rasgos } \\
\hline $\begin{array}{c}\text { Cisalhamento (soma } \\
\text { vetorial) na seção efetiva } \\
\text { paralela às superfícies de } \\
\text { contato }\end{array}$ & $\begin{array}{c}0,30 \mathrm{f}_{\mathrm{w}} \text {, excetuando-se a } \\
\text { tensão de cisalhamento no } \\
\text { metal base, que não deverá } \\
\text { exceder } 0,40 \mathrm{f}_{\mathrm{y}}\end{array}$ & $\begin{array}{c}\text { Metal de solda com um nível de resistência } \\
\text { igual ou inferior que o metal de solda } \\
\text { compatível é permitido }\end{array}$ \\
\hline \multicolumn{2}{|c}{} & \begin{tabular}{c} 
\\
\hline
\end{tabular}
\end{tabular}


(a) Metal de solda com um nível de resistência acima do metal de solda compatível é permitido.

(b) Soldas de filete e soldas de entalhe de penetração parcial, ligando os elementos componentes de perfis soldados (mesas e almas), podem ser calculadas sem considerar as tensões de tração ou de compressão nesses elementos, paralelas ao eixo da solda 


\section{CAPÍTULO 5 - CONEXÕES PARAFUSADAS SUJEITAS A CARREGAMENTO EXCÊNTRICO}

A capacidade das ligações de impedir a rotação relativa local das peças ligadas, é responsável pelo comportamento final da estrutura, no que se diz respeito a rotações e deslocamentos.

Levando isso em consideração, as ligações tanto parafusadas quanto soldadas, devem ser projetadas considerando as seguintes hipóteses:

- nos locais onde foram previstas ligações rígidas, deverão ser previstos detalhes que impeçam a rotação relativa.

- nos locais onde foram previstas ligações flexíveis, deverão ser previstos detalhes que propiciem a rotação relativa, com um mínimo possível de restrição.

Desta maneira são definidas três categorias de conexões:

- engastadas ou rígidas: são ligações onde é garantida a continuidade da estrutura e as rotações relativas entre as partes são restringidas ao máximo, ou seja, a ligação é tal que após o carregamento, o giro relativo não supera $10 \%$ do correspondente à condição de rótula perfeita.

- articuladas ou flexíveis: são ligações onde a restrição a rotação relativa entre os elementos deve ser a mínima possível, ou seja, essa rotação relativa deve atingir após o carregamento $80 \%$ ou mais da correspondente à condição de rótula perfeita.

- semi-rígidas: são ligações onde o giro relativo está compreendido entre 10\% e 80\% do correspondente à condição de rótula perfeita.

O AISC/LRFD 93 [ 4 ] apresenta as seguintes categorias de conexões:

- categoria FR (fully restrained) totalmente restringida; são conexões com rigidez suficiente para manter inalterados os ângulos entre os perfis que se interceptam.

- categoria PR (partially restrained) parcialmente restringida; são conexões com rigidez insuficiente para manter inalterados os ângulos entre os perfis que se interceptam. 
$\mathrm{Na}$ categoria PR, a quantia de restrição, quando se deseja leva-lá em consideração no cálculo das ligações ou na estabilidade da estrutura, deve estar documentada em literatura técnica ou ser estabelecida por meios analíticos ou empíricos. Quando a restrição é ignorada, as conexões são assumidas como rótuladas (simple framing).

Um aspecto interessante em vista do que foi dito é que a maioria das ligações se enquadram como semi-rígidas. Hoje em dia a utilização destas ligações devido ao desenvolvimento tecnológico de computadores e softwares se tornou viável, pois, antes havia uma dificuldade de avaliação do grau de rigidez da conexão e sua consideração na análise, além da dificuldade de se estabelecer uma relação de dependência entre o momento resistente e a rotação.

A fig. 5-1 ilustra exemplos de conexões consideradas rígidas, semi-rígidas e flexíveis.

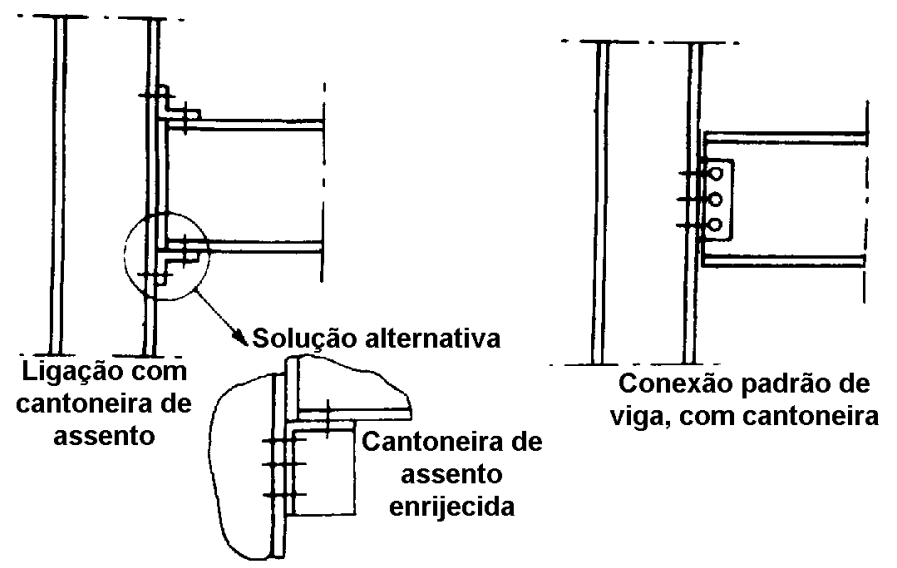

(a)
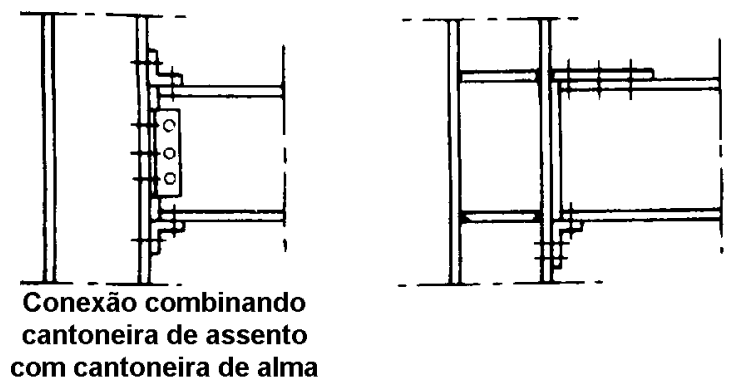

(b)

FIGURA 5-1 Tipos de conexões viga-pilar, (a) conexões consideradas flexíveis; (b) conexões consideradas semirígidas; (c) conexões consideradas rígidas. Adaptada de KULAK et al. [ 34 ]. 


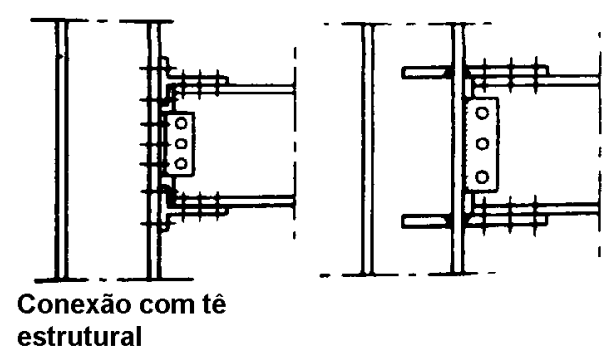

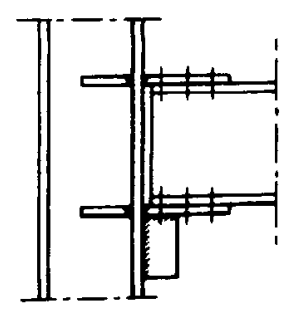

(c)

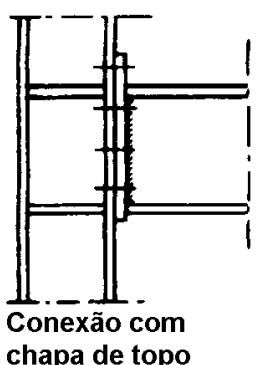

chapa de topo

FIGURA 5-1 Tipos de conexões viga-pilar, (a) conexões consideradas flexíveis; (b) conexões consideradas semirígidas; (c) conexões consideradas rígidas. Adaptada de KULAK et al. [ 34 ].

A linha de ação das forças em perfis conectados, devem em geral, sempre passar através do centróide do grupo de parafusos, onde nessas condições, segundo CRAWLEY \& DILLON [ 19 ], a distribuição da força pode ser assumida como uniformemente entre os parafusos. Todavia, é muitas vezes impraticável ou impossível arranjar os perfis para que esta condição seja satisfeita, e como conseqüência disso, o grupo de parafusos muitas vezes fica sujeito à forças excêntricas. Quando a força excêntrica atua no plano de cisalhamento dos parafusos, como mostra a fig. 5-2a, a chapa rotaciona, produzindo cisalhamento adicional nos parafusos. Já quando a força excêntrica atua fora do plano de cisalhamento dos parafusos, como na fig. 5-1b, as superfícies de contato situadas na região tracionada entre os perfis, sofrem alívio de contato ou se separam, causando nos parafusos tração e cisalhamento.

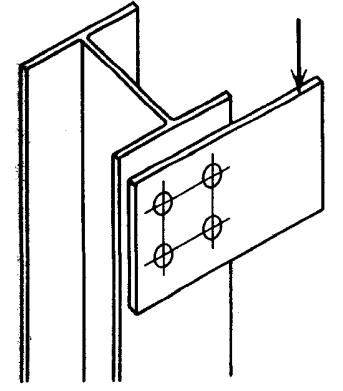

(a) Força no plano de cisalhamento dos parafusos

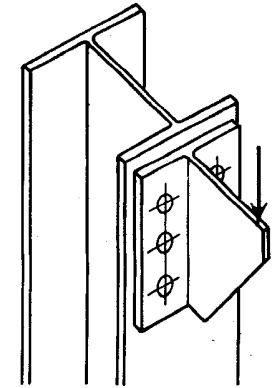

(b) Força fora do plano de cisalhamento dos parafusos FIGURA 5-2 Conexões parafusadas sob força excêntrica. Adaptada de CRAWLEY \& DILLON [ 19 ]. 


\subsection{Grupo de parafusos sob força cortante e momento de torção}

Neste caso, referido na fig. 5-2a, o grupo de parafusos, devido a excentricidade da força aplicada, é sujeito a uma "força cortante" e um "momento torçor". Tanto o momento quanto a força provocam uma força cortante nos parafusos, e ambos os efeitos devem ser considerados na determinação da capacidade da conexão.

Segundo KULAK et al. [ 34 ], o efeito de uma força excêntrica em um grupo de conectores foi estudado já no ano de 1870. Por um longo período, o cálculo levou em consideração os princípios elásticos, assumindo que a rotação na conexão ocorria aproximadamente em torno do centro de gravidade do grupo de conectores. Isto significou que o problema deveria ser tratado como uma simples superposição de uma força centrada e de um momento torçor. A hipótese de rotação em torno do centro de gravidade foi a base para o cálculo das tabelas do AISC Manual of Steel Construction publicado em 1970, apesar de reconhecido que o método produzia resultados conservadores. Por essa razão, foi permitida a utilização de ajustes empíricos.

A hipótese da rotação da conexão em torno do centro de gravidade, identifica que as forças nos conectores não são compatíveis com os deslocamentos necessários para tal rotação. Um artigo publicado em 1914 relatado em trabalhos de P. Gullander da Universidade Chalmers Technical at Gothenburg, Suécia, sugeriu que a rotação fosse considerada ocorrendo em torno de um centro instantâneo. Cálculos feitos com esse princípio conduziu a um conjunto de forças que foram consistentes com os deslocamentos impostos nesses conectores.

A primeira aplicação do conceito de centro instantâneo, foi feita por Yarimci e Slutter, que realizaram ensaios em conexões rebitadas. Desde então, trabalhos experimentais e analíticos têm sido conduzidos em conexões parafusadas, com o objetivo de apresentar informações relativas à resistência última de tais conexões.

O comportamento de vários parafusos sob diferentes excentricidades pode ser representado por curvas força versus rotação, do tipo mostrada na fig. 5-3. A linha reta desde a origem até o ponto $A$ representa a rotação elástica e o seguimento de transição $A B$ identifica deslocamentos tanto elásticos quanto plásticos. Além do 
ponto $B$, a rotação é principalmente produzida por deslocamentos plásticos. Este segmento da curva termina com o colapso.

A mínima folga resultante entre o parafuso e o furo, minimiza o deslizamento da ligação. Na prática, os parafusos são usualmente colocados em furos padrão, e o deslizamento ocorre quando a resistência ao atrito da conexão é excedida. O deslizamento levará um ou mais parafusos em contato com a chapa. Depois disso, a conexão comporta-se da mesma maneira que a apresentada na fig. 5-3.

O deslizamento esperado depende da folga no furo, do parafuso e do alinhamento dos furos na conexão. A rotação devida ao deslizamento, decresce rapidamente com um aumento da distância do mais afastado parafuso ao centro de rotação do grupo de parafusos. Na maioria das situações práticas os deslizamentos serão tão pequenos que não terão efeitos significativos nas condições de serviço da estrutura.

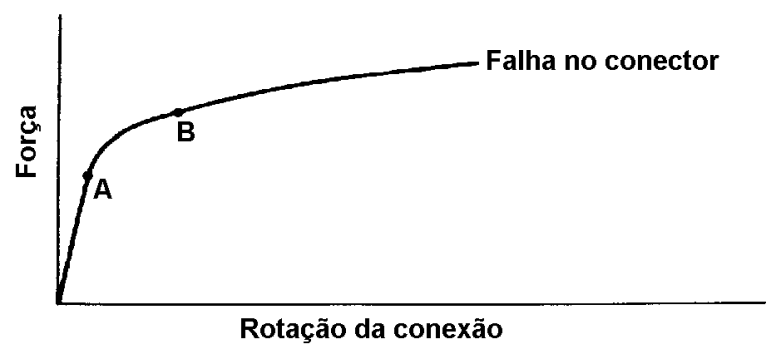

FIGURA 5-3 Gráfico força versus rotação, idealizado para um grupo de parafusos solicitados excentricamente. Adaptada de KULAK et al. [ 34 ].

Desta forma, segundo SALMON \& JOHNSON [ 60 ], duas análises são empregadas para projeto: (1) a tradicional análise elástica (método vetorial), assumindo que não há nenhum atrito entre as chapas "rígidas" e os parafusos “elásticos" e (2) uma análise plástica (método do centro instantâneo de rotação), na qual é assumida rotação do grupo de parafusos solicitado excentricamente, em torno de um centro de rotação, sendo que a deformação de cada parafuso é proporcional à sua distância em relação ao centro de rotação.

$\mathrm{Na}$ análise elástica admite-se uma seção transversal constituída pelas áreas dos parafusos, submetida à uma força cortante excêntrica (fig. 5-4a), a qual é substituída por uma força cortante centrada (fig. 5-4b) e um momento no plano da 
referida seção (fig. 5-4c). Admite-se ainda que a chapa é rígida (indeformável), que os parafusos apresentam comportamento elástico-linear e o atrito é desprezado.

A força resultante nos parafusos é dada pela resultante vetorial das forças provenientes da força centrada e do momento. Admite-se que a força centrada seja uniformemente distribuída entre os parafusos e o momento provoque forças que são proporcionais e perpendiculares ao raio vetor dos referidos parafusos.

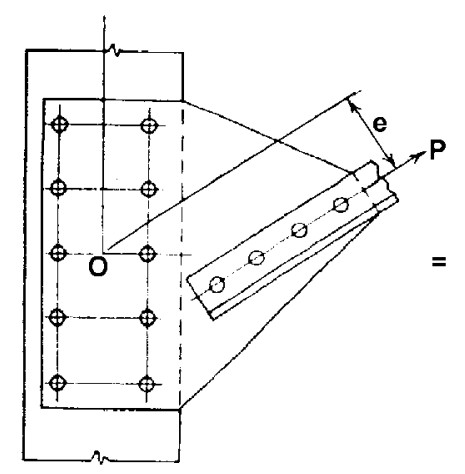

(a)

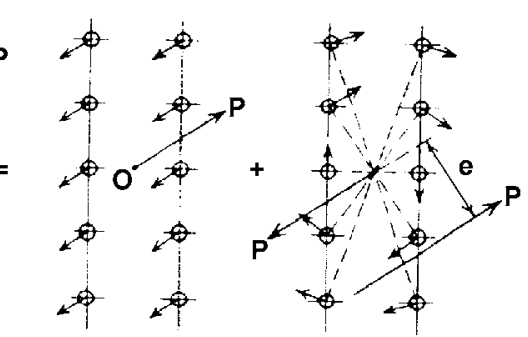

(b)

FIGURA 5-4 Excentricidade no plano de cisalhamento dos parafusos. Adaptada de GAYLORD et al. [ 27 ].

Para a solução deste problema, é necessário determinar a força nos parafusos para o caso do momento P.e (fig. 5-4c). Segundo GAYLORD et al. [ 27 ], se a chapa gira como corpo rígido em torno do centro de rotação $O$ e os parafusos se comportam elasticamente, a rotação da chapa produz deformações que são proporcionais e perpendiculares ao raio vetor $r$. Como a tensão $\left(f_{v}\right)$ é proporcional à deformação, conclui-se que a força nos parafusos também é proporcional e perpendicular ao raio vetor $r$, ou seja, $\mathrm{f}_{\mathrm{v}}=\mathrm{kr}$, onde $k$ é uma constante. Desta forma, a força no parafuso, proveniente do momento, é dada por:

$$
\mathrm{R}_{\mathrm{M}}=\mathrm{f}_{\mathrm{v}} \mathrm{A}_{\mathrm{p}}=\mathrm{krA}_{\mathrm{p}}
$$

$\mathrm{Na}$ fig. 5-5b a força resultante $R_{M}$ em um parafuso é decomposta nas componentes $R_{M x}$ e $R_{M y}$, que são:

$$
\mathrm{R}_{\mathrm{Mx}}=\mathrm{R}_{\mathrm{M}} \operatorname{sen} \theta=\frac{\mathrm{R}_{\mathrm{M}}}{\mathrm{r}} \mathrm{y} \quad \text { e } \quad \mathrm{R}_{\mathrm{My}}=\mathrm{R}_{\mathrm{M}} \cos \theta=\frac{\mathrm{R}_{\mathrm{M}}}{\mathrm{r}} \mathrm{x}
$$

Substituindo a expressão 5.1.1 nas expressões 5.1.2, tem-se:

$$
\mathrm{R}_{\mathrm{Mx}}=\mathrm{kA}_{\mathrm{p}} \mathrm{y} \quad \text { e } \quad \mathrm{R}_{\mathrm{My}}=\mathrm{kA}_{\mathrm{p}} \mathrm{X}
$$




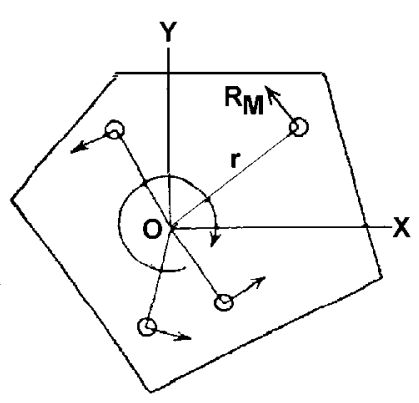

(a)

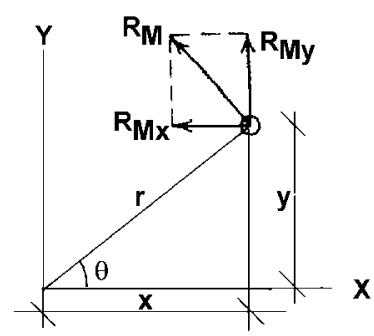

(b)

FIGURA 5-5 Força resultante devido ao momento. Adaptada de GAYLORD et al. [ 27 ].

Aplicando as expressões de equilíbrio de forças na fig. 5-5a, e usando as expressões 5.1.1 e 5.1.3, tem-se:

$$
\begin{aligned}
& \sum \mathrm{R}_{\mathrm{Mx}}=\mathrm{k} \sum \mathrm{A}_{\mathrm{p}} \mathrm{y}=0 \\
& \sum \mathrm{R}_{\mathrm{My}}=\mathrm{k} \sum \mathrm{A}_{\mathrm{p}} \mathrm{x}=0 \\
& \sum \mathrm{R}_{\mathrm{M}} \mathrm{r}=\mathrm{k} \sum \mathrm{A}_{\mathrm{p}} \mathrm{r}^{2}=\mathrm{M}
\end{aligned}
$$

Pelas duas primeiras expressões vê-se que o centro de rotação $O$ é o centróide do grupo de parafusos. Pela terceira expressão, tem-se que $\mathrm{k}=\frac{\mathrm{M}}{\sum \mathrm{A}_{\mathrm{p}} \mathrm{r}^{2}}$, que quando substituída na expressão 5.1.1 fornece:

$$
\mathrm{R}_{\mathrm{M}}=\frac{\mathrm{MrA}_{\mathrm{p}}}{\sum \mathrm{A}_{\mathrm{p}} \mathrm{r}^{2}}
$$

Se os parafusos são de mesma área, tem-se $\sum \mathrm{A}_{\mathrm{p}} \mathrm{r}^{2}=\mathrm{A}_{\mathrm{p}} \sum \mathrm{r}^{2}$, deste modo, a expressão 5.1.5 torna-se:

$$
\mathrm{R}_{\mathrm{M}}=\frac{\mathrm{Mr}}{\sum \mathrm{r}^{2}}
$$

Substituindo a expressão 5.1.6 em 5.1.2 e desde que $\mathrm{r}^{2}=\mathrm{x}^{2}+\mathrm{y}^{2}$, obtém-se a força segundo as componentes $x$ e $y$ :

$$
\mathrm{R}_{\mathrm{Mx}}=\frac{\mathrm{M}}{\sum \mathrm{x}^{2}+\sum \mathrm{y}^{2}} \mathrm{y} \quad \text { e } \quad \mathrm{R}_{\mathrm{My}}=\frac{\mathrm{M}}{\sum \mathrm{x}^{2}+\sum \mathrm{y}^{2}} \mathrm{x}
$$


Considerando agora a força $P$ da fig. 5-4b, nas componentes $P_{x}$ e $P_{y}$, tem-se que a força em qualquer parafuso é expressa como:

$$
\mathrm{R}_{\mathrm{Px}}=\frac{\mathrm{P}_{\mathrm{x}} \mathrm{A}_{\mathrm{pi}}}{\sum \mathrm{A}_{\mathrm{p}}} \quad \text { e } \quad \mathrm{R}_{\mathrm{Py}}=\frac{\mathrm{P}_{\mathrm{y}} \mathrm{A}_{\mathrm{pi}}}{\sum \mathrm{A}_{\mathrm{p}}}
$$

Como os parafusos são de mesma área as expressões 5.1.8 tornam-se:

$$
\mathrm{R}_{\mathrm{Px}}=\frac{\mathrm{P}_{\mathrm{x}}}{\mathrm{n}} \quad \text { e } \quad \mathrm{R}_{\mathrm{Py}}=\frac{\mathrm{P}_{\mathrm{y}}}{\mathrm{n}}
$$

onde: $\mathrm{n}=$ número de parafusos

A força cortante resultante no parafuso $R_{R}$ é dada por:

$$
\mathrm{R}_{\mathrm{R}}=\sqrt{\left(\mathrm{R}_{\mathrm{Px}}+\mathrm{R}_{\mathrm{Mx}}\right)^{2}+\left(\mathrm{R}_{\mathrm{Py}}+\mathrm{R}_{\mathrm{My}}\right)^{2}}
$$

Com base nesta análise, pode-se notar que em geral o parafuso mais afastado em relação ao centróide é o mais solicitado.

Segundo GAYLORD et al. [ 27 ], o conservadorismo desta análise elástica foi demostrado por ensaios patrocinados pelo AISC, sendo que na sua sétima edição (Manual of Steel Construction 1970) apresentou um critério para corrigir a solicitação nos parafusos, que era baseado na utilização de uma excentricidade reduzida $e_{r}$, ao invés da excentricidade verdadeira $e$. As expressões empíricas para a determinação da excentricidade reduzida estão apresentadas a seguir:

- para parafusos igualmente espaçados em uma só coluna:

$$
\mathrm{e}_{\mathrm{r}}=\mathrm{e}-2,54\left(\frac{1+2 \mathrm{n}}{4}\right)
$$

- para parafusos igualmente espaçados em duas ou mais colunas:

$$
\mathrm{e}_{\mathrm{r}}=\mathrm{e}-2,54\left(\frac{1+\mathrm{n}}{2}\right)
$$

onde: $\mathrm{n}=$ número de parafusos em uma linha paralela à direção da força aplicada $\mathrm{e}=$ excentricidade verdadeira $\mathrm{em} \mathrm{cm}$ 
Tendo em vista o caráter conservador da análise elástica, foram propostos vários modelos teóricos mais realistas para a avaliação da capacidade destas conexões. Dentre estes, o mais difundido e adotado pelo AISC, que consiste numa análise plástica, é o método do centro instantâneo de rotação. Admite-se que a força excêntrica provoque uma translação associada à uma rotação do grupo de parafusos em torno do seu centróide, efeito este que pode ser substituído por uma rotação equivalente em torno de um ponto, que é o centro instantâneo de rotação (CIR), fig. $5-6$.

Nesta análise, determina-se a capacidade global da conexão, ou seja, o valor da força $P$ que conduz à "plastificação" dos parafusos mais solicitados.

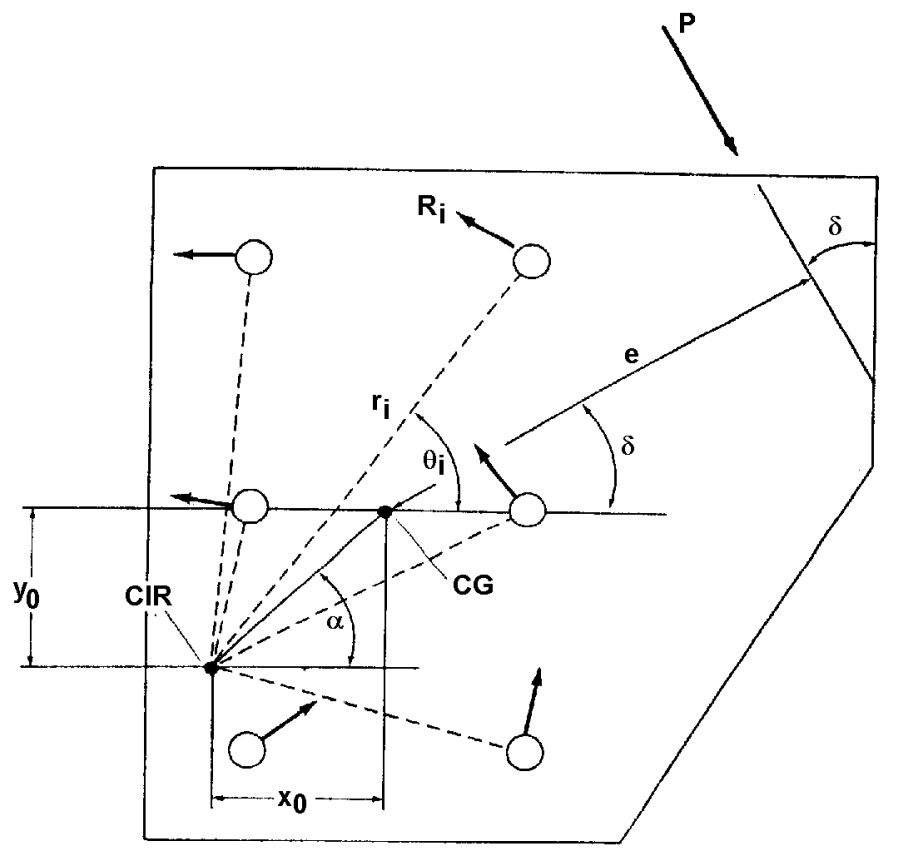

(a)

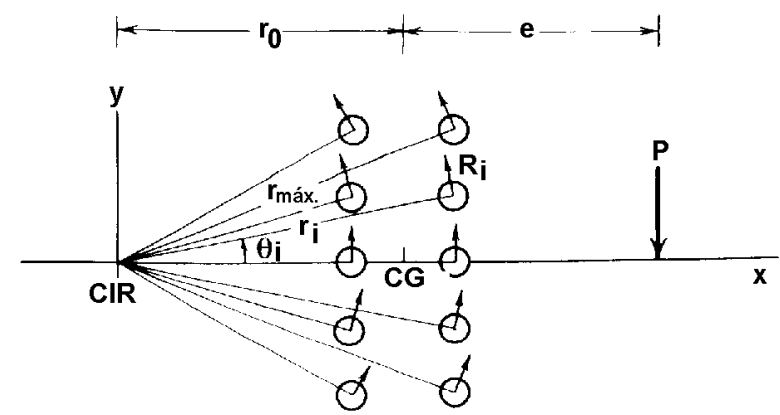

(b)

FIGURA 5-6 (a) Centro instantâneo de rotação para grupo de parafusos sob força qualquer; (b) centro instantâneo de rotação para grupo de parafusos sob força paralela às colunas de parafusos. Adaptada de SALMON \& JOHNSON [ 60 ] e KULAK et al. [ 34 ]. 
Impondo-se as condições de equilíbrio com base nas componentes $x$ e $y$ das forças, obtém-se as seguintes expressões:

$$
\begin{aligned}
& \sum \mathrm{F}_{\mathrm{x}}=0 \Rightarrow \sum_{\mathrm{i}=1}^{\mathrm{n}} \mathrm{R}_{\mathrm{i}} \operatorname{sen} \theta_{\mathrm{i}}=\mathrm{P} \operatorname{sen} \delta \\
& \sum \mathrm{F}_{\mathrm{y}}=0 \Rightarrow \sum_{\mathrm{i}=1}^{\mathrm{n}} \mathrm{R}_{\mathrm{i}} \cos \theta_{\mathrm{i}}=\mathrm{P} \cos \delta \\
& \sum \mathrm{M}=0 \Rightarrow \sum_{\mathrm{i}=1}^{\mathrm{n}} \mathrm{R}_{\mathrm{i}} \mathrm{r}_{\mathrm{i}}=\mathrm{P}\left(\mathrm{e}+\mathrm{x}_{0} \cos \delta+\mathrm{y}_{0} \operatorname{sen} \delta\right)
\end{aligned}
$$

onde: $\mathrm{x}_{0}, \mathrm{y}_{0}, \alpha=$ coordenadas do $\mathrm{CG}$, tendo como origem o CIR

$\mathrm{r}_{\mathrm{i}} ; \theta_{\mathrm{i}}=$ coordenadas polares do parafuso $i$

$\mathrm{e}=$ excentricidade da força em relação ao $\mathrm{CG}$ do grupo de parafusos

$\delta=$ ângulo da força aplicada $P$ em relação ao eixo $y$

As expressões 5.1 .13 contém três incógnitas $P, x_{0}$ e $y_{0}$, necessárias para a determinação exata da localização do centro instantâneo de rotação $\left(\mathrm{x}_{0}, \mathrm{y}_{0}\right)$ e da magnitude da força aplicada $P$. Quando a força resistente $R_{i}$ é proporcional ao deslocamento, ou quando o ângulo $\delta$ é igual a zero ou noventa graus, o ângulo $\alpha$ é igual ao ângulo $\delta$ e a última expressão das 5.1.13 torna-se:

$$
\sum \mathrm{M}=0 \Rightarrow \sum_{\mathrm{i}=1}^{\mathrm{n}} \mathrm{R}_{\mathrm{i}} \mathrm{r}_{\mathrm{i}}=\mathrm{P}\left(\mathrm{e}+\mathrm{r}_{0}\right)
$$

onde: $r_{0}=$ distância entre o CIR e o CG da conexão, como mostra a fig. 5-6b

Segundo GAYLORD et al. [ 27 ], a falha no parafuso pode ser associada à uma deformação máxima pré-estabelecida, avaliada experimentalmente. Desta forma, o parafuso mais afastado em relação ao centro instantâneo de rotação, será o primeiro a atingir esta condição. A deformação dos outros parafusos pode ser facilmente avaliada por uma simples proporção de distâncias e a força nos respectivos parafusos é então calculada mediante uma relação força-deformação préestabelecida.

Crawford e Kulak apresentam uma expressão proposta por Fisher, a qual é recomendada pelo AISC e descrita a seguir:

$$
R_{i}=R_{\text {ult }}\left(1-e^{-\mu \Delta i}\right)^{\lambda}
$$


onde: $\mathrm{R}_{\mathrm{i}}=$ força resultante de cisalhamento no parafuso em qualquer deformação dada

$\mathrm{R}_{\mathrm{ult}}=$ resistência de cálculo do parafuso ao cisalhamento

$\Delta_{\mathrm{i}}=$ deformação no parafuso que inclui deformações no parafuso por cisalhamento, flexão, esmagamento e ainda a deformação local das chapas.

$\mathrm{e}=$ base logarítmica natural

Os coeficientes $\lambda$ e $\mu$ são coeficientes de regressão. $O$ valor de $\lambda$ é tomado como 0,55 . Já o valor de $\mu$ é tomado igual a 10 quando se usa a deformação em polegadas ou 0,39 quando se usa a deformação em milímetros.

A máxima força que pode ser aplicada à conexão (ou a capacidade da conexão) corresponde a se atingir a deformação máxima pré-estabelecida no parafuso mais afastado em relação ao centro instantâneo de rotação.

Segundo SALMON \& JOHNSON [ 60 ], como a relação entre $\Delta_{i}$ e $R_{i}$ não é linear, as expressões 5.1 .13 não podem ser resolvidas diretamente, assim a localização do centro instantâneo de rotação deve ser calculada por tentativas. Desta forma, admite-se uma posição para o centro instantâneo de rotação e determinam-se as coordenadas de cada parafuso. A seguir, admite-se que o parafuso mais afastado atinja a deformação máxima pré-estabelecida (de falha) $\Delta_{\max }$ e conseqüentemente a força última $R_{u l t}$. A deformação máxima é obtida em ensaio de cisalhamento em um único parafuso, e é admitida como $8,9 \mathrm{~mm}$ (0,34 polegadas). A deformação dos outros parafusos é calculada pela relação linear:

$$
\Delta_{\mathrm{i}}=\frac{\mathrm{r}_{\mathrm{i}}}{\mathrm{r}_{\max }} \Delta_{\max }
$$
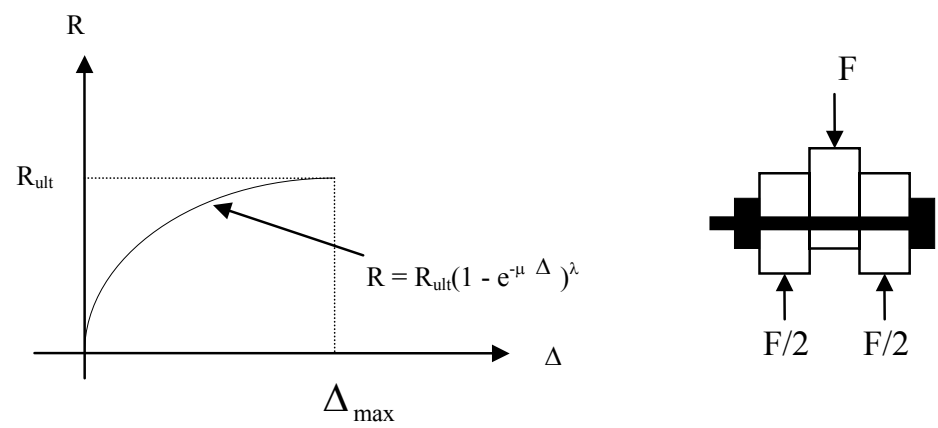

FIGURA 5-7 Curva força-deformação em parafusos. Adaptada de MALITE et al. [ 40 ]. 
Pela expressão 5.1 .15 calculam-se os valores $R_{i}$ para cada parafuso, e pelas expressões 5.1.13 as componentes horizontal e vertical das forças $R_{i}$ e o momento correspondente. Arbitra-se um valor para a posição do centro instantâneo de rotação $e$ e calculam-se os valores da força $P$ pelas expressões 5.1 .13 . Se os valores de $P$ obtidos pelas três expressões não forem iguais, arbitra-se uma nova posição do centro instantâneo de rotação e o processo é repetido até que haja convergência.

Segundo KULAK et al. [ 34 ], no caso de ligações por atrito, a curva força versus deformação de uma ligação carregada excentricamente, pode ser aproximada por uma linha reta representando a rotação elástica (ver fig. 5-3). Durante este estágio a força aplicada é totalmente equilibrada pela resistência ao atrito entre as partes constituintes da conexão. Nesta fase, a capacidade da conexão é determinada com base na iminência do deslizamento na conexão.

De maneira a se determinar a força que causará o deslizamento, são admitidas as seguintes hipóteses: para qualquer valor da força a conexão rotaciona em torno do centro instantâneo de rotação; na força de deslizamento da conexão, a máxima resistência ao deslizamento de cada parafuso é alcançada; a resistência ao deslizamento de cada parafuso pode ser representada por uma força, atuando perpendicularmente ao raio da rotação.

Deste modo, segundo MALITE et al. [ 40 ], a força em cada parafuso é a mesma e é dada pela sua resistência ao deslizamento, não sendo necessário calcular $\Delta_{i}$, sendo:

$$
\mathrm{R}_{\mathrm{i}}=\phi_{\mathrm{v}} \mathrm{R}_{\mathrm{nv}}
$$

onde: $\mathrm{R}_{\mathrm{nv}}=$ resistência nominal ao deslizamento

Segundo KULAK et al. [ 34 ], a validade da análise pelo método do centro instantâneo de rotação tem sido avaliada pela comparação com resultados experimentais. Observou-se que a força de falha da conexão mostrou-se de 5 a 14\% menor que a determinada teoricamente por tal método. Uma das razões para tal diferença, é que a deformação máxima do parafuso observada na conexão (vários parafusos) é menor que a observada nos ensaios com um único parafuso.

Nos ensaios com um único parafuso, a direção da força e da deformação são invariáveis ao longo do ensaio, o que não ocorre na conexão carregada 
excentricamente, uma vez que o centro instantâneo de rotação muda de posição em função do valor da força aplicada.

O AISC/LRFD 86 [ 3 ] apresenta tabelas com a capacidade de conexões carregadas excentricamente, calculadas pelo método do centro instantâneo de rotação, e apresentadas sob a forma:

$$
\mathrm{P}_{\mathrm{u}}=\mathrm{C} \phi \mathrm{r}_{\mathrm{v}}
$$

onde: $\phi \mathrm{r}_{\mathrm{v}}=$ resistência de cálculo de um único parafuso

$\mathrm{P}_{\mathrm{u}}=$ força fatorada na conexão, atuando em uma dada excentricidade, para um dado arranjo de parafusos

$\mathrm{C}=$ coeficiente adimencional que provem da relação entre $P$ e $r_{v}$.

Valores para C são tabelados pelo AISC/LRFD 86 [ 3 ].

No desenvolvimento destas tabelas, foi adotada a curva força-deformação obtida para parafusos A325 de diâmetro $19 \mathrm{~mm}$ (modelo com único parafuso com corte duplo - fig. 5-7), onde $\mathrm{R}_{\mathrm{ult}}=2 \tau_{\mathrm{u}} \mathrm{A}_{\mathrm{b}}=330 \mathrm{kN}\left(\tau_{\mathrm{u}}=0,7 \mathrm{f}_{\mathrm{u}}=0,7 \mathrm{x} 825=577 \mathrm{MPa}\right)$. A deformação última é 0,34 ” (8,64 mm).

De maneira a exemplificar os métodos de cálculo de conexões parafusadas sob carregamento excêntrico, ou seja, o método vetorial, o método vetorial com excentricidade corrigida e o método do centro instantâneo de rotação, foi determinada a capacidade $P_{u}$ de conexões do tipo contato $\left(P_{u}\right.$ de cálculo) e do tipo atrito ( $P_{u}$ nominal), tomando-se a conexão da fig. 5-8.

Nesta análise foi atribuído um parâmetro adimensional $e / k$ que corresponde à excentricidade relativa da conexão. A dimensão $k$ é a distância entre os parafusos mais afastados entre si. 


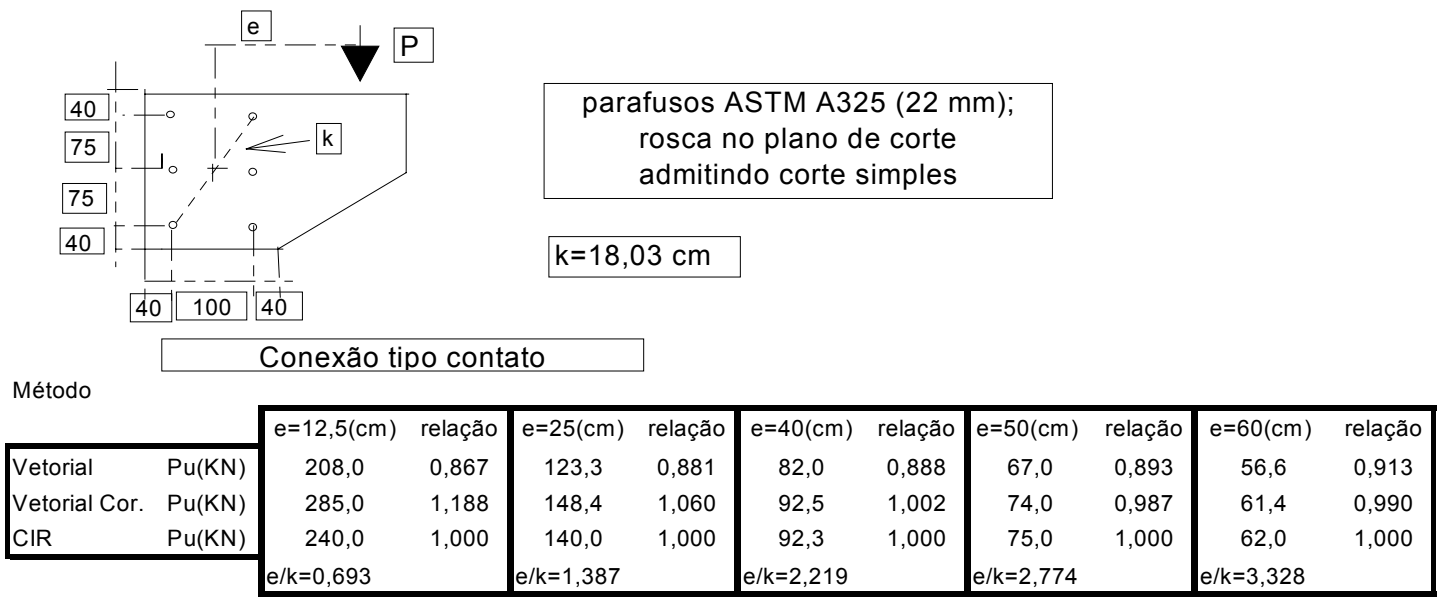

\begin{tabular}{|c|c|c|c|c|c|c|c|c|c|c|c|}
\hline & \multicolumn{4}{|c|}{ Conexão tipo atrito } & \multirow[b]{2}{*}{ relação } & \multirow{2}{*}{$\mathrm{e}=40(\mathrm{~cm})$} & \multirow[b]{2}{*}{ relação } & \multirow[b]{2}{*}{$e=50(\mathrm{~cm})$} & \multirow[b]{2}{*}{ relação } & \multirow[b]{2}{*}{$\mathrm{e}=60(\mathrm{~cm})$} & \multirow[b]{2}{*}{ relação } \\
\hline & & $\mathrm{e}=12,5(\mathrm{~cm})$ & relação & $\mathrm{e}=25(\mathrm{~cm})$ & & & & & & & \\
\hline Vetorial & $\mathrm{Pu}(\mathrm{KN})$ & 113,5 & 0,880 & 66,8 & 0,862 & 44,5 & 0,851 & 36,3 & 0,856 & 30,7 & 0,865 \\
\hline Vetorial Cor. & $\mathrm{Pu}(\mathrm{KN})$ & 155,5 & 1,205 & 80,4 & 1,037 & 50,2 & 0,960 & 40,4 & 0,953 & 33,3 & 0,938 \\
\hline CIR & $\mathrm{Pu}(\mathrm{KN})$ & 129,0 & 1,000 & 77,5 & 1,000 & 52,3 & 1,000 & 42,4 & 1,000 & 35,5 & 1,000 \\
\hline & & $e / k=0,693$ & & $e / k=1,387$ & & $e / k=2,219$ & & $\mathrm{e} / \mathrm{k}=2,774$ & & $e / k=3,328$ & \\
\hline
\end{tabular}

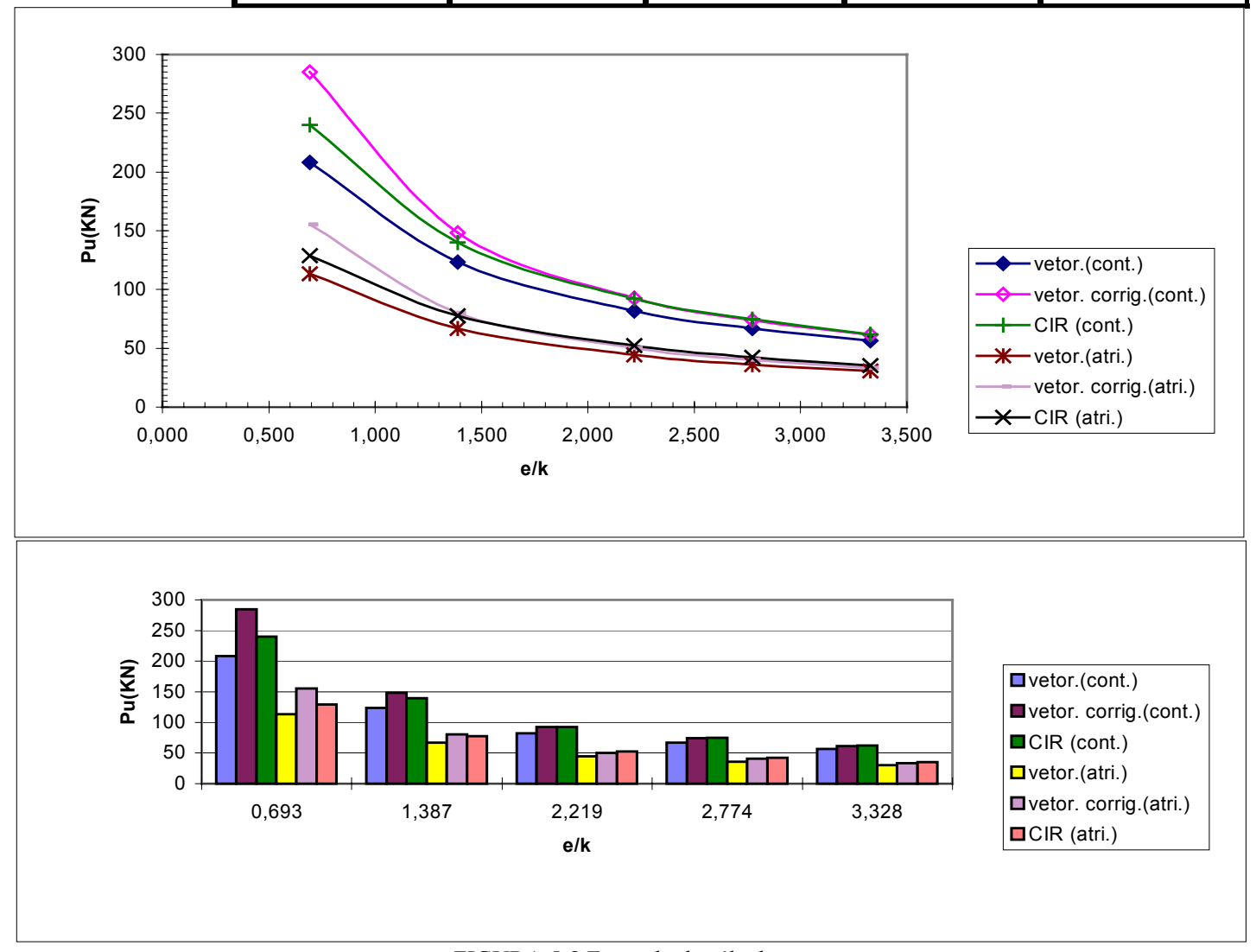

FIGURA 5-8 Exemplo de cálculo.

Comparando-se o método vetorial com o método do CIR e analisando outros tipos de conexões, observou-se, que dependendo da forma e disposição dos parafusos, os valores obtidos das forças últimas calculadas pelo método vetorial, 
chegam a ser $10 \%$ a $30 \%$ inferiores aos obtidos pelo método do CIR. Isso mostra que o método vetorial é conservador.

Tomando-se o método do CIR como referência, uma vez que apresenta resultados relativamente próximos dos experimentais, observou-se que o método vetorial corrigido, para o caso de pequenas excentricidades, conduziu a valores de $P_{u}$ $20 \%$ superiores. Com o aumento da excentricidade esse valor diminuiu, chegando a ser ligeiramente inferior (5\%).

Pela análise desenvolvida conclui-se que o método vetorial corrigido constitui-se numa razoável aproximação para certos valores de excentricidade, uma vez que conduz a valores próximos aos obtidos pelo método do CIR. Entretanto, conforme já descrito, para pequenas excentricidades esse método pode conduzir a valores de $P_{u} 20 \%$ superiores aos do método do CIR, devendo-se portanto utilizá-lo com certa cautela. Desta forma, conclui-se que o método vetorial corrigido de maneira geral não é uma boa aproximação.

Conforme descrito por OWENS \& CHEAL [ 50 ], nas ligações por contato a força cortante nos parafusos é muito influenciada pelo ajuste dos mesmos nos respectivos furos, ou seja, os parafusos serão solicitados a partir do instante que entrarem em contato com a parede do furo. Este trabalho "não homogêneo" da conexão corresponde à uma situação desfavorável e é a justificativa de vários autores para a utilização de métodos conservadores para sua análise, como por exemplo, o clássico método vetorial.

Por outro lado, admitindo-se uma razoável ductilidade da conexão (interação parafusos - metal base), há possibilidade de redistribuição da força entre os parafusos, e os métodos de análise plástica (como o método do CIR proposto pelo AISC) têm conduzido a valores da força última $P_{u}$ compatíveis com os observados experimentalmente. 
Neste caso, a força excêntrica atua fora do plano de cisalhamento dos parafusos, provocando uma "força cortante" e um "momento fletor" no grupo de parafusos, podendo conduzir à uma combinação de tração e cisalhamento em alguns parafusos e esta solicitação combinada deve ser admitida na verificação da capacidade da conexão.

A figura 5-9 ilustra a conexão de um "tê" a um elemento rígido, constituída por dez parafusos dispostos em duas colunas. Segundo GAYLORD et al. [ 27 ], se o "Tê" também for admitido rígido, ao se aplicar uma pré-tração uniforme nos parafusos, é razoável admitir uma distribuição também uniforme da pressão de contato entre as partes (fig. 5-9a). Na presença do momento fletor $M_{l}$ não ocorre o descolamento entre as partes e a distribuição da pressão de contato pode ser assumida como linearmente distribuída (fig. 5-9b).

Se o momento fletor $M_{2}$ leva ao descolamento da parte superior, a força de tração nos parafusos pode ser assumida como linearmente distribuída se o parafuso mais solicitado permanecer em regime elástico-linear (fig. 5-9c). Caso contrário, ocorrerá a plastificação progressiva dos parafusos e da parte inferior da conexão (comprimida), o que caracteriza o estado limite último de plastificação total com o correspondente momento fletor $M_{3}$ (fig. 5-9d).

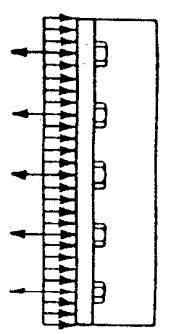

(a)

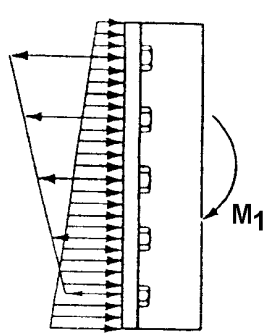

(b)

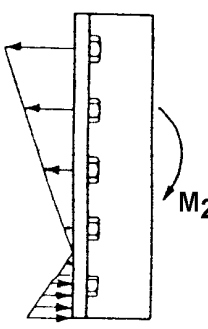

(c)

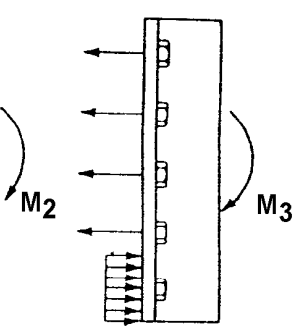

(d)

FIGURA 5-9 Tração nos parafusos. Adaptada de GAYLORD et al. [ 27 ].

Nas conexões por atrito com parafusos uniformemente distribuídos, tem-se a situação ilustrada na fig. 5-9b, onde a linha neutra da distribuição de tensões do momento fletor contém o centro de gravidade da área correspondente à região conectada. A parte inferior da chapa fica sujeita a um acréscimo de pressão de contato, enquanto a parte superior sofre um alívio de pressão de contato, o que está 
melhor ilustrado na fig. 5-10 onde são considerados separadamente os efeitos da prétração nos parafusos e do momento fletor.

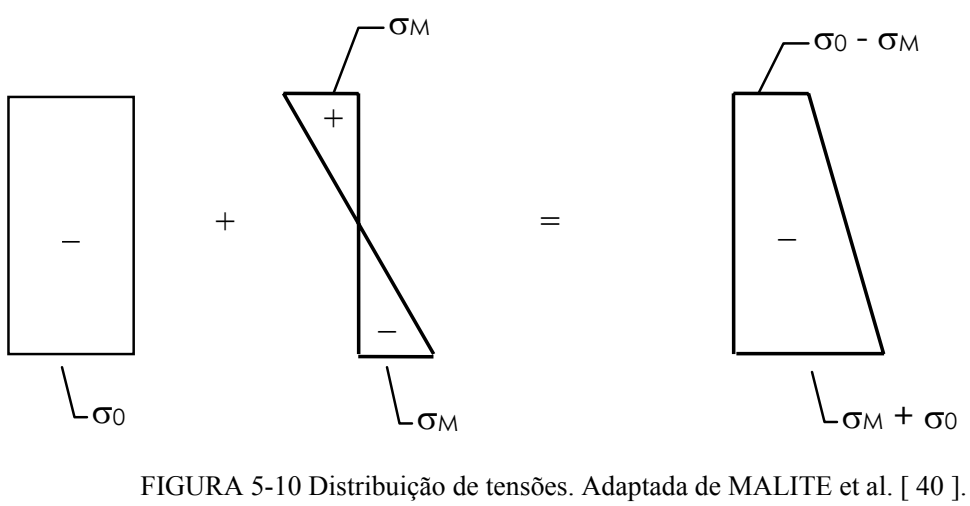

Segundo MALITE et al. [ 40 ], a pressão de contato inicial $\sigma_{0}$ é assumida como sendo uniformemente distribuída na área de contato da chapa e igual a:

$$
\sigma_{0}=\frac{\sum \mathrm{T}_{\mathrm{b}}}{\mathrm{A}_{\mathrm{c}}}
$$

onde: $\mathrm{A}_{\mathrm{c}}=$ área de pressão de contato (área da chapa)

$\mathrm{T}_{\mathrm{b}}=$ força de pré-tração no parafuso

A tensão de tração normal $\sigma_{M i}$ devida ao momento aplicado, que varia linearmente com a distância do parafuso à linha neutra, e deve sempre ser menor que $\sigma_{0}$ é:

$$
\sigma_{\mathrm{Mi}}=\frac{\mathrm{M}}{\mathrm{I}} \mathrm{y}_{\mathrm{i}}=\frac{12 \mathrm{M}}{\mathrm{bd}^{3}} \mathrm{y}_{\mathrm{i}}
$$

onde: $\mathrm{I}=$ momento de inércia da seção de contato (

$\mathrm{d}=$ altura da chapa

$\mathrm{b}=$ largura da chapa

$\mathrm{y}_{\mathrm{i}}=$ ordenada do parafuso genérico em relação à linha neutra

A tração $T_{i}$ em cada parafuso é:

$\mathrm{T}_{\mathrm{i}}=\sigma_{\mathrm{Mi}} \frac{\mathrm{bp}}{\mathrm{m}}=\frac{12 \mathrm{Mp}}{\mathrm{d}^{3} \mathrm{~m}} \mathrm{y}_{\mathrm{i}}$

onde: $\quad$ b.p $/ \mathrm{m}=$ área de contribuição do parafuso

$\mathrm{m}=$ número de colunas de parafusos 
$\mathrm{p}=$ espaçamento dos parafusos

Para o topo da chapa, $\mathrm{y}_{\mathrm{i}}=\mathrm{d} / 2$, portanto:

$\mathrm{T}=\frac{12 \mathrm{Mp}}{\mathrm{d}^{3} \mathrm{~m}} \frac{\mathrm{d}}{2}=\frac{6 \mathrm{Mp}}{\mathrm{d}^{2} \mathrm{~m}}$

Como o parafuso extremo dista $p / 2$ do topo, a tração $T$ é:

$\mathrm{T}=\frac{6 \mathrm{Mp}}{\mathrm{d}^{2} \mathrm{~m}}\left(\frac{\mathrm{d}-\mathrm{p}}{\mathrm{d}}\right)$

Esta expressão fornece a força de tração no parafuso crítico, ou seja, aquele sujeito ao maior alívio de pressão de contato.

Um outro procedimento para calcular a tração nos parafusos, apresentado pela bibliografia, é admitir que somente as áreas da seção transversal dos parafusos compreendem como seção resistente, deste modo:

$$
\sigma_{M i}=\frac{M}{I} y_{i}=\frac{M}{\sum A_{p} y_{i}{ }^{2}} y_{i}
$$

onde: $\mathrm{A}_{\mathrm{p}}=$ área bruta do parafuso

Nesta análise, a área de referência não é mais a área da chapa, mas sim a área bruta dos parafusos, portanto a pressão de contato inicial, ou seja, aquela proveniente da pré-tração, é dada por:

$$
\sigma_{0}=\frac{T_{b}}{A_{p}}
$$

Sabendo que $T_{i}=A_{p} \sigma_{M i}$ e que os parafusos são iguais, utilizando a expressão 5.2.6, tem-se:

$$
\mathrm{T}_{\mathrm{i}}=\frac{\mathrm{M}}{\sum \mathrm{y}_{\mathrm{i}}^{2}} \mathrm{y}_{\mathrm{i}}
$$

Para determinar $\sum y_{i}^{2}$ para um número ímpar de parafusos, tem-se segundo a fig. 5-11a: 


$$
\begin{aligned}
\sum y_{i}^{2} & =2\left[p^{2}+(2 p)^{2}+(3 p)^{2}+\ldots+(k p)^{2}\right]= \\
& =2 p^{2}\left(1^{2}+2^{2}+3^{2}+\ldots+k^{2}\right)
\end{aligned}
$$

A soma dos $k$ termos entre parênteses é $(k / 6)(k+1)(2 k+1)$. Pela figura 511a $\mathrm{k}=(\mathrm{n}-1) / 2$, onde $n$ é o numero de parafusos em uma coluna, então:

$$
\sum \mathrm{y}_{\mathrm{i}}^{2}=2 \mathrm{p}^{2}\left(\frac{\mathrm{n}-1}{12}\right)\left(\frac{\mathrm{n}-1}{2}+1\right)(\mathrm{n})=\frac{\mathrm{np}^{2}\left(\mathrm{n}^{2}-1\right)}{12}
$$

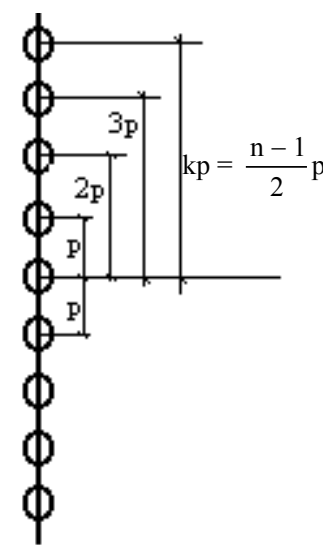

(a)

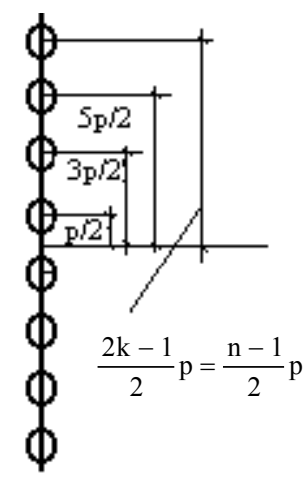

(b)

FIGURA 5-11 Distribuição dos parafusos (a) número ímpar de parafusos; (b) número par de parafusos. Adaptada de GAYLORD et al. [27].

De maneira similar, para número par de parafusos (fig. 5-11b) tem-se:

$$
\begin{aligned}
\sum \mathrm{y}_{\mathrm{i}}^{2} & =2\left[(\mathrm{p} / 2)^{2}+(3 \mathrm{p} / 2)^{2}+(5 \mathrm{p} / 2)^{2}+\ldots+\left(\frac{2 \mathrm{k}-1}{2} \mathrm{p}\right)^{2}\right]= \\
& =\left(\mathrm{p}^{2} / 2\right)\left[1^{2}+3^{2}+5^{2}+\ldots+(2 \mathrm{k}-1)^{2}\right]
\end{aligned}
$$

A soma dos $k$ termos entre parênteses é $(\mathrm{k} / 3)(2 \mathrm{k}+1)(2 \mathrm{k}-1)$. Para este caso $\mathrm{k}=\mathrm{n} / 2$, deste modo:

$$
\sum \mathrm{y}_{\mathrm{i}}^{2}=\left(\mathrm{p}^{2} / 2\right)(\mathrm{n} / 6)(\mathrm{n}+1)(\mathrm{n}-1)=\frac{\mathrm{np} \mathrm{p}^{2}\left(\mathrm{n}^{2}-1\right)}{12}
$$

Deve-se notar que as expressões 5.2.10 e 5.2.12 foram deduzidas para uma coluna de parafusos, devendo multiplicá-las pelo número de colunas $m$.

Com isso, substituindo a expressão 5.2.10 ou 5.2.12 na expressão 5.2.8, temse a força de tração em cada parafuso: 


$$
\mathrm{T}_{\mathrm{i}}=\frac{12 \mathrm{M}}{\mathrm{mnp}^{2}\left(\mathrm{n}^{2}-1\right)} \mathrm{y}_{\mathrm{i}}
$$

Neste caso, para conexões com número par ou ímpar de parafusos, a distância do CG da conexão ao parafuso mais extremo é $p(n-1) / 2$, deste modo obtém-se a força de tração no parafuso extremo, que é:

$$
\mathrm{T}=\frac{12 \mathrm{M}}{\mathrm{mnp}^{2}\left(\mathrm{n}^{2}-1\right)} \frac{\mathrm{p}(\mathrm{n}-1)}{2}=\frac{6 \mathrm{M}}{\operatorname{mnp}(\mathrm{n}+1)}
$$

Isolando $n$ na expressão 5.2.14 e tomando $\mathrm{T}=\mathrm{T}_{\mathrm{b}}$, obtém-se a expressão para o cálculo do número mínimo de parafusos por coluna:

$$
\mathrm{n}=\sqrt{\left(\frac{6 \mathrm{M}}{\mathrm{mpT}_{\mathrm{b}}}+\frac{1}{4}\right)}-\frac{1}{2}
$$

Segundo MALITE et al. [ 40 ], além de verificar se não haverá descolamento, ou seja, $\sigma_{0} \geq \sigma_{\mathrm{Mi}}$, que é uma condição exigida para conexões por atrito, verifica-se também a resistência global ao deslizamento, dada pela somatória das resistências ao deslizamento dos parafusos, que deve ser maior que a força cortante na conexão. A favor da segurança, os acréscimos de pressão de contato não devem ser considerados.

$$
\left(\phi_{\mathrm{v}} \mathrm{R}_{\mathrm{nv}}\right)_{\text {total }}=\sum\left(\phi_{\mathrm{v}} \mathrm{R}_{\mathrm{nv}}\right)_{\mathrm{i}}>\mathrm{V}_{\mathrm{n}}
$$

onde: $\quad \phi_{\mathrm{v}} \mathrm{R}_{\mathrm{nv}}=$ resistência de cálculo ao deslizamento

$\mathrm{V}_{\mathrm{n}}=$ cortante nominal, já que se trata de estado limite de utilização

Além dessa verificação feita em estado limite de utilização (conexão tipo atrito), deve-se fazer a verificação em estado limite de último, como uma conexão tipo contato.

Para comparar os dois procedimentos apresentados anteriormente: (1) considerando a área da chapa como área de referência e (2) considerando apenas a área dos parafusos como área resistente, desenvolveu-se o exemplo ilustrado a seguir (fig. 5-12): 
- parafusos ASTM A325, diâmetro $16 \mathrm{~mm}$

- esforços nominais: $\mathrm{V}_{\mathrm{n}}=280 \mathrm{kN} ; \mathrm{M}_{\mathrm{n}}=3.500 \mathrm{kN}$.cm

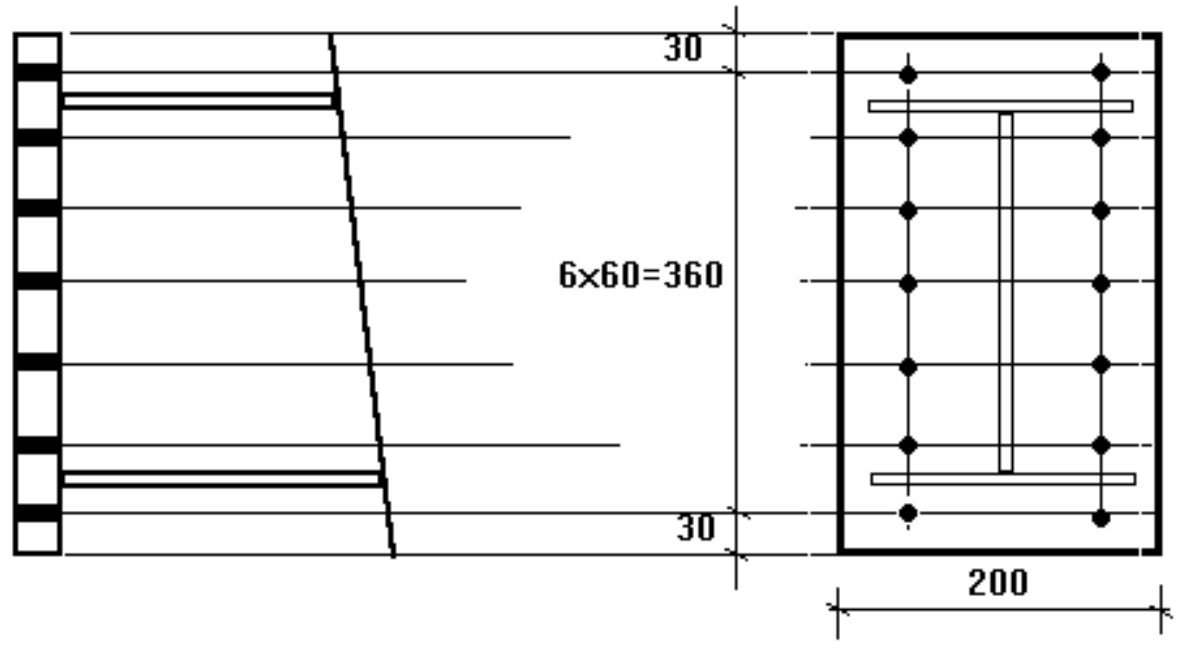

FIGURA 5-12 Dimensões da conexão adotada no exemplo.

Utilizando a expressão 5.2.15 para verificar se a quantidade de parafusos é suficiente no que se refere ao momento fletor, admitindo que $T$ é a pré-tração $T_{b}$ aplicada no parafuso, tem-se:

$$
\begin{aligned}
& \mathrm{T}_{\mathrm{b}}=0,7 \mathrm{~A}_{\mathrm{r}} \mathrm{f}_{\mathrm{u}}=0,7 \times 1,46 \times 82,5=84,3 \mathrm{kN} \\
& \mathrm{n}=\sqrt{\left(\frac{6 \mathrm{M}}{\mathrm{mpT}}+\frac{1}{4}\right)}-\frac{1}{2}=\sqrt{\left(\frac{6 \times 3500}{2 \times 6 \times 84,3}+\frac{1}{4}\right)}-\frac{1}{2}=4,1<7
\end{aligned}
$$

Verificando se não há descolamento da chapa $\left(\sigma_{M}<\sigma_{0}\right)$ :

(1) $\sigma_{0}=\frac{\sum \mathrm{T}_{\mathrm{b}}}{\mathrm{A}_{\mathrm{c}}}=\frac{14 \times 84,3}{20 \times 42}=1,41 \mathrm{kN} / \mathrm{cm}^{2}$

$$
\sigma_{\mathrm{M}}=\frac{12 \mathrm{M}}{\mathrm{bd}^{3}} \mathrm{y}=\frac{12 \times 3500}{20 \times 36^{3}} 21=0,95 \mathrm{kN} / \mathrm{cm}^{2}<\sigma_{0}
$$

(2) $\sigma_{0}=\frac{T_{b}}{A_{p}}=\frac{84,3}{1,98}=42,9 \mathrm{kN} / \mathrm{cm}^{2}$

$$
\sigma_{\mathrm{M}}=\frac{\mathrm{M}}{\sum \mathrm{A}_{\mathrm{p}} \mathrm{y}_{\mathrm{i}}^{2}} \mathrm{y}=\frac{3.500}{4.053} 18=15,5 \mathrm{kN} / \mathrm{cm}^{2}<\sigma_{0}
$$


Notar que no procedimento (1) a verificação do descolamento é feita na extremidade da chapa, enquanto no procedimento (2) essa verificação é feita na posição do parafuso.

Cálculo da resistência global ao deslizamento $\left(\sum \phi_{\mathrm{v}} \mathrm{R}_{\mathrm{nv}}\right)_{\mathrm{i}}$ :

TABELA 5-1 Resistência ao deslizamento.

\begin{tabular}{|c|c|c|c|c|c|c|}
\hline & \multicolumn{2}{|c|}{ Procedimento (1) } & & \multicolumn{3}{|c|}{ Procedimento (2) } \\
\hline $\mathrm{yi}$ & $\mathrm{T}$ & $\mathrm{Tb}-\mathrm{T}$ & $\phi \mathrm{vRnv}$ & $\mathrm{T}$ & $\mathrm{Tb}-\mathrm{T}$ & $\phi \mathrm{Rnv}$ \\
\hline 18,00 & 30,61 & 53,70 & 30,07 & 31,25 & 53,07 & 29,72 \\
\hline 12,00 & 20,41 & 63,91 & 35,79 & 20,83 & 63,48 & 35,55 \\
\hline 6,00 & 10,20 & 74,11 & 41,50 & 10,42 & 73,90 & 41,38 \\
\hline 0,00 & 0,00 & 84,32 & 47,22 & 0,00 & 84,32 & 47,22 \\
\hline$-6,00$ & $-10,20$ & 84,32 & 47,22 & $-10,42$ & 84,32 & 47,22 \\
\hline$-12,00$ & $-20,41$ & 84,32 & 47,22 & $-20,83$ & 84,32 & 47,22 \\
\hline$-18,00$ & $-30,61$ & 84,32 & 47,22 & $-31,25$ & 84,32 & 47,22 \\
\hline SOM. & & & 296,23 & & & 295,51 \\
\hline $\mathrm{M}(\mathrm{kN} . \mathrm{cm})$ & $\mathrm{p}(\mathrm{cm})$ & $\mathrm{d}(\mathrm{cm})$ & $\mathrm{m}$ & $\operatorname{Ar}\left(\mathrm{cm}^{\wedge} 2\right)$ & $\mathrm{fu}\left(\mathrm{kN} / \mathrm{cm}^{\wedge} 2\right)$ & $\mathrm{n}$ \\
\hline 3500,00 & 6,00 & 42,00 & 2,00 & 1,46 & 82,50 & 7,00 \\
\hline
\end{tabular}

Nota: Os acréscimos de pressão de contato foram desprezados.

Da tabela anterior:

$\left(\sum \phi_{\mathrm{v}} \mathrm{R}_{\mathrm{nv}}\right)=296,23 \mathrm{kN} \mathrm{p} /$ procedimento $(1)$

$\left(\sum \phi_{\mathrm{v}} \mathrm{R}_{\mathrm{nv}}\right)=295,51 \mathrm{kN} \mathrm{p} /$ procedimento (2)

Como a resistência global ao deslizamento $\left(\sum \phi_{\mathrm{v}} \mathrm{R}_{\mathrm{nv}}\right)$ obtida pelos dois procedimentos resultou maior que a força cortante $\left(\mathrm{V}_{\mathrm{n}}=280 \mathrm{kN}\right)$, a conexão analisada é satisfatória.

Deve-se notar que a diferença obtida pelos dois procedimentos é desprezível, o que era previsível tendo em vista que ambos adotaram as mesmas hipóteses, diferindo apenas na escolha da área de referência.

É importante registrar que deve ser verificado também o estado limite último, admitindo conexão por contato e tomando-se obviamente as solicitações de cálculo.

Analisando conexões por atrito com parafusos posicionados apenas nas extremidades, a hipótese de distribuição de pressão de contato uniforme $\sigma_{0}$ não é mais verificada, e a posição da linha neutra referente à distribuição de tensões 
oriundas do momento fletor $\sigma_{M i}$ não é mais facilmente identificada. Neste caso, a bibliografia apresenta o modelo teórico que admite que as resultantes de tração e compressão têm como linha de ação o centro das mesas do perfil, como ilustrado na fig. 5-13.

$$
\mathrm{T}_{\mathrm{r}}=\mathrm{C}=\frac{\mathrm{M}_{\mathrm{n}}}{\mathrm{Z}}
$$

onde: $\mathrm{z}=$ distância entre o centro das mesas do perfil

$\mathrm{T}_{\mathrm{r}}=$ tração resultante

$\mathrm{M}_{\mathrm{n}}=$ momento fletor nominal

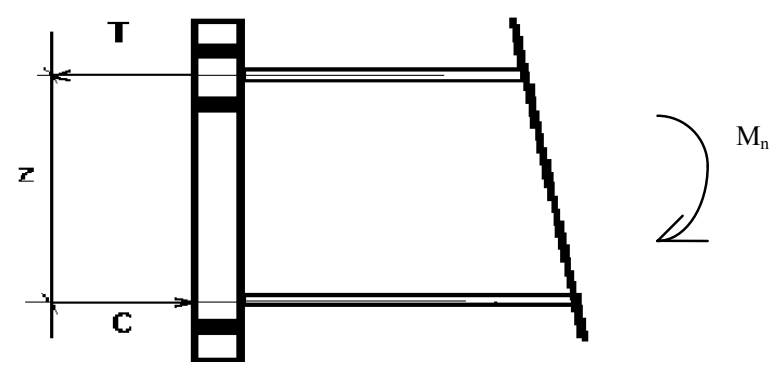

FIGURA 5-13 Conexões por atrito com parafusos nas extremidades. Adaptada de MALITE et al. [ 40 ].

Deste modo, a força de tração $T$ em cada parafuso na região tracionada é obtida dividindo-se a tração $T_{r}$ pelo número de parafusos $n$, situados nesta região:

$$
\mathrm{T}=\frac{\mathrm{T}_{\mathrm{r}}}{\mathrm{n}}
$$

Em seguida deve-se fazer as verificações de resistência ao deslizamento, da mesma maneira que no caso de distribuição de parafusos uniformes, não considerando acréscimos de pressão de contato.

Considerando agora conexões tipo contato e parafusos nas extremidades, tomando-se uma análise elástica, tem-se uma distribuição de tensões como na fig. 59c, onde as tensões nos parafusos variam linearmente com a sua distância em relação à linha neutra. Neste caso, devido a inexistência da pressão de contato, uma parte da chapa resulta comprimida, enquanto a outra descola, causando tração nos parafusos situados nesta região.

A força cortante de cálculo $V_{d}$ é admitida igualmente distribuída entre os parafusos: 


$$
\mathrm{F}_{\mathrm{vd}}=\frac{\mathrm{V}_{\mathrm{d}}}{\mathrm{n}}
$$

onde: $\mathrm{F}_{\mathrm{vd}}=$ força cortante de cálculo nos parafusos

$\mathrm{n}=$ número total de parafusos

Com isso, os parafusos situados na região comprimida ficam solicitados apenas à força cortante, enquanto aqueles situados na região tracionada à cisalhamento e tração.

A posição da linha neutra, neste caso, é facilmente determinada, pois ela passa no centro de gravidade da seção (flexão simples). Assim, igualando o momento estático da porção tracionada com o momento estático da porção comprimida (ver figura 5-14), resulta:

$$
\frac{\mathrm{y}}{2}(\mathrm{yb})=\sum \mathrm{A}_{\mathrm{i}}\left(\mathrm{d}_{\mathrm{i}}-\mathrm{y}\right)
$$

onde: $\mathrm{y}=$ posição da linha neutra em relação à extremidade inferior

$\mathrm{A}_{\mathrm{i}}=$ área dos parafusos tracionados, à distância $d_{i}$ em relação à extremidade da chapa

$\mathrm{b}=$ largura da chapa

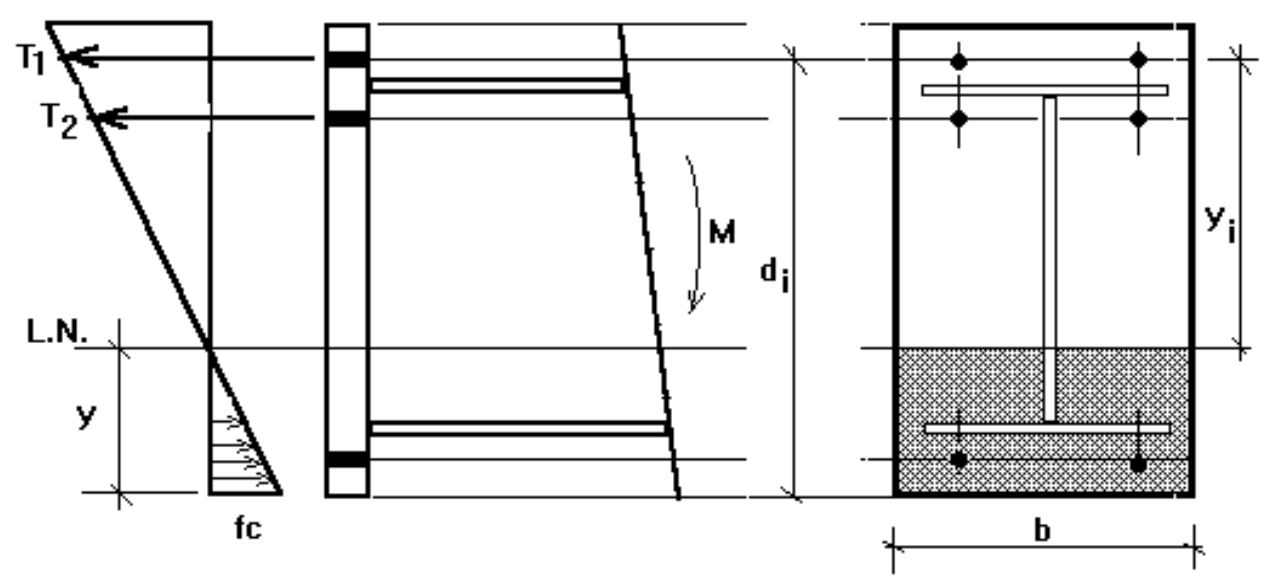

FIGURA 5-14. Conexões por contato com parafusos nas extremidades. Adaptada de MALITE et al. [ 40 ].

Deste modo, a força de tração $T_{i}$ em cada parafuso, devida ao momento fletor é: 


$$
\mathrm{T}_{\mathrm{i}}=\frac{\mathrm{MA}_{\mathrm{p}}}{\mathrm{I}} \mathrm{y}_{\mathrm{i}}
$$

onde: $\mathrm{I}$ = momento de inércia, calculado tomando-se a área comprimida da chapa e a área dos parafusos tracionados:

$$
\mathrm{I}=\mathrm{b} \frac{\mathrm{y}^{3}}{3}+\sum \mathrm{A}_{\mathrm{i}} \mathrm{y}_{\mathrm{i}}^{2}
$$

A força de tração em cada parafuso, pode também ser obtida da mesma maneira que foi calculada pelo método simplificado, usado no caso de conexões por atrito com parafusos na extremidade, sendo:

$$
\mathrm{T}=\frac{\mathrm{T}_{\mathrm{r}}}{\mathrm{n}}
$$

Com isso, devem ser verificadas as resistências de cálculo à tração, ao corte e tração e corte combinados, que devem ser maiores que as respectivas solicitações de cálculo. Além disso, deve-se verificar a pressão de contato nos furos, cuja resistência deve ser maior que a força cortante. A máxima tensão de contato na parte comprimida deve também ser verificada, onde $\sigma_{\mathrm{c}} \leq 0,9 \mathrm{f}_{\mathrm{y}}$.

Para comparar os momentos últimos obtidos pelo método elástico tradicional, pelo método simplificado e pelo método plástico, desenvolveu-se um exemplo (fig. 5-15), onde foram adotados os seguintes parâmetros:

- parafusos ASTM A325, diâmetro $19 \mathrm{~mm}\left(\mathrm{~A}_{\mathrm{p}}=2,85 \mathrm{~cm}^{2}\right)$

- metal base ASTM A36

- esforço de cálculo $\mathrm{V}_{\mathrm{d}}=360 \mathrm{kN}$ 

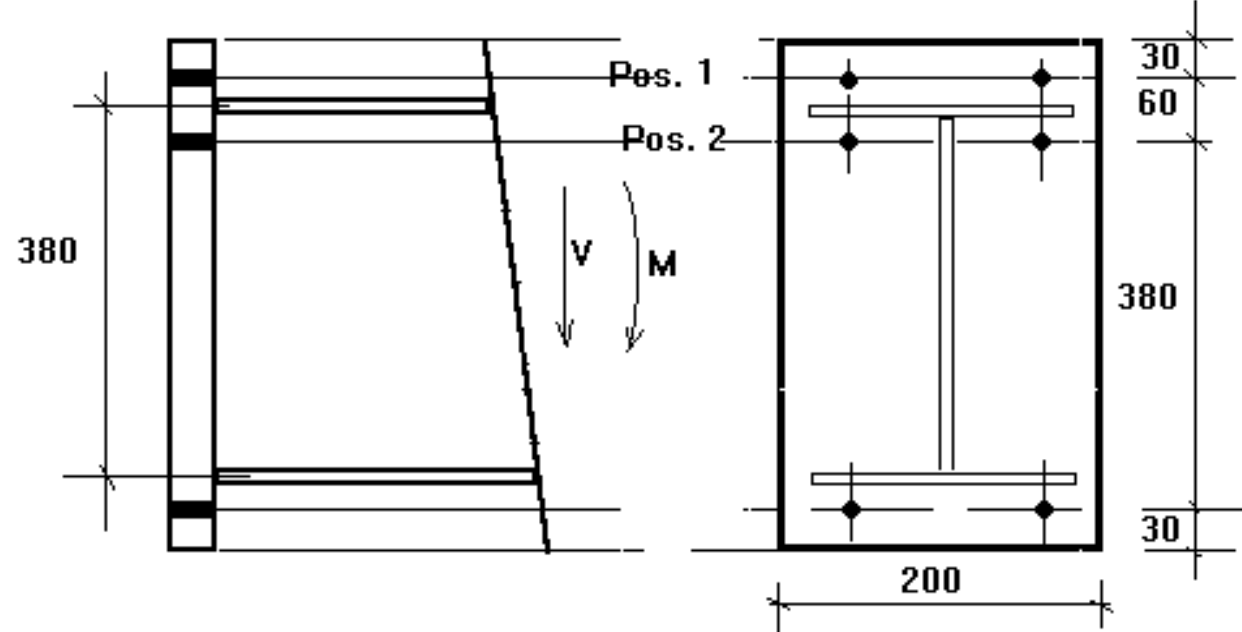

FIGURA 5-15 Dimensões da conexão adotada no exemplo.

Pelo método tradicional a posição da linha neutra (expressão 5.2.19) é:

$$
\begin{aligned}
& \frac{\mathrm{y}}{2}(\mathrm{yb})=\sum \mathrm{A}_{\mathrm{i}}\left(\mathrm{d}_{\mathrm{i}}-\mathrm{y}\right)=>20 \frac{\mathrm{y}^{2}}{2}=2 \mathrm{x} 2,85 \mathrm{x}(47-\mathrm{y})+2 \mathrm{x} 2,85 \mathrm{x}(41-\mathrm{y}) \\
& \therefore \mathrm{y}=6,54 \mathrm{~cm}
\end{aligned}
$$

Com isso, tem-se que o momento de inércia (expressão 5.2.21) é:

$$
\begin{aligned}
& I=b \frac{y^{3}}{3}+\sum A_{i} y_{i}^{2}=\frac{20 \times 6,54^{3}}{3}+2 \times 2,85 \times 40,46^{2}+2 \times 2,85 \times 34,46^{2} \\
& I=17.964,5 \mathrm{~cm}^{4}
\end{aligned}
$$

O momento último $M_{e u}$ pode ser calculado tomando-se como referência a linha neutra (fig. 5-14), resultando:

$$
\mathrm{M}_{\mathrm{ue}}=\frac{\mathrm{f}_{\mathrm{c}} \mathrm{b}}{3} \mathrm{y}^{2}+\sum \mathrm{y}_{\mathrm{i}} \mathrm{T}_{\mathrm{i}}
$$

onde: $f_{c}=$ tensão de compressão máxima

Desta maneira determinando o momento último para a conexão da fig. 5-15, tem-se que a máxima resistência de cálculo do parafuso, atuando tração e cortante admitindo rosca inclusa no plano de corte é:

$$
\phi_{t} R_{n t} \leq 0,69 A_{p} f_{u}-1,93 V_{d}=0,69 \times 2,85 \times 82,5-1,93 \times 360 / 6=46,44 \mathrm{kN}
$$


Sendo 46,44 kN a resistência à tração do parafuso, este valor é atribuído aos parafusos mais extremos da região tracionada (posição 1). Admitindo-se distribuição linear de tensões, obtém-se a tensão junto aos parafusos da posição $2 \sigma_{M 2}$ e a tensão de compressão $f_{c}$.

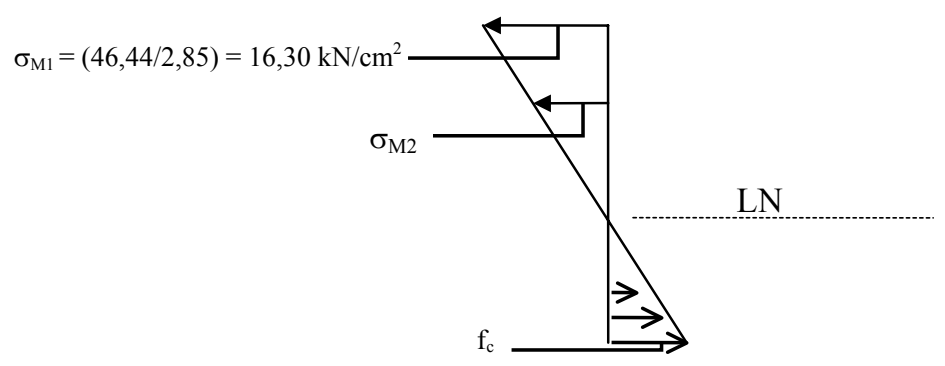

FIGURA 5-16 Determinação das tensões admitindo distribuição linear.

$$
\begin{aligned}
& \frac{\sigma_{\mathrm{M} 2}}{34,46}=\frac{16,30}{40,46}=>\sigma_{\mathrm{M} 2}=13,88 \mathrm{kN} / \mathrm{cm}^{2} \\
& \therefore \mathrm{T}_{2}=13,88 \times 2,85=39,55 \mathrm{kN} \quad \text { e } \quad \mathrm{T}_{1}=46,44 \mathrm{kN}
\end{aligned}
$$$$
\frac{\mathrm{f}_{\mathrm{c}}}{6,54}=\frac{16,30}{40,46}=>\mathrm{f}_{\mathrm{c}}=2,64 \mathrm{kN} / \mathrm{cm}^{2}<0,9 \mathrm{f}_{\mathrm{y}}=0,9 \times 25=22,5 \mathrm{kN} / \mathrm{cm}^{2} \quad \text { OK }
$$

Finalmente, pela expressão 5.2.22 tem-se:

$$
\begin{aligned}
& \mathrm{M}_{\mathrm{ue}}=\frac{\mathrm{f}_{\mathrm{c}} \mathrm{b}}{3} \mathrm{y}^{2}+\sum \mathrm{y}_{\mathrm{i}} \mathrm{T}_{\mathrm{i}}=\frac{2,64 \times 20}{3} 6,54^{2}+46,44 \times 2 \times 40,46+39,55 \times 2 \times 34,46 \\
& \mathrm{M}_{\mathrm{ue}}=7.235 \mathrm{kN} . \mathrm{cm}
\end{aligned}
$$

Pelo método simplificado, ou seja, admitindo-se a linha de ação das resultantes de tração e compressão no centro das mesas do perfil, obtém-se:

$$
\begin{aligned}
& \mathrm{T}_{\mathrm{r}}=4 \times 46,44=185,76 \mathrm{kN} \\
& \mathrm{C}=\mathrm{T}_{\mathrm{r}} \\
& \mathrm{M}_{\mathrm{us}}=\mathrm{T}_{\mathrm{r}} \mathrm{Z}=185,76 \times 38=7.059 \mathrm{kN} . \mathrm{cm}
\end{aligned}
$$

Pela análise plástica (ver fig. 5-9d), admite-se que todos os parafusos da região tracionada atingem sua resistência à tração $(46,44 \mathrm{kN})$, e a região comprimida atinge a plastificação total (distribuição retangular de tensão). Com base nestas 
hipóteses é possível calcular a posição da linha neutra plástica (LNP) e finalmente o momento último $M_{u p}$ (ver fig. 5-17):

$$
\mathrm{T}_{1}=\mathrm{T}_{2}=2 \mathrm{x} 46,44=92,88 \mathrm{kN}
$$

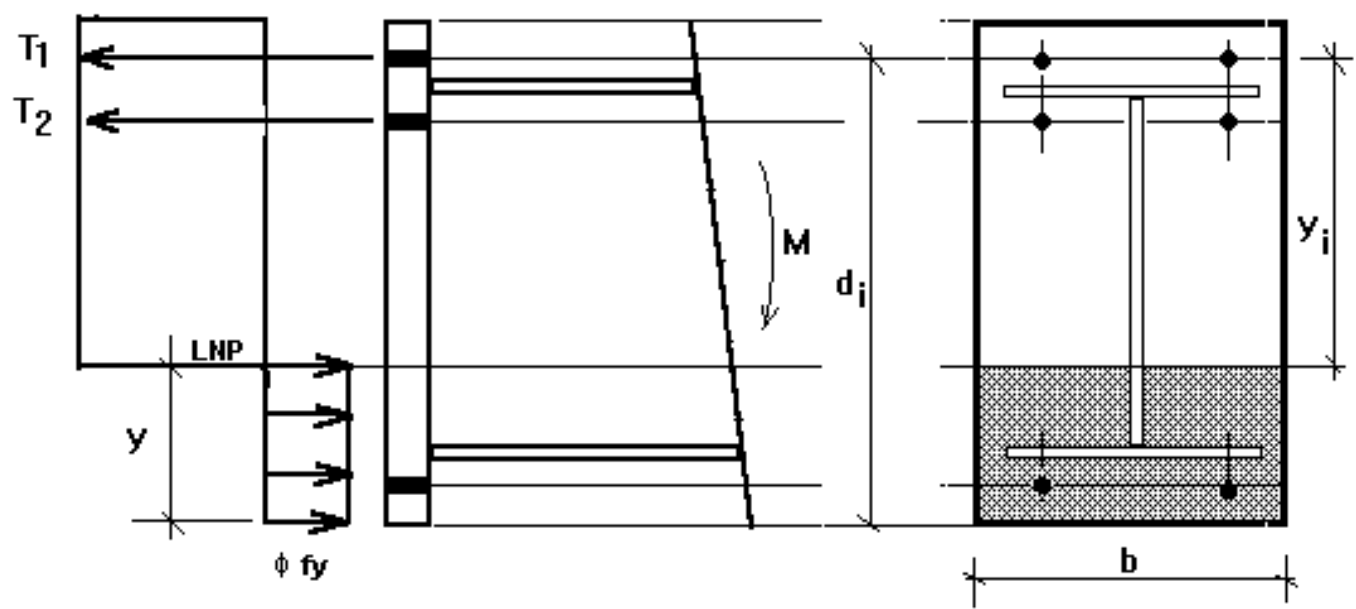

FIGURA 5-17 Distribuição de tensões considerando análise plástica.

Por equilíbrio das resultantes de tração e compressão:

$$
\begin{aligned}
& \phi \mathrm{f}_{\mathrm{y}} \mathrm{yb}=\sum \mathrm{T}_{\mathrm{iu}} \\
& \mathrm{y}=\frac{\sum \mathrm{T}_{\mathrm{iu}}}{\phi \mathrm{f}_{\mathrm{y}} \mathrm{b}}=\frac{2 \times 92,88}{0,9 \times 25 \times 20}=0,41<3 \mathrm{~cm}
\end{aligned}
$$

A posição da linha neutra deve ser recalculada, uma vez que os parafusos inferiores também estão contidos na região tracionada:

$$
\mathrm{y}=\frac{3 \times 92,88}{0,9 \times 25 \times 20}=0,62 \mathrm{~cm}
$$

Finalmente, o momento último $M_{u p}$ pode ser calculado tomando-se como referência a LNP.

$$
\mathrm{M}_{\mathrm{up}}=\frac{\phi \mathrm{f}_{\mathrm{y}} \mathrm{b}}{2} \mathrm{y}^{2}+\sum \mathrm{y}_{\mathrm{i}} \mathrm{T}_{\mathrm{iu}}
$$

onde: $\mathrm{y}_{\mathrm{i}}=$ ordenada do parafuso genérico $i$ em relação à LNP 


$$
\mathrm{M}_{\text {up }}=\frac{0,9 \times 25 \times 20}{2} \times 0,62^{2}+2 \times 46,44(46,38+40,38+2,38)=8.366 \mathrm{kN} \cdot \mathrm{cm}
$$

TABELA 5-2 Quadro resumo dos $\mathrm{M}_{\mathrm{u}}$.

\begin{tabular}{|c|c|c|}
\hline Método & $\mathrm{M}_{\mathrm{u}}(\mathrm{kN} . \mathrm{cm})$ & Relação \\
\hline Elástico tradicional & $7.235(1)$ & 1,00 \\
\hline Simplificado & $7.059(2)$ & 0,97 \\
\hline Plástico & $8.366(3)$ & 1,16 \\
\hline
\end{tabular}

É importante registrar que a hipótese da plastificação total requer uma elevada ductilidade dos parafusos, de maneira a permitir redistribuição de esforços e conduzir ao colapso simultâneo de todos os parafusos da região tracionada, o que não é observado na prática, principalmente quando se trata de parafusos de alta resistência.

Considerando agora uma conexão tipo contato, com parafusos uniformemente distribuídos, tem-se em regime elástico uma distribuição de tensões como na fig. 59c. As hipóteses neste caso são as mesmas adotadas para as conexões tipo contato, com parafusos não uniformemente distribuídos, ou seja na extremidade. Contudo, devido a uniformidade da distribuição dos parafusos, segundo MALITE et al. [ 40 ], pode ser feita uma simplificação de cálculo, que considera a região tracionada como sendo uma seção retangular fictícia, como mostra a fig. 5-18.

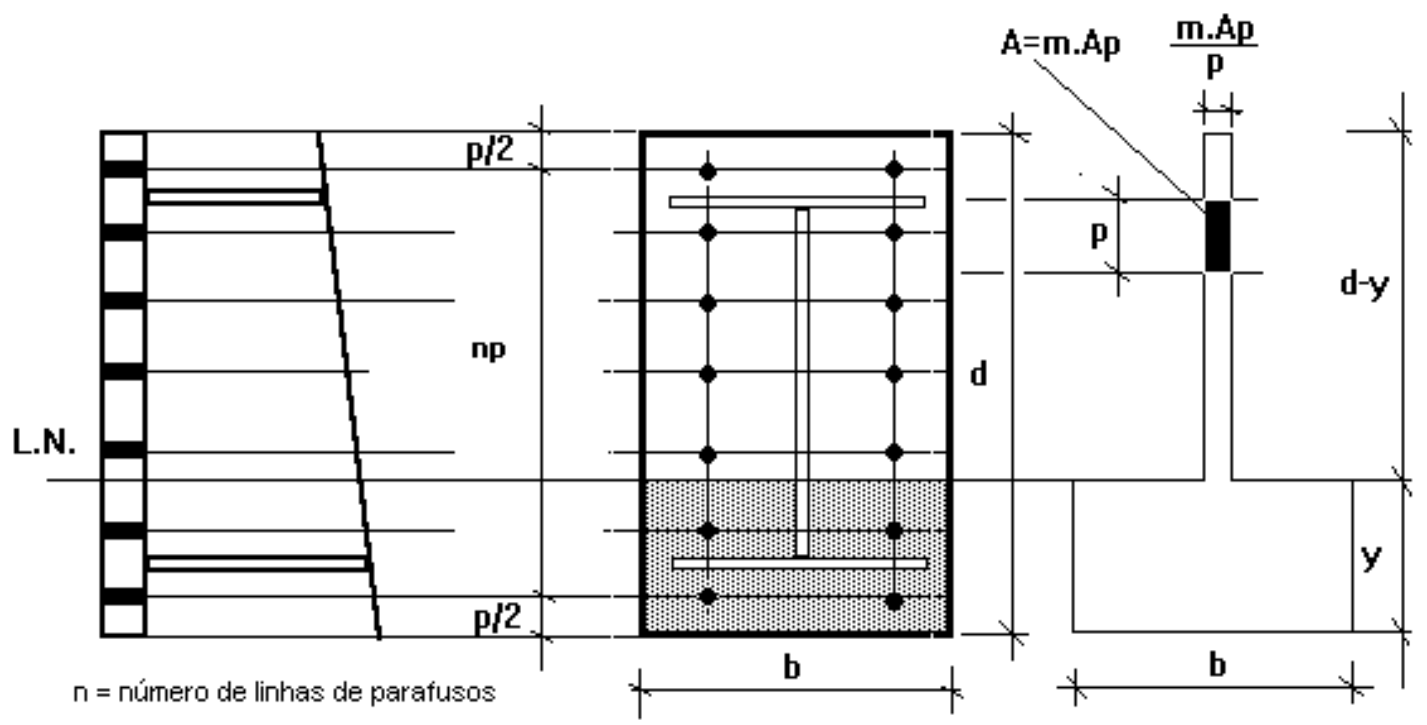

FIGURA 5-18 Conexão por contato com parafusos uniformemente espaçados. Adaptada de MALITE et al. [ 40 ]. 
Para formar essa área fictícia é tomada a área bruta dos parafusos existentes na mesma linha $m . A_{p}$, distribuída em uma altura de contribuição $p$ (que é o espaçamento dos parafusos).

Com isso, a posição da linha neutra é obtida pela igualdade de momento estático das partes tracionada e comprimida em relação à LN:

$$
\frac{y}{2}(y b)=\frac{\mathrm{mA}_{\mathrm{p}}}{\mathrm{p}} \frac{(\mathrm{d}-\mathrm{y})^{2}}{2}
$$

onde: $y=$ posição da linha neutra

$\mathrm{m}=$ número de colunas de parafusos

$\mathrm{p}=$ espaçamento dos parafusos

$\mathrm{b}, \mathrm{d}=$ largura e altura da chapa, respectivamente

$\mathrm{A}_{\mathrm{p}}=$ área bruta do parafuso

Com isso, tem-se o momento de inércia em relação à LN:

$\mathrm{I}=\frac{b \mathrm{y}^{3}}{3}+\frac{\mathrm{mA}_{\mathrm{p}}}{\mathrm{p}} \frac{(\mathrm{d}-\mathrm{y})^{3}}{3}$

Deste modo, a força de tração em cada parafuso devida ao momento fletor é:

$\mathrm{T}=\frac{\mathrm{M}}{\mathrm{I}} \mathrm{y}_{\mathrm{i}} \mathrm{A}_{\mathrm{p}}$

A força cortante $V_{d}$ é admitida igualmente distribuída entre os parafusos, ou seja:

$$
\mathrm{F}_{\mathrm{vd}}=\frac{\mathrm{V}_{\mathrm{d}}}{\mathrm{n}}
$$

\subsection{Efeito alavanca}


Conexões sujeitas a força fora do plano de cisalhamento dos parafusos, como as conexões das figuras 5-2b e 5-19, podem resultar em adicional força de tração nos parafusos, denominada força alavanca.

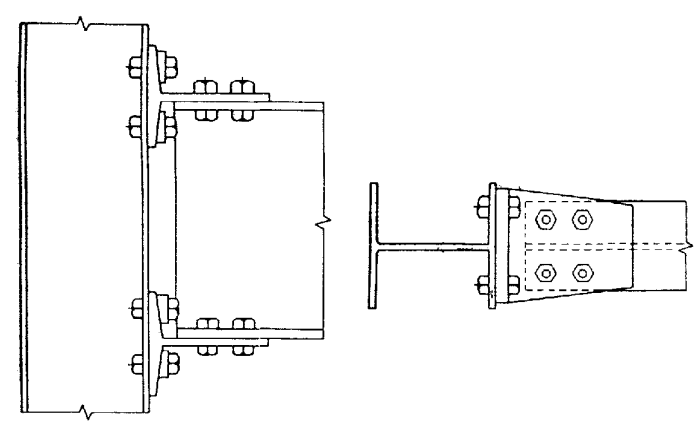

FIGURA 5-19 Conexão viga pilar com tê nas mesas. Adaptada de GAYLORD et al. [ 27 ].

Segundo KULAK et al. [ 34 ], devido a simetria da conexão da fig. 5-19, os parafusos podem ser assumidos como sendo igualmente tracionados. Uma força de tração externa aplicada na conexão reduz a pressão de contato entre a mesa do tê e a mesa do pilar. Todavia, dependendo da rigidez à flexão do tê, forças adicionais podem ser desenvolvidas junto à extremidade da mesa. Este fenômeno é conhecido por efeito alavanca e é ilustrado na fig. 5-20. O efeito alavanca aumenta a força no parafuso e este aumento deve geralmente ser levado em consideração na análise da conexão. Ensaios indicam que esse efeito pode reduzir a resistência estática e à fadiga de ligações parafusadas e rebitadas.

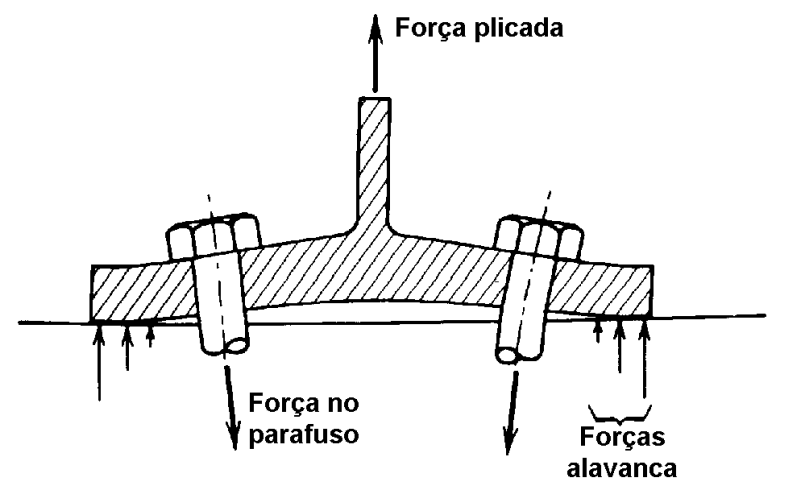

FIGURA 5-20 Deformação da ligação, mostrando o efeito alavanca. Adaptada de KULAK et al. [ 34 ]. 
As idealizações usadas para avaliar as forças alavanca, têm somente o intuito de avaliar o acréscimo da força axial no parafuso. Contudo, a deformação das partes conectadas também resultam em flexão do corpo do parafuso e flexão local da porca ou da cabeça do parafuso, que podem ser significativas.

Quantificar o efeito alavanca de maneira precisa é uma tarefa complexa. Segundo OWENS \& CHEAL [ 50 ], existem variáveis que interferem nesse fenômeno e que devem ser analisadas. Algumas delas são: imperfeições e ajuste na distribuição das forças, a avaliação da verdadeira "rigidez" do parafuso, a incerteza na distribuição do contato entre a cabeça do parafuso e a extremidade da chapa, a incerteza na linha de ação das forças de contato, devido as curvaturas iniciais induzidas na extremidade da chapa e efeitos locais ao longo da espessura na vizinhança dos furos.

Segundo KULAK et al. [ 34 ], se a mesa do tê é suficientemente rígida, como mostra a fig. 5-21a, não há deslocamento significativo e é possível ignorar a flexão, pois as deformações do parafuso provenientes da flexão da mesa são pequenas, quando comparadas com as provenientes da força externa. Com isso, pequena força alavanca será desenvolvida, e tal efeito pode ser desprezado.

Para forças aplicadas que são menores que a soma das pré-trações atuantes nos parafusos, não há significativa separação dos componentes da conexão e somente há modestas mudanças nessas pré-trações. Uma vez que a força aplicada excede a soma das pré-trações, a chapa separa-se inteiramente da base. Contudo, se for usada uma chapa mais flexível, como na figura $5-21$ b, o comportamento se torna mais complexo.

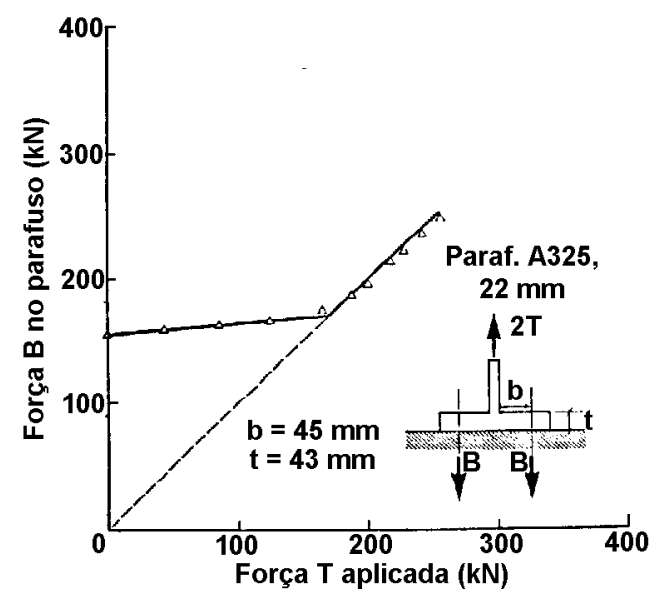

(a) Chapa espessa

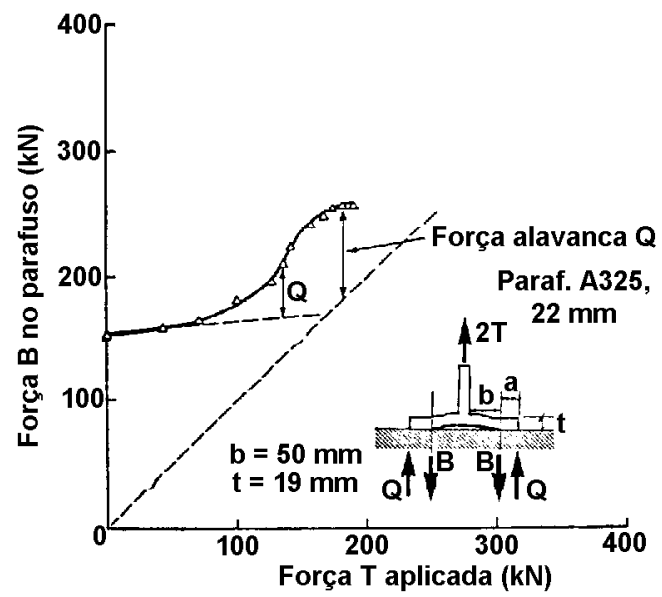

(b) Chapa fina 
Inicialmente, a força externa reduz a pressão de contato entre a mesa e a base até a separação ocorrer. A flexão da mesa desenvolve forças alavanca atuando entre o eixo do parafuso e a extremidade da mesa, como ilustrado na fig. 5-20.

Resultados de ensaios têm confirmado que propriedades de rigidez da mesa e dos parafusos são fatores significativos no efeito alavanca. Outros fatores, tal como a pré-tração dos parafusos, o comprimento de pega e o número de linhas de parafusos, também têm sido estudados.

Quando uma conexão do tipo mostrada na fig. 5-22a tem mais que duas fileiras de parafusos paralelas a alma, a efetividade da fileira externa pode ser severamente reduzida, devido a flexibilidade da mesa. Ensaios têm mostrado que a deformação dos parafusos internos aumentam, e continuam assim até a falha ocorrer. Todavia, inicialmente, a deformação dos parafusos externos diminuem levemente ou permanecem constantes. Deste modo, a maior parcela da força é equilibrada pelos parafusos internos. A falha dos parafusos internos ocorre antes que os parafusos externos sejam solicitados de maneira significativa. Aumentando-se a rigidez à flexão da mesa, observa-se uma maior eficiência estrutural da conexão. Este fato comprova a ineficácia dos parafusos externos, que pode ser melhorada com o aumento da rigidez à flexão da mesa, como mostrado na fig. 5-22b, onde foram soldados dois enrijecedores.

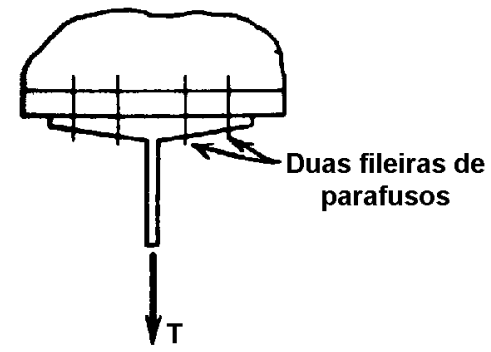

(a)

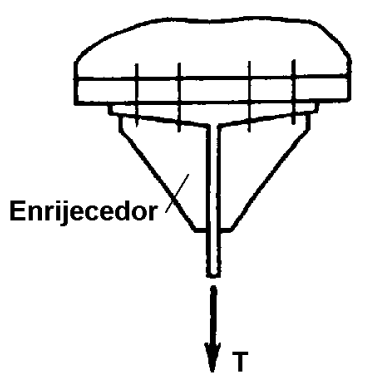

(b)

FIGURA 5-22 Conexões com quatro fileiras de parafusos; (a) sem enrijecimento; (b) enrijecida. Adaptada de KULAK et al. [ 34 ].

Vários estudos teóricos e experimentais do efeito alavanca têm resultado em diversos modelos matemáticos. Entre esses, pode-se destacar o apresentado por Douty e McGuire em 1965, cujo esquema de forças no tê está apresentado na fig. 523. 
Inicialmente mostra-se o tê sem forças externas (fig. 5-23a), apenas com a pré-tração nos parafusos $T_{0}$ e a resultante da pressão de contato $C_{0}$, que não é uniformemente distribuída. Em seguida, aplicando-se uma força externa $2 T$ suficiente para provocar o descolamento das partes, ocorre um aumento na tração no parafuso, conduzindo ao valor $B$ (fig. 5-23b). Devido à flexão da mesa do tê, aparecem pressões de contato cuja resultante $Q$ é denominada força alavanca. Admite-se, por simplificação, que a linha de ação da força alavanca $Q$ passa pela extremidade da mesa (fig. 5-23c).

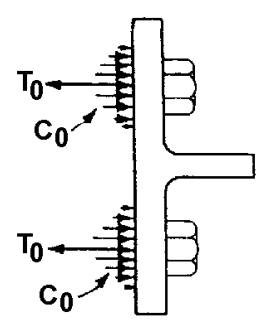

(a)

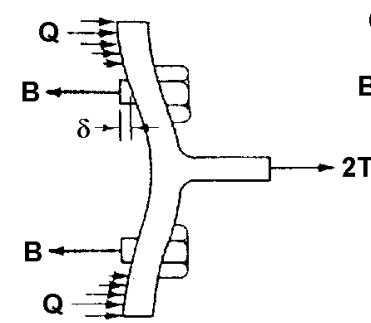

(b)

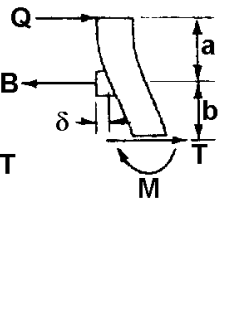

(c)

FIGURA 5-23 Esquema de forças do efeito alavanca, modelo de Douty e McGuire. Adaptada de GAYLORD et al. [ 27 ]

GAYLORD et al. [ 27 ], assume que o deslocamento $\delta$ da mesa pode ser igualado ao alongamento do parafuso, para se obter a relação entre a tração no parafuso e a força aplicada. Admitindo-se também um comportamento elástico-linear da mesa, $\delta$ é facilmente calculado. A seguinte expressão semi-empírica, sugerida por Douty e McGuire, considerando as propriedades dos parafusos e do material conectado e a geometria da conexão, foi obtida mediante alguns ajustes na expressão resultante da força alavanca, com o intuito de simplifica-lá e leva-lá à melhor conformidade com resultados de ensaios:

$$
\frac{Q}{T}=\frac{15 a b^{2} A_{p}-p t^{4}}{10 a^{2}(a+3 b) A_{p}+5 p t^{4}}
$$

onde: $A_{p}=$ área do parafuso

$\mathrm{p}=$ largura de contribuição da mesa por par de parafusos

$\mathrm{t}=$ espessura da chapa

$\mathrm{a}, \mathrm{b}=$ dimensões mostradas na figura 5-23c 
Segundo KULAK et al. [ 34 ], essa relação semi-empírica sugerida por Douty e McGuire para a força alavanca foi simplificada pela ASCE em 1971, resultando:

$$
\frac{\mathrm{Q}}{\mathrm{T}}=\left(\frac{3 \mathrm{~b}}{8 \mathrm{a}}-\frac{\mathrm{t}^{3}}{20}\right)
$$

Contudo, como é ilustrado na fig. 5-24, esta expressão fornece resultados conservadores.

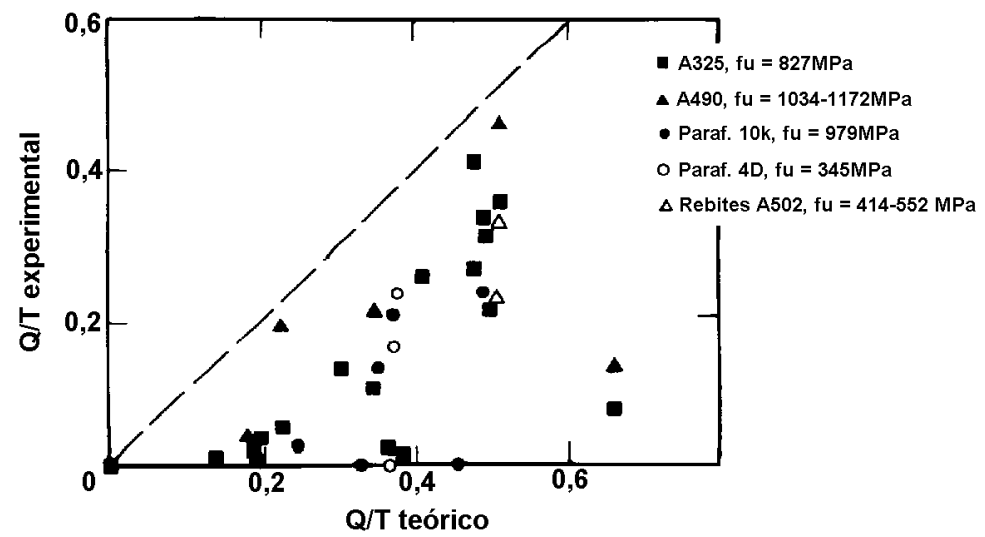

FIGURA 5-24 Comparação entre resultados experimentais e analíticos pela expressão da ASCE (5.3.2). Adaptada de KULAK [ 34 1.

Segundo GAYLORD et al. [ 27 ], a solução deste problema torna-se mais simples, ao assumir que a força última é alcançada com o desenvolvimento de uma rótula plástica na junção mesa-alma $\left(\mathrm{M}=\mathrm{M}_{\mathrm{p}}\right)$. Pela fig. 5-23c, tem-se duas equações de equilíbrio:

$$
\begin{aligned}
& \mathrm{T}+\mathrm{Q}=\mathrm{B} \\
& \mathrm{Tb}-\mathrm{Q} \mathrm{a}=\mathrm{M}_{\mathrm{p}}
\end{aligned}
$$

Dividindo a expressão. 5.3.3 pela expressão 5.3.4 e resolvendo em função de Q/T tem-se:

$$
\frac{\mathrm{Q}}{\mathrm{T}}=\frac{\mathrm{b}-\mathrm{M}_{\mathrm{p}} / \mathrm{B}}{\mathrm{a}+\mathrm{M}_{\mathrm{p}} / \mathrm{B}}
$$

Sabendo-se que $\mathrm{M}_{\mathrm{p}}=\mathrm{Zf}_{\mathrm{y}}=\mathrm{f}_{\mathrm{y}} \mathrm{pt}^{2} / 4$, e tomando-se a tração no parafuso igual a sua resistência à tração $B_{R}=f_{u} A_{p}$, a relação $M_{p} / B$ na expressão 5.3.5 torna-se:

$$
\frac{M_{p}}{B}=\frac{f_{y} p t^{2}}{4 f_{u} A_{p}}=\frac{f_{y} p t^{2}}{f_{u} \pi d^{2}}=\frac{\beta p t^{2}}{d^{2}}
$$


onde: $\quad d=$ diâmetro do parafuso

$$
\beta=\frac{f_{y}}{f_{u} \pi}
$$

Substituindo este resultado na expressão 5.3.5 tem-se:

$$
\frac{\mathrm{Q}}{\mathrm{T}}=\frac{\mathrm{bd}^{2}-\beta \mathrm{pt}^{2}}{\mathrm{ad}^{2}+\beta p \mathrm{t}^{2}}
$$

Entretanto, a análise teórica baseada em elementos finitos mostrou que, para a maioria dos casos estudados, o parafuso atinge a falha antes que a rótula plástica seja formada. Deste modo, a expressão 5.3.7 foi calibrada em 1974 por NAIR et al. ${ }^{3}$ apud KULAK et al.. [ 34 ] resultando:

$$
\begin{array}{ll}
\frac{\mathrm{Q}}{\mathrm{T}}=\frac{100 b \mathrm{~d}^{2}-18 \mathrm{pt}^{2}}{70 a d^{2}+21 p \mathrm{t}^{2}} & \text { para parafusos A325 } \\
\frac{\mathrm{Q}}{\mathrm{T}}=\frac{100 \mathrm{bd}^{2}-14 \mathrm{pt}^{2}}{62 \mathrm{ad}^{2}+21 p \mathrm{t}^{2}} & \text { para parafusos A490 }
\end{array}
$$

Nota: Dimensões em polegadas

Estas expressões fornecem resultados mais próximos dos valores experimentais, se comparada à expressão 5.3.2. A fig. 5-25 apresenta uma comparação entre resultados analíticos provenientes das expressões 5.3 .8 e 5.3 .9 e resultados experimentais. É importante alertar que tais expressões empíricas foram determinadas para casos específicos (tipo de parafuso e metal base), portanto podem não ser adequadas para outras situações.

\footnotetext{
${ }^{3}$ R. S Nair, P. C. Birkemoe, and W. H. Munse, "High Strength Bolts Subjected to Tension and Prying," Journal of the Structural Division, ASCE, Vol. 100, ST2, February 1974.
} 


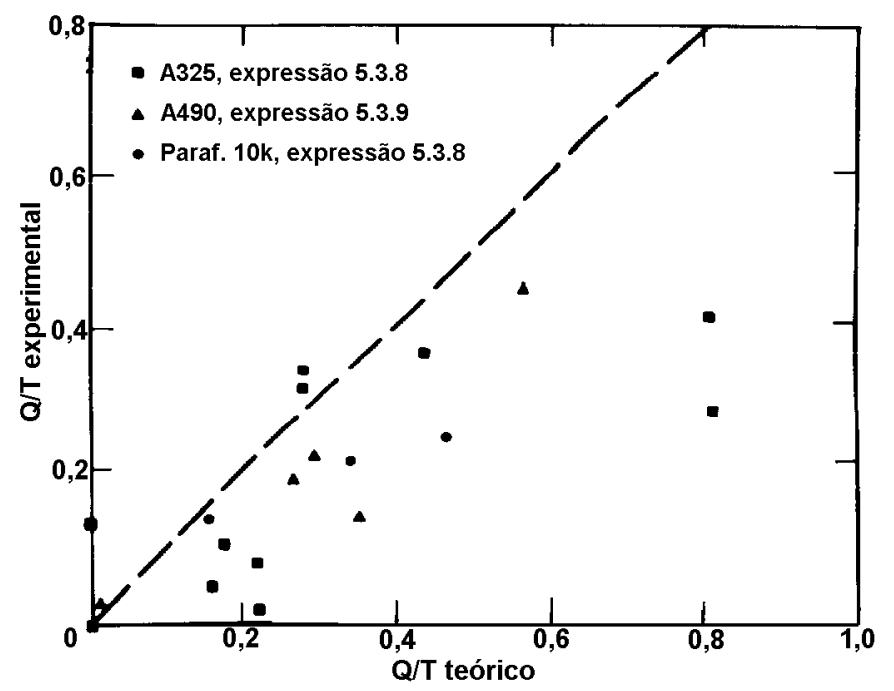

FIGURA 5-25 Comparacão.entre resultados analíticos e experimentais. Adaptada de KULAK et al. [34 ].
Um outro modelo utilizado para a analise do efeito alavanca e o proposto por McCauley (data não encontrada) que é demostrado a seguir, segundo OWENS \& CHEAL [ 50 ].

Inicialmente é considerado que o tê sofre uma deformação elástica, e tomando uma origem no ponto $C$, como mostra a fig. 5-26, tem-se:

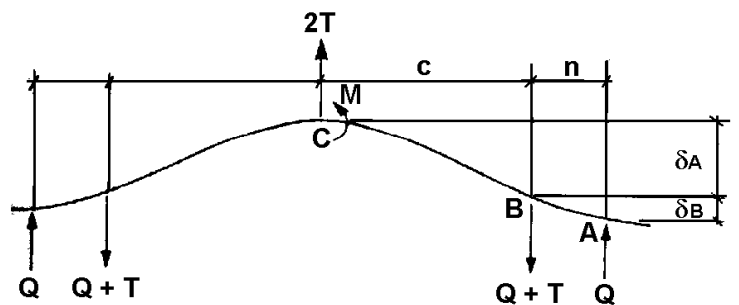

FIGURA 5-26 Esquema de forças do efeito alavanca, modelo de McCauley. Adaptada de OWENS \& CHEAL [ 50

$$
\begin{aligned}
& \text { Em C, } x=0, y=0 \text { e } d_{y} / d_{x}=0 \\
& \text { EI } \frac{d^{2} y}{d_{x}{ }^{2}}=M-T x+(Q+T)(x-c) \\
& \text { EI } \frac{d_{y}}{d_{x}}=M x-\frac{T}{2} x^{2}+\frac{(Q+T)}{2}(x-c)^{2} \\
& \text { EIy }=\frac{M}{2} x^{2}-\frac{T}{6} x^{3}+\frac{(Q+T)}{6}(x-c)^{3}
\end{aligned}
$$

Em B, $x=c, y=\delta_{\mathrm{A}}$

$$
\mathrm{EI} \delta_{\mathrm{A}}=\frac{\mathrm{M}}{2} \mathrm{c}^{2}-\frac{\mathrm{T}}{6} \mathrm{c}^{3}
$$


Em A, $x=n+c, y=\delta_{A}+\delta_{B}$

$$
\operatorname{EI}\left(\delta_{\mathrm{A}}+\delta_{\mathrm{B}}\right)=\frac{\mathrm{M}}{2}(\mathrm{n}+\mathrm{c})^{2}-\frac{\mathrm{T}}{6}(\mathrm{n}+\mathrm{c})^{3}+\frac{(\mathrm{Q}+\mathrm{T})}{6} \mathrm{n}^{3}
$$

Pelas expressões 5.3.13 e 5.3.14, isolando EI $\delta_{\mathrm{B}}$, tem-se:

$$
E I \delta_{B}=\frac{M}{2}\left(n^{2}+2 n c\right)-\frac{T}{6}\left(n^{3}+3 n^{2} c+3 n c^{2}\right)+\frac{(Q+T)}{6} n^{3}
$$

Tomando-se o momento em relação a $C$ obtém-se:

$\mathrm{M}=(\mathrm{Q}+\mathrm{T}) \mathrm{c}-\mathrm{Q}(\mathrm{n}+\mathrm{c})=\mathrm{Tc}-\mathrm{Qn}$

Através das expressões 5.3.15 e 5.3.16, tem-se:

$$
\begin{aligned}
& 6 \mathrm{EI} \delta_{\mathrm{B}}=3 \operatorname{Tnc}^{2}-\mathrm{Q}\left(2 \mathrm{n}^{3}+6 \mathrm{n}^{2} \mathrm{c}\right) \\
& \mathrm{Q}=\frac{\mathrm{T}-\left(2 \mathrm{EI} \delta_{\mathrm{B}}\right) /\left(n c^{2}\right)}{(2 / 3)(\mathrm{n} / \mathrm{c})^{2}+2(\mathrm{n} / \mathrm{c})}
\end{aligned}
$$

Substituindo na expressão 5.3 .17 a distância $c$ pela distância $b$ mostrada na fig. 5-23c, esta expressão pode ser reescrita usando as seguintes suposições:

$$
\frac{1}{(2 / 3)(n / c)^{2}+2(n / c)}=\frac{b}{2 n}
$$

(2) $\quad \mathrm{c}^{2}=1,5 \mathrm{~b}^{2}$ no termo $\left(2 \mathrm{EI} \delta_{\mathrm{B}}\right) /\left(\mathrm{nc}^{2}\right)$

Assumindo estas considerações, a expressão 5.3.17 torna-se:

$$
\mathrm{Q}=\frac{\mathrm{b}}{2 \mathrm{n}}\left(\mathrm{T}-\frac{4 \mathrm{EI} \delta_{\mathrm{B}}}{3 \mathrm{nb} \mathrm{b}^{2}}\right)
$$

Quando uma força externa é aplicada em uma conexão com parafusos prétracionados, no estágio inicial ocorre um pequeno e gradual aumento da tração nos parafusos e um conseqüente alívio da pressão de contato entre as chapas. Se tal força é removida e o limite de escoamento do parafuso é ultrapassado, observa-se uma 
perda de pré-tração nos parafusos. A intensidade desta perda depende do alongamento residual dos parafusos.

Admitindo-se a tensão de prova de carga $p_{0}$ (definida no capítulo 1 ), o alongamento do parafuso é $p_{0} / E$ vezes o comprimento de pega. O alongamento $\delta_{p}$ é $p_{0} t / E$, onde $t$ é a espessura da chapa.

Considerando típicas curvas força-alongamento para parafusos de alta resistência, verifica-se que a deformação na chapa junto ao eixo do parafuso é limitada em $\delta_{p} / 3$.

Substituindo na expressão 5.3.18, tem-se:

$$
\begin{array}{ll}
\delta_{\mathrm{B}}=\frac{\delta_{\mathrm{p}}}{3}=\frac{\mathrm{p}_{0} \mathrm{t}}{3 \mathrm{E}} & \mathrm{I}=\frac{\mathrm{pt}^{3}}{12} \\
\mathrm{Q}=\frac{\mathrm{b}}{2 \mathrm{n}}\left(\mathrm{T}-\frac{\mathrm{p}_{0} \mathrm{pt}^{4}}{27 \mathrm{nb}^{2}}\right) &
\end{array}
$$

onde: $\mathrm{p}=$ largura de contribuição da mesa por par de parafusos

Quando os parafusos são apertados apenas na sua condição de pré-torque, ao se aplicar uma força externa esta é transferida quase que imediatamente para os parafusos, o que leva a maiores alongamentos que na situação anterior.

Neste caso, as curvas força-alongamento indicam que $\delta_{B}$ é limitada em $2 \delta_{p} / 3$.

Substituindo na expressão 5.3.18, tem-se:

$$
\begin{array}{ll}
\delta_{\text {B }}=\frac{2 \delta_{\mathrm{p}}}{3}=\frac{2 \mathrm{p}_{0} \mathrm{t}}{3 \mathrm{E}} & \mathrm{I}=\frac{\mathrm{pt}^{3}}{12} \\
\mathrm{Q}=\frac{\mathrm{b}}{2 \mathrm{n}}\left(\mathrm{T}-\frac{2 \mathrm{p}_{0} \mathrm{pt}^{4}}{27 \mathrm{nb}^{2}}\right) &
\end{array}
$$

Deste modo, uma expressão para se avaliar a mínima força alavanca pode ser escrita como:

$$
Q=\frac{b}{2 n}\left(T-\frac{\beta \gamma p_{0} p^{4}}{27 n b^{2}}\right)
$$

onde: $\beta=1$ para parafusos pré-tracionados

$\beta=2$ para parafusos na condição de pré-torque 
$\gamma=1,0$ para cálculo em serviço

$\gamma=1,5$ para cálculo com forças fatoradas (estados limites)

Segundo o STEEL DESIGNERS' MANUAL [ 68 ], quando o segundo termo da expressão 5.3.21 é maior que $T$, a força alavanca dada por essa expressão deve ser tomada como zero.

Ao se admitir a formação de rótulas plásticas na chapa, junto ao eixo do parafuso e na junção mesa-alma, pode-se desprezar o segundo termo entre parênteses da expressão 5.3.21, que é relativamente pequeno, obtendo-se a expressão geral:

$$
\mathrm{Q}=\frac{\mathrm{Tb}}{2 \mathrm{n}}
$$

Segundo OWENS \& CHEAL [ 50 ], quando a distância da linha do parafuso à extremidade da mesa é relativamente grande, a força alavanca atuará em algum ponto intermediário, e não na extremidade da mesa. Para determinar a distância $n$ deste ponto intermediário, assume-se que a inclinação da mesa em $A$ (fig. 5-26) é zero:

$$
\begin{aligned}
& \text { Em A, } x=n+c ; \frac{d_{y}}{d_{x}}=0 \\
& 0=M(n+c)-\frac{T}{2}(n+c)^{2}+\frac{(Q+T)}{2} n^{2}
\end{aligned}
$$

A expressão para $Q$, sem simplificação é:

$$
\mathrm{Q}=\frac{\mathrm{T}-\left(\frac{\beta \gamma \mathrm{p}_{0} \mathrm{pt}^{4}}{18 \mathrm{nc}^{2}}\right)}{\frac{2}{3}\left(\frac{\mathrm{n}}{\mathrm{c}}\right)^{2}+2\left(\frac{\mathrm{n}}{\mathrm{c}}\right)}
$$

Pelas expressões 5.3.16, 5.3.23 e 5.3.24, tem-se que $M=\frac{\beta \gamma \mathrm{p}_{0} \mathrm{pt}^{4}}{6 \mathrm{n}^{2}}\left(1+\frac{\mathrm{n}}{\mathrm{c}}\right)$. Assumindo então $\mathrm{M}=\mathrm{Kf}_{\mathrm{y}} \frac{\mathrm{pt}^{2}}{4}$ e $\gamma=1,5$, onde $K$ é o fator que relaciona $M$ com o 
momento de plastificação na junção mesa-alma e $f_{y}$ é a tensão ao escoamento da mesa, tem-se:

$$
\mathrm{n}=\mathrm{t} \sqrt{\frac{\beta \mathrm{p}_{0}}{\mathrm{Kf}_{\mathrm{y}}}\left(1+\frac{\mathrm{n}}{\mathrm{c}}\right)}
$$

Quando as rótulas plásticas são assumidas na junção mesa-alma e junto ao eixo do parafuso, o momento junto ao eixo do parafuso é igual a:

$$
\mathrm{M}_{\mathrm{B}}=\mathrm{Qn}=\frac{\mathrm{f}_{\mathrm{y}}}{\gamma} \frac{\mathrm{pt}^{2}}{4} \text { e } \gamma=1,5
$$

Se a inclinação da mesa em $A$ é nula:

$$
\delta_{\mathrm{B}}=\frac{\mathrm{Qn}^{3}}{6 \mathrm{EI}}
$$

Pelas expressões 5.3.26 e 5.3.27 e se $\delta_{B}=\frac{\beta p_{0} t}{3 E}$ como anteriormente estabelecido, e sabendo que $\mathrm{I}=\frac{\mathrm{pt}^{3}}{12}$, tem-se:

$$
n=t \sqrt{\frac{\beta p_{0}}{f_{y}}}
$$

As análises simplificadas ignoram efeitos, tal como a compressão local das chapas e deformações por cisalhamento. $\mathrm{Na}$ ausência de resultados de ensaios para calibração, é proposta que a seguinte expressão, para um máximo valor de $n$, seja usada no lugar das expressões 5.3.25 e 5.3.28:

$$
\mathrm{n}=1,1 \mathrm{t} \sqrt{\frac{\beta \mathrm{p}_{0}}{\mathrm{f}_{\mathrm{y}}}}
$$

Na prática, usando parafusos de alta resistência, são recomendados os valores $\mathrm{n}=1,5 \mathrm{t}$ para parafusos pré-tracionados e $\mathrm{n}=2,0 \mathrm{t}$ para parafusos colocados na condição de pré-torque. 
Um outro modelo teórico, adotado pelo AISC/LRFD 86 [ 3 ], para avaliar a força alavanca foi proposto por STRUIK \& BACK ${ }^{4}$ apud KULAK et al. [ 34 ], em 1969. Esse modelo é o mais utilizado, pois conduz a resultados mais próximos dos obtidos por ensaios, além de ser um dos modelos mais simples.

O modelo de viga mostrado na fig. 5-27, foi usado para descrever o efeito alavanca em um tê com sua mesa parafusada a uma base rígida. A aproximação não é restringida para específicas combinações de parafusos e chapas, desde que todos os parâmetros principais que influenciam o efeito alavanca são incluídos no modelo. A força alavanca $Q$ é assumida atuando na extremidade da mesa e admite-se a plastificação da seção 1-1. O momento fletor na interface entre a alma e a mesa é tomado como $M_{1}$, e o momento na linha do parafuso é tomado como $M_{2}$.

Por equilíbrio:

$\mathrm{M}_{1}+\mathrm{M}_{2}-\mathrm{Tb}=0$

O momento $M_{2}$ é dado por:

$\mathrm{M}_{2}=\mathrm{Qa}$

Também por equilíbrio:

$\mathrm{T}+\mathrm{Q}-\mathrm{B}=0$

onde: $\mathrm{T}=$ força de tração no parafuso sem incluir o efeito alavanca

$\mathrm{B}=$ força de tração no parafuso incluindo o efeito alavanca

\footnotetext{
${ }^{4}$ J. H. A. Struik and J. de Back, Testes on Bolted T-Stubs with Respect to a Bolted Beam-to-Column Connections, Reported 6-69-13, Stevin Laboratory, Delft University of Technology, Delft, the Netherlands, 1969.
} 


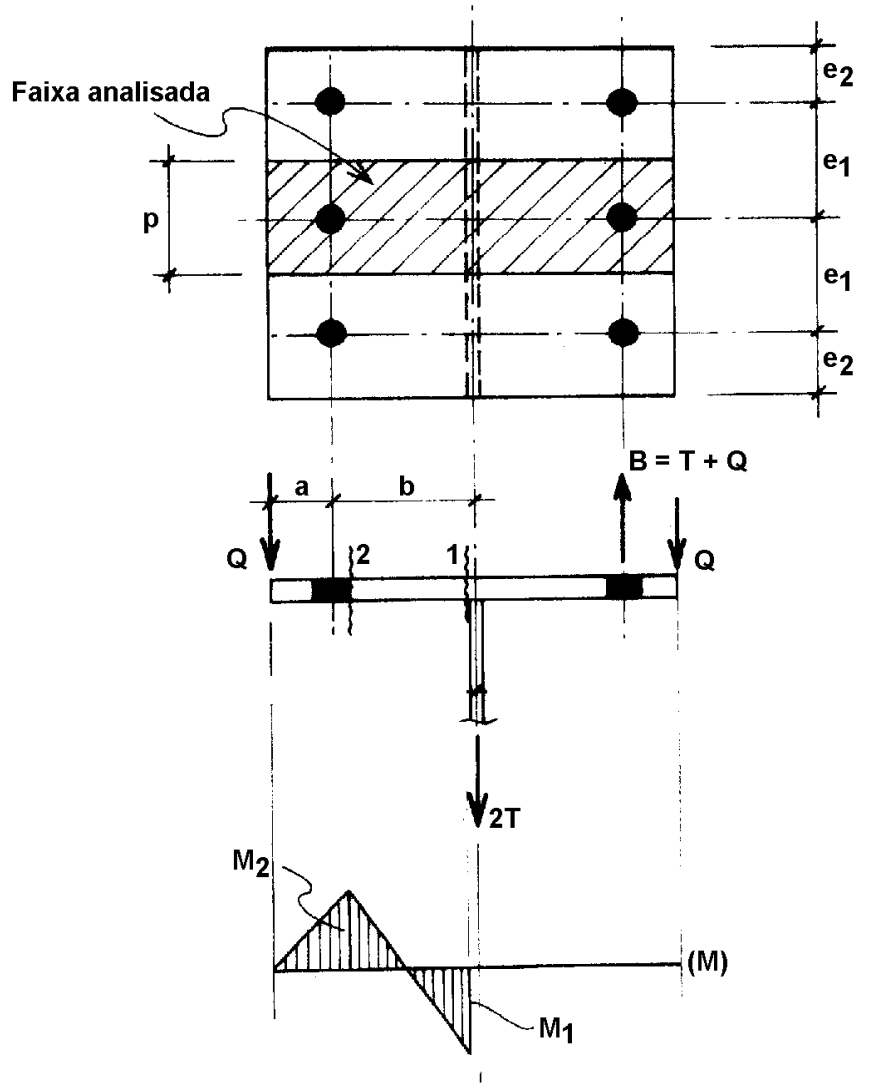

FIGURA 5-27 Efeito alavanca: modelo de viga. Adaptada de MALITE et al. [ 40 ].

Definido o parâmetro geométrico $\delta$ como sendo a relação entre a largura de contribuição líquida da mesa $\left(p-d^{\prime}\right)$ e a correspondente largura bruta $p$, pode-se definir também outro parâmetro, denominado $\alpha$, que é a relação $M_{2} / \delta M_{1}$. Portanto:

$$
\mathrm{M}_{2}=\alpha \delta \mathrm{M}_{1}
$$

onde: $\delta=1-\mathrm{d} ' / \mathrm{p}$

d' = diâmetro do furo, paralelo a alma do tê

$\mathrm{p}=$ largura de contribuição por par de parafusos (ver fig. 5-27) e é dada por:

- entre dois parafusos: $p=2 p_{1}$

- entre parafuso e borda: $\mathrm{p}=\mathrm{p}_{1}+\mathrm{p}_{2}$

Sendo $p_{1}$ o menor valor entre $e_{1} / 2$ ou $b+d / 2$ e $p_{2}$ o menor valor entre $e_{2}$ ou $b$ $+d / 2$ ( $d$ é o diâmetro nominal do parafuso).

Da expressão 5.3.30, $\mathrm{M}_{2}=\mathrm{Tb}-\mathrm{M}_{1}$, que substituindo na expressão 5.3.33 resulta:

$$
\alpha=\frac{\mathrm{M}_{2}}{\delta \mathrm{M}_{1}}=\frac{\mathrm{Tb}-\mathrm{M}_{1}}{\delta \mathrm{M}_{1}}
$$


Por hipótese, o momento fletor na seção 1-1 $M_{l}$ é igualado à resistência de cálculo ao momento fletor (plastificação total), resultando::

$$
\mathrm{M}_{1}=\phi_{\mathrm{b}} \mathrm{M}_{\mathrm{n}}=0,9\left(\mathrm{Zf}_{\mathrm{y}}\right)=0,9\left(1,5 \mathrm{Wf}_{\mathrm{y}}\right)=0,9\left(1,5 \frac{\mathrm{pt}^{2}}{6} \mathrm{f}_{\mathrm{y}}\right)
$$

Analisando os valores de $\alpha$ obtidos pela expressão 5.3.34, conclui-se que:

- se $\alpha>1 \Rightarrow M_{2}>\delta M_{1}$, ou seja, a condição de resistência não é verificada, significa que o momento $M_{2}$ é maior que o momento resistente de cálculo (plastificação total da seção).

- se $\alpha<0 \Rightarrow$ não há efeito alavanca, ou seja, a hipótese adotada não se verificou.

- se $0<\alpha<1 \Rightarrow$ a hipótese adotada se verifica e a força alavanca $Q$ é obtida pelas expressões 5.3.30 e 5.3.31:

$$
\mathrm{Q}=\frac{\mathrm{Tb}-\mathrm{M}_{1}}{\mathrm{a}}
$$

De modo a se obter uma mínima espessura de chapa $t_{\min }$ para que não ocorra o efeito alavanca, ou seja, $\mathrm{Q}=0$, basta igualar o parâmetro $\alpha$ a zero na expressão 5.3.34 e utilizar a expressão 5.3.35:

$$
\begin{aligned}
& \mathrm{M}_{1}=\phi_{\mathrm{b}} \mathrm{M}_{\mathrm{n}}=\mathrm{Tb} \\
& \mathrm{Tb}=0,9\left(1,5 \frac{\mathrm{pt}^{2}}{6} \mathrm{f}_{\mathrm{y}}\right) \therefore \mathrm{t}_{\text {min }}=\sqrt{\frac{4,44 \mathrm{~Tb}}{\mathrm{pf}_{\mathrm{y}}}}
\end{aligned}
$$

Como uma alternativa, THORNTON [ 70 ] em 1985 recomendou o cálculo de um parâmetro $\beta$ :

$$
\beta=\frac{\mathrm{a}}{\mathrm{b}}\left(\frac{\mathrm{B}_{\mathrm{R}}}{\mathrm{T}}-1\right)
$$

onde: $B_{R}=$ resistência de cálculo à tração do parafuso

Então $\alpha$ é tomado da seguinte maneira: 
se $\beta \geq 1$ adotar $\alpha=1$ (significa a maior força alavanca possível pelo modelo) se $\beta<1$ adotar $\alpha$ como sendo o menor valor entre $\frac{1}{\delta}\left(\frac{\beta}{1-\beta}\right)$ e 1,0

Esse valor de $\alpha$, segundo o AISC/LRFD 86 [ 3 ] é usado para determinar a

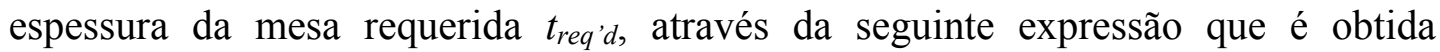
substituindo a expressão 5.3.33 na expressão 5.3.30, obtendo $\mathrm{M}_{1}=\frac{\mathrm{Tb}}{1+\alpha \delta}$, que por sua vez é substituída na expressão 5.3.35, resultando:

$$
\mathrm{t}_{\text {req'd }}=\sqrt{\frac{4,44 \mathrm{~Tb}}{\mathrm{pf}_{\mathrm{y}}(1+\delta \alpha)}}
$$

se $t_{\text {req'd }} \leq t$, espessura da mesa é adequada

se $t_{\text {req'd }}>t$, espessura da mesa inadequada - adotar espessura maior ou enrijecedores

onde: t: espessura da mesa disponível

Para se determinar a força alavanca, o AISC/LRFD 86 [ 3 ] utiliza a seguinte formulação:

$$
\alpha=\frac{1}{\delta}\left[\frac{T / B_{R}}{\left(t / t_{c}\right)^{2}}-1\right]
$$

onde: $\mathrm{t}_{\mathrm{c}}=$ espessura da mesa para desenvolver a resistência $B_{R}$ nos parafusos sem efeito alavanca $=\sqrt{\frac{4,44 \mathrm{~B}_{\mathrm{R}} \mathrm{b}}{\mathrm{pf}_{\mathrm{y}}}}$

Se $\alpha<0$ usar $\alpha=0$, deste modo:

$$
\mathrm{Q}=\mathrm{B}_{\mathrm{R}} \delta \alpha \frac{\mathrm{b}}{\mathrm{a}}\left(\frac{\mathrm{t}}{\mathrm{t}_{\mathrm{c}}}\right)^{2}
$$

Deve-se notar que o AISC/LRFD 86 [ 3 ] considera o valor de $p$ como o comprimento da mesa, paralelo a alma, contribuindo para cada parafuso e a distância 
$a$, que é a distância do eixo do parafuso à extremidade da mesa do tê não deve ser maior que $1,25 b$.

De acordo com KULAK et al. [ 34 ], resultados experimentais e a relação alavanca $Q / T$, obtida através desse método, são comparadas na fig. 5-28 para diferentes tipos de parafusos.

Da figura 5-28 pode-se notar que a força alavanca avaliada por este modelo apresenta valores relativamente elevados. Esta diferença pode ser atribuída principalmente ao encruamento do aço (strain-hardening) e à distribuição da pressão de contato.

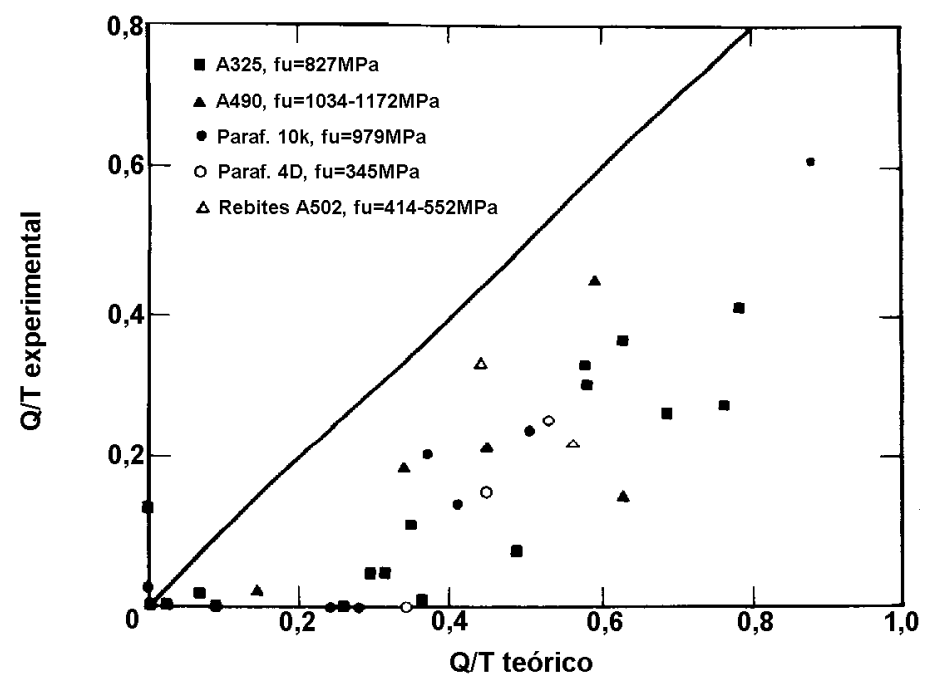

FIGURA 5-28 Comparação entre razões Q/T teóricas e analíticas. Adaptada de KULAK et al. [ 34 ].

O modelo assume que a força $B$ no parafuso tem como linha de ação o seu eixo longitudinal. Entretanto, devido à deformação da mesa, esta força tem sua linha de ação deslocada, devendo situar-se entre o eixo do parafuso e a extremidade de sua cabeça (fig. 5-29a). Isto diminui a distância $b$ e influencia a relação $Q / T$ diretamente.

Tendo em vista esta observação, a formulação deste modelo foi corrigida adotando valores modificados de $a$ e $b$, mostrados na fig. 5-29a e definidos como: $a$ ' $=a+d / 2$ e $b^{\prime}=b-d / 2$.

Ensaios têm indicado que esta é uma hipótese razoável, quando a distância do parafuso à borda da mesa não é muito maior que a distância $b$. Portanto, como já mencionado, é recomendado que essa distância de extremidade seja limitada em $1,25 b$. 


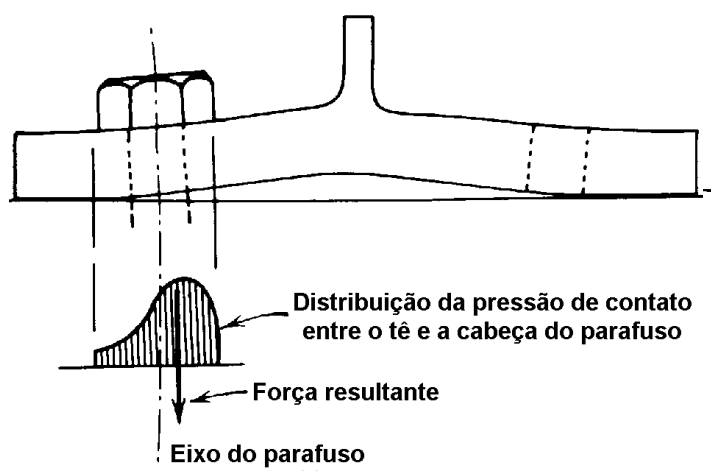

(a)

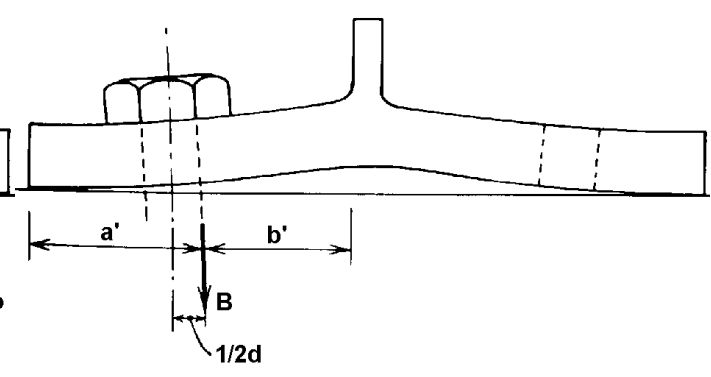

(b)

FIGURA 5-29 (a) Influência das deformações da mesa na localização da força resultante no parafuso; (b) definição de b' e a'. Adaptada de KULAK et al. [34 ].

Como ilustrado na fig. 5-30a, a força alavanca calculada com as dimensões modificadas apresenta-se em maior conformidade com resultados experimentais, resultando ainda em valores conservadores para a maioria dos casos.

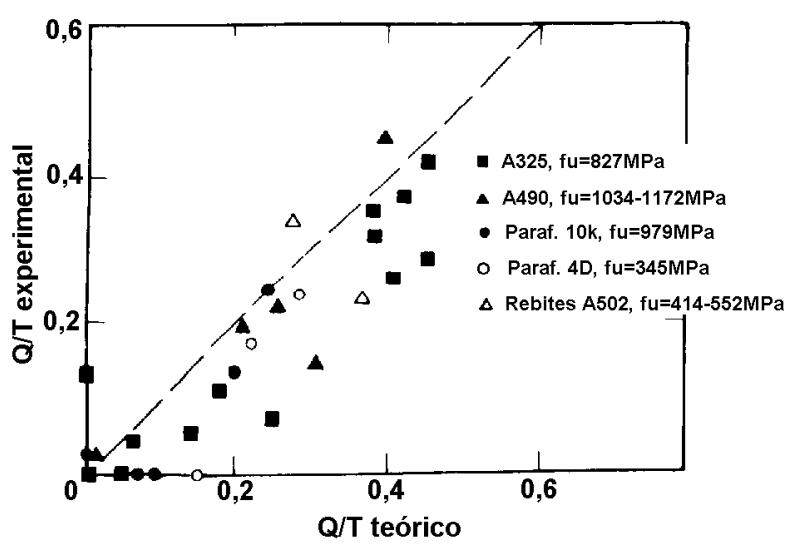

FIGURA 5-30 Comparação entre razões Q/T analíticas e experimentais com as distâncias modificadas. Adaptada de KULAK et al. [ 34 ].

Para exemplificar a aplicação dos modelos apresentados, foi desenvolvido o seguinte exemplo (fig. 5-31), considerando: (1) modelo de Struik e Back (AISC), (2) modelo de McCauley e (3) modelo de Douty e McGuire.

- aço ASTM A36

- parafusos ASTM A325 - diâmetro 16 mm e furos padrão 

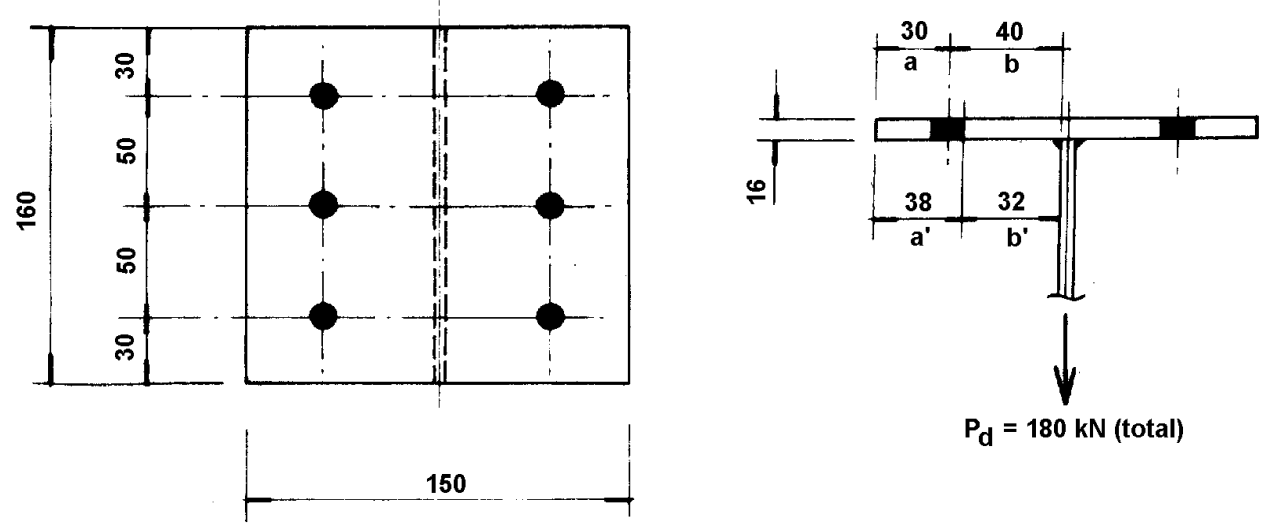

FIGURA 5-31 Conexão do exemplo para a avaliação do efeito alavanca. Adaptada de MALITE et al. [ 40 ].

Modelo (1), utilizando as distâncias modificadas $a^{\prime}$ e $b^{\prime}$.

Distâncias de referência:

$\mathrm{a}^{\prime}=\mathrm{a}+\mathrm{d} / 2=30+16 / 2=38 \mathrm{~mm}$

$b^{\prime}=b-d / 2=40-16 / 8=32 \mathrm{~mm}$

Largura de contribuição $p$ :

$\mathrm{p}_{1}$ é o menor valor entre $50 / 2$ ou $40+16 / 2 \therefore \mathrm{p}_{1}=25 \mathrm{~mm}$

$\mathrm{p}_{2}$ é o menor valor entre 30 ou $40+16 / 2 \therefore \mathrm{p}_{2}=30 \mathrm{~mm}$

- para parafusos centrais: $\mathrm{p}=2 \mathrm{p}_{1}=50 \mathrm{~mm}$ (crítico)

- para parafusos extremos: $p=p_{1}+p_{2}=55 \mathrm{~mm}$

Força de tração por parafuso:

$\mathrm{T}_{\mathrm{d}}=180 / 6=30 \mathrm{kN}$ por parafuso

Parâmetro geométrico $\delta$ :

$\delta=1-d^{\prime} / p=1-(16+1,5) / 50=0,65$

O momento resistente de cálculo (plastificação) pela expressão 5.3.35 é:

$\mathrm{M}_{1}=0,9\left(1,5 \frac{\mathrm{pt}^{2}}{6} \mathrm{f}_{\mathrm{y}}\right)=0,9\left(1,5 \frac{5 \mathrm{x} 1,6^{2}}{6} 25\right)=72 \mathrm{kN} . \mathrm{cm}$

O parâmetro $\alpha$ pela expressão 5.3.34 é: 


$$
\alpha=\frac{\mathrm{Tb}^{\prime}-\mathrm{M}_{1}}{\delta \mathrm{M}_{1}}=\frac{30 \times 3,2-72}{0,65 \times 72}=0,51<1,0 \quad \text { OK }
$$

Com isso, a força alavanca pela expressão 5.3.36 é:

$$
\mathrm{Q}=\frac{\mathrm{Tb}^{\prime}-\mathrm{M}_{1}}{\mathrm{a}^{\prime}}=\frac{30 \times 3,2-72}{3,8}=6,32 \mathrm{kN}
$$

Utilizando agora a alternativa indicada pelo AISC/LRFD 86 [ 3 ], tem-se através da expressão 5.3.39, o valor de $\beta$ :

$$
\beta=\frac{\mathrm{a}^{\prime}}{\mathrm{b}^{\prime}}\left(\frac{\mathrm{B}_{\mathrm{R}}}{\mathrm{T}}-1\right)=\frac{38}{32}\left(\frac{91,9}{30}-1\right)=2,45>1 \quad \therefore \quad \alpha=1
$$

onde: $\quad B_{R}=\phi_{t} R_{n t}=0,75 \times 0,75 \times 1,98 \times 82,5=91,9 \mathrm{kN}$

Calculando a espessura requerida para a mesa, pela expressão 5.3.40:

$$
\mathrm{t}_{\text {req'd }}=\sqrt{\frac{4,44 \mathrm{~Tb}^{\prime}}{\mathrm{pf}_{\mathrm{y}}(1+\delta \alpha)}}=\sqrt{\frac{4,44 \times 30 \times 32}{50 \times 25 \mathrm{x}(1+0,65 \times 1)}}=1,44 \mathrm{~cm}<1,6 \mathrm{~cm} \quad \text { OK }
$$

Determinando o valor de $\alpha$ pela expressão 5.3.41 para determinar a força alavanca:

$$
\begin{aligned}
& \mathrm{t}_{\mathrm{c}}=\sqrt{\frac{4,44 \mathrm{~B}_{\mathrm{R}} \mathrm{b}^{\prime}}{\mathrm{pf}_{\mathrm{y}}}}=\sqrt{\frac{4,44 \times 91,9 \times 32}{50 \times 25}}=3,23 \mathrm{~cm} \\
& \alpha=\frac{1}{\delta}\left[\frac{\mathrm{T} / \mathrm{B}_{\mathrm{R}}}{\left(\mathrm{t} / \mathrm{t}_{\mathrm{c}}\right)^{2}}-1\right]=\frac{1}{0,65}\left[\frac{30 / 91,9}{(1,6 / 3,23)^{2}}-1\right]=0,51
\end{aligned}
$$

Deste modo a força alavanca, pela expressão 5.3.42 é:

$$
\mathrm{Q}=\mathrm{B}_{\mathrm{R}} \delta \alpha \frac{\mathrm{b}^{\prime}}{\mathrm{a}^{\prime}}\left(\frac{\mathrm{t}}{\mathrm{t}_{\mathrm{c}}}\right)^{2}=91,9 \times 0,65 \times 0,51 \frac{32}{38}\left(\frac{1,6}{3,23}\right)^{2}=6,27 \mathrm{kN}
$$

Deve-se notar que os valores de $\alpha$ e $Q$ obtidos pelas expressões 5.3 .41 e 5.3.42, respectivamente, são os mesmos obtidos pelas expressões 5.3.34 e 5.3.36. 


\section{Modelo (2)}

Inicialmente é necessário determinar a posição da força alavanca que é o menor valor entre a distância do eixo do parafuso à borda e $n$ que é dado pela expressão 5.3.29:

$$
\mathrm{n}=1,1 \mathrm{t} \sqrt{\frac{\beta \mathrm{p}_{0}}{\mathrm{f}_{\mathrm{y}}}}=1,1 \times 16 \sqrt{\frac{2 \times 512}{250}}=35,6 \mathrm{~mm}>30 \mathrm{~mm} \quad \therefore \quad \mathrm{n}=30 \mathrm{~mm}
$$

Pela expressão simplificada 5.3.22, tem-se a força alavanca:

$$
\mathrm{Q}=\frac{\mathrm{Tb}}{2 \mathrm{n}}=\frac{30 \times 40}{2 \times 30}=20,00 \mathrm{kN}
$$

Pela expressão não simplificada 5.3.21 tem-se:

$$
\begin{aligned}
& \mathrm{Q}=\frac{\mathrm{b}}{2 \mathrm{n}}\left(\mathrm{T}-\frac{\beta \gamma \mathrm{p}_{0} \mathrm{pt}^{4}}{27 \mathrm{nb}^{2}}\right)=\frac{40}{2 \times 30}\left(30-\frac{2 \times 1,5 \times 0,512 \times 50 \times 16^{4}}{27 \times 30 \times 40^{2}}\right)=\frac{2}{3}(30-3,88) \\
& \mathrm{Q}=17,41 \mathrm{kN}
\end{aligned}
$$

\section{Modelo 3}

Pela expressão 5.3.8 pode-se diretamente determinar a força alavanca, com dimensões fornecidas em polegadas:

$$
\begin{aligned}
& \frac{\mathrm{Q}}{\mathrm{T}}=\frac{100 \mathrm{bd}^{2}-18 \mathrm{pt}^{2}}{70 \mathrm{ad}^{2}+21 \mathrm{pt}^{2}}=\frac{100(40 / 25,4)(5 / 8)^{2}-18(50 / 25,4)(16 / 25,4)^{2}}{70(30 / 25,4)(5 / 8)^{2}+21(50 / 25,4)(16 / 25,4)^{2}} \\
& \frac{\mathrm{Q}}{\mathrm{T}}=0,974 \quad \therefore \mathrm{Q}=29,52 \mathrm{kN}
\end{aligned}
$$

Pela expressão simplificada 5.3.2 a força alavanca é:

$$
\begin{aligned}
& \frac{\mathrm{Q}}{\mathrm{T}}=\left(\frac{3 \mathrm{~b}}{8 \mathrm{a}}-\frac{\mathrm{t}^{3}}{20}\right)=\left(\frac{3 \times 40}{8 \times 30}-\frac{(16 / 25,4)^{3}}{20}\right) \\
& \frac{\mathrm{Q}}{\mathrm{T}}=0,487 \therefore \mathrm{Q}=14,63 \mathrm{kN}
\end{aligned}
$$

TABELA 5-3 Quadro resumo das forças alavanca.

\begin{tabular}{|l|c|}
\hline \multicolumn{1}{|c|}{ MODELO } & FORÇA ALAVANCA Q (kN) \\
\hline $\begin{array}{l}\text { (1) Struik e Back } \\
\text { expressões 5.3.36 ou 5.3.42 }\end{array}$ & 6,32 \\
\hline
\end{tabular}




\begin{tabular}{|l|c|}
\hline (2) McCauley & 17,41 \\
expressão 5.3.21 & 20,00 \\
expressão 5.3.22 (simplificada) & \\
\hline (3) Douty e McGuire & 29,52 \\
expressão 5.3.8 & 14,63 \\
\hline expressão 5.3.2 (simplificada) & \\
\hline
\end{tabular}

Pode-se notar as grandes diferenças encontradas para a força alavanca segundo os vários modelos analisados. Tais diferenças são justificáveis tendo em vista o caráter simplista das hipóteses adotadas para a representação de um fenômeno físico “complicado". O modelo de viga, proposto por Struik e Back e recomendado pelo AISC conduziu aos menores valores da força alavanca e conforme pode ser visualizado na fig. 5-30 trata-se de um modelo conservador para a maioria dos casos analisados. 


\section{CAPÍTULO 6 - CONEXÕES SOLDADAS SUJEITAS A CARREGAMENTO EXCÊNTRICO}

Assim como nas conexões parafusadas, quando a linha de ação da força passa pelo centro de gravidade do grupo de soldas, é razoável admitir distribuição uniforme de tensões, caso contrário, tem-se uma situação de carregamento excêntrico (fig. 6-1) e tal ocorrência deve ser admitida no projeto.

$\mathrm{Na}$ conexão da fig. 6-1a, a força excêntrica está contida no plano do grupo de soldas, portanto trata-se de uma situação de força cortante associada a um momento de torção relacionados ao referido grupo de solda. Já na fig. 6-1b, onde a força não está contida no plano do grupo de soldas, tem-se uma situação de força cortante associada a momento fletor. Em ambos os casos, as tensões adicionais provenientes do momento devem ser avaliadas e consideradas no projeto.

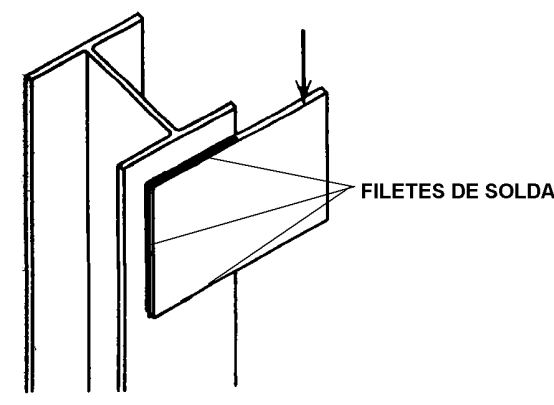

(a) Força no plano das soldas

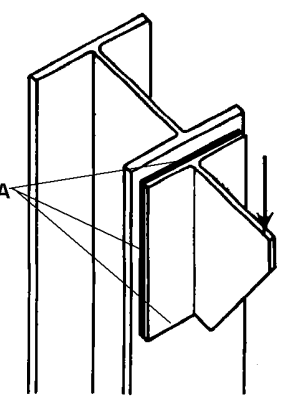

(b) Força fora do plano das soldas

FIGURA 6-1 Conexões soldadas com carregamento excêntrico. Adaptada de CRAWLEY \& DILLON [ 19]

\subsection{Grupo de soldas sob força cortante e momento de torção}

Conforme já mencionado no capítulo anterior, a clássica análise vetorial elástica, apesar da simplicidade de aplicação, muitas vezes conduz a resultados muito conservadores se comparados aos obtidos pelo método do centro instantâneo de rotação e os obtidos experimentalmente.

No caso de grupo de soldas carregados excentricamente, as hipóteses do método vetorial elástico são as mesmas já apresentadas para o caso das conexões parafusadas. Segundo SALMON \& JOHNSON [ 60 ], a força excêntrica é substituída por uma força centrada e um correspondente momento de torção, onde a 
força cortante é equilibrada por tensões uniformemente distribuídas ao longo da solda e o momento de torção equilibrado por tensões proporcionais à distância em relação ao centro de gravidade do grupo de soldas e com direção perpendicular ao correspondente raio vetor. A tensão resultante, num determinado ponto, é dada pela soma vetorial destas duas parcelas.

A figura 6-2a mostra, para exemplificar, uma solda constituída por dois cordões verticais. A força excêntrica $P$, dividida em suas componentes $P_{x}$ e $P_{y}$, estão no plano das soldas. Na fig. 6-2b as forças excêntricas são substituídas pelas forças concêntricas $P_{x}$ e $P_{y}$, mais os momentos $\mathrm{M}_{\mathrm{x}}=\mathrm{P}_{\mathrm{x}} \mathrm{e}_{\mathrm{y}}$ e $\mathrm{M}_{\mathrm{y}}=\mathrm{P}_{\mathrm{y}} \mathrm{e}_{\mathrm{x}}$. As forças concêntricas são assumidas como sendo uniformemente distribuídas no comprimento total do grupo de soldas. Deste modo, segundo CRAWLEY \& DILLON [ 19 ], designando $F_{x}$ e $F_{y}$ como as forças por comprimento de solda, resultantes apenas das forças $P_{x}$ e $P_{y}$, concêntricas, tem-se:

$$
\mathrm{F}_{\mathrm{x}}=\frac{\mathrm{P}_{\mathrm{x}}}{\mathrm{L}} \quad \text { e } \quad \mathrm{F}_{\mathrm{y}}=\frac{\mathrm{P}_{\mathrm{y}}}{\mathrm{L}}
$$

onde: $\mathrm{L}=$ comprimento total do grupo de soldas

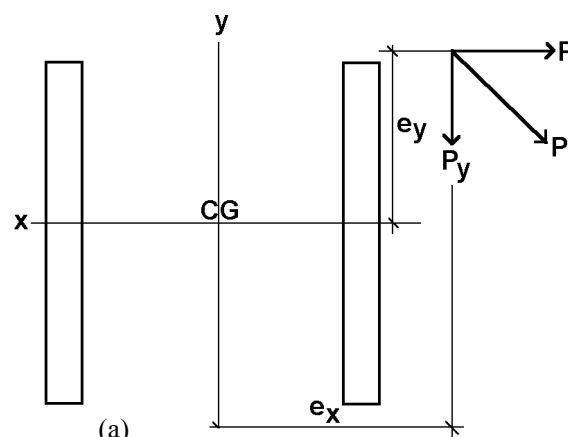

(a)
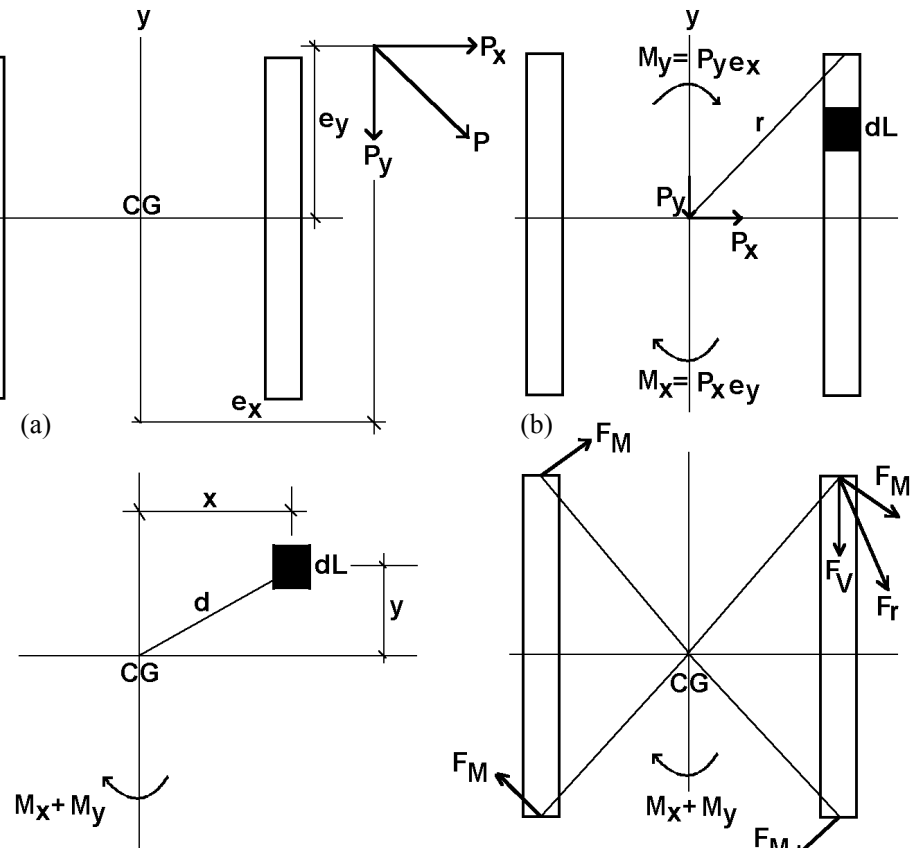

(c)

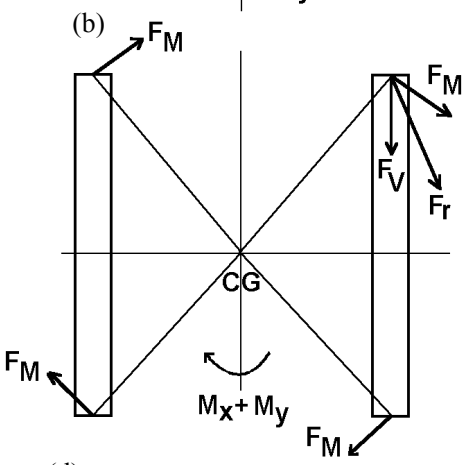

(d)

FIGURA 6-2 Excentricidade no plano das soldas. Adaptada de CRAWLEY \& DILLON [ 19 ].

Em adição às forças $F_{x}$ e $F_{y}$, existem as forças $F_{M x}$ e $F_{M y}$ que resultam do momento. Uma porção elementar de solda $d L$, é mostrada na fig. 6-2c. Este elemento 
pode ser qualquer porção de comprimento da solda, localizado à uma distância $d$ do centro de gravidade do conjunto de soldas, tendo coordenadas $x$ e $y$.

Em se tratando de uma análise elástica, a deformação é proporcional à distância em relação ao centro de gravidade, e a tensão é proporcional à deformação. Assim, a força unitária $F_{M}$ também é proporcional à distância em relação ao centro de gravidade, com isso:

$$
\mathrm{F}_{\mathrm{M}}=\mathrm{F}_{0} \mathrm{~d}=\mathrm{F}_{0} \sqrt{\mathrm{x}^{2}+\mathrm{y}^{2}}
$$

onde: $\mathrm{F}_{0}=$ força por comprimento de solda localizada à uma distância unitária do CG do grupo de soldas

A força neste comprimento elementar é $F_{M}(d L)$ e o momento:

$$
\mathrm{dM}_{\mathrm{y}}+\mathrm{dM}_{\mathrm{x}}=\mathrm{F}_{\mathrm{M}}(\mathrm{dL}) \mathrm{d}
$$

onde: $\mathrm{dM}_{\mathrm{x}}, \mathrm{dM}_{\mathrm{y}}=$ momento devido às forças

Substituindo a equação 6.1.2 na equação 6.1.3 tem-se:

$\mathrm{dM}_{\mathrm{y}}+\mathrm{dM}_{\mathrm{x}}=\mathrm{F}_{0}\left(\mathrm{x}^{2}+\mathrm{y}^{2}\right) \mathrm{dL}$

O momento total na solda é a soma dos efeitos de todas as porções elementares, e este deve ser igual ao momento aplicado para estabelecer equilíbrio, assim:

$$
\mathrm{M}_{\mathrm{y}}+\mathrm{M}_{\mathrm{x}}=\sum\left[\mathrm{F}_{0}\left(\mathrm{x}^{2}+\mathrm{y}^{2}\right) \mathrm{dL}\right]
$$

Sabendo que a força $F_{0}$ é constante para qualquer configuração de solda, temse:

$$
F_{0}=\frac{M_{y}+M_{x}}{\sum x^{2} d L+\sum y^{2} d L}
$$

Cada termo do denominador da expressão 6.1.6, deve ser reconhecido como o momento de inércia total da linha das soldas, com relação aos eixos $y$ e $x$, com isso:

$$
F_{0}=\frac{M_{y}+M_{x}}{I_{y}+I_{x}}
$$


A máxima força na solda ocorre no ponto mais afastado em relação ao centro de gravidade, e sua direção é perpendicular à linha que une esse ponto ao CG. O comprimento $r$ na fig. 6-2b representa esta distância, e a força $F_{M}$ representa a máxima força por comprimento de solda, portanto:

$$
F_{M}=\frac{M_{y}+M_{x}}{I_{y}+I_{x}} r
$$

Sabendo que $\mathrm{M}_{\mathrm{y}}=\mathrm{P}_{\mathrm{y}} \mathrm{e}_{\mathrm{x}}$ e $\mathrm{M}_{\mathrm{x}}=\mathrm{P}_{\mathrm{x}} \mathrm{e}_{\mathrm{y}}$ e $\mathrm{I}_{\mathrm{y}}+\mathrm{I}_{\mathrm{x}}=\mathrm{I}_{\mathrm{p}}$, tomando as componente $x \mathrm{e}$ $y$ de $F_{M}$ tem-se:

$$
F_{M x}=\frac{P_{y} e_{x}+P_{x} e_{y}}{I_{p}} r \frac{y}{r} \quad \text { e } \quad F_{M y}=\frac{P_{y} e_{x}+P_{x} e_{y}}{I_{p}} r \frac{x}{r}
$$

Sendo $x$ e $y$ as componentes de $r$, e Ip o momento de inércia polar, que é dado por:

$$
\mathrm{I}_{\mathrm{p}}=\mathrm{I}_{\mathrm{x}}+\mathrm{I}_{\mathrm{y}}=\sum \mathrm{I}_{\mathrm{xx}}+\sum 1_{\mathrm{s}} \mathrm{y}^{2}+\sum \mathrm{I}_{\mathrm{yy}}+\sum 1_{\mathrm{s}} \mathrm{x}^{2}
$$

onde: $x^{2}, y^{2}=$ distâncias ao quadrado do centro de gravidade do grupo de soldas ao centro de gravidade dos segmentos de soldas individuais

$1_{\mathrm{s}}=$ comprimento da solda

$\mathrm{I}_{\mathrm{xx}}, \mathrm{I}_{\mathrm{yy}}=$ momentos de inércia das linhas de soldas individuais, com respeito a seus próprios eixos centroidais (admitindo-se espessura unitária)

É importante registrar que no cálculo do momento de inércia a espessura da solda é considerada unitária, portanto resulta um momento de inércia com unidade de comprimento ao cubo. Assim, obtém-se a força resultante $F_{r}$ (para espessura unitária) mediante a soma vetorial das parcelas provenientes da força concêntrica e do momento de torção (ver fig. 6-2d).

A tensão num determinado ponto da solda pode ser obtida dividindo-se a força unitária resultante $F_{r}$ pela espessura.

$$
\mathrm{F}_{\mathrm{r}}=\sqrt{\left(\mathrm{F}_{\mathrm{x}}+\mathrm{F}_{\mathrm{Mx}}\right)^{2}+\left(\mathrm{F}_{\mathrm{y}}+\mathrm{F}_{\mathrm{My}}\right)^{2}}
$$


Essa soma vetorial não deverá exceder a resistência da solda no ponto crítico, levando em consideração a ruptura da solda na seção efetiva e o escoamento do metal base na face de fusão.

A análise elástica clássica é baseada na hipótese que a resposta da solda não varia com a orientação da força em relação ao eixo longitudinal da solda. $\mathrm{Na}$ realidade, como já apresentado e discutido, a resposta da solda varia consideravelmente com a direção da força. Diante deste fato, OWENS \& CHEAL [ 50 ] apresentam um procedimento aproximado para a verificação de grupo de soldas sob carregamento excêntrico, onde os cordões de soldas são admitidos solicitados na direção de sua maior resistência, ou seja, perpendicularmente ao seu eixo longitudinal.

Por exemplo, na fig. 6-3, o cordão vertical é responsável por equilibrar o momento $M$ e os cordões horizontais, a força $P$.
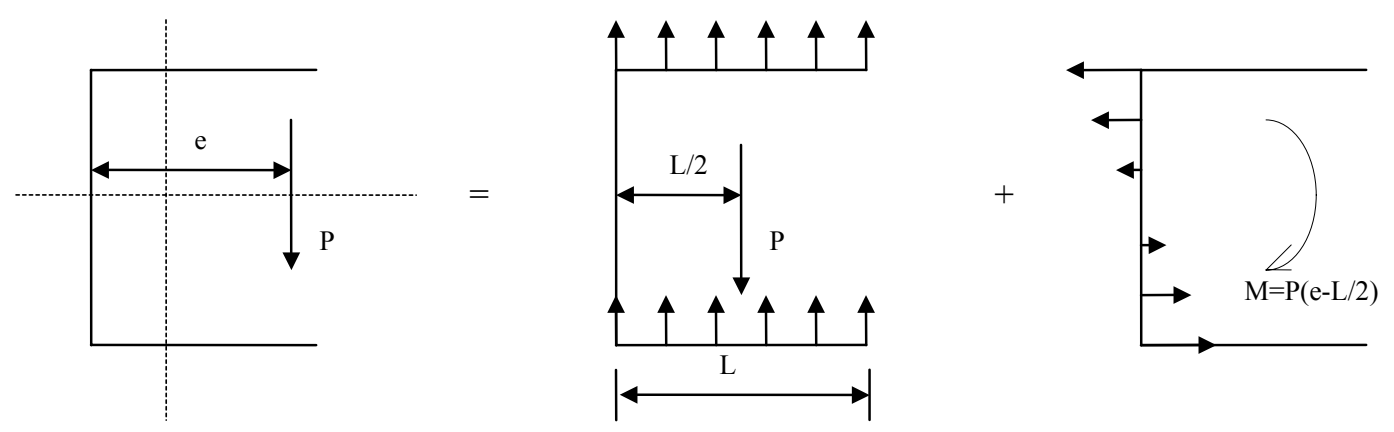

FIGURA 6-3 Análise do grupo de soldas apresentada em OWENS \& CHEAL [ 50 ].

SALMON \& JOHNSON [ 60 ] apresentam a análise de grupo de soldas sob carregamento excêntrico com base no método do centro instantâneo de rotação (CIR), de maneira similar à apresentada para o caso de conexões parafusadas. Desta forma, a resistência de uma configuração de cordões de solda solicitados excentricamente, pode ser determinada pela localização do centro instantâneo de rotação, usando a relação força-deformação do cordão de solda. De um modo diferente à conexões parafusadas, onde a relação força-deformação independe da direção da força, cujo cisalhamento atua na seção transversal circular do parafuso, a resistência do cordão de solda depende do ângulo entre a força aplicada e o eixo da solda. 
O mais recente trabalho de KULAK \& TIMMLER ${ }^{5}$ apud SALMON \& JOHNSON [ 60 ], formam as bases da apresentação que se segue. A formulação utilizada no AISC/LRFD [ 3 ] de 1986, também é baseada nesse trabalho.

O procedimento consiste em dividir os cordões de solda em pequenos elementos, como na fig. 6-4. Quando a força excêntrica causa translação e rotação do conjunto, haverá algum ponto sobre o qual haverá apenas rotação. Esse ponto de rotação é chamado de centro instantâneo de rotação. A resistência de um segmento de solda à qualquer distância do centro instantâneo, é proporcional a tal distância e atua em uma direção perpendicular à direção radial do segmento. Segundo GAYLORD et al. [ 27 ], baseado em resultados de ensaios de conexões feitas com eletrodos E70, com soldas de 1/4”, tem-se que a resistência última pode ser expressa por:

$$
\mathrm{R}_{\mathrm{i}, \mathrm{ult}}=\frac{(10+\theta)}{10+0,582 \theta}\left(0,791 \mathrm{f}_{\mathrm{w}} \mathrm{a}\right)
$$

onde: $\mathrm{R}_{\mathrm{i} \text {,ult }}=$ força última de cisalhamento em um elemento de comprimento unitário, em kips por polegada $\theta=$ ângulo agudo entre a força e o eixo da solda, em graus $\mathrm{f}_{\mathrm{w}}=$ resistência do eletrodo de solda, em ksi $\mathrm{a}=$ dimensão da garganta efetiva da solda, em polegadas

\footnotetext{
${ }^{5}$ KULAK, G. L., TIMMLER, P. A. "Tests on Eccentrically Loaded Fillet Welds," Structural Engineering Report No. 124, Department of Civil Engineering, University of Alberta, Edmonton, Alberta, December, 1984 (23pp).
} 


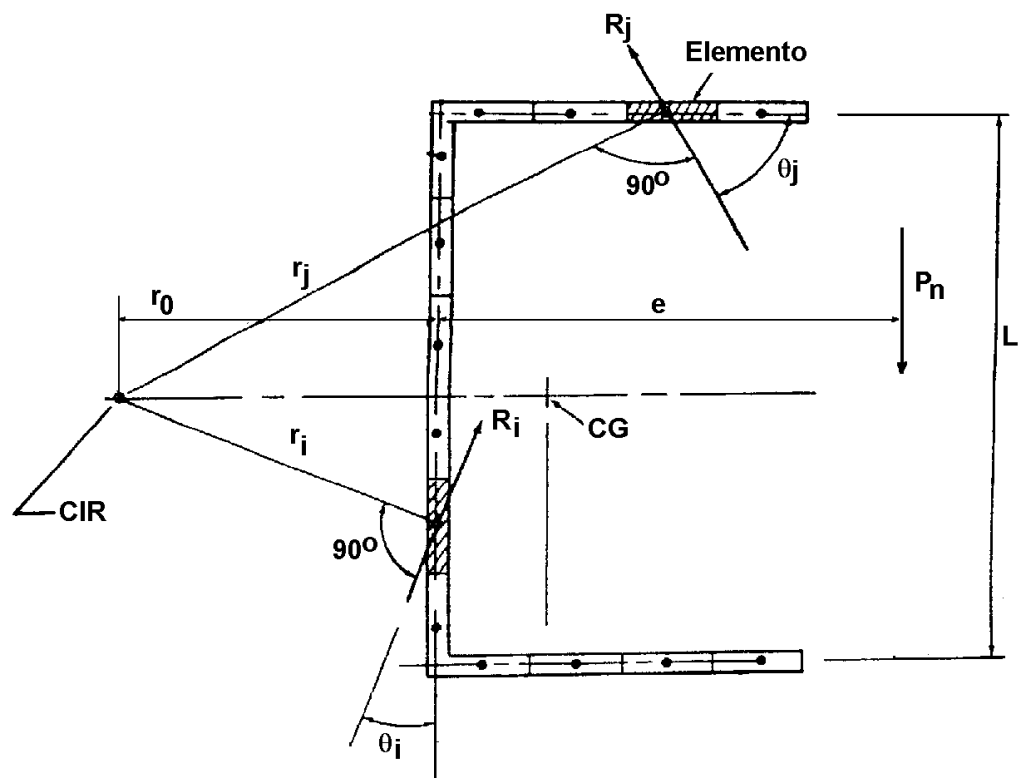

FIGURA 6-4 Grupo de soldas sob carregamento excêntrico: método do centro instantâneo de rotação. Adaptada de SALMON \& JOHNSON [ 60 ].

A deformação $\Delta_{i, \max }$, na ruptura, em um elemento é avaliada por:

$$
\Delta_{\mathrm{i}, \max }=\Delta_{0}(\theta / 5+1)^{-0,47}
$$

onde: $\Delta_{0}=0,11$ ", que é a deformação para $\theta=0$, valor este baseado em ensaios

É necessário primeiro determinar o elemento crítico. Devido as deformações nos segmentos de solda serem assumidas variando linearmente com suas distâncias $r_{i}$ em relação ao centro instantâneo, o elemento com o menor valor de $\Delta_{\mathrm{i}, \max } / \mathrm{r}_{\mathrm{i}}$ será o crítico. Com o elemento crítico determinado, as deformações $\Delta_{i}$ nos outros elementos é dada por:

$$
\Delta_{\mathrm{i}}=\frac{\mathrm{r}_{\mathrm{i}}}{\mathrm{r}_{\mathrm{i}, \max }} \Delta_{\mathrm{i}, \max }
$$

onde: $\Delta_{\mathrm{i}, \max }=$ valor da deformação no elemento crítico

$r_{i, \max }=$ distância radial do elemento crítico

Com as deformações determinadas pela expressão 6.1.14, a resistência em cada elemento de solda por unidade de comprimento é calculada por:

$$
\mathrm{R}_{\mathrm{i}}=\mathrm{R}_{\mathrm{i}, \mathrm{ult}}\left[1-\mathrm{e}^{-\mu \Delta_{\mathrm{i}}}\right]^{\lambda}
$$


A expressão 6.1 .15 corresponde à uma curva, tal como aquelas mostradas na fig. 4-17 do capítulo 4.

O AISC/LRFD 86 [ 3 ], apresenta a expressão 6.1.15 da seguinte maneira:

$$
\mathrm{R}_{\mathrm{i}}=\mathrm{R}_{\mathrm{i}, \text { ult }}\left[1-\mathrm{e}^{-\mathrm{k}_{1} \Delta_{\mathrm{i}} / \Delta_{0}}\right]^{\mathrm{k}_{2}}
$$

onde: $\mathrm{R}_{\mathrm{i}}=$ resistência ao cisalhamento de um elemento, em kips por polegada

$\mathrm{e}=$ base logarítmica natural $=2,718$

$\mathrm{k}_{1}=\mu \Delta_{\mathrm{o}}=8,274 \mathrm{e}^{0,0114 \theta}$

$\mathrm{k}_{2}=\lambda=0,4 \mathrm{e}^{0,0146 \theta}$

Com isso, os passos para o procedimento descrito anteriormente são os seguintes:

- deve-se dividir o filete de solda em segmentos unitários;

- assumir uma posição para o CIR;

- assumir que as forças resistentes $R_{i}$ ou $R_{j}$ atuando em qualquer segmento de solda, possuem uma direção perpendicular à linha que une o CIR ao centro do segmento de solda, e com isso calcular $x_{i}, y_{i}$ e $r_{i}$ em relação ao centróide de cada segmento, onde atua $R_{i}$ ou $R_{j}$ ( $i$ refere-se aos elementos verticais e $j$ aos horizontais);

- calcular o ângulo $\theta$ entre a direção das $R_{i}$ e $R_{j}$ e o eixo da solda;

- calcular a máxima deformação $\Delta_{i, \max }$ para cada segmento, que pode ocorrer com um particular ângulo $\theta$, antes da falha de um segmento de solda (expressão 6.1.13);

- calcular $\Delta_{\mathrm{i}, \max } / \mathrm{r}_{\mathrm{i}}$ para cada segmento;

- com o segmento crítico identificado (o elemento com o menor valor de $\Delta_{\mathrm{i}, \max } / \mathrm{r}_{\mathrm{i}}$ ), as deformações compatíveis $\Delta_{i}$ podem ser calculadas para cada elemento;

- calcular a força última de cisalhamento $R_{i, u l t}$ para cada segmento de solda;

- calcular $\mathrm{k}_{1}$ e $\mathrm{k}_{2}$ para cada segmento;

- calcular a força resistente $R_{i}$ para cada segmento, que ocorre quando o segmento crítico atinge sua condição de falha;

- usando as condições de equilíbrio da estática, calcular a força $P_{n}$ que corresponde à resistência nominal da conexão. $\mathrm{O}$ valor de $P_{n}$ correto é aquele onde se 
verificar a igualdade das equações de equilíbrio (6.1.17), caso contrário deve-se tentar outra posição do CIR.

$$
\begin{array}{ll}
\sum \mathrm{M}=0 & \mathrm{P}_{\mathrm{n}}=\left(\sum \mathrm{R}_{\mathrm{i}} \mathrm{r}_{\mathrm{i}}+\sum \mathrm{R}_{\mathrm{j}} \mathrm{r}_{\mathrm{j}}\right) /\left(\mathrm{e}+\mathrm{r}_{0}\right) \\
\sum \mathrm{F}_{\mathrm{x}}=0 & \mathrm{P}_{\mathrm{n}} \operatorname{sen} \alpha=\sum \mathrm{R}_{\mathrm{i}} \operatorname{sen} \theta_{\mathrm{i}}+\sum \mathrm{R}_{\mathrm{j}} \cos \theta_{\mathrm{j}} \\
\sum \mathrm{F}_{\mathrm{y}}=0 & \mathrm{P}_{\mathrm{n}} \cos \alpha=\sum \mathrm{R}_{\mathrm{i}} \cos \theta_{\mathrm{i}}+\sum \mathrm{R}_{\mathrm{j}} \operatorname{sen} \theta_{\mathrm{j}}
\end{array}
$$

onde: $\mathrm{e}=$ excentricidade em relação ao ponto de referência

$\mathrm{r}_{0}=$ distância do CIR ao ponto de referência

$\mathrm{i}=$ elementos verticais

$\mathrm{j}=$ elementos horizontais

$\mathrm{R}=$ componente de resistência

Depois de feita a análise, o cálculo é corrigido para que a máxima força em qualquer segmento de solda não exceda a máxima resistência nominal do filete. Isto é feito dividindo-se a resistência nominal do filete de solda, pela máxima força resistente encontrada e multiplicando $P_{n}$ por esse valor. Outra alternativa de cálculo é usar a máxima resistência nominal do filete, como a própria força resistente $R_{i}$ de todos os segmentos de solda que ultrapassem este valor.

As equações anteriores obtidas para o método do centro instantâneo de rotação, foram revisadas em 1993, para refletir os trabalhos de MIAZGA \& KENNEDY $^{6}$, LESIK \& KENNEDY ${ }^{7}$ e KENNEDY et al. ${ }^{8}$ apud SALMON \& JOHNSON [ 60 ]. Essas equações são apresentadas também no apêndice J2.4 do AISC/LRFD 93 [ 4 ].

O procedimento geral da análise não é alterado, todavia, a resistência de um dado segmento de solda não é limitada ao máximo valor de $0,6 \mathrm{f}_{\mathrm{w}} \mathrm{a}$ como foi usado previamente no desenvolvimento das tabelas dos manuais do AISC.

\footnotetext{
${ }^{6}$ MIAZGA, G. S., KENNEDY, D. J. L. "Behavior of Fillet Welds as a Function of the Angle of Loading ," Canadian Journal of Civil Engineering, 16, 1989, 583-599.

${ }^{7}$ LESIK, D. F., KENNEDY, D. J. L. "Ultimate Strength of Fillet Welded Connections Loaded in Plane," Canadian Journal of Civil Engineering, 17, 1990, 55-67.

${ }^{8}$ KENNEDY, D. J. L., MIAZGA, G. S., LESIK, D. F. "Discussion of Fillet Weld Shear Strength," Welding Journal, 55, May 1990, 44-46.
} 
De acordo com o AISC/LRFD 93 [ 4 ], a resistência de cálculo de um segmento de solda por unidade de comprimento é dada como:

$$
\phi \mathrm{R}_{\mathrm{n}}=\phi 0,60 \mathrm{f}_{\mathrm{w}}\left(1,0+0,5 \operatorname{sen}^{1,5} \theta\right) \mathrm{a}
$$

onde: $\phi=0,75$

$\theta=$ ângulo da força medido através do eixo longitudinal da solda, em graus

Essa resistência como uma função de $\theta$, pode ser usada no lugar da resistência constante apresentada na seção 4.4 do capítulo 4 .

Quando o segmento de solda é parte de uma configuração sujeita a cisalhamento excêntrico no plano, usando um procedimento de centro instantâneo de rotação, que satisfaça a compatibilidade de deformação junto com o comportamento força-deformação não linear, a resistência dada pela expressão 6.1 .18 é modificada através do AISC/LRFD 93 [ 4 ], tornando-se:

$$
\mathrm{R}_{\mathrm{i}}=0,60 \mathrm{f}_{\mathrm{w}} \mathrm{a}\left(1,0+0,5 \operatorname{sen}^{1,5} \theta\right)\left[\frac{\Delta_{\mathrm{i}}}{\Delta_{\mathrm{m}}}\left(1,9-0,9 \frac{\Delta_{\mathrm{i}}}{\Delta_{\mathrm{m}}}\right)\right]^{0,3}
$$

onde: $\mathrm{R}_{\mathrm{i}}=$ resistência nominal do segmento de solda $i$ em kips/pol.

$\theta=$ ângulo da força resistente medido através do eixo longitudinal da solda, em graus

$\Delta_{\mathrm{i}}=\mathrm{r}_{\mathrm{i}} \frac{\Delta_{\mathrm{u}}}{\mathrm{r}_{\text {crit }}}=$ deformação do elemento de solda “i”, linearmente proporcional à deformação crítica baseada na posição do centro instantâneo de rotação $r_{\text {crit }}=$ distância do centro instantâneo de rotação ao elemento de solda, tendo a mínima razão $\Delta_{\mathrm{u}} / \mathrm{r}_{\mathrm{i}}$

$\Delta_{\mathrm{m}}=0,209(\theta+2)^{-0,32} \mathrm{~b}=$ deformação do elemento na máxima resistência, em polegadas

$\Delta_{\mathrm{u}}=1,087(\theta+6)^{-0,65} \mathrm{~b} \leq 0,17 \mathrm{~b}=$ deformação do elemento quando a falha é iminente, usualmente um elemento mais distante do centro instantâneo de rotação

$\Delta_{\mathrm{i}} / \Delta_{\mathrm{m}}=$ razão da deformação no elemento $i$ com sua deformação em máxima resistência $\mathrm{b}=$ dimensão da perna do filete de solda, em polegadas 
A diferença básica de procedimento desse método com o anterior é no cálculo das deformações $\Delta_{m}$ e $\Delta_{u}$, que podem ocorrer com particular ângulo $\theta$ do segmento de solda. Com isso, o segmento crítico é aquele onde a razão de seu $\Delta_{u}$ com sua distância radial $r_{i}$ é a menor. Conseqüentemente, as deformações compatíveis $\Delta_{i}$ são então calculadas para cada segmento de solda e a resistência nominal $R_{i}$ é calculada para cada segmento usando a expressão 6.1.19.

Da mesma maneira as três equações de equilíbrio são verificadas para a determinação correta do centro instantâneo de rotação.

Deve-se notar que a correção feita na força $P_{n}$ ou a modificação feita na força resistente, para que a máxima força em qualquer segmento de solda não exceda a máxima resistência nominal do filete, quando são utilizadas as equações propostas pelo AISC/LRFD 86 [ 3 ], não são necessárias.

De maneira a exemplificar e comparar os procedimentos de cálculo, para seguinte conexão soldada da fig. 6-5, foram calculadas as forças nominais $P_{u}$, pelos métodos: vetorial; método do CIR corrigindo a resistência no final do procedimento; método do CIR usando como força resistente máxima a resistência nominal do filete $\left(R_{i, \max }\right)$; e pelo método do CIR usando a formulação proposta no AISC/LRFD [ 4 ] de 1993. Foi também admitido que o metal base não governa a resistência. Foi arbitrado um adimensional e/k para se ter uma idéia da dimensão da excentricidade, em relação a forma da conexão. A dimensão $k$ é duas vezes a distância da extremidade do filete horizontal ao centro do filete vertical. 


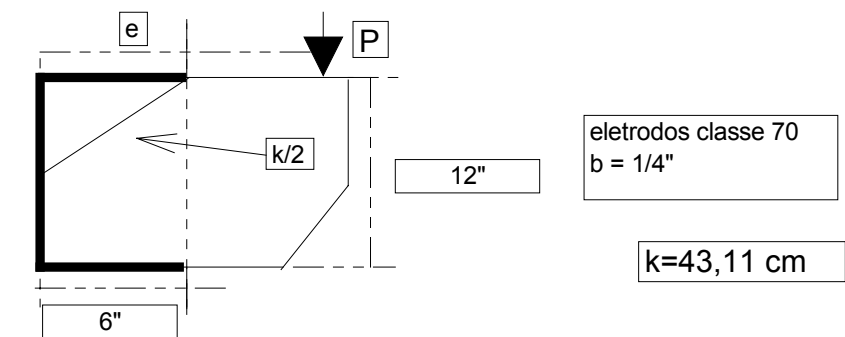

Método

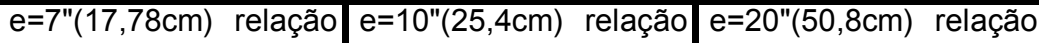

Vetorial

354,5

0,552

263,5

0,554

140,0

0,583

CIR(corrigido)

477,6

0,743

349,9

0,735

173,5

195,1

381,6

0,802

240,2

CIR (LRFD 1993) $\mathrm{Pu}(\mathrm{kN}) \quad 642,7$

1,000

475,9

1,000

$e / k=1,179$

0,722

0,812

$e / k=0,589$

1,000

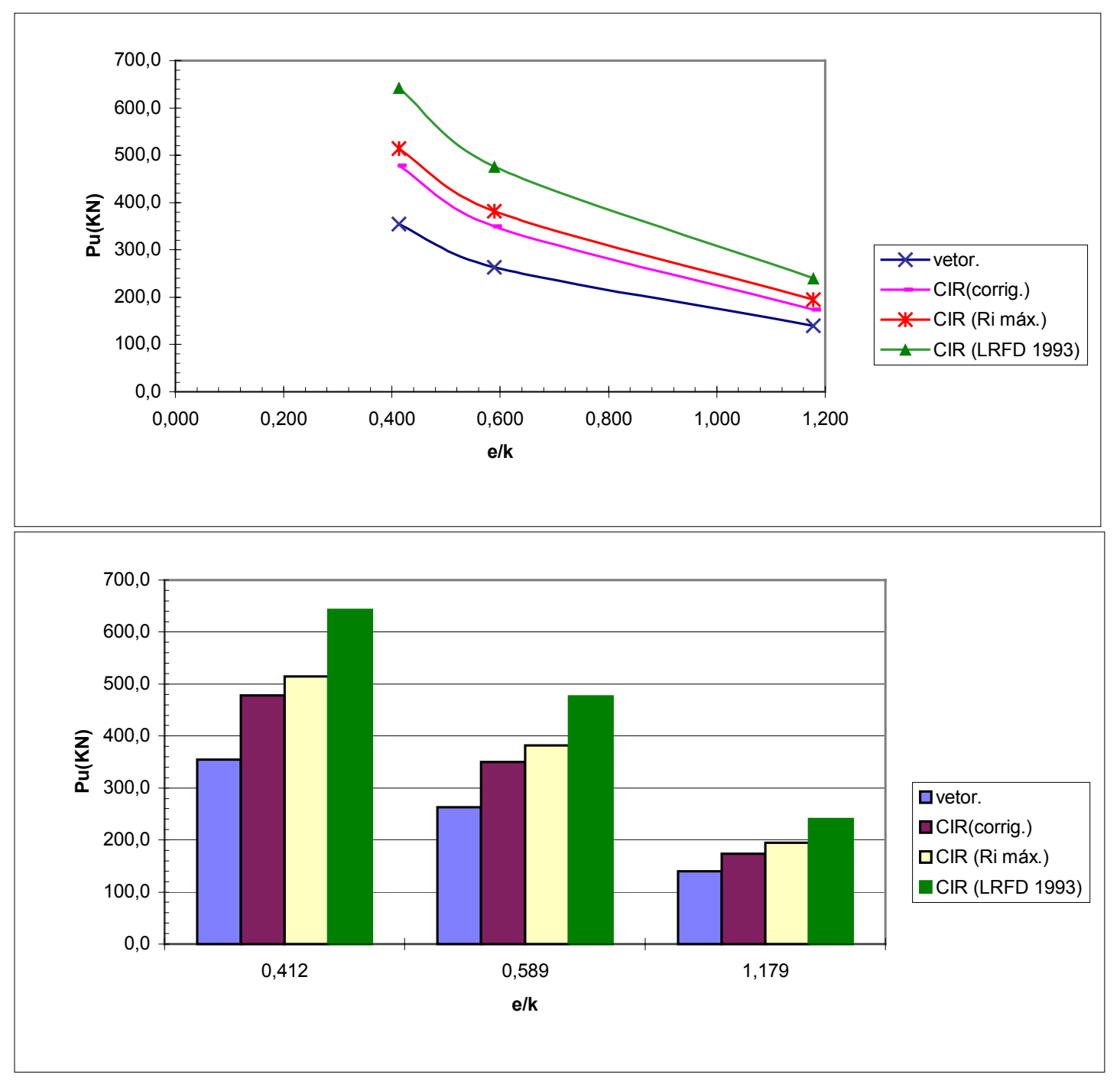

FIGURA 6-5 Análise de conexão soldada sob carregamento 
Comparando-se o método vetorial com o método do CIR utilizando a formulação proposta pelo AISC/LRFD [ 4 ] de 1993, observou-se que as forças nominais $P_{u}$ obtidas através do método vetorial, chegam a ser bastante inferiores às obtidas pelo outro método, provando quanto o método vetorial é conservador.

\subsection{Grupo de soldas sob força cortante e momento fletor}

Neste caso conforme já ilustrado na fig. 6-1b, a força atua fora do plano do grupo de soldas, correspondendo a uma situação de força cortante associada a momento fletor.

Admitindo a análise elástica (método vetorial), assume-se que a resposta da solda é linear e invariante com a direção da força. A formulação apresentada a seguir é válida para qualquer configuração de solda, executada num mesmo plano. A fig. 66 mostra um grupo de soldas constituído por dois cordões verticais e um horizontal, submetido à uma força excêntrica $P$ contida no plano $y z$.

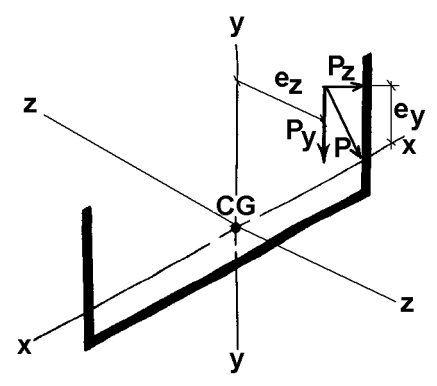

(a)

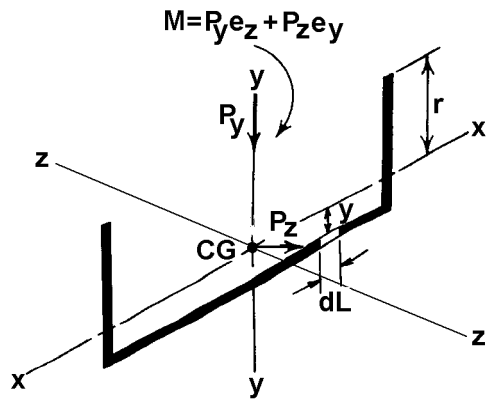

(b)

FIGURA 6-6 Excentricidade fora do plano das soldas. Adaptada de CRAWLEY \& DILLON [ 19 ].

A força excêntrica $P$ na fig. 6-6a, é substituída pelas forças concêntricas $P_{y}$ e $P_{z}$ e pelos momentos $P_{y} e_{z}$ e $P_{z} e_{y}$, como na fig. 6-6b. As forças concêntricas são assumidas, por simplificação, como sendo uniformemente distribuídas sobre o comprimento da solda

Segundo CRAWLEY \& DILLON [ 19 ], designando $F_{z}$ e $F_{y}$ como forças por unidade de comprimento de solda, resultante da força aplicada, tem-se:

$$
\mathrm{F}_{\mathrm{z}}=\frac{\mathrm{P}_{\mathrm{z}}}{\mathrm{L}} \quad \text { e } \quad \mathrm{F}_{\mathrm{y}}=\frac{\mathrm{P}_{\mathrm{y}}}{\mathrm{L}}
$$

onde: $\mathrm{L}=$ comprimento total do grupo de soldas 
A força proveniente do momento fletor não apresenta distribuição uniforme, uma vez que varia em função da distância $y$ em relação ao centro de gravidade do grupo de soldas. Esta força atua perpendicularmente ao plano das soldas.

Definido $F_{0}$ como sendo a força por comprimento de solda à uma distância unitária do eixo $x-x$, pode-se obter a força por unidade de comprimento à uma distância qualquer $y$ em relação ao eixo $\mathrm{x}-\mathrm{x}$ como $F_{0} y$, e a força no elemento de comprimento $d L$ como $F_{0} y d L$. Assim:

$$
\mathrm{dM}=\left(\mathrm{F}_{0} \mathrm{ydL}\right) \mathrm{y}
$$

onde: $\mathrm{dM}=$ parcela do momento referente ao elemento de ordenada $y$ em relação ao eixo $\mathrm{x}-\mathrm{x}$

Por equilíbrio, o momento total no grupo de soldas, dado pelo somatório dos $d M$ de todas as porções elementares, deve ser igual ao momento externo $\mathrm{M}=\mathrm{P}_{\mathrm{y}} \mathrm{e}_{\mathrm{z}}+$ $\mathrm{P}_{\mathrm{z}} \mathrm{e}_{\mathrm{y}}$ :

$$
\mathrm{M}=\sum\left(\mathrm{F}_{0} \mathrm{y}^{2} \mathrm{dL}\right)
$$

Sabendo que $F_{0}$ permanece constante, tem-se:

$$
\mathrm{F}_{0}=\frac{\mathrm{M}}{\sum \mathrm{y}^{2} \mathrm{dL}}
$$

O termo $\sum y^{2} d L$ deve ser reconhecido como o momento de inércia para uma linha de solda com relação ao eixo x-x, fornecendo o valor em comprimento ao cubo. A máxima força, ocorre no ponto mais afastado em relação ao eixo x-x. Com isso, considerando $r$ esta distância e sabendo que $\mathrm{M}=\mathrm{P}_{\mathrm{y}} \mathrm{e}_{\mathrm{z}}+\mathrm{P}_{\mathrm{z}} \mathrm{e}_{\mathrm{y}}$, tem-se:

$$
F_{M}=\frac{M}{I_{x}} r=\frac{P_{y} e_{z}+P_{z} e_{y}}{I_{x}} r
$$

onde: $\mathrm{F}_{\mathrm{M}}=$ força proveniente do momento (admitindo espessura unitária)

$\mathrm{I}_{\mathrm{x}}=$ momento de inércia em relação ao eixo $\mathrm{x}-\mathrm{x}$ (admitindo espessura unitária)

Deste modo, o efeito combinado da força concêntrica e do momento será a soma vetorial dessas forças (admitindo espessura unitária), resultando: 


$$
\mathrm{F}_{\mathrm{r}}=\sqrt{\mathrm{F}_{\mathrm{y}}^{2}+\left(\mathrm{F}_{\mathrm{M}}+\mathrm{F}_{\mathrm{z}}\right)^{2}}
$$

A tensão num determinado ponto da solda pode ser obtida dividindo-se a força unitária resultante $F_{r}$ pela espessura. Nos projetos, deve-se verificar os estados limites últimos aplicáveis, ou seja, a ruptura da solda na seção efetiva e o escoamento do metal base na face de fusão.

Segundo MALITE et al. [ 40 ], admitindo que qualquer solicitação atuante num cordão de solda se traduza em tensões de cisalhamento na seção efetiva da solda ou na face teórica de fusão (que é a hipótese admitida para conexões soldadas sob carregamento excêntrico no plano ou fora dele), tem-se que a verificação da solda consiste na busca de seu ponto crítico, ou seja, aquele de maior tensão resultante. Com isso, pode-se notar que na conexão da fig. 6-7a, as tensões devido ao momento são linearmente distribuídas (hipótese já mencionada), mas as tensões devido a força vertical são admitidas uniformemente distribuídas na nervura vertical, desprezando a contribuição da mesa do console. Com isso, o ponto crítico se encontra na base inferior do console.

Da mesma maneira, analisando uma conexão soldada viga-pilar, sujeita a momento e cortante, pode-se admitir uma distribuição linear de tensões ao longo de toda a seção, devido ao momento, mas a distribuição das tensões devido a força vertical é somente considerada ao longo da alma, desprezando-se a contribuição das mesas, como mostra a fig. 6-7b. Com isso, tem-se dois pontos críticos a serem verificados, os pontos $A$ e $B$.
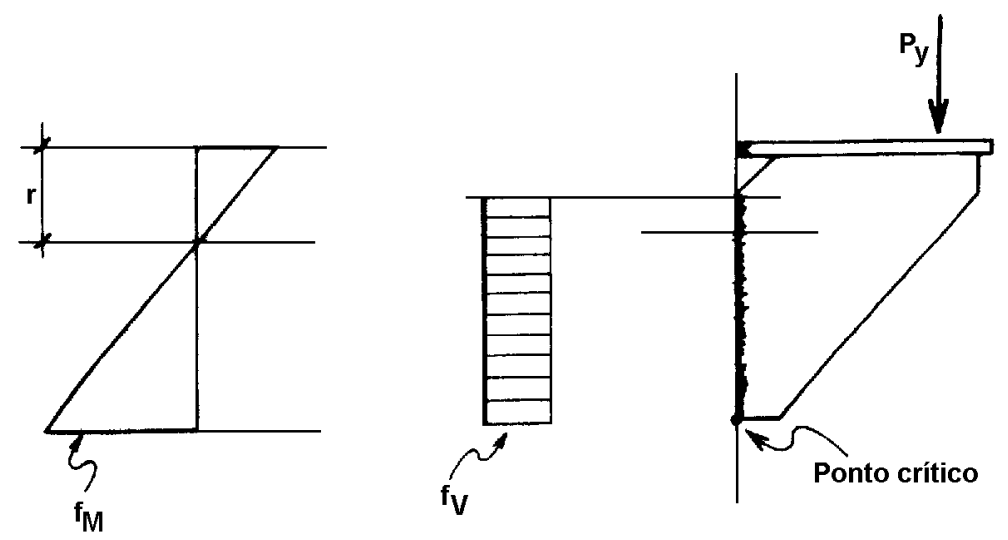

(a) 

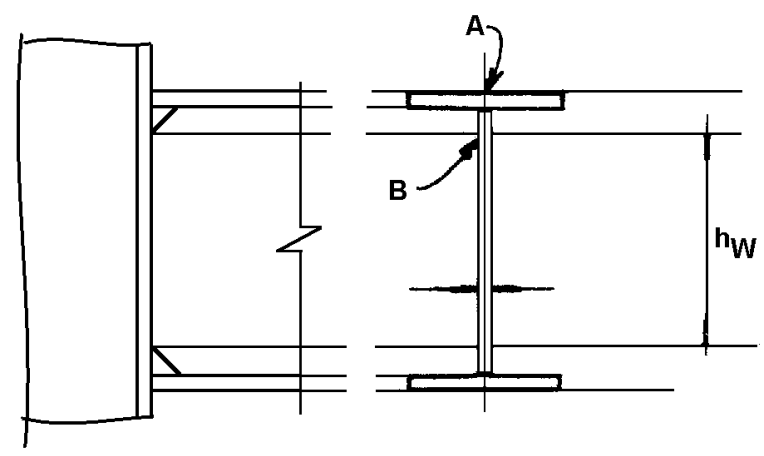

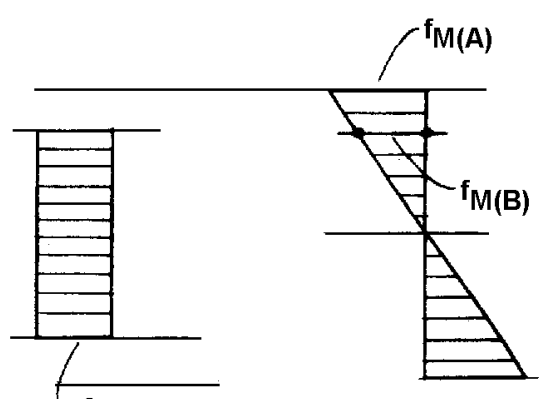

(b)

FIGURA 6-7 Distribuição de tensões na solda. (a) Console conectado à um pilar; (b) perfil I conectado à um pilar (conexão viga-pilar). Adaptada de MALITE et al. [ 40 ].

Segundo SALMON \& JOHNSON [ 60 ], o método do centro instantâneo de rotação também pode ser aplicado nestes casos. Como já foi mencionado, a resistência de um cordão de solda depende da direção da força em relação ao seu eixo (ângulo $\theta_{i}$ ), portanto não faz diferença se a força excêntrica atuar fora ou no plano do grupo de soldas. Desta forma, pode-se empregar a mesma formulação já apresentada para conexões soldadas com força no plano das soldas (seção 6.1).

Tomando-se o método do centro instantâneo de rotação, um procedimento alternativo é apresentado por DAWE \& KULAK [ 21 ]. Tal procedimento é apresentado a seguir.

Na figura 6-8 são apresentadas duas conexões com carregamento excêntrico, onde na parte (a) mostra-se uma situação onde o cordão de solda não é "restringido" pelo elemento de apoio. Já na parte (b), tem-se tal "restrição" junto à porção comprimida, desde que se admita, por hipótese, a contribuição do contato entre as partes conectadas. 


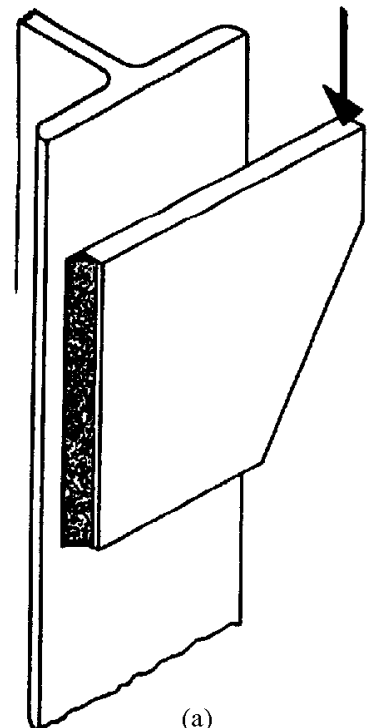

(a)

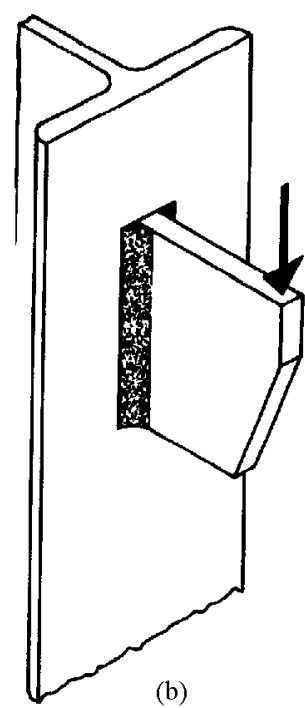

(b)

FIGURA 6-8 (a) Cordão de solda sem "restrição"; (b) cordão de solda com "restrição" na zona comprimida. Adaptada de DAWE \& KULAK [ 21 ].

Os princípios básicos e o procedimento de cálculo para esse processo, são similares ao método do centro instântaneo de rotação, para conexões sob força cortante no plano (as forças atuando na solda podem ser vistas na fig. 6-9). Com isso, a resposta força-deformação para essa solda pode ser expressa pela expressão 6.1.15, reproduzida a seguir:

$$
\mathrm{R}_{\mathrm{i}}=\mathrm{R}_{\mathrm{i}, \mathrm{ult}}\left[1-\mathrm{e}^{-\mu \Delta_{\mathrm{i}}}\right]^{\lambda}
$$

As relações empíricas para $R_{i, u l t}, \mu$ e $\lambda$, como função do ângulo $\theta$, foram estabelecidas por BUTLER \& $\mathrm{KULAK}^{9}$ apud DAWE \& KULAK [ 21 ]. Essas relações foram obtidas para um elemento de solda de 1" $(25 \mathrm{~mm})$ de comprimento tendo uma dimensão nominal de 1/4" (6,3 mm) e formado com eletrodos E60, em um metal base ASTM A36. Portanto tem-se que:

$$
\begin{aligned}
& \mathrm{R}_{\mathrm{i}, \text { ult }}=\frac{10+\theta_{\mathrm{i}}}{0,92+0,0603 \theta_{\mathrm{i}}} \\
& \mu=75 \mathrm{e}^{0,0114 \theta_{\mathrm{i}}} \\
& \lambda=0,4 \mathrm{e}^{0,0146 \theta_{\mathrm{i}}}
\end{aligned}
$$

\footnotetext{
${ }^{9}$ BUTLER, L.J., KULAK, G.L. "Strength of Fillet Welds as a Function of Direction of Load," Welding Journal, Welding Research Council, Vol. 36, No. 5, May, 1971, pp. 231s-234s.
} 


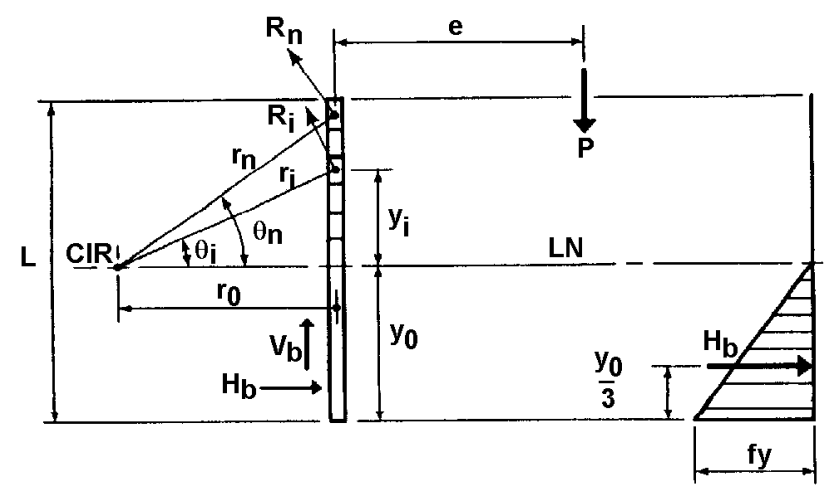

FIGURA 6-9 Forças atuando na solda. Modelo de DAWE \& KULAK [ 21 ].

A máxima deformação na linha da solda ocorrerá no elemento mais distante do centro instantâneo de rotação. Esta deformação é determinada pela seguinte expressão empírica:

$$
\Delta_{\max }=0,225\left(\theta_{\mathrm{n}}+5\right)^{-0,47}
$$

Desde que a deformação em cada elemento de solda é assumida variando linearmente com a distância do centro instantâneo de rotação, tem-se:

$$
\Delta_{\mathrm{i}}=\frac{\mathrm{r}_{\mathrm{i}}}{\mathrm{r}_{\mathrm{n}}} \Delta_{\max }
$$

Dessa forma, a força $R_{i}$ em cada elemento possui suas componentes vertical e horizontal dadas por:

$$
\begin{aligned}
& \mathrm{R}_{\mathrm{iv}}=\frac{\mathrm{r}_{0}}{\mathrm{r}_{\mathrm{i}}} \mathrm{R}_{\mathrm{i}} \\
& \mathrm{R}_{\mathrm{ih}}=\frac{\mathrm{y}_{\mathrm{i}}}{\mathrm{r}_{\mathrm{i}}} \mathrm{R}_{\mathrm{i}}
\end{aligned}
$$

Considera-se que as chapas conectadas na zona comprimida da conexão, estão em contato direto no instante em que a força última é alcançada. Com isso, referindo-se a fig. 6-9, será assumida que a distribuição de tensão, na zona comprimida abaixo da linha neutra é triangular, com a máxima ordenada igual ao limite escoamento do material da chapa. A força horizontal resultante desta distribuição de tensão está localizada à uma distância de dois terços de $y_{0}$ abaixo da 
linha neutra. A hipótese da distribuição triangular de tensões corresponde a resultados mais próximos da força última experimental do que as hipóteses de distribuição retangular ou parabólica.

O comprimento da solda na zona comprimida, abaixo da linha neutra, é assumido para resistir à componente vertical da força. Tomando $\delta$ como sendo a componente vertical da deformação em cada elemento de solda na zona tracionada e referindo-se a fig. 6-9, tem-se:

$$
\delta=\frac{\mathrm{r}_{0}}{\mathrm{r}_{\mathrm{i}}} \Delta_{\mathrm{i}}
$$

Substituindo o valor de $\Delta_{i}$ da expressão 6.2.11, na expressão 6.2.14, tem-se:

$$
\delta=\frac{\mathrm{r}_{0}}{\mathrm{r}_{\mathrm{n}}} \Delta_{\max }
$$

Através da expressão 6.2.15 pode-se notar que $\delta$ tem um valor constante. Por essa razão, de acordo com esta análise, a solda apresenta deformação vertical uniforme ao longo de seu comprimento. A força vertical $V_{b}$, resistida pelo comprimento de solda abaixo da linha neutra pode, por essa razão, ser expressa por:

$$
\mathrm{V}_{\mathrm{b}}=\frac{\mathrm{y}_{0}}{\left(\mathrm{~L}-\mathrm{y}_{0}\right)} \sum_{1}^{\mathrm{n}} \mathrm{R}_{\mathrm{iv}}
$$

onde: $\mathrm{L}=$ comprimento total da solda

O termo $H_{b}$ é a resultante das tensões mostradas na fig. 6-9 e é dada por:

$$
\mathrm{H}_{\mathrm{b}}=\frac{\mathrm{y}_{0} \mathrm{f}_{\mathrm{y}} \mathrm{t}}{2}
$$

onde: $f_{y}=$ tensão de escoamento do material da chapa

$\mathrm{t}=$ espessura da chapa

Tomando a somatória de momento de todas as forças, sobre o centro instantâneo de rotação, tem-se:

$$
\mathrm{P}\left(\mathrm{e}+\mathrm{r}_{0}\right)-\sum_{1}^{\mathrm{n}}\left(\mathrm{R}_{\mathrm{i}} \mathrm{r}_{\mathrm{i}}\right)-\mathrm{r}_{0} \mathrm{~V}_{\mathrm{b}}-\frac{2}{3} \mathrm{y}_{0} \mathrm{H}_{\mathrm{b}}=0
$$


A somatória das forças verticais na conexão produz:

$$
\sum_{1}^{\mathrm{n}} \mathrm{R}_{\mathrm{iv}}+\mathrm{V}_{\mathrm{b}}-\mathrm{P}=0
$$

Isolando $P$ na expressão 6.2.18 e substituindo-o na expressão 6.2.19, tem-se:

$$
\sum_{1}^{\mathrm{n}} \mathrm{R}_{\mathrm{iv}}+\mathrm{V}_{\mathrm{b}}-\left[\sum_{1}^{\mathrm{n}} \frac{\mathrm{R}_{\mathrm{i}} \mathrm{r}_{\mathrm{i}}+\mathrm{r}_{0} \mathrm{~V}_{\mathrm{b}}+\frac{2}{3} \mathrm{y}_{0} \mathrm{H}_{\mathrm{b}}}{\mathrm{e}+\mathrm{r}_{0}}\right]=0
$$

A somatória das forças horizontais fornece:

$$
\mathrm{H}_{\mathrm{b}}-\sum_{1}^{\mathrm{n}} \mathrm{R}_{\mathrm{ih}}=0
$$

Deste modo, um valor inicial para $y_{0}$ é utilizado na expressão $6.2 .20 \mathrm{e}$ sucessivos valores de $r_{0}$ são escolhidos iterativamente até que a expressão seja satisfeita. $O$ par de valores $r_{0}$ e $y_{0}$ que satisfaça esta expressão, é então usado para avaliar os termos da expressão 6.2.21. Se esta expressão é também satisfeita, a força última pode ser obtida e é dada pela expressão 6.2.19. Se a expressão 6.2.21 não é satisfeita, então um outro valor de $y_{0}$ é escolhido e o procedimento repetido. 


\section{CAPÍTULO 7 - EMENDAS EM BARRAS E OUTRAS CONEXÕES}

\subsection{Emendas em barras}

$\mathrm{Na}$ maioria das estruturas metálicas surge a necessidade de se executar emendas em barras, devido principalmente as limitações de comprimento máximo dos perfis laminados (12 metros) e chapas, ou mesmo por limitações de transporte e/ou dificuldades no manuseio e montagem.

Como critérios de projeto, uma emenda deve ser projetada tendo em vista os seguintes aspectos:

- apresentar resistência igual ou superior às solicitações: trata-se de uma condição de resistência, aplicável ao dimensionamento de qualquer elemento estrutural, seja uma barra ou conexão;

- apresentar uma resistência igual ou superior a pelo menos $50 \%$ da capacidade da barra: trata-se de uma condição de compatibilidade, ou seja, propiciar que a resistência da emenda não seja muito inferior à capacidade da barra, independentemente do valor das solicitações;

- apresentar concepção tal que as concentrações de tensões sejam amenizadas e ainda apresentar facilidades de execução, evitando-se por exemplo, soldas de execução complicada e instalação de parafusos em locais de difícil acesso.

\subsubsection{Emendas de pilares de edifícios}

Nos edifícios de altura elevada e nos edifícios industriais com ponte rolante, é comum a adoção de pilares com altura variável, uma vez que há significativa variação na intensidade dos esforços, portanto torna-se inevitável a existência de emendas.

No caso de pilares predominantemente comprimidos, a norma brasileira NBR 8800 [ 7 ] prevê a emenda por contato entre as partes, desde que usinadas, entretanto sempre há necessidade de se prever meios e elementos de ligação posicionados de modo a manter alinhadas todas as partes da ligação e dimensionados para $50 \%$ da compressão de cálculo. Além disso, tais ligações devem ser dimensionadas também 
para resistir à totalidade das solicitações de cálculo que não sejam transmitidas por contato, incluindo os casos de inversão de esforços.

Segundo o Manual Brasileiro para Cálculo de Estruturas Metálicas ${ }^{10}$ [ 14 ], as emendas mais empregadas são feitas com parafusos de alta resistência prétracionados. Entretanto, o emprego das ligações soldadas de campo vem sendo desenvolvido, devido a maior simplicidade na fabricação das peças.

As emendas parafusadas podem ser executadas com cobrejuntas ou com chapas de topo, como mostram as figuras 7-1a e b. Já as soldadas podem ser executadas ligando-se diretamente um perfil ao outro ou usando-se uma chapa transversal, como mostram as figuras $7-1 \mathrm{c}$ e $\mathrm{d}$.

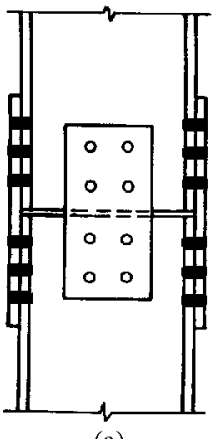

(a)

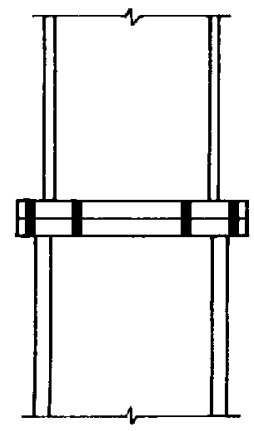

(b)

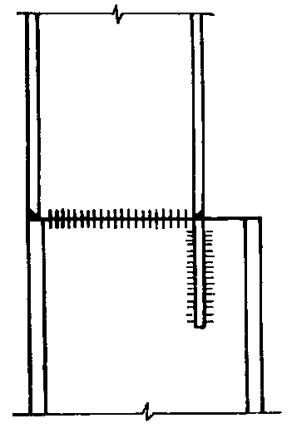

(c)

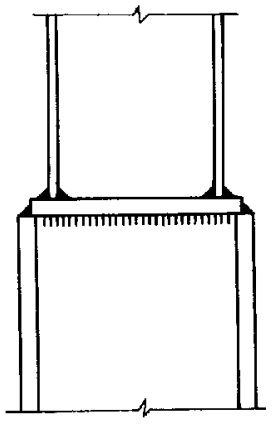

(d)

FIGURA 7-1 Tipos de emendas. (a) Emenda parafusada com cobrejuntas; (b) emenda parafusada com chapa de topo; (c) emenda soldada ligada diretamente; (d) emenda soldada com chapa de topo. Adaptada do Manual Brasileiro para Cálculo de Estruturas Metálicas [ 14 ].

Nas ligações parafusadas com chapa de topo, como mostrada na fig. 7-1b, são soldadas chapas às extremidades dos perfis. Essas ligações podem ser rotuladas ou engastadas, dependendo da disposição dos conectores.

$\mathrm{Na}$ prática, este tipo de ligação pode ocorrer em edifícios elevados, onde as emendas com cobrejuntas apresentam o inconveniente de aumentar a espessura do perfil, dificultando a proteção contra fogo no local da emenda, já a chapa de topo, devido à sua pequena espessura, pode ser embutida na laje do piso.

As emendas de pilares executadas na fábrica, devido à maior simplicidade de projeto e fabricação, além de um melhor controle de qualidade são, na grande maioria, ligações soldadas.

\footnotetext{
10 - BRASIL. Ministério da Industria e do Comércio. Secretaria de Tecnologia Industrial. Manual brasileiro para cálculo de estruturas metálicas/MIC.STI - -[ 14 ] Brasília: STI/MIC, 1986/1988. v. I e v.III, tomo II.
} 
No caso de solicitações relativamente pequenas, as cobrejuntas das mesas são utilizadas somente em um dos lados do perfil, já as da alma são sempre posicionadas nos dois lados, como mostra a fig. 7-2a. Já no caso de altas solicitações é aconselhável utilizar cobrejuntas dos dois lados das mesas, como mostra a fig. 7-2b, pois o duplo cisalhamento nos parafusos reduz o seu número à metade.

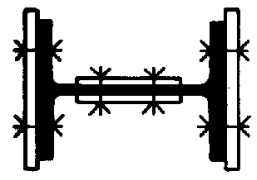

(a) Pequenas solicitações

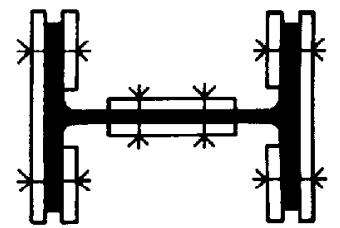

(b) Elevadas solicitações

FIGURA 7-2 Emendas com cobrejuntas. Adaptada do Manual Brasileiro para Cálculo de Estruturas Metálicas [ 14 ].

No caso de variação na espessura da mesa ou da alma, folgas superiores a $1 \mathrm{~mm}$ devem ser compensadas com chapas de enchimento, como mostra a fig. 7-3.

FIGURA 7-3 Emenda no local de variação de seção. Adaptada do Manual Brasileiro para Cálculo de Estruturas Metálicas [ 14 ].

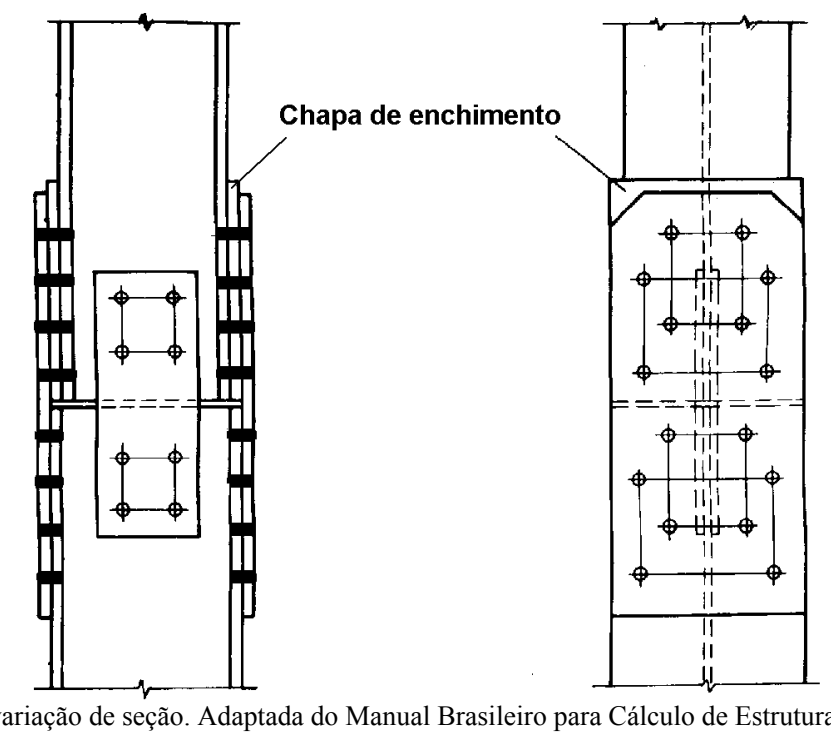

\subsubsection{Emendas em vigas}

As emendas soldadas em vigas devem ser feitas, preferencialmente, com solda em chanfro de penetração total, a qual permite uma transmissão "direta" de esforços, evitando-se concentração de tensão. Em vigas de grandes dimensões, é conveniente conectar as mesas em seção diferente da emenda da alma, como mostra a fig. 7-4a. 
Neste tipo de emenda, a seqüência de soldagem é importante, de modo a evitar esforços internos causados pelo resfriamento dos cordões de solda. PFEIL [ 53 ] recomenda soldar inicialmente as mesas, e em seguida executar a solda da alma e completar a solda de composição da alma com as mesas.

As emendas soldadas também podem ser executadas com o auxílio de cobrejuntas e soldas de filete, como mostra a fig. 7-4b. Além da estética em geral desagradável, um inconveniente deste detalhe é a considerável concentração de tensão em alguns pontos, o que deve ser evitado em alguns casos, como por exemplo, nas situações de fadiga.

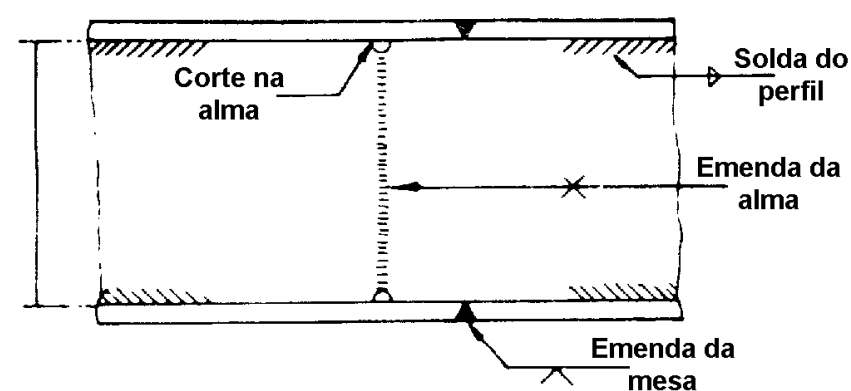

(a)
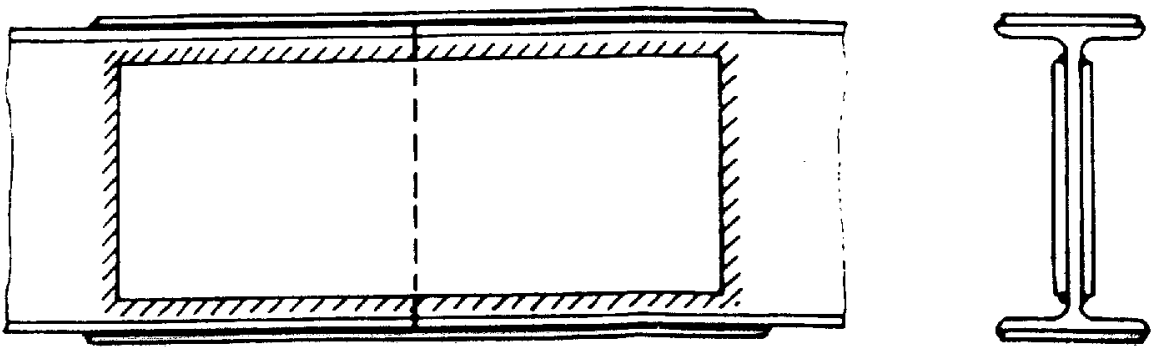

(b)

FIGURA 7-4 (a) Emenda de viga com solda em chanfro; (b) emenda de viga com chapas e solda de filete. Adaptada de PFEIL \& PFEIL [ 54 ].

As emendas parafusadas são mais empregadas nas conexões de campo e são executadas com chapas ou perfis auxiliares (cobrejuntas). Na fig. 7-5 mostra-se a emenda de um perfil "I" laminado, com cobrejuntas e parafusos.
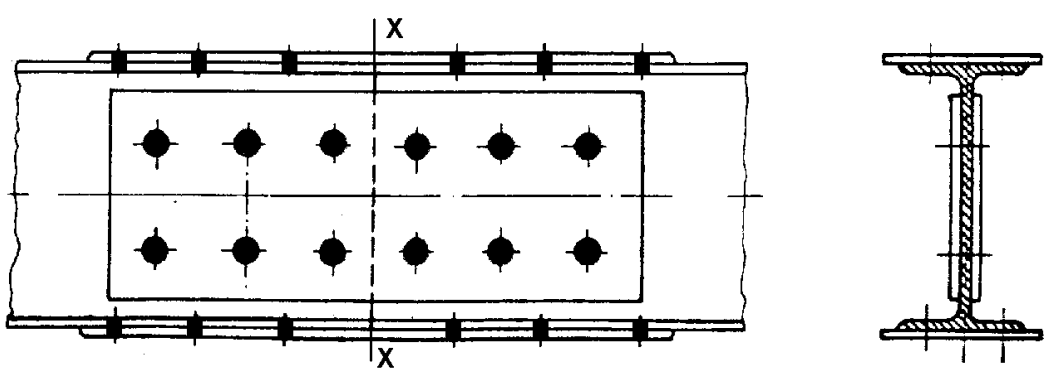

FIGURA 7-5 Emenda parafusada de perfil laminado. Adaptada de PFEIL \& PFEIL [ 54 ]. 
Segundo PFEIL [ 53 ], as emendas devem estar localizadas de preferência em seções pouco solicitadas. Entretanto, as emendas de campo ficam, muitas vezes, determinadas por condições de transporte e montagem.

Segundo QUEIROZ [ 56 ], os esforços ou as tensões são determinados nos elementos planos da seção do perfil (almas e mesas) com base nos esforços solicitantes da seção teórica de ligação, situada no plano X-X da fig. 7-5. Os esforços ou resultantes de tensões em cada elemento plano são, então, aplicados no par de cobrejuntas correspondente, como se elas fossem subdivididas pelo plano X-X, e transferidos para o centro de gravidade do grupo de parafusos (ou se for o caso, das soldas de filete), com a devida variação do momento, devida à excentricidade das forças.

Nesse caso, os parafusos das mesas e das almas devem ser verificados, além da verificação do esmagamento dos furos, rasgamento entre furos e rasgamento entre furos e bordas de todos os elementos envolvidos (mesas, almas e cobrejuntas de mesas e almas). Para as cobrejuntas das mesas e da alma, deve-se verificar o escoamento, a ruptura, o colapso por rasgamento e a flambagem local. Para as mesas e alma dos perfis, deve-se verificar a ruptura e o colapso por rasgamento.

Segundo PFEIL \& PFEIL [ 54 ], a emenda da fig. 7-5 está em geral sujeita a um momento fletor $M$ e a um esforço cortante $V$. Levando em consideração que a distribuição do momento fletor é feita com base na compatibilidade de curvatura na seção da emenda $\left(\mathrm{M}_{\mathrm{w}} / \mathrm{EI}_{\mathrm{w}}=\mathrm{M}_{\mathrm{f}} / \mathrm{EI}_{\mathrm{f}}=\mathrm{M} / \mathrm{EI}\right)$, a parcela de momento fletor transmitida pelas mesas $M_{f}$ pode ser calculada pela proporção entre o momento de inércia das mesas $I_{f}$ e o momento de inércia total $I_{t}$. Com isso:

$$
\mathrm{M}_{\mathrm{f}}=\mathrm{M} \frac{\mathrm{I}_{\mathrm{f}}}{\mathrm{I}_{\mathrm{t}}} \approx \mathrm{M} \frac{\mathrm{A}_{\mathrm{f}}}{\mathrm{A}_{\mathrm{f}}+\mathrm{A}_{\mathrm{w}} / 6}
$$

onde: $\mathrm{A}_{\mathrm{f}}=$ área de cada mesa

$\mathrm{A}_{\mathrm{w}}=$ área da alma

O esforço na cobrejunta da mesa resulta:

$$
F=\frac{M_{f}}{h_{f}}
$$


onde: $h_{\mathrm{f}}=$ distância entre os centros das mesas

Este esforço $F$ é admitido como uniformemente distribuído entre os parafusos da mesa. A parcela de momento fletor $M_{w}$ absorvida pela alma se calcula na proporção do momento de inércia $I_{w}$ da alma para o momento de inércia total. As cobrejuntas transmitem o momento $M_{w}$ acrescido do momento $V . a$, sendo $a$ a excentricidade, ou seja, a distância entre o centro de gravidade do grupo de parafusos e a seção da emenda. Portanto:

$$
\mathrm{M}_{\mathrm{w}}=\mathrm{M} \frac{\mathrm{I}_{\mathrm{w}}}{\mathrm{I}_{\mathrm{t}}}+\mathrm{Va} \approx \mathrm{M} \frac{\mathrm{A}_{\mathrm{w}} / 6}{\mathrm{~A}_{\mathrm{f}}+\mathrm{A}_{\mathrm{w}} / 6}+\mathrm{Va}
$$

Considerando o método vetorial elástico, o esforço em um parafuso da alma, devido ao momento aplicado, é proporcional à distância do mesmo ao centro de gravidade do grupo de parafusos. Com isso, utilizando as expressões 5.1.7, 5.1.9 e 5.1.10, do capítulo 5.1, obtidas para o método vetorial, tem-se o esforço resultante no parafuso mais solicitado da alma:

$$
\mathrm{R}_{\mathrm{R}}=\sqrt{\left(\mathrm{R}_{\mathrm{Mx}}\right)^{2}+\left(\mathrm{R}_{\mathrm{V}}+\mathrm{R}_{\mathrm{My}}\right)^{2}}
$$

onde: $\mathrm{R}_{\mathrm{Mx}}=\frac{\mathrm{My}}{\sum \mathrm{x}^{2}+\sum \mathrm{y}^{2}}, \mathrm{R}_{\mathrm{My}}=\frac{\mathrm{Mx}}{\sum \mathrm{x}^{2}+\sum \mathrm{y}^{2}} \mathrm{e}_{\mathrm{V}}=\frac{\mathrm{V}}{\mathrm{n}}$

onde: $\mathrm{x}, \mathrm{y}=$ coordenadas dos parafusos em relação ao $\mathrm{CG}$ do conjunto $\mathrm{n}=$ número de parafusos na alma

Uma simplificação da análise apresentada anteriormente é amplamente divulgada na bibliografia, como por exemplo em OWENS \& CHEAL [ 50 ], onde admite-se que o momento fletor seja integralmente transmitido pelas mesas e a cortante pela alma.

Assim como já apresentado para o caso dos pilares, pode-se executar emendas em vigas mediante o emprego de chapa de topo (fig. 7-6). Quando a seção da emenda é submetida a momento fletor relativamente pequeno, é razoável empregar uma chapa de topo cuja altura coincide com a altura da viga, e conseqüentemente os parafusos são posicionados na região contida entre as mesas 
(fig. 7-6a). Caso contrário, busca-se uma maior rigidez à flexão do conjunto, adotando-se chapas de topo "estendidas", ou seja, com altura superior à altura da viga e parte dos parafusos tracionados são posicionados na região externa da viga (fig. 7-6b).

Caso haja variação de altura da viga, é usual a colocação de enrijecedores longitudinais na alma da viga de maior altura, como indicado nas figuras 7-6c e 7-6d, correspondendo a um "prolongamento" da mesa de menor altura.

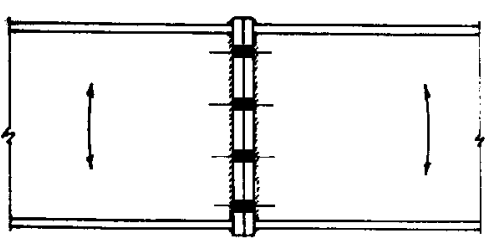

(a)

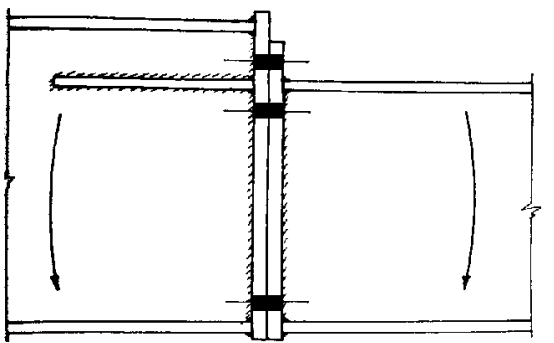

(c)

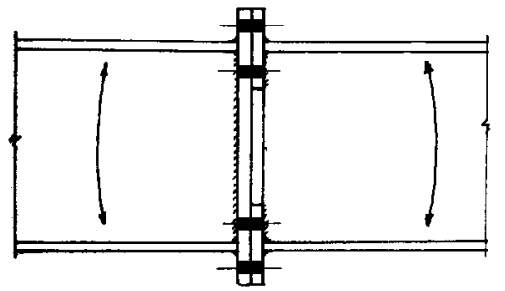

(b)

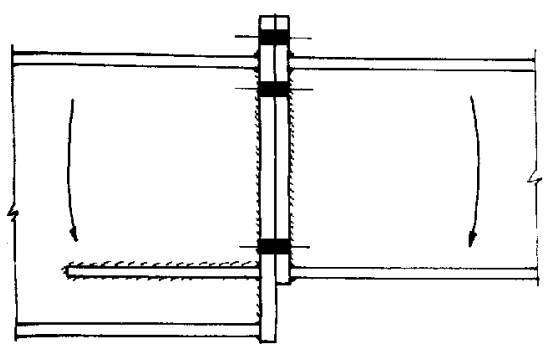

(d)

FIGURA 7-6 Emendas em vigas com chapa de topo. (a) Chapa de topo pequena; (b) chapa de topo duplamente estendida; (c) e (d) emendas entre elementos de tamanhos diferentes. Adaptada de OWENS \& CHEAL [ 50 ].

\subsubsection{Emendas em barras axialmente solicitadas}

As barras constituídas por cantoneira simples ou dupla são amplamente empregadas em treliças e sistemas de contraventamento, sendo portanto, predominantemente solicitadas axialmente, ou seja, tracionadas ou comprimidas. A fig. 7-7a ilustra a emenda de cantoneira simples e as figs. 7-7b e 7-7c referem-se à emendas em cantoneira dupla.

Segundo MALITE et al. [ 40 ], a emenda de cantoneira simples pode ser feita utilizando-se como cobrejunta uma cantoneira de mesma seção transversal da barra a ser emendada, o que garante que a tensão média seja a mesma da barra, pois é estabelecida a igualdade de áreas. 

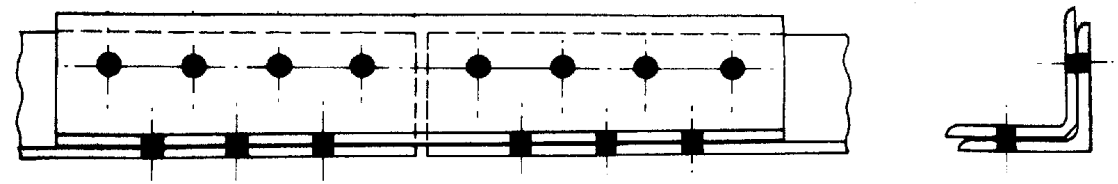

(a)
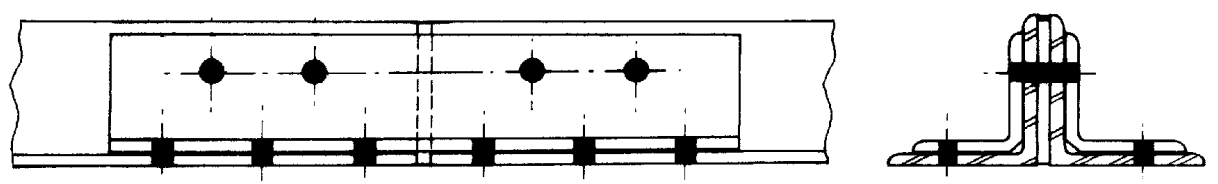

(b)
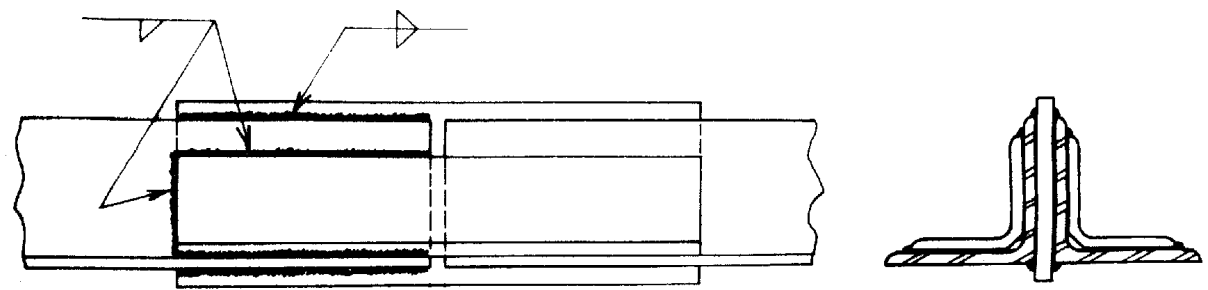

(c)

FIGURA 7-7 (a) Emenda parafusada com cantoneira simples; (b) emenda parafusada com cantoneira dupla e chapa de miolo; (c) emenda soldada com cantoneira dupla e chapa de miolo. Adaptada de MALITE et al. [ 40 ].

É importante registrar que para as emendas parafusadas, deve-se verificar o cisalhamento nos parafusos e a pressão de contato nos furos, incluindo a possibilidade de rasgamento entre furos ou entre furo e borda, aplicável tanto à barra quanto às cobrejuntas.

No caso de emenda de cantoneira simples, não é necessário verificar a cobrejunta, já que ela possui a mesma seção da barra. Entretanto, no caso de emenda de cantoneira dupla, deve-se determinar a parcela de esforço normal recebida pelas cantoneiras laterais e pela chapa de miolo. Desta forma, admitindo compatibilidade de deformação na seção da emenda, a parcela da força normal $N_{i}$ transmitida para cada elemento é proporcional à sua área:

$$
\mathrm{N}_{\mathrm{i}}=\frac{\mathrm{A}_{\mathrm{cob}}}{\mathrm{A}_{\mathrm{t}}} \mathrm{N}_{\mathrm{d}}
$$

onde: $\quad \mathrm{A}_{\mathrm{cob}}=$ área da cobrejunta (área de uma cantoneira ou área da chapa de miolo, dependendo do elemento que se deseja determinar o esforço $N_{i}$ )

$\mathrm{A}_{\mathrm{t}}=$ área total das cobrejuntas

$\mathrm{N}_{\mathrm{d}}=$ solicitação normal de cálculo 
Deve-se notar que a quantidade e a distribuição dos parafusos na emenda podem ser definidas levando-se em consideração o número de planos de corte necessários para cada elemento de cobrejunta. Analisando a emenda da fig. 7-7b, os parafusos que interceptam a chapa de miolo possuem quatro planos de corte enquanto os outros apenas um.

De maneira a se determinar a quantidade de planos de corte $m_{i}$ necessários por elemento, basta dividir a parcela de esforço normal que esse elemento transmite pela resistência de cálculo do parafuso à força cortante $\phi_{v} R_{n v}$, por plano de corte:

$$
\mathrm{m}_{\mathrm{i}}=\frac{\mathrm{N}_{\mathrm{i}}}{\phi_{\mathrm{v}} \mathrm{R}_{\mathrm{nv}}}
$$

No exemplo da fig. 7-7b, admitindo-se que a chapa de miolo necessite de quatro planos de corte, são necessários dois parafusos, uma vez que cada parafuso contribui com dois planos de corte para o equilíbrio da referida chapa.

Admitindo-se agora que cada cobrejunta lateral (cantoneira) necessite de cinco planos de corte, são necessários três parafusos por cantoneira, uma vez que já foram definidos dois parafusos na região da chapa de miolo, portanto dois planos de corte contribuindo para cada cantoneira, e cada parafuso complementar contribui com apenas um plano de corte.

As emendas em perfis "I" ou "U", solicitados axialmente, podem ser projetadas de maneira análoga a apresentada para as cantoneiras, estabelecendo cobrejuntas cujas áreas sejam compatíveis com a área da barra a ser emendada.

No caso de emendas soldadas como na fig. 7-7c, a parcela de esforço normal para cada elemento pode também ser determinada pela equação 7.1.5. Com isso, o comprimento de solda necessário $L_{s}$, tanto na chapa de miolo quanto na cantoneira lateral pode ser determinado dividindo-se a parcela de esforço normal, pela resistência de cálculo do filete $\phi R_{n}$ por unidade de comprimento, levando-se em consideração a ruptura da solda na seção efetiva e o escoamento do metal base na face de fusão.

$$
\sum \mathrm{L}_{\mathrm{s}}=\frac{\mathrm{N}}{\phi \mathrm{R}_{\mathrm{n}}}
$$




\subsection{Solda de composição em perfis}

Segundo MALITE et al. [ 40 ], a fabricação de perfis através da composição de chapas é uma prática bastante comum. Isto ocorreu devido à necessidade de se obter perfis diferentes dos laminados disponíveis no mercado.

Até a década de 50 tal composição era feita com a utilização de rebites, mas com o aprimoramento das técnicas de soldagem, a grande maioria dos perfis compostos passaram a ser confeccionados por meio de soldas.

No Brasil, devido à pequena gama de perfis laminados e a total inexistência de laminados de abas planas, resta a opção de perfis soldados. Esses perfís apresentam custos mais elevados em comparação com os laminados, mas apresentam como vantagem a grande liberdade de escolha das dimensões da seção transversal. A fig. 7-8 mostra os tipos mais comuns de perfis soldados.

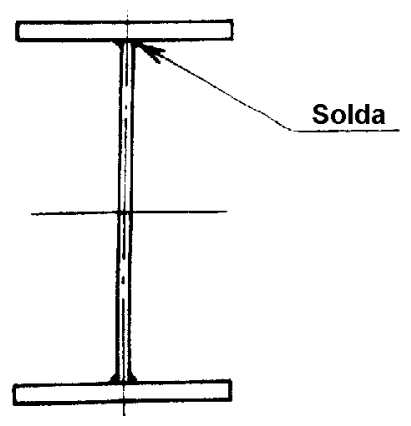

(a)

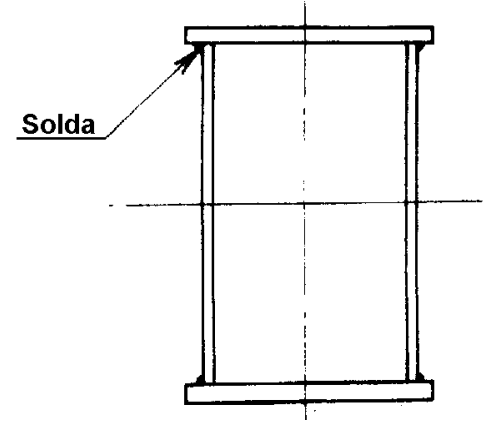

(b)

FIGURA 7-8 Exemplos de perfis soldados. (a) Perfil I; (b) seção caixão. Adaptada de MALITE et al. [ 40 ].

A solda de composição, que pode ser filete ou chanfro, deve resistir às tensões normais e de cisalhamento na interface mesa-alma, conferindo o trabalho conjunto destes elementos. A fig. 7-9 ilustra a distribuição destas tensões na seção transversal, proveniente da flexão.

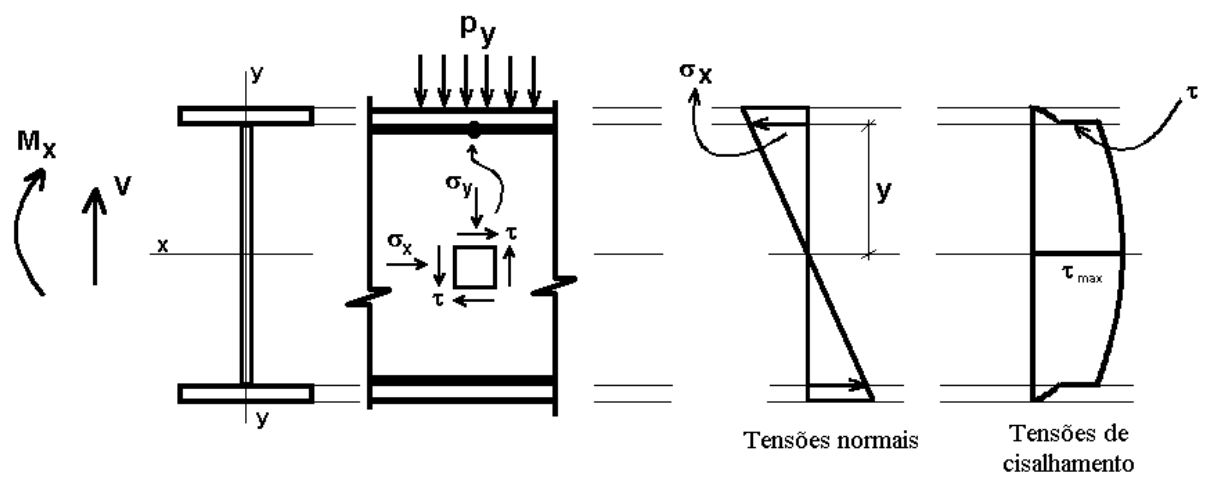

FIGURA 7-9 Distribuição de tensões normais e de cisalhamento na flexão. Adaptada de SCHULTE \& YAGUI [ 63 ]. 
No caso geral, devem ser admitidas as seguintes tensões:

a) tensão normal perpendicular ao eixo da solda $\left(\sigma_{y}\right)$

$$
\sigma_{\mathrm{y}}=\frac{\mathrm{p}_{\mathrm{y}}}{\mathrm{a}}
$$

b) tensão normal paralela ao eixo da solda $\left(\sigma_{x}\right)$

$$
\sigma_{x}=\frac{M_{x}}{I_{x}} y
$$

c) tensão de cisalhamento $(\tau)$

$$
\tau=\frac{\mathrm{VM}_{\mathrm{s}}}{\mathrm{I}_{\mathrm{x}} \mathrm{t}}
$$

onde: $p_{y}=$ força perpendicular ao eixo da barra, admitida uniformemente distribuída no trecho analisado

$\mathrm{M}_{\mathrm{x}}=$ momento fletor em relação ao eixo $x$

$\mathrm{V}=$ força cortante

$\mathrm{I}_{\mathrm{X}}=$ momento de inércia em relação ao eixo de flexão $x$

$\mathrm{M}_{\mathrm{S}}=$ momento estático correspondente à interface mesa-alma

$\mathrm{t}$ = garganta efetiva da solda ou dimensão teórica da face de fusão. Por exemplo, admitindo-se solda de composição constituída por dois filetes, $\mathrm{t}=$ $2 \mathrm{a}(\mathrm{a}=$ garganta efetiva $=0,7 \mathrm{~b})$, ou $\mathrm{t}=2 \mathrm{~b}(\mathrm{~b}=$ dimensão efetiva ou perna do filete)

$\mathrm{y}=$ distância da interface mesa-alma à linha neutra

É importante salientar que as tensões $\sigma_{x}, \sigma_{y}$ e $\tau$ devem ser avaliadas para uma mesma seção transversal da barra. A consideração do efeito combinado das tensões normais e de cisalhamento pode ser feita mediante um critério de resistência, como por exemplo o critério da energia de distorção (von Mises), o qual estabelece uma tensão ideal $\sigma_{i}$, cujo valor para o estado plano de tensões é dado por:

$$
\sigma_{\mathrm{i}}=\sqrt{\sigma_{\mathrm{x}}^{2}+\sigma_{\mathrm{y}}^{2}-\sigma_{\mathrm{x}} \sigma_{\mathrm{y}}+3 \tau^{2}}
$$


Para o método dos estados limites, o valor de cálculo da tensão ideal $\sigma_{i d}$, deve ser igual ou inferior à resistência de cálculo da solda.

Em seções delgadas de abas largas, como as seções "I", “U” ou caixão, é razoável admitir que a tensão de cisalhamento seja uniformemente distribuída ao longo da altura da alma, desprezando a contribuição das mesas (fig. 7-10), o que implica num erro relativamente pequeno. Com esta aproximação, a tensão de cisalhamento é dada por:

$$
\tau=\tau_{\mathrm{m}}=\frac{\mathrm{V}}{\mathrm{A}_{\mathrm{w}}}
$$

onde: $\tau_{\mathrm{m}}=$ tensão de cisalhamento média na alma

$\mathrm{A}_{\mathrm{w}}=$ área da alma

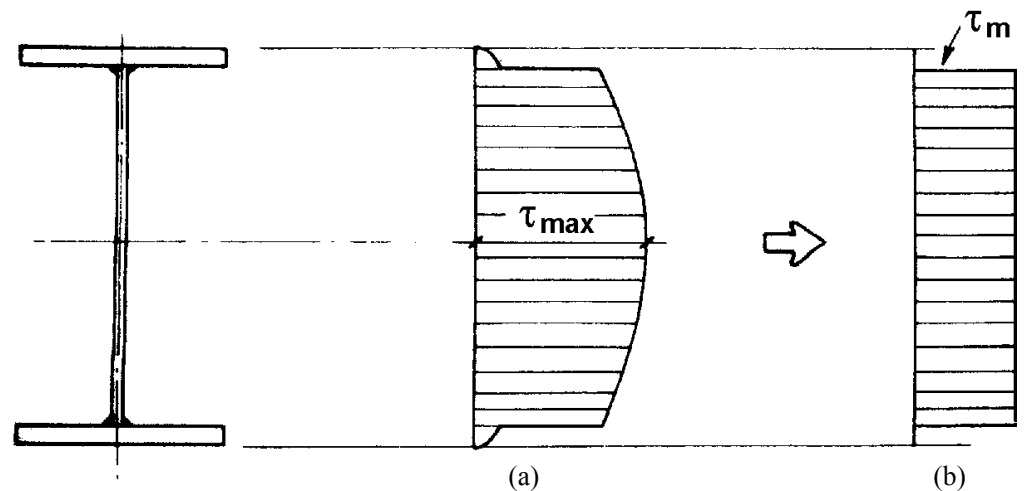

FIGURA7-10 (a) Distribuição real da tensão de cisalhamento em seção I, (b) distribuição uniforme da tensão de cisalhamento na alma em seção I. Adaptada de MALITE et al. [ 40 ].

Segundo PFEIL \& PFEIL [ 54 ], ensaios demostram que o dimensionamento das soldas de composição de perfis, não submetidos a elevadas forças concentradas, pode ser feito considerando apenas a tensão de cisalhamento na interface mesa-alma.

Quando o perfil é projetado para uma determinada utilização, ou seja, sabese a priori quais as ações e os correspondentes esforços, a solda é naturalmente dimensionada para tais esforços. Contudo, na maioria dos casos, os perfís soldados são fabricados para uso geral e conseqüentemente os esforços não são previamente conhecidos. Nestes casos, a solda de composição deve ser projetada para uma força cortante igual à própria resistência da seção à força cortante. 


\subsection{Ligações flexíveis}

Segundo MAGALHÃES \& MALITE [ 38 ], levando-se em consideração a questão das conexões flexíveis, uma alternativa muito utilizada consiste na adoção de cantoneiras de assento fixadas à mesa do pilar, no caso de conexões viga-pilar, ou fixadas na alma da viga, no caso de conexões viga-viga. Essas cantoneiras, que podem ser tanto soldadas (fig. 7-11a) quanto parafusadas (figuras 7-11b e c), são de grande utilidade na montagem da viga e, eventualmente, a cantoneira localizada junto a mesa inferior, pode ser verificada para resistir à totalidade da força cortante atuante. Para garantir a estabilidade lateral da seção do apoio, utiliza-se outra cantoneira junto à mesa superior e/ou uma chapa ou cantoneira na alma.

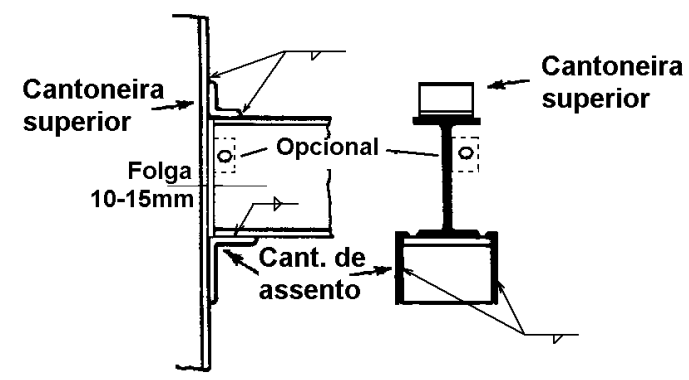

(a)

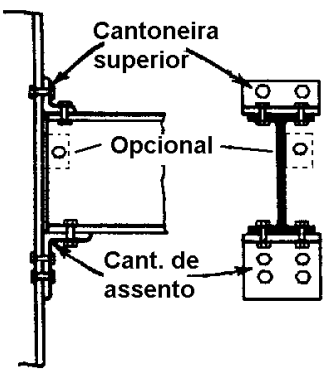

(b)

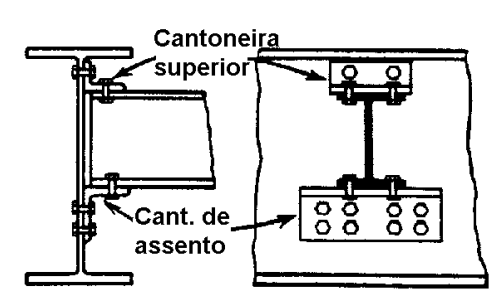

(c)

FIGURA 7-11 Ligações flexíveis com cantoneiras de assento. (a) Conexão viga-pilar com cantoneiras soldadas; (b) conexão vigapilar com cantoneiras parafusadas; (c) conexão viga-viga com cantoneiras parafusadas. Adaptada de CRAWLEY \& DILLON [ 19

Os norte-americanos adotam esta ]. solução com intensa freqüência, tanto que os manuais do AISC apresentam tabelas específicas para o dimensionamento destes elementos. Já no Brasil e em muitos países da Europa, este tipo de conexão é pouco utilizado, dando-se preferência às clássicas conexões flexíveis com cantoneiras de alma, exemplificadas posteriormente na fig. 7-16. Em alguns casos utiliza-se as cantoneiras de assento somente como elementos auxiliares na montagem, onde estas podem ser parafusadas no pilar e posteriormente removidas. 
Estes tipos de conexões, devido a restrição ao giro da extremidade da viga ser relativamente pequena, podem ser consideradas como flexíveis, ou seja, admitidas como apoio simples.

Segundo PFEIL [ 53 ], em conexões com cantoneiras de assento, utilizandose uma cantoneira relativamente fina na parte superior ou na parte lateral, a flexibilidade desse tipo de ligação é garantida, adotando-se uma tensão de flexão elevada na cantoneira de apoio. Além disso, no caso de cantoneiras soldadas, as soldas são posicionadas de maneira a produzir pequena rigidez, como mostra a fig. 7$11 \mathrm{a}$.

Segundo MAGALHÃES \& MALITE [ 38 ], já que a cantoneira superior e/ou a cantoneira de alma optativa são elementos puramente construtivos, cuja função principal é impedir deslocamentos laterais da viga no apoio, admite-se que a força cortante é totalmente resistida pela cantoneira de assento. Nesse caso, estes elementos considerados construtivos não são verificados, mas sim adotados de maneira adequada. O AISC/LRFD 86 [ 3 ] recomenda que a espessura mínima da aba da cantoneira superior deve ser $1 / 4$ " $(6,3 \mathrm{~mm})$.

Em relação à cantoneira de assento, cabe analisar os seguintes itens:

- Determinação da extensão mínima $N$ do apoio (ver fig. 7-12):

Essa verificação é feita levando em consideração o estado limite último de escoamento da alma da viga, caso não haja enrijecedores de alma no apoio.

$$
\mathrm{f}_{\mathrm{d}}=\frac{\mathrm{R}_{\mathrm{d}}}{\mathrm{t}_{\mathrm{w}}(\mathrm{N}+\mathrm{k})} \leq \phi \mathrm{f}_{\mathrm{y}} \rightarrow \mathrm{N} \geq \frac{\mathrm{R}_{\mathrm{d}}}{\phi \mathrm{f}_{\mathrm{y}} \mathrm{t}_{\mathrm{w}}}-\mathrm{k}
$$

onde: $\mathrm{R}_{\mathrm{d}}=$ reação de apoio de cálculo

$\mathrm{t}_{\mathrm{w}}=$ espessura da alma da viga

$\mathrm{k}=$ espessura da mesa apoiada na cantoneira de assento no caso de perfis soldados;

$\mathrm{k}$ = espessura da mesa apoiada na cantoneira de assento, mais o raio de concordância entre mesa e alma, no caso de perfis laminados

$\phi=0,90$

$\mathrm{f}_{\mathrm{y}}=$ limite de escoamento do aço 
Como pode-se notar na expressão 7.3.1, admitiu-se um espraiamento de tensões a $45^{\circ}(1: 1)$, como mostra a fig. $7-12$, que é o recomendado pela norma brasileira NBR 8800 [ 7 ]. Tendo em vista o caráter conservador desta hipótese, o AISC/LRFD 86 [ 3 ] recomenda adotar um espraiamento na proporção 2,5:1.

Recomenda-se que a dimensão da aba da cantoneira não deve ser inferior a 3" (76mm).

- Determinação da espessura mínima $t$ da aba da cantoneira:

A aba horizontal da cantoneira é verificada como uma viga em balanço, tomando-se como referência uma seção crítica localizada à uma distância de 3/8" $(10 \mathrm{~mm})$ da face interna da cantoneira, como mostra a fig. 7-12. Com isso, admitindose a resultante da pressão de contato $R$ localizada no centro da área de contato, temse:

$$
\mathrm{e}=\mathrm{e}_{\mathrm{f}}-\mathrm{t}-10 \mathrm{~mm}
$$

onde: $e_{\mathrm{f}}=$ folga $+\mathrm{N} / 2$

Admitindo-se plastificação total da seção crítica, tem-se a espessura requerida:

$$
\mathrm{M}_{\mathrm{d}}=\mathrm{R}_{\mathrm{d}} \mathrm{e} \leq \phi_{\mathrm{b}} \mathrm{M}_{\mathrm{pl}}=\phi_{\mathrm{b}} \frac{\mathrm{Lt}^{2}}{4} \mathrm{f}_{\mathrm{y}} \quad \therefore \quad \mathrm{t} \geq \sqrt{\frac{4 \mathrm{R}_{\mathrm{d}} \mathrm{e}}{\phi_{\mathrm{b}} \mathrm{Lf}_{\mathrm{y}}}}
$$

onde: $\phi_{\mathrm{b}}=0,9$

$\mathrm{L}=$ comprimento da cantoneira 

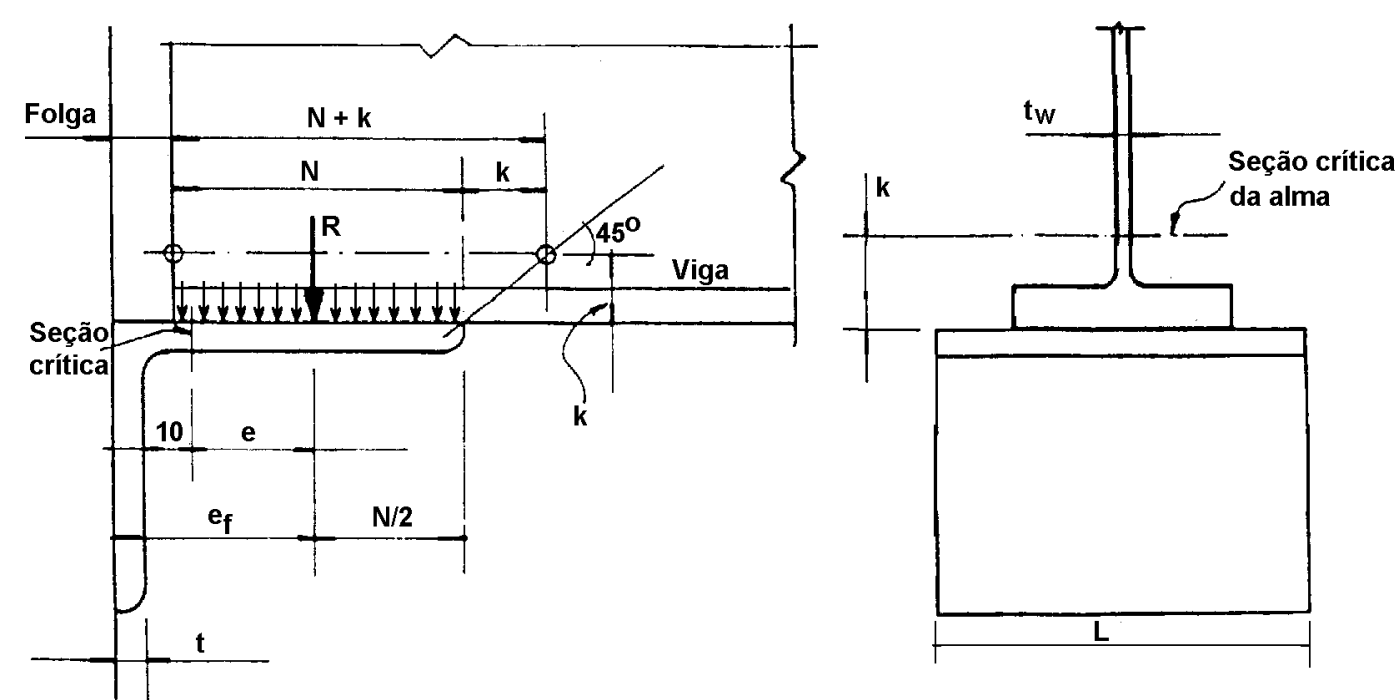

FIGURA 7-12 Vigas apoiadas em cantoneiras de assento. Adaptada de MAGALHÃES \& MALITE [ 38 ].

A distribuição uniforme da pressão de contato é considerada uma hipótese conservadora, uma vez que esta depende da rigidez à flexão da aba da cantoneira. Se a aba for "muito" rígida, a resultante se aproxima da extremidade da cantoneira, como pode ser visto na fig. 7-13a. Caso contrário, se a aba da cantoneira apresentar pequena rigidez, esta se desloca acompanhando o giro da viga. Isto faz com que a distribuição de pressão de contato se inverta, fazendo a resultante aproximar-se da extremidade da viga, como mostra a fig. 7-13b.

Geralmente, a rigidez à flexão da aba da cantoneira é relativamente pequena, refletindo uma situação próxima à da fig. 7-13b. Conseqüentemente, o braço de alavanca obtido pela equação 7.3.2, resulta em valores exagerados. Por essa razão, BLODGETT [ 12 ] e o manual AISC/LRFD 86 [ 3 ], com base na condição de escoamento da alma da viga, recomendam adotar uma região de contato reduzida, onde o valor de $N$ é obtido pela igualdade na equação 7.3.1, ao invés de se tomar o comprimento total da aba (ver fig. 7-13c). Deste modo:

$$
\mathrm{N}=\frac{\mathrm{R}_{\mathrm{d}}}{\phi \mathrm{f}_{\mathrm{y}} \mathrm{t}_{\mathrm{w}}}-\mathrm{k}
$$

Esse tipo de redução somente faz sentido, quando se adota uma aba da cantoneira maior que a necessária, considerando como região efetiva de contato apenas aquela definida pela extensão $N$, reduzindo-se assim, o braço de alavanca. 


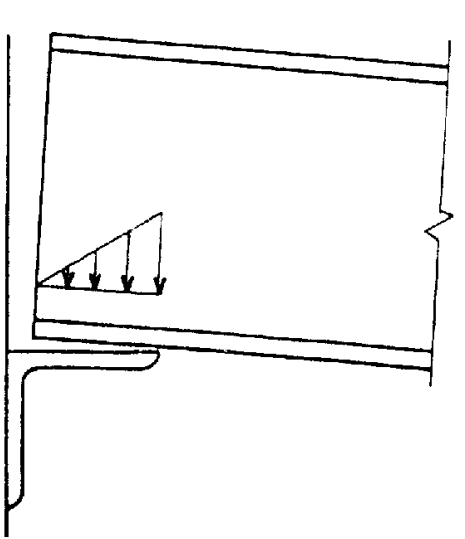

(a)

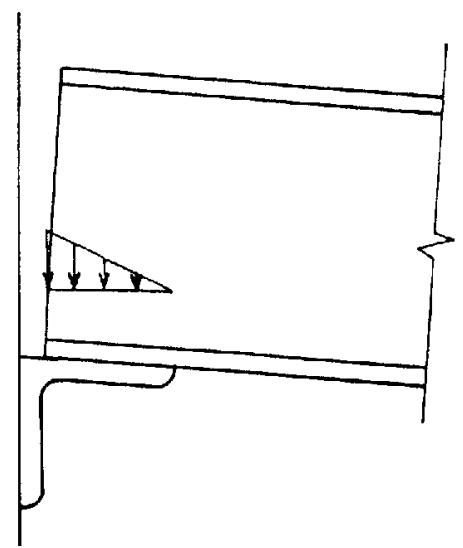

(b)

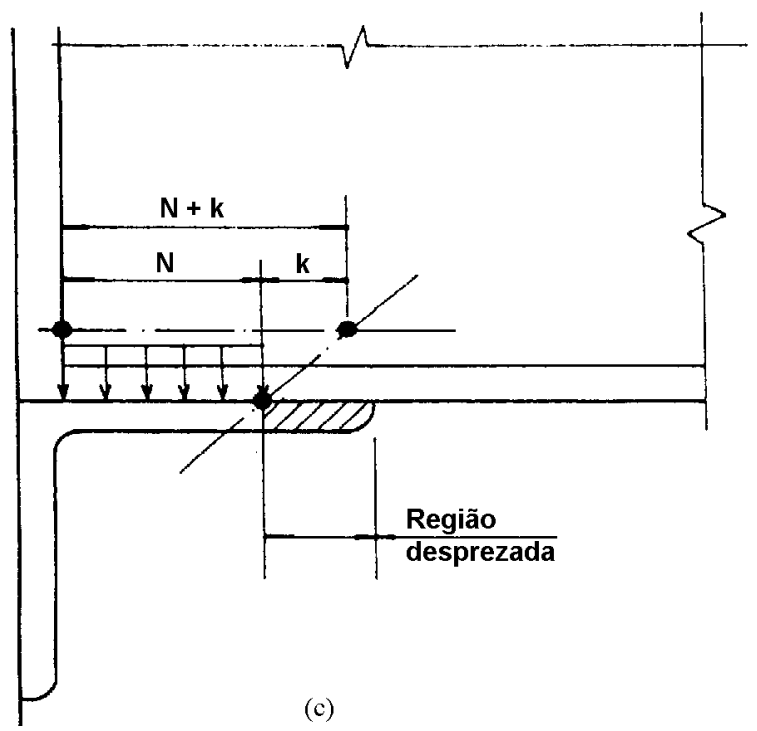

FIGURA 7-13 Distribuição da pressão de contato, (a) considerando aba da cantoneira com elevada rigidez; (b) considerando aba da cantoneira com pequena rigidez; (c) distribuição da pressão de contato na região reduzida. Adaptada de MAGALHÃES \& MALITE [ 38 ].

- Determinação da dimensão da aba vertical da cantoneira:

A dimensão da aba vertical é determinada em função do comprimento de solda necessário, ou no caso de abas parafusadas da quantidade de parafusos necessários. Da mesma forma que para a aba horizontal, deve-se adotar no mínimo uma aba de 3" (76mm).

Tanto o grupo de parafusos quanto o conjunto de soldas devem ser verificados considerando-se a força cortante associada com o momento fletor.

No caso de soldas, as tensões provenientes da força cortante são admitidas uniformemente distribuídas na solda vertical (fig. 7-14a), enquanto que as tensões provenientes do momento fletor são assumidas como linearmente distribuídas 
(figuras 7-14b e c). Deste modo, o ponto crítico da solda é aquele correspondente ao máximo valor da resultante vetorial de tensões.

$$
\mathrm{f}_{\mathrm{R}}=\sqrt{\mathrm{f}_{\mathrm{V}}^{2}+\mathrm{f}_{\mathrm{M}}^{2}}
$$

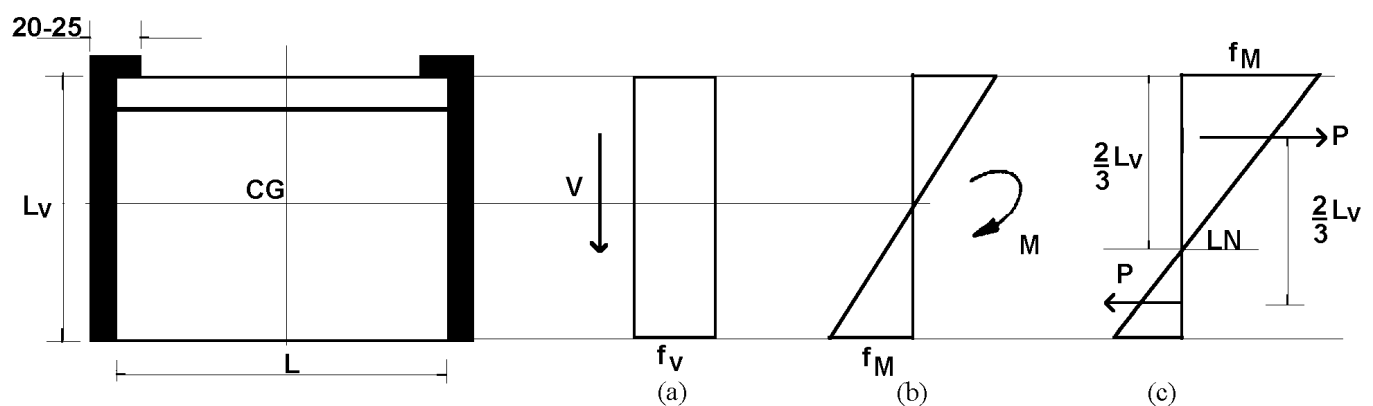

FIGURA 7-14 Distribuição de tensão na solda. (a) Distribuição de tensão devido à força cortante; (b) distribuição de tensão devido ao momento fletor, com relação ao CG; (c) distribuição de tensão devido ao momento fletor, com relação à LN. Adaptada de MAGALHÃES \& MALITE [ 38 ] e BLODGETT [ 12 ].

Pode-se notar através da fig. 7-14c, que a distribuição da tensão devido ao momento fletor não é mais considerada em relação ao centro de gravidade do conjunto das soldas, como na fig. 7-14b, mas sim em relação a posição da linha neutra, que é assumida a $2 / 3$ da parte superior da cantoneira. Levando isso em consideração BLODGETT [ 12 ], apresenta o seguinte desenvolvimento para a determinação da força resultante na solda.

Analisando a fig. 7-14c, tem-se:

Momento (em cada cordão de solda $)=\frac{\mathrm{R}}{2}\left(\mathrm{e}_{\mathrm{f}}\right)=\mathrm{P} \frac{2}{3} \mathrm{~L}_{\mathrm{v}}$

$$
\mathrm{P}=\frac{1}{2}\left(\mathrm{f}_{\mathrm{M}}\right) \frac{2}{3}\left(\mathrm{~L}_{\mathrm{v}}\right)
$$

Deste modo, tem-se que a força por unidade de comprimento, devido ao momento fletor na solda é:

$$
\mathrm{f}_{\mathrm{M}}=\frac{2,25 \mathrm{Re}_{\mathrm{f}}}{\mathrm{L}_{\mathrm{v}}{ }^{2}}
$$

E a força resultante por unidade de comprimento, devido à força cortante é:

$$
f_{v}=\frac{R}{2 L_{v}}
$$


Com isso, tomando a soma vetorial das duas componentes tem-se:

$$
f_{R}=\sqrt{\left(\frac{R}{2 L_{v}^{2}}\right)^{2}+\left(\frac{2,25 \mathrm{Re}_{f}}{L_{v}^{2}}\right)^{2}}=\frac{R}{2 L_{v}^{2}} \sqrt{L_{v}^{2}+20,25 e_{f}^{2}}
$$

É interessante notar que se o comprimento da cantoneira de assento em relação à dimensão da sua aba for relativamente grande, a verificação da $a b a$ horizontal admitindo-se uma faixa em balanço, conforme descrito anteriormente, deixa de ser razoável. Desta forma, recomenda-se executar uma solda na face horizontal da cantoneira como mostra a fig. 7-15, que impede a entrada de umidade e sujeira, consistindo em um aspecto positivo em relação à corrosão.

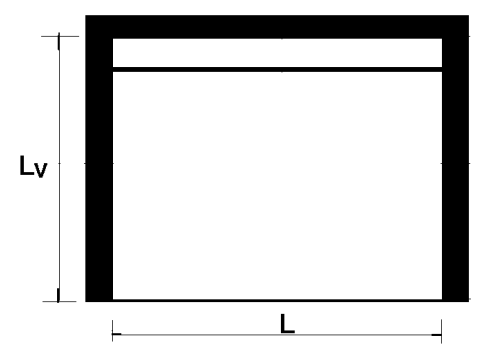

FIGURA 7-15 Detalhe de solda recomendado. Adaptada de MAGALHÃES \& MALITE [ 38 ].

No caso de ligações flexíveis com cantoneiras na alma, como mencionado anteriormente, bastante utilizadas no Brasil, os elementos podem ser apoiados por meio de duas cantoneiras flexíveis ligadas à alma da viga e à peça suporte, como mostra a fig. 7-16.

Segundo PFEIL [ 53 ], a altura das cantoneiras deve ser suficiente para fornecer restrição lateral à viga junto aos apoios. Geralmente, essas cantoneiras possuem entre $1 / 2$ a $2 / 3$ da altura da alma da viga. Contudo, a espessura das cantoneiras deve ser pequena, de maneira a garantir a flexibilidade da ligação. 


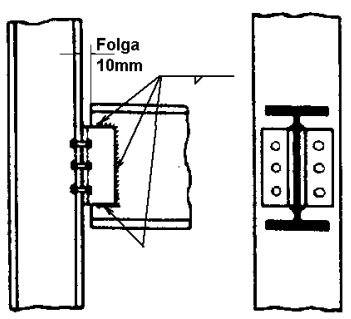

(a)

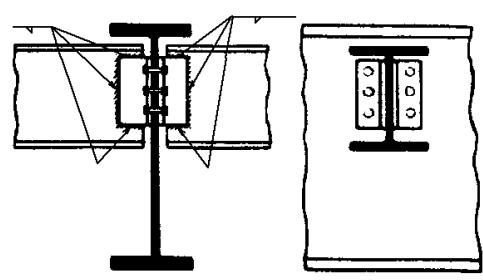

(c)

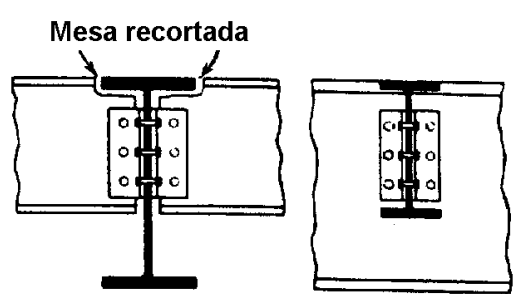

(b)

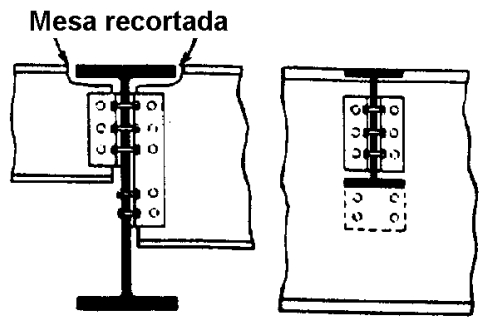

(d)

FIGURA 7-16 Conexões flexíveis com cantoneiras de alma. (a) Conexão viga-pilar; (b) conexão viga-viga com mesa recortada; (c) conexão viga-viga com mesas em planos diferentes. (d) conexão viga-viga com variação de seção. Adaptada de CRAWLEY \& DILLON [ 19 ].

Em vigas com seção "I", a maior parcela do momento fletor é equilibrada pelas mesas, enquanto o elemento responsável pela resistência à força cortante é a alma. Desta forma, ao se admitir uma ligação articulada, procura-se apenas transmitir força cortante, ficando claro que a ligação somente deve ser feita através da alma. Entretanto, alguma restrição ao giro ocorrerá e este fato deve ser levado em consideração no dimensionamento da conexão.

De maneira a analisar este tipo de conexão, tem-se a cantoneira soldada na viga e parafusada no elemento suporte, como mostra a fig. 7-17.

Para se analisar a solda cantoneira-alma, admite-se a existência de uma rótula na face do pilar ou na linha de centro da alma suporte, no caso de conexão viga-viga, recaindo-se então num caso de grupo de soldas sob carregamento excêntrico. Pelo método vetorial, as tensões na solda são avaliadas tomando-se a força centrada $V_{d} / 2$, ou seja, atuando no centro de gravidade do grupo de soldas e o momento de torção dado por $V_{d} / 2$ vezes a excentricidade $e_{1}$.

A hipótese de se admitir uma rótula junto à seção do apoio é conservadora, pois despreza o momento de reação que apareceria nesta região, entretanto, simplifica a análise. 


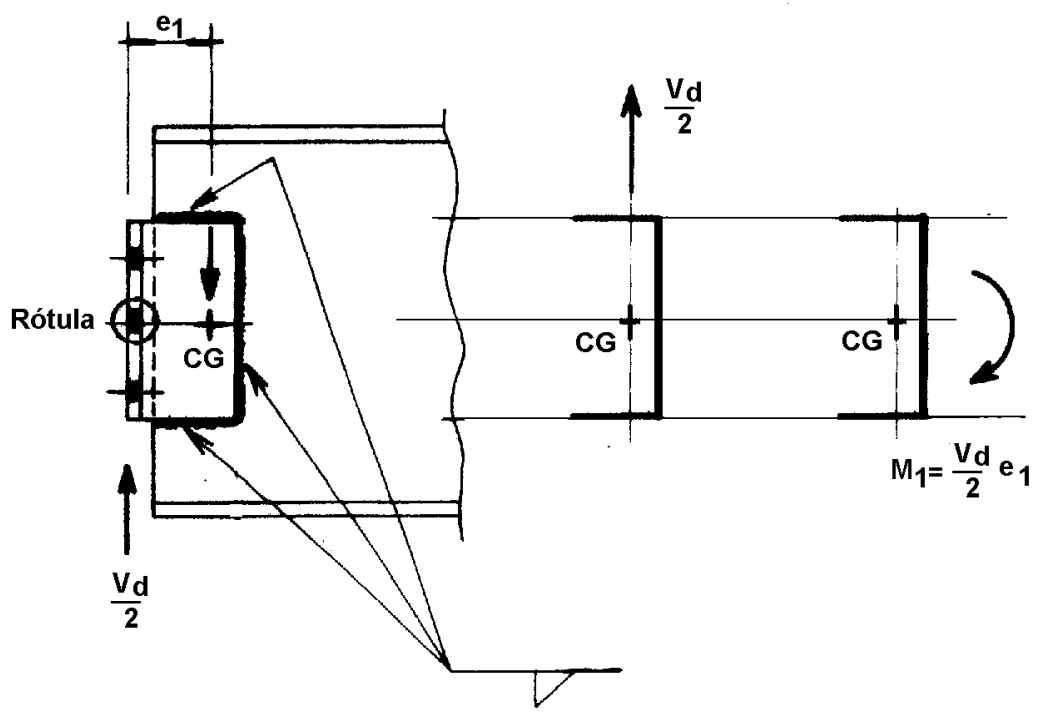

FIGURA 7-17 Hipótese da distribuição da força e momento na solda da cantoneira. Adaptada de MALITE et al. [ 40 ].

Tomando as tensões no ponto crítico, mostrado na fig. 7-18, e fazendo a soma vetorial dessas tensões, tem-se:

$$
\mathrm{F}_{\mathrm{R}}=\sqrt{\left(\mathrm{F}_{\mathrm{Mx}}\right)^{2}+\left(\mathrm{F}_{\mathrm{My}}+\mathrm{F}_{\mathrm{V}}\right)^{2}}
$$

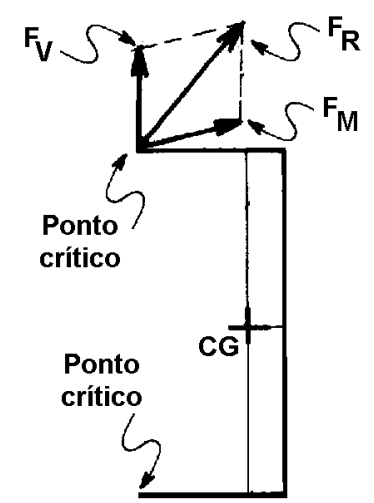

FIGURA 7-18 Tensões no ponto crítico da solda. Adaptada de MALITE et al. [ 40 ].

Com a tensão crítica obtida, deve-se verificar a ruptura da solda na seção efetiva e o escoamento do metal base na face de fusão.

$\mathrm{Na}$ verificação dos parafusos, os mais críticos são os superiores, pois são solicitados à tração e cortante simultaneamente. A tração é proveniente do momento de extremidade $M_{1}$ e a cortante da ação combinada da força cortante $V_{d}$ e do momento $M_{2}$. Da mesma maneira que efetuado para a determinação das forças na solda, é admitida uma rótula no centro de gravidade do conjunto de soldas. 
Analisando apenas um lado da conexão, devido à simetria, e admitindo distribuição linear de deformações (ver fig. 7-19), pode-se calcular a força de tração nos parafusos:
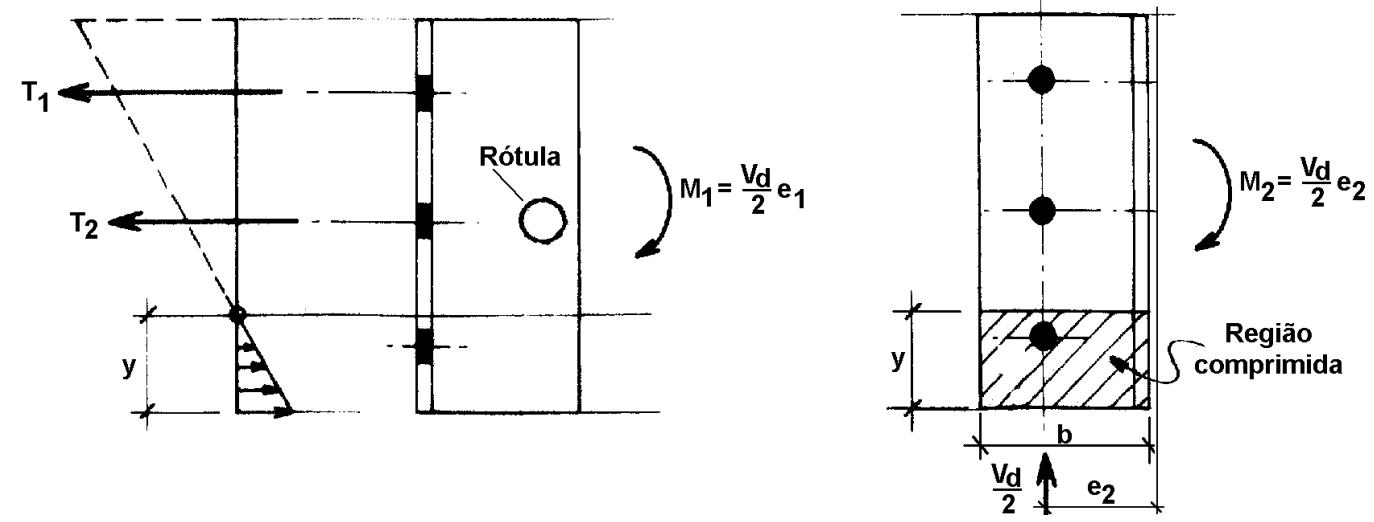

FIGURA 7-19 Distribuição das forças de tração nos parafusos. Adaptada de MALITE et al. [ 40 ].

A linha neutra é determinada igualando o momento estático da porção tracionada com o momento estático da porção comprimida:

$$
\frac{\mathrm{y}}{2}(\mathrm{yb})=\sum \mathrm{A}_{\mathrm{i}}\left(\mathrm{d}_{\mathrm{i}}-\mathrm{y}\right)
$$

Com a linha neutra obtém-se o momento de inércia:

$$
\mathrm{I}=\mathrm{b} \frac{\mathrm{y}^{3}}{3}+\sum \mathrm{A}_{\mathrm{i}} \mathrm{y}_{\mathrm{i}}^{2}
$$

onde: $\mathrm{d}_{\mathrm{i}}=$ distância do parafuso genérico em relação a base da cantoneira.

$\mathrm{y}_{\mathrm{i}}=$ distância do parafuso genérico em relação a linha neutra

Deste modo, a força de tração no parafuso mais solicitado é:

$$
\mathrm{T}_{1}=\frac{\mathrm{M}_{1} \mathrm{~A}_{\mathrm{p}}}{\mathrm{I}} \mathrm{y}_{1}
$$

Levando em consideração o método vetorial elástico, tem-se as seguintes forças de cisalhamento atuando no parafuso, como mostra a fig. 7-20: 


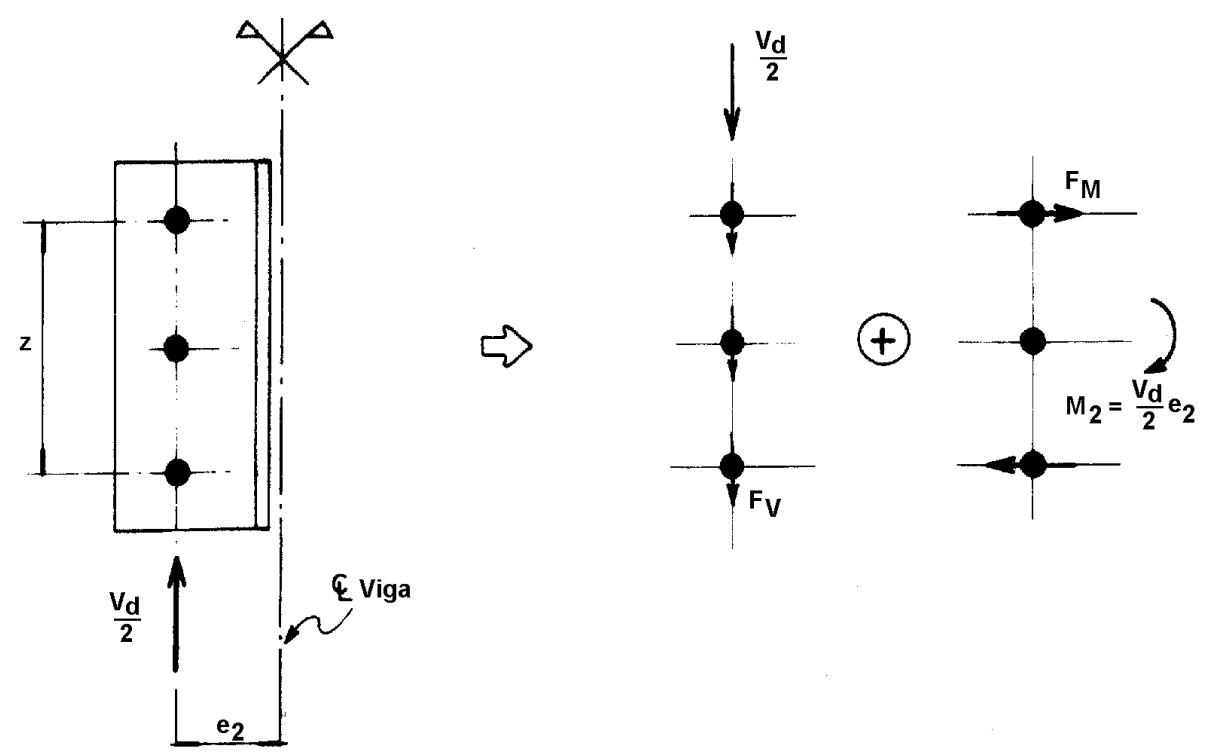

FIGURA 7-20 Forças de cisalhamento nos parafusos. Adaptada de MALITE et al. [ 40 ].

Através de soma vetorial das forças, tem-se a força de cisalhamento resultante atuando no parafuso mais solicitado:

$$
\mathrm{F}_{\mathrm{p}}=\sqrt{\mathrm{F}_{\mathrm{V}}^{2}+\mathrm{F}_{\mathrm{M}}{ }^{2}}=\sqrt{\left(\frac{\mathrm{V}_{\mathrm{d}} / 2}{\mathrm{n}}\right)^{2}+\left(\frac{\mathrm{M}_{2}}{\mathrm{z}}\right)^{2}}
$$

onde: $\mathrm{n}=$ número de parafusos por cantoneira

Com essas forças de tração e de cisalhamento assim determinadas, deve-se verificar as resistências de cálculo, quanto ao cisalhamento, tração e a combinação dos dois, além da pressão de contato nos furos.

No caso da verificação da cantoneira deve-se levar em consideração dois estados limites últimos que são:

- escoamento por tensões de cisalhamento na seção bruta:

$\phi \mathrm{R}_{\mathrm{n}}=0,9\left(0,6 \mathrm{f}_{\mathrm{y}}\right) \mathrm{A}_{\mathrm{g}}$

- ruptura por tensões de cisalhamento na seção líquida:

$\phi \mathrm{R}_{\mathrm{n}}=0,75\left(0,6 \mathrm{f}_{\mathrm{u}}\right) \mathrm{A}_{\mathrm{n}}$

onde: $\mathrm{A}_{\mathrm{g}}=$ área bruta da cantoneira

$\mathrm{A}_{\mathrm{n}}=$ área líquida da cantoneira, ou seja, área bruta menos a área dos furos 
Segundo QUEIROZ [ 56 ], o par de cantoneiras deve estar localizado próximo à mesa superior da viga, permitindo, é claro, a execução das soldas superiores da ligação.

Outro tipo de ligação flexível utilizada são as ligações utilizando chapas de extremidade, que consiste de uma chapa de cisalhamento soldada na alma da viga, perpendicularmente ao seu eixo longitudinal, como mostra a fig. 7-21.

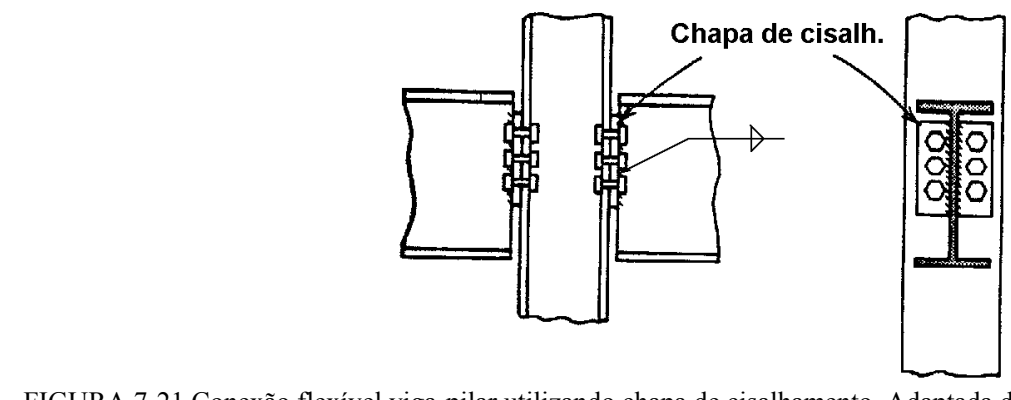

FIGURA 7-21 Conexão flexível viga-pilar utilizando chapa de cisalhamento. Adaptada de CRAWLEY \& DILLON [ 19 ].

Segundo o Manual Brasileiro para Cálculo de Estruturas Metálicas [ 14 ], o comprimento da chapa de cisalhamento deve ser menor que alma da viga e devem ser usadas soldas de filete em ambos os lados da alma.

Este tipo de ligação pode ser comparado ao de cantoneiras duplas, uma vez que, possuindo mesmas espessuras, mesmo gabarito e comprimento de ligação, estas ligações possuem similares capacidades de resistência e de rotação.

A fabricação da ligação com chapa de cisalhamento requer maior cuidado no corte do perfil, tomando-se cuidado em manter a perpendicularidade das suas extremidades, bem como o paralelismo da chapas da ligação. Deve-se observar ainda, que o efeito da contraflecha na viga não deve afetar a perpendicularidade das chapas de cisalhamento, o que poderia ocasionar dificuldades no alinhamento e conseqüentemente na montagem da estrutura.

É sugerido que a espessura destas chapas fique entre 6,0 e $10,0 \mathrm{~mm}$, de maneira a proporcionar uma liberdade de rotação adequada. Recomenda-se ainda, que não deve haver retorno da solda junto à alma. 
Uma importante verificação que deve ser feita em relação aos elementos de ligação é o colapso por rasgamento. Desta forma, devem ser analisadas todas as possibilidades de colapso por rasgamento ao longo das seções críticas. Na fig. 7-22 são mostrados exemplos de colapso por rasgamento, para algumas ligações.

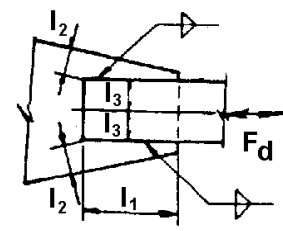

(1a)

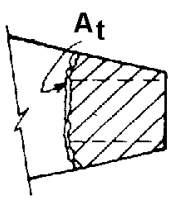

(1b)

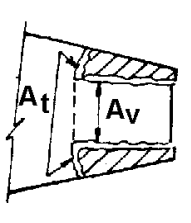

(1c)

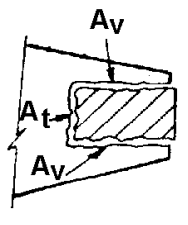

(1d)

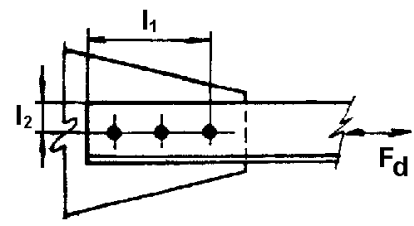

(2a)

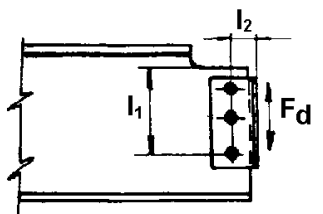

(3a)

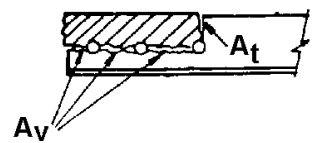

(2b)

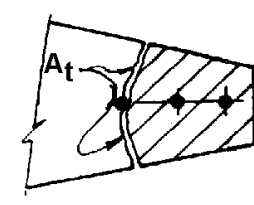

(2c)

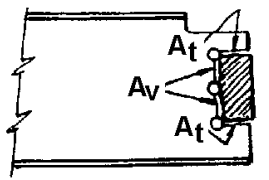

(3c)

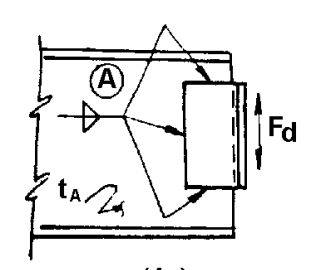

(4a)

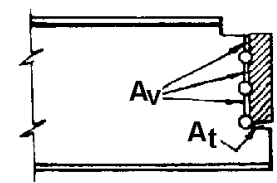

(3b)

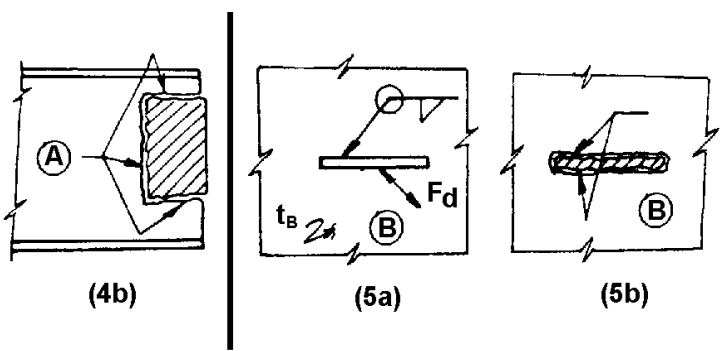

FIGURA 7-22 Exemplos de colapso por rasgamento. Adaptada de QUEIROZ [ 56 ].

Nos casos das figuras 7-22(1c), (2b) e (3b), caso se tenha $1_{1} \geq 31_{2}$, e no caso da fig. 7-22(1d), caso se tenha $1_{1} \geq 31_{3}$, a NBR 8800 [ 7 ] considera que as tensões de cálculo são constantes e podem ser determinadas dividindo a força de cálculo $F_{d}$ pela área da seção de rasgamento $\left(\mathrm{A}_{\mathrm{v}}+\mathrm{A}_{\mathrm{t}}\right)$, onde $A_{v}$ é a área de cisalhamento e $A_{t}$ é a área sujeita a tensões normais. Entretanto, tais tensões de cálculo devem ser consideradas de cisalhamento, mesmo as que atuam em $A_{t}$. 
Em situações como as mostradas nas figuras 7-22(4) e (5), a superposição de valores elevados de tensões normais e de cisalhamento no metal base adjacente à solda, nas chapas $A$ e $B$, respectivamente, torna necessária a aplicação de um critério de resistência (pode-se utilizar o critério da energia de distorção) para determinar as tensões equivalentes. Entretanto, alternativamente, pode-se determinar as tensões de cálculo no metal base adjacente à solda, multiplicando as tensões resultantes de cálculo na solda por $2 a / t_{A}$ para a chapa $A$ e por $2 a /\left(2 t_{B}\right)$ para chapa $B$, considerando as tensões assim obtidas como de cisalhamento, independentemente de sua direção ( $a$ é a garganta efetiva da solda de filete).

Segundo a NBR 8800 [ 7 ], a resistência de cálculo ao rasgamento, em termos de tensão, é dada por $\phi R_{n}$, com base em escoamento para seção bruta e ruptura para seção líquida. Como as tensões obtidas, na maioria dos casos, são consideradas como de cisalhamento, tem-se:

- escoamento para seção bruta: $\phi \mathrm{R}_{\mathrm{n}}=0,9\left(0,6 \mathrm{f}_{\mathrm{y}}\right)$

- ruptura para seção líquida: $\phi \mathrm{R}_{\mathrm{n}}=0,75\left(0,6 \mathrm{f}_{\mathrm{u}}\right)$

Segundo o AISC/LFRD 93 [ 4 ], o cisalhamento em bloco é um estado limite em que a resistência é determinada pela soma da resistência ao cisalhamento de um “caminho de falha" e a resistência à tração de um segmento perpendicular. Quando a resistência à ruptura na seção líquida é usada para determinar a resistência de um segmento, o escoamento na seção bruta deve ser usado no segmento perpendicular.

Duas possíveis resistências dos blocos de cisalhamento podem ser calculadas: resistência à ruptura $f_{u}$ na seção líquida tracionada combinada com escoamento por cisalhamento $0,6 f_{y}$ na seção bruta no plano de cisalhamento (expressão 7.4.1), ou ruptura $0,6 f_{u}$ na área líquida de cisalhamento combinada com escoamento $f_{y}$ na área bruta tracionada (expressão 7.4.2). Deste modo, a resistência de cálculo à ruptura do bloco de cisalhamento, deve ser determinada como segue:

a) Quando $f_{u} A_{n t} \geq 0,6 f_{u} A_{n v}$ :

$\phi \mathrm{R}_{\mathrm{n}}=\phi\left(0,6 \mathrm{f}_{\mathrm{y}} \mathrm{A}_{\mathrm{gv}}+\mathrm{f}_{\mathrm{u}} \mathrm{A}_{\mathrm{nt}}\right)$

b) Quando $0,6 \mathrm{f}_{\mathrm{u}} \mathrm{A}_{\mathrm{nv}}>\mathrm{f}_{\mathrm{u}} \mathrm{A}_{\mathrm{nt}}$ :

$$
\phi \mathrm{R}_{\mathrm{n}}=\phi\left(0,6 \mathrm{f}_{\mathrm{u}} \mathrm{A}_{\mathrm{nv}}+\mathrm{f}_{\mathrm{y}} \mathrm{A}_{\mathrm{gt}}\right)
$$

onde: $\phi=0,75$ 
$\mathrm{A}_{\mathrm{gv}}=$ área bruta sujeita ao cisalhamento

$\mathrm{A}_{\mathrm{gt}}=$ área bruta sujeita à tração

$\mathrm{A}_{\mathrm{nv}}=$ área líquida sujeita ao cisalhamento

$\mathrm{A}_{\mathrm{nt}}=$ área líquida sujeita à tração

A expressão que controla é aquela que produz a maior força de ruptura. Isto pode ser explicado pelos dois exemplos extremos mostrados na fig. 7-23. No caso (a), a força total é resistida principalmente por cisalhamento, portanto a ruptura por cisalhamento, não escoamento por cisalhamento, deverá controlar o modo de rasgamento do bloco de cisalhamento, deste modo deve-se usar a expressão 7.4.2. Para o caso (b), o cisalhamento do bloco não poderá ocorrer até que a área tracionada rompa (expressão 7.4.1).

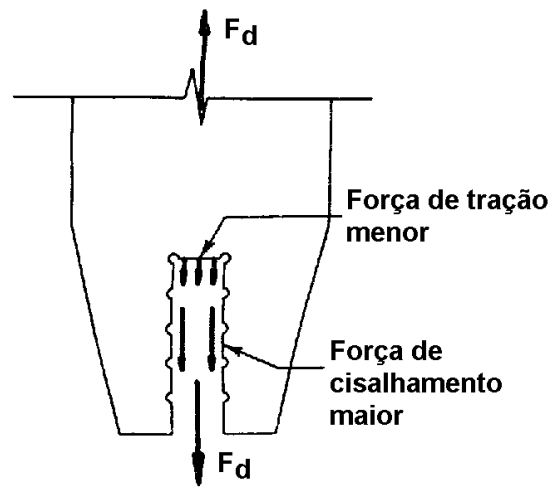

(a)

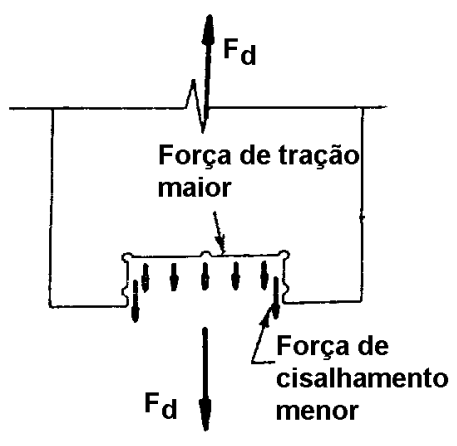

(b)

FIGURA 7-23 Bloco de cisalhamento em tração. Adaptada do AISC/LRFD 93 [ 4 ].

Segundo o EUROCODE 3 [ 24 ], a falha em um bloco de cisalhamento deve ser prevenida pelo uso de espaçamentos apropriados dos furos. Este modo de falha geralmente consiste na ruptura à tração ao longo da linha dos furos dos conectores na face tracionada, acompanhada pelo escoamento da seção bruta em cisalhamento na coluna dos furos dos conectores ao longo da face de cisalhamento, como mostra a fig. 7-24.

O valor de cálculo da resistência efetiva do bloco de cisalhamento $V_{\text {eff.Rd }}$ ( similar a $\phi R_{n}$ ) deve ser determinado como:

$$
\mathrm{V}_{\text {eff.Rd }}=\left(\mathrm{f}_{\mathrm{y}} / \sqrt{3}\right)\left(\mathrm{A}_{\mathrm{v} . \mathrm{eff}} / \gamma_{\mathrm{M}_{0}}\right)
$$


Onde $A_{v . e f f}$ é a área efetiva de cisalhamento, e deve ser determinada da seguinte maneira:

$A_{v . e f f}=t L_{v . e f f}$

onde: $\mathrm{L}_{\mathrm{v} \text {.eff }}=\mathrm{L}_{\mathrm{v}}+\mathrm{L}_{1}+\mathrm{L}_{2}$ mas $\mathrm{L}_{\mathrm{v} . \text { eff }} \leq \mathrm{L}_{3}$

$\mathrm{L}_{1}=\mathrm{a}_{1}$ mas $\mathrm{L}_{1} \leq 5 \mathrm{~d}$

$\mathrm{L}_{2}=\left(\mathrm{a}_{2}-\mathrm{kd}_{\mathrm{o.t}}\right)\left(\mathrm{f}_{\mathrm{u}} / \mathrm{f}_{\mathrm{y}}\right)$

$\mathrm{L}_{3}=\mathrm{L}_{\mathrm{v}}+\mathrm{a}_{1}+\mathrm{a}_{3}$ mas $\mathrm{L}_{3} \leq\left(\mathrm{L}_{\mathrm{v}}+\mathrm{a}_{1}+\mathrm{a}_{3}-\mathrm{nd}_{\mathrm{o.v}}\right)\left(\mathrm{f}_{\mathrm{u}} / \mathrm{f}_{\mathrm{y}}\right)$

$\mathrm{d}=$ diâmetro nominal dos conectores

$\mathrm{d}_{\mathrm{o} . \mathrm{t}}=$ dimensão do furo na face tracionada, geralmente o diâmetro do furo, mas para furos alongados horizontalmente o comprimento alongado deverá ser usado

$\mathrm{d}_{\text {o.v }}=$ dimensão do furo na face cisalhada, geralmente o diâmetro do furo, mas para furos alongados verticalmente o comprimento alongado deverá ser usado $\mathrm{n}=$ número dos furos na face de cisalhamento

$\mathrm{t}=$ espessura da chapa

$\mathrm{k}=0,5$ para uma coluna de conectores

$\mathrm{k}=2,5$ para duas colunas de conectores

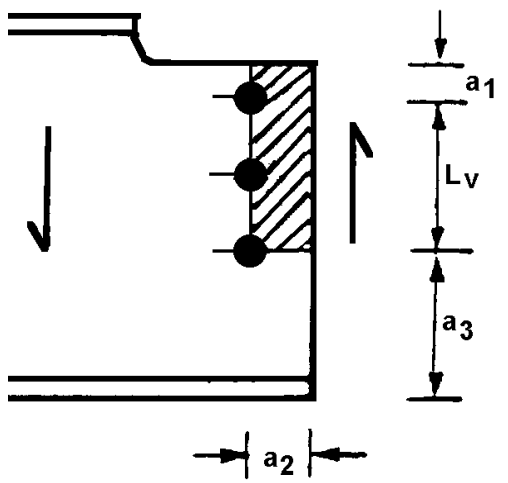

(a)

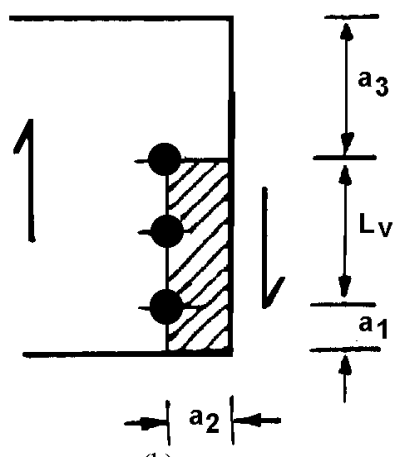

(b)

FIGURA 7-24 (a), (b), (c) Exemplos de cisalhamento em bloco (área efetiva de cisalhamento); (d) dimensão dos furos. Adaptada do EUROCODE 3 [ 24 ]. 


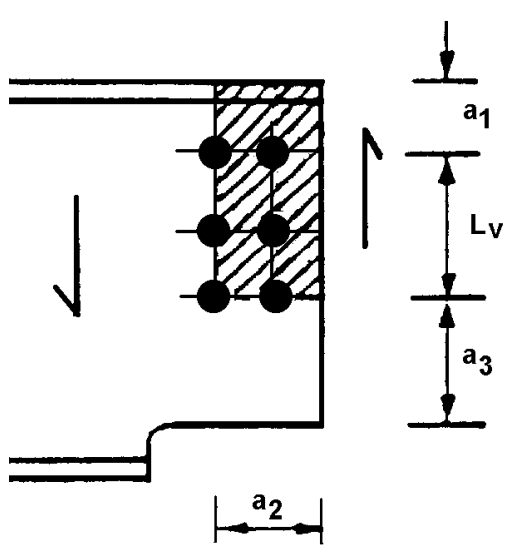

(c)

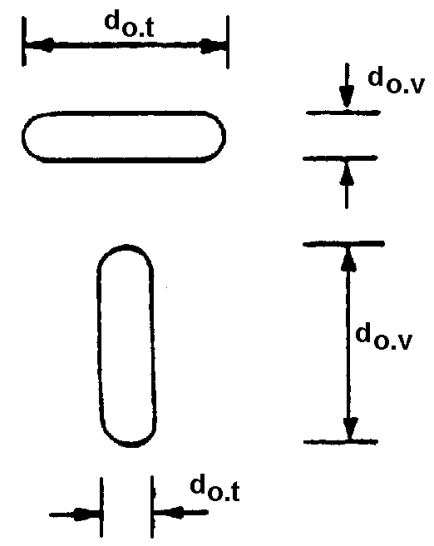

(d)

FIGURA 7-24 (a), (b), (c) Exemplos de cisalhamento em bloco (área efetiva de cisalhamento); (d) dimensão dos furos. Adaptada do EUROCODE 3 [ 24 ].

\subsection{Ligações com pinos}

Os pinos são conectores de grande diâmetro, que trabalham isoladamente, sem comprimir transversalmente as chapas. Os pinos trabalham por cisalhamento de sua seção transversal e pelo contato de sua superfície com as chapas conectadas.

Segundo PFEIL [ 53 ], existem os seguintes tipos de pinos estruturais:

- pinos que devem permitir elevados movimentos, como o que ocorre, por exemplo, nas torres de guindastes, pontes basculantes, entre outros. Eles trabalham com tensões de contato moderadas, ou seja, $\sigma_{\mathrm{c}}<0,4 \mathrm{f}_{\mathrm{y}}$. Estes pinos devem sempre estar lubrificados de maneira a reduzir o desgaste por atrito e corrosão.

- pinos que transmitem pequenas rotações, que são provocadas por deformações elásticas. Estes trabalham com tensões de contato mais elevadas, $\sigma_{\mathrm{c}}<$ $0,8 \mathrm{f}_{\mathrm{y}}$, e dispensam lubrificação.

Geralmente, os pinos são feitos com aço forjado ou laminado, sendo posteriormente torneados para as dimensões desejadas. Pinos com diâmetro de até 4" (100 mm) são usualmente feitos com uma cabeça fixa em uma extremidade e um pino de segurança na outra, como mostra a fig. 7-25a. Já pinos com diâmetro superiores, até 10" (250 mm), possuem geralmente as extremidades rosqueadas, para que se possa prender porcas especiais de segurança, como na fig. 7-25b. 

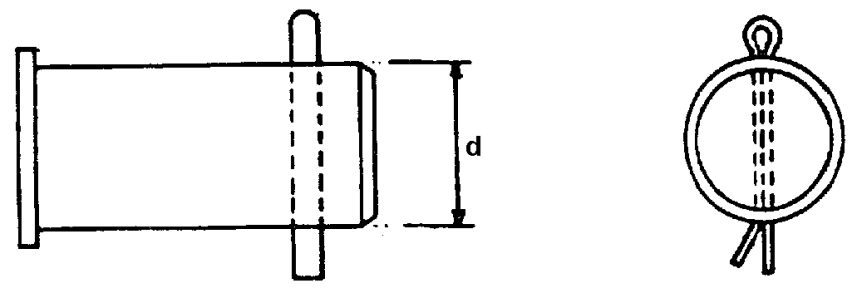

(a) $38 \mathrm{~mm}<$ d $<100 \mathrm{~mm}$
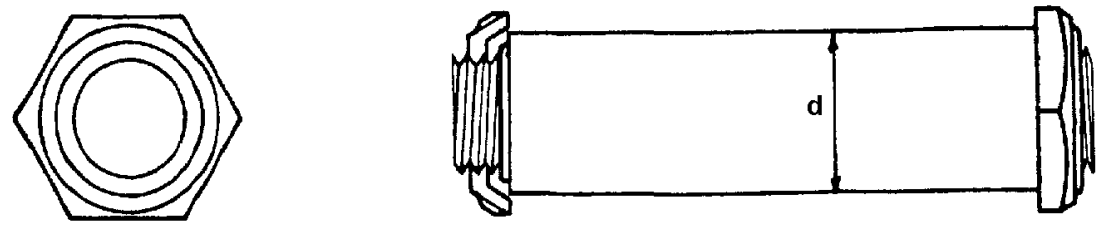

(b) $100 \mathrm{~mm}<\mathrm{d}<250 \mathrm{~mm}$

FIGURA 7-25 Exemplos de pinos. Adaptada de PFEIL [ 53 ].

Em muitos casos, quando as distâncias entre as chapas são elevadas, as tensões de flexão nos pinos são determinantes. Deste modo, segundo a NBR 8800 [ 7 ], no caso do cálculo dos momentos fletores em um pino, admite-se que as tensões de contato são uniformemente distribuídas ao longo da espessura. Se o pino passa através de chapas, cuja espessura é maior que a metade do diâmetro do pino, deve-se levar em consideração a variação das tensões de contato ao longo da espessura. Conseqüentemente, os momentos fletores atuando no pino devem ser determinados levando em consideração esta distribuição de tensão.

De acordo com a NBR 8800 [ 7 ], deve-se fazer três verificações de cálculo, que são:

- resistência de cálculo à flexão do pino:

$\phi_{\mathrm{b}} \mathrm{M}_{\mathrm{n}}=\phi_{\mathrm{b}} 1,2 \mathrm{Wf}_{\mathrm{y}}$

onde: $\mathrm{W}=$ módulo resistente elástico da seção do pino

$\mathrm{f}_{\mathrm{y}}=$ limite de escoamento do material do pino

$\phi_{\mathrm{b}}=0,9$

- resistência de cálculo ao corte do pino

$\phi_{\mathrm{v}} \mathrm{V}_{\mathrm{n}}=\phi_{\mathrm{v}} 0,60 \mathrm{~A}_{\mathrm{w}} \mathrm{f}_{\mathrm{y}}$

onde: $A_{w}=$ área efetiva de cisalhamento da seção do pino $=0,75 \mathrm{~A}_{\mathrm{g}}$

$\mathrm{A}_{\mathrm{g}}=$ área bruta da seção transversal do pino 
$\mathrm{f}_{\mathrm{y}}=$ limite de escoamento do material do pino

$\phi_{\mathrm{v}}=0,9$

- resistência de cálculo ao esmagamento do pino

$\phi \mathrm{R}_{\mathrm{n}}=\phi \operatorname{td}\left(1,5 \mathrm{f}_{\mathrm{y}}\right)$

onde: $\mathrm{t}=$ espessura da chapa

$\mathrm{d}=$ diâmetro do pino

$\mathrm{f}_{\mathrm{y}}=$ limite de escoamento do material do pino

$\phi=0,75$

Segundo a NBR 8800 [ 7 ], no dimensionamento das chapas de ligação (ver fig. 7-26), a resistência de cálculo à tração dessas chapas é baseada no estado limite de escoamento da seção líquida efetiva, ou seja:

$$
\phi_{\mathrm{t}} \mathrm{N}_{\mathrm{n}}=\phi_{\mathrm{t}} \mathrm{A}_{\mathrm{e}} \mathrm{f}_{\mathrm{y}}=\phi_{\mathrm{t}} 0,75 \mathrm{~A}_{\mathrm{n}} \mathrm{f}_{\mathrm{y}}
$$

onde: $A_{n}=2 b_{1} t_{1}$

$\phi_{\mathrm{t}}=0,90$

Além disso, são recomendadas as seguintes relações geométricas (ver fig. 726):

$$
\begin{aligned}
& b_{1} \leq 4 t_{1} ; b_{2} \geq 1,33 b_{1} ; b_{3} \geq 1,33 b_{1} \\
& d_{h} \geq 1,25 b_{1} ; d_{h} \leq\left\{\begin{array}{l}
d_{p}+0,8 m m \\
5 t_{1} \text { para } f_{y} \geq 420 M P a
\end{array}\right.
\end{aligned}
$$

A resistência de cálculo da chapa à pressão de contato, para o caso de pinos através de furos mandrilhados ou broqueados é:

$$
\phi \mathrm{R}_{\mathrm{n}}=\phi \operatorname{td}\left(1,5 \mathrm{f}_{\mathrm{y}}\right)
$$

onde: $f_{y}=$ tensão de escoamento do material da chapa

$$
\phi=0,75
$$




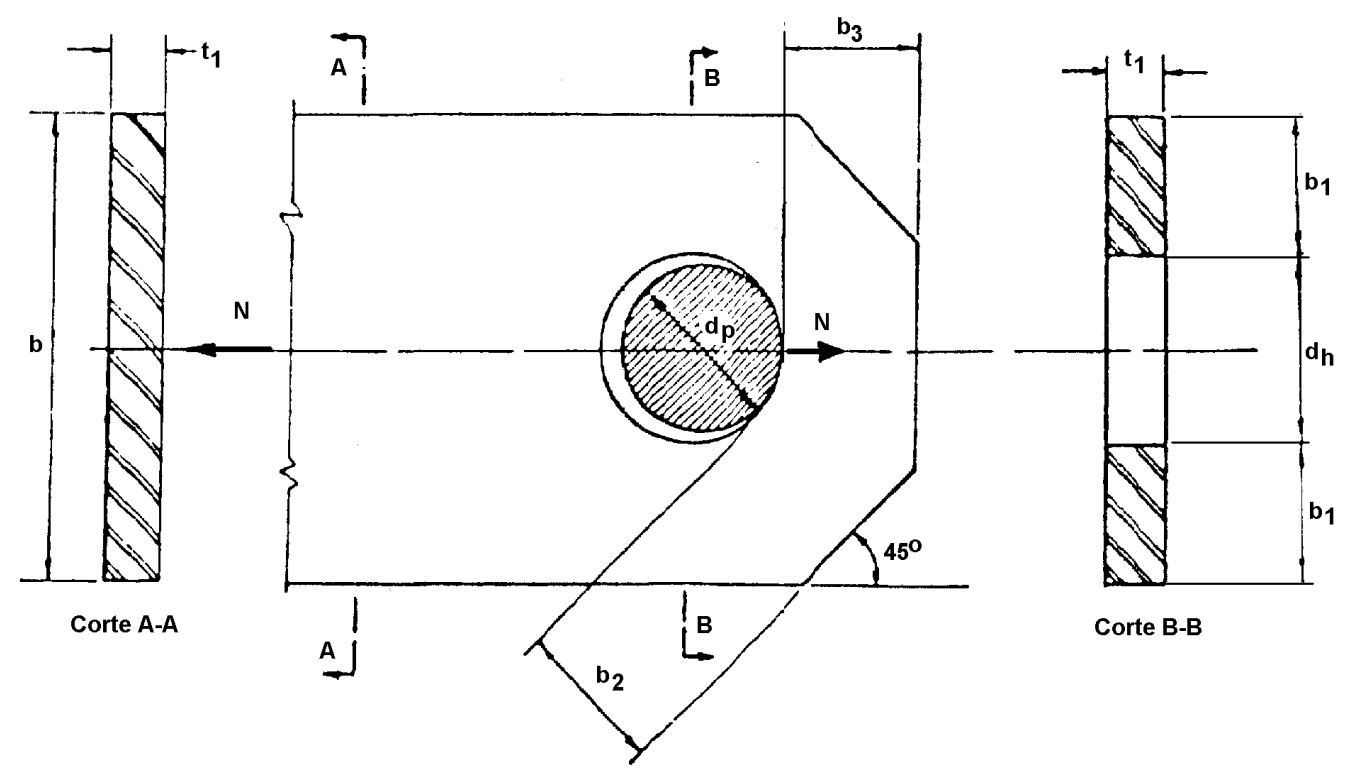

FIGURA 7-26 Chapa ligada por pino. Adaptada da NBR 8800 [ 7 ].

Em geral utilizam-se chapas de reforço na região do pino, de maneira a reduzir a pressão de contato.

Um procedimento alternativo ao aumento da espessura de contato do pino com chapa de reforço é a utilização de barras com olhal (ver fig. 7-27) de espessura constante e largura ampliada.

A resistência de cálculo à tração de olhais é determinada considerando o estado limite de escoamento da seção bruta:

$$
\phi_{\mathrm{t}} \mathrm{N}_{\mathrm{n}}=\phi_{\mathrm{t}} \mathrm{A}_{\mathrm{g}} \mathrm{f}_{\mathrm{y}}
$$

onde: $\mathrm{A}_{\mathrm{g}}=\mathrm{bt}$

$\phi_{\mathrm{t}}=0,90$

Além disso, são recomendadas as seguintes relações geométricas (ver fig. 727):

$$
\begin{aligned}
& d_{p} \geq 0,88 b \\
& 0,67 b \leq b_{1} \leq 0,75 b \\
& d_{h} \leq\left\{\begin{array}{l}
d_{p}+0,8 m m \\
5 t \text { para } f_{y} \geq 420 M P a
\end{array}\right.
\end{aligned}
$$




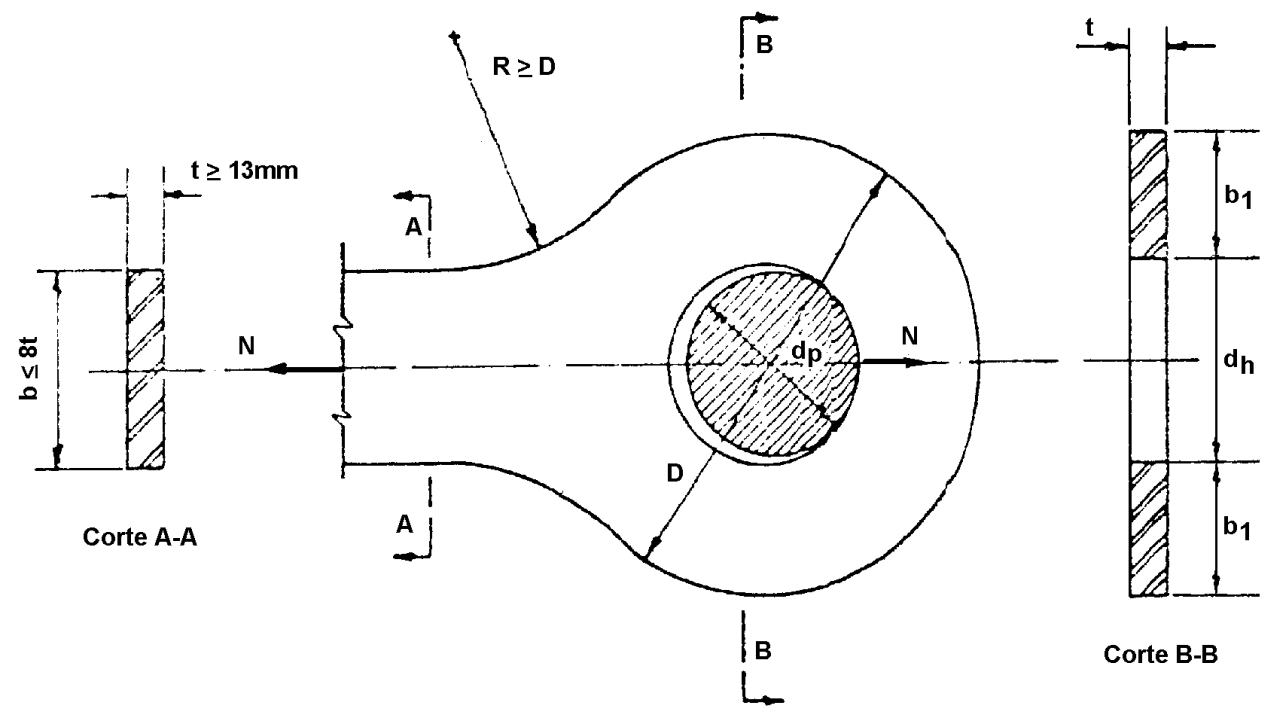

FIGURA 7-27 Barra com olhal. Adaptada da NBR 8800 [ 7 ].

O AISC/LRFD 93 [ 4 ], não especifica nenhuma verificação no corpo do pino, mas subentende-se que sua resistência de cálculo à flexão deve ser verificada, tanto para momento fletor quanto para força cortante.

Segundo o AISC/LRFD 93 [ 4 ], a resistência de cálculo da chapa de ligação deve ser o menor valor obtido entre os seguintes estados limites (ver fig. 7-28):

- tração na seção líquida efetiva:

$\phi_{\mathrm{t}} \mathrm{N}_{\mathrm{n}}=\phi_{\mathrm{t}} 2 \mathrm{tb}_{\mathrm{eff}} \mathrm{f}_{\mathrm{u}}$

- cisalhamento na seção efetiva:

$\phi_{\mathrm{sf}} \mathrm{N}_{\mathrm{n}}=\phi_{\mathrm{sf}} 0,6 \mathrm{~A}_{\mathrm{sf}} \mathrm{f}_{\mathrm{u}}$

onde: $\mathrm{t}=$ espessura da chapa

$b_{\text {eff }}=2 t+16 \mathrm{~mm}$, mas não maior que a distância do canto do furo à extremidade medida na direção normal à força aplicada

$\mathrm{A}_{\mathrm{sf}}=2 \mathrm{t}(\mathrm{a}+\mathrm{d} / 2)$

$\mathrm{a}=$ menor distância da extremidade do furo à extremidade da chapa medida paralelamente à direção da força aplicada

$\mathrm{d}=$ diâmetro do pino

$\phi_{\mathrm{t}}=\phi_{\mathrm{sf}}=0,75$ 


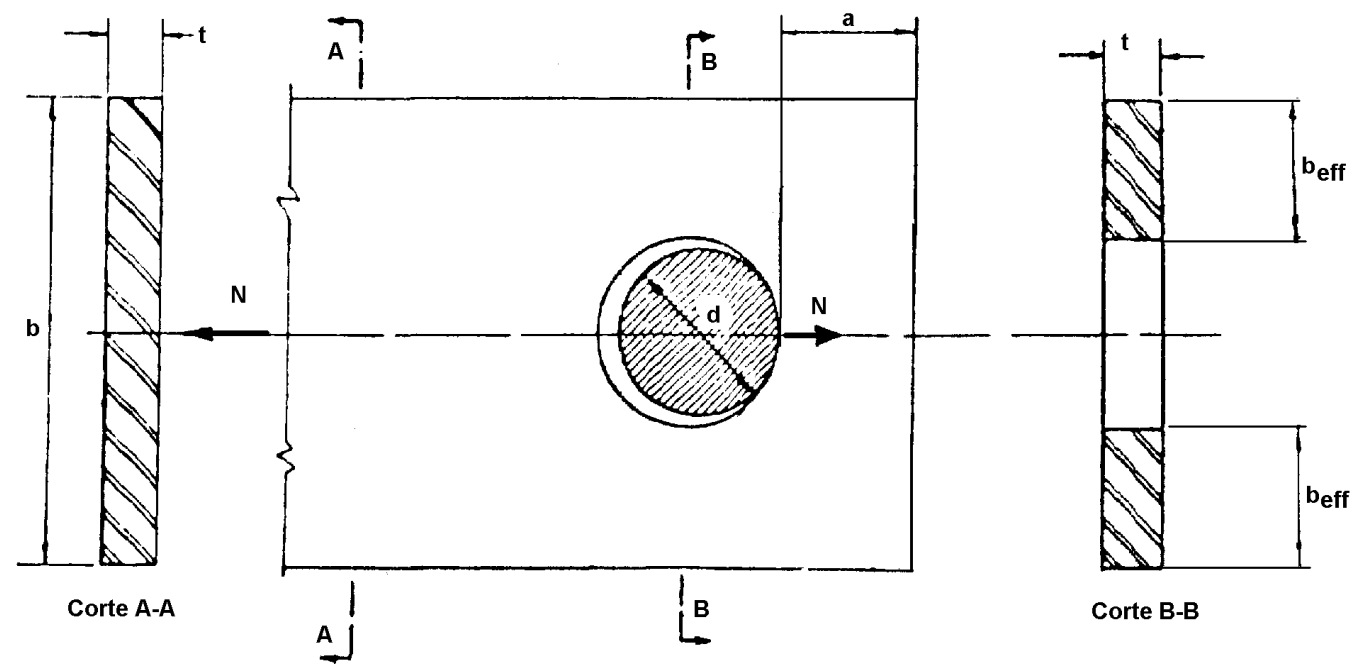

FIGURA 7-28 Chapa ligada por pino de acordo com o AISC/LRFD 93 [ 4 ].

- pressão de contato (esmagamento) na chapa:

Para o caso de pinos em furos mandrilhados ou broqueados, tem-se:

$\phi \mathrm{R}_{\mathrm{n}}=1,8 \mathrm{f}_{\mathrm{y}} \mathrm{A}_{\mathrm{pb}}$

onde: $\mathrm{A}_{\mathrm{pb}}=$ área efetiva de pressão de contato

$\phi=0,75$

- para escoamento da seção bruta:

$\phi_{\mathrm{t}} \mathrm{N}_{\mathrm{n}}=\phi_{\mathrm{t}} \mathrm{f}_{\mathrm{y}} \mathrm{A}_{\mathrm{g}}$

onde: $\mathrm{A}_{\mathrm{g}}=$ área bruta da chapa

$\phi_{\mathrm{t}}=0,90$

No caso de olhais a resistência de cálculo à tração deve ser obtida de acordo com os seguintes estados limites:

- escoamento da seção bruta:

$\phi_{\mathrm{t}} \mathrm{N}_{\mathrm{n}}=\phi_{\mathrm{t}} \mathrm{f}_{\mathrm{y}} \mathrm{A}_{\mathrm{g}}$

onde: $\mathrm{A}_{\mathrm{g}}=$ área bruta da chapa $(b t)$

$\phi_{\mathrm{t}}=0,90$

- ruptura da seção líquida:

$\phi_{\mathrm{t}} \mathrm{N}_{\mathrm{n}}=\phi_{\mathrm{t}} \mathrm{f}_{\mathrm{u}} \mathrm{A}_{\mathrm{e}}$ 
onde: $\mathrm{A}_{\mathrm{e}}=$ área líquida efetiva

$\phi_{\mathrm{t}}=0,75$

Segundo o EUROCODE 3 [ 24 ], os momentos fletores em um pino devem ser calculados como indica a fig. 7-29, com isso:

$$
\mathrm{M}_{\mathrm{Sd}}=\frac{\mathrm{F}_{\mathrm{Sd}}}{8}(\mathrm{~b}+4 \mathrm{c}+2 \mathrm{a})
$$

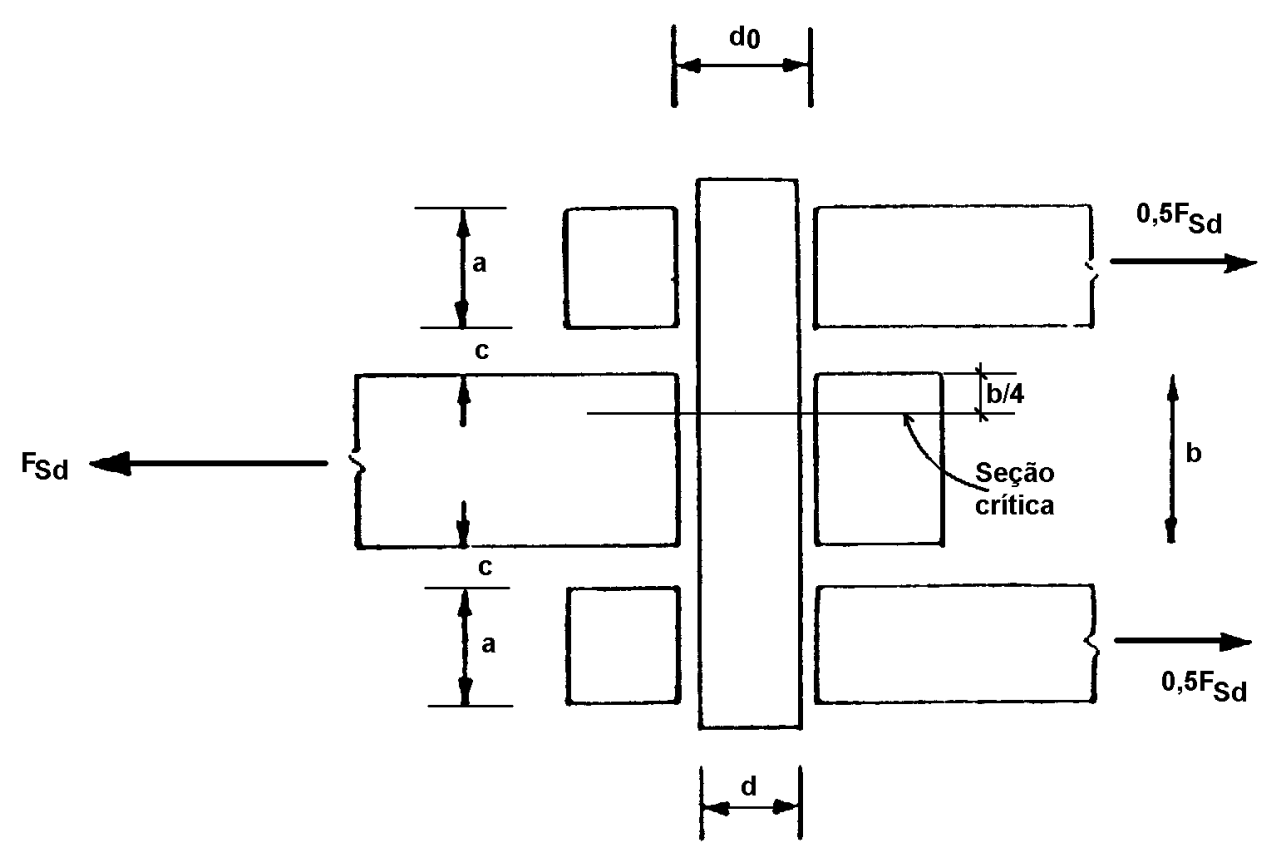

FIGURA 7-29 Forças atuantes no pino. Adaptada do EUROCODE 3 [ 24 ].

Em estado limite último as forças e momentos de cálculo em um pino não devem exceder as seguintes resistências de cálculo:

- para cisalhamento do pino:

$\mathrm{F}_{\mathrm{v} \cdot \mathrm{Rd}}=\frac{0,6 \mathrm{Af}_{\mathrm{up}}}{\gamma_{\mathrm{Mp}}}$

onde: $\mathrm{A}$ = área bruta da seção transversal do pino

$\mathrm{f}_{\text {up }}=$ limite de resistência à tração do material do pino

$\gamma_{\mathrm{Mp}}=1,25$

- para flexão no pino: 


$$
\mathrm{M}_{\mathrm{Rd}}=\frac{0,8 \mathrm{Wf}_{\mathrm{yp}}}{\gamma_{\mathrm{Mp}}}
$$

onde: $\mathrm{f}_{\mathrm{yp}}=$ limite de escoamento do material do pino

- para flexão e cisalhamento combinados no pino:

$$
\left[\frac{\mathrm{M}_{\mathrm{Sd}}}{\mathrm{M}_{\mathrm{Rd}}}\right]^{2}+\left[\frac{\mathrm{F}_{\mathrm{v} . \mathrm{Sd}}}{\mathrm{F}_{\mathrm{v} . \mathrm{Rd}}}\right]^{2} \leq 1
$$

- para pressão de contato na chapa:

$$
F_{b . R d}=\frac{1,5 f_{y} t d}{\gamma_{M p}}
$$

onde: $\mathrm{t}=$ espessura da chapa

$\mathrm{d}=$ diâmetro do pino

$\mathrm{f}_{\mathrm{y}}=$ limite de escoamento do material da chapa

A geometria das chapas em conexões com pinos deve estar de acordo com as dimensões indicadas na fig. 7-30.

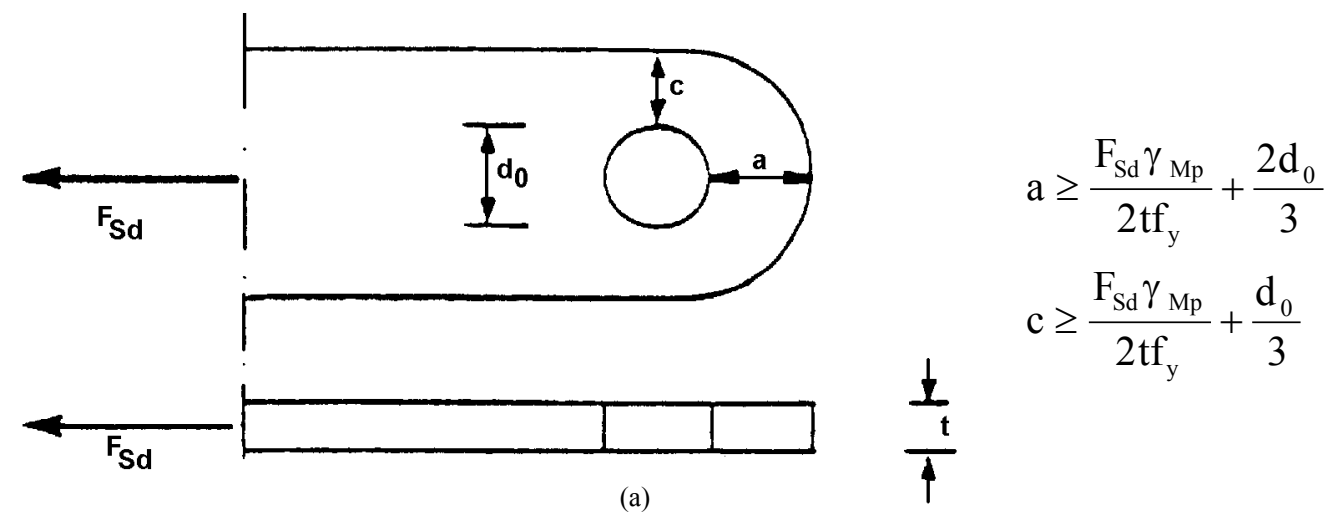

FIGURA 7-30 Condições geométricas para chapas em conexões com pinos. (a) Quando é dada a espessura; (b) quando é dada a geometria. Adaptada do EUROCODE 3 [ 24 ]. 


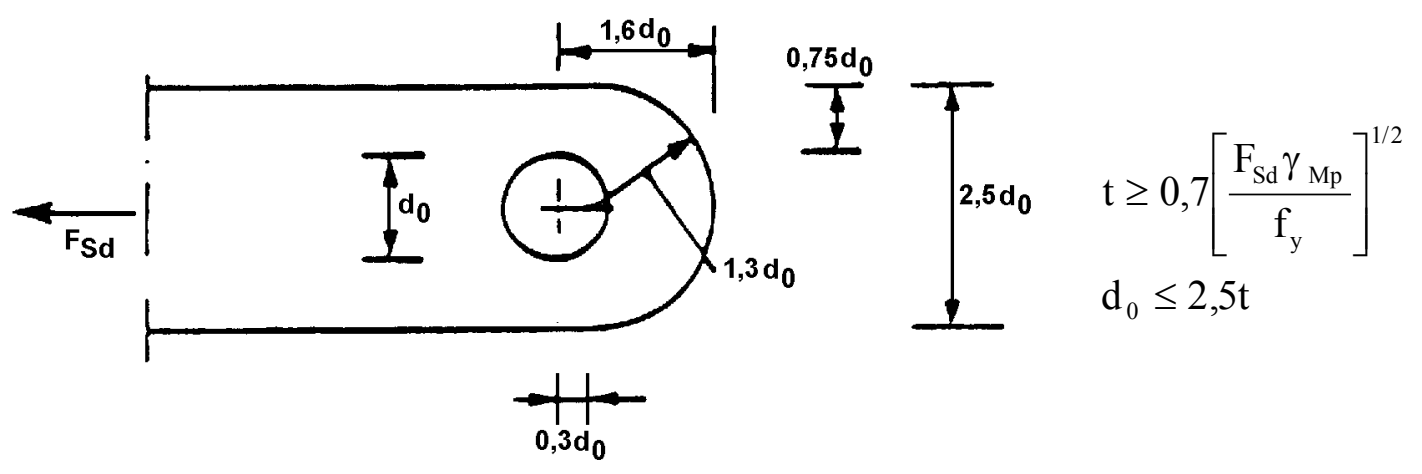

(b)

FIGURA 7-30 Condições geométricas para chapas em conexões com pinos. (a) Quando é dada a espessura; (b) quando é dada a geometria. Adaptada do EUROCODE 3 [ 24 ]. 


\section{COMENTÁRIOS FINAIS E CONCLUSÕES}

As ligações entre elementos estruturais sempre implicou em preocupações e conseqüentemente tem sido tema de muitas pesquisas, não só nas estruturas de aço, mas nas estruturas em geral. As estruturas metálicas, constituídas pela associação de elementos relativamente pequenos (perfis, chapas, etc.) apresentam geralmente uma elevada quantidade de pontos de conexão, quer na fábrica ou na obra, o que torna este item extremamente relevante do ponto de vista da segurança estrutural e do ponto de vista econômico. Em outras palavras, de nada adianta projetar adequadamente as barras de uma estrutura se suas ligações são projetadas de maneira inadequada.

Um projeto adequado de uma ligação consiste não somente na análise estrutural, mas também na análise de viabilidade técnico-econômica da utilização de um determinado dispositivo de ligação e do respectivo detalhe construtivo, o que requer por parte do engenheiro de estruturas, ao menos um conhecimento básico sobre as características do dispositivo a ser adotado e suas implicações.

Neste trabalho, por se tratar de uma revisão bibliográfica, procurou-se apresentar de forma abrangente as características dos principais dispositivos de ligação (parafusos e soldas), as prescrições de normas para a avaliação da resistência e por fim, os modelos teóricos clássicos usualmente empregados para a avaliação de solicitações em ligações parafusadas e soldadas.

Uma vez que o tema é muito abrangente e pesquisado há muitos anos, a pesquisa bibliográfica remete a uma infinidade de trabalhos. Na parte referente aos processos de soldagem, foi relacionado um vasto material na área de Engenharia de Materiais, o qual aborda a classificação de eletrodos, fluxos, e misturas gasosas mais usuais e suas implicações e as variáveis que interagem no processo, como tensão, corrente, velocidade de deposição, etc. Nos livros destinados ao dimensionamento de elementos de estruturas metálicas, tal assunto é geralmente tratado de maneira muito superficial ou até mesmo totalmente omitido.

Do ponto de vista econômico, as juntas soldadas normalmente são mais interessantes que as parafusadas, pois conduzem a detalhes mais simples e envolvem uma menor quantidade de elementos (chapas de topo, cobrejuntas, etc.). Entretanto, 
requer mão-de-obra mais qualificada e particulares condições de execução, o que as tornam muitas vezes inadequadas para o trabalho de campo (obra). Nas publicações mais antigas, é comum encontrar a seguinte observação: as ligações soldadas são mais interessantes para a execução em fábrica e as ligações parafusadas para execução na obra. Com o avanço e a automatização dos processos de soldagem, assim como dos meios de inspeção e controle de qualidade, a tendência é que as ligações soldadas passem a ser cada vez mais interessantes nas ligações de obra.

Quanto a avaliação da resistência de parafusos e soldas, a maior parte da bibliografia pesquisada enfoca as prescrições das normas norte-americanas do AISC e a normalização européia (EUROCODE). Quanto às normas do AISC, vale registrar que a segunda edição do manual em estados limites (AISC/LRFD 93) apresenta algumas modificações de ordem prática em relação à primeira edição (AISC/LRFD 86), e também é dividida em dois volumes, sendo o segundo volume destinado apenas ao projeto de ligações. É importante lembrar que a norma brasileira NBR 8800 foi baseada numa edição preliminar do AISC/LRFD 86, portanto segue a mesma filosofia de dimensionamento.

As prescrições contidas no AISC/LRFD são praticamente as mesmas apresentadas pelo AISC/ASD (tensões admissíveis) já de longa data, havendo porém uma alteração referente ao método de introdução da segurança, ou seja: de tensões admissíveis para estados limites. Entretanto, pode-se dizer que o resultado final ao se utilizar um método ou outro não apresenta diferenças significativas, pois a versão em estados limites tem seus coeficientes calibrados em relação aos clássicos fatores de segurança adotados pelo AISC/ASD.

Um fato importante a ser mencionado é a introdução, pelo AISC/LRFD de 1993, da alternativa de se determinar a resistência de cordões de solda em função da sua direção em relação à solicitação. Nas edições anteriores, a resistência de cordões de solda era determinada somente pela situação mais desfavorável, ou seja, cordões de solda paralelos à solicitação.

Quanto às prescrições do EUROCODE 3, embasadas em estudos do ECCS e nas considerações de diversas normas européias, como as normas britânicas BS 5950 (edifícios) e BS 5400 (pontes), pode-se registrar que, de uma maneira geral, são 
estabelecidos quase que os mesmos estados limites últimos verificados pelas normas do AISC, entretanto com um simbologia bem diferente, o que pode causar confusão aos usuários não familiarizados.

Nos capítulos referentes à avaliação de solicitações em parafusos e soldas, procurou-se mostrar de uma maneira clara, porém sem esquecer o mínimo rigor necessário a um trabalho técnico, os modelos teóricos clássicos usualmente empregados nos projetos de ligações.

Tais modelos clássicos adotam uma série de hipóteses simplificadoras, permitindo avaliar as solicitações em parafusos e soldas de maneira simples e envolvendo uma quantidade relativamente pequena de cálculos. Devido à simplicidade procurada, tais modelos quase sempre conduzem a resultados conservadores, porém há muito tempo aceitáveis pelo meio técnico.

Nos capítulos cinco e seis são apresentados os dois modelos teóricos mais empregados para a análise de grupo de parafusos e soldas submetidos a carregamento excêntrico: o método vetorial (ou elástico) e o método do centro instantâneo de rotação. Este último conduz a resultados mais próximos aos obtidos experimentalmente, entretanto consiste num procedimento interativo, requerendo evidentemente maior número de cálculos. Desta maneira, torna-se viável a sua utilização quanto se dispõe de alguma ferramenta computacional.

As edições do AISC/LRFD (86 e 93) trazem tabelas referentes ao método do centro instantâneo de rotação, envolvendo vários casos comuns na prática, as quais permitem avaliar a capacidade de tais ligação de maneira rápida e prática.

Outro fenômeno relevante a ser comentado é o efeito alavanca em parafusos, cujos modelos teóricos apresentados na literatura conduzem a resultados muito discrepantes. Muitos pesquisadores têm se dedicado ao estudo deste fenômeno, que exerce grande influência no comportamento de ligações semi-rígidas, entretanto, devido à complexibilidade e à grande variabilidade de condicionantes do fenômeno, as conclusões dos trabalhos experimentais e as propostas a nível de modelo teórico ainda são muito dispersas. 
Conclusões e comentários mais detalhados sobre os dispositivos de ligação, sobre a avaliação de sua resistência e sobre os modelos teóricos para avaliação de solicitações já foram apresentados nos capítulos correspondentes e portanto, torna-se desnecessário e repetitivo transcrevê-los. 


\section{REFERÊNCIAS BIBLIOGRÁFICAS}

[ 1 ] AMERICAN INSTITUTE OF STEEL CONSTRUCTION (1989). Allowable stress design (ASD). Chicago, AISC.

[ 2] AMERICAN INSTITUTE OF STEEL CONSTRUCTION (1984). Engineering for steel construction: a source book connections. Chicago, AlSC.

[ 3 ] AMERICAN INSTITUTE OF STEEL CONSTRUCTION (1986). Load and resistance factor design (LRFD). Chicago, AISC.

[ 4] AMERICAN INSTITUTE OF STEEL CONSTRUCTION (1993). Load and resistance factor design (LRFD). Chicago, AISC.

[ 5 ] AMERICAN INSTITUTE OF STEEL CONSTRUCTION (1990). Load and resistance factor design of simple shear connections. Chicago, AISC.

[ 6] ASSOCIAÇÃO BRASILEIRA DE NORMAS TÉCNICAS (1968). NB 14/68Cálculo e execução de estruturas de aço (edifícios).

[ 7] ASSOCIAÇÃO BRASILEIRA DE NORMAS TÉCNICAS (1986). NBR 8800/86 - Projeto e execução de estruturas de aço de edifícios. Rio de Janeiro.

[ 8 ] AZCÚNAGA, F.R.A. (1958). Construcciones metalicas. 4.ed. Madrid, Patronato de Publ. de La Escuela de Ing. Indust.

[ 9] BAlliO, G.; MAZZOLANI, F.M. (1983). Theory and design of steel structures. London: Chapman \& Hall. 
[ 10 ] BEEDLE, L.S. (1964). Structural steel design. New York, Ronald Press.

[ 11 ] BELLEI, I.H. (1994). Edificios industriais em aço: projeto e cálculo. Sao Paulo: PINI.

[12 ] BLODGETT, O.W. (1963). Design of welded structures. Cleveland, Ohio, The James F. Lincoln Arc Welding Foundation.

[ 13 ] BOWLES, J.E. (1980). Structural steel design. New York, McGraw-Hill.

[ 14 ] BRASIL. Ministério da Industria e do Comércio. Secretaria de Tecnologia Industrial (1986/1988). Manual brasileiro para cálculo de estruturas metálicas. Brasília, STI/MIC. v. 1 e v. 3, tomo 2.

[ 15 ] BRESLER, B.; LIN, T. Y. (1960). Design of steel structures. New York, Wiley.

[ 16 ] CARNASCIALI, C.C. (1974). Estruturas metálicas na prática. São Paulo, McGraw-Hill.

[ 17 ] COOPER, S.E. (1985). Designing steel structures: methods and cases. Englewood Cliffs, NJ, Prentice-Hall.

[ 18 ] COUNCIL ON TALL BUILDINGS AND URBAN HABITAT (1993). Semirigid connections in steel frames. New York, McGraw-Hill.

[19] CRAWLEY, S.W.; DILLON, R.M. (1993). Steel buildings: analysis and design. 4.ed. New York, John Wiley \& Sons.

[ 20 ] CUNHA, L.J.G. (1985). Solda: como, quando e por que. Porto Alegre, Sagra Editora. 
[ 21 ] DAWE, J.L.; KULAK, G.L. (1974). Welded connections under combined shear and moment. Journal of the Structural Division, ASCE, v.100, n.ST4, p.727-741, April .

[ 22 ] ENGLEKIRK, R. (1994). Steel structures: controlling behavior through design. New York, John Wiley \& Sons.

[23] EUROPEAN CONVENTION FOR CONSTRUCTIONAL STEELWORK (1978). European recommendations for steel construction. Brussels, ECCS. (Publication n.23)

[ 24 ] EUROCODE 3 (1996). Design of steel structures. (ENV 1993-1.3: 1996)

[ 25 ] FABER, O. (1955). Constructional steel work. London, E. \& F. N. Spon.

[26] FANELLA, D.A. et alii (1992). Steel design for engineers and architects. 2.ed. New York, Van Nostrand Reinhold.

[ 27 ] GAYLORD, H.E.; GAYLORD, C.N.; STALLMEYER, J.E. (1992). Design of steel structures. 3.ed. New York, McGraw-Hill.

[ 28 ] GESCHWINDNER, L.F.; DISQUE, R.O.; BJORHOVDE, R. (1994). Load and resistence factor design of steel structures. Englewood Cliffs, NJ, Prentice Hall.

[29] GOMES, S.I.N. Processos de soldagem com proteção gasosa "GMAW" aplicado em aços estruturais. São Carlos, EESC-USP.

[ 30 ] GRINTER, L.E. (1941). Design of modern steel structures. New York, The Macmillan Company. 
[ 31 ] GUSTIN, E. (1956). Estructuras metalicas. Zaragoza, Editorial Reverté.

[ 32 ] HAYWARD, A.; WEARE, F. (1990). Steel detailer's manual. Oxford, BSP.

[ 33 ] HICKS, J. G. (1987). Welded joint design. 2.ed. Oxford, BSP Professional Books.

[ 34 ] KULAK, G.L.; FISHER, J.W.; STRUIK, J.H.A. (1987). Guide to design criteria for bolted and riveted joints. 2.ed. New York, John Wiley \& Sons.

[ 35 ] LAMAS, A.R.G.; BENTO, J.A.R.S.P.; MARTINS, L.M.C.D. (1982). Vigas mistas: dimensionamento de seções e influência da interação parcial entre aço e betão no comportamento elástico e elasto-plástico. In: JORNADAS PORTUGUESAS DE ENGENHARIA DE ESTRUTURAS, Lisboa.

[ 36 ] LOTHERS, J.E.(1972). Design in structural steel. 3.ed. Englewood Cliffs, NJ, Prentice-Hall.

[ 37 ] MacGINLEY, T.J.; ANG, T.C. (1988). Structural steelwork: design to limit state theory. London, Butterworth.

[ 38 ] MAGAlHÃES, J.R.M.; MALITE, M. (1995). Consoles de aço: análise teórica e experimental de um caso típico. São Carlos, EESC-USP.

[39] MALITE, M. et alii (1994). Elementos de estruturas de aço: dimensionamento. São Carlos, EESC-USP. 139p.

[ 40 ] MALITE, M. et alii ( 1994). Ligações em estruturas de aço. São Carlos, EESC-USP. 126p.

[ 41 ] McCORMAC, J.C. (1981). Structural steel design. 3.ed. New York, Harper \& Row. 
[ 42 ] McGUIRE, W.; WINTER, G. (1968). Steel structures. Englewood Cliffs, NJ, Prentide-Hall.

[ 43 ] MODERN welded structures (1965). Cleveland, Ohio, The James F. Lincoln. Arc Welding Foundation. 3v.

[44] MONTEIRO, J.A.P. (1979). Ligações utilizando parafusos de alta resistência. São Carlos. Dissertação (Mestrado em Engenharia de Estruturas) - Escola de Engenharia de São Carlos, Universidade de São Paulo.

[ 45 ] MUKHANOV, K. (1980). Estruturas metálicas. Moscou, MIR.

[ 46 ] NACHTERGAL, C. (1969). Estructuras metalicas: calculos y construccion. Trad. de Sebastian L. Camarasa. Barcelona, Blume.

[ 47 ] NARAYANAN, R, ed. (1985). Steel framed structures: stability and strength. London, Elsevier.

[ 48 ] NEGRI, J. (1957). Las construcciones metalicas. Buenos Aires, Centro Estudiantes de Ing. La Linea Recta.

[49 ] NEWMAN, M. (1988). Structural details for steel construction. New York, McGraw-Hill.

[ 50 ] OWENS, G.W.; CHEAL, B.D. (1989). Structural steelwork connections. London, Butterworth.

[ 51 ] PARKER, H.; AMBROSE, J. (1983). Simplified design of structural steel. 5.ed. New York, A. Wiley-Interscience Publication. 
[ 52 ] PAVLOVIC, M.N. (1986). Steel structures: recent research advances and their aplications to design. London, Elsevier.

[ 53 ] PFEIL, W. (1976). Estruturas de aço. Rio de Janeiro, LTC.

[ 54 ] PFEIL, W.; PFEIL, M. (1995). Estruturas de aço: dimensionamento prático. 6.ed. Rio de Janeiro, LTC.

[ 55 ] PRELORENTZOU, P.A. (1991). Um estudo sobre ligações viga-coluna em estruturas de aço. São Carlos. Dissertação (Mestrado em Engenharia de Estruturas) - Escola de Engenharia de São Carlos, Universidade de São Paulo.

[56 ] QUEIROZ, G. (1989). Elementos das estruturas de aço. 2.ed. Belo Horizonte, publicado pelo autor.

[ 57 ] QUITES, A.M.; DUTRA, J.C. (1979). Tecnologia da soldagem a arco voltaico. Florianópolis, EDEME.

[ 58 ] RHODES, J., ed. (1991). Design of cold formed steel members. London, Elsevier Applied Science.

[ 59 ] SALMON, C.G.; JOHNSON, J.E. (1990). Steel structures: design and behaviour. 3.ed. New York, Harper \& Row.

[ 60 ] SALMON, C.G.; JOHNSON, J.E. (1996). Steel structures: design and behaviour. 4.ed. New York, Harper \& Row.

[61] SANTOS, A.F. (1977). Estruturas metálicas: projeto e detalhes para fabricação. 3.ed. São Paulo, McGraw-Hill. 
[62 ] SCHULTE, H. (1964). Estruturas metálicas. São Carlos, EESC-USP. (Publicação $n^{\circ}$ 95)

[ 63 ] SCHULTE, H.; YAGUI, T. (1981). Estruturas de aço. São Carlos, EESC.

[ 64 ] SEMINÁRIO USO DO AÇO NA CONSTRUÇÃO, 4., São Paulo, 1989. Anais. São Paulo, EPUSP.

[ 65 ] SIDERBRÁS (1980). Elementos estruturais e ligações. Açominas. v.3

[ 66 ] SIDERBRÁS (1988). Ligações em estruturas metálicas: publicações técnicas para o desenvolvimento da construção metálica. Brasília.

[ 67 ] SMITH, J.C. (1996). Structural steel design LRFD approach. 2.ed. New York, John Wiley \& Sons.

[ 68 ] STEEL designers' manual (1992). Edited by Graham W. Owens, Peter R. Knowles, Patrick T. Dowling. Oxford, Blackwell Scientific.

[ 69 ] THAHAIR, N.S.; BRADFORD, M.A. (1991). The behaviour and design of steel structures. 2.ed. London, Chapman \& Hall.

[ 70 ] THORNTON, W.A (1985). Prying action: a general treatment. Engineering Journal, AISC, v.22, n.2, p. 67-75, Second Quarter.

[ 71 ] URQUHART, L.C.; O'ROURKE, C.E. (1930). Design of steel structures. New York, McGraw-Hill.

[ 72 ] WAINER, E.; BRANDI, S.D.; MELLO, F.D.H. (1992). Soldagem: processos e metalurgia. São Paulo, Edgard Blücher. 
[ 73 ] WILLIAMS, C.D.; HARRIS, E.C. (1957). Structural design in metals. 2.ed. New York, The Ronald Press Company.

[74 ] ZIGNOLI, V.(1978). Construcciones metalicas. Traducción por Joaquim R. Monteverde. Madrid, Dossat. 2v. 